

\section{UNIVERSIDAD POLITÉCNICA DE MADRID}

ESCUELA TÉCNICA SUPERIOR DE INGENIEROS DE MONTES
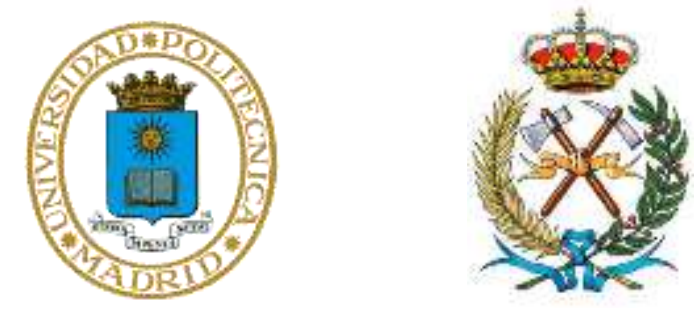

EVOLUCIÓN HISTÓRICA DE LOS BOSQUES EN SIERRA

MADRONA Y VALLE DE ALCUDIA (CIUDAD REAL) Y

DINÁMICA DEL PINAR RELICTO DE NAVALMANZANO

TESIS DOCTORAL

JESÚS CHARCO GARGÍA

Licenciado en Geografía

Madrid, 2016 
ESCUELA TÉCNICA SUPERIOR DE INGENIEROS DE MONTES UNIVERSIDAD POLITÉCNICA DE MADRID

\title{
EVOLUCIÓN HISTÓRICA DE LOS BOSQUES EN SIERRA \\ MADRONA Y VALLE DE ALCUDIA (CIUDAD REAL) Y \\ DINÁMICA DEL PINAR RELICTO DE NAVALMANZANO
}

\section{TESIS DOCTORAL}

\author{
JESÚS CHARCO GARGÍA \\ Licenciado en Geografía
}

DIRECTORES:

LUIS GIL SÁNCHEZ

Doctor Ingeniero de Montes
NIKOLAOS NANOS

Doctor Ingeniero de Montes

Madrid, 2016 
Tribunal nombrado por el Mgfco. y Excmo. Sr. Rector de la Universidad Politécnica de Madrid, el día 18 de diciembre de 2015.

Presidente: Dr. Alfonso San Miguel Ayanz

Vocal: Dr. Helios Sainz Ollero

Vocal: Dr. José María Barreda Fontes

Vocal: Dr. Ramiro García Río

Secretaria: Dra. Inés González Doncel

Suplente: Dr. Rafael Navarro Cerrillo

Suplente: Dr. Juan Carlos Moreno Saiz

Realizado del acto de defensa y lectura de la Tesis el día 29 de enero de 2016 en Madrid.

Calificación

EL PRESIDENTE

LOS VOCALES

EL SECRETARIO 
A mis padres, que me dieron la vida 


\section{AGRADECIMIENTOS.}

Este apartado de la tesis sin duda es uno de los más fáciles y difíciles de redactar al mismo tiempo. Fácil porque se redacta al final, cuando todo lo duro parece haber pasado, pero sin duda complicado por temor a que alguien que se lo merece, por despiste, quede fuera. Han sido tantas las personas que han colaborado que difícilmente no quedará alguien sin citar, alguien que debería haber estado con una nota en el cuaderno de agradecimientos diario que nunca existió.

En primer lugar mi mayor agradecimiento es para Luis Gil, por mostrarme siempre su apoyo, sacando tiempo de donde parecía no haberlo. Él me metió en la cabeza el interés de estudiar uno de los bosques más interesantes de España y aún de Europa, el pinar de la sierra de Navalmanzano. Gracias Luis, por tu continuo apoyo, enseñanzas e infinita paciencia conmigo.

Un agradecimiento especial también, como no podía ser de otra manera, para Nikolaos Nanos, que se atrevió a codirigir esta tesis, con el que tanto aprendí de estadística y estructuración científica de proyectos. La introducción al " $\mathrm{R}$ " fue mi gran descubrimiento. Muchas gracias Nikos por todo el tiempo que me has dedicado.

El desarrollo de los trabajos se enmarcó en el Convenio de Conservación y mejora de los recursos genéticos de coníferas. N ${ }^{\circ}$ P000720376, de la entonces Escuela Técnica Superior de Ingenieros de Montes de Madrid (Universidad Politécnica de Madrid). También fueron financiados en buena parte por la Consejería de Medio Ambiente de la Junta de Comunidades de Castilla-La Mancha, mediante subvención acogida a la orden 29/2/1996. Por su parte, la colaboración técnica del Centro de Investigaciones Ambientales del Mediterráneo (CIAMED) también ha sido muy importante, aportando vehículos todo terreno, equipos y material informático, óptico y fotográfico. La Cooperativa de Servicios forestales (COSERFO) prestó durante varios días el GPS inframétrico que permitió la precisa georreferenciación del pinar.

En los apartados de Cartografía, Inventario y Germinación, tanto en los trabajos de campo como en el procesamiento de datos, colaboraron activamente jóvenes estudiantes, y licenciados del departamento de Geografía y Ordenación del Territorio de la Universidad de Castilla-La Mancha. En especial, Miguel González del Cerro, pero sin olvidar los importantes apoyos de Antonio García Villaraco, Gema Sánchez y Jesús Francisco Santos. Otros muchos amigos, la mayoría estudiantes, ingenieros y licenciados en diversas universidades de Madrid, Castilla-La Mancha y Andalucía también colaboraron, especialmente en los trabajos de campo, entre quienes quiero destacar a Arturo Menor, Fernando Pavón, Marisa Nogueras, Emilio David Parreño, Gema Fresneda, Santiago Camarena, Vicente Luchena, David Sierra y Javier Diego Laguna. Muchas gracias a todos por acompañarme por esas cumbres de Sierra Madrona, en invierno y en verano, madrugando y trasnochando. Aunque la verdad es que entre tanto esfuerzo también hubo momentos inolvidablemente buenos. No es momento de contar aquí anécdotas, tal vez en otra tesis, pero memorables fueron las fiestas nocturnas en Fuencaliente, Mestanza o Valmayor ... Sin vosotros, trabajos como el desmenuce de los archivos de la desamortización o el inventario del pinar relicto, hubieran sido mucho más difíciles de realizar. 
También, por supuesto, un agradecimiento especial a Xavi Rigata y Begoña Álvarez, por su ayuda inicial con las ingentes cantidades de datos que se iban produciendo y los nuevos programas y capas de SIG.

Aunque he dado tumbos por todos los municipios de Sierra Madrona y el Valle de Alcudia, sin duda me une una relación especialmente cercana a Fuencaliente, en cuyos montes se encuentra el pinar de Navalmanzano. ¡Cuántos paisanos me habrán ayudado de un modo u otro!. No obstante quiero destacar a algunos de ellos, a los que les tengo especial cariño por su continuo apoyo. Selín y Nani, fueron casi mi familia adoptiva en la sierra. El Chano, en el pueblo, siempre tan dispuesto a colaborar en lo que fuera menester. ¡Y cómo no!, el alcalde, Santiago Canales, con el que no faltaron ni faltan largas conversaciones sobre lo que conviene o deja de convenir a la sierra. A todos mi más profundo agradecimiento, por lo mucho que he aprendido sobre la sierra con vosotros, y por lo extraordinariamente bien que siempre os habéis portado conmigo y con quienes me acompañaban.

En las grandes fincas privadas, de no muy fácil acceso, conté desde siempre con la amistad y colaboración de sus propietarios, que me permitieron desarrollar en ellas cuantos estudios y experimentos fueron necesarios. En este sentido guardo un recuerdo y un cariño muy especial hacia D. Carlos Aguilar, propietario de La Torrecilla, que en paz descanse. Un agradecimiento también muy especial a Santiago Sanz Pastor, propietario de Valmayor, quien además de permitirme el acceso a su magnífica finca, me honra con su sincera amistad.

Pero todo esto hubiera sido más complicado de no haber contado en más de una ocasión con la guardería de la comarca, tanto la de la Consejería de Medio Ambiente, como la del Ayuntamiento de Fuencaliente, Bienvenido Acero, Diego Valverde, Juan Carlos Torres, Paco Ramírez, Juan Manuel Sánchez y David Núñez. A todos, y que me perdone si alguien olvidé, muchísimas gracias.

Según escribo van desfilando por mi mente más y más personas y personajes en Almodóvar del Campo, Mestanza, Puertollano, Alamillo, El Hoyo, Brazatortas, Cabezarrubias, Guadalmez, Almadén o Andújar. De muchos de ellos no recuerdo el nombre, es posible que algunos ni me lo dijeran, y me duele, porque en alguna ocasión me resolvieron dudas o apuros en el campo. Muchos son pastores, otros guardas, gente de campo, a veces muy mayores, con los que tanto me gustaba hablar y aprender. Con sus vivencias, y las que recuerdan que les contaban sus antepasados, con su conocimiento del monte y de la microtoponímia, con frecuencia ayudan a entender y complementar lo que se halla en los archivos históricos del último siglo.

En ayuntamientos, museos y archivos, siempre fui bien recibido o al menos se me permitió desarrollar sin problemas mi búsqueda de información. También en la sede de la Asociación para el Desarrollo del Valle de Alcudia y Sierra Madrona, en Almodóvar.

Alejándonos del campo quiero destacar especialmente a mi maestro y amigo José Luís García Rayego, profesor de la UCLM en Ciudad Real, en el Dpto. de Geografía y Ordenación del 
Territorio, de quien aprendí muchísimo sobre geomorfología, flora y vegetación de Sierra Madrona y Valle de Alcudia. En la E.T.S. de Ingenieros Agrónomos y de Montes de la Universidad de Córdoba, se me acogió y facilitó todo el apoyo por parte de Rafael Navarro y su equipo, para evaluar la idoneidad de aplicar a Sierra Madrona los modelos de máxima entropía (MAXENT). Finalmente no se aplicaron por su baja consistencia a escala local, pero el proceso fue altamente constructivo para entender mejor las múltiples variables que condicionan la distribución potencial de los bosques. Un agradecimiento también muy especial a Helios y Angeles por aguantarme durante este último año.

En la ETS de Ingeniería de Montes, Forestal y del Medio Natural que para nosotros siempre será la Escuela de Montes, donde he pasado encerrado este último año, he podido sobrevivir, sin ver el campo, gracias a los compañeros que me han hecho muy agradable la estancia. Desde Chechu por su apoyo con los ensayos de germinación en 2005 hasta los ahora presentes. No he querido molestarlos mucho, pero cada vez que he necesitado algo siempre me han ayudado con rapidez, eficacia y desenfado. María, Elena, Robert, Jesús, Pau, Martin, Aida, Li, Unai, Álvaro, Victoria, Juanan, Oscar, Davides (Meden y Macaya), Guille, Eva, José Carlos. Muchas gracias a todos por estar aquí.

Como siga, parecerá que todo me lo han dado hecho pero, aunque no haya sido así, sí que es cierto que he tenido la inmensa fortuna de contar con el apoyo y amistad de gente maravillosa. 


\section{INDICE}

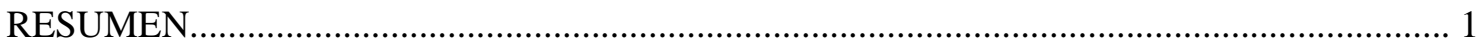

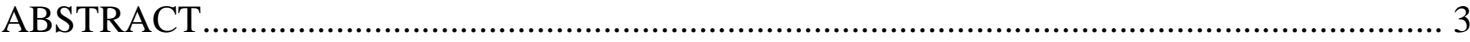

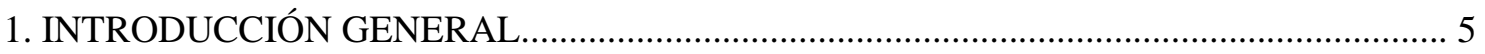

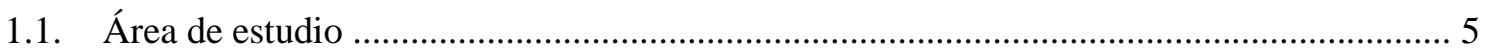

1.2. Origen y evolución de los bosques en Sierra Madrona y Valle de Alcudia........................ 11

1.3. Primeros impactos humanos sobre los bosques y el paisaje.

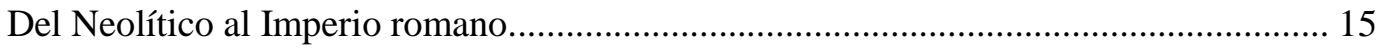

1.4. Historia reciente y perspectivas de futuro, objetivos de la tesis...................................... 18

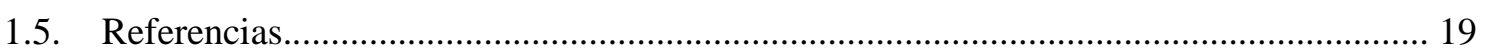

2. EVOLUCIÓN DE LOS BOSQUES DE SIERRA MADRONA Y VALLE DE ALCUDIA:

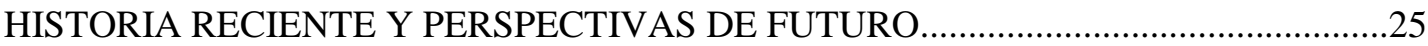

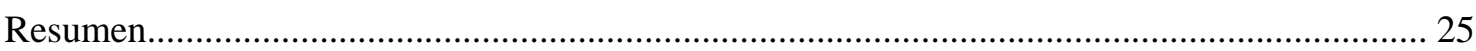

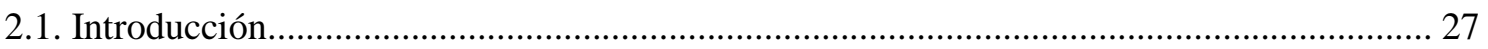

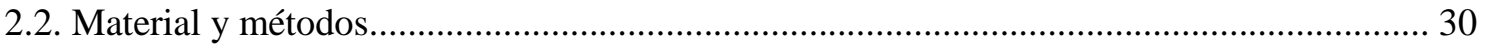

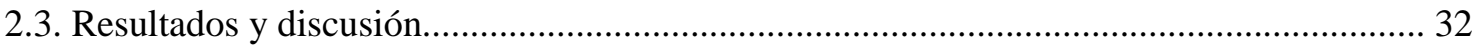

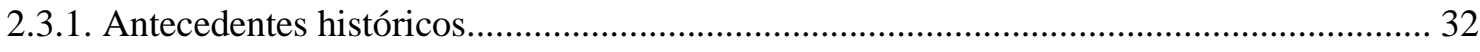

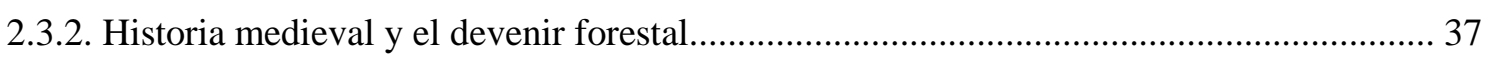

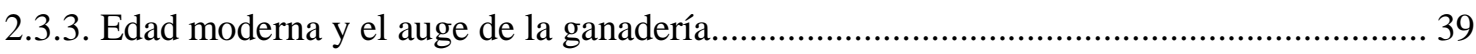

2.3.4. El estado de los montes de Sierra Madrona y Valle de Alcudia a finales del siglo XVI según las Relaciones Topográficas de Felipe II........................................... 46

2.3.5. Siglos XVII y XVIII, el cenit de la ganadería, el crecimiento de los pueblos

y el renacimiento de la minería. Repercusiones sobre los montes........................................51

2.3.6. Siglos XVI-XVIII primeras desamortizaciones del Valle de Alcudia..................................66

2.3.7. Los bosques de Sierra Madrona y Valle de Alcudia en el siglo XIX..................................70

2.3.8. Las desamortizaciones de siglos XIX y XX en Sierra Madrona y Valle de Alcudia.........78

2.3.9. El destino de las fincas vendidas durante los procesos desamortizadores.........................97

2.3.9.1. Uso ganadero y mantenimiento de las dehesas.........................................................97

2.3.9.2. Los intentos de poner en cultivo al Valle de Alcudia.................................................100

2.3.9.3. La reapertura de viejas minas y la exploración del territorio en busca de nuevas.

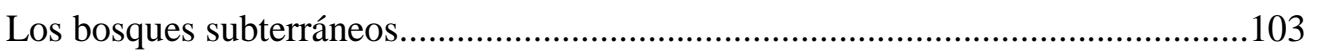

2.3.10. Los bienes exceptuados de la desamortización, montes, dehesas y minas......................107

2.3.11. El estado actual de los montes en Sierra Madrona y Valle de Alcudia............................125

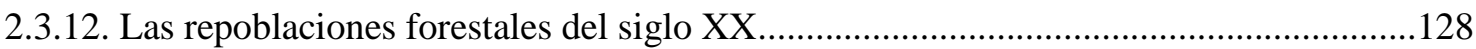

2.3.13. El abandono del medio rural de finales del siglo XX y nuevos usos del territorio.........138 


\section{EL PINAR DE NAVALMANZANO; UN BOSQUE EN PELIGRO DE EXTINCIÓN} QUE RESUME LA HISTORIA NATURAL DE SIERRA MADRONA............................ 155

Resumen 155

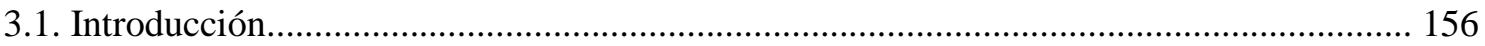

3.1.1. Evolución del género Pinus en la península Ibérica....................................................... 156

3.1.2. El último bosque de $P$. pinaster de Sierra Morena.......................................................... 158

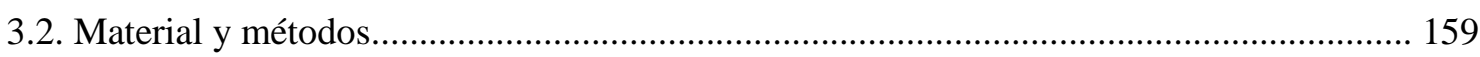

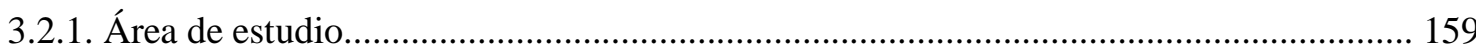

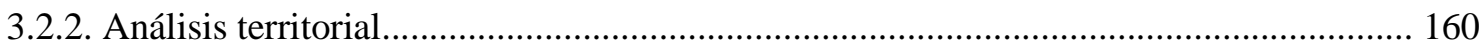

3.2.3. Inventario dasométrico del pinar de Navalmanzano.................................................... 162

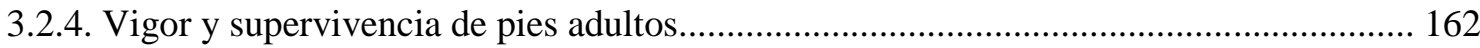

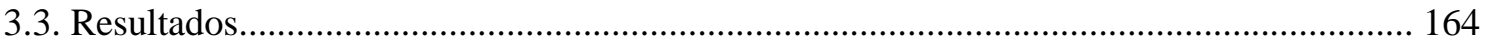

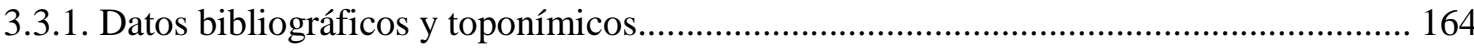

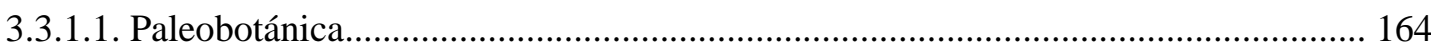

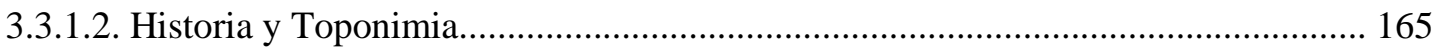

3.3.2. Inventario dasométrico del pinar de Navalmanzano............................................... 174

3.3.3. Características de los 7 pinos aislados en la sierra de Navalmanzano y en

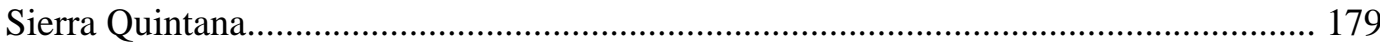

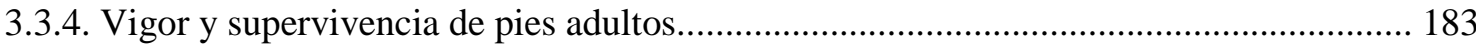

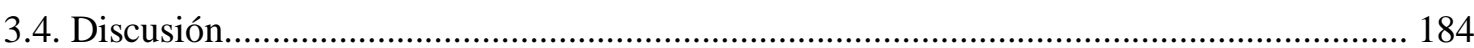

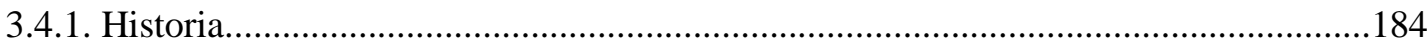

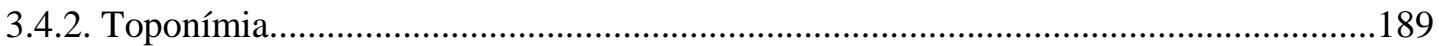

3.4.3. El pinar de Navalmanzano: inventario y evolución reciente.........................................191

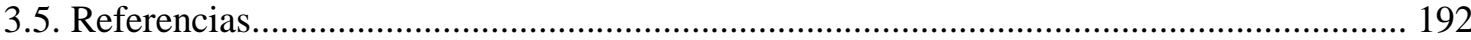

\section{ANÁLISIS DEL REGENERADO EN EL PINAR DE NAVALMANZANO:}

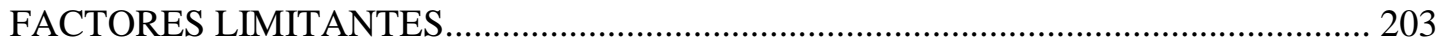

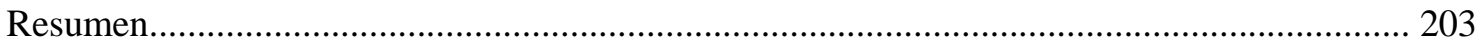

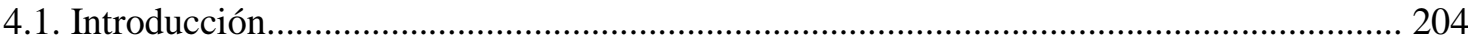

4.1.1. Regeneración natural en masas de Pinus pinaster ............................................................. 204

4.1.2. Impacto de la expansión demográfica de la ardilla roja................................................... 206

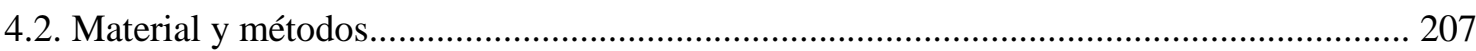

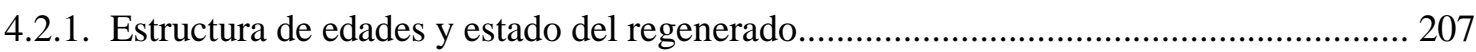

4.2.2. Evaluación del banco aéreo de semillas y obtención de piñones...................................... 208

4.2.3. Determinación de la temperatura de apertura de las escamas........................................... 209 
4.2.4. Ensayos de germinación en campo y laboratorio................................................................209

4.2.5. Influencia de la ardilla en el banco aéreo de semillas..................................................... 210

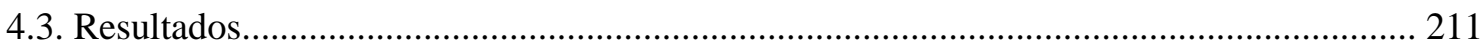

4.3.1. Estructura de edades y estado del regenerado............................................................... 211

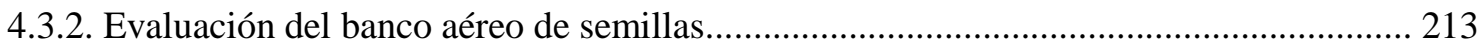

4.3.3. Determinación de la temperatura de apertura de los conos.......................................... 217

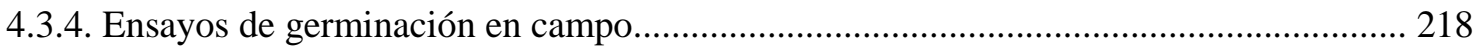

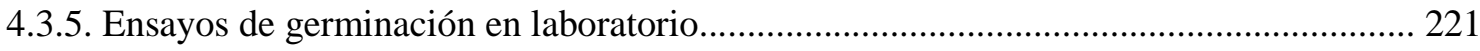

4.3.6. Influencia de la ardilla en el banco aéreo de semillas........................................................ 222

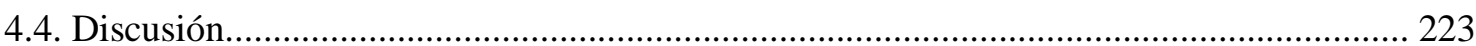

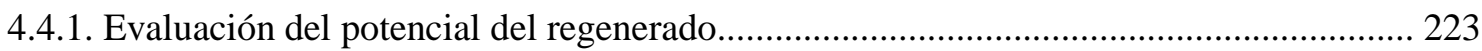

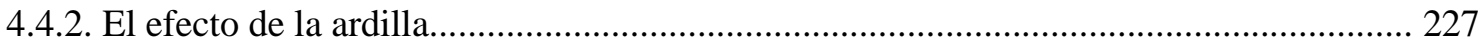

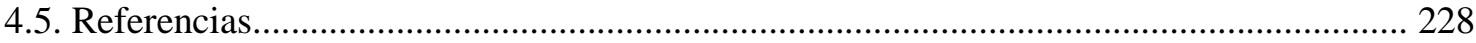

5. IMPACTO DEL ESCODADO DEL CIERVO SOBRE EL PINAR DE

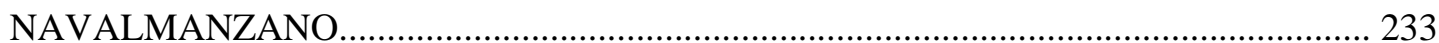

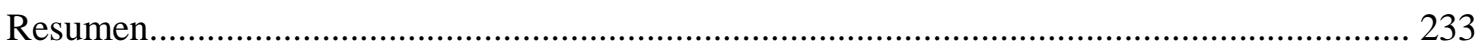

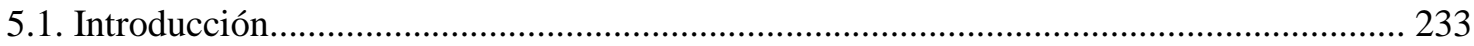

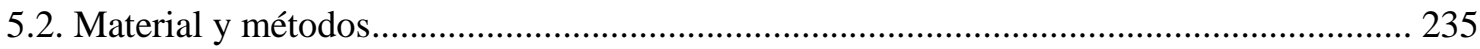

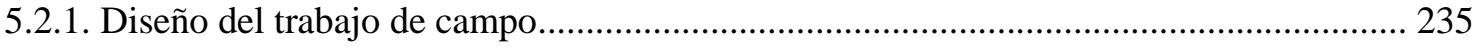

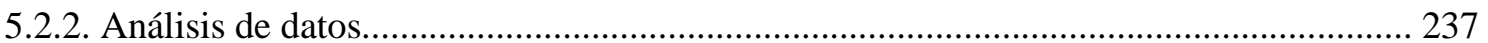

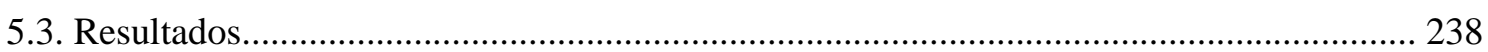

5.3.1. Distribución de los daños causados por el ciervo................................................................ 238

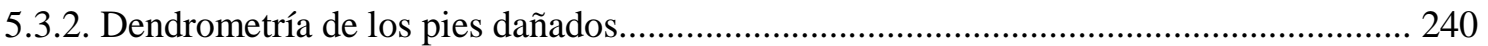

5.3.3. Evolución de los daños causados durante el periodo 2003- 2015.................................... 244

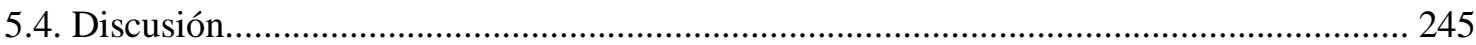

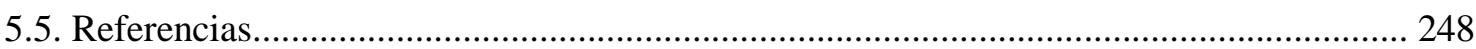

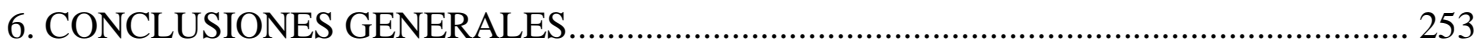

ANEXO. Topónimos referentes a pinos encontrados en Sierra Morena..................................257 


\section{RESUMEN}

Se realiza un estudio multidisciplinar sobre la evolución histórica de una diversificada comunidad forestal para entender mejor su significado actual y poder así planificar más adecuadamente su futura gestión. Se contribuye además a reinterpretar los paisajes forestales ibéricos al demostrar la presencia histórica de especies autóctonas actualmente ausentes por causas antrópicas. Para tal fin se ha seleccionado la comarca de Sierra Madrona y Valle de Alcudia (Ciudad Real), por su alta diversidad forestal en el conjunto ibérico, europeo y mediterráneo. Aunque se revisan literatura científica paleobotánica e historiográfica antigua, medieval y moderna, el estudio se centra en los últimos 3 siglos, en los que se puede sintetizar su historia pues hasta el siglo XX pervivían aquí estructuras paisajísticas y sociales primitivas.

Durante la Reconquista será la Orden Militar de Calatrava y, luego la Corona, quienes ostenten la propiedad de la comarca y disfruten de la riqueza de sus pastos y del monopolio mundial del merino, cuya lana era uno de los valores más cotizados de la Bolsa de Amsterdam hasta la aparición de los textiles sintéticos. Además existía una gran riqueza minera (mercurio, plata, plomo y otros metales). La población comarcal mantuvo largos conflictos con la demanda minera de leña y madera, y con los ganaderos invernantes que veían en el arbolado excelentes pastos de vuelo (ramón y bellota). Junto a la ganadería trashumante bajo la protección privilegiada de la Corona y centrada en el valle de Alcudia coexistía la ganadería local de pequeños propietarios que incendiaban reiteradamente las sierras para sus rebaños de cabras.

Entre los siglos XVIII y XX el estado vende la mayor parte de la comarca. Tanto los montes vendidos como los exceptuados de las desamortizaciones corrieron suerte diversa pero en general el impacto (ambiental, paisajístico y florístico) de las ventas no fue negativo, especialmente en las dehesas vendidas a ganaderos invernantes. Otros montes serranos antes de su venta ya eran jarales que ahora evolucionan hacia el bosque al haber desaparecido los incendios. La comarca tiende hoy hacia nuevos modelos de aprovechamiento compatibles con la recuperación del bosque: caza mayor, saca de corcho o turismo rural.

En la tesis se aborda también el estado actual de conservación de uno de los enclaves más emblemáticos de la comarca: el pinar de Pinus pinaster de la sierra de Navalmanzano. No solamente la presencia de este pinar refuta la idea de autores que consideraban a los pinares naturales ausentes en la mayor parte del SO ibérico, también la localización de 83 topónimos referentes a pinos (en el conjunto de Sierra Morena). A través del análisis paleobotánico e histórico se demuestra, además, que $P$. pinaster tenía una presencia muy importante en la comarca pero que desapareció por causas antrópicas.

Resulta llamativo que, a pesar de la milenaria orientación agroganadera (además de minera) de la comarca, el pinar haya podido sobrevivir hasta la actualidad. Su situación actual es el resultado de un prolongado aprovechamiento económico y social (tal y como se describe en la primera parte de la tesis). El último pinar natural de Sierra Morena posee una superficie de 12,25 ha y según el primer inventario realizado en 2003, cuenta con 1212 pies, con una 
estructura de masa irregular. En ese año se estimaron unas existencias de 749 conos maduros cerrados/ha. Cada piña con una media de 72,4 semillas y el porcentaje de germinación -medido en pruebas de germinación- fue del 66\% (en 2003 el banco aéreo contaba con unas 36.000 semillas viables/ha). Los análisis realizados sobre las distancias de dispersión de semillas muestran, además, que la distancia media de dispersión efectiva es bastante reducida (13 - $24 \mathrm{~m}$ de media).

Los resultados de una muestra de edades de 72 pies indican que a partir del año 2005 el regenerado observado es escaso. La incorporación de nuevos individuos en la masa se ha visto reducida durante los últimos años por la disminución del banco aéreo de semillas, causado por una población de ardilla instalada recientemente. Uno de los resultados más llamativos muestra que en 2005 este esciúrido había consumido un 30\% de los conos cerrados, porcentaje elevado al $70 \%$ en 2009.

Adicionalmente, se analiza el efecto del escodado producido por el ciervo sobre este pinar que en el año 2003 afectaba al $33 \%$ de los pies. Analizada la evolución del nivel de daños entre 2003 y 2009 se observa una tendencia creciente, tanto por el número de árboles dañados como por la intensidad del daño. El uso de un cercado de exclusión experimental durante 12 años (2003-2015) muestra que el escodado es otra amenaza para la supervivencia de este pinar. Para proteger a este bosque en peligro de extinción se plantea la reducción de la densidad de ciervo hasta niveles compatibles con la conservación de la masa forestal. 


\begin{abstract}
A multidisciplinary study has been performed to better understand the evolution of a diverse forest community and its present structure and to be able to plan adequately its future management. This thesis also helps to reinterpret the Iberian forest landscapes by showing the historical presence of native species that are currently absent due to anthropogenic causes. The region selected for this analysis was Sierra Madrona and the Alcudia Valley (Ciudad Real), due to its high forest diversity within the Iberian, European and Mediterranean context. Although paleobotanical, ancient, medieval and modern scientific and histographical literature are reviewed, this study mainly focuses on the last three centuries because these synthesize its history as primitive landscape and social structures survived in this region until the twentieth century.
\end{abstract}

First the Military Order of Calatrava and later the Crown held the property of the region after the Reconquista. They exploited the rich pastures of the region and benefited from the world monopoly of merino wool, which was one of the most valuable securities of the Amsterdam Stock Exchange until the appearance of synthetic textiles. The region was also rich in minerals (mercury, silver, lead and other metals). The local population needs remained in conflict with the mining demand for fuel-wood, and with wintering livestock breeders who saw in the trees excellent flight pastures (leaves and acorns). Next to the nomadic livestock, protected by the Crown and centered in the valley of Alcudia, coexisted local livestock smallholders who repeatedly burned the mountains for their herds of goats.

Between the XVIII and XX centuries the state sold most of the region. The fate of woodlands sold and also those exempted from the sales was diverse. However, overall impact on the environment, landscape and flora was not very negative, especially in the meadows sold to big wintering stockbreeders. Some areas were completely covered by shrubs (without trees) before the sales took place as a result of the continuous fires during the last centuries. The region now tends to new use of territory models compatible with the recovery of the forest, such as big game hunting, cork production and rural tourism.

The thesis also discusses the current state of conservation of one of the most emblematic sites of the region: the Pinus pinaster forest of Navalmanzano. The presence of this forest and the location of 83 place names relating to pines in the whole of Sierra Morena refutes the hypothesis proposed by some authors that states that pine forests were absent in most of southwest Iberia. Palaeobotanical and historical analyses also support the thesis of P. pinaster being more extensively preset in the region and that humans caused its local disappearance.

It is striking that despite the ancient livestock breeding orientation of the region, in addition to mining, the pine forest survived until today. Its current situation is the result of a prolonged economic and social use (as described in the first part of the thesis). This last natural pine forest of Sierra Morena only occupies an area of 12.25 ha. According to the inventory performed in 2003, it is composed by 1,212 individuals and has an irregular structure. In that year the stock of 
mature closed cones per ha was estimated to be of 749. Each cone contained an average of 72.4 seeds and $66 \%$ were viable as shown by germination trials. Therefore, in 2003 air bank was about 36,000 viable seeds/ha. Analyses of the seed dispersal distances also show that the average distance of effective dispersion is quite small (13 to $24 \mathrm{~m}$ on average).

The age of 72 pines was measured. The results indicate that since 2005 there is a lack of regeneration. The reduction in pine recruitment in recent years can be attributed to the declining air seed bank, caused by a recently installed squirrel population. One of the most striking results shows that in 2005 this mammal had consumed $30 \%$ of closed cones, and this percentage raised to $70 \%$ in 2009.

Finally, the effect produced by the deer rubbing in this forest was analyzed in 2003 . This deer action affected 33\% of the pines. The evolution of the level of damage between 2003 and 2009 was analyzed. The results show a growing trend in the number of trees and the intensity of the damage. An experiment with exclusion fencing for 12 years (2003-2015) shows that the rubbing is another threat to the survival of this pine forest. In light of these results, a measure proposed for the conservation of this endangered forest is the reduction of deer density. 


\section{CAPITULO 1 \\ INTRODUCCIÓN GENERAL}

Los procesos que determinaron la evolución biológica hasta los paisajes actuales se iniciaron con los grandes cambios preantrópicos (Montero \& Martín-Consuegra 2004; Carrión et al. 2006; Devesa \& Carrión 2012). Estos procesos motivaron que los ecosistemas naturales experimentaran grandes cambios preantrópicos, espaciales y temporales. El conocimiento de estos cambios y su relación con la evolución de la paleobiodiversidad cobra cada día mayor importancia pues puede ser parte fundamental de la comprensión y resolución de problemas ambientales actuales (Volkheimer 2002; Gillson 2015). Las diversas especies arbóreas y arbustivas de Sierra Madrona y Valle de Alcudia tienen su origen en el Terciario, aunque serán primero las glaciaciones del Cuaternario y, la acción antrópica, después, las que irán definiendo el paisaje actual. En tiempos históricos, la mayor trasformación del paisaje forestal ha sido por causas antrópicas (e.g. Valbuena-Carabaña et al. 2010). Aun teniendo en cuenta el pasado preantrópico, en esta tesis se prestará especial atención a la historia de los últimos 3 siglos, la más reciente y, por tanto, la que más afecta actualmente a los paisajes forestales.

La elección de Sierra Madrona y el Valle de Alcudia como sujeto de la presente tesis doctoral responde a la alta diversidad forestal de esta comarca en el conjunto ibérico, europeo y mediterráneo. Máxime cuando incluye restos de bosques ya desaparecidos de amplias zonas como el pinar de Navalmanzano, de gran interés biogeográfico.

\section{1. Área de estudio}

Sierra Madrona y el Valle de Alcudia forman una gran comarca natural bien definida. Ambas unidades geográficas se funden en la denominada sierra de la Umbría de Alcudia que si bien pertenece al dominio de Sierra Madrona, constituye el eje montañoso meridional que da sentido al Valle de Alcudia. Es decir, la sierra de la Umbría de Alcudia es el nexo de unión entre ambas "subcomarcas". (Fig. 1.1). Existen otras divisiones artificiales pero aquí se propone una delimitación del área de estudio basada exclusivamente en aspectos geográficos naturales. Aunque el resultado puede serlo, el método no es nada nuevo, pues ya desde antiguo se han utilizado líneas de cumbres y ríos para trazar divisiones administrativas. Así, la delimitación territorial entre el Arzobispado de Córdoba y la Orden Militar de Calatrava se hizo, en el siglo XIII, siguiendo la línea de cumbres de Sierra Quintana y el río Guadalmez. Delimitación natural por el sur de la comarca aquí estudiada que se mantiene hasta la actualidad, separando las provincias de Ciudad Real, Córdoba y Jaén (Fig. 1.2).

El relieve y las diversas unidades de paisaje han sido definidas en varias publicaciones durante las últimas décadas (e.g. Poblete \& Serrano 1991; García Rayego \& López López 1991; García Rayego 1995; Acosta et al. 1998). El paisaje lo define la gran amplitud del Valle de Alcudia, con $120 \mathrm{~km}$ de largo y unos $12 \mathrm{~km}$ de ancho, las 2 largas sierras que lo flanquean (sierra de la 
Solana de Alcudia y sierra de la Umbría de Alcudia) y el complejo de Sierra Madrona, el más elevado y escarpado de toda Sierra Morena (mayores altitudes en torno a los $1200 \mathrm{~m}$, con la máxima en el pico Bañuela -1322 m-). A diferencia de las comarcas del entorno como La Mancha, La Serena o Los Pedroches, posee relieves más o menos accidentados, sin llanuras de consideración (Fig. 1.3). Geológicamente se sitúa en el Macizo Hercínico Ibérico, en el dominio geológico de la zona definida por Julivert et al. (1972) como Centroibérica y formada por materiales muy antiguos (precámbricos y paleozoicos) con depósitos Plio-Cuaternarios (rañas) y un pasado volcánico significativo.

La temperatura media anual ronda $\operatorname{los} 15^{\circ} \mathrm{C}\left(14,7^{\circ} \mathrm{C}\right)$ pero con un tenue gradiente de este (unos $\left.14,5^{\circ} \mathrm{C}\right)$ a oeste $\left(\sim 16,5^{\circ} \mathrm{C}\right)$, según aumenta la influencia atlántica y desciende la continentalidad. $\mathrm{El}$ contraste entre las temperaturas medias del verano y del invierno es acusado, con unos $25^{\circ} \mathrm{C}$ en verano (máximas de hasta $48^{\circ} \mathrm{C}$ y unos $6{ }^{\circ} \mathrm{C}$ en invierno (con mínimas de hasta $-12,5^{\circ} \mathrm{C}$ ).

Las precipitaciones medias anuales son de $566 \mathrm{~mm}$. El rango oscila entre los $450 \mathrm{~mm}$ en zonas del centro del Valle de Alcudia (con un mínimo de $381 \mathrm{~mm}$ en el embalse del Montoro -datos facilitados por Repsol-) y los 700 mm en Sierra Madrona (AEMET).

La flora y vegetación de la comarca, en particular, y de Sierra Morena oriental, en general, fue estudiada ya en el siglo XIX por Laguna (1868, 1870) y Willkomm (1861-1880). Más recientemente por Rivas Goday y sus discípulos con una decena de trabajos (e.g. Rivas Goday 1950; Rivas Goday et al. 1954; Ocaña 195; Ladero 1987; Rivas Martínez et al. 1986; Cano \& Valle 1990; Pérez-Chiscano 1994 o Cano et al. 2004. Destaca el reciente libro sobre flora y vegetación de García Río (2006).

Los bosques y dehesas del fondo del Valle de Alcudia, y las comarcas del entorno, están ahora dominados por la encina (Quercus ilex L. ). Otras formaciones forestales, con mayor o menor cobertura según las condiciones edafoclimáticas son los bosques esclerófilos de alcornoque $(Q$. suber L.) con peral silvestre (Pyrus bourgaeana L.), madroño (Arbutus unedo L.) y labiérnago (Phillyrea angustifolia L.), así como los semicaducifolios de quejigo [Q. faginea subsp. broteroi (Cout.) A. Camus] y los caducifolios de roble ( $Q$. pyrenaica Willd.). Los últimos forman bosques en las umbrías de las sierras más altas, llevando en su cortejo florístico árboles semicaducifolios y caducifolios como el quejigo moruno ( $Q$. canariensis Willd.), el arce (Acer monpessulanum L.), el cerezo silvestre (Prunus avium L.) y serbales como Sorbus torminalis (L.) Crantz., S. aria (L.) Crantz. y S. domestica L. En zonas más soleadas y rocosas perviven formaciones de enebro de la miera (Juniperus oxycedrus var. badia $\mathrm{H}$. Gay) y, en vertientes más secas y cálidas, las expuestas al sur, se desarrollan a veces importantes formaciones de acebuche (Olea europaea var. sylvestris (Mill.) Lehr). En el fondo de los valles, en cursos de aguas permanentes o semipermanentes, son comunes los bosques riparios de fresno (Fraxinus angustifolia Vahl.), aliso (Alnus glutinosa (L.) Gaertn.) y cuatro especies de sauces (Salix spp.). Cabe también destacar, por su importancia biogeográfica, al pinar de Pinus pinaster Ait. de la sierra de Navalmanzano. 


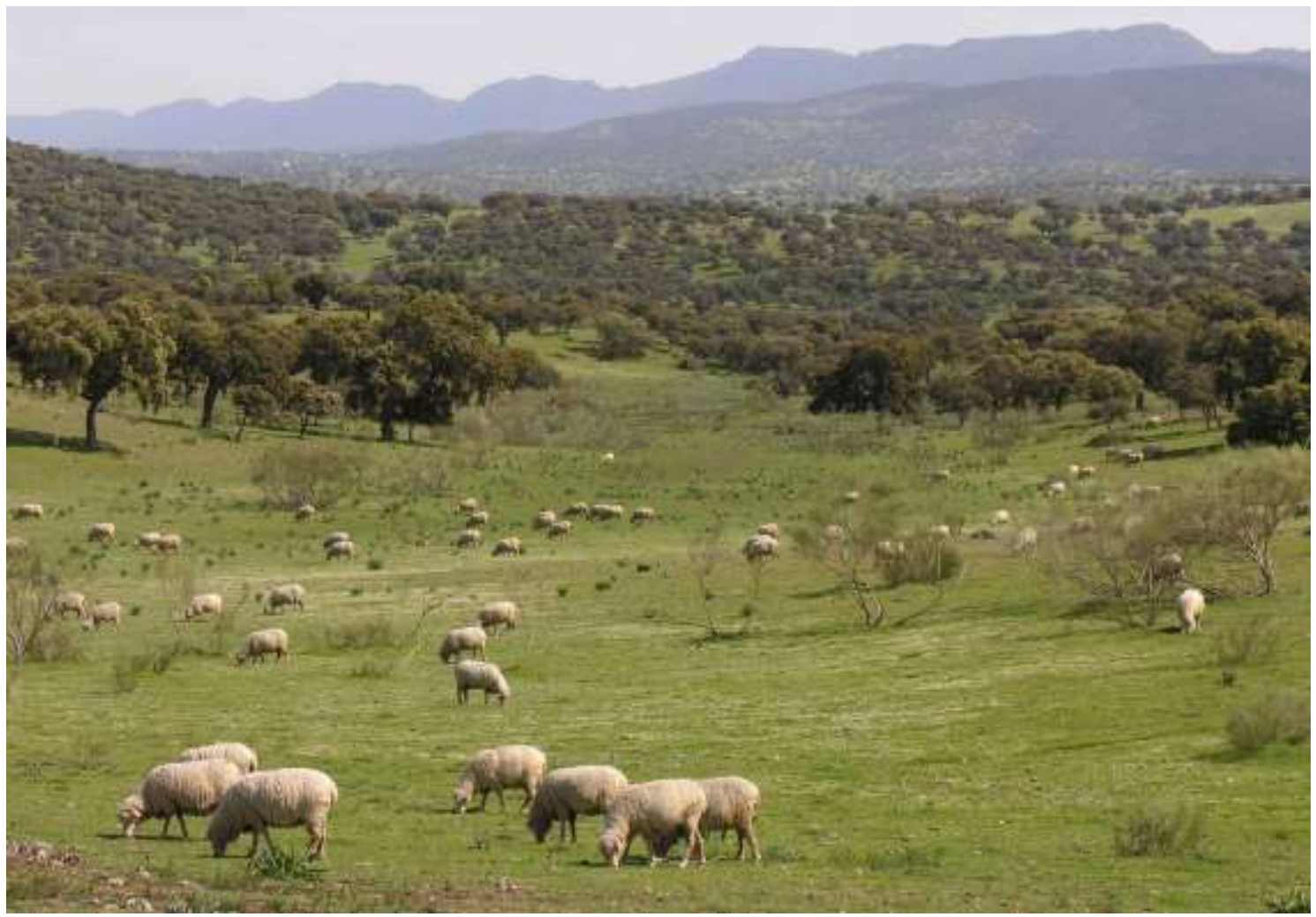

Fig. 1.1. Típica imagen del Valle de Alcudia con la gran línea de cumbres de Sierra Madrona al fondo.

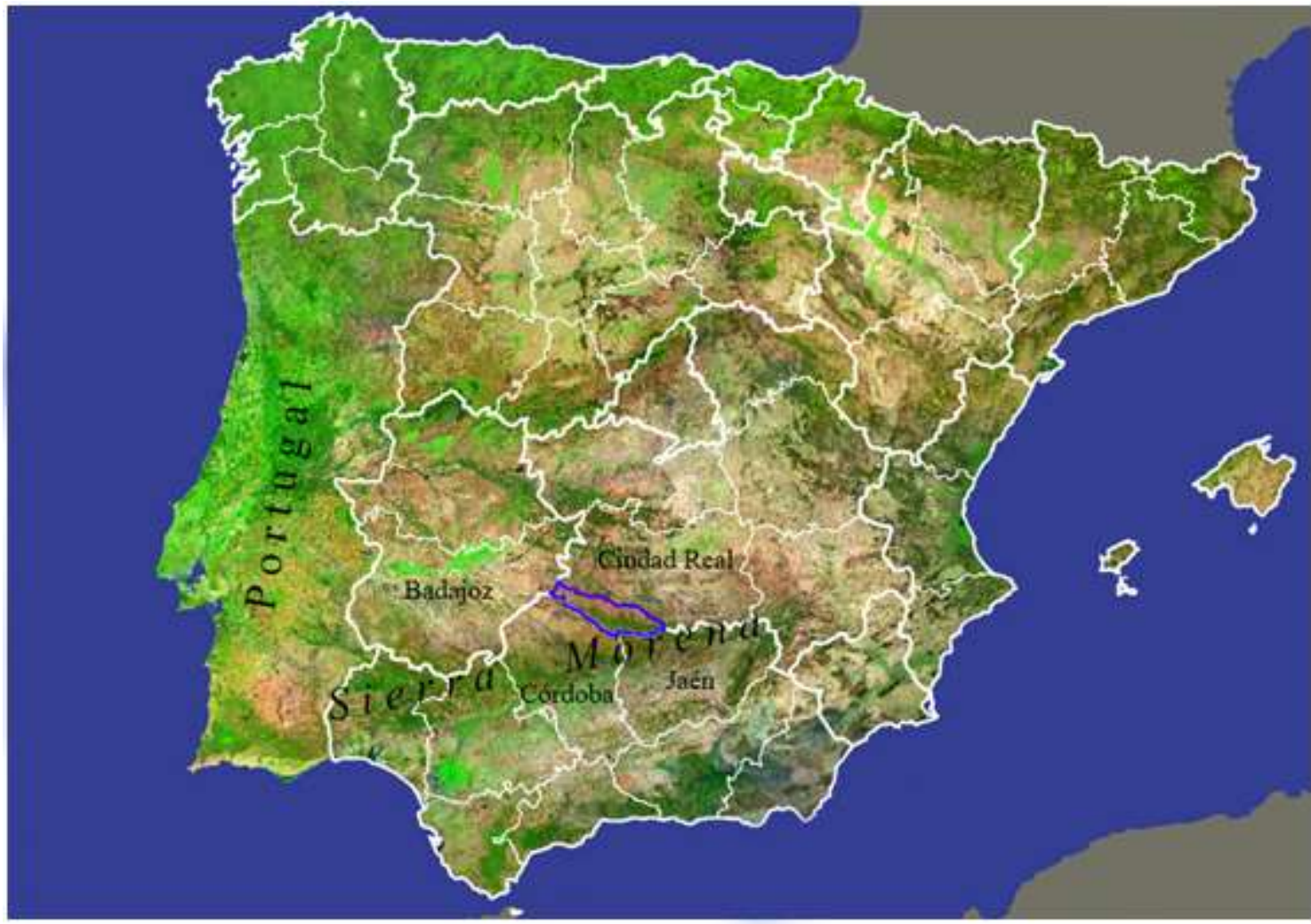

Fig. 1.2. Localización del área de estudio y sus límites en trazo azul. Mapa base: IGN. Aunque situada básicamente en la provincia de Ciudad Real, tiene importantes conexiones geoclimáticas, biológicas e históricas con las provincias limítrofes de Badajoz, Córdoba y Jaén. 


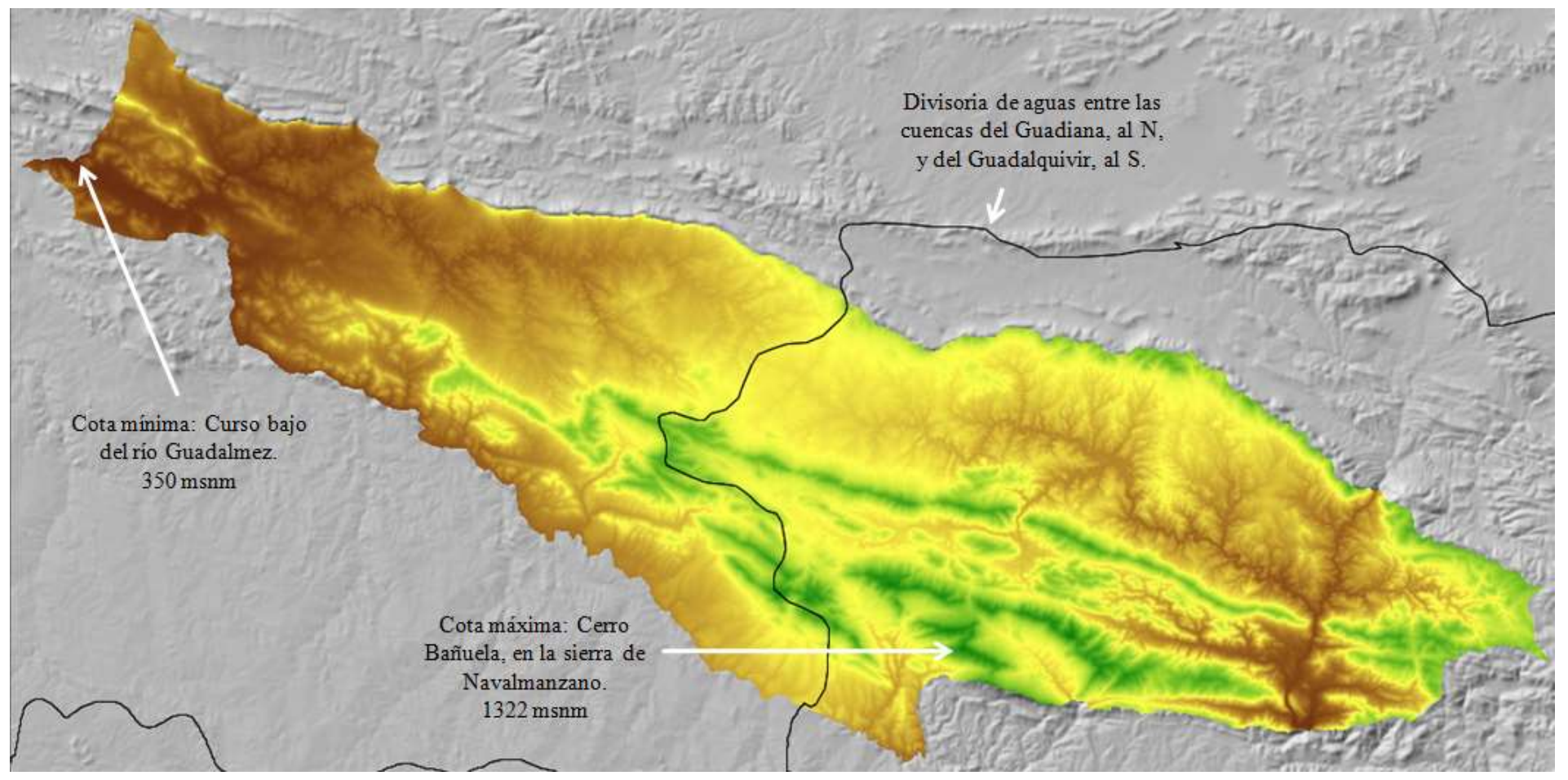

Fig. 1.3. Modelo de elevaciones del terreno mostrando un relieve abrupto, sin ninguna llanura relevante. Por su situación entre La Mancha y la depresión del Guadalquivir, es zona de cabecera de 2 grandes cuencas hidrográficas.

El matorral, que en algunas laderas, especialmente de solana, puede llegar a ser dominante, está compuesto principalmente por jara pringosa (Cistus ladanifer L.) y otras cistáceas (Cistus spp, Halimium spp. y Helianthemum spp.), brezos (especialmente Erica arborea L. y E. australis L.), genistas (Genista hirsuta Vahl.), romero (Rosmarinus oficinalis L.), lavanda o cantueso (Lavandula stoechas L.). Cuando la intervención humana cesa durante décadas, lo normal aquí es que estos matorrales evolucionen hacia el bosque (Charco \& García Rayego 2002).

Aunque ya es una rareza, el pinar autóctono de $P$. pinaster supone uno de los bosques de mayor interés científico. Este pinar goza de figuras de protección gracias a los trabajos previos a esta Memoria iniciados en el año 2002 y a la sensibilidad de los botánicos locales. Actualmente es "Hábitat de Interés Comunitario", catalogado como "Pinar natural de Pinus pinaster de Navalmanzano" en la categoria "Hábitat de Protección Especial 9540, de Pinares mediterráneos de pinos mesogeanos endémicos".

Entre la fauna cabe destacar al ciervo (Cervus elaphus L.) como la especie de mayor importancia socioeconómica en la comarca. También destacan por su importancia ecológica y socioeconómica el águila imperial ibérica (Aquila adalberti Brehm), el buitre negro (Aegypius monachus L.) o la cigüeña negra (Ciconia nigra L.), que suponen un recurso económico cada vez mayor a través del turismo ornitológico (e.g. Gosalves 2010).

La comarca de Sierra Madrona y el sector meridional del Valle de Alcudia, tienen la calificación de área crítica para las aves citadas y para el lince ibérico. Por el Decreto 275/2003, de 09 de 
septiembre, se aprobaron los planes de recuperación de las tres aves y se declararon zonas sensibles las áreas críticas para su supervivencia en Castilla-La Mancha. Y por Decreto 276/2003, de igual fecha, el relativo a los planes de recuperación y zonas sensibles del lince ibérico (Lynx pardinus Temminck). Todas estas áreas se hallan bien representadas en la comarca.

Por estos y otros valores naturales la comarca está declarada como Lugar de Importancia Comunitaria con la denominación de LIC "Sierra Morena” (ES4220014). También es Zona de Especial Protección para las Aves (ZEPA) mediante el Decreto 82/2005, de 12 de julio. Todas estas figuras han incluido a la comarca en la Red Natura 2000 con la denominación de "Sierra Morena" código ES0000090.

Existen varios espacios protegidos de interés natural pero el más importante por su extensión, declarado por Ley 6/2011, de 10 de marzo, es el Parque Natural del Valle de Alcudia y Sierra Madrona, aprobada por las Cortes de Castilla-La Mancha el 10 de marzo de 2011 y publicada en el Diario Oficial de Castilla-La Mancha no 56 de 22-03-2011. Con una superficie de 149.463 ha, más otras 1.156 ha de las Zonas Periféricas de Protección.

En cuanto al poblamiento humano, la comarca reúne a 12 municipios, 8 con su casco urbano y todo su término en el área de estudio y 4 con gran parte del término incluido pero con el recinto urbano fuera (Fig. 1.4). El término de Almodóvar del Campo es el de mayor superficie de la comarca y el $3^{\circ}$ mayor de España, en él se incluye casi la mitad del Valle de Alcudia.

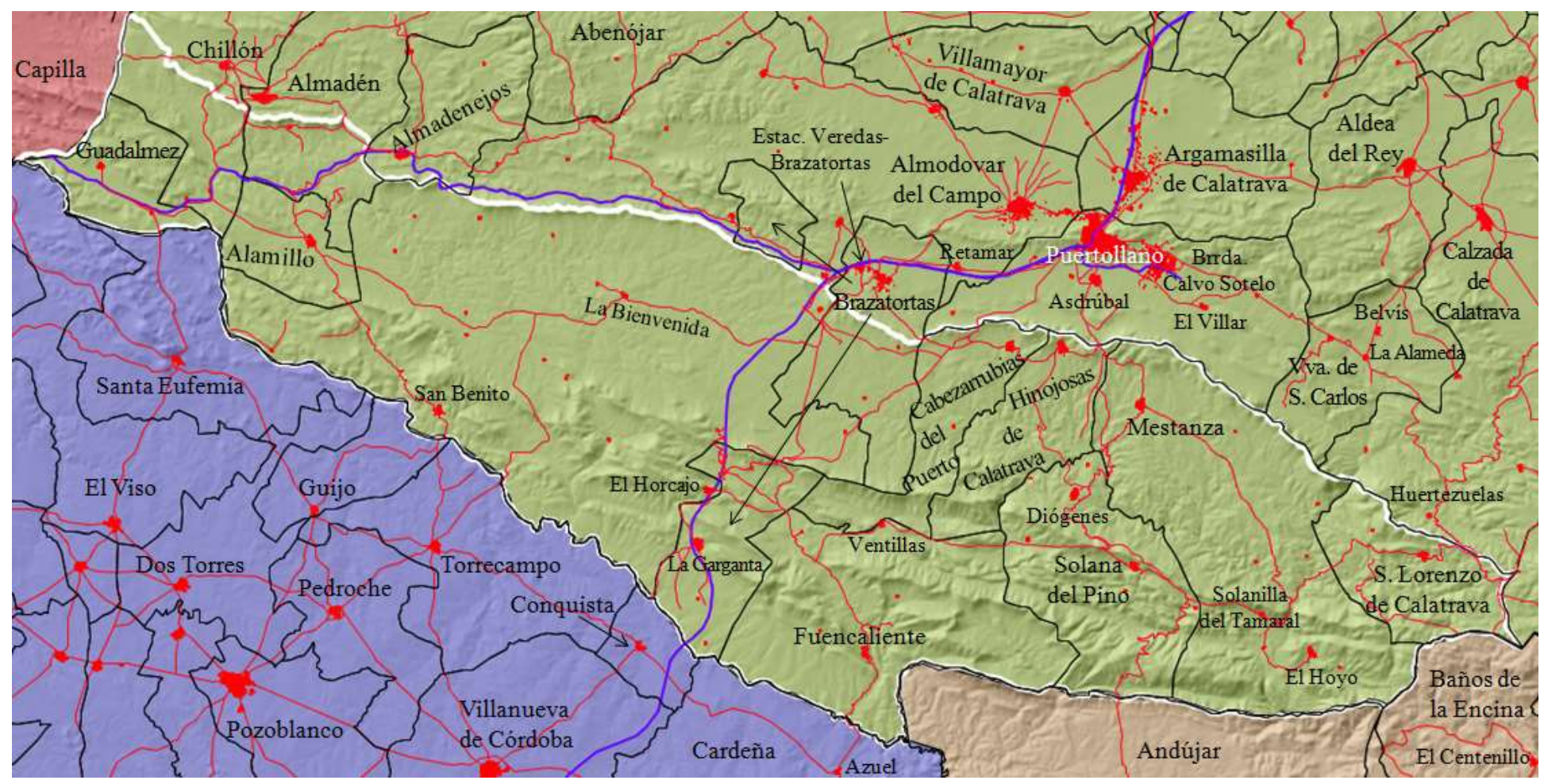

Fig. 1.4. Pueblos, términos municipales, infraestructuras y entorno inmediato. Los colores diferencian las provincias de Ciudad Real, Jaén (SE), Córdoba (SO) y Badajoz (NO). Líneas negras: términos municipales. Líneas rojas: carreteras. Líneas azules: ferrocarriles. Línea blanca: área de estudio. Los nombres con menor tamaño de letra corresponden a pedanías, poblados mineros y/o aldeas. 
La población actual es de 20.282 habitantes (INE 2015) y posee una densidad de población de 6,93 habitantes $/ \mathrm{km}^{2}$ (Tabla 1.1). Muy baja respecto al conjunto de España (92 h/km²).

\begin{tabular}{|c|c|c|c|}
\hline \multicolumn{4}{|c|}{$\mathrm{N}^{0}$ de habitantes y densidad de población } \\
\hline $\begin{array}{l}\text { Localidad, con sus pedanías y } \\
\text { aldeas }\end{array}$ & $\begin{array}{l}\text { Habitantes } \\
\text { en } 2014\end{array}$ & Sup. $\mathbf{k m}^{2}$ & $\begin{array}{l}\text { Densidad } \\
\mathbf{h a b} / \mathbf{k m}^{2}\end{array}$ \\
\hline Guadalmez & 841 & 72,0 & 11,68 \\
\hline Chillón & 1.983 & 207,8 & 9,54 \\
\hline Almadén & 5.861 & 239,6 & 24,46 \\
\hline Alamillo & 531 & 67,3 & 7,89 \\
\hline Almodóvar del Campo & 6.582 & $1.208,3$ & 5,45 \\
\hline Brazatortas & 1.037 & 271,8 & 3,82 \\
\hline Cabezarrubias del Puerto & 528 & 100,6 & 5,25 \\
\hline Hinojosas de Calatrava & 498 & 102,5 & 4,86 \\
\hline Fuencaliente & 1.088 & 269,9 & 4,03 \\
\hline Solana del Pino & 363 & 180,1 & 2,02 \\
\hline Mestanza & 744 & 370,0 & 2,01 \\
\hline San Lorenzo de Calatrava & 226 & 105,7 & 2,14 \\
\hline Total & 20.282 & $3.195,6$ & - \\
\hline Media & $1.690,20$ & 266,30 & 6,93 \\
\hline Mediana & 792,50 & 193,93 & 5,05 \\
\hline Desviación estándar & $2.078,42$ & 298,20 & 6,03 \\
\hline
\end{tabular}

Tabla 1.1. Datos demográficos de la comarca Sierra Madrona y Valle de Alcudia. Fuente INE (2015).

Por actividades, el sector primario (agricultura, ganadería y montes) sigue siendo el más importante en la comarca. El otro sector importante de actividad es el terciario (servicios turísticos, construcción, asesorías, etc). La minería, antaño tan importante en la comarca, ha desaparecido por completo. En el sector secundario existen algunas actividades de envasado y manufactura de productos agroalimentarios (aceite, queso y otros derivados lácteos, embutidos, miel, etc). Aunque no sea un sector de actividad propiamente dicho, la consolidación del estado de bienestar, con subvenciones a numerosas actividades, prestaciones a desempleados y pensiones a jubilados, permite también la entrada en la comarca de una considerable fuente de ingresos.

Además de la comarcalización Agraria que el Ministerio de Agricultura creó en 1976, actualizada para la provincia de Ciudad Real en 2010 (MAGRAMA 2012), hay otra comarcalización importante para aprovechar los programas de desarrollo y las iniciativas comunitarias LEADER y PRODER. El objetivo de estos programas fue aplicar un modelo de desarrollo rural de carácter integrador y el fomento de actividades públicas y privadas. El proceso comenzó a finales de la década de 1980 con la formación de los Grupos de Acción Local, que activaban estos programas en cada comarca. La Asociación para el Desarrollo de la Comarca de Almadén "Montesur", trabaja en la parte occidental de la comarca aquí propuesta, coincidiendo con el área de la comarca agraria "Montes Sur". La Asociación para el Desarrollo Sostenible del Valle de Alcudia, actúa en las partes central y oriental, en una zona que, en el área de estudio aquí propuesta, coincide con la comarca agraria "Pastos" (Fig. 1.5). 


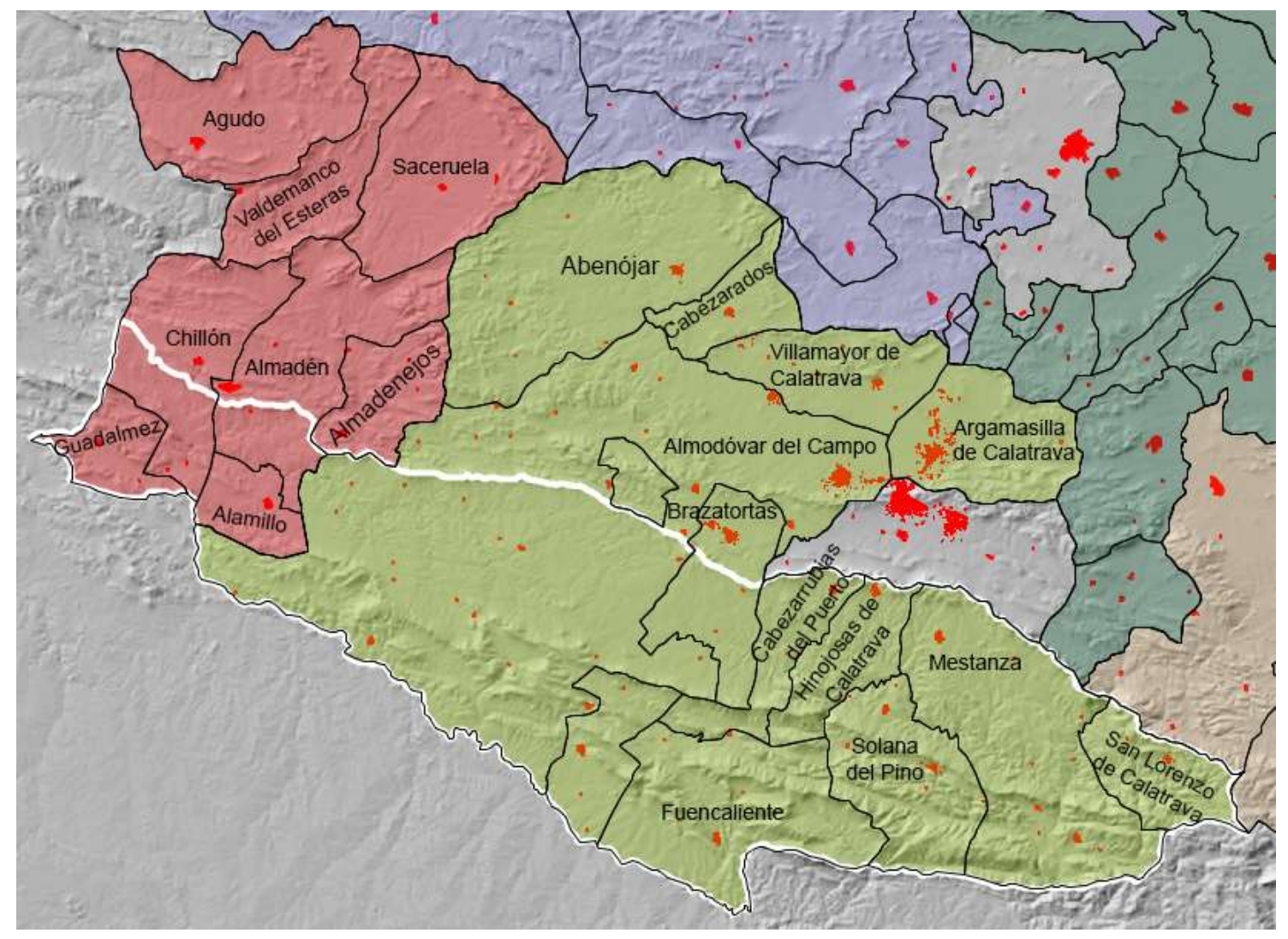

Fig. 1.5. Comarcalización a efectos de agricultura, ganadería y desarrollo rural. El área de estudio se ve así dividida en 2 partes. A occidente, en rojo, la comarca agraria "Montes Sur", área de actuación de la Asociación para el Desarrollo de la Comarca de Almadén "Montesur". En el centro y oriente, en verde, la comarca agraria "Pastos" zona de actuación de la Asociación para el Desarrollo Sostenible del Valle de Alcudia.

Al contrario que en el pasado, hoy es una comarca moderna, con todo tipo de servicios, bien comunicada tanto con el exterior como entre pueblos y fincas.

\subsection{Origen y evolución prehistórica de los bosques en Sierra Madrona y Valle de Alcudia}

Entre la geoflora paleotropical (Mai 1989; Knobloch et al. 1993) los pinos estuvieron bien representados, con dominio de los termófilos durante el Paleógeno, por su clima más cálido. Tras las sequías del Mioceno y el enfriamiento del Plioceno, las laurisilvas desaparecieron y en algunas zonas los pinos ocuparon su lugar, Pinus fluvimajoricus, P. praepinaster, P. halepensis у P. canariensis (ver revisión en Pais 2010). Las fagáceas perennifolias del Terciario (Quercus, Castanopsis, Trigonobalanus, Trigonobalanopsis, Lithocarpus) experimentaron una destacada diversificación, llegando a nuestros días como dominantes las del género Quercus. Este género aparece a finales del Cretácico (Pokrovskaia 1950; Salgado 1984), se consolida a principios del Terciario y al menos desde el Oligoceno ya está bien representado en España (e.g. Polo et al. 1987; Sanz de Siria 1996). La mayor parte de las especies de árboles y arbustos actuales de Sierra Madrona y Valle de Alcudia ya tenían ancestros muy similares en el Terciario (Fig. 1.6). 

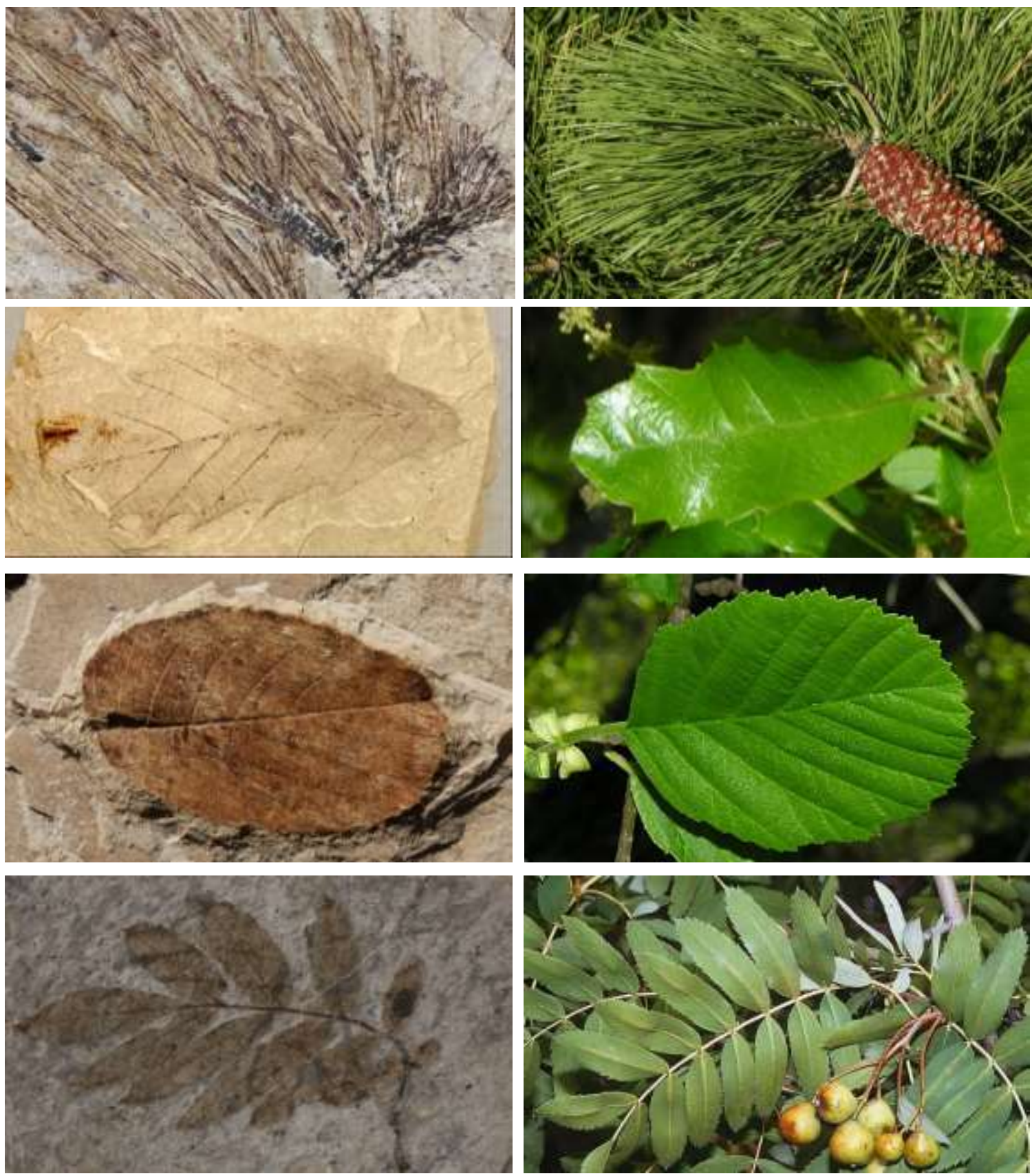

Fig. 1.6. Especies fósiles del Terciario ibérico (fotos E. Barrón) y de especies actuales presentes en Sierra Madrona y Valle de Alcudia de los mismos géneros (fotos J. Charco). De arriba-abajo: Pinus hepios y $P$. pinaster, Quercus hispanica y Q. faginea, Alnus sp. y A. glutinosa, Sorbus sp. y S. domestica.

Durante el Terciario, las perturbaciones sufridas por incendios forestales (e.g. Barrón 2002, Pausas \& Keeley 2009), a veces provocados por el activo vulcanismo Plio-Pleistocénico del Campo de Calatrava, generaron grandes espacios abiertos. Pero lejos de recuperarse el bosque tras la perturbación, las manadas de grandes herbívoros mantendrían praderas herbáceas configurando un entorno sabanoide similar al del actual Valle de Alcudia (Fig. 1.7). No se puede entender el paisaje ibérico del Terciario solo con el registro paleobotánico. Por ello, se empieza a prestar una mayor atención a estos otros aspectos fundamentales (Samdom et al. 2013). 


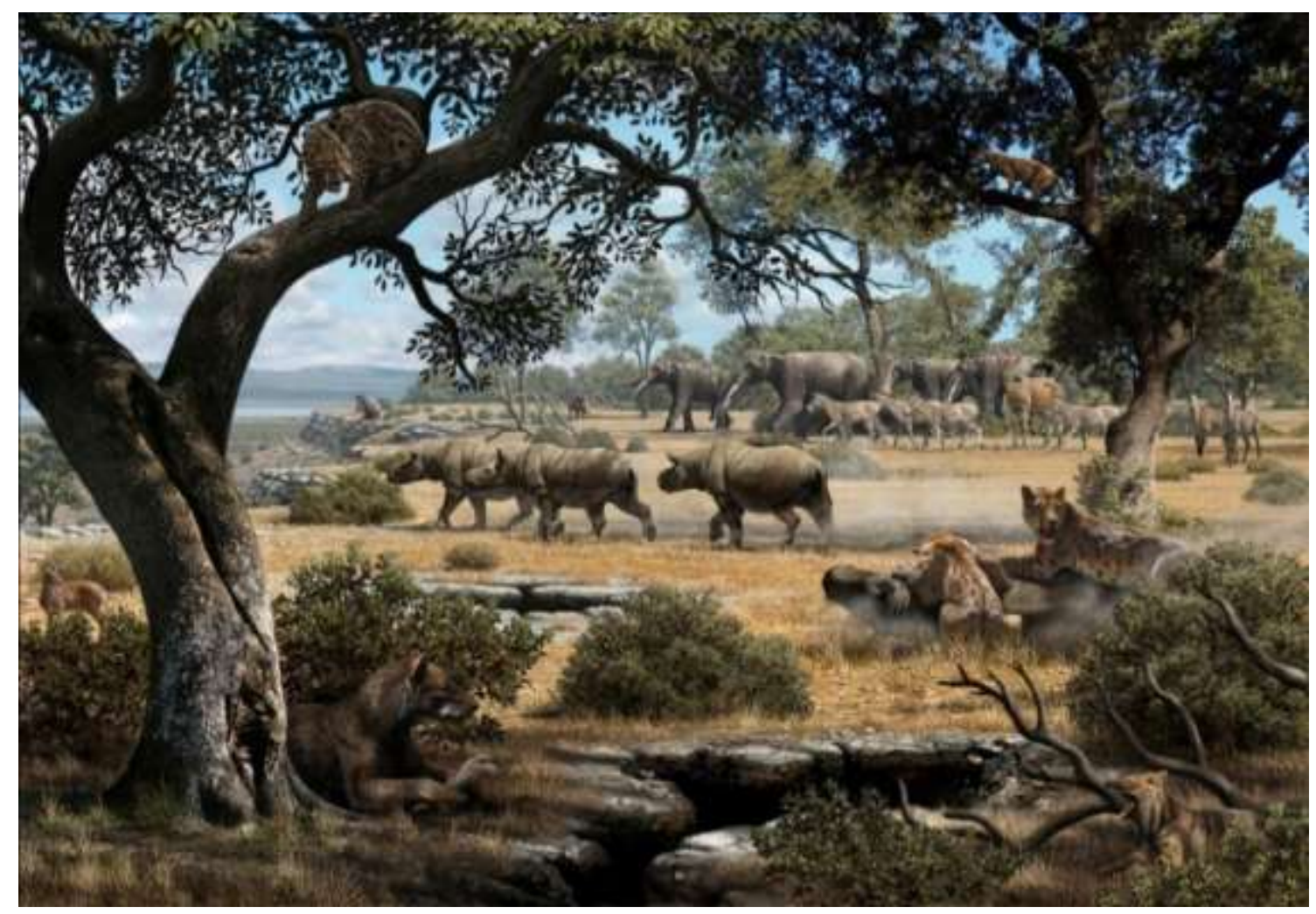

Fig. 1.7. Paleoambiente del centro de España durante el Mioceno superior. A pesar de la diversificada comunidad de carnívoros, los grandes herbívoros formarían manadas de cientos e incluso de miles de individuos que mantendrían los bosques aclarados en las zonas más llanas. Ilustración de Mauricio Antón.

La mayoría de los géneros y especies del Terciario se extinguieron aquí y en toda la Península ibérica antes de la llegada del Cuaternario (Postigo et al. 2009). En resumen, durante el Terciario, el paisaje de Sierra Madrona sería en esencia boscoso, con densas laurisilvas de fagáceas perennifolias y lauráceas, especialmente en las umbrías, mientras que el Valle de Alcudia, aunque potencialmente forestal, mantendría una vegetación de tipo sabanoide debido al impacto de la megafauna. El Valle de Alcudia en el Terciario probablemente fuera un pastizal con árboles dispersos muy similar al actual, especialmente a partir del Mioceno, aunque con un mayor número de especies arbóreas, un mayor número de especies de grandes herbívoros y nula presencia humana.

A lo largo del Cuaternario el clima se irá haciendo más frío. En las cumbres de Sierra Madrona se observan importantes procesos de gelifracción cuaternarios, pero no glaciarismo; es decir no hubo hielos perpetuos. Esta sierra de alineaciones montañosas E-O desempeñaría un papel de refugio para numerosas especies durante el Cuaternario.

Las glaciaciones extinguieron de la península ibérica a las especies arbóreas de géneros como Cathaya, Elaeagnus, Engelhardia, Eucommia, Keteleeria, Liquidambar, Nyssa, Parrotia, Parthenocissus, Pterocarya, Sciadopitys, Symplocos y Tsuga. Ya en el Pleistoceno medio desaparecen Aesculus, taxodiáceas y mimosoideas, poco después los géneros Ostrya y Carya. 
Las sucesivas glaciaciones incrementaron la pérdida de taxones terciarios y, en la última, se pierde el género Picea y casi también Carpinus (Postigo-Mijarra et al. 2010). En los últimos periodos glaciares ya sólo dos géneros dominarán en el paisaje forestal, Pinus, en los periodos glaciares, y Quercus, en los interglaciares (Fig. 1.8).
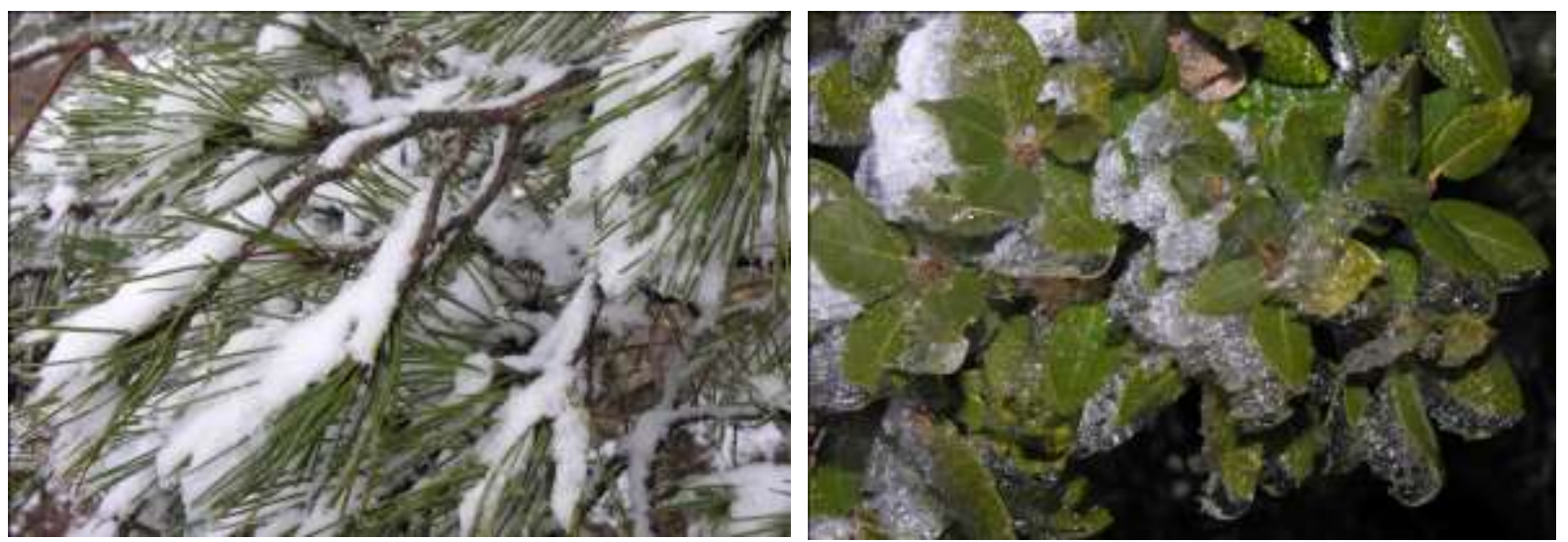

Fig. 1.8. Los géneros Pinus y Quercus (perennifolios y caducifolios) han mostrado ser los mejor adaptados al Cuaternario entre los numerosos géneros de especies arbóreas ibéricas. Ambos soportan bien el frío, el calor y la sequía. Los rangos de tolerancia edafoclimática de sus diferentes especies son la clave de su éxito.

La dualidad Pinus/Quercus hoy ha desaparecido y la dominancia generalizada es la de Quercus, en especial de la encina, la especie más rústica del género y con mayor capacidad de formación de polen y de bellota que, junto a la calidad de su carbón, la convirtieron en el árbol más interesante para la frutalización del bosque ibérico (Fig. 1.9).

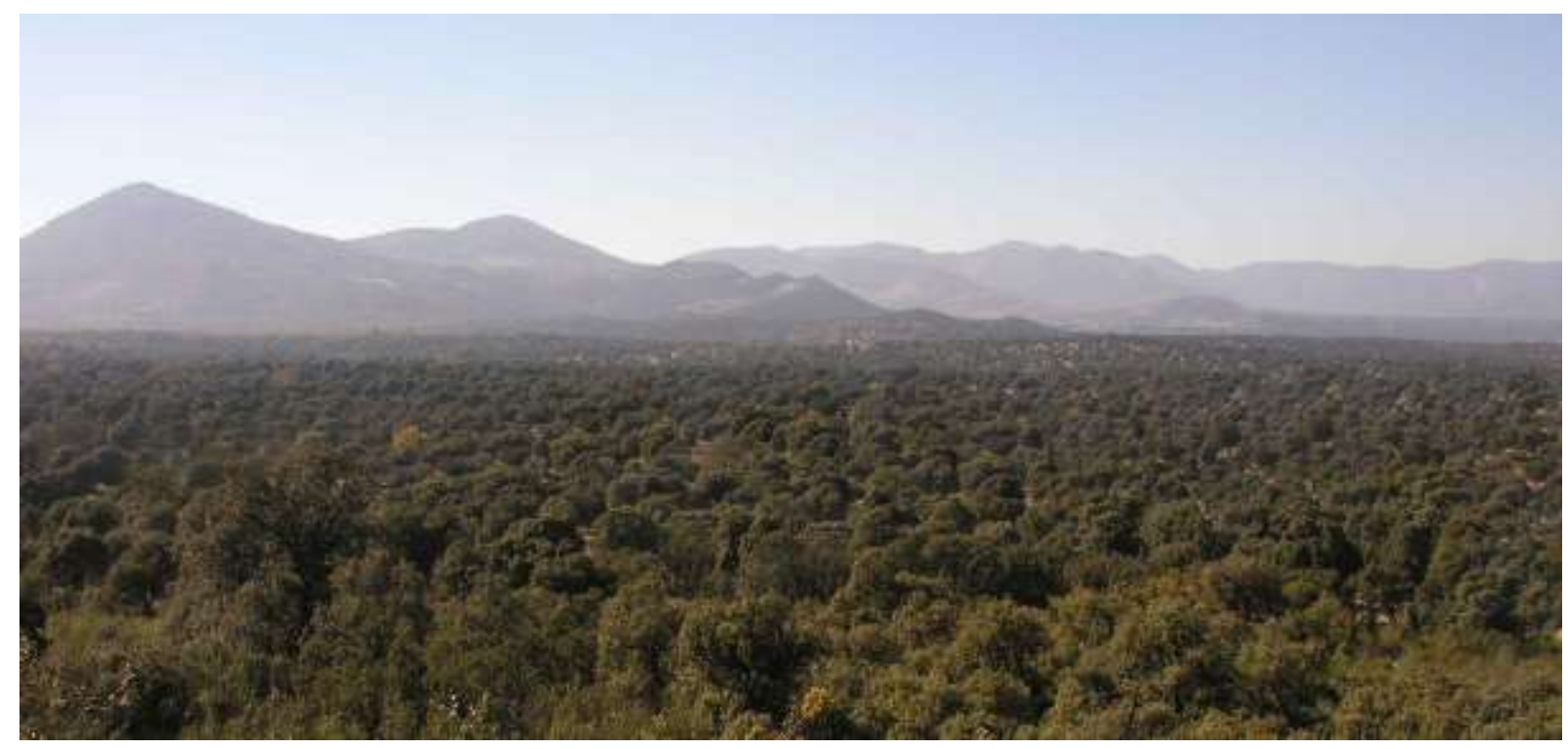

Fig. 1.9. El Valle de Alcudia durante el óptimo climático del Holoceno estaría cubierto por un denso y extenso bosque. Con dominio de Quercus estarían $Q$. ilex, $Q$. suber y $Q$. faginea. En las sierras esta diversidad se ampliaría con los géneros Pinus (P. pinaster) y Juniperus (J. oxycedrus), en los peores sustratos de las solanas, y con los robles (Q. pyrenaica), en las umbrías. 
Durante el Pleistoceno vivieron en la península ibérica 4 ó 5 especies de homínidos, cuya presencia en el área de estudio se ha detectado en yacimientos, al menos, desde el Pleistoceno inferior en zonas del Tajo, (Pinedo y Puente Pino) y del Campo de Calatrava (Porzuna, el Martinete, Albalá y en otros yacimientos o restos de industria lítica achelense y musteriense dispersa por ríos y lagunas) (e.g. Santonja \& Villa 2006, De la Torre 2007). Ninguna de estas especies causó impactos de consideración sobre los bosques del Pleistoceno, al no desarrollar actividades agroganaderas. A partir del Mesolítico y, más especialmente en el Neolítico, desde hace al menos 7000 años, es el último homínido superviviente del Cuaternario, Homo sapiens sapiens Mayr, quién se estableció en poblados cada vez más permanentes (e.g. Bueno et al. 2007). La sedentarización, junto a la ganadería, la agricultura, la minería y las guerras asociadas, marcaron el inicio de la deforestación de origen antrópico.

La frondosidad de los bosques y la abundancia de fauna aumentaron según avanzaba el Holoceno, hasta llegar al óptimo climático (hace unos 9000 años) en que se estabilizó un paisaje forestal dominado, en el Campo de Calatrava, por bosques de Quercus perennifolios y caducifolios, con presencia también, aunque en menor medida de Pinus y Olea (Dorado-Valiño et al. 2002). Todo esto permitía al hombre diversificar y enriquecer considerablemente su dieta y calidad de vida. Aunque ya había exterminado a los mayores mamíferos (mamuths, rinocerontes, bisontes, renos, ...), o habían emigrado hacia el Norte, la caza seguía siendo abundante con especies como los uros, encebras, ciervos, corzos, cabras monteses, jabalís ... y los numerosos conejos.

\subsection{Primeros impactos humanos sobre los bosques y el paisaje. Del Neolítico al Imperio romano.}

La sedentarización implicó, hace unos 3000 años, la obligada distribución del territorio según aumentaba la densidad de población y el número de aldeas y pueblos. Las diferentes entidades ibéricas (olcades, bastetanos, vettones, lusitanos, carpetanos ...) tendrían su espacio, cultura y poder delimitados espacialmente (e.g. Bermejo 2011; Collado 2014). A ambos lados de Sierra Morena oriental se situaba la Oretania, con importantes ciudades en el norte, desde Sisapo, en el Valle de Alcudia, hasta Libisosa (Albacete), y en el sur, donde destacaban especialmente Orissia y Castulo (Jaén). A ciudades con más de 14 ha de superficie, como Lacurris (Alarcos, Ciudad Real), se unirían numerosos poblados menores. En total se han registrado más de 200 yacimientos solo en la Oretania septentrional (e.g. García Huerta \& Morales 2007) (Figs. 1.10 y 1.11). El impacto que causaron los oretanos sobre los bosques y los suelos que cubrían debió ser considerable. Además de la agricultura, ganadería y guerra, desarrollaron la minería (Contreras \& Cámara 2005). La explotación minera (y la incipiente industria metalúrgica) suponía la tala de miles de árboles para entibar y fabricar sistemas constructivos (escaleras, tornos, norias, bombas, etc.), así como para quemar en los hornos para la trasformación del mineral y el servicio a la población minera. 

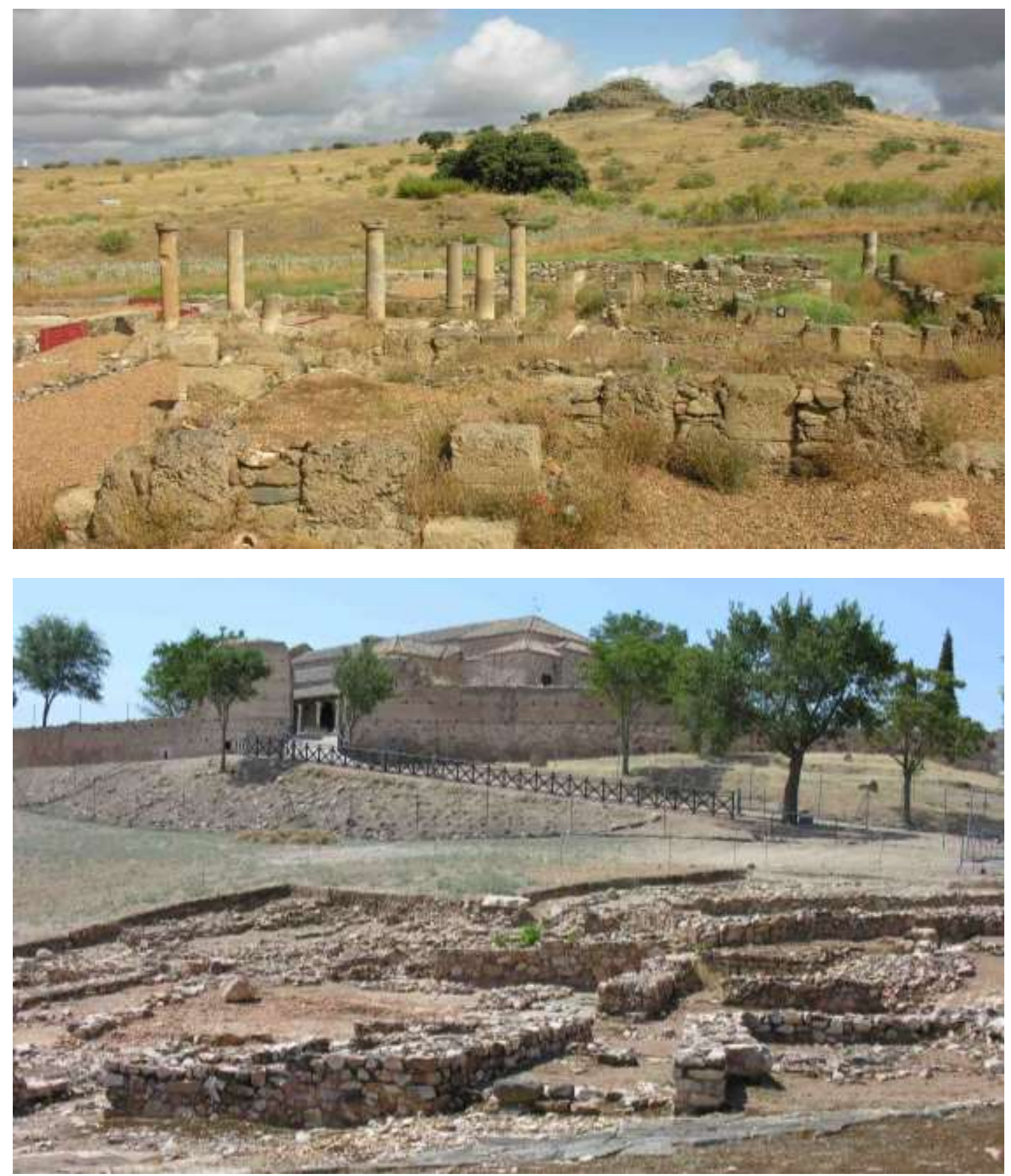

Figs. 1.10 y 1.11. Arriba, ruinas de Sisapo, en el centro del Valle de Alcudia, importante ciudad íbera entre la Oretania y la Turdetania, que debía su prosperidad a los recursos mineros de la zona (plomo, plata y cinabrio). Abajo, excavaciones en Lacurris (Alarcos, al sur de Ciudad Real), una de las ciudades más importantes de la Oretania septentrional. Lacurris se abandonó en el periodo romano pero Sisapo siguió creciendo hasta convertirse en la cabeza del distrito minero romano septentrional de Sierra Morena.

Tras más de 200 años de guerras con cartagineses, primero, y con romanos, después, las tierras hispanas se pacifican en el año $19 \mathrm{aC}$. Las ciudades oretanas que prosperaron en el periodo romano son la señalada Sisapo (en el Valle de Alcudia, Oretania septentrional) y Cástulo (en el alto Guadalquivir, Oretania meridional), que crecerán hasta ser las dos cabezas del distrito minero de Sierra Morena. Los romanos abrieron y explotaron numerosas minas por toda Sierra 
Madrona y el Valle de Alcudia, creando poblados mineros, lavaderos de mineral, nuevas vías de comunicación, etc. (Fernández Rodríguez \& García Bueno 1993; Hevia 2003; Zarzalejos 2011).

Con los visigodos la minería decae hasta casi desaparecer, tras más de 1000 años de explotación metalífera iniciada en el Calcolítico. En la provincia de Ciudad Real parece que solo se mantuvieron Oretum y Laminium mientras que, en el resto del territorio, la ruralización fue un hecho, con la población dispersa por pequeños poblados (vicus) y grandes casas de labranza (villae) (Izquierdo 2002a).

El fin del primer gran periodo de explotación minera y deforestación tras la caída de Roma no implicó siempre la regeneración de los bosques primigenios. El proceso de pérdida de los horizontes edáficos superficiales, solo permitió en muchas zonas la recuperación de plantas de porte herbáceo, base de la ganadería. Este aprovechamiento se convertirá en la principal riqueza durante el periodo musulmán. Toda la parte norte de Sierra Morena oriental quedó comprendida en la Marca Media (Al-Targ al-awsat), con capital en Toledo, siendo la ciudad más cercana al área de estudio Calatrava (Qual-at Rabah) y algunas fortalezas dispersas como Hisn Al Kudiat (probablemente junto a la antigua Sisapo) y Karacawa (Caracuel). Los árabes explotaron las minas de Almadén, de los que recibieron su nombre (Al maden en árabe es "la mina"), y la zona estuvo sometida a escaramuzas, saqueos y batallas de muy diverso tipo, primero entre los musulmanes de Toledo y Córdoba, luego entre ellos y con los cristianos y finalmente solo contra los cristianos (Izquierdo 2002b). En este estado de inseguridad permanente solo un aprovechamiento móvil como la ganadería podía tener sentido económico en tierras de frontera durante casi 800 años.

A medida que la reconquista avanzaba los ganaderos castellanos fueron llegando a Sierra Morena. Esta nueva ganadería se organizó, en los siglos XI y XII, a través de mestas de ganaderos y cobró progresivamente un valor económico estratégico. Así, Alfonso VII, en 1156 inició el proceso de protección de los ganados de las órdenes monásticas en sus desplazamientos entre estivaderos e invernaderos y fue Alfonso X quien creó, en 1273, el "Concejo de la Mesta de los pastores de mio regno", que tanta repercusión tendría en el devenir del Valle de Alcudia hasta la actualidad (e.g. Gascón 1978). La ganadería tuvo que lograr privilegios y una jurisdicción especial para que resolver los conflictos generados al atravesar comarcas agrícolas pertenecientes a las Comunidades de Villa y Tierra que se establecían conforme las fronteras avanzaban hacia el sur.

Tras la reconquista, fue la Orden Militar de Calatrava la que ostentó la propiedad de Sierra Madrona, del Valle de Alcudia y de otros territorios distribuidos por el centro y sur de España. Si bien la gestión de los territorios de la Orden se distribuía en encomiendas entre diferentes caballeros, gran parte del Valle de Alcudia dependerá de la Mesa Maestral, es decir, sus rentas eran para el Gran Maestre de la Orden.

Conscientes de la extraordinaria riqueza de los pastos del Valle de Alcudia y lo que ello suponía para mantener el monopolio mundial del merino, los grandes maestres de la Orden de Calatrava 
y la Corona se esforzaron, tanto en favorecer a los ganaderos trashumantes, como en asegurarse la posesión de estos rentables pastos.

En los últimos 3 siglos se puede sintetizar la historia forestal de la comarca pues hasta el siglo XVIII pervivían estructuras medievales que ya existían en gran parte hace 2000 años. Incluso a mediados del siglo XX la gente seguía construyendo y viviendo temporal o permanentemente en chozos, con una agricultura y ganadería que poco habían avanzado desde el Neolítico (Romano \& Sanz 1967).

\subsection{Historia reciente y perspectivas de futuro, objetivos de la tesis}

Un aspecto muy importante de la historia natural de Sierra Madrona y Valle de Alcudia es que, a pesar de miles de años de explotación de sus recursos forestales, su compleja estructura geomorfológica favorece un variopinto mosaico de topoclimas que actúan como refugios para una gran diversidad de especies. Esta diversidad específica se manifiesta notablemente si se compara con la presente en comarcas vecinas de Castilla-La Mancha, Extremadura y Andalucía.

Habida cuenta del valioso patrimonio histórico y natural de la comarca, mucho se ha publicado sobre ella, con trabajos generales (e.g. García Rayego \& López López 1991; Quirós \& Planchuelo 1992; Acosta et al. 1995, 1998; García Canseco 1999) y, entre los específicos, dedicados al medio natural están el Plan de Ordenación de Montes de Fuencaliente (Heredia 1910), la tesis doctoral de Sarrión (2001) que relaciona la flora de líquenes epífitos con el estado de conservación de los bosques o el PORN del P.N. Valle de Alcudia y Sierra Madrona (Junta de Comunidades de CLM 2010). Así como publicaciones monográficas sobre pinturas rupestres (Fernández Rodríguez 2003), minería (Hevia (2003), flora y vegetación (García Río 2006) o aves (Gosalves 2010). Poco hay publicado sin embargo sobre uno de los aspectos más importantes: la historia de sus bosques, que no es sino la historia de esta comarca eminentemente forestal.

Para comprender la evolución del paisaje forestal se realiza una revisión histórica a lo largo el capítulo 2 de esta Tesis. Se inicia en la transición de la Edad Media a la Edad Moderna (siglos XV y XVI), cuando el latifundio de la Orden Militar de Calatrava pasa a ser administrado por la Corona. Se continúa con los siglos XVII y XVIII, cuando se produce un importante aumento de la población y de las roturaciones de montes, el auge de la minería o la creación de la Academia de Minería y Geografía Subterránea de Almadén en 1777. Todo ello en el marco de un proceso modernizador, iniciado por Carlos III, que culminaría con una primera desamortización del Valle de Alcudia en 1769-1770. Posteriormente se analizan las descripciones del estado de los montes de la comarca que hiciera Madoz (1846-1850) en su Diccionario Geográfico y Estadístico, las desamortizaciones liberales de los siglos XIX y XX o los trabajos del Cuerpo de Ingenieros de Montes que se hace cargo de la gestión en 1859 de los montes exceptuados y de los sucesivos Catálogos de Montes Públicos. El volumen de ventas de bienes desamortizados ha sido objeto de estudio por diversos autores en Castilla-La Mancha (e.g. del Valle Calzado 2015), pero no el impacto del proceso de privatización de tierras sobre los bosques, dehesas y 
pastos de Sierra Madrona y Valle de Alcudia. El objetivo es intentar comprender qué tipo de tierras y montes se vendieron y cuál fue su destino.

En los 3 siguientes capítulos se presta una atención especial a los bosques olvidados de Sierra Madrona: los pinares autóctonos de $P$. pinaster. En especial al pinar de la sierra de Navalmanzano, el último ya en toda Sierra Morena, superviviente a los periodos glaciares e interglaciares del Cuaternario, a las múltiples talas de arbolado necesarias para abastecer a las minas y a los incendios de los pastores locales. A principios del siglo XXI del pequeño pinar de Fuencaliente no se conocían ni su distribución exacta ni ningún otro dato relevante más allá de la existencia de pinos de pequeño porte sobre una ladera rocosa expuesta al sur (Laguna 1868, 1870; Gil 1995). Por ello se inicia su estudio en el año 2002 ya que parece ser una de las poblaciones más interesantes de $P$. pinaster en toda su área de distribución en el Mediterráneo occidental. Debido a su carácter marginal, su peculiar historia de supervivencia y su papel bioindicador para la reinterpretación de los paisajes forestales de los países mediterráneos.

Este pinar en la actualidad podría estar en peligro de extinción por nuevas amenazas, hipótesis que se configura como el principal objetivo de estudio.

Como parte experimental se presta atención especial al estado actual del pinar de Navalmanzano. Los resultados obtenidos entre los años 2002 y 2015, se exponen y discuten con la pretensión de explicar la pervivencia de esta formación, analizar su situación actual, entender los parámetros que pudieran afectar a su futura evolución y proponer medidas de conservación.

\subsection{Referencias}

Acosta, A. (Coord.). 1995. Planificación estratégica de ecoturismo en el Valle de Alcudia. Diputación Provincial de Ciudad real. 370 pp + anexo cartográfico.

Acosta, A. (Coord.). 1998. El Valle de Alcudia. Naturaleza y patrimonio cultural. Diputación Provincial de Ciudad real. 373 pp.

AEMET. Datos históricos de estaciones meteorológicas solicitadas del area de estudio y entorno inmediato. Info general en: http://www.aemet.es/es/portada

Barrón, E. 2002. Indicios de paleoincendios en el Terciario de la Península Ibérica. Nemus. Revista de l'Ateneu de Natura, 1: 5-16.

Bermejo, J. 2011 (2a ed.). Breve historia de los íberos. Ediciones Nowtilus S.L. 352 pp.

Bueno, P., Barroso, R. \& de Balbín, R. 2007. Agricultores y metalúrgicos en la Meseta Sur. En Pereira (Coord.). Prehistoria y protohistoria de la Meseta Sur (Castilla-La Mancha). Biblioteca Añil. 57-94.

Cano, E. \& Valle, F. 1990. Formaciones boscosas en Sierra Morena oriental (Andalucía, España). Acta Botanica Malacitana 15: 231-237.

Cano, E., García Fuertes, A., Torres, J.A., Pinto, C.J., Cano, A., Montilla, R.J., Muñoz, J. J., Ruiz, L, \& Rodríguez, A., 2004. Estudio de los quejigares de Sierra Morena oriental. Lagascalia 24: 51-61. 
Carrión, J.S, Fernández, S., González Sampériz, P., López Merino, L., Peña, L., Burjachs, F., López Sáez, J.A., García Antón, M., Carrión, Y., Uzquiano, P., Postigo, J.M., Barrón, E., Allué, E., Badal E, Dupré, M., Fierro, E., Munuera, M., Rubiales, J.M., García Amorena I, Jiménez Moreno, G., Gil Romera G, Leroy S, García Martínez, M.S., Montoya, E, Fletcher W., Yll, E., Vieira, M., Rodríguez-Ariza, M.O., Anderson S, Peñalba C, Gil García, M.J., Pérez Sanz, A, Albert, R.M., Díez, M.J., Morales, C., Gómez Manzaneque, F., Parra, I., Ruiz Zapata B, Riera, S., Zapata L, Ejarque A, Vegas T, Rull V, Scott L, Abel Schaad, D., Andrade, A., Manzano, S., Navarro C, Pérez Díaz S, Moreno E, Hernández-Mateo L, Sánchez Baena, J.J., Riquelme, J.A., Iglesias R, Franco F, Chaín C, Figueiral I, Grau E, Matos M, Jiménez Espejo F, Valle, M., Rivas, R., Arribas, A, Garrido G, Muñiz F, Finlayson G., Finlayson, C., Ruiz, M., Pérez Jordá, G. \& Miras, Y. 2012. Paleoflora y Paleovegetación de la Península Ibérica e Islas Baleares: Plioceno-Cuaternario. Ministerio de Economía y Competitividad, Madrid.

Carrión, J.S., Fernandez, S. \& Fuentes, N. (Eds.) 2006. Paleoambiente y cambio climático. Fund. Séneca. Ag. de Ciencia y Tecnología de la Región de Murcia. 258 pp.

Charco, J. \& García Rayego, J.L. 2002. Análisis de la evolución de bosques mediterráneos mediante fotointerpretación: el caso de Sierra Madrona (Sierra Morena oriental, Ciudad Real). En: J. Charco (Coord.). La regeneración natural del bosque mediterráneo en la península Ibérica. ARBA-MIMAM. Madrid. 197-216.

Collado, B. 2014. Los íberos y su mundo. AKAL. 272 pp.

Contreras, F. \& Cámara, J.A. 2005. La producción metalúrgica en las comunidades de la Edad del Bronce del Alto Guadalquivir. El proyecto Peñalosa, Actas del II Simposio sobre Minería y Metalurgia Históricas en el Sudoeste Europeo (Madrid, 24 a 27 de Junio de 2004), Madrid.

De la Torre, I. 2007. La ocupación paleolítica de la Meseta Sur. En Pereira (Coord.), Prehistoria y protohistoria de la Meseta Sur (Castilla-La Mancha). Biblioteca Añil. 17-39.

Del Valle, A.R. 2015. El poder de la propiedad. Élites y desamortización en la España interior (Madrid y Castilla-La Mancha). Biblioteca Añil. 267 pp.

Delibes, G. \& Romero, F. 1992. El último milenio a.C. en la cuenca del Duero. Reflexiones sobre la secuencia cultural. Complutum, 2-3: 233-258.

Devesa, J.A. \& Carrión, J.S. 2012. Las plantas con flor: apuntes sobre su origen, clasificacion y diversidad. Ed. Universidad de Córdoba. 528 pp.

Dorado, M., Valdeolmillos, A., Ruiz Zapata, M.B., Gil García, M.J. \& Bustamante, I. 2002. Climatic changes since the Lateglacial/Holoceno transition in the Mancha plain (South Central Iberian Peninsula, Spain) andtheir evidence in Las Tablas Daimiel marshlands. Quaternary International, 93-94: 73-84.

Fernández Rodríguez, M. \& García Bueno, C. 1993. La minería romana de época republicana en Sierra Morena: el poblado de Valderrepisa (Fuencaliente, Ciudad Real) [Apéndice: monedas halladas en el nacimiento de Valderrepisa (Fuencaliente, Ciudad Real)]. En: Mélanges de la Casa de Velázquez. Tomo 29-1, Antiquité et Moyen-Age. 25-50. 
Fernández Rodríguez, M. 2003. Las pinturas rupestres esquemáticas del Valle de Alcudia y Sierra Madrona. Mancomunidad de municipios del Valle de Alcudia y Sierra Madrona. Ciudad Real. 344 pp.

García Canseco, V. 1999. El Valle de Alcudia. Ed. Esfagnos. 224 págs.

García Huerta, R. \& Morales, F. 2007. Los oretanos. En Pereira (Coord.), Prehistoria y protohistoria de la Meseta Sur (Castilla-La Mancha). Biblioteca Añil. 217-238.

García Rayego, J. L. 1995. Los Paisajes naturales de la Comarca de Los Montes-Campo de Calatrava. Tesis Doctoral. Universidad Complutense de Madrid. Facultad de Geografía e Historia. Departamento de Análisis Geográfico Regional Y Geografía Física.

García Rayego, J.L. \& López López. J. 1991. Sierra Morena. En Guía de los espacios naturales de Castilla-La Mancha. Junta de Comunidades de Castilla-La Mancha: 559-578.

García Río, R. 2006. Flora y vegetación de Sierra Madrona y Valle de Alcudia. Bases científicas para su conservación. Centro de Investigaciones Ambientales del Mediterráneo (CIAMED). Ciudad Real. 336 pp.

Gascón, F. 1978 (2 $2^{a}$ ed. 1994). El Valle de Alcudia durante el siglo XVIII. Ediciones del Orto. $609 \mathrm{pp}$.

Gil, L. 1995. Los pinares de Fuencaliente. Montes, 39: 94.

Gillson, L. 2015. Biodiversity Conservation and Environmental Change: Using palaeoecology to manage dynamic landscapes in the Anthropocene. Oxford University Press. 240 pp.

Gosalves, R.U. (Comp.) 2010. El Valle de Alcudia y Sierra Madrona, Paraíso Europeo para la Observación de Aves. Asociación para el Desarrollo Sostenible del Valle de Alcudia.

Hevia, P., (2003): El Patrimonio Minero del Valle de Alcudia y Sierra Madrona. (Mancomunidad de Municipios del Valle de Alcudia y Sierra Madrona).Ciudad Real.

INE. 2015. Instituto Nacional de Estadística. www.ine.es

Izquierdo, R. 2002a. Época visigoda. En: Castilla-La Mancha medieval. Biblioteca Añil. Ciudad Real: 13-36.

Izquierdo, R. 2002b. Etapa de dominio musulmán (siglos VIII-XI). En: Castilla-La Mancha medieval. Biblioteca Añil. Ciudad Real: 37-72.

Julivert, M., Fontboté, J.M., Ribero, A. \& Conde, L.S. 1972. Mapa tectónico de la Península Ibérica y Baleares. E. 1:1.000.000. IGME.

Knobloch, E., Kvacek, Z., Buzek, C., Mai, D.H. \& Batten, J.D. 1993. Evolutionary significance of floristic changes in the Northern Hemisphere during the Late Cretaceous and Palaeogene, with particular reference to Central Europe. Review of Palaeobotany and Palynology, 78: $41-54$.

Ladero, M., 1987. España lusoextremadurense. En: La vegetación de España. Peinado, M. y Rivas Martínez, S., ed. Universidad de Alcalá de Henares, Alcalá de Henares, 453-486.

Laguna, M. 1868. Un pedazo de Sierra Morena. Revista Forestal Económica y Agrícola, 1: 437 450.

Laguna, M. 1870. Resumen de los trabajos verificados por la Comisión de la Flora Forestal Española durante los años de 1867 y 1868. Madrid. 
MAGRAMA. 2012. Caracterización de las comarcas agrarias de España. Tomo 16. Provincia de Ciudad Real. Grupo de Agroenergética de la Escuela Técnica Superior de Ingenieros Agrónomos de la Universidad Politécnica de Madrid (GA- UPM). Ed. Secretaría General Técnica. Ministerio de Agricultura, Alimentación y Medio Ambiente. 155 pp.

Mai, D.H. 1989. Development and regional differentiation of the European vegetation during the Tertiary. Plant Systematics and Evolution. 162: 79-91.

Montero, A. \& Martin Consuegra, E. (Eds.) 2004. La flora a través del tiempo. Monografías del Jardín Botánico de Córdoba. Vol. II, 106 pp.

Ocaña, M. 1959. Estudio fitoecológico del Valle de Alcudia (Ciudad Real). II.- El medio y la vegetación. Anales Edaf. y Fisiol. Veg. 18(2): 629-669.

Pais, J. 2010. Plantas do neogénico e paleoclimas. Evidências em Portugal. In Neiva, J.M.C., Ribeiro, A., Victor, L.M., Noronha, F. \& Ramalho, M. (Eds.). Ciências Geológicas: Ensino e Investigação. Vol. I: 357-363.

Pausas, J.G. \& Keeley, J.E. 2009. A Burning Story: The Role of Fire in the History of Life. BioScience 59. 7: 593-601. doi:10.1525/bio.2009.59.7.10.

Perez Chiscano, J. L. 1994. Los adelfares en la provincia corológica luso-extremadurense (Península Ibérica). Stvdia Botanica 12: 203-218.

Poblete, M.A. \& Serrano, E. 1991. Valle de Alcudia. En: Guía de los espacios naturales de Castilla-La Mancha. Junta de Comunidades de Castilla-La Mancha: 539-558.

Pokrovskaia, I.M. 1950. Analyse pollinique. B.R.G.M. Service information, n 24, 434 pp. Moscú. En ruso, traducción al francés en 1958.

Polo, M.A., Alonso-Gavilán, G. \& Valle, M.F. 1987. Bioestratigrafía y paleogeografía del Oligoceno-Mioceno del borde SO de la fosa de Ciudad Rogrigo (Salamanca). Studia geologica salmanticensia, 24: 229-245.

Postigo, J.M., Barrón, E., Gómez Manzaneque, F. \& Morla, C. 2009. Floristic changes in the Iberian Peninsula and Balearic Islands (south-west Europe) during the Cenozoic. Journal of Biogeography, 36: 2025-2043.

Postigo, J.M., Morla, C., Barrón, E, Morales, C. \& García, S. 2010. Patterns of extinction and persistence of Arctotertiary flora in Iberia during the Quaternary. Review of Palaeobotany and Palynology, 162: 416-426.

Quirós, F. \& Planchuelo, G. 1992. El Paisaje Geográfico. Valle de Alcudia, Campo de Calatrava y Campo de Montiel. 436 págs.

Rivas Goday, S. 1950. Una visita geobotánica al valle de Alcudia y Sierra Madrona. Memoria de la Inspección Provincial de Farmacia y Colegio Oficial de Farmacéuticos de Ciudad Real. Ciudad Real.

Rivas Goday, S., Monasterio, M. \& Fernández Galiano, E. 1954. Islas atlánticas en pleno dominio de la flora mediterránea (Provincia de Ciudad Real). Anales de la Real Academia de Farmacia, 20 (5): 405-412.

Rivas Martínez, S., de la Fuente, V. \& Sánchez Mata, D. 1986. Alisedas mediterráneoiberoatlánticas en la Península Ibérica. Stvdia Botanica 5: 9-38.

Romano, V. \& Sanz, F. 1967. El Valle de Alcudia. Alfagura. 303 pp. 
Salgado, M.L. 1984. Reconstrucción del ambiente a través de los granos de polen. Investigación y Ciencia, 96, 6-16.

Sandom, C.J., Ejrnæs, R., Hansen, M.D.D. \& Svenning, J.C. 2014. High herbivore density associated with vegetation diversity in interglacial ecosystems. PNAS vol. 111. 11: 41624167 doi/10.1073/pnas.1311014111.

Santonja, M. \& Villa, P. 2006. The Acheulian of Western Europe. En Goren-Inbar, N. \& Sharon, G. (Eds.). Axe Age, Acheulian Tool-making from Quarry to Discard. 429-478.

Sanz de Siria, A. 1996. Estudio paleoeológico y paleoclimático de la macroflora oligocena de Cervera (Lleida, España). Treb. Mus. Geol. Barcelona 5, 143-170.

Sarrión, F. J. 2001. Flora y vegetación de líquenes epífitos de Sierra Madrona-Valle de Alcudia (Ciudad Real). Relaciones con el estado de conservación de sus bosques. Tesis Doctoral. Universidad Complutense de Madrid.

Valbuena Carabaña, M., López de Heredia, U., Fuentes Utrilla, P., González Doncel, I. \& Gil, L. 2010. Historical and recent changes in the Spanish forests: A socio-economic process. Review of Palaeobotany and Palynology, 162: 492-506.

Volkheimer, W. 2002. Historia paleontológica de la diversidad: sus implicaciones ambientales y la aportación de la paleobotánica y palinología a este campo. Coloquios de Paleontología 53: $147-152$

Willkomm, H.M. \& Lange, J.M.C. 1861-1880. Prodromus Florae Hispanicae. 3 Vols. Stuttgart.

Zarzalejos, M. 2011. La investigación arqueológica de los paisajes mineros antiguos en la vertiente norte de Sierra Morena (provincia de Ciudad Real). De Re Metallica, 17: 55-66. 


\section{CAPITULO 2}

\section{EVOLUCIÓN DE LOS BOSQUES DE SIERRA MADRONA Y VALLE DE ALCUDIA: HISTORIA RECIENTE Y PERSPECTIVAS DE FUTURO}

\section{Resumen}

Sierra Madrona y Valle de Alcudia es una comarca con una larga tradición minera, con periodos de gran intensidad de forma intermitente y por ser tierra de frontera durante el periodo bélico entre los siglos V y XIII que impuso su dedicación a la ganadería semoviente. La Mesta mantuvo su poderío hasta el siglo XIX. La utilización de los recursos naturales por grandes propietarios como el Estado o la Orden Militar de Calatrava forjó grandes latifundios. La deforestación fue el medio necesario para el aprovisionamiento de maderas para entibar galerías, leñas para hornos y fundiciones de mineral así como para uso doméstico. El resultado fue el predominio de monte bajo y rasos que permitía el mantenimiento de la cabaña caprina, capaz de alimentarse de pastos leñosos.

Los diversos avatares históricos han supuesto una continua deforestación pero el abandono de los usos milenarios, el éxodo rural a partir de los años 60 y una gestión forestal que se inició en 1859 ha permitido sobrevivir a algunos reductos de bosque, ahora en plena expansión. Durante los últimos milenios el proceso de eliminación del monte consistía en arrancar las cepas para que no rebrotara, como única opción para un uso agrícola general o esporádico cuando las tierras poseían cierta pendiente, por lo que un gran porcentaje de la comarca carece de arbolado.

Sin un conocimiento somero de lo que fue la utilización del territorio durante la Edad Media no es fácil entender las causas de deforestación durante la Edad Moderna, teniendo en cuenta los usos e intereses de los diversos propietarios de la comarca: la Orden Militar de Calatrava, desde el siglo XII al XV, la corona y los pueblos, desde el XVI al XIX y, finalmente, tras las desamortizaciones del siglo XIX, principalmente los particulares y pueblos, desde el XIX a la actualidad. El paso de la propiedad pública a privada fue un proceso generalizado, la excepción fue la inclusión de una pequeña parte del patrimonio de los pueblos en el primero de los Catálogos de Montes Públicos exceptuados de la Desamortización, de 1862. Relación de montes en la que solo podían figurar pinos, hayas y robles, pues tanto el Ministerio de Hacienda como los futuros compradores solo deseaban los ricos pastos de invernada de la ganadería trashumante. El que los robledales fueran reduciendo su extensión con el paso de los siglos a una presencia testimonial y que la encina fuera la especie dominante, impidió que pudieran ser exceptuados, lo que supuso el paso de casi el $100 \%$ de los encinares de la comarca a manos privadas.

El impacto de las minas y de la ganadería sobre los bosques debió ser importante hasta la despoblación de la comarca tras el declive del imperio romano en el siglo V. La recuperación del bosque fue posible durante más de 800 años, es decir hasta los primeros siglos del dominio calatravo y, aunque se cortasen árboles y se quemaran los montes, el poder de regeneración de 
las especies de Quercus y de su dispersión se mantenían en gran parte, en particular para la encina. La colonización emprendida por la Orden de Calatrava y otras Ordenes Militares (OOMM) en otras partes de España, solo pudo realizarse mediante el atractivo de dar en propiedad o arriendo tierras a los pueblos existentes o de nueva creación. Fue el origen de los montes de los pueblos. La creciente población aspiraba a cultivar la tierra y las roturaciones fueron cada vez más numerosas, lo que incrementaría continuamente y durante siglos sus conflictos con los intereses de las minas, por la leña y la madera, y con los ganaderos invernantes que veían en el arbolado unos excelentes pastos de vuelo (ramón y bellota).

Había 2 tipos de ganaderos. Por un lado los procedentes del norte de Castilla que invernaban con ovejas merinas, principalmente en el Valle de Alcudia por sus valiosos pastos de suelo y vuelo. Aclararon los montes de mayor valor evolutivo y suelos más profundos, para transformarlos en dehesas con un número reducido de árboles que además eran podados con frecuencia, básicamente encinas, por el mayor valor de su fruto para la montanera. Por otro lado estaban los ganaderos locales (estantes o trasterminantes), excluidos de los mejores pastos del Valle de Alcudia, incendiaban cada 3-6 años las sierras con objeto de reducir el tamaño de la cubierta vegetal para hacerla accesible al ganado, principalmente de cabras.

El descubrimiento de América y del valor del mercurio para la amalgama de la plata de sus minas, implico mayores exigencias de producción a las minas de Almadén. Esto a su vez implicó un mayor consumo de leña y madera local para sus hornos y para el entibado, que se calcula podría situarse en torno a las $29.000 \mathrm{Tm}$ de madera/año a principios del siglo XVIII. Al mismo tiempo el continuo incremento de la población de la comarca exigía más tierras para cultivar, aumentando sin cesar las roturaciones legales o ilegales, así como las necesidades de pastos para sus rebaños de ovejas, cabras, bueyes, mulas y cerdos. En todo este contexto de conflictividad social y continua deforestación la Corona decide ir vendiendo tierras de las OOMM a partir del siglo XVI, durante el reinado de Carlos I, que luego continuará Felipe II. Aunque la superficie de tierras vendidas durante sus reinados es considerable, afectó poco al conjunto de los inmensos latifundios de las OOMM. Posteriormente, en el siglo XVIII, Felipe V desamortiza la Serena (Badajoz) y poco después Carlos III el Valle de Alcudia. De esta segunda comarca salen a la venta 140 millares de los que en realidad solo se venden 41, el resto queda en manos del Estado. Serán las desamortizaciones liberales del siglo XIX las que realmente pongan a la venta la totalidad del Valle de Alcudia y la mayor parte de Sierra Madrona.

Los montes vendidos corrieron una suerte muy diversa pero se puede clasificar en 3 grupos:

1. Montes destinados a uso ganadero invernante tradicional. Estos ganaderos mantuvieron un arbolado cuyo valor en algunos casos superaba el 50\% del valor total de la finca.

2. Montes que se intentaron poner en cultivo, actividad poco rentable a medio y largo plazo, desastrosa para suelos y arbolado, que en buena medida se perdieron. Se confirmó claramente la nula vocación agraria de la comarca frente a su gran potencial silvopastoral.

3. Montes comprados por particulares o compañías mineras que acabaron siendo en gran parte talados para abastecer a minas y poblados mineros. 
Una característica común a casi todos ellos es que fueron intensamente carboneados, especialmente los dedicados a usos agrícolas, a mediados del siglo XX. Sobre los montes no vendidos también existen 3 grupos básicos en cuanto a su destino:

1. Montes de los pueblos que se repartieron en lotes entre los vecinos para su puesta en cultivo a principios del siglo $\mathrm{XX}$, alguno se mantuvo en cultivo pero la mayoría fueron abandonados siendo de nuevo dedicados a pastos.

2. Montes del Estado (Dehesa de Castilseras) o de los pueblos que generalmente fueron conservados e incluso mejorados.

3. Montes de los pueblos que hoy forman parte del Catálogo de Montes de Utilidad Pública de la Junta de Castilla-La Mancha. Muchos de los cuales fueron consorciados con el PFE, luego ICONA, para la repoblación con pinos.

Con todo este análisis se ha podido ver que la desamortización supuso una importante pérdida de la propiedad pública pero no fue especialmente negativa para el monte, pues gran parte de las fincas arboladas, las compraron ganaderos invernantes que, en esencia, mantuvieron el arbolado existente. El gran daño a los montes procedía antes, durante y después de la desamortización decimonónica, de la minería y de la tradición de los pastores locales de incendiar los montes serranos cada 3-6 años a fin de generar pastos herbáceos para sus rebaños. Principalmente por este último motivo a mediados del siglo XIX 32 montes en la sierra (66.500 ha), antes de su venta, ya eran jarales (formaciones pirófitas). Tras el abandono de la minería y de la tradición pastoril de quemar los montes, ahora la comarca en general tiende hacia nuevos modelos de explotación compatibles con la recuperación de los bosques.

\subsection{Introducción}

La orografía y escasa densidad de población de Sierra Madrona, junto a la minería y el destino pastoral del Valle de Alcudia, han determinado que su territorio apenas fuera cultivado, siendo su aprovechamiento histórico y actual el silvopastoral (MAGRAMA 2012). Otro uso tradicional, la minería, ha desaparecido pues la mayoría de las explotaciones mineras se agotaron y la de mercurio se clausuró en 2003 por sus efectos perniciosos sobre los sistemas naturales. Los bosques de la comarca fueron transformados por la actividad minera desde tiempos prerromanos hasta mediados del siglo XX, con un paréntesis de unos 1000 años entre la época bajo imperial romana y el fin del dominio musulmán del territorio (e.g. Quirós 1969; Hevia 2003; Zarzalejos 2011). La actividad minera requirió de montes abastecedores de leñas en decenas de km, especialmente en torno a las minas de Almadén. Este uso tendría un efecto general en la estructura de la primitiva masa forestal y una actuación diferencial entre las especies dominantes según su capacidad frutícola y rebrotadora, siendo ambas impropias de las coníferas del género Pinus, en particular la respuesta a la tala, lo que afecto de forma negativa a lo que pudieron ser sus formaciones naturales. 
La Orden Militar de Calatrava, propietaria de toda la comarca durante siglos, favoreció la ganadería frente a la agricultura, al contrario que en territorios vecinos de La Mancha pertenecientes a las OOMM, donde primó el desarrollo agronómico (Ruíz Gómez 2002). El carácter pecuario del Valle de Alcudia se debe a la falta de poblamiento humano y su idoneidad como zona de invernada del ganado merino que agostaba en las sierras de Segovia, Soria, Burgos, La Rioja, Cuenca y Teruel. La trashumancia fue una de las principales riquezas del reino de Castilla, a la que la Corona favoreció frente a otros intereses locales (Klein 1979; Laguna Sanz 1986; López Salazar 1987; García Martín 2006).

Aunque resulte importante para entender la historia forestal moderna y contemporánea de la comarca, no se profundizará en el origen, evolución ni estructura organizativa de la Orden Militar de Calatrava ni sobre asuntos mineros, ni ganaderos. Estos temas son ya relativamente bien conocidos y aquí se dedicará una especial atención a la evolución de los bosques. La Orden Militar de Calatrava ha sido objeto de diversos estudios (Rades y Andrada 1572; Corchado 1984; Rodríguez Picavea 1994 o López Salazar 1994), la explotación minera (Hervada 1894; Matilla 1958; Quirós 1969; Matilla 1978, Beltrán 1992; Gómez Vozmediano 2000; Hevia 2003; Zarzalejos et al. 2004, Zarzalejos 2011 o Gil Bautista 2012), el uso ganadero (De Terán 1952; ICONA-DGBA 1991-1997; García Martín \& Sánchez Benito 1997; Rodríguez Pascual 2001; Bensusan 2003; Herraiz 2010; Manzano \& Casas 2010; Casas 2012), incluida la creación y evolución de La Mesta en el marco de la Corona de Castilla (Klein 1979; García Martín 1988, 1990, 2006; Marín Barriguete 1992; Díez Navarro (ed.) 1994) e incluso el impacto ambiental de la trashumancia en España (Ruiz \& Ruiz 1986; Cabo Alonso 1998; Ruiz 2001; FEAGAS 2011; González 2008) y en Europa (Bunce et al. 2004). En cuanto a los pastos en general cabe destacar a San Miguel (2001), más en concreto sobre pastos en dehesas a San Miguel (1994) y, más recientemente, a López-Sánchez (2015).

El proceso de consolidación del latifundio calatravo se trazó durante las etapas bélicas del periodo musulmán, iniciará su desmembración con la llegada de los Austrias, luego con los Borbones y será finalmente liquidado por los gobiernos liberales del siglo XIX. El declive de la Mesta fue iniciado por Campomanes, ministro de Hacienda en 1760, al opinar que es preciso abolir la Mesta pues es una amenaza para la propiedad y para la solvencia de la Real Hacienda (Gil 2008). En 1766 una primera Real Provisión permite la venta de bienes de propios. En 1779 se prohíbe a los ganaderos trashumantes aprovechar los pastos de los viñedos y olivares tras la recogida de la cosecha; en 1788 se concede a los dueños la facultad de cerrar propiedades para impedir la entrada del ganado. Ya bajo la etapa de Carlos IV se suprime en 1795 la jurisdicción especial de la Mesta y se dicta su sometimiento a la ordinaria. En 1813, bajo la etapa constitucional, se deroga el sistema de tasación de pastos y el derecho de posesión, claves de toda la legislación que había favorecido a la ganadería trashumante frente a la local y a la agricultura.

Jovellanos, con su Expediente de la Ley Agraria de 1795 será el precursor del movimiento desamortizador de posteriores décadas. En 1812, las Cortes de Cádiz emprendieron la tarea de configurar una nueva sociedad basada en la interpretación individualista de los principios 
teóricos de libertad, igualdad y propiedad. Para plasmar sus ideales empezaron por desvincular los bienes de la nobleza y desamortizar los eclesiásticos y municipales. Los liberales, según avanzaba el siglo XIX suprimieron las órdenes monásticas y enajenaron parte del patrimonio de la Iglesia y su derecho a cobrar tributos. En 1834 se autorizó a los ayuntamientos a la venta de sus bienes de propios, en realidad una desamortización civil voluntaria. Sin embargo, la primera guerra carlista (1833-1840), junto a la pérdida de las Colonias americanas impondrán una deuda pública del nuevo régimen insostenible y los momentos de máximo apuro económico del régimen liberal. Para soslayar esta situación se promulga en 1836 la desamortización de Mendizábal. En 1837, otra ley ampliaría la acción desamortizadora, al sacar a la venta los bienes del clero secular, aunque su enajenación no se hizo efectiva hasta septiembre de 1841, bajo la regencia de Espartero. Esta desamortización incluía las propiedades de las órdenes militares. El sistema del antiguo régimen se estaba demoliendo.

De 1845 a 1854, durante la Década Moderada, se ralentizaron e incluso se paralizaron las ventas. La Iglesia, que excomulgaba a los compradores, reconoció el proceso en el Concordato de 1851. Posteriormente, en 1855, Madoz promulgaría la Desamortización que lleva su nombre y que afectó al patrimonio que faltaba por vender de la iglesia y órdenes militares, más los bienes municipales, de instrucción pública, de beneficencia y de la Corona. Tuvo 3 fases: la de 1855-1856 (durante el Bienio Progresista), la de 1858-1897 (la más intensa por el gran volumen de venta de tierras) y a partir de 1898, cuando ya poco quedaba por vender y el proceso languidecía. La última subasta conocida en Castilla-La Mancha es de 1910 (Del Valle 2015). Con el estatuto municipal de Calvo Sotelo de 1924 las leyes desamortizadoras de bienes municipales quedaron derogadas.

La historiografía de las desamortizaciones ha sido estudiada con cierto detalle. En Castilla-La Mancha se dispone de los estudios de Feijoo (1990) y Del Valle (2015), además de estudios de ámbito provincial, comarcal y local. En la provincia de Ciudad Real figuran los de Quirós (1964), Simón Segura (1974) y Del Valle (1996, 1997). La del Valle de Alcudia de 1769-70 fue abordada por Corchado (1973) y Gascón (1978). En esencia, las desamortizaciones aquí son conocidas pero, apenas estos estudios han tratado el destino y situación actual de los montes desamortizados.

No obstante, la pérdida pública y la regresión forestal de gran parte de las propiedades vendidas con las desamortizaciones fue un hecho conocido por los facultativos recién nacidos (1848) del ramo de montes. El Dictamen de la Junta Facultativa de Ingenieros de Montes de 20-12-1858 precisaba la experiencia anterior:

[...] Los montes que fueron vendidos a los particulares con motivo de la Ley de desamortización de 1855, han tenido la misma suerte que los desamortizados en otras épocas: unos han sido descuajados, otros talados; ninguno mejorado [...]

La Ley de Presupuestos para el año de 1856 y los seis primeros meses de 1857 (Ley 1857) estimaba que los ingresos de la venta de los bienes del Estado, del Clero y el 20 por 100 de los Propios era de 371.789.623 reales de vellón. La Estadística del ramo [de montes] del Ministerio 
de Fomento en noviembre de 1857 relaciona para todas las provincias el número de montes, la cabida en fanegas castellanas y su valor. En ella, consta que en la provincia de Ciudad Real se vendieron 39 montes que sumaban 146.045 fanegas y un valor de 46.199 .800 reales de vellón. La Tabla 2.1, compara los valores de la provincia de Ciudad Real en relación con algunas provincias próximas y permite observar que estas provincias ingresaron 161 millones de reales, el $44 \%$ de la cantidad total estimada. La provincia manchega es, después de Jaén, la que más ingresos aporta con sus 39 montes; y, por detrás de Badajoz, la que poseen un valor mayor por monte enajenado, si bien el valor medio de la fanega es, después de Jaén, el más bajo.

\begin{tabular}{|c|r|r|r|r|r|}
\hline \multicolumn{1}{|c|}{$\begin{array}{c}\text { Ciudad } \\
\text { Real }\end{array}$} & \multicolumn{1}{c|}{ Jaén } & \multicolumn{1}{c|}{ Córdoba } & \multicolumn{1}{c|}{ Badajoz } & \multicolumn{1}{c|}{ Cáceres } \\
\hline $\mathrm{N}^{\mathrm{o}}$ de montes & 39 & 98 & 13 & 12 & 14 \\
\hline Superficie en fanegas & 146.045 & 227.389 & 42.715 & 45197 & 41.130 \\
\hline $\begin{array}{c}\text { Ingresos reales de } \\
\text { vellón }\end{array}$ & 46.199 .800 & 71.282 .600 & 13.614 .280 & 18.306 .160 & 12.339 .000 \\
\hline $\begin{array}{c}\text { Valor fanega } \\
\text { castellana }\end{array}$ & 8,111 & 3,198 & 24,517 & 33,752 & 21,428 \\
\hline $\begin{array}{c}\text { Valor monte (rs } \\
\text { vellón) }\end{array}$ & 1.184 .610 & 727.373 & $1.047 .252,00$ & 1.525 .513 & 881.357 \\
\hline
\end{tabular}

Tabla 2.1. Resultado de las ventas en noviembre de 1857 de la Ley Madoz en la provincia de Ciudad Real y otras del entorno. Estadística del ramo [de montes] del Ministerio de Fomento de 1857.

Los montes exceptuados de estos procesos desamortizadores fueron conformando los Catálogos de Montes de Utilidad Pública. La inclusión de los montes en estos catálogos en principio debía garantizar su conservación y mejora. Sobre la génesis y evolución de estos catálogos se han publicado numerosos trabajos en las últimas décadas (e.g. Gordo \& Gil 1990; Mangas 2001, 2002; Calvo 2001, 2003).

En este capítulo se estudia la evolución histórica de los montes desde la Edad Media y se plantea la hipótesis de que los bosques, matorrales y dehesas de Sierra Madrona y Valle de Alcudia debieron sufrir una gran devastación tras ser vendidos a particulares en las desamortizaciones del siglo XIX. Para aproximar la exactitud de estas ideas se acude a los textos históricos que describan o apuntan al estado de los montes de la comarca en la Edad Moderna y Contemporánea, antes de los procesos desamortizadores de los siglos XVIII al XX, y cuál ha sido su destino.

\subsection{Material y métodos}

La búsqueda bibliográfica e historiográfica se ha centrado en obras de diferentes autores y, siempre que ha sido posible, se han buscado las fuentes originales. Se ha revisado gran parte de la documentación en aquellos archivos, a cuyas abreviaturas se hará referencia en el texto: 
AHN Archivo Histórico Nacional

AP.PR.A. Archivo de Palacio. Patrimonio Real. Alcudia

ACMH Archivo Central del Ministerio de Hacienda

AHP Archivo Histórico Provincial de Ciudad Real

AHM Archivo Histórico Municipal de Ciudad Real

ADP Archivo de la Diputación Provincial de Ciudad Real

AMAC Archivo Municipal de Almodóvar del Campo

BOP Boletín Oficial de la Provincia de Ciudad Real

BOC Bulario de la Orden Militar de Calatrava

Otras abreviaturas utilizadas serán:

OOMM Órdenes Militares

RRTT Relaciones Topográficas de Felipe II

CME Catastro del Marqués de la Ensenada

DGE Diccionario Geográfico Estadístico, de Madoz

BOVBN Boletín oficial de ventas de bienes nacionales

BOPCR Boletín oficial de la provincia de Ciudad Real

El estado y composición específica de los montes del siglo XVI se analizará a través de las respuestas dadas por los pueblos de la comarca en las Relaciones Topográficas de Felipe II, de 1575 y 1578. Sobre este material se han realizado varias revisiones y ediciones. La primera se debe al ciudadrealeño Carmelo Viñas junto a Ramón Paz en 1971, la última es del infanteño Javier Campos y Fernández de Sevilla (2009). De igual modo se acude a la información de los corresponsales de Pascual Madoz, recopiladas, casi tres décadas después, en su Diccionario geográfico-estadístico-histórico de España y sus posesiones de ultramar (1846-1850).

La información y cuantificación de las fincas y montes vendidos y su arbolado, durante los procesos desamortizadores, procede de los números disponibles del siglo XIX del BOVBN, completado, cuando ha sido posible, con los informes de tasación previa a la venta, que suelen reflejar la superficie de la finca, su uso y sus valores de renta y venta. A veces se incluye la cantidad de arbolado, a que especies pertenecía y su valoración en función de su calidad, lo que permite conocer la esencia del estado de los montes durante el siglo XIX.

También se ha recurrido a los abundantes recursos accesibles en "internet" y, para el análisis de los múltiples datos obtenidos, se han utilizado diferentes programas informáticos, principalmente el programa estadístico "R" y el Sistema de Información Geográfica GvSIG. 


\subsection{Resultados y Discusión}

\subsubsection{Antecedentes históricos}

La primera referencia sobre los bosques de Sierra Madrona es de Estrabón (Geografía, III, 157) que acerca de la Oretania, el territorio que se extendía a ambos lados de Sierra Morena oriental, comenta:

[...] el país de los oretanos lo cruza una cordillera cubierta de densos bosques y corpulentos árboles $[\ldots]$

Plinio el Viejo (Historia Natural, XVI, 6, 15) destaca una particularidad que es general a gran parte del país:

[...] La bellota constituye incluso ahora el principal recurso de muchos pueblos hasta cuando disfrutan de paz; y asimismo cuando escasean los cereales se obtiene harina moliendo bellotas tostadas, y luego se amasa una especie de pan. Más aún, actualmente en las Hispanias se sirven bellotas en la comida como segundo plato: la misma bellota resulta más dulce torrada en la ceniza $[\ldots]$

Domergue (1990) enumera la existencia de 241 minas romanas en el entorno de Sierra Morena (39 en Ciudad Real, 22 en Jaén, 83 en Córdoba, 40 en Badajoz, 13 en Sevilla y 44 en Huelva). Esta abundancia y sus efectos colaterales dan sentido a la frase de Plinio que describe los alrededores de las zonas mineras (HN, XXXIII, 21, 67):

[...] Cetero montes Hispaniarum aridi sterilisque et in quibus nihil aliudgignatur huic bono fertiles esse coguntur $[\ldots]$

Su traducción (Bejarano 1987) sería "Por otra parte, los montes de las Hispanias áridos y estériles y en los que ninguna otra cosa se cría, están obligados a ser fértiles en esta riqueza [la minera]". Aridez y esterilidad que, en nuestra opinión, aludía a la causada por la creación de paisajes desforestados para el desarrollo de las operaciones mineras. En el caso de Rio Tinto, Luzón (1970) estima la existencia de 20 millones de Tm de escorias de tiempos romanos y opina que para generarlas serían necesarias 6 millones de toneladas de carbón. Mientras que Salkield (1970) señala que $1 \mathrm{Tm}$ de escoria de pirita de cobre requeriría de 1,8 Tm de carbón vegetal. Cifras dispares en cuanto al requerimiento de madera por Tm de carbón vegetal, pero que permiten considerar que llevaron a la tala de cientos de miles de árboles al año y la pérdida del arbolado y a la esterilidad del suelo en las comarcas mineras como señaló Plinio. Domergue (1990) alude a la existencia de la mina del río Valmayor (Ciudad Real) como productora de plomo y plata y poseedora de una fundición. Es frecuente la asimilación de la ciudad de Sisapo, mencionada por Cicerón, Vitruvio y Plinio con la mina moderna de Almadén, aunque hoy está identificada con la Bienvenida (Zarzalejos 1994), localidad situada en pleno Valle de Alcudia. Su origen ha sido datado de finales del siglo VIII, a.C. (Fernández Ochoa et al. 1994) y la ocupación romana en el siglo II a.C., alcanzando su prosperidad y expansión en la época augústea: una ciudad rodeadas por una muralla de 3 metros de ancho y 28 bastiones (Zarzalejos 
2011). El registro de elementos afines en yacimientos significativos del entorno sisaponense, como la mina Diógenes (Solana del Pino) productora de plata y plomo, o las de mercurio en las proximidades de Almadén situadas en los lugares de Las Cuevas, Entredicho, Nueva Concepción o Guadalperal (Domergue 1990), avalan los inicios y la extensión de las primeras y severas transformaciones forestales en el valle de Alcudia.

La deforestación por los incendios practicados por los pastores facilitaba la observación y localización de la riqueza minera. Esta conexión se puede deducir de las manifestaciones de autores grecolatinos clásicos como Timeo:

[...] Se dice que cuando en Iberia los bosques habían sido encendidos por los pastores y la tierra se había calentado, fluía plata del suelo, y cuando además se producían grietas y la tierra reventaba, se acumulaban grandes masas de plata $[\ldots]$

O la debida a Posidonio, quien visitó la Bética hacia el año 100 a.C., y relata como una opinión extendida que al incendiarse un bosque, ascendía a la superficie oro y plata (en Blázquez 1970).

Durante la crisis del siglo III, se inició la decadencia de la minería y se abandona a inicios del siglo $\mathrm{V}$, cuando suevos, vándalos y alanos se expanden por la península ibérica. La nueva situación supuso el despoblamiento de las zonas mineras y el abandono del comercio y otras actividades ligadas (e.g. Izquierdo 2002a), lo que motivó la falta de mantenimiento de las importantes vías de comunicación de la etapa altoimperial, la pérdida paulatina de la red de calzadas que atravesaban la comarca (e.g. Corchado 1969; Carrasco 2006) y el aislamiento y despoblación de las zonas de difícil orografía.

El periodo visigodo no supuso recuperación económica, su estabilidad impuso la ruralización de la sociedad, el abandono de la actividad comercial y un vacío poblacional de grandes áreas (e.g. Izquierdo 2002a). El Fuero Juzgo (RAE 1815) promulgado por Recesvinto en el año 654 fue el cuerpo legislativo que rigió en la península ibérica durante la presencia goda y supuso el establecimiento de una norma de justicia común para visigodos e hispanorromanos. Esta legislación dio lugar a la defensa de las especies forestales productoras de fruto y, con ello, la defensa de la ganadería, junto a la frutalización y privatización del monte. Aspectos que muestra, en su versión romance del siglo XIII, el Título V del Libro VIII: de los pvercos qve pascen, al recoger las leyes que afectan a los ganados y en particular a la montanera:

I. De los puercos que comen la lande. Que dicta: Quien falla puercos aienos en su monte en tiempo de la lande [...] tome pennos al pastor, é fagalo saber al sennor de los puercos [...]

II. De los puercos que pascen la lande que es de dos companneros.

III. Si los puercos comen la lande por pleyto, que dén diezmo de los puercos.

IV. De los puercos que andan por el monte errados.

V. Si alguna grey [rebaño] de algún omne entra en las mieses.

VI. De las animalias que andan erradas. 
VII. Que aquel que falla animalia que la debe guardar.

VIII. Que aquel que falla la animalia errada non la debe señalar ni tusar [trasquilar].

Aprovechamiento pecuario que lo era con carácter de autosuficiencia y apoyo a la agricultura, pues la cabaña ganadera estaba limitada por la capacidad pastante durante el estío y la falta de mercados externos. La caída económico social tiene su reflejo en las necrópolis visigodas localizadas que, además de escasas, se caracterizan por unos ajuares pobres que reflejan la penuria económica en el sur de la submeseta meridional (Izquierdo 2002a). La comarca se administraba desde su capital Oretum (junto a la actual Granátula de Calatrava) donde se hallaba el obispado (Hervás y Buendía 1918).

Bajo la dominación árabe, en el siglo X la cora de Firris y Fahs al Ballut o "Llano de las Bellotas" abarcaba términos de las provincias de Córdoba, Sevilla, Huelva, Ciudad Real y Badajoz, estando atravesada por los montes al-Baranis (que muy probablemente se refieran a Sierra Morena o parte de ella). Así se expresa el geógrafo Abu Abdalá Mohamed al Idrisi, que vivió en Córdoba, en su "Descripción de España y Africa":

[...] Después la provincia de las Cuevas, donde está Zorita, Hita y Calatrava. Después la de Balálita (Fahs-al-Ballut), donde hay diversos lugares fortificados, siendo los más importantes Pedroche, Gafic, Hins-ibn-Harón (castillo de Aznarón, en Chillón). También hay otros que no son tan grandes $[\ldots]$

Al Balálita será el nombre con el que la conocerán los historiadores (Hervás y Buendía 1918; Agostini 1926). También Al Razi menciona la comarca en su descripción geográfica del AlAndalus, escrita en el siglo X. El capítulo XXIII, según la transcripción del manuscrito de Santa Catalina de Toledo (Catalán \& de Andrés 1975), se titula: "Del termino de Alleris [Oretum] e del Llano de las Vellotas". En él se encuentra el texto que sigue:

[...] E Alleris yaze contra el sol leuante de Cordoua e al setentrion. E Alleris es villa en que moraron los barbaros. E en su termina ha vn llano muy fermoso e muy bueno que es çercado de los montes que lo fazen muy fermoso e mui bueno. E en su término yaze el venero de que sacan el azogue, e de allí lo lieuan a todas las partes del mundo:non lo ay sinon allí. E sacan y mucho bermellón e muy bueno [...] E lo demás desta tierra non ay otros arboles sinon ençinas, e por eso le llaman el Llano de las Bellotas; e son mas dulçes que quantas ha en España [...]”"

El campo de Calatrava, durante la época musulmana tuvo una densidad de población baja por su condición de frontera permanente. Entre los siglos X y XIII, solo se conocen 20 núcleos de población (Retuerce \& Lozano 1985, Retuerce 1995; Izquierdo 2002b). Ciudades antiguas, como Sisapo, son abandonadas. Las únicas poblaciones de importancia fueron Calatrava, Almodóvar del Campo y Almedina, con castillos y poblados destacables en Chillón, Caracuel y Mestanza, todos con frecuencia asediados y destruidos (Hervás y Buendía 1899). Con la descomposición del Califato, tendrán lugar diferentes rebeliones entre los grupos de poder. La mina de Almadén se siguió explotando como señalan Al Idrisi y Al Razi, o por existencia de la 
pila mercurial del palacio de Medina Azahara situada en el centro del salón de los Califas (Sánchez Albornoz 1946). Un gran pilón de mercurio que al circular reflejaba la luz solar sobre el techo dorado y paredes relucientes, así parecía que era el salón el que giraba, con la sorpresa de los presentes.

A partir del siglo XI, las incursiones castellano-leonesas hacia el Sur son cada vez más frecuentes. En 1063 llegan hasta Sevilla durante el reinado de Fernando I, y con Alfonso VI, en 1072 devastan los alrededores de Córdoba. Lo que contribuye a la inestabilidad de esta comarca fronteriza y a la extensión del vacío económico y demográfico. El paso por Fuencaliente de tropas oficiales, rebeldes o razzias de mercenarios era habitual y, por tanto el dominio de la zona, vital. El itinerario de Alfonso VII, en 1130, señala que:

[...] Ganó dessa yda este rey don Alfonso demás a Alarcos [...] a Caracoy (Carcuel), et al Pedroch (Pedroche) et a Sancta Offimia (Santa Eufemia) et Mestanza et al Alcudia et Almodovar $[\ldots]$

En 1164, Alejandro III aprueba la fundación de la Orden Militar de Calatrava. En 1187, poseía la mitad de las minas y castillos de Chillón y Almadén, los castillos de Caracuel, Alarcos, Benavente, Zuhera, Piedrabuena, Malagón y Guadalerzas y, ya en 1198, la Orden obtiene casi todo lo que hoy es la provincia de Ciudad Real para su colonización y defensa. Su continuo apoyo militar a los sucesivos reyes fue premiado con donativos que hicieron de la Orden una gran potencia política, económica y militar. En los siglos XIV y XV la Orden poseía 2 grandes Encomiendas en Calatrava y Alcañiz, 84 Encomiendas menores y 72 Iglesias (López González et al. 1988).

En un contexto inestable y de destrucción, las extensiones serranas permitían a pastores locales aprovechar el territorio y la posibilidad de desplazarse a zonas seguras dentro de las sierras frente a cualquier incursión de uno u otro bando que buscara la ganancia derivada de la rapiña (Figs. 2.1 y 2.2). Su conocimiento del terreno explica que un pastor, según cuentan las crónicas castellanas, guiara en 1212 a través de Sierra Morena a las tropas castellanas, navarras y aragonesas, por el lugar más adecuado para atacar al enemigo musulmán en las Navas de Tolosa.

Dueña la Orden de Calatrava de la mina de Almadén por donación real en 1249, iniciará la producción de bermellón en 1286, producto demandado por los mercaderes extranjeros. La inicia conforme se le otorga la protección real para su exportación, privilegio que amplia en 1308 Fernando IV al otorgar a la Orden el monopolio de su venta, lo que realiza para que sus beneficios permitieran que pudiera conservar sus castillos frente a los moros. 


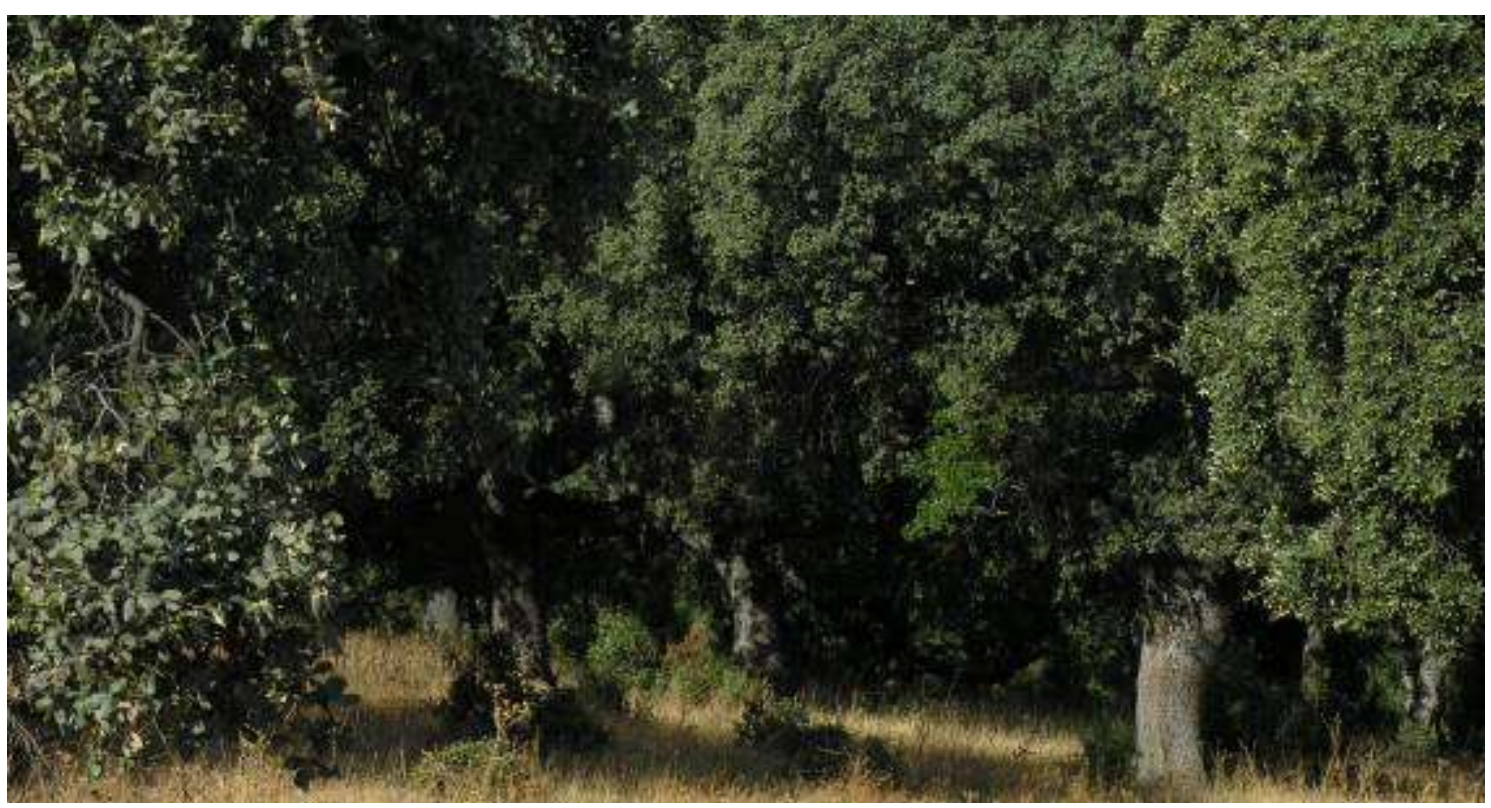

Fig. 2.1. Durante la reconquista, en el siglo XII, el despoblamiento permitió la recuperación de densos y extensos bosques en las zonas menos transitadas, la mayor parte de Sierra Madrona y Valle de Alcudia.

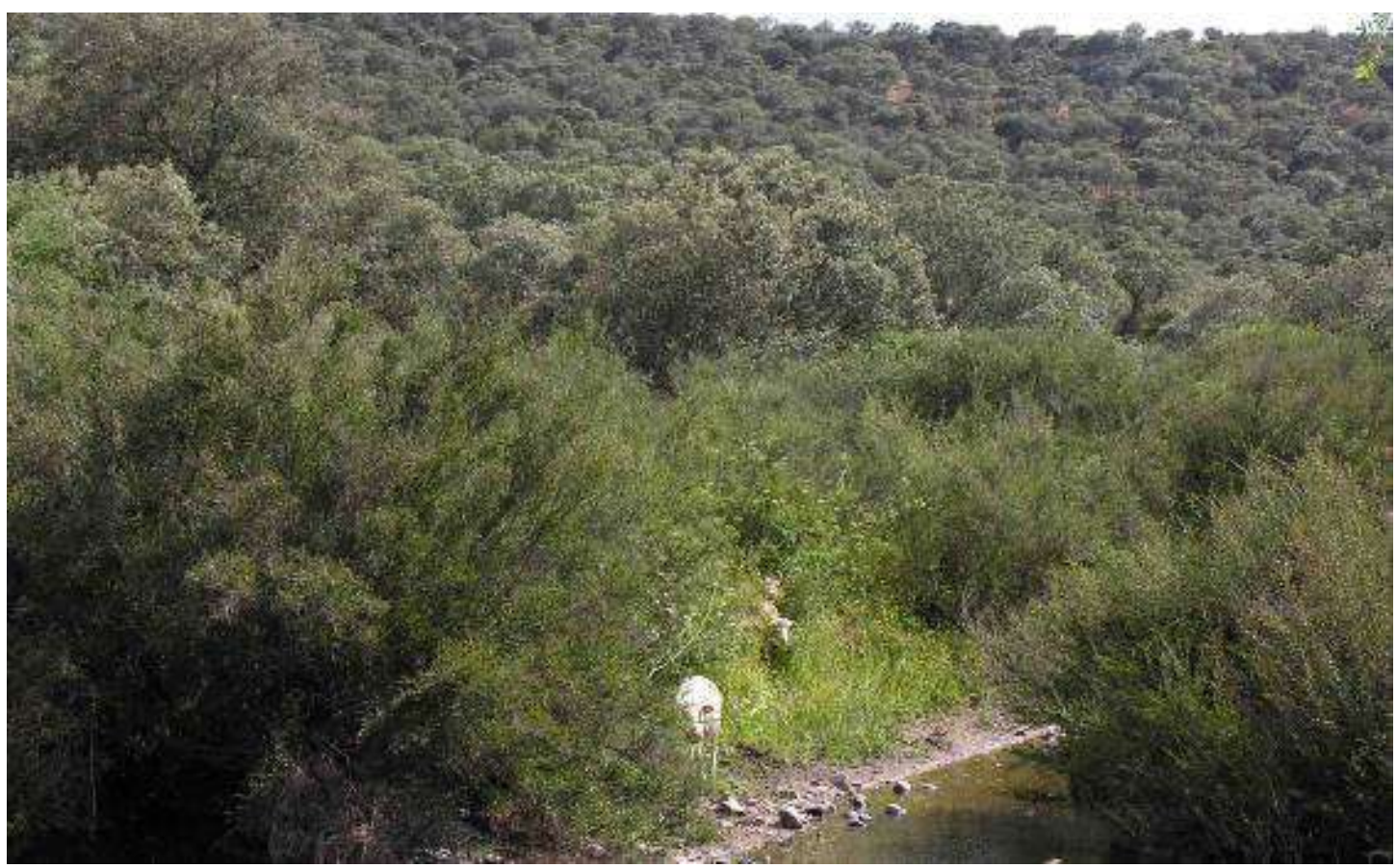

Fig. 2.2. En la Edad Media los rebaños disfrutaron de amplios territorios en la sierra para su aprovechamiento, encontraban abundancia de pastos y refugio frente a cualquier "razzia". La carne fue objeto de suministro a los diferentes bandos y un recurso económico de primer orden.

La historia de la Mina a partir de esta etapa la describe Matilla (1958). El rey Alfonso XI la arrendará desde 1348 hasta 1387 y en el contrato se estipula que la leña solo la podrían llevar los vasallos de Almadén y de la puebla de Gargantiel. Después pasaría a mercaderes genoveses a los que se otorga que corten la madera para la mina en cualquier lugar donde la Orden tenga estos privilegios, y la leña y el carbón en todo el término de Almadén. En 1400 los arrendadores 
pueden pacer sus bueyes y bestias en las dehesas de Almadén y en todo el campo que está a ojo del dicho lugar del Almadén. Acabado el periodo bélico, el Rey Católico quedará como administrador apostólico vitalicio de la Mesa Maestral a partir de 1487 y, en 1523, consigue la Corona la administración perpetua. Las concesiones anteriores se mantienen y se permite al arrendador alquilar bueyes y carretas de cualquier parte para llevar leña y madera a la obra. Una condición curiosa del arriendo de 1488 es la autorización a designar cinco personas en Almagro que puedan sacar, traer y cortar leña de Zacatena para sus propias casas. La documentación sin aludir especies marca diferencias entre madera, leña y carbón para las necesidades mineras.

\subsubsection{Historia medieval y el devenir forestal}

Aunque vinculado a especies y espacios de interés cinegético, el Libro de la Montería de Alfonso XI (1350) es el primer catálogo de los montes de España cuya fragosidad forestal mantenía abundancia de fauna mayor. A su vez, el título sirve para destacar que la silva latina se redujo a las zonas abruptas al utilizar una voz que deriva del latín mons, montis (Gil 2003). La reducción del espacio forestal se deduce no solo de la concreción del espacio forestal a las zonas montañosas, también por la equivalencia de voces en el Liber Iudiciorum o Fuero Juzgo entre la copia latina del siglo X y la romance del siglo XIII (RAE 1815). Así, lo evidencia al comparar la Ley II, título II, del libro VIII, relativa al castigo a los incendiarios en montes (lat. silva) ajenos. En la versión latina del siglo X menciona:

[...] Si quis qualemcumque silvam incenderir alienam, sive piceas arbores vel caricas, hoc est ficus, aut cuius libet generis arbores igne cremaverit, a iudice correptus $C$. flagella suscipiat, et pro damno satisficiat $[\ldots]$

Al traducir esta Ley, la copia romance del siglo XIII, dice:

[...] Si algun omne enciende monte aieno, ó árbores de qual manera quier, prendalo el iuez, é faga dar C. azotes, é faga enmienda de lo que quemó [...]

El cambio de 'monte' por 'silva' muestra la característica del territorio al que se reducen las formaciones forestales. Además, en la versión latina los pinos son citados explícitamente, pues la voz 'picea' alude a su condición de productor de pez (lat. pix, picea); sustancia hoy poco conocida, pero hasta hace pocas décadas de gran valor económico. En sus Etimologías (Oroz y Marcos 1983) dice San Isidoro (XVII, VII, 31): Pinus arbor picea. Cuando Alfonso de Palencia en 1490 efectúa una recopilación de la evolución de los vocablos latinos al castellano vulgar, menciona: Picea se dize arbol que suda pez y tomo nombre por la pez (Hill 1957).

A mediados del siglo XIV, el Libro de la Montería relaciona 126 montes en el Campo de Calatrava, al tiempo que señala la toponimia en uso. Los múltiples nombres de lugar han sido recogidos como fuente de documentación para la lexicología histórica (Rhustaller 1995) y permite el análisis de los citados en el capítulo XVII dedicados a los montes de tierra de la Orden de Calatrava, los de enrrededor de Puerto Llano y los de allende el Canpo de Alcudia. Cabe señalar que, esta zona no es de las más prolíficas en monterías del rey, lo que aboga a una 
carencia de infraestructuras, pero permite comparar la abundancia de unas especies frente a otras como vegetación identificadora. Los términos más numerosos se refieren al roble, una de las especies más exigentes en suelos desarrollados y climas frescos, que figura en seis ocasiones, pero solo una como formación (robredo), mientras que las restantes se pueden interpretar como masa en degradación (robrediello) o como un árbol individual (robre) en las restantes cuatro. Curiosamente, siguen los sauces en cuatro ocasiones, dos como formación (salzeda) y las demás en regresión (salzedilla y salzeio). El castaño, árbol de mayor nivel evolutivo en la dinámica de los bosques ibéricos aparece en dos, una como masa forestal (castañar) y la segunda como árbol solitario (castaño). Otros dos topónimos se dedican al enebro, una como árbol individual y otra a un enebral. Ya con un solo registro figuran alcornoque, azebuchar, endrinal, enzina, fresneda, peraleda y sarçuela. Otros topónimos relacionados con el resultado del uso del territorio son colmenar (4), una dehesa, una figera, una maleza y mata en otra ocasión.

El obligado proceso de colonización se inició con la llegada al Campo de Calatrava de colonos procedentes de Castilla y Navarra, traídos por el Abad Fitero, uno de los dos fundadores de la Orden. A los colonos se les asignaron tierras para labor y cría de ganados y a los concejos, tanto a los primeros como a los que fueron surgiendo, dehesas comunales. Entre otros motivos de atracción a la comarca estaba la concesión por Fernando III y confirmado por Alfonso X en 1254 (BOC 89), de la minería en el entorno:

[...] Y hágase la extracción de la plata en la forma acostumbrada; y los mineros tengan derecho al agua, leñas y carbón según costumbre; y sus vecinos y moradores gocen igualmente de los pastos con sus ganados [...]

Concesiones que favorecen el poblamiento por el disfrute gratuito de montes y pastos. La explotación de las minas se arrendaba a valencianos, genoveses y alemanes (Hervás y Buendía 1918, Matilla 1958). Se otorgaron privilegios como exenciones fiscales y derechos de tala de madera a los propietarios y arrendatarios de los pozos para su explotación. La búsqueda de nuevos veneros de mercurio, plata y plomo se extendieron por todo el territorio por lo que se tuvo que regular la tala de árboles y el emplazamiento de los lavaderos de mineral para reducir la contaminación de las aguas y no perjudicar a los rebaños (Gómez Vozmediano 2000).

Hacia el siglo XV los Maestres ejercían jurisprudencia sobre un vasto territorio poco poblado, la colonización había sido lenta pero exitosa (Rodríguez Picavea 1994; Ruiz Gómez 1992, 2002). La Orden implantaría un sistema de gestión territorial cuya actividad era la ganadería, para lo cual se regulaban los aprovechamientos de pastos y el arbolado. Las dehesas fueron el principal valor de la Orden, cuya extensión era incompatible con la admisión de colonos en busca de tierras para roturar y cultivar, creándose numerosos conflictos (Corchado 1977, 1984; Gascón 1978, 1981; López Salazar 1986, 1987). Conflictos que, incluso, afectaron a la mejor de todas las dehesas, el Valle de Alcudia, que se la había reservado el Gran Maestre. 
En el Tratado de Montería, atribuido a Fernando de Iranzo, Comendador de Montizón, entre los años 1456-1473 (Valverde 1996), se describen los bosques, el clima y la vegetación en Sierra Morena oriental:

[...] Estos tales montes de arboleda llamanse oquedales, porque tienen lo espeso en lo alto e lo güeco en lo baxo, que se puede andar sin empacho [...]

[...] Los montes e espesuras baxas son estas: madroñales, coxcojales, matapardales, xarales, estepares, lentiscares, aunque esta tal natura de matas pocas veces se hace en las partes muy frias. E hay entre el espesura del arboleda y espesura baxa otro medio, que no es güeco para poder andar, a lo menos cabalgando, ni tampoco es espeso por lo bajo; esto tal en esta tierra dícese fendal; es monte muy abrigado, tanto que en ellos guarescen los ganados de las nieves $[\ldots]$

Estas referencias, comparadas con los nombres de lugar del Libro de la Montería, muestra el cambio sobre el paisaje anterior, en apenas un siglo está formado por dehesas (oquedales) y una gran variedad de matorrales, donde las voces coxcojales y matapardales, reflejan la degradación de los bosques de las especies de Quercus. No parece adecuado que identificara correctamente a $Q$. coccifera como tal y no lo pudiera hacer con el resto del género; tampoco que los verdaderos coscojares tuvieran más importancia que cualquiera de las otras especies presentes, para que éstas y, en particular al matorral de encina no poseyera denominación propia. Queda una tercera formación con la denominación ignorada de fendal para formaciones abrigadas que no se pueden cabalgar ni los domina el matorral. El término se puede interpretar como un tipo de monte ya con apertura de la masa; pues a fender Alfonso de Palencia (1490) le da el sentido de abertura de la tierra (Hill 1957). En el Valle de Alcudia y otras zonas serranas se transformó la mayoría de los bosques en montes más o menos aclarados (montes huecos o dehesas). Es decir, se iba roturando el matorral sin quemarlo, seguido de pastoreo que agotaba las reservas del rebrote, manteniendo un cierto número de árboles, cuya especie predominante posiblemente cambiaría y la densidad iría disminuyendo con el paso de los siglos.

\subsubsection{La Edad Moderna y el auge de la ganadería.}

Cerca del final de la reconquista, los Reyes Católicos obtienen de Inocencio VIII, en 1492, cartas apostólicas para que los caballeros de las OOMM, so pena de nulidad, en lo sucesivo no pueden designar los altos cargos y el maestrazgo pase a perpetuidad a la corona. Cartas que confirmará Adriano IV (4 de mayo de 1523). Sierra Madrona y el Valle de Alcudia se conocerán en conjunto como "Real Valle de Alcudia" (Quirós 1964) que seguirá bajo arriendo de pastos de invernadero, agostadero y montanera. Su importancia para la Orden de Calatrava, la Mesta y la Corona procedía de la calidad textil del vellón de merino, uno de los valores más cotizados en todas las plazas de cambio como las de Brujas y Amberes. Su lana era reclamada por las manufacturas textiles de toda Europa y propició que las merinas formaran el grueso de la cabaña en la segunda mitad del siglo XVII (Le Flem 1975). Este monopolio permanecería en manos españolas durante más de 5 siglos (García Sanz 1978). 
Es tradición oral hasta la actualidad que los ganados trashumantes entraran al Valle de Alcudia el 29 de septiembre, día de San Miguel, y permanecieran ocho meses, saliendo el 30 de abril. El valor de los pastos de agostadero era mínimo y, a veces, los ganaderos invernantes también los arrendaban para que no entraran otros rebaños durante el verano. La montanera empezaba el día de San Lucas (18 de octubre) y solía estar incluida en el arriendo de los pastos (pastos de suelo y vuelo), salvo en las cercanías de pueblos o sierras que solían arrendarse para ganado porcino.

Los ganados invernantes acudían desde el Norte por las cañadas Riojana, Soriana oriental y Conquense. Confluían unas con otras hasta formar la Vereda Mayor de Alcudia, por la que transitaban más de 100.000 ovejas anuales. La Vereda Mayor de Alcudia era una cañada con una anchura 4 o 5 veces superior a la media del resto de cañadas ( 90 varas $=75 \mathrm{~m}$ ). A la entrada al Valle tenía una anchura de 400 varas y llegaba hasta las 1.000 varas en La Veredilla. Lo que permite hacerse una idea de las cargas ganaderas que tuvo el Valle de Alcudia,

Los mejores pastos (Fig. 2.3) eran usados como invernadero por las ovejas merinas de los grandes ganaderos, que los arrendaban por periodos de 10 años y volvían a "poseerlos" por sucesivos periodos de 10 años, con el tiempo, aunque no legalmente, estos grandes y poderosos arrendatarios serían, en la práctica, los dueños de los terrenos (Gascón 1978). Por lo que serán conocidos como "posesioneros". Su poder incluso enfrentó a los arrendadores de la dehesa de Castilseras con los asentistas de la mina en los años 1567 y 1568 (Matilla 1958) por el mucho terreno que rompían y roturaban, con grave daño para la mina al impedir el aumento y crecimiento del monte.

Bajo esta situación, los pastores locales se vieron obligados a pastar sus rebaños en las sierras, donde la especie más adecuada era la cabra, (Fig. 2.4), adaptada a la calidad de los pastos leñosos en cualquier época del año. La pacificación del territorio aumentó la población y pudo disponer de mayores rebaños, con lo que surge una sobreexplotación ganadera de las sierras (Fig. 2.5) y los inevitables conflictos. La quema de los montes cada 3-6 años aumentaba el pasto herbáceo y reducía la altura del leñoso, haciendo accesibles sus brotes del año a la boca de los animales (Fig. 2.6). En tiempos de Felipe II el proceso era bien conocido como evidencia una Orden del año 1565 (AHM, Legajo 131):

[...] Para que en los montes que se quemaren en todo el Campo de Calatrava, por 5 años, no dejen entrar ganados en ellos, porque los mismos ganaderos los quemaban adrede para que sus ganados tuvieran tallos y retoños nuevos que comer, en perjuicio de los árboles [...] 


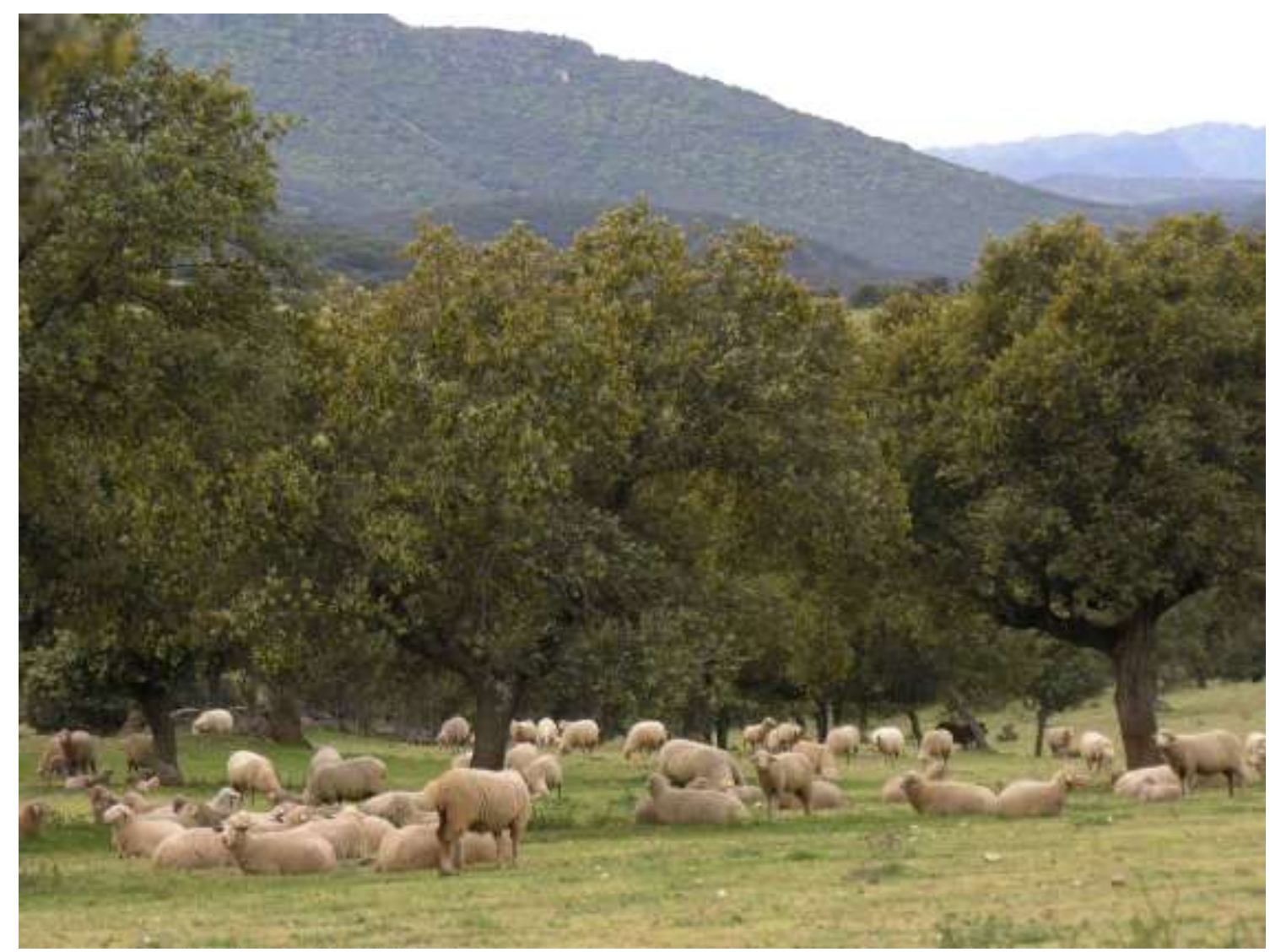

Fig. 2.3. Desde la Edad Media las zonas más llanas del Valle de Alcudia fueron parcialmente descuajadas para crear montes aclarados, de forma que pudieran convivir pastos herbáceos y arbolado productor de ramón y bellotas, por lo que se favoreció especialmente a la encina. Se trata de un conjunto de pastos de suelo y vuelo, muy valorados como invernadero para la oveja merina. Mientras los bosques y matorrales quedaron relegados a las sierras.

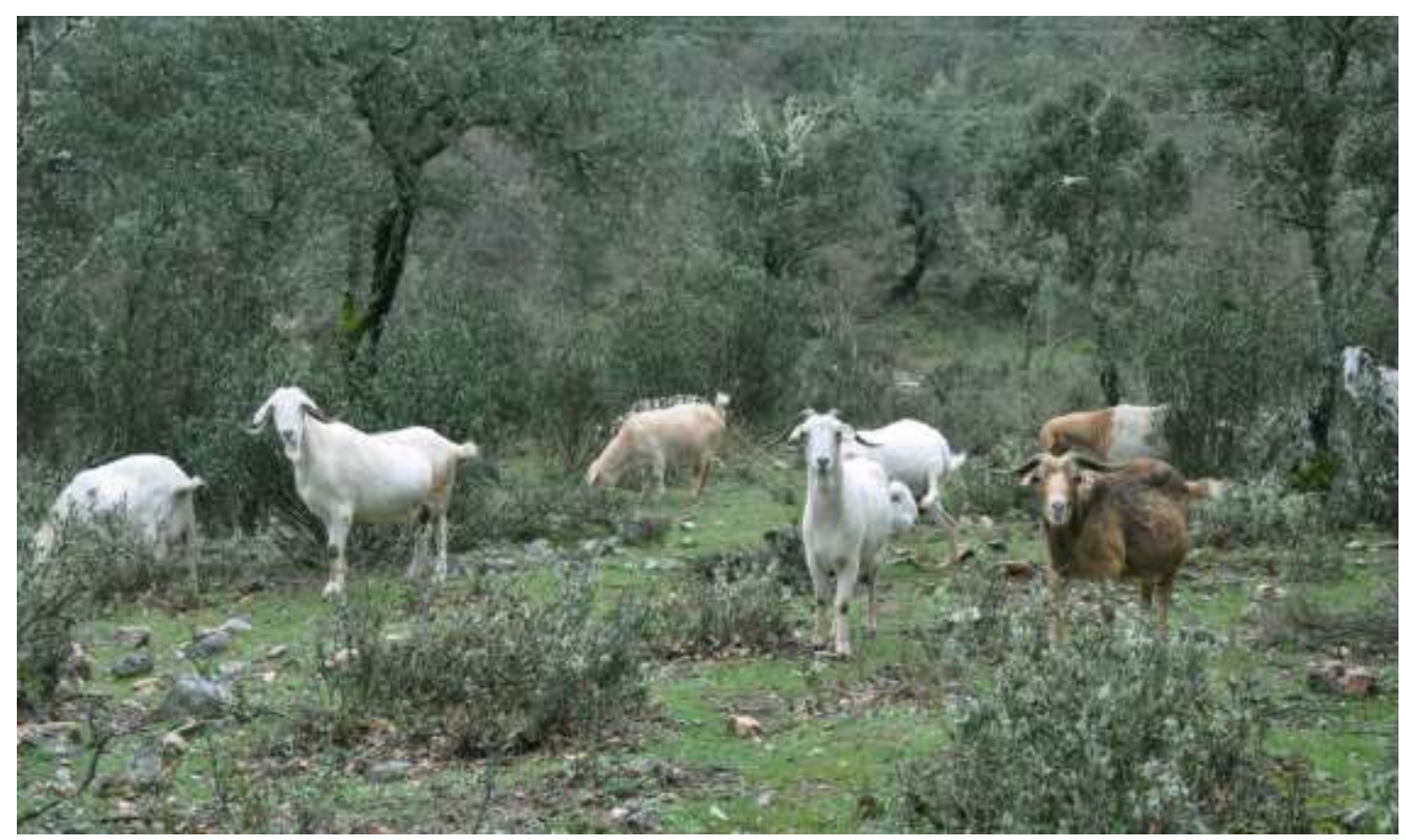

Fig. 2.4. En las sierras, como en el valle de Alcudia, el arbolado era aprovechado principalmente para abastecer las minas de Almadén, pero mientras que en el valle se descepaba para evitar la regeneración del arbolado (ver Fig. 2.3), en las sierras no, manteniéndose el matorral y restos dispersos de los antiguos bosques. Aquí el ganado predominante era el cabrío. 


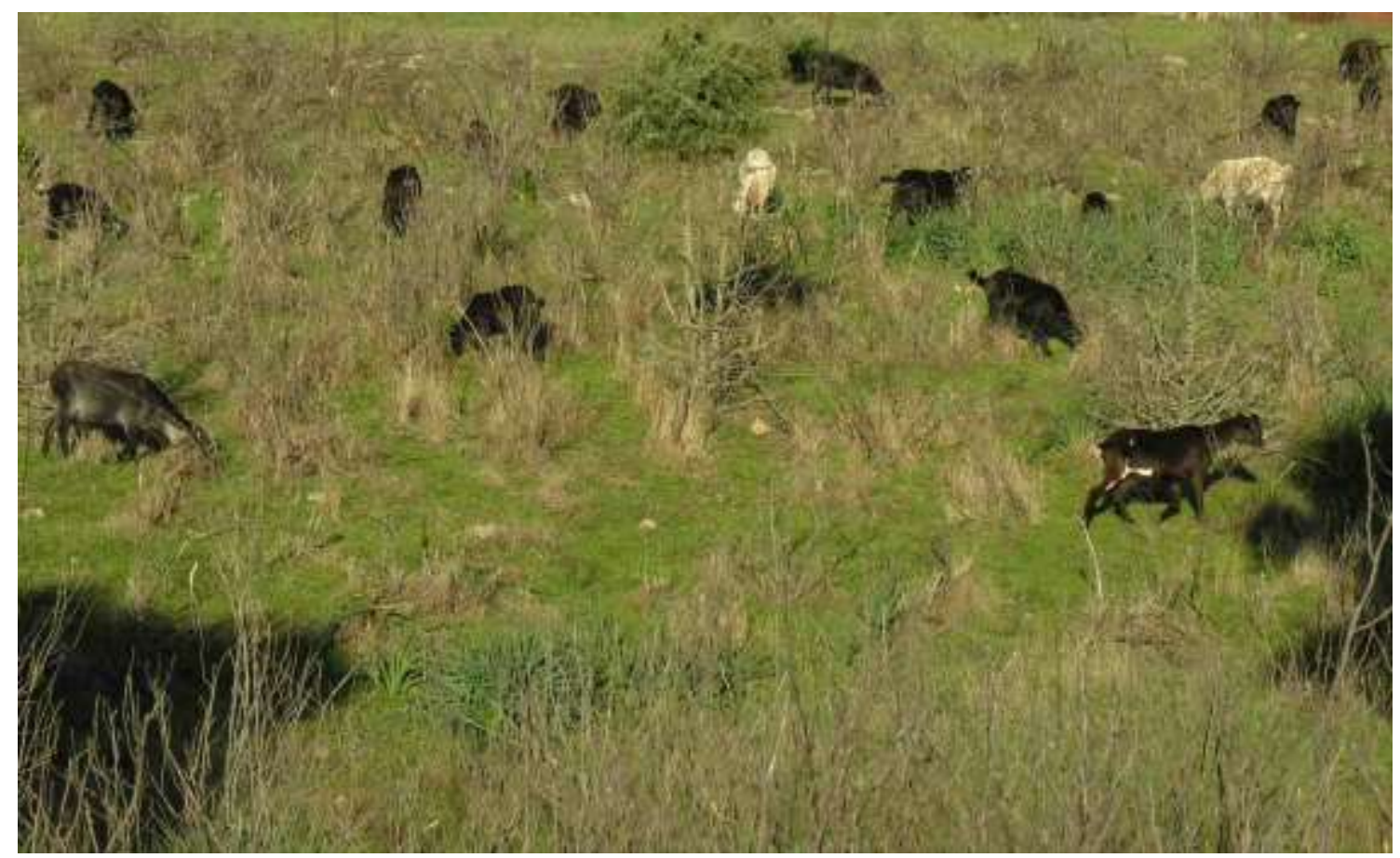

Fig. 2.5. Las facilidades otorgadas por la Orden Militar de Calatrava para colonizar su "Campo" motivó una creciente llegada de colonos y expansión demográfica que se tradujo en un considerable aumento del número de rebaños cabríos pastando por las sierras. Rebaños de miles de cabras arrasaron con la vegetación leñosa allá donde su presión era más intensa. Obsérvese el enebro del centro de la imagen (especie poco palatable) como ha sido consumido todo su follaje hasta donde alcanzar a comer las cabras.

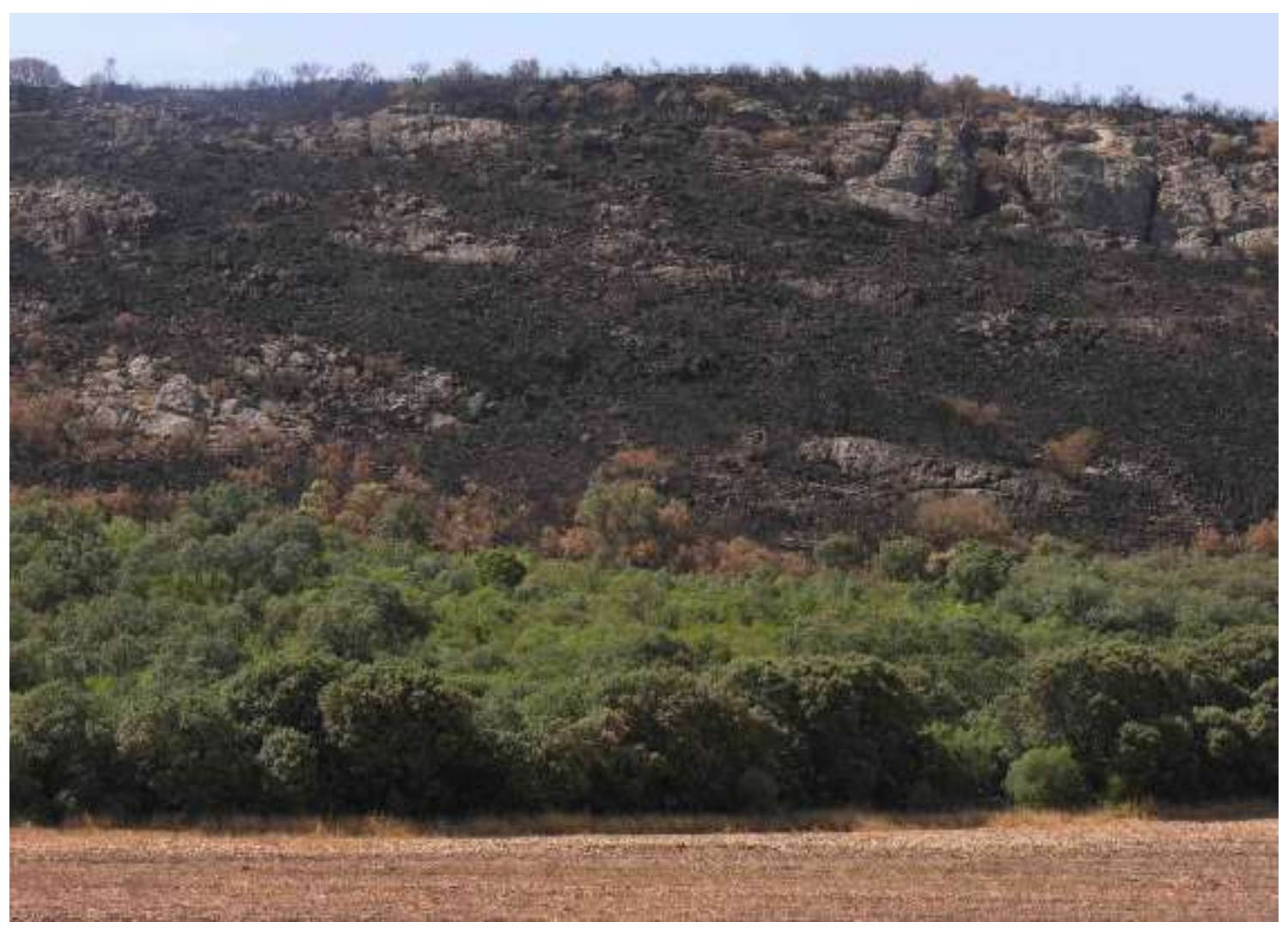

Fig. 2.6. Las sierras se incendiaban cada 3-6 años por los pastores para eliminar la vegetación leñosa, favorecer la reducción de la talla del matorral, la aparición de un rebrote menos leñoso y más luz para la expansión del pasto herbáceo. 
Reflejo también de estos incendios pastoriles puede verse en el Memorial presentado en 1570 (AHN OOMM legajo 37.091) por el Comendador de la Dehesa de Castilseras y un representante de los Fúcares (arrendatarios de las minas de Almadén), que deseaban reducir el matorral de las dehesas de pasto:

[...] por ser los montes de la dicha encomienda que confinan con los del pozo del Almaden muy cerrados y espesos, no pueden crecer ni medrar los arboles y por el fuego que hacen en ellos los pastores $[\ldots]$ corren mucho peligro de quemarse $[\ldots]$

El problema de los incendios de los pastores parecía grave por lo que se insistía en la necesidad de clarear los densos montes de algunas dehesas (AHN OOMM legajo 43.928):

[...] han quemado más de cien mil encinas y, si se ara y se siembra, no pegarán fuego por guardar los panes [así, las encinas] estaran conservadas y guardadas porque en poder de Miguel Martin y sus consortes [los arrendatarios] siempre pegaban fuego a la dicha dehesa para arrasar la tierra para el ganado y que de ello venia gran daño a la dehesa y las encinas y a la demás leña de donde resultaba perjuicio para el azogue y beneficio de la obra de Su Majestad en la dicha villa de Almaden, los cuales inconvenientes cesaran si se labra para pan aquello que es para labor de pan, porque no osaran pegar fuego porque los panes no se quemen y de esta manera habra gran madera y leña para la dicha obra y en muy pocos años $[\ldots]$

Esta situación causada por las necesidades de los pastores locales, se produce en un contexto de auge de La Mesta, situación que manifiesta uno de sus grandes protectores, Felipe II, quién al dirigirse a las Cortes de Valladolid, 1558 y a las de Toledo, 1560, denuncia:

[...] Porque nos fue hecha relación, que en Andalucía y Extremadura, y Reino de Toledo y otras partes de nuestros Reynos acontece quemarse algunos montes para mas crecimientos dellos y del pasto, y destas quemas resultan muchos daños, y después de quemado, como echan junto al suelo tallos frescos y tiernos, los ganados cabrios los comen luego mejor que otro ningun pasto, de que resultan, que las encinas y otros arboles no tornan a lo ser, y pierdese la bellota y la cria de los puercos: fuénos pedido, que para el remedio mandasemos, que cada y quando acaeciere quemarse algun monte, dentro de cinco o seis años no entrase en él ningun ganado so grandes penas [...]

Ley que perjudica a los ganaderos locales, aludidos por el tipo de ganado que se quiere erradicar. En esta lucha de intereses por la tierra y sus recursos, ya figura la encina como la especie protagonista de las dehesas, y evidencia la necesidad de quemar que tenían los pastores, fuera cual fuera su ámbito de actuación pastoril. Actividad que es innata en el nombre que recibieron los ganados de La Mesta, agrupados bajo la denominación de "Cabaña Real": el de "trashumantes" (Gil 2008), aludiendo a la práctica de la quema necesaria de los lugares de invernada y estivada cada cierto periodo de tiempo para pastar (tras-fumo) los brotes jóvenes a su regreso. 
Al mismo tiempo continuaban llegando colonos, humanizando cada vez más Sierra Morena. Sin embargo, no supuso un gran poblamiento, frente al interés de emigrar a América, pues en marzo de 1567, Felipe II en la Nova Recopilación (Libro $7^{\circ}$, título 22, De los despoblados y su repoblación), aparece la obligación de colonizar, entre el Campo de Calatrava y Andalucía, con 6.000 labradores y artesanos alemanes y flamencos.

Una aproximación a la población existente la proporciona el Padrón de Pecheros elaborado en 1528 por Carlos I (INE 2008) con objeto de cubrir la carga fiscal denominada el Servicio. En los datos de población no cuentan ni con la Iglesia ni la Nobleza, pero incluye viudas, menores y pobres. Desafortunadamente, y a diferencia de otros territorios, el Campo de Calatrava ( $n^{\circ} 7$ Fig. 2.7) posee un cómputo total en las 44 entidades de población, 10.681 vecinos pecheros. Entre ellas figura 'Avanilla', situado en Murcia, va en este Partido porque es de la Orden de Calatrava, de Luciana señala que es de reciente población y excluye a Picón. Al sumar los de la villa de Ciudad Real, el Campo de Calatrava totaliza 11.905 vecinos pecheros. Resultando ser la cifra más baja cuando se compara con los territorios que la rodean. La de mayor peso demográfico en pecheros es Córdoba ( $\mathrm{n}^{\circ} 8$ en la Fig. 2.7) que posee 31.757 pecheros, de los que corresponden a la ciudad 5.845 pecheros. Jaén $\left(\mathrm{n}^{\circ}\right.$ 17) tiene 25.918 pecheros, de los que la ciudad cuenta con 4.253 pecheros; el territorio en Castilla de la Orden de Santiago $\left(n^{\circ} 6\right)$ tiene 15.855 pecheros y su ciudad más poblada es Ocaña con 1306 pecheros. La Mesa Arzobispal de Toledo ( $\mathrm{n}^{\circ}$ 21) cuenta con 19.183 pecheros, de los pertenecen a la ciudad de Talavera 1115 pecheros y a la villa de Alcalá de Henares 850 pecheros. Finalmente Toledo ( $\left.n^{\circ} 31\right)$ cuenta con 18.601 pecheros.

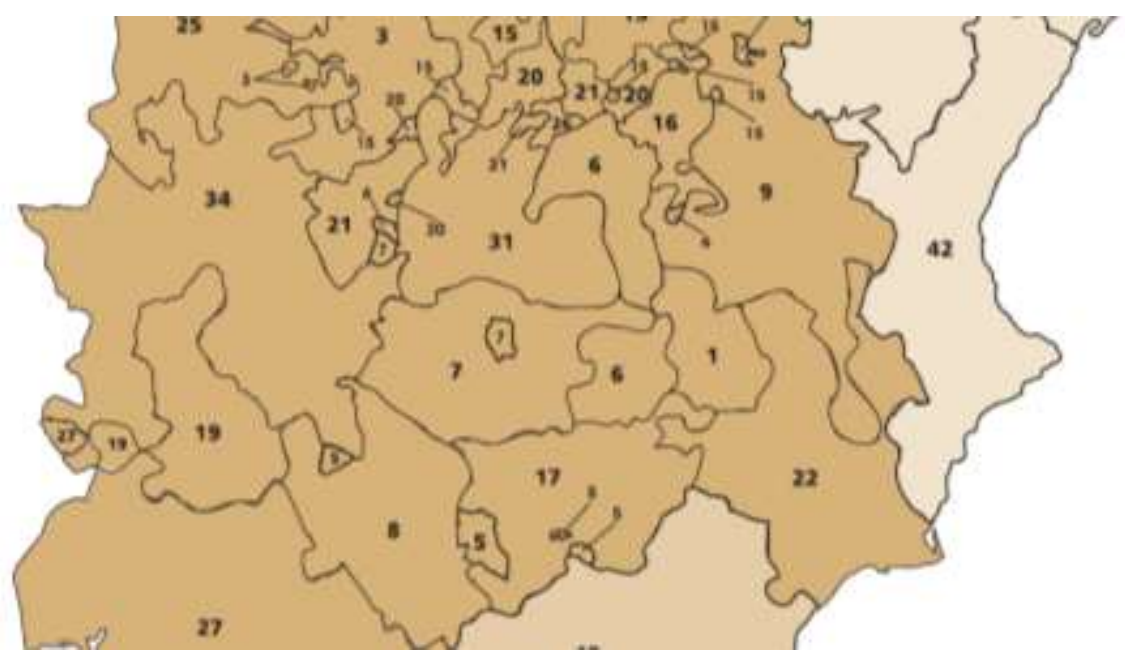

Fig 2.7. Localización de algunos territorios que conforman el Padrón de Pecheros elaborado en 1528 por Carlos I. El Campo de Calatrava figura con el número 7 e incluye como enclavado Ciudad Real.

Este menor poblamiento en relación a su entorno territorial lo confirma el Censo de Castilla de 1591 (INE 1985), que constituye la trascripción del único vecindario completo para Castilla y 
que aumenta la cifra a 19.212 vecinos pecheros en el Campo de Calatrava, sin incluir Ciudad Real que cuenta con 1.211 vecinos. El aumento de vecinos pecheros se incrementa un 79,9\%, mientras que la villa de Ciudad Real se mantiene prácticamente igual, con un descenso del 1,1\% de pecheros. Aumentos similares a los que tiene la Mesa Arzobispal de Toledo o Jaén y superiores a los de Córdoba que son del 45,5\%.

Este Censo adolece igualmente de la falta de consignación por entidades de población. Lo que no ocurre en otros territorios y permite opinar que no tuviera una gran importancia económica. Por otras parte el número de poblaciones se reduce a 40. Desaparece del Censo de 1591 "Huerta de Val de Caravanos", se sitúa fuera del Campo de Calatrava a 'Avanilla' y a Picón, se une El Viso con Santa Cruz, Valenzuela con Villarubia, y se separan La Cañada y El Moral, que aparecían unidas en el censo de pecheros.

Sin embargo, las relaciones de vecindad dadas por los obispos de la Corona de Castilla en 1587 (González 1829), permite conocer los vecinos de las 17 villas del partido de Almodóvar del Campo. La cabeza de partido cuenta con 1.200 vecinos, le sigue Puertollano con 1.100, Piedrabuena 600, Argamasilla 500, Almadén 400, Mestanza, 300, Villamayor 200, Corral 200, Saceruela 200, Alcolea 140, Cañada del Moral y Fuencaliente, cada una con 100, Cabeza Arados 80, Luciana 70, Puebla de Don Rodrigo 60, Caracuel 40 y Los Pozuelos 40. En total 5.330 vecinos. Es decir una cifra inferior a la tercera parte de la población de todo el Campo de Calatrava.

Cabe pensar que este bajo poblamiento está en relación con la influencia de los ganaderos trashumantes y que la dedicación de las sierras al pastoreo no era libre. Al ser propiedad de los ayuntamientos, los regidores controlaban su arrendamiento, bien a ganaderos locales, de pueblos próximos u otro tipo de propietarios. Mestanza, en cuyo término se sitúan parte del Valle de Alcudia y Sierra Madrona, durante el siglo XVIII contaba con unas 1.475 ovejas y unas 1.126 cabras, pero en sus anexos de San Lorenzo y El Hoyo, eminentemente serranos, había 3 ovejas y unas 1521 cabras (Pozuelo \& Pozuelo 1994). En 1786, los rebaños de cabras que pastaban en las sierras de Almodóvar podían superar las 1.000 cabezas (AMAC 4-1786 y 25-1774).

Sin embargo, antes de finalizar el siglo XVI, en 1593 se realiza el deslinde y amojonamiento del "Real Valle de Alcudia" (Quirós 1964) por Gonzalo Portillo del Pulgar y se efectúa la valoración de la carga ganadera que la cifra en 197.489 ovejas. (AMAC Acuerdos, 1768, 23 junio). En 1736 se situó en 139.500 ovejas en invierno (AP.RP.A. Sec. 15, Legajo 6º 1 , folios 364-381). Llamativamente, a mediados del XIX Madoz, en su DGE, afirma:

\section{[...] pueden pastar mas de 300.000 cab. de ganado lanar y 3 a 4.000 reses vacunas [...]}

Estos bailes de cifras difícilmente pueden orientar sobre la carga ganadera, cuya evaluación era a efectos recaudatorios y el ocultamiento de cifras siempre iba en beneficio de los poderes locales. Cifras además cuyo control escapaba a una validación precisa como lo muestran la asignación del número de vecinos pecheros al conjunto del Campo de Calatrava. 


\subsubsection{El estado de los montes de Sierra Madrona y Valle de Alcudia a finales del siglo XVI según las Relaciones Topográficas de Felipe II.}

Las Relaciones Topográficas de Felipe II de los pueblos de la comarca, responden a los Cuestionarios del jesuita Páez de Castro respondidos por los lugareños comisionados por las autoridades de los pueblos en 1575 o 1578, repetición motivada por que el rey no quedó satisfecho con todas las respuestas. Estas respuestas han sido muy valoradas por los historiadores hasta el punto de que Campos y Fernández de Sevilla (2009), que reproduce y comenta las de la provincia de Ciudad Real, considera que:

[...] pocos territorios disponen de una radiografía tan auténtica, verdadera y completa de su lejano ayer, y por eso más interesante, como los pueblos de la antigua Castilla La Nueva, fundamentalmente, que fueron los que respondieron al cuestionario filipino [...]

En cualquier caso, proporcionan información sobre el estado y composición de los montes a finales del XVI. Se expondrán algunas de las respuestas más relevantes para conocer el estado de los montes. Aunque a veces se han considerado otras respuestas, la más importante para conocer el estado de los montes es la que se ofrece a la pregunta $\mathrm{n}^{\circ} 18$ :

[...] Si es tierra abundosa, o falta de leña, y de donde se proveen; y si montañosa, de qué monte y arboleda, y qué animales, cazas y salvajinas se crían y hallan en ella. [...]

Pese a la precisión de esta pregunta no elaboran un apartado relativo a la riqueza forestal y lo incluyen en la riqueza agropecuaria. Señal precisa de que los montes ya no eran los protagonistas del territorio a finales del siglo XVI. Al exponer las respuestas a la pregunta $18 \mathrm{de}$ todos los pueblos de la comarca (expuestos aquí de oeste a este) permite, conjuntamente con otras respuestas, valorar el contexto espacial y temporal del estado de los montes en la comarca.

\section{Chillón (incluye a Guadalmez)}

$18[\ldots]$ y en los demás es tierra más montosa que rasa [...] es tierra que tiene medianamente leña para proveerse los vecinos de ella, y en ella hay en sus términos encina y xara, cepas de retama, carrasca y iharneca y lantisco, y tiene algunos montes, laderas y rasos donde hay encinares, alcornoques, acebuches, madroño y romero, lentisco, tomillo, escobilla, benezo [brezo], quizuela, lojarance [...]

20 [...] y se dice Guadarniel [el río Guadalmez] y corre cara al puniente, y en el hay mucho número de arboleda de fresnos y zauzos [sauces] y adelfales [...]

22 [...] este pueblo tiene dos dehesas boyales. [...] la dehesa de la Pared, [...] la cual es abundante de pasto y arboledas de carrascos y alcornoques; [...] y la dehesa del Campo la cual tiene grande montaña de carrascos y algunos alcornoques [...] y que no hay bosques sino mucha diversidad de montes como hemos dicho [...]

$30[\ldots]$ los edificios de las casas [...] madera de encina, alcornoque y alguna de pino [...] 
35 [...] unos labran lana merina [...] otros tienen oficios de labradores [...] y otros tienen huertas y crias de ganados cabrios y lanares y vacunos y otros [...] son tenderos, sastres y zapateros y tintoreros $[\ldots]$

Almadén (incluye a Alamillo)

18 [...] Esta tierra es falta de pan y vino y se provee de La Mancha; tiene montes de encinas y xara y alcornoques y otros árboles [...]

$24[\ldots]$ hay tres dehesas $[\ldots]$ y son de su Majestad [...] la villa tiene dos dehesas [...]

26 [...] esta villa se labra poco por la dificultad de los muchos montes y aspereza; crianse ganados cabríos y otros, aunque no en mucha cantidad [...]

$39[\ldots]$ habrá en todo cuatrocientos e cincuenta vecinos $[\ldots]$

$40[\ldots]$ son por la mayor parte labradores pobres $[\ldots]$ no hay hijosdalgo alguno $[\ldots]$

$45[\ldots]$ los términos comunes son malos y de poco aprovechamiento [...]

Castilseras (población que ya no existe. Entonces era la Encomienda de Castilseras)

$18[\ldots]$ es abundosa de encinas e montes e jarales [...]

24 [...] la dicha Encomienda es dehesa e tiene dieciséis millares [...]

$33[\ldots]$ es ocho las casas de los vecinos [...]

\section{Almodóvar del Campo (incluye a Brazatortas)}

18 [...] La tierra de la villa y su comarca no es muy fructífera ni abundosa aunque no es falta de leña, la cual se provee de los montes comarcanos que en el término comun y valdío se crían de encinares y otras fustas y montes bajos de encina recia y medida. $Y$ así en algunas partes es tierra montosa de árboles de encina y alcornoque y quejigos [...]

24 [...] En el término de esta villa está el Valle de Alcudia, dehesa de su Majestad entre todas las de su reino y maestrazgos insignes y de mucho valor y precio; tiene ciento y cuarenta millares de tierra según la medida común y ordinaria, de los cuales en el término de esta villa hay ciento, es tierra en parte rasa, y en otras poblada de muchas encinas, fértil y abundante de yerba y fruto para los ganados que en ella se apacientan y extrema, muy abrigada y acomodada a los dichos ganados [...] los demás términos desta villa son comunes a los concejos y vecinos de las villas de Puertollano, Fuencaliente, Argamasilla, Villamayor, Cabezarados que gozan y pastan con sus ganados los dichos términos como los de la dicha villa de Almodovar [...] 
$39[. .$.$] se cuentan de las aldeas inclusas en su termino habrá en todos mil y trescientos$ [vecinos]

40 [...] la mayor parte dellos es de labradores y habra hasta trece o catorce casas de hijosdalgo $[\ldots]$

Puertollano (incluye a Cabezarrubias del Puerto e Hinojosas de Calatrava)

18 [...] la villa es abundosa de leña, y aunque vale algo cara y se proveen de la dicha leña de montes de la dicha villa como son xara, madroño, quexigo, labernago, chaparro y coscoja y otro monte; y que no hay otras arboledas más del dicho monte [...]

24 [...] la dehesa que dicen del Oihuelo que es de la Encomienda desta villa [...] y caben dos mil y cien cabezas de ganado de lana [...] la dehesa de las Porras y se habitan en ella seis mil cabezas de ganado de lana [...] la Clavería que son ocho millares de ganado de lana [...] en las dichas dos dehesas hay mucho monte de encinas, en el cual los vecinos de esta villa pueden cortar guardando la carta real que habla sobre la conservación de los montes, y también pueden cazar; y lo mismo en la dehesa del Ochuelo [...] la dehesa de Villa Hoyuelo $[\ldots]$ que caben tres mil cabezas de ganado de lana $[\ldots]$

26 [...] poblada en tierra aspera de piedras y cercada de sierras y que en su término lo que valía algo es las dehesas y tierras de Encomienda que de suso están dichos es tierra de muy poca labor $[\ldots]$

$39[\ldots]$ que hay en su termino habrá hasta mil casas y vecinos de ellas $[\ldots]$

40 [...] son labradores y mercaderes y oficiales [...] siete u ocho hombres que están en posesión de hijosdalgo $[\ldots]$

$45[\ldots]$ para las ovejas que crian tienen compradas posesión de seis millares de tierra de tierra en el valle de Alcudia y para los demas ganados los llevan y sustentan en los términos de Mestanza y Fuencaliente y en parte de los términos de Almodovar [...]

\section{Fuencaliente}

$17[\ldots]$ esta en un hoyo cercada de sierras [...] muy fragoso y aspero de sierras por ser como es Sierra Morena [...]

18 [...] que la tierra es muy abundante de leña de muchas y diversas montañas como es robles, alcornoques, quexijos y encinas y otros montes comunes como son jarales, romero, arraigan, brezales, labiérnagos y madroños [...]

$24[\ldots]$ hay una sola dehesa que se dice Maza de Vieja, para las bestias de labor [...] la cual es muy pequeña y montosa por estar entre sierras y muy grandes montañas [...] 
26 [...] se siembra poco por ser como la tierra es muy fragosa y montosa y de mucho coste de labrar la tierra y desmontarla hasta la poner en disposición de sembrarla [...]

$39[\ldots]$ tiene ahora de presente ciento veinte casa y vecinos $[\ldots]$

$40[\ldots]$ todos los vecinos que la villa tiene son labradores y que no hay hidalgos [...]

$45[\ldots]$ que no tiene propios ninguno $[\ldots]$ salvo las penas $[\ldots]$ del fuego y cortas de los montes $[\ldots]$

$57[\ldots]$ tiene un lugar que es anejo, que tiene hasta treinta vecinos $[\ldots]$

Una reflexión sobre el contenido de las respuestas debe considerar los factores que dotan de subjetividad a su interpretación. Así, el nivel de formación y conocimiento del redactor, el interés personal de agradar a los diferentes niveles que lo reciben y la desconfianza a que los textos pudieran ser usados para aumentar la presión tributaria. Llamativamente solo se califica a los labradores como pobres en Almadén, la única villa en la que la agricultura no caracteriza a su vecindario como la principal fuente de ingresos.

Destaca el uso de la palabra de monte o montaña sin sentido orográfico y facilita interpretar que las zonas descritas llevan siglos de transformación y de sustitución o expansión de la especie más rústica y adaptada a la actividad e intereses de los propietarios. La riqueza léxica de los matorrales de degradación, donde predomina el jaral, manifiesta la diversidad y abundancia de las plantas de baja talla en todos los pueblos, excepto en Almódovar, donde el interés humano y la aptitud del terreno hace que los distintos tipos de especies arbóreas solo se personalicen en la encina, el árbol más interesante para el ganadero y para la frutalización del monte. Proceso de frutalización del monte, iniciado en el mundo romano como silva glandaria y reiterado en el Fuero Juzgo visigótico, para afirmar el origen milenario de las dehesas (Gil 2010)

Gracias al uso del fuego y descepes se extirpaban otras especies mientras que se favorecería a la encina, la especie productora de la mejor bellota, la mejor leña y el mejor carbón de todas las especies de Quercus. Al comparar el carbón de rebollo con el de encina, un carbonero de las dehesas de Sayago (Zamora) señalaba que son como "el hígado y el bofe" (Sánchez Gómez 1993). La preferencia de la encina, en ausencia del hombre, se basa en su adaptación ecológica a ser especie pionera y escasa en formaciones sobre terrenos con profundidad edáfica. $\mathrm{Su}$ condición de rara en las extensas formaciones forestales de fagáceas, llevó a la selección de individuos poseedores de gran cantidad de polen para que, cómo parental, pudiera acceder a encinas distantes como progenitor materno y, ésta, produjera muchas bellotas. Una elevada formación de fruto permite que su dispersión por las aves encuentre un lugar donde no dominen Castanea o Quercus con mayor nivel evolutivo. En un territorio no intervenido y con una dinámica natural, la expansión del encinar sería a favor de pinares ecotónicos, cuya dinámica histórica hubiera generado suelos de buen perfil edáfico a los que, sin dificultad, Q. ilex los desplazaría en un solo ciclo; aún más corto si el hombre aplica fuego y pastoreo, que elimina a la conífera incapaz de rebrotar. Situación que la explica Chillón, cuando dice que en la madera 
de sus casas hay: alguna de pino. No cabe considerar el argumento de que se trajera de fuera, por el coste económica que ello implicaría y la presencia de encina y alcornoque.

La transformación de robledales mesófilos o mediterráneos a encinares o terrenos agronómicos, exigió un histórico descepe, que se podía realizar a mano, mediante yuntas de bueyes, o por agotamiento de las cepas tras reiterados ciclos de fuego y pastoreo. Este proceso conlleva la desaparición de la protección del suelo por la cobertura del arbolado y el inicio de procesos erosivos que arruinaban la fertilidad del suelo para la presencia de especies exigentes o cultivos pero, no, para plantar encinas. $Q$. ilex, junto con la coscoja, son las especies de mayor rusticidad de todo el género. En Almodóvar se menciona la presencia de montes bajos de encina recia y medida. El empleo de monte bajo apoya que muchos de esos encinares no tuvieran el porte propio de un árbol bajo condiciones naturales e, incluso su porte de menor tamaño le llevara a ser la especie a la que se alude como carrascales, voz que para Sebastián de Covarrubias (1611) es una especie de encina pequeña y a la que asimila con la coscoja. Siglos después abundará el término chaparro, voz de origen prerromana, que alude a una mata de encina o roble, de muchas ramas y poca altura (Corominas y Pascual 1984). 'Chaparro' expresa la condición de permanencia pero no de medrar hacia lo alto, resultado de la supervivencia en suelos erosionados sin capacidad de acumular agua y, por ello, tener que superar el prolongado estío mediterráneo, más exacerbado en las formaciones de baja densidad abiertas a los vientos veraniegos, lo que la encina consigue con un porte de tamaño reducido.

Es decir los montes de mayor suelo y con formaciones de mayor valor evolutivo ya no figuran con la frecuencia que poseían en el Libro de la Montería dos siglos antes. Una respuesta indicadora es de la de Fuencaliente, el municipio más alejado de las áreas humanizadas y entonces el menos transformado. En su respuesta menciona a robledales, alcornocales, quejigales y, en último lugar, la encina. La razón la explican: de mucho coste de labrar la tierra $y$ desmontarla. El término de 'desmonte' es revelador de la pérdida de la masa forestal a excepción de en el ámbito serrano. Deforestación que fue objetivo de los ganaderos trashumantes, tal como lo manifiesta en 1771 el Honrado Concejo General de la Mesta de estos Reynos cuando, en respuesta al Expediente que inicia el Diputado de las Ciudades de Badajoz, Mérida, Trujillo, Medellín y Alcántara y de toda la provincia de Extremadura, en su Memorial de 1771 afirman Extremadura necesita de desmontes, no de montes.

En las zonas más llanas de las sierras y, especialmente, en el Valle de Alcudia, dominaría el paisaje adehesado con varias especies, pero con predominio de la encina. Mientras que en las sierras habría pocas y malas tierras aptas para el cultivo. En otras zonas de colonización más antigua del Campo de Calatrava o La Mancha, el avance de la agricultura deforestó la casi totalidad de su territorio. El auge económico de la Mesta lo manifiesta el Valle de Alcudia, calificada en las RRTT como la mejor dehesa de su Majestad entre todas las de su reino, que acoge a 140.000 ovejas que pastan en tierra en parte rasa, y en otras poblada de muchas encinas, fértil y abundante de yerba y fruto para los ganados. En este contexto silvopastoral el máximo valor de la comarca son las rentas de las dehesas en las que inverna el ganado merino, cuyo arriendo monopolizan los grandes ganaderos trashumantes por ejercer el derecho de 
posesión hasta 1813. En siglos anteriores estas rentas las obtenía indirectamente de la exportación de la lana castellana, monopolizada por el Consulado de Burgos, creado por la reina Isabel en 1494 (Basas 1994). Se trataba de una asociación de comerciantes que compraban la lana a los propietarios de rebaños mesteños, y la enviaba a Laredo o Bilbao para exportarla a Flandes en barcos organizados por el consorcio del Consulado. Tras pasar el Valle de Alcudia y otras dehesas de las OOMM a la Corona el beneficio de esta se multiplicó, como la protección a la Mesta y al Consulado de Burgos, en perjuicio de la industria textil nacional.

\subsubsection{Siglos XVII y XVIII, el cenit de la ganadería, el crecimiento de los pueblos y el renacimiento de la minería. Repercusiones sobre los montes.}

Aunque todo estaba regulado por la Corona y los pueblos, un constante crecimiento de la población motivaba que los conflictos por la tierra, pastos, leñas o frutos (bellotas) fueran frecuentes en la Comarca (Gascón 1978). En 1568 se aprobó una normativa para evitar los abusos en los cortes de ramas de encina pero continuaron y medio siglo después, en 1621, conforme escaseaba la leña, su precio se duplicó con respecto a los años inmediatamente anteriores (Matilla 1958).

Las roturaciones fueron particularmente importantes entre 1593 y 1602. En la Dehesa de las Navas se descuajó la mayor parte de las 9150 ha de monte bravo que tenía; en las de Gargantiel, Tiñosas y Rincón también se roturaron grandes superficies para labor. En otras 9 dehesas más se realizaron importantes roturaciones de monte bravo, en algunas incluso se eliminó el monte por completo (ACMH. Leg. 3823). La Encomienda de Puertollano dio a censo perpetuo a algunos de sus vecinos 250 fanegas para su roturación y puesta en cultivo. En 1627 la Encomienda de Obrería dio otras 385 fanegas con el mismo fin (AHN. Consejo de Ordenes. Legajos 4367 y 4376).

Medidas que no fueron suficientes por la pobreza del creciente número de labradores, manifestada en las Relaciones de Felipe II. Situación económica que imponía a la población roturar, con o sin permiso, nuevas superficies de terreno para cultivar la tierra. Para evitar los abusos, ya de antiguo, la Orden Calatrava y luego la Corona, legislaron y mantuvieron guardas por todo el Valle. La Cédula dada en Madrid por Carlos II el 1 de agosto de 1686 (AMAC 481710), establecía que entre las funciones de los guardas estaba:

[...] poder prender a las personas que hicieran rompimientos de tierra, cortas, talas, quemas y daños en los dichos montes y dehesas, arado y usurpado alguna parte de ella y de sus veredas y montes, labrados, chozas o ventas, corrales, zahúrdas, colmenares y otros edificios procurándolo hacer suyo propio [...]

El Guarda Mayor de Alcudia, nombrado por el Rey, cuyo cargo (AMAC 48-1710), le otorgaba mayor autoridad: 
[...] prender a todas y cualquier persona que hubieren hecho o hizieren rrompimiento de tierras, cortas, talas, quema y daños en los dichos montes y dehesas, arado y usurpado alguna parte de ella y de sus veredas y montes [...]

Junto a estos guardas "oficiales" repartidos por toda la comarca, los arrendatarios de pastos tenían sus propios guardas.

Además de las históricas villas de Almadén, Almodóvar y Mestanza, más luego Puertollano, comienzan a surgir en sus términos municipales aldeas que se acabarán configurando 9 pueblos más. Estos nuevas poblaciones irán independizándose a lo largo de los siglos XIX y XX. San Lorenzo de Calatrava (en 1842) y Solana del Pino (1891) se independizaron de Mestanza; Alamillo y Almadenejos (1836) de Almadén; Cabezarrubias del Puerto (1842) e Hinojosas de Calatrava (1843) de Puertollano; Brazatortas (1867) de Almodóvar y, finalmente, Guadalmez (1927) de Chillón. Los trazados de los nuevos términos municipales siguieron en buena los límites de las antiguas Comunidades de Pastos. establecidas entre municipios y cuyo origen se remonta a la Baja Edad Media (Gascón 1978, 1981), estando bien documentadas a partir del siglo XVI. Pese a estas concordias por el aprovechamiento de los pastos, no la habrá entre pueblos, ni entre estos con sus ganaderos, ni entre todos ellos con los ganaderos trashumantes.

El aumento del número de pueblos y población implicaba no solo mayor explotación y roturaciones en los montes serranos, también un incremento de la conflictividad con los posesioneros. Uno de los casos más grave, que reflejaba muy bien las tensiones que motivaban los supuestos privilegios de los ganaderos trashumantes frente a la creciente población local fue el acaecido en el vecino pueblo de Abenójar en 1619. Francisco de Neyla y Salcedo, ganadero soriano, posesionero de 8 quintos en la dehesa de Villagutierre, emprendió un pleito por los daños que los vecinos le ocasionaban, valorados en unos 6000 ducados. Estos daños se los provocaban los vecinos con sus ganados, especialmente de cerda, en su dehesa, desde hacía 8 años, para aprovechar además de la hierba, la bellota, cogiéndola y vareándola antes de que llegaran los ganados de Neyla desde Soria

[...] y por que como no está madura, no quiere caer, suben a las encinas y con puñados cortan las cogollas y ramas para que caiga la dicha bellota y el ganado la coma ... de tal manera que cuando vienen a entrar en ella los ganados lanares del dicho don Francisco no la pueden pastar, por estar toda (además de sin bellotas) volcada y hozada ... lo peor era que, debiendo la justicia de la dicha villa castigar a los delicuentes y satisfacerle de sus agravios y daños, no lo hacía; antes, por ser los ganados (del pueblo) de gente rica y poderosa, disimulaban con ellos y los ayudaban y fomentaban a hacer los dichos daños y talar la dicha dehesa [...]

Los criados de Neyla eran vapuleados y amenazados, de modo que nadie quería servirle. Los que sufrieron el acoso de los vecinos del pueblo declararon:

[...] dijeron (los vecinos de Abenójar) que no tenían nada que perder, y que habían salido al camino de Almodóvar y, si les hacía agravio el dicho don Francisco a los de Abenojar, darle una puñalada y que él y a sus mayorales y pastores nos les convenía volver a aquella tierra [...] le amenazaron diciendo que si las guardas se ponían en impedirles que no metiesen sus 
ganados en la dicha tierra los habían de matar, aunque fuese delante del Santísimo Sacramento $[\ldots]$

Estos datos, de diversos documentos (en Roldán et al. 1993), confirman que la tranquilidad de bosques y pastores trashumantes medievales estaba llegando a su fin.

En 1714, las Ordenanzas Municipales de Almodóvar del Campo, redactadas por Orden Real, mediante Decreto del Rey Felipe V, del 8 de abril de 1713, intentarán poner freno a los abusos y regular el aprovechamiento de los montes públicos para evitar su agotamiento al tiempo que pretendía, ante el estado de escasez que debían padecer sus vecinos, facilitar el cultivo y la ganadería. Ya no hay alusión al quejigo como la hubo en 1578 y se van a permitir desmontes y rozas con plena libertad, regular incendios, descortezados y aprovechamiento de leñas y otros productos forestales. Los artículos que tratan de la gestión de montes señalan:

44. Ordenaron y mandaron que en la dehesa de Navalromo, respecto de estar muy zerrada sin haver pie de árbol caudal, como de enzina o alcornoque o que dicho monte sirve de embarazo al pasto y es causa de criar lobos, que se pueda desmontar libremente, [...]

48. Ordenaron y mandaron que los vecinos de esta villa, de sus aldeas y caserios, libremente, puedan hacer rozas en los baldios y términos comunes para sembrar cualquiera genero de semillas, con tal de que dexen libres las enzinas y alcornoques [...]

49. Y para evitar los daños de que los inzendios resultan y pueden resultar ordenaron y mandaron que dichas rozas no se enziendan ni quemen hasta el dia 8 de septiembre [...]

52. Ordenaron y mandaron que no se descortezen las enzinas ni alcornoques para sacar curtido, ora sea por vecino, ora sea por forastero [...]

54. Ordenaron y mandaron que en los baldios, montes brabos y términos de esta villa, puedan sus vezinos cortar la leña que necesitan para sus casas, lavores y aperos sin pena ni calumnia alguna; $y$ siendo forastero se les lleve por cada pie de marca $1.200 \mathrm{mrs}$. Y cada rama que cortaran 600 mrs. [...]

56. Ordenaron y mandaron que los vezinos del reynado de Cordova, no puedan sacar carbón, corteza, teguillo, corchos ni otro genero de aprovechamiento sin lizencia del ayuntamiento de esta villa $[\ldots]$

Este articulado manifiesta la visión de los regidores y autoridades del Municipio, como son la falta de aprecio por el monte bajo (que no se cultiva, dificulta el pastoreo y cría lobos). Solo se valora el arbolado que produce frutos, en especial encinas, pues el alcornoque tiene mayor interés para extraerle la casca, muy rica en taninos para el curtido de las pieles y colorantes, con la consecuente muerte del árbol. La saca del corcho estaba permitida pero entonces apenas se comercializaba. Acciones que se permiten a los vecinos se prohibían a los forasteros y, ante una acción ilegal, la sanción solía ser el doble a los forasteros. 
Las referencias a los lobos son una constante en toda comarca ganadera. En Sierra Madrona y Valle de Alcudia, desde la Edad Media hasta el siglo XX, el lobo, como la langosta, son plagas a exterminar, por el daño que causaban a la ganadería directamente (el primero) o a pastos y cultivos (la segunda). Gascón (1978) estima, a partir de los datos disponibles de caza anuales, la caza de 3500 lobos en Almodóvar durante el siglo XVII, por lo que en el total de la comarca la cifra podría situarse en torno a los 8000 lobos. Siguiendo ese ejercicio de Gascón, se puede ver que en el siglo XVIII son numerosos los años en que se supera la caza de 40 lobos anuales, por lo que obtendríamos unos 4800 lobos muertos en Almodóvar y en torno a los 12.000 en toda la comarca de Sierra Madrona y Valle de Alcudia en ese siglo. La caza de más lobos en el siglo XVIII no implica que hubiera más que en el anterior, lo que sí había era un mayor estímulo oara acabar con ellos. Una provisión de Felipe V, de 13 de junio de 1708, aprobada a petición del ayuntamiento de Almodóvar del Campo (AMAC 30-1708), era motivada por qué:

[...] ay muchas dehesas que están muy montuosas y sirven para el pasto de los ganados en las cuales se crian muchos lobos y zorras y otros animales dañinos que se comen los ganados siendo de grave perjuicio a los dueños de ellos [...] para que entre los dueños de los ganados que pastan en dichos montes y dehesas se haga un Repartimiento de la cantidad que se gastase en la matanza de dichos lobos y zorras por redundar todo en su mayor veneficio [...]

Lo que se cerró en 44 reales por cada lobo presentado o por cada camada de más de 3 cachorros. Agostini (1926) relaciona varios documentos para reiterar la miseria y presión de las crecientes poblaciones para invadir y roturar campos. En uno (del año 1749) se compatibilizan las roturaciones con los intereses de la Cabaña Real en el Campo de Calatrava; otro (1750) es sobre las condiciones para hacer rozas en Alcudia; otro más de 1772 es sobre un mayoral que, al enfrentarse a 4 individuos que cojían bellotas, acaba apaleado. En 1780 un guarda y otro hombre pegan a un criado por coger bellota y, en 1782, por la recolección de bellotas se produce otra trifulca.

En época de Carlos III el proceso colonizador se intensifica. El rey impulsó la creación de nuevos núcleos de población para evitar que territorios, más o menos boscosos, siguieran estando deshabitados, "improductivos" y siguieran siendo refugio de asaltadores de caminos, en particular el que unía Madrid con Andalucía. Junto a estas repoblaciones de gran coste para las arcas reales, las colonizaciones espontáneas eran más eficaces, como fue el caso del Pardillo, entre el Campo de Calatrava y Sierra Morena. En El Pardillo se concentraron todos los ingredientes de un proceso de colonización, deforestación y desamortización traumática que con frecuencia se dieron entre los siglos XVIII y XIX. En su política de colonización de Sierra Morena, el Rey autorizó, en mayo de 1772, a 70 labradores de Belvís para la construcción de un oratorio y 15 casas en una zona montuosa conocida como El Pardillo. El resultado fue que, tan sólo un año después, ya se había edificado el oratorio y 43 casas, estando otras 20 en construcción. La eficacia de los colonos, al descuajar los montes, crear tierras de cultivo y construir partiendo de la nada un nuevo núcleo de población motivó que el Rey, agradecido, por Real Cédula, de 20 de Junio de 1773, acordase la creación de una población en el quinto "El 
Pardillo" como Villa independiente, con jurisdicción propia. La localidad pasó a llamarse en reconocimiento y gratitud al Rey, Villanueva de San Carlos.

Otro ejemplo fue la colonización de Almuradiel, también en la Sierra Morena oriental de Ciudad Real. El Conde de Floridablanca, en memoria presentada a Carlos III sobre su gestión entre 1777 y 1788 cita

[...] La población de Almuradiel formada en medio del camino nuevo de Andalucía [...] es otro ejemplo de agricultura para los lugares comarcanos, pues donde solo había selvas y soledades espantosas e infructíferas, se ven ahora en pocos años edificios públicos, casas de colonos, plantios y tierras cultivadas [...]

Frente al auge de las roturaciones solo el valor de la ganadería merina, de los pastos y el poder de propietarios y posesioneros podían impedirlas. El precio y la calidad de la lana de merino aumentaban los beneficios que reportaban a la monarquía. Se ha estimado que la productividad media de lana pasó de 1,9 Kg/cabeza de ganado, a principios del siglo XVII, a 2,04 kg/cabeza, a finales del XVIII (Martínez Fronce 1989), es decir, un exiguo 7\% en casi 2 siglos. Era una riqueza asegurada pero por la que poco se hacía para mejorarla.

La Contaduría General de la Orden de Calatrava regulaba el contrato de arriendo o "Recudimiento" de los pastos de invierno entre los ganaderos y la Corona, es decir, los precios eran controlados por la Corona y la Mesta. El negocio era bueno y explica las actuaciones de la Orden de Calatrava, la Mesta y la Corona, para el mantenimiento de pastos y arbolado, que frenaban el proceso de roturaciones con finas agrícolas. A comienzos del siglo XVIII, las 3/4 partes de la cabaña que invernaba en Alcudia pertenecía a 9 grandes familias ( 5 de Madrid, 2 de Toledo y 2 de Ciudad Real) (Gascón 1978). Este autor recoge el interés de proteger los pastos en el Valle durante el siglo XVIII:

[...] La preocupación por conservar la vegetación fue siempre constante [...] el cuidado forestal de Alcudia se encomendaba a la Guardería Mayor del Valle [...] Además, la Villa de Almodóvar tenía también el cargo de Guarda Mayor de los baldios y Montes propios de la villa. Unos y otros actuaron en bastantes ocasiones de forma mancomunada en su labor de protección [...]

El beneficio de la Corona era importante, por ser poseedora de una cabaña merina famosa, la de "El Escorial" y por los cuantiosos beneficios de los impuestos de exportación de lana e importación de manufacturas textiles de Inglaterra y Flandes. El padre Alonso Cano (1762) estimaba que la Hacienda percibía el 50 por 100 del producto integro de la ganadería.

Pero mientras que en el Valle de Alcudia los pastos y arbolado eran protegidos, en Sierra Madrona, los ganaderos locales y de pueblos próximo fueron deforestando la comarca. Cabañas de cientos de ovejas y de cientos e incluso miles de cabras, más adaptadas al matorral, promovían el que sus propietarios practicaran incendios recurrentes, seguidos de pastoreo y la inevitable erosión del suelo. Aunque el Valle de Alcudia también se quemaba, parece que solía ser de forma accidental o por extensión de los fuegos provocados en la sierra. Uno de los más 
devastadores incendios del que se tiene noticia fue en verano de 1686 (AMAC 17-1688). Durante más de dos días el fuego arrasó miles de hectáreas:

[...] se quemó casi la mitad del dicho Real Valle en términos de Almodovar, Mestanza y Almadén y se causó perdida a la Real Hacienda de mas de doscientos mil ducados [...]

Si el fuego llegó desde Mestanza hasta Almadén la superficie quemada superaría las 80.000 ha. Hay registro de otro gran incendio en el verano de 1717 (AMAC 48-1717) que afectó también a gran parte del Valle:

[...] en la Dehesa y Real Valle de Alcudia que está en la jurisdicción desta villa, se ha lebantado un fuego y que se ha quemado mucha parte de su arbolado [...]

Como también el incendio de 1721 (AMAC 17-1721, 30-1721 y 32-1721):

[...] en una dehesa como la del Real Valle de Alcudia, que es la joya mas apreciable de la Real Persona y que tanto se debe mirar y mira por su conservación por lo ynportante que es para serbizio de la Real fabrica de azogues sus maderas [...]

El culpable fue identificado y se le condenó a 20 años, pues además de numerosas encinas, se habían quemado 36 colmenas y unos 40 alcornoques (Gascón 1978).

Tales actuaciones afectaban al arbolado y, en el caso de la encina, a su valiosa montanera. Los incendios alarmaban a los asentistas de las minas, como a pequeño talleres y a los habitantes, que necesitaban su leña y madera; pero unos y otros miraban más por sus necesidades momentáneas, prescindiendo del futuro. En el AMAC están documentados incendios durante el siglo XVIII, que manifiestan su obligada regularidad para interés de ciertos ganaderos y manifiesto desprecio a las autoridades encargadas de impedirlos: 1730, 1732, 1741, 1742, 1743, $1744,1748,1765,1767,1784$, etc. En el incendio de 1765 se habla de numerosos encinares, alcornoques y colmenas. En este caso los culpables fueron unos pastores de Brazatortas haciendo una roza y la multa fue de 3.000 rs.

Los incendios de los pastores locales fueron una constante hasta la segunda mitad del siglo XX (Fig. 2.8). El perjuicio a los colmenares (Fig. 2.9), distribuidos por los montes de las sierras, suponían una pérdida a numerosas familias que vivían en el monte y conocían quien lo transitaba, por lo que entre los mismos vecinos se llegó a situaciones muy tensas. Hasta un 20\% de los vecinos de la comarca vivían de las colmenas. En 1747, el Memorial de Colmenas (AMAC 12-1747) refleja el número por municipio: Almadén (2500 colmenas), Almodóvar (1900), Mestanza (2741) y Puertollano (1774). En total, la comarca sumaba 8915 colmenas, pero como no se censarían todas, la cifra real superaría las 10.000. Datos de incendios que acabaron con colmenares son frecuentes en el AMAC, por ejemplo en 1659, 1665, 1687, 1721 o 1765. 


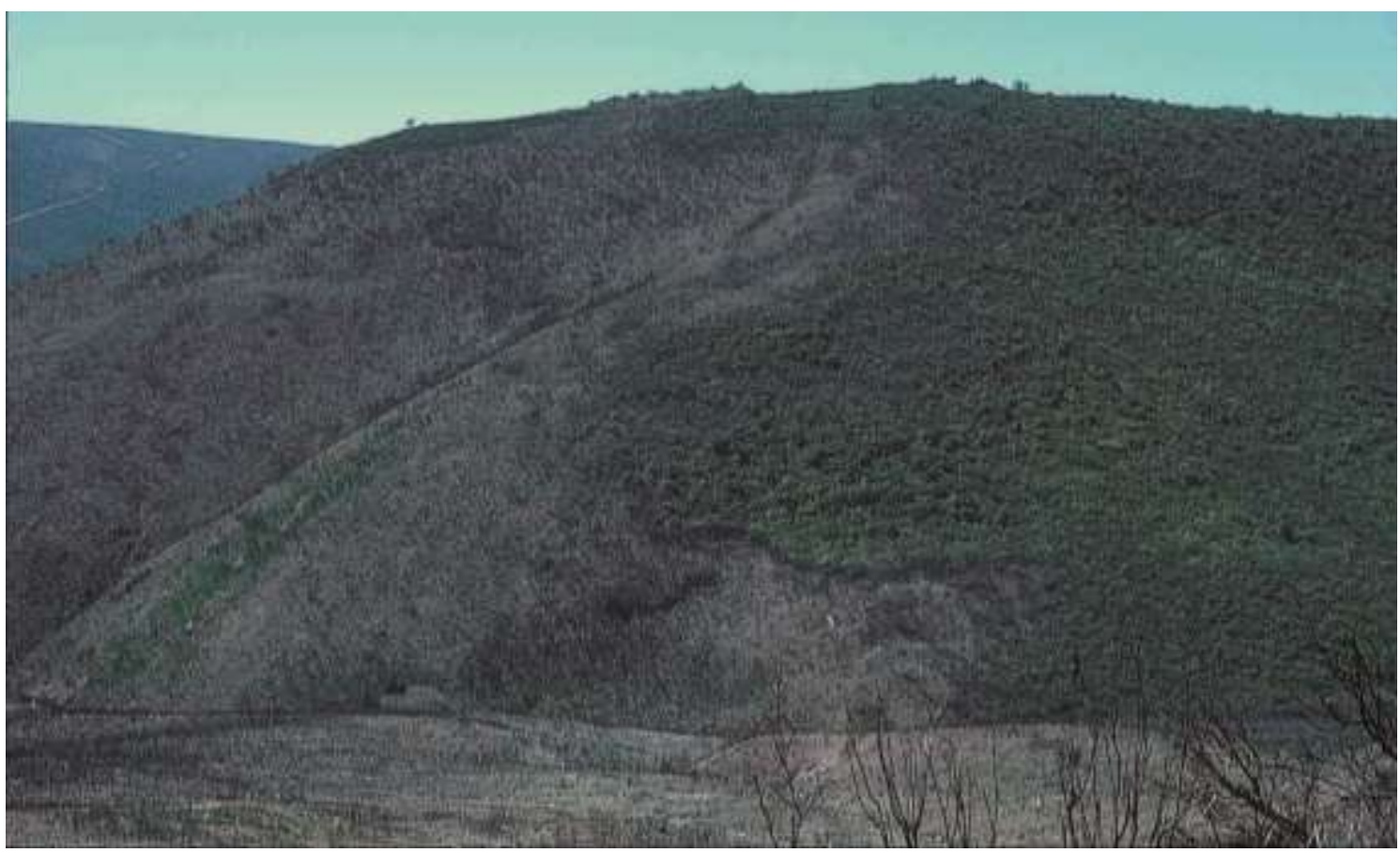

Fig. 2.8. Fotografía de 1986 en Solana del Pino. Fue uno de los últimos grandes incendios de Sierra Madrona, probablemente provocado por los últimos pastores que seguían la tradición de quemar los montes para favorecer los pastos herbáceos y "limpiarlos de maleza y alimañas".

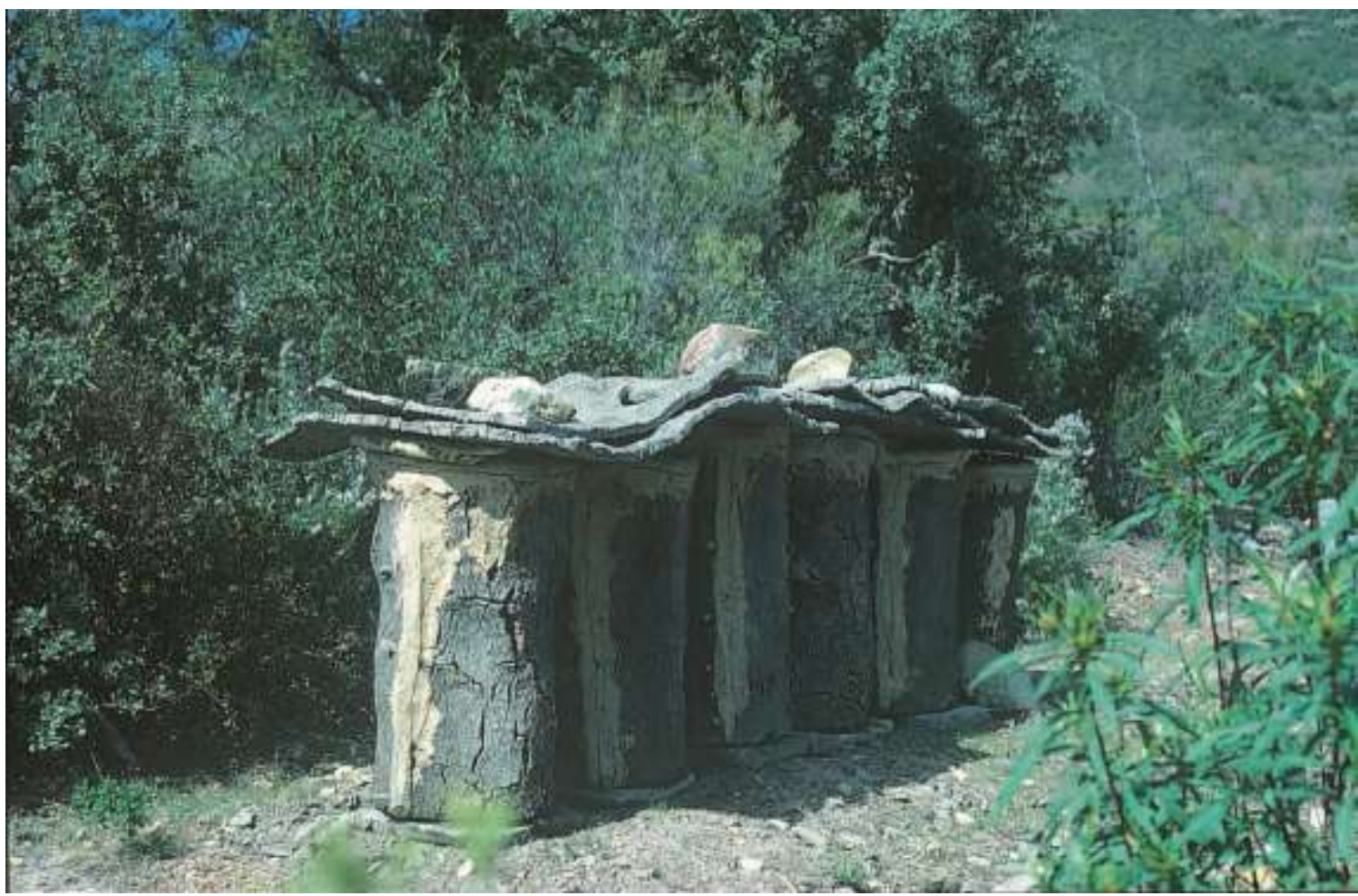

Fig. 2.9. Fotografía de 1987 cuando aún eran comunes las colmenas de corcho en los montes de Sierra Madrona y otras áreas del SO ibérico. Las colmenas eran de corcho por su facilidad de ejecución, ligereza para el transporte y ser ignífugo. Los incendios afectaban a los colmeneros por la muerte de las abejas que se alimentaban de las flores del matorral y la pérdida de la miel por las elevadas temperaturas. 
En el siglo XVIII, según se deduce del Catastro del Marqués de la Ensenada (1759) sólo un $15 \%$ de la superficie del Campo de Calatrava estaba cultivada (86\% cereal de secano, $12 \%$ viñas y olivas) correspondiendo el $85 \%$ restante a montes (54\%) y pastos (31\%). El cultivo se desarrollaría más (hasta un 30\% en Cabezarrubias) o menos (un 4,5\% en Mestanza) según el tipo de propiedad, mientras que en las zonas más alejadas o abruptas de los pueblos casi todo sería monte.

Al describir el Catastro los usos del término municipal de Puertollano, que incluía el centro del Valle de Alcudia y llegaba por el sur hasta Ventillas, en Sierra Madrona, se refleja la dualidad de la explotación ganadera del territorio. Según el Catastro, de las casi 50.000 cuerdas de calatrava de extensión ${ }^{1}, 26.577$ (un 53\%) eran montes y sierras solo aptas para ganado cabrío o estériles, 12.870 cuerdas de tierras adehesadas para pastos de ganado lanar (en el Valle de Alcudia) y 9.550 cuerdas, principalmente en torno a la villa, dedicadas a la agricultura de secano. Los bosques (es decir, las densas formaciones arbóreas naturales) habían desaparecido y lo más natural que quedaba era una enorme extensión de monte bajo muy propicio para la explotación de más de 2000 colmenas y enjambres.

Al tiempo que roturaciones e incendios asolaban las sierras, la minería va a experimentar también un gran auge. Reduciría la talla de los montes arbolados, en especial de los abundantes Quercus, para aumentar sensiblemente los matorrales, que admitían la extracción de leña hasta su agotamiento por sobrexplotación. A partir del descubrimiento de América se multiplica el valor y el interés por las minas de Almadén. En una Real Provisión, de 27 de abril de 1557 en Valladolid (AHN OOMM legajo 44.148), las dehesas que abastecían de leña y madera a las minas de Almadén eran las de Corral de Sancho, Palazuelas, Saladillo, Alamillo, Castilseras, Pinganos, Rincones, Navas y Gargantiel. La vigilancia de estas dehesas para proteger leña y madera, corría a cargo de guardas designados por el gobernador de la mina.

Hacia 1620 los vecinos de Alamillo utilizaban más de 600 carretas para llevar leña a las minas de Almadén para cocer el metal del azogue (Salazar y Castro en Hervás y Buendía 1918). La madera que requerían las minas pronto agotó el arbolado del entorno y llevó a tomar medidas. Las evidencia el superintendente y gobernador de Almadén, Francisco Javier Sánchez de Villegas, en el documento en el que expone su gestión (AHN Minas de Almadén 1646):

$7^{\circ}$. Que ha establecido un nuevo método de labores y fundiciones con el ahorro anual de 500.000 rs además de una disminución de la madera empleada en las fortificaciones, que aún es de mayor consideración que el dinero.

Para solventar el abastecimiento de madera, tras el cese del arriendo a los Fúcares en 1645, se empleó a los carreteros de Almodóvar del Pinar (Cuenca), que pertenecían a la junta y hermandad de Cuenca-Guadalajara de la Cabaña Real de Carreteros del Reino (creada por los

\footnotetext{
${ }^{1}$ Según Gascón (1981) cada cuerda eran 89 varas castellanas y 4 novenos en cuadro. Como la superficie era la suma de las superficies actuales de Puertollano, Cabezarrubias e Hinojosas (42.980 ha), cada cuerda de calatrava tendría una superficie aproximada de 0,86 ha.
} 
Reyes Católicos en 1498, y conocidos como la "Mesta de Carreteros", por sus privilegios). Almodóvar del Pinar vincularía su existencia al Valle de Alcudia, distante $330 \mathrm{~km}$, para abastecer de leñas y de madera a la mina, con sus bueyes y carretas de las partes donde se cortara, y llevar el azogue hasta Sevilla, Lisboa y otros puertos del norte, de donde partiría para América y otros destinos europeos. El oficio lo habían iniciado con el transporte de la madera de sus pinares a los centros de consumo, al igual que el otro gran núcleo de carreteros de la época que procedían de las montañas de Burgos-Soria (Gil Crespo 1957).

En el "Balance sacado del Libro Mayor de la contaduría de las Minas de Almadén. Años 16091637", figuran entre los deudores 1.016 .808 maravedies de "madera de pino" y entre los acreedores 76.782 mvs. de "cubos de pino" y 108.953 mvs. de "pertigos de pino" (Matilla 1958). El gran consumo de leña de los hornos obligó, cuando la Real Hacienda asumió la administración en 1646, a que se consignaran para el servició de las minas nuevas dehesas. Estas fueron las de "Laparede" y "San Elifonso" en la jurisdicción de Chillón; la del Chiquero en el término de Almodóvar del Campo y, también en este término, las de "Venoxa", Guindalero y Lopejón, poseedoras de madera de roble que venían vendiendo a la mina para fajados, tablas, limones, pértigas, ejes y para otros empleos (Matilla 1987).

En su contrato con la Corona se les reservó a los carreteros entre 7 y 10 millares de la Dehesa de Castilseras para alimentación de sus bueyes, que eran «peguntados», o marcados con pez, para reconocer el derecho a los pastos. Esta práctica permite conocer el número de carretas contratadas cada año por el número de bueyes marcados. Así, en 1659 se peguntaron 2.271 bueyes; en 1660, 2.799; en 1661, 1.166; en 1662, 2.385; en 1663, 1.502; en 1664, 2.030 y en 1665, 1.587, lo que supuso para los 7 años 4.580 carretas, con obligación de conducir 21.373 carretas de madera de entibar o sus equivalentes para otros usos (Matilla 1987). Este destino de la Dehesa de Castilseras evitaría su descuaje en las enajenaciones de 1769 y 1770 (Quirós 1965). Pero la magnitud de las necesidades de la mina de leña y madera siguió en aumento, cuyo estado se aproxima en 1700 (AMAC 10-1700):

[...] y el ymbierno van a servir a $V$. A. para conducir toda la leña y madera que es nezesaria para el avono y beneficio de la Real Mina del Almaden sin mas premio ni sueldo que a sus personas y criados tratarlos y rregularlos por travaxadores de la Mina para darles los bastimentos y alimentos sin tributos ni sisas y a los bueies de sus carreterias se les apaziencia de balde en la dehesa de Alcudia que esta proxima y el travaxo es tan considerable que conduziran en cada ymbernadero de catorze a quinze mil carretadas de madera y leña llevando vigas que se necesitan de dos carretas de seis y ocho pares de Bueies en tanto grado que si mis partes mudaran el ymbernadero y se rretiraran de trabaxar de dicha conduzion zesaria la fabrica y labor de la mina por ser el material mas nezesario el de la madera para apuntalar las cuebas $[\ldots]$

Unas cifras de abastecimiento de entre 14.000 y 15.000 carretadas de madera anuales explican el agotamiento que deparaba a los montes en una mina con más de mil años de explotación, en la que el paisaje ya respondía a las utilidades que reportaban los montes. Cada carga de un 
horno de "reververo" o aludeles, establecidos por Bustamante en 1645, necesitaba 3 carretadas de 80 arrobas $(920 \mathrm{~kg}$ ) cada una, tirada por dos bueyes, como consta en los contratos de las minas, y podían funcionar hasta 10 hornos/día (Gil Bautista 2012). Unos $2700 \mathrm{~kg}$ de leña/horno, multiplicado por 10 hornos/día, requieren unos $27.600 \mathrm{~kg}$ diarios, es decir $10.074 .000 \mathrm{~kg} / \mathrm{año}$. Como este tipo de hornos se instaló en Almadén hacia 1647 (Mansilla \& Iraizoz 2012) y se usaron hasta 1928 (DOCLM 1992), son 281 años de uso. Esto implica un consumo de leña en ese periodo de $2.830 .794 \mathrm{Tm}$, solo para los hornos.

Ahora bien, las 14.500 carretadas/año, a unos $920 \mathrm{~kg} /$ carretada, son $13.340 .000 \mathrm{~kg}$ de leña suministrada al año. Si los hornos necesitaban, unas $10.000 \mathrm{Tm} / \mathrm{año}$, el resto, unas 3.340 Tm/año, se utilizarían para el fuego doméstico de los edificios de la administración y otros usos, como útiles para las minas, construcciones y entibado, entre las que se encontraban las vigas de pino, especie no citada de forma explícita, que requerían para su trasporte "dos carretas de seis y ocho pares de bueyes". El cómputo total de leña y madera para esos 281 años sería de 3.748 .540 de Tm. Aunque no todos los días funcionaran los 10 hornos, la demanda exigía otras actuaciones destacadas, aunque puntuales, por otros motivos como el incendio que comenzó en enero de 1755 y fue apagado en julio de 1757, inutilizando la mina.

Poco antes de su pérdida de servicio, una Resolución de Carlos III, de 14 de diciembre de 1754 (AMAC Acuerdos, año 1755, 20 de febrero), había demandado la intensificación de la actividad minera:

[...] las Minas del Almadén han sido siempre uno de los objetos de mas atención para el Ministerio de Yndias, porque de las abundantes remesas de Azogue a Nueva España, se sigue el mas continuado beneficio de las minas de plata de aquel Reyno, cuios aumentos en estos últimos años han sido y son tan considerables que se hace preciso repetir los embios de Azogue con mas frecuencia y en maiores cantidades que se han dispuesto regularmente [...]

Reabrir la mina tenía como problema añadido los problemas de escasez de leña en un radio considerable en torno a las minas, pues los pueblos incluidos en la consignación, además, dificultaban los envíos, por lo que una Resolución de Carlos III de 1754 había dispuesto que:

[...] ninguna basta por defecto de leña y madera de que ha tiempo se experimenta notable falta a causa de que sin embargo de haver consignadas distintas dehesas para el servicio de las minas, las reyteradas competencias que en distintas ocasiones movieron al Superintendente Los Subdelegados de la Cabaña Real y de Carreteros, las Justicias de los pueblos comprehendidos en la consignación y los Comendadores y dueños de Dehesas, han impedido comummente el efecto de la misma consignación [...]

Esta Resolución, concluye que, a pesar de la oposición de pueblos y ganaderos, se otorga a las minas de Almadén un área de servidumbre mucho mayor. La zona de servidumbre de las minas pasó del radio de 4 leguas a la redonda del siglo XVI, a las 10 leguas en 1739 y hasta las 14 leguas (unos $78 \mathrm{~km}$ ) serían dispuestas para abastecimiento de madera y leña a las minas en esta disposición de 1754. Distancia que incluía 59 ciudades, lugares y villas en la Provincia de la Mancha (en las que se incluían Alcoba, Arroba, Fontanarejo, Navalpino, o Retuerta del 
Bullaque) con distancias de hasta $150 \mathrm{~km}$ por caminos hasta Nava de Estena. De la provincia de Córdoba la servidumbre incluyó 50 lugares, con toda la comarca de Los Pedroches y distancias de más de $200 \mathrm{~km}$ por caminos hasta Linares. En la Provincia de Extremadura fueron 70, con gran parte de la comarca de La Serena y distancias hasta Azuaga de $130 \mathrm{~km}$ o de 160 a Miajadas. El superintendente pidió la relación de montes que tenían o las posibilidades de nuevas plantaciones. La regulación de las cortas de leñas destinada a las minas de Almadén era más que necesaria y se tuvieron que redactar diversos documentos, de los que al menos uno se encuentra en el AMAC (del año 1774). La deforestación era un hecho.

La inutilización de la mina supuso el encargo que recibe el irlandés William Bowles de su compatriota Ricardo Wall, ministro de Carlos III, como aquel señala en su dedicatoria "al Rei". Bowles (1775) reparó el daño para:

[...] poner corriente aquel inexausto mineral de mercurio, sin el qual se cortaba el principal nervio del Comercio de estos Reinos con los de Indias [...]

Reparación que exigiría la total renovación del entibamiento. Proceso que, como narra Bowles, ya había sido necesario rehacerlo conforme la Corona retiró el arriendo a los Fúcares en 1645 para administrarla por su cuenta, y que necesitó de 45.000 árboles para sostener las galerías de la mina. Afirmación de Bowles que Matilla (1987) interpreta como "torticera" al referirse a las consignaciones de nuevas dehesas en 1646, de las que la documentación señala que solo se cortarían unos 1000 árboles para la entibación, pues se obtenían de 4 a 6 piezas de cada árbol y el número de portadas puestas en los 13 meses siguientes fue de 2.673 (Matilla 1987). Pero que da una idea de la madera que se había quemado en el incendio de la mina de 1755 y el número aproximado de árboles necesario para la entibación.

Pero lo cierto es que tras el incendio se tuvo que renovar toda la entibación y en ella participará la madera de pino. Consta que, en 1756, se trajo de la Sierra de Segura (AMAC 1756), con una distancia cercana a los $300 \mathrm{~km}$.

La Resolución de Carlos III de 1754 para incrementar la producción de las minas de Almadén venía dada por la disminución de la producción de las minas de mercurio de Huancavelica (Perú) (Fig. 2.12), que prácticamente agotaría sus reservas hacia 1770 (Feliciano 1999). La mina de Huencavelica o Santa Bárbara no producía oro ni plata pero si el mercurio necesario para la amalgama de esos metales preciosos, por lo que era una de las minas más valiosas de la América hispana. Este agotamiento de la mina de azogue americana exigió un incremento de la producción de las minas de Almadén y, por tanto, un aumento de la deforestación en Sierra Madrona, Valle de Alcudia, La Serena y otras áreas del entorno. 


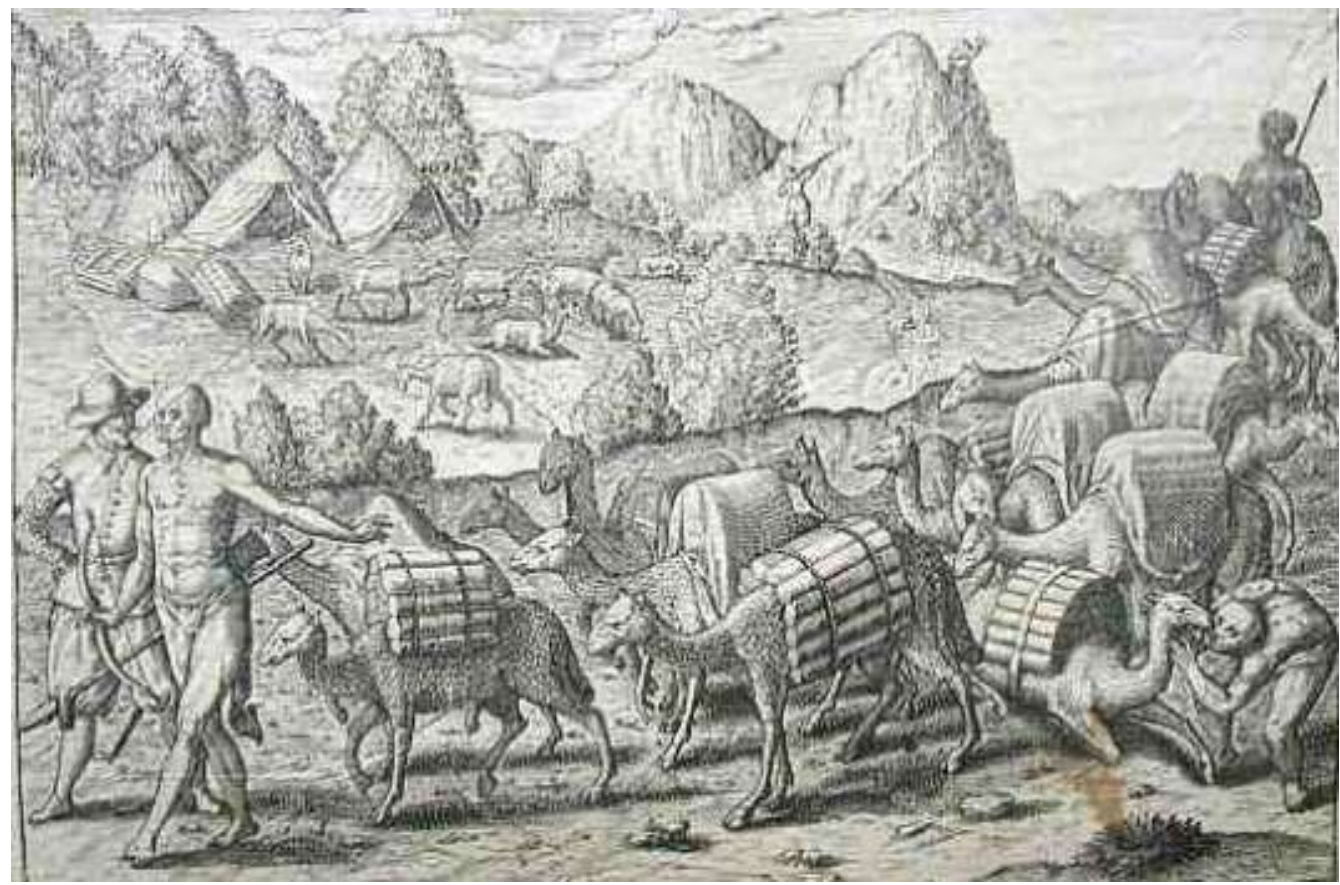

Fig. 2.12. Trasporte de mercurio desde Huencavelica a Potosí. Aunque parezca un hecho lejano, la existencia de esta mina peruana evitó una mayor deforestación del Valle de Alcudia.

Es probable que nuevos métodos de entibamiento, entre ellos la mampostería, redujeran las necesidades de madera pues, si en 1751 había entre maestros y oficiales 5 hombres para dirigir este sector, en 1770 se había reducido a 3 (Catastro de Ensenada y Padrón General de 1770). A finales ya del siglo XVIII y durante el XIX los documentos de la época se refieren al hablar del abastecimiento de los hornos de la mina, solo a leña o a monte bajo, pero no citan madera, ni árboles, ni bosque (Betancourt 1783; Cavanillas 1838; Zuaznavar 1880). Las cortas de madera eran selectivas en función de su uso para entibar y otras construcciones y útiles de las minas (Figs. 2.10, 2.11 y 2.12). En el caso de la encina, se buscaba por su resistencia mecánica, como bien lo expresó Hugh James Rose en 1875 (museo minero de Linares), en su visita a una mina del complejo Linares-La Carolina:

$[\ldots]$ y de repente tienes que escalar por un pasaje bajo y oscuro, cubierto con pesados troncos de encina y tablones, capaces de soportar quinientas toneladas de granito [...]

Como por las cortas de madera no se pagaba nada, los montes no se recuperaban, pues la regeneración natural estaba impedida por la saca de leñas y el pastoreo. Para contribuir a recuperar los bosques y mejorar el abastecimiento de leña y madera para las minas, en noviembre de 1778 se dispuso que se pagasen las cortas según justa tasación, pero pagando solo la mitad y la otra cuando hubieran arraigado tantos árboles como los talados (Matilla 1987).

La madera de pino fue el elemento de sustitución con el fin y objeto de conservar los pocos árboles de encina de magnitud que existen en lo consignado. Se mandó emplear esta madera para brocales, husos de tornos y wantrones largos (Matilla 1987).

Gracias a la importancia nacional (y mundial) de las minas de mercurio de Almadén, fueron conocidas por geógrafos, geólogos e ingenieros que levantaron mapas, planos y perfiles de gran 
calidad para la época (Figs. 2.13 y 2.14). Hoy contribuyen enormemente a un mejor conocimiento de la historia minera, pero también socioeconómica y forestal de la comarca.
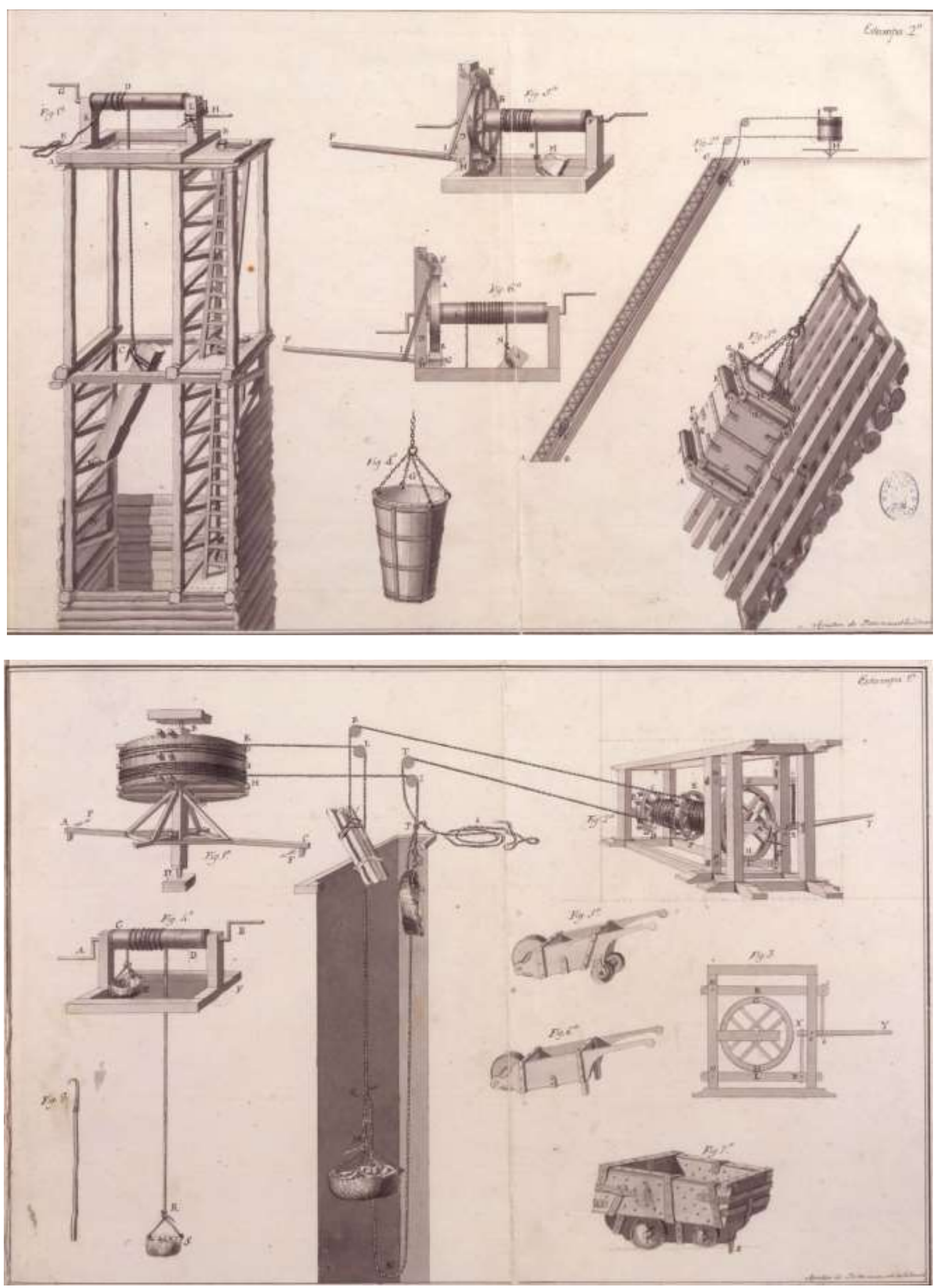

Figs. 2.10 (arriba) y 2.11 (abajo). Aunque el principal consumo de leña de las minas de Almadén era para los hornos y la madera de roble, encina o quejigo para entibamientos, también era necesaria para toda una serie de construcciones y herramientas de carga, trasporte, desagües, etc. Láminas de Agustín de Betancourt, Segunda Memoria sobre las minas de Almadén (1783). 


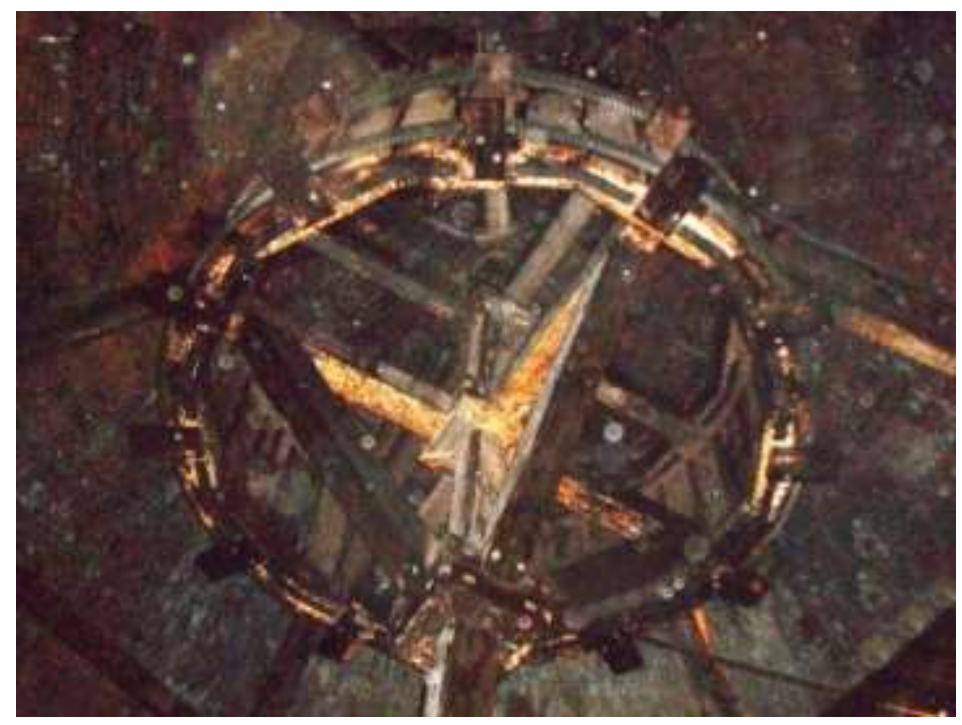

Fig. 2.12. Para la extracción del mineral y del agua de las minas de Almadén, así como su abastecimiento de madera, se necesitaban sistemas mecánicos como la gran "prensa" o baritel de la imagen, en el cerco de San Mateo (fotografiada en 2009, ver también este tipo de máquina de madera en la Fig 2.14, del siglo XVIII). Obsérvense los reflejos ante la luz del flash de la cámara, por la alta humedad del ambiente.

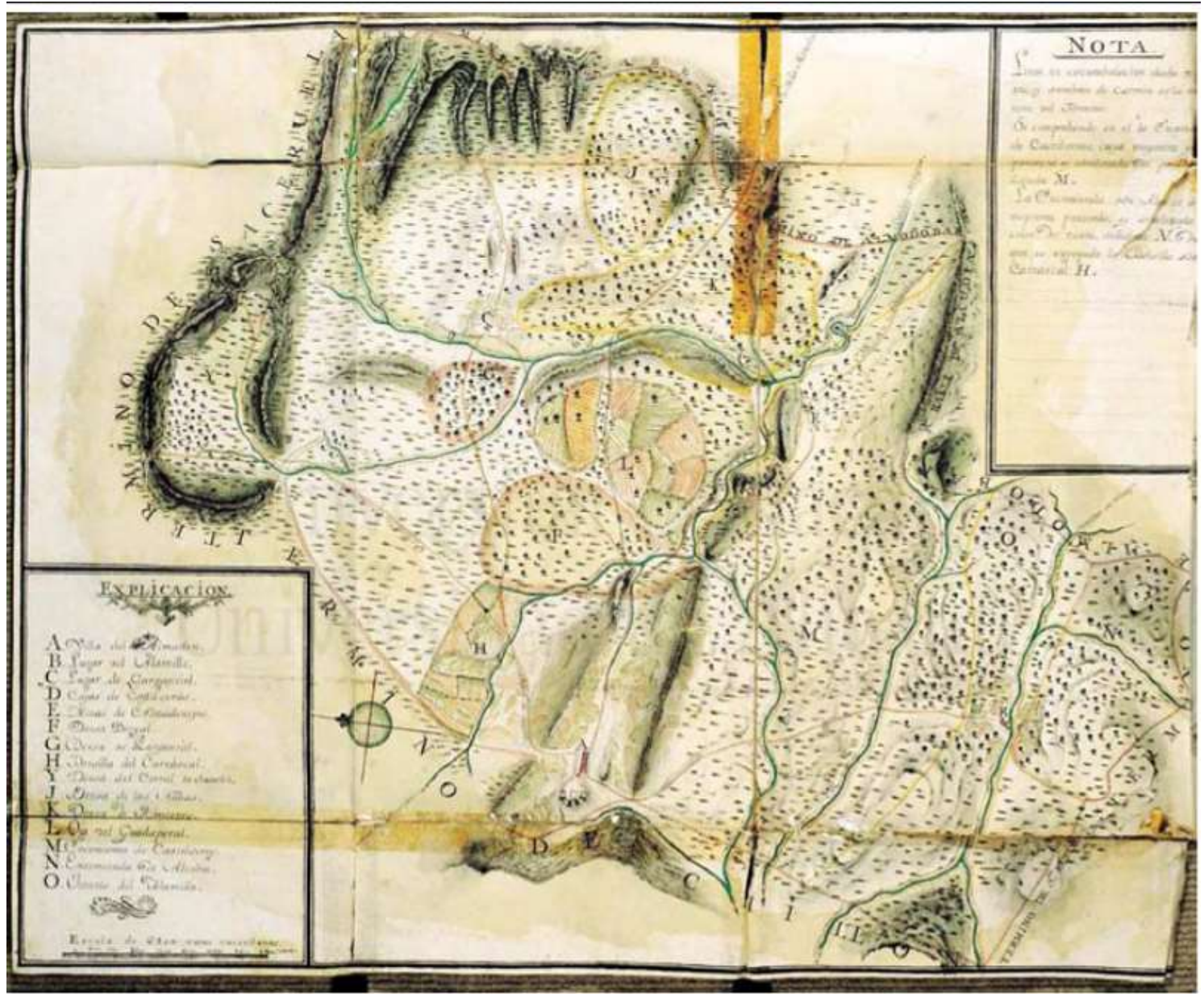

Fig. 2.13. Mapa de la jurisdicción de la villa de Almadén a finales del siglo XVIII. Es uno de los más bellos planos del Catastro del Marqués de la Ensenada. Puede verse como además de algunos cultivos, la mayor parte del territorio seguía teníendo bosques aclarados. Casi toda la mitad derecha se corresponde con la Dehesa de Castilseras, reservada para los bueyes y usos de los carreteros que, tanto abastecían de leña y madera a las minas como trasportaban el azogue a los puertos de mar. AHP, legajo 642. 


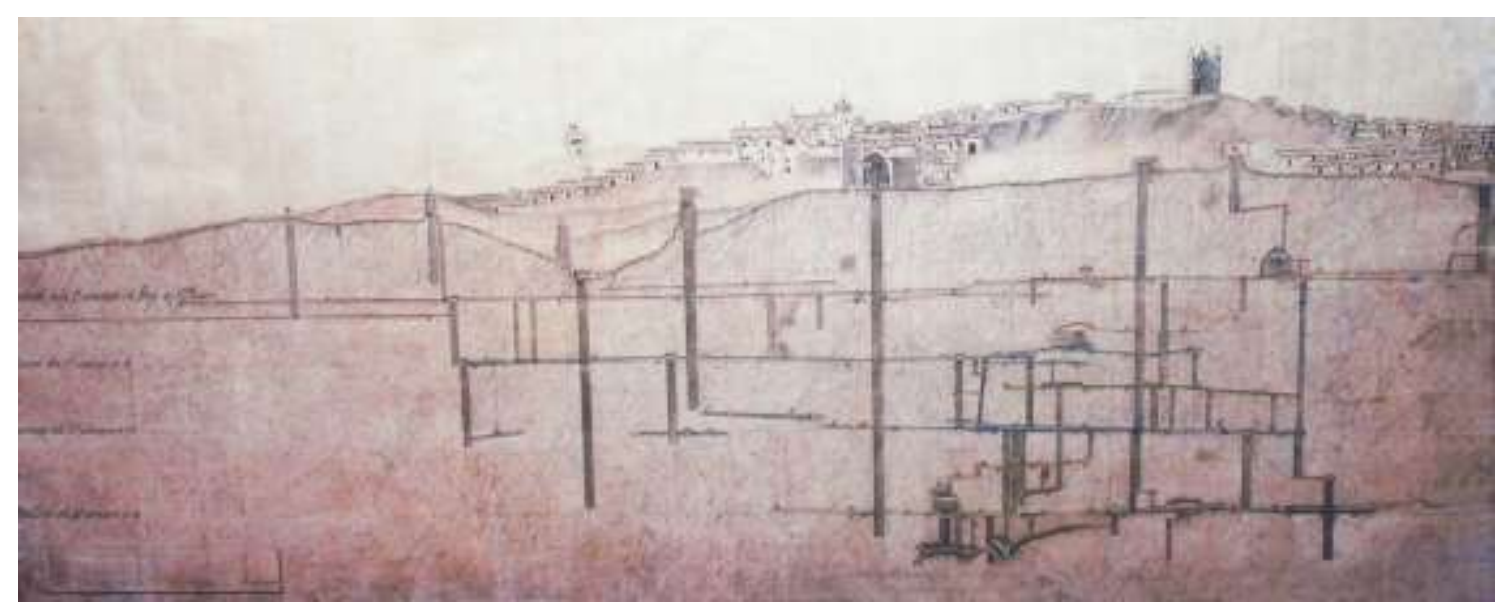

Fig. 2.14. Perfil de las minas de Almadén a finales del siglo XVIII, realizado por Diego de Larrañaga y Braulio Correas (1792). Puede verse el gran entramado de galerías subterráneas y lo que esto implicaba para la tala de árboles necesaria para asegurlas frente a derrumbes. Museo de las minas de Almadén.

Las piezas de madera más largas eran los llamados "asnados de burro" que eran de madera de encina con 5 a 6 varas de largo (3,6 a 4,2 m), los largueros de torno que median 4 varas de largo $(3,36 \mathrm{~m})$ y media de ancho $(0,4195 \mathrm{~m})$, y los pies de burro que median 4 varas, con la particularidad de que los de roble siempre eran más caros que los de encina (Gil Bautista 2012). Pero para que a mediados del siglo XVIII hubiera que traer madera de la sierra de Segura (probablemente pino), implica que los pinos de la zona ya habrían desaparecido y el monte alto de encinas, alcornoques, quejigos, robles, fresnos y otras especies arbóreas había sido ya también casi eliminado en 14 leguas (unos $78 \mathrm{~km}$ ) a la redonda (dispuestas en la citada Disposición de 1754).

Durante siglos los árboles usados por su abundancia y cualidades para entibar y piezas de construcción fueron la encina, el quejigo y el roble, frente al alcornoque, también presente o el pino mayoritariamente ausente. A finales del siglo XIX y especialmente en el XX se usó también el pino e incluso el eucalipto (por lo que pueden verse hoy eucaliptales en el entorno de varias minas de la comarca). Sin embargo, el árbol principal para la entibación, siguió siendo la especie que había alcanzado la preponderancia respecto a los demás Quercus de la zona: la encina. Preponderancia que mantiene a finales del siglo XX, no sólo en la comarca sino en todo el país; pues su superficie suponía el 39,2\% del área forestal arbolada, a la que seguía muy de lejos las demás como el rebollo ( $Q$. pyrenaica) con un $6,47 \%$, el alcornoque con un $4,47 \%$ y el quejigo ( $Q$. faginea) presentaba el 4,34 \% (Maldonado et al. 1998). Proporciones que constituyen una distorsión ecológica, por ser rebollo, alcornoque y quejigo especies de mayor significado evolutivo y con capacidad para desplazar a la encina. 


\subsubsection{Siglos XVI-XVIII primeras desamortizaciones del Valle de Alcudia}

Las ventas de los bienes de las OOMM las inició a principios del siglo XVI Carlos I, cuyos apuros económicos le habían llevado a obtener en 1529 de Clemente VII una bula para enajenar el señorío jurisdiccional y solariego o pleno de las OOMM, hasta conseguir 40.000 ducados. La bula se confirmó en 1536 y supuso juros sobre el Valle de Alcudia y otras zonas del Campo de Calatrava. Posteriormente, Felipe II, obtuvo de Pío V, en 1569, facultades para vender bienes de las OOMM, que confirmó Gregorio XIII en 1574 (Corchado 1984). El resultado fue la venta de 7 encomiendas, aunque ninguna en el interior del Valle de Alcudia. Proporcionó a la Corona 76.607.242 mrs. y significó la pérdida del 24\% del territorio de la Orden Militar de Calatrava (AHN OOMM legajo 35.544). Las ventas siguieron con Felipe IV hasta bien entrado el siglo XVII.

En 1592 el Procurador General de Almodóvar del Campo y Procurador General de la Orden de Calatrava, Juan Bautista de la Fuente, refleja sus temores sobre las consecuencias de estas ventas:

[...] Yo contradije la conpra de la jurisdicción que algunos particulares pretenden ansi por los daños que a Su Magestad se les siguen y perdida de las alcabalas porque las tales rentas los alcaldes ordinarios sus deudos y amigos y parientes las pondran y se les remataran en menos de lo que valen y perdera la hacienda y patrimonio real gran forma en cada año, como porque los montes y las dehesas boyales no se conservaran ante ellas y el Valle de Alcudia de que Su Magestad se siguen tanto aprovechamiento se talara y en Sierra Morena, termino y jurisdicción de esta villa se seguirán hurtos, robos y salteamientos y otros delictos que los alcaldes ordinarios no acostumbran a castigar con aquel rigor con el de la gravedad de ellos requiere y de la dicha causa a que cada dia vienen jueces y pesquisidores a castigar los delictos que los dichos alcaldes ordinarios disimulan y no castigan, demas de ellos proprios serán los que destruiran las dichas dehesas, panes y viñas con sus ganados en perjuicio de los pobres $[\ldots]$

Texto (AMAC legajo 1/1592/121) que manifiesta el dominio de las clases privilegiadas de la España rural, como expresaría décadas después el Conde Duque de Olivares: «los regidores hacen lo que quieren, usurpando a los pobres sus haciendas, atropellándolos y rejándolos» (Elliot \& de la Peña 1979) y preludio de lo que serán las desamortizaciones del siglo XIX y de las revueltas populares de los siglos XIX y XX. Las relaciones entre los diversos poderes y vasallos, rara vez fue a favor de los últimos. Cuando en 1768 fueron elegidos 2 diputados del Común, junto al Personero, como cabezas del Ayuntamiento entregaron al Gobernador de Almadén un memorial con la queja de que al repartirse las suertes de roza y labor se escogían las primeras para el gobernador y regidores. Estimaban que se debía atender primero a los pegujaleros más pobres. El Gobernador respondió «en Almadén no se necesitan más diputados que yo» (Matilla 1987).

En 1734 el Rey Felipe V había incorporado a la Corona procedente de la Orden de Alcántara la "Real Dehesa de la Serena" que comprendía superficie de terreno que alimentaba a 243,5 
millares de merinas para iniciar la primera gran desamortización. Sentó un precedente claro y sirvió de experiencia para los grandes procesos desamortizaciones que vendrían después. En 1762, reinando Carlos III, el comisionado para la venta de La Serena, Manuel Ventura Figueroa, encabezó una comisión para estudiar los diferentes aspectos del Valle de Alcudia que posibilitaran su venta y minimizaran conflictos (AMAC 55-1774). Lo que más importaba eran los límites, la distribución de la propiedad, de los derechos y del régimen de aprovechamiento. Los resultados pusieron de manifiesto el beneficio de los posesioneros y los privilegios de la Mesta. El valor de las dehesas era desproporcionadamente alto comparado con lo poco que pagaban por ellas y, por otro lado, la comisión fue consciente de que el valor de los pastos y arbolado de las partes central y occidental eran muy superiores al valor de las dehesas de la parte oriental. La comisión en consecuencia sugiere y es aprobado, por Real Resolución de 20 de marzo de 1768, la realización de un nuevo estudio para el:

[...] deslinde y amojonamiento, media y tasacion de las deesas y millares comprendidos en el Real Valle de Alcudia [...] y habiéndolas evacuado y dado cuenta a S. M. se sirvió acordar por otra Real Orden de quatro de febrero de mil setecientos sesenta y nueve, se procediese a la enajenación del expresado Real Valle [...]

La tasación fue de 48.736 .395 reales, que era lo mínimo que esperaba ingresar la Real Hacienda, por los 199 millares en que se repartía el Valle de Alcudia. Cuya superficie real es ambigua por la ya aludida diferencia en una superficie tan vasta. Así los BOVBNs, citan millares desde 200 a 800 ha (a veces superan ambos extremos), pero la media ronda las 500 ha, por lo que 147 millares tendrían probablemente entre 60.000 y 80.000 ha. En 1769, por la Real Resolución citada, se puso a la Venta el Valle de Alcudia.

El conflicto surgió con los posesioneros del Valle que, por la renovación no interrumpida del arrendamiento, pretendían el derecho de propiedad de los pastos que desde décadas o siglos venían usando. Pero mientras mostraban su oposición a la enajenación, las ofertas de compra empezaron a llegar, incluso procedentes de los propios posesioneros.

La Dirección General de Temporalidades, organización creada para administrar los bienes confiscados a los jesuitas, compró 2/3 del Valle, por considerar que era una rentable y segura inversión para la Real Hacienda (Corchado 1973; Gascón 1978). Esto supuso que la mayor parte del valle siguiese en manos del Estado aunque con diferente "propietario". De los 147 millares del Valle de Alcudia, la citada D.G. de Temporalidades adquirió 99, otros 7 se reservaron para el servicio de las minas de Almadén (Dehesa de Castilseras) por lo que realmente lo que salió a la venta a particulares fueron tan solo 41 millares. Esos 41 millares fueron adquiridos principalmente por ganaderos invernantes (Tabla 2.2). 


\begin{tabular}{|l|c|c|c|}
\hline \multicolumn{4}{|c|}{$\begin{array}{l}\text { Desglose del destino de los } 147 \text { millares de la primera desamortización } \\
\text { del Valle de Alcudia (1769-1770) }\end{array}$} \\
\hline Comprador & Procedencia & $\begin{array}{c}N^{\circ} \text { de } \\
\text { millares }\end{array}$ & Precio \\
\hline Dirección General de Temporalidades & 99 & $14.682 .436 \mathrm{rs}$ \\
\hline Abastecimiento de las minas de Almadén & 7 & - \\
\hline Marqués de los Castillejos & Cádiz & 8 & $2.150 .708 \mathrm{rs}$ \\
\hline Comunidad y Tierra de Segovia & Segovia & 7 & $2.282 .794 \mathrm{rs}$ \\
\hline Fundación Ochoa de Ondategui & Segovia & 5 & $1.845 .127 \mathrm{rs}$ \\
\hline Juan de Albarellos y Soto & La Rioja & 5 & $1.579 .617 \mathrm{rs}$ \\
\hline Marqués de las Hormazas & Madrid & 3 & $1.185 .000 \mathrm{rs}$ \\
\hline Marqués de Somoruelos & Madrid & 3 & $664.910 \mathrm{rs}$ \\
\hline Manuel Iñiguez Valdeosera & Cádiz & 3 & $549.850 \mathrm{rs}$ \\
\hline Marqués de Zambrano & Madrid & 2 & $784.178 \mathrm{rs}$ \\
\hline José Joaquín Rodríguez y Riba & Madrid & 2 & $515.076 \mathrm{rs}$ \\
\hline Pablo Rodríguez Berdocio & Badajoz & 1 & $419.588 \mathrm{rs}$ \\
\hline Lorenzo Bernardo de Orduña & La Rioja & 1 & $354.740 \mathrm{rs}$ \\
\hline Colegio Seminario de Cáceres & Cáceres & 1 & $306.280 \mathrm{rs}$ \\
\hline Total & & $\mathbf{1 4 7}$ & $\mathbf{2 7 . 3 2 0 . 3 0 4}$ rs \\
\hline
\end{tabular}

Tabla 2.2. Destino e ingresos de las ventas de la primera desamortización del Valle de Alcudia (17691770). Elaboración propia basada en diferentes datos de archivo y Gascón (1978).

El valor de venta fue de 27.320.304 rs frente a los casi 50 millones previstos. Pero como la mitad corresponde a la Corona, en realidad se reduce a tan solo 12.6 millones de rs, en torno a la quinta parte del total previsto. En 1773 la Compañía de Jesús se disuelve y, en consecuencia los 99 millares de la D.G. de Temporalidades pasan de nuevo a la Real Hacienda.

A pesar de los cambios de titularidad el destino del Valle e Alcudia siguió siendo el mismo que tenía desde la Edad Media. Sin embargo, en lo económico experimentó un enorme cambio sobre los arrendamientos de los pastos: su precio subió a más del doble. En la última década del siglo, tan solo unos 20 años después, su precio volvió a duplicarse (Gascón 1981).

A partir de 1793 ocuparía la dirección del país Manuel Godoy, valido del rey Carlos IV hasta el final de su reinado en 1808. Pero antes ya había acumulado poder y distinciones. Carlos IV había comprado los 99 millares de la Real Hacienda para fundar el título de Duque de Alcudia. Título que, por Real Decreto de 10 de Abril de 1792, le concedió a Godoy (Godoy 1836). Así, la propiedad de la mayor parte del Valle de Alcudia pasa a manos de una sola persona. En el trasfondo, estaba la renta anual de un millón de reales que producía su propiedad (AP.PR.A. Legajo 2.5). El Duque de Alcudia inicia en 1792 el desahucio de los antiguos arrendatarios en sus propiedades, algunos de gran peso, pues tan solo 6 posesioneros disfrutaban de 71 de los 99 millares. El Duque compró posteriormente 14 millares más en el Valle, con lo cual su propiedad ascendía a 113 millares. Creó una cabaña ganadera propia, pero al tener demasiadas tierras para ella, muchas de estas fueron de nuevo arrendadas (Gascón 1978).

El poder de Godoy puso coto a los abusos que cometían las minas de Almadén y los carreteros de Almodóvar del Pinar cortando madera. Aunque el Valle y las propiedades de Godoy debían surtir de madera a las minas, Godoy no se opuso pero lo que hizo fue frenar los abusos. Para 
ello nombró a un Juez Conservador y numerosos guardas para la vigilancia y protección de sus dehesas (AMAC 29-1799):

[...] en atención a los graves perjuicios que se seguian al arbolado de dicho Valle con las cortas, que fuera de tiempo, mandava hacer el Gobernador de las Reales Minas de Almadén $[\ldots]$

Tras el Motín de Aranjuez, en 1808, los bienes de Godoy fueron confiscados, entre ellos el Valle de Alcudia que pasa de nuevo al poder de la Real Hacienda, que los cede para su administración, por Real Orden de 22 de marzo de 1809, a la Superintendencia de las Minas de Almadén (AMAC 43-1812). El proceso que siguió fue intenso pero breve, según Corchado (1973) y Gascón (1978): en noviembre la administración francesa los "desamortiza" de nuevo, vendiéndolos a particulares que apenas los disfrutaron pues, expulsados los franceses y restablecido el Rey Fernando VII, las ventas quedaron anuladas y el Valle de Alcudia de nuevo en poder de la Corona. En 1820, durante el Trienio Liberal, la administración del Valle se incorporó al Crédito Público, luego, en 1823 de nuevo al Patrimonio Real. De donde ya pasaría a la Administración de Bienes Nacionales, donde permanecería hasta su progresiva venta en las desamortizaciones del siglo XIX.

Los primeros años del siglo XIX constituyen un periodo en el que la falta de control por la situación bélica y los cambios de gobierno, de gestión y titularidad afectarán a montes y pastos. La trashumancia se resentirá durante la guerra. Los grandes cabañas serán expoliadas por los ejércitos de uno y otro bando para salir del país y extenderse por el resto del mundo. Lo que supondrá el fin del monopolio español y el precio de la lana de oveja merina española irá cayendo conforme las cabañas foráneas incrementen cantidad y calidad. También son muy graves los conflictos entre ganaderos posesioneros y nuevos ganaderos que intentan arrendar pastos, derivando en numerosos pleitos e incluso situaciones violentas y quema de montes por venganzas. La inestabilidad durante la guerra, y tras la anulación de la venta del Valle por Fernando VII, genera un clima de gran conflictividad e inseguridad en la zona. El vacío legal y de vigilancia de cualquier tipo fue aprovechado por numerosos vecinos de los pueblos para roturar montes, máxime porque al disminuir la cabaña ganadera se produjo un exceso de tierras de pastos (AHN Consejo de Ordenes. Legajos 4108 y 4116). De esa época, sólo se conocen una mínima parte por testimonios escritos. En 1811, los vecinos de Hinojosas piden permiso para arar 2 quintos de la encomienda de Puertollano (AHN Consejo de Ordenes. Legajo 4354). En 1812, varios vecinos del Villar y Puertollano empiezan a romper, en la encomienda de la Obrería, el quinto Quintillo. Los vecinos de Mestanza roturaron otros 3 quintos. La roturación de tierras tenía el inconveniente de un gran esfuerzo, pero la miseria de la mayoría de los habitantes y la avaricia de otros les empujaba a roturar aquí y allá continuamente, de forma legal las menos e ilegal las más. Reestablecida la paz y un cierto orden, en 1829 los vecinos de Mestanza solicitaron un quinto de la dehesa de Barrancos para roturarlo, pero se les denegó. La razón fue que eran más seguras y permanentes las rentas de los pastos (AHN Consejo de Ordenes. Legajo 4354). 
En los peores terrenos serranos, la riqueza de los suelos y los métodos de cultivo eran tan pobres que tras roturar el monte sólo se hacía una siembra de trigo, cebada o centeno cada varios años. En Fuencaliente el cultivo de cereales se realizaba cada 6 años. La práctica de las rozas se conoce en Almodóvar, Puertollano, Mestanza y Fuencaliente, haciéndose generalmente una siembra cada 10, 12 o hasta 20 años (vecinos de la comarca com. pers.)

\subsubsection{Los bosques de Sierra Madrona y Valle de Alcudia en el siglo XIX}

A partir de 1808, los avatares de los montes fueron parejos a la convulsión política del país, repleto de guerras ajenas y propias, pérdida de las colonias, asonadas militares, revoluciones liberales y contrarrevoluciones, junto al enfrentamiento entre facciones políticas. La Constitución de Cádiz plasmó su relación con los montes en el Decreto de Cortes de 4 de enero de 1813 al considerar que la reducción de los terrenos comunes a dominio particular era una de las providencias que más imperiosamente reclamaba el bien de los pueblos y el fomento de la agricultura e industria (Mangas 1984). Deseo al que le seguirá poco después una Real Cédula de 27 de septiembre de 1814 sobre la confiscación y compra de bienes nacionales durante el gobierno del "intruso" y que funda su resolución en la necesidad de poner pronto remedio a los males que esta sufriendo el Estado por las escandalosas talas, incendios y destrozos de toda especie que experimentan los montes del Reino y amenazan su total ruina.

El paisaje general de la provincia de Ciudad Real se deduce de la reflexión que hará el militar Diego Medrano Treviño, diputado a Cortes por la provincia de La Mancha durante el Trienio Liberal y Ministro de la Gobernación en 1822 que, posteriormente, volvería a ser diputado tras el retorno de los liberales a la muerte de Fernando VII. En su visión del estado económico y social de la provincia Medrano y Treviño (1843) alude a la percepción visual del territorio manchego:

[...] verían en muchos parages miserables chaparros, restos de montes que fueron ó principio de los que pudieran llegar a ser; pero que intereses mal entendidos por una parte y efectos de mala administración por otra habían dejado destruir ó no se cuidaban de fomentar y no pocos que caminan rápidamente a su destrucción total, porque reglamentos mal concebidos ó no bien ejecutados servían solo para encadenar el uso infundadamente, al paso que permitían el abuso contrariando en uno y otro caso el poderoso interés individual [...] verían aguas desperdiciadas: malas comunicaciones interiores en detestables caminos [...] verían escasez de población como consecuencia precisa de la penuria de medios de subsistencia [...] señales evidentes de la inercia, del olvido y del descuido mas absoluto de una buena administración pública [...] ya por la falta de riegos, ya por la del arbolado que es el conductor de las lluvias frecuentes [...] la escasez de medios de subsistencia y de población [...] la falta del fomento del arbolado, que atrae las lluvias y los rocíos [...] 
Poco después aparecerá una de las fuentes de información general más utilizadas sobre la España de mediados del siglo XIX: el Diccionario Geográfico y Estadístico de Madoz (18471849). En ella es posible extraer comentarios que tienen relación con el estado de los montes de la comarca. La valiosa información que ofrece fue fruto de los colaboradores provinciales con los que contó. Estos son los comentarios sobre el estado de los montes en los pueblos de la comarca:

\title{
Alamillo
}

[...] ald. ped. del ayunt. y partido judicial de Almadén [...] el terreno es árido, de monte bajo, formando cord. [...] tiene mucho ganado cabrio y algun vacuno [...] 202 vec., 815 alm. [...]

\section{Alcudia}

[...] pertenece al Real Patrimonio [...] es de monte y llano; comprende 162 millares, donde pueden pastar mas de 300.000 cab. de ganado lanar, 3 a 4000 reses vacunas, y esta poblado de corpulentas encinas, cuyo fruto es sabrosísimo [...]

\begin{abstract}
Almadén
[...] le compone [el partido judicial] de 7 v., y 5 ald., que forman al todo los 7 ayuntamientos [Agudo, Almadanejos, Chillón, Fuencaliente, Saceruela y Valdemanco] [...] Todos ellos [los montes del part. jud.] estan poblados de encinas, robles, quejigos, acebuches, jaras, madroños y otros arbustos que forman bosques espesos, en los cuales se abrigan lobos, zorros, jabalies, ciervos, gatos monteses y otras diferentes especies de caza mayor, y mucha menor [...] Podría calcularse en 33,560 fan. de extensión [su term. mun.] para labor; pero su ínfima clase si se esceptúa la deh. de Castilseras [...] pedregoso y estéril, como es el terreno, no se atiende a su cultivo [...] solo quedan aplicadas a la labor 14,172 fanegas, 1 celemin y dos cuartillos [...] del Real Patrimonio son 3,183 fanegas y del Establecimiento y mineros, 4,144 fanegas de Castilseras, de propios son 2,840 fanegas y valdias 1,160 [...] El arbolado silvestre suma 55,350 encinas [de ellas en Castilseras 50.000] 900 robles, 798 quejigos y 240 acebuches [...] 1,729 vec. en todo el término municipal; 8,645 alm. [...]
\end{abstract}

\section{Almodóvar del Campo}

[...] se compone de 13 v., lugares y 18 ald., que forman 18 ayuntamientos [Abenojar, Aldea del Rey, Argamasilla de Calatrava, Belvis, Brazatortas, Cabezarados, Cabezarrubia, Caracuel, Corral de Caracuel, Hinojosas, Mestanza, Puerto llano, Tirteafuera, Villamayor de Calatrava y Villanueva de San Carlos] [...] participa de monte y llano [...] es pedregoso, de miga y no se riega; del cultivado son 1,500 fanegas de primera calidad, 2,500 de segunda y 3,000 de tercera 
[...] hay tambien montes de roble, alcornoque y encina que suministran combustible y madera para los aperos de labranza [...] 1,124 vec.; 5,620 alm. [...]

\section{Chillón (incluye Guadalmez)}

[...] comprende 33,840 fan. y 10 celemines de tierra, que se distribuyen de la forma siguiente; 570 fan. de viña, 93 de parrales; 4,515 de pasto y matorral; 900 en deh. de encinar; 2,099 en encinas fuera de deh; 495 y 6 celemines en tierra cercada; 5,587 en 4 hojas para sembradura; 9,499 y 6 celemines de tierra montuosa; 44 y 10 celemines de regadio [...]

\section{Fuencaliente}

[...] el terreno es montuoso y estéril en su mayor parte pero con buenas arboledas de robles y quegigo que surten de maderas a las minas de Almadén y pudiera tener buenos encinares, si en vez de continuar la plantación de este utilísimo árbol, como principiaron en 1804, no hubieran cortado los que ya había; hay también muchas jaras, modroñeras, mirtos, lentiscos, alisos y se encuentran unos 10,000 olivos, arbustos y plantas medicinales [...] se mantiene mucho ganado cabrío, poco vacuno, menos lanar y de cerda, de 1,200 a 1,400 colmenas de esquisita miel y abunda toda especie de caza mayor y menor [...] 421 vec., 2,105 alm. [...]

Mestanza (incluyendo su aldeas)

[...] el terreno es montuoso y de poca miga por estar cuajado de grandes filones de pizarra, quebrado con algunas cañas de buena calidad, encinares descuidados y cord. que dividen y deslindan el Real Valle de Alcudia [...] 432 vec., 2,160 alm. [...] los fondos de propios, que consisten en los pastos de los montes y derechos de vino [...]

\section{Puertollano}

[...] comprende [...] las deh. de pastos que forman los 11 quintos de propios, á 450 fanegas de tierra cada uno, y tierra de labor [...] es de secano, pedregoso y algo de miga [...] No hay bosques ni arbolado, pues solo se conoce el monte bajo, del que los habitantes cortan para sus usos domésticos [...] 504 vec., 2,520 alm. [...]

\section{Solana del Pino}

[...] ald. con alc. p. [...] el terreno es montuoso y de sierras [...] 100 vec., 396 alm. [...]

Pese a la situación general de la comarca, las zonas más abruptas y umbrosas de las sierras, por su extensión, aun albergaban algunas formaciones que, aunque ya alejadas de sus estructuras 
naturales por la presencia del fuego, aun mantenían algo de bosque y restos de lo que fue una rica fauna. Ejemplo de ello es el testimonio del entomólogo José María de la Fuente, sacerdote que ejerció en Almodóvar del Campo de 1879 hasta 1888 y, probablemente el mejor naturalista de época en la provincia. En su obra (De la Fuente 1929) cita al pito negro (Dryocopus martius) en los bosques de Fuencaliente. Este gran pájaro carpintero vive actualmente en los bosques de abedules, robles, hayas y coníferas de la Cordillera Cantábrica, Pirineos y otras zonas boscosas templadas de Eurasia. Si en un pasado no lejano aún vivía en Sierra Madrona suponía la permanencia de manchas de robledales con cierta entidad, más o menos densos. Un siglo más tarde, Sarrión \& Burgaz (2002), también encuentran líquenes epífitos propios de robledales con gran antigüedad.

Fuera de los robledales más inaccesibles (melojares y quejigares), el resto del monte era talado, quemado o roturado de forma habitual. Bien para abastecimiento de minas y pueblos, para generar pastos herbáceos o para el cultivo agrícola. Según el DGE de Madoz, en Fuencaliente la producción agraria a mediados del siglo XIX era principalmente de cereal, algo de legumbres, olivos, hortalizas y frutas, gran cantidad de ganado cabrío seguido de vacuno, lanar y de cerda, y colmenares. Su población en 1849 era casi el doble (2015 hab.) que la actual (1082 hab) (INE 2015). Pero en otros pueblos vecinos, serranos, como Solana del Pino, su producción agraria era casi nula, estando dedicada su población casi por completo a la ganadería (ganado cabrío, vacuno y de cerda), también con una población superior (396 hab.) a la actual (353 hab.) (INE 2015). La densidad de población de Fuencaliente era unas 3 veces mayor que la de Solana $\left(0,075 \mathrm{hab} / \mathrm{km}^{2}\right.$ frente a $\left.0,023 \mathrm{hab} / \mathrm{km}^{2}\right)$ pero en cualquier caso, sorprende que, con una población de media muy superior a la actual, dedicada casi por completo a la ganadería, y unos montes más o menos arrasados, sobrevivieran los robledales. Pero así lo confirman también los ingenieros de montes decimonónicos.

La tónica general pues en la comarca eran dehesas con arbolado disperso en el Valle de Alcudia y matorrales en las sierras (Figs. 2.16 y 2.17), con áreas más reducidas de cultivo de cereal (principalmente), huertos y olivar en el entorno de los pueblos (Fig. 2.18) y algunos robledales todavía en monte alto en las umbrías de las zonas serranas más altas y alejadas (Fig. 2.19). 


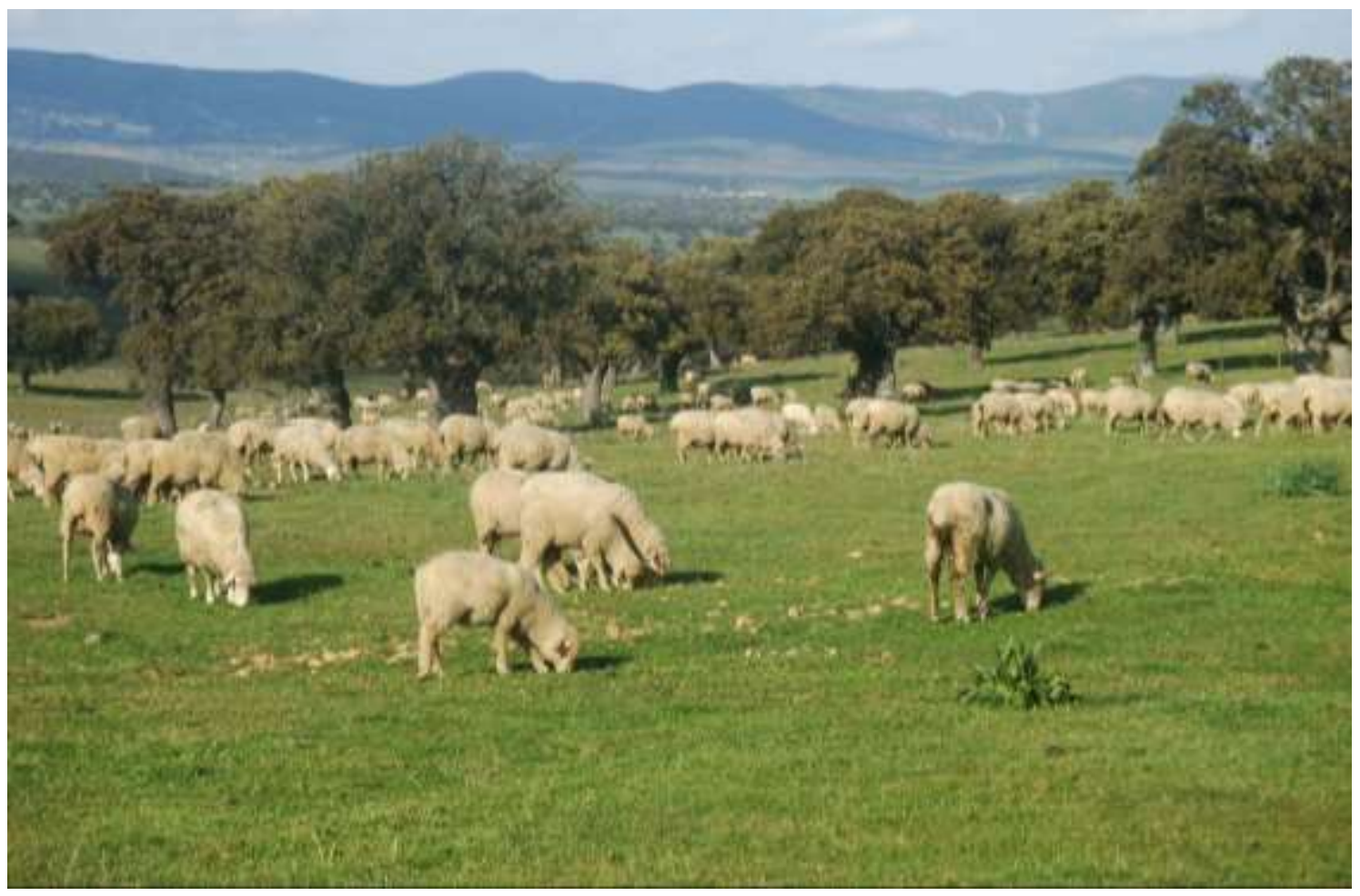

Fig. 2.16. A mediados del siglo XIX el Valle de Alcudia mantenía su aspecto adehesado y uso principal ganadero, con oveja merina. Sin embargo la intensidad de la explotación minera durante siglos y el envejecimiento de los árboles, sin regenerado posible, clareaba cada vez más las dehesas.

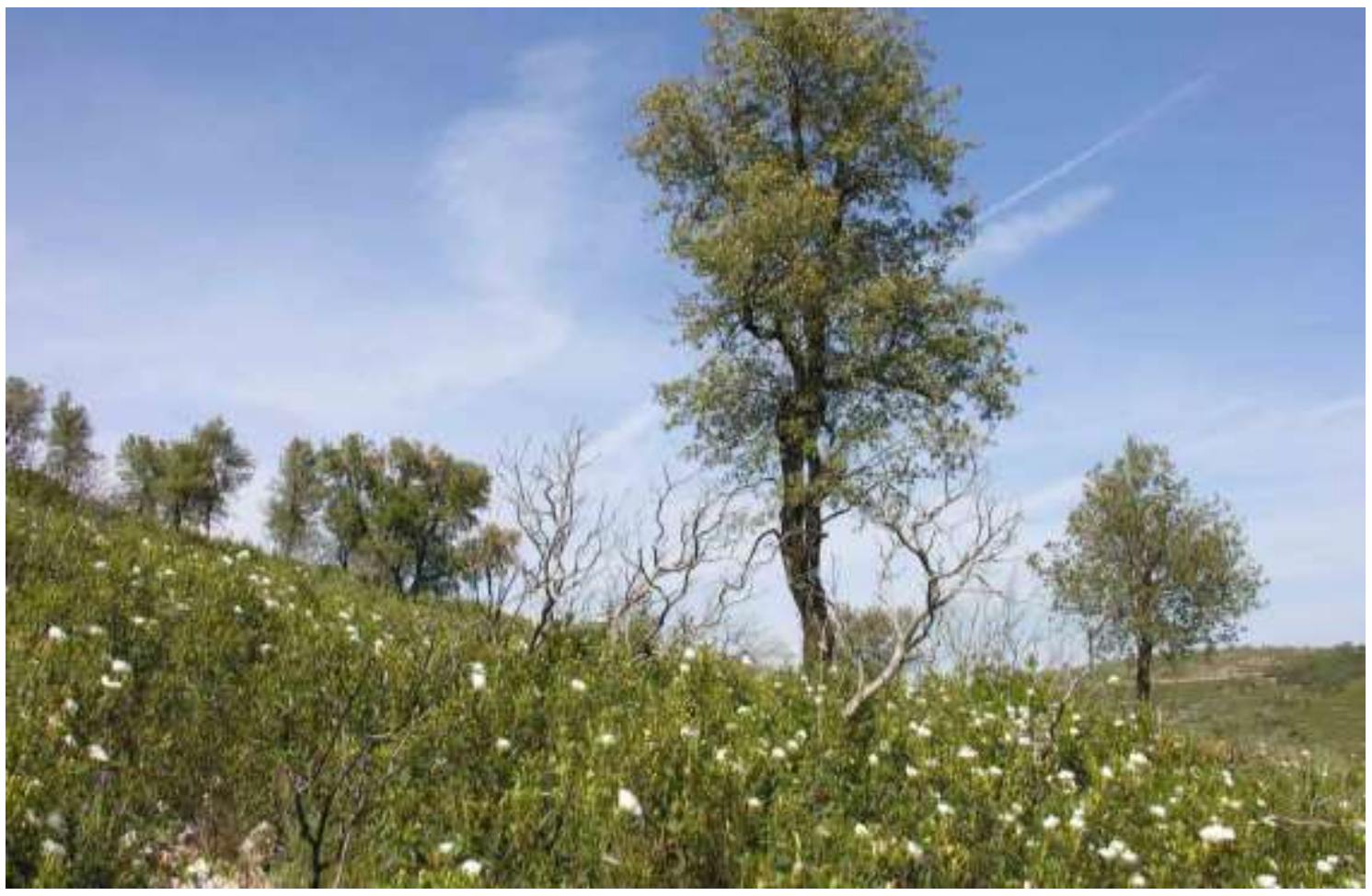

Fig. 2.17. Incendios cada 3-6 años provocados por los pastores en las sierras y el sobrepastoreo eliminaban la cubierta vegetal temporalmente y daban paso a la erosión, al agotamiento de las cepas y a una menor densidad arbórea. El paisaje originalmente boscoso pasaba a ser y se perpetuaba como un inmenso jaral de Cistus ladanifer, especie pirófita cuya germinación favorecen los incendios. Entre este matorral solo destacan jóvenes alcornoques debido a la protección que les brinda su corteza ignífuga y su gran potencial de rebrote de tronco y ramas que mantiene la esbeltez de su porte. 


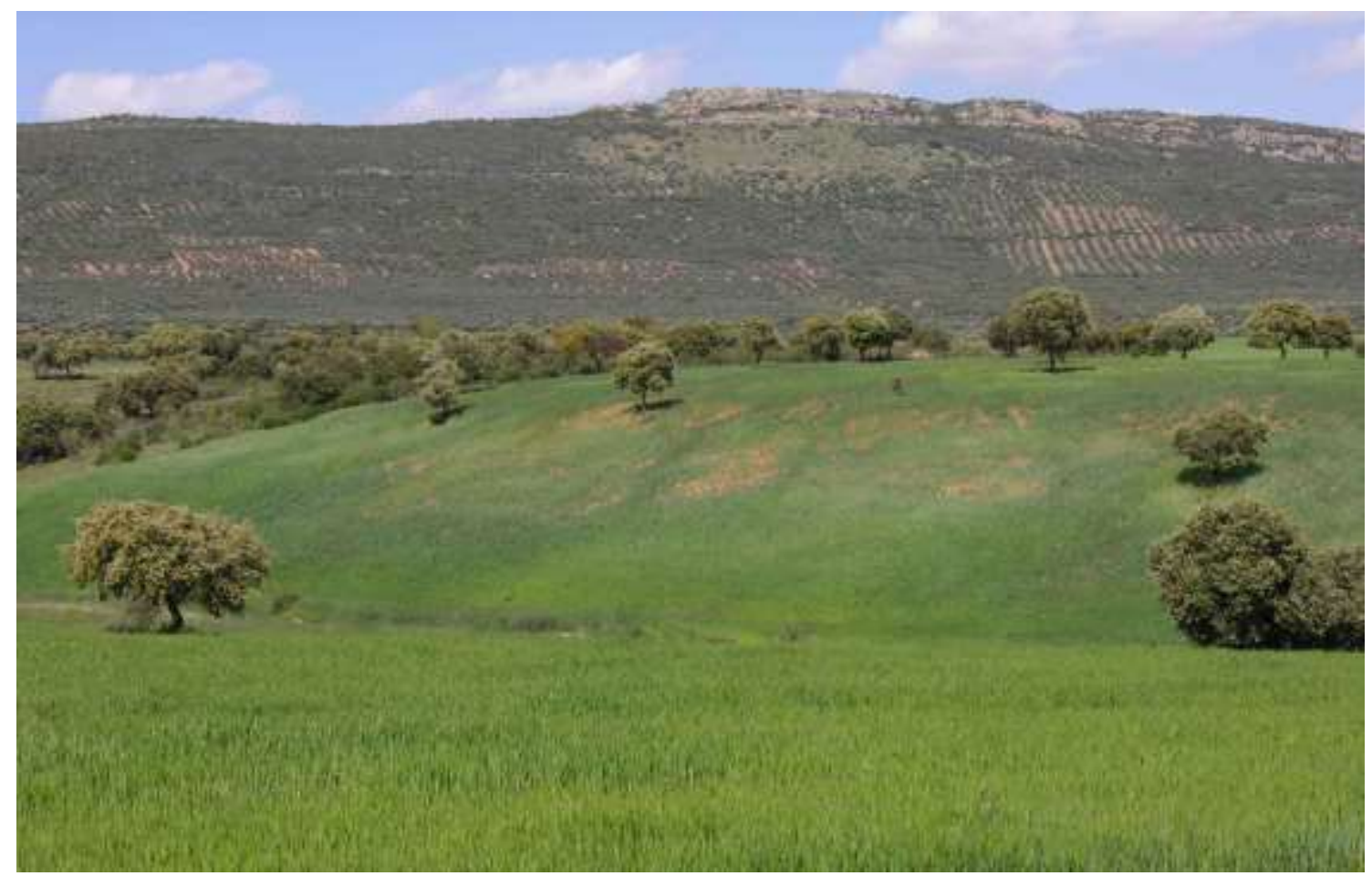

Fig. 2.18. En las proximidades de los pueblos, a mediados del siglo XIX y principios del XX se consolida y extiende la agricultura. La parte baja y más llana del Valle de Alcudia queda reservada como pastos de invierno para la oveja merina, salvo en las proximidad de pueblos donde se cultivan cereales, las laderas como olivar y, las cumbres y más lejanas tierras serranas, para apicultura y pasto de ganado cabrío.

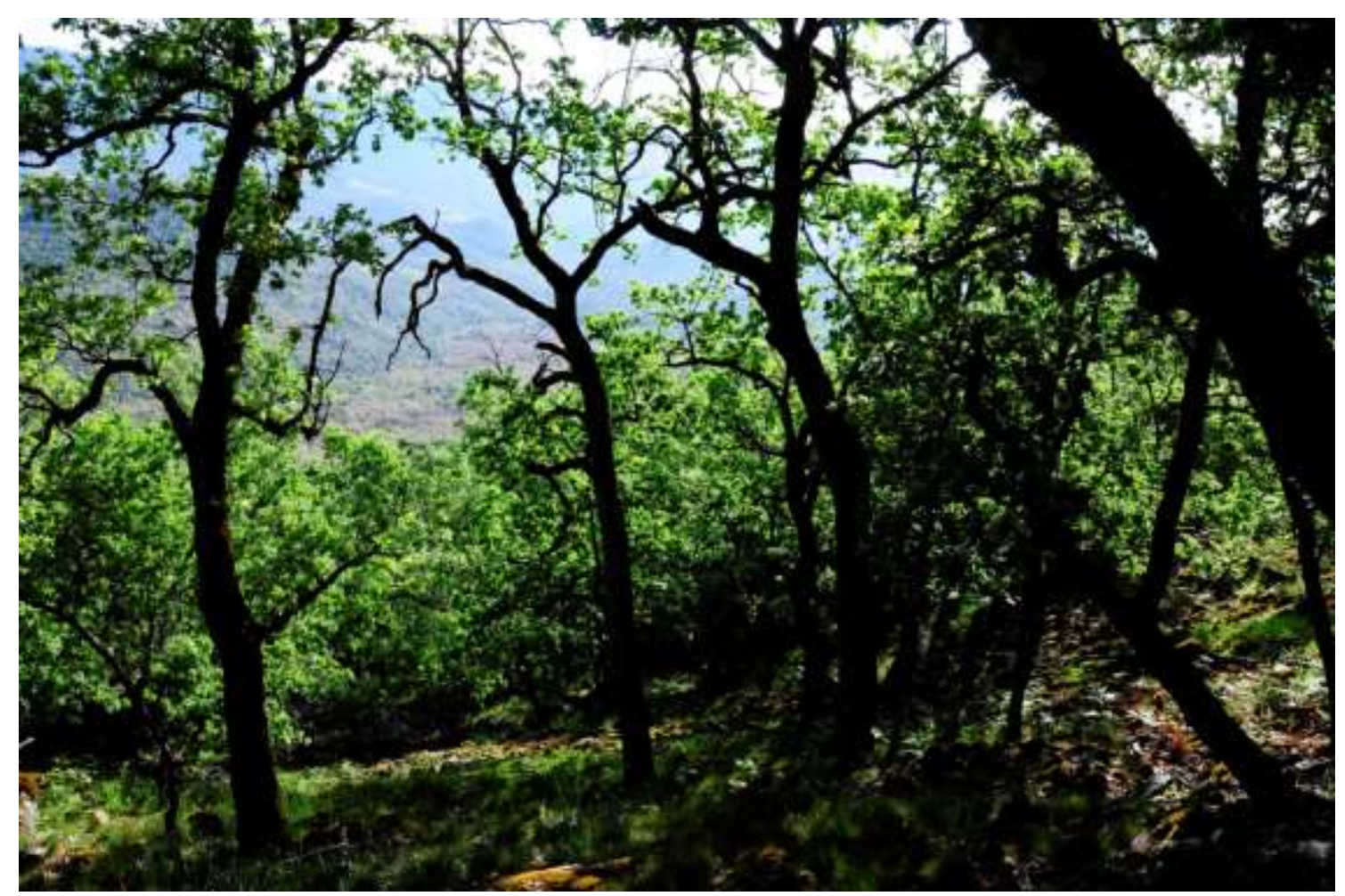

Fig. 2.19. Los robledales de Fuencaliente sobrevivieron hasta mediados del siglo XIX como formaciones forestales. La baja densidad de población de esta zona, el difícil acceso y lejanía de las minas, así como un hábitat de umbrías pedregosas reducía tanto su interés agronómico y como la propagación del fuego. 
Máximo Laguna visita la comarca en 1867 (Laguna 1868) y describe la zona como un territorio dominado por el monte bajo, con algunos rodales de robles, quejigos y dehesas de encinas en los valles. También cita que las primeras repoblaciones forestales en sierra Morena se comenzaron a realizar en 1767 obteniéndose nulos resultados y, observó en su recorrido que los vecinos de Fuencaliente habían empezado a hacer plantaciones de olivos y a cultivar robles y quejigos en los montes de la Cereceda y las Ventillas.

A finales del siglo un hecho trascendental tendrá lugar en la provincia de Ciudad Real: la llegada y proliferación del viñedo, como a finales del XVIII había ocurrido con el olivar. Su impacto sobre los bosques no ha sido estudiado pero debió ser considerable pues para un mismo beneficio requería una superficie de tierra mucho menor. Es decir, el afán roturador disminuyó. De acuerdo con Esteban (1991), los agricultores manchegos se adelantaron medio siglo a las palabras de Julio Senador para la Meseta Norte:

[...] Este trigo les hunde. Ahi está nuestro "peligro amarillo". El porvenir es del viñedo, del bosque y del ganado [...]

A mediados del siglo XIX, en 1865, la cabaña ganadera española supera los 37 millones de cabezas (Tabla 2.3), cifra que multiplicaba 58 veces la cabaña de 1799 y la lanar 75,5 veces. La entidad de tal cabaña es suficiente para entender como la superficie forestal del país se había destinado a pastos herbáceos o leñosos, usos ambos incompatibles con la regeneración forestal, por lo que los árboles presentes en la actualidad son una parte de los que ya estaban al producirse la desamortización de las dehesas que, como tales, han permanecido. Destaca que el lanar no trashumante (estante más trasterminante) sumaba en el conjunto de la provincia de Ciudad Real 287.395 cabezas, de las cuales pastaban en las dehesas de los partidos judiciales de Almadén y Almodóvar del Campo el 27,3\% de dicha cifra. También destaca en dichos partidos judiciales el ganado vacuno, pues en sus dehesas pastan el 67,4\% de la cabaña provincial. En relación al ganado cabrío, la provincia acogía un 4,15\% de la cabaña nacional. Pero en los montes de los partidos judiciales de Almadén y Almodóvar del Campo pastaban el 66,9\% del caprino provincial.

\begin{tabular}{|c|c|c|c|c|c|c|c|c|}
\hline & ESPAÑA & $\begin{array}{c}\text { Ciudad } \\
\text { Real }\end{array}$ & $\begin{array}{c}\text { Ciudad } \\
\text { Real }\end{array}$ & Almadén & $\begin{array}{l}\text { Almodóvar } \\
\text { del Campo }\end{array}$ & $\begin{array}{c}\text { Ciudad } \\
\text { Real }\end{array}$ & Almadén & $\begin{array}{l}\text { Almodóvar } \\
\text { del Campo }\end{array}$ \\
\hline \multirow{2}{*}{$\begin{array}{l}\text { Tipo de } \\
\text { ganado }\end{array}$} & Total & Total & \multicolumn{3}{|c|}{ No trashumantes } & \multicolumn{3}{|c|}{ Trashumantes } \\
\hline & cabezas & cabezas & cabezas & cabezas & cabezas & cabezas & cabezas & cabezas \\
\hline caballar & 680.373 & 10.539 & 10.302 & 1.122 & 1.787 & 237 & 62 & 41 \\
\hline mular & 1.021 .5 & 31.442 & 30.070 & & 2.288 & 1.012 & 158 & 95 \\
\hline asnal & 1.298 .334 & 35.067 & 34.471 & 1.682 & 4.995 & 596 & 176 & 98 \\
\hline vacuno & 2.967 .303 & 22.783 & 21.673 & 5.543 & 7.492 & 1.110 & & 442 \\
\hline lanar & 22.468 .969 & 297.693 & 287.395 & 25.057 & 53.310 & 10.298 & & 8.454 \\
\hline cabrío & 4.531 .228 & 188.120 & 178.089 & 35.756 & 56.015 & 10.031 & 474 & 2.006 \\
\hline cerda & 4.351 .736 & 57.350 & 55.962 & 9.468 & 11.422 & 1.388 & 317 & 100 \\
\hline total & 37.319 .455 & 642.944 & 617.962 & 79.518 & 137.309 & 24.672 & 1.187 & 11.236 \\
\hline
\end{tabular}

Tabla 2.3. Tamaño de la cabaña ganadera en España y la provincia de Ciudad Real. Diferenciando en la provincia la cabaña trashumante de la no trashumante en los partidos judiciales de Almadén y Almodóvar del Campo. Fuente: Junta General de Estadística (1868). 
Pero a pesar de este enorme auge de la ganadería, la lana merina española va perdiendo su hegemonía en los mercados extranjeros, tras haberla ostentado durante más de 5 siglos, lo que supone un duro revés para el modelo de la trashumancia (García Sanz 1978) y el inicio del declive de esta práctica ancestral. Las razones son varias, pero se inician con la salida en 1765 hacia Sajonia de la cabaña de "El Escorial” y en 1786 hacia Rambouillet, de merinos de varias cabañas leonesas (Conde de Montarco 1959). La descendencia de estos rebaños logró su total adaptación en Francia, Alemania, Reino Unido, Región del Cabo, Argentina o Australia. La calidad de la lana merina española se argumentaba en los largos desplazamientos entre los pastos de agostadero e invernadero, en el doblaje de las madres para que 2 ovejas amantaran a una solo cría, y el efecto que esta práctica suponía en la selección genética, al reducir a la mitad los corderos paridos en el otoño (Valverde 2005). Practica que era una singularidad propia de España en esta época; cómo señalaría el fundador de la escuela de ingenieros de Montes, Agustín Pascual (1859-1861):

[...] La preocupación que en que en algun tiempo tuvieron nuestros ganaderos, de que la selecta raza merina era un don particular de España que ninguna otra podía poseer, lo cual hizo se mirara con indiferencia y aún con desprecio la exportación a otros reinos; pero la experiencia les hizo ver muy pronto lo contrario y lo inútil que era tratar de poner coto a un daño de tanta trascendencia para su industria $[\ldots]$

Fuera de nuestras fronteras, en pocas generaciones se mejoró la calidad de su lana y el tamaño de los rebaños, lo que supuso la ruina de los ganaderos trashumantes que veían como ya en 1840, la demanda del mercado británico se había reducido un 95\% (Tabla 2.4), cifra que era poco más de la quinta parte de la exportada en 1814 y durante siglos la totalidad de la demandada por los mercados europeos.

\begin{tabular}{|c|c|c|c|c|c|}
\hline & $\mathbf{1 8 0 0}$ & $\mathbf{1 8 1 4}$ & $\mathbf{1 8 2 7}$ & $\mathbf{1 8 4 0}$ & Diferencia \% \\
\hline España & 7.794 .751 & 9.234 .991 & 4.347 .613 & 1.704 .200 & $5 \%$ \\
\hline Alemania & 421.350 & 3.595 .146 & 22.007 .178 & 15.819 .500 & $47 \%$ \\
\hline Australia & $250(1806)$ & s.d. & s.d. & 16.256 .250 & $48 \%$ \\
\hline
\end{tabular}

Tabla 2.4. Importación de lana merina en Gran Bretaña (libras). Fuente: Collantes \& Alfaro (1855). Obsérvese el espectacular crecimiento de las importaciones de lana merina alemana entre 1800 y 1827.

Los argumentos dejaron de ser válidos con el establecimiento del merino fuera de nuestro país, donde: no era necesaria la trashumancia, no era necesario reducir los corderos a la mitad y la selección genética no se dejaba en manos de mayorales. 
El Censo de 1865, elaborado por la Junta General de Estadística, es de una gran fiabilidad. La "Introducción" al Censo, obra de Agustín Pascual, al tiempo vocal de la Junta, refleja la situación de la trashumancia en España.

[...] Mientras se creía que los dos viajes anuales influían en la finura de la lana merina por la continuidad de una aire siempre benigno y templado, por el uso de un alimento siempre fresco y verde [...] la experiencia de Alemania y el ensayo hecho en el bosque de Riofrío mostraban que los ganados estantes daban productos superiores a los trashumantes [...] iquién dijera que el ganado merino, la riqueza querida de los españoles, había de ser sojuzgado por un sistema advenedizo! ; que había de desaparecer en un día tanto tropel de pastores y de prácticas como se empleaban en su cría y conducción!; que lejos de recibir aumentos de terrenos, objeto constante de los desvelos mesteños, había de abandonar sus mas antiguas y preciadas habitaciones! Fundada la trashumación en la cantidad y no en la calidad, la verdad nueva se encontró con que la mayor parte de las cabañas españolas eran muy inmensas, existiendo algunas con treinta mil y mas cabezas [...]

\subsubsection{Las desamortizaciones de los siglos XIX y XX en Sierra Madrona y Valle de Alcudia}

Castilla-La Mancha fue la región de España con mayor venta de fincas entre 1836 y 1924. En total 1.605.683 ha vendidas, seguida de Extremadura, con 1.153.383 ha. A Ciudad Real le correspondió el 47,16\% del total de la comunidad, un total de 757.211 ha (Del Valle 2015).

En cuanto a los montes, la superficie vendida según el GEHR (revisión del estudio de 1994) oscila entre los 7 y 8 millones de ha en el conjunto nacional. De estas, 1.295.140 ha en CastillaLa Mancha, es decir, en esta región el 80,66\% de las tierras vendidas fueron montes. La provincia de todo el estado con más montes vendidos fue Ciudad Real, con 513.864 ha. El porcentaje medio de montes supone el $67,86 \%$ con respecto al total de tierras vendidas. Pero como en la parte de la provincia ocupada por la llanura manchega se vendieron básicamente tierras de cultivo, en el resto de la provincia casi todo fueron montes.

La aportación de tierras de la provincia de Ciudad Real, se explica por ser la encina una especie que no fue exceptuada de la desamortización, por su mayor interés para los compradores y con mayores posibilidades de alcanzar precios destacados en las subastas. Las grandes posesiones de las OOMM y, más en especial de la Orden Militar de Calatrava, propietaria, entre otros terrenos, de Sierra Madrona y el Valle de Alcudia constituían grandes atractivos, tanto para el Ministerio de Hacienda como para compradores. No todo procedía de las tierras calatravas (propiedad ya del Estado), pues en los procesos de colonización y segregación de términos se habían cedido una parte como montes de propios o comunales a los pueblos. Esto implicó que, aunque el origen del dominio fuera calatravo, en el siglo XIX mucho de lo que se vendió en la provincia de Ciudad Real fueron montes propiedad de los pueblos. En la provincia de Ciudad Real, una vez más a la cabeza de España en cuanto a ventas también en este aspecto, se vendió el 86,9\% del monte público (GEHR 1994). Es decir, que mientras en otras provincias más septentrionales se exceptuaron más monte públicos, en la provincia de Ciudad Real (y otras de Extremadura y 
Andalucía occidental) esta figura de propiedad y uso prácticamente se erradicó de lo público, por considerar a los encinares y alcornocales como terrenos agronómicos. Era el resultado de la frutalización del monte mediante la eliminación de robles, quejigos y alcornoques. En la provincia de Ciudad Real, en la desamortización de Madoz, se vendieron 1.167 fincas (310.941,3 ha) con una extensión media de 266,44 ha de montes de los pueblos y 174 fincas (54.816,3 ha) de la Mesa Maestral (Del Valle 1997), con una superficie media de 315,04 ha.

Sin embargo, el mayor número de ventas se produjo, como en otras áreas de España, en la desamortización de Madoz (Tabla 2.5).

\begin{tabular}{|l|r|c|r|r|r|r|r|}
\hline \multicolumn{7}{|c|}{ Tierra vendida (ha) en relación a la superficie de cada término municipal } \\
\hline & $\begin{array}{c}\text { Años } \\
\mathbf{1 8 3 6 - 1 8 5 4}\end{array}$ & $\mathbf{\%}$ & $\begin{array}{c}\text { Años } \\
\mathbf{1 8 5 5 - 1 9 2 4}\end{array}$ & $\mathbf{\%}$ & $\begin{array}{c}\text { Total } \\
\text { venta }\end{array}$ & $\begin{array}{c}\text { Total sup } \\
\text { municipal }\end{array}$ & $\begin{array}{c}\text { \% del } \\
\text { total }\end{array}$ \\
\hline Alamillo & 0 & 0,00 & $1.050,68$ & 15,54 & $1.050,68$ & 6.763 & 15,54 \\
\hline Almadén & 2,68 & 0,01 & 130,50 & 0,54 & 133,18 & 23.964 & 0,56 \\
\hline Almodóvar & $11.469,42$ & 9,49 & $33.376,20$ & 27,62 & $44.845,62$ & 120.827 & 37,12 \\
\hline Brazatortas & 0 & 0,00 & $5.328,60$ & 19,60 & $5.328,60$ & 27.182 & 19,60 \\
\hline Cabez/Hinos & 0,00 & 0,00 & $18.695,17$ & 92,04 & $18.695,17$ & 20.311 & 92,04 \\
\hline Chillón & 136,58 & 0,66 & $11.662,50$ & 56,13 & $11.799,08$ & 20.778 & 56,79 \\
\hline Fuencaliente & 3,22 & 0,01 & $10.091,78$ & 37,40 & $10.095,00$ & 26.985 & 37,41 \\
\hline Guadalmez & 0 & 0 & 29,35 & 0,41 & 29,35 & 7199 & 0,41 \\
\hline Mestanza & $2.932,70$ & 7,93 & $2.122,71$ & 5,74 & $5.055,41$ & 37.000 & 13,66 \\
\hline San Lorenzo & 0 & 0,00 & 115,28 & 1,09 & 115,28 & 10.573 & 1,09 \\
\hline Total & $\mathbf{1 4 . 5 4 4 , 6 0}$ & 5,37 & $\mathbf{8 2 . 6 0 2 , 7 7}$ & 30,50 & $\mathbf{9 7 . 1 4 7 , 3 7}$ & $\mathbf{2 7 0 . 8 5 5}$ & $\mathbf{3 5 , 8 7}$ \\
\hline
\end{tabular}

Tabla 2.5. Distribución de la superficie de tierra vendida en cada término municipal de Sierra Madrona y Valle de Alcudia durante los procesos desamortizadores de Mendizábal y Espartero (18361845) y Madoz (1855-1924). Cabez/Hinos = se consideran conjuntamente los datos de Cabezarrubias del Puerto e Hinojosas de Calatrava dada la dificultad de separarlos en tanto que en los BOVBN suelen reflejarse en Puertollano, ciudad de la que hasta 1842-43 dependían.

Basado en datos de Ortiz Heras (1992), Del Valle $(1996,1997)$ y propios obtenidos del AHP para Brazatortas, Hinojosas de Calatrava y Guadalmez. Superficies municipales del Instituto Geográfico Nacional.

Las cifras de la Tabla 2.5 y la Fig. 2.20 hay que tomarlas con cautela por diversos motivos. Al no haberse independizado Cabezarrubias e Hinojosas de Puertollano hasta 1842 y 1843 la distribución de las fincas subastadas en Puertollano y esas 2 localidades deben ser separadas adecuadamente con un detallado estudio finca por finca para situarla correctamente en su actual término municipal. Por ejemplo, hemos examinado en los BOVBN 23 fincas en lo que antes fue la encomienda de Clavería, en el centro del Valle de Alcudia, registradas como pertenecientes a Puertollano, cuando desde 1943 deberían haberse consignado ya en los términos de Cabezarrubias e Hinojosas. Esto nos ha planteado inicialmente bastantes problemas de interpretación, como a Del Valle $(1996,1997)$ que entre los 2 grandes procesos desamortizadores cifra la venta de 24.161 ha en Puertollano, cuando su término solo tiene 22.674 ha. En Guadalmez, antes dependiente de Chillón, además de las 11 pequeñas fincas de la Iglesia que en total apenas superaban las 30 ha, se expropiaron las mayores fincas Dehesa de 
Guadalmes, en 1859, y Umbría del Abulagar, en 1884 (AHP Sección Hacienda. Legajos 45 y 46) que deben situarse ya en Guadalmez. Por otro lado los datos se hallan supravalorados con respecto al área de estudio en tanto que Chillón, Almadén, Almodóvar y Brazatortas poseen parte de su término municipal fuera del Valle de Alcudia. En cambio se hallan infrarrepresentados en tanto que faltan varios expedientes en los archivos. Ante la falta de estos expedientes resulta imposible obtener datos exactos. En cualquier caso los datos de la Tabla 2.5 y la Fig. 2.20, permiten ofrecer una idea muy aproximada del volumen de operaciones de ventas de esos años. En Sierra Madrona y Valle de Alcudia se debió vender un mínimo de 100.000 ha.

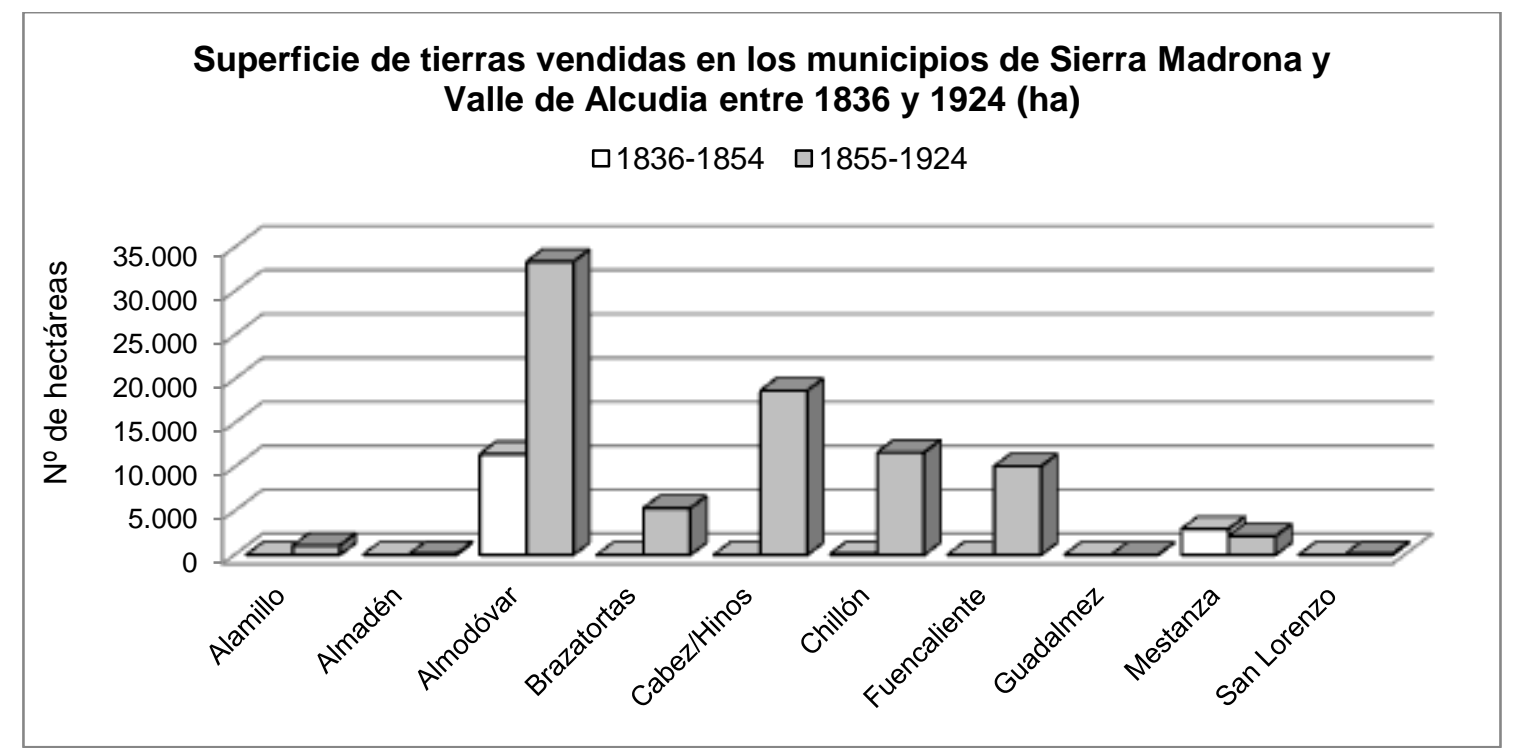

Fig. 2.20. Distribución de la superficie de tierras vendidas en los municipios de Sierra Madrona y Valle de Alcudia durante los procesos desamortizadores del siglo XIX. Basado en la tabla 2.5.

Sobre la distribución espacial de las tierras vendidas puede verse en la Fig. 2.20 como la mayor parte se vendió en Almodóvar del Campo (44.845 ha), entendible pues su término municipal ocupa el $44,7 \%$ de la comarca.

En nuestra revisión de archivos sobre las ventas en Sierra Madrona y Valle de Alcudia se han procurado descartar, cuando se identificaban correctamente, las fincas de Chillón, Almadén, Almodóvar y Brazatortas situadas fuera del Valle de Alcudia. Así, en total, tras varias revisiones se han seleccionado 314 fincas rústicas subastadas entre las que disponían de una adecuada información (descripción, tasación, subasta, remate y/o adjudicatario). En las Figs. 2.21 y 2.22 se han representado según fueron saliendo a subasta y rematadas a lo largo del siglo XIX. Poner una finca a la venta no significaba venderla, de hecho eran frecuentes las subastas consideradas nulas. Las fincas sin vender salían de nuevo a subasta, por eso la suma de las fincas subastadas en la Fig. 2.21 es de 336, un número superior al de las 314 fincas representadas. 


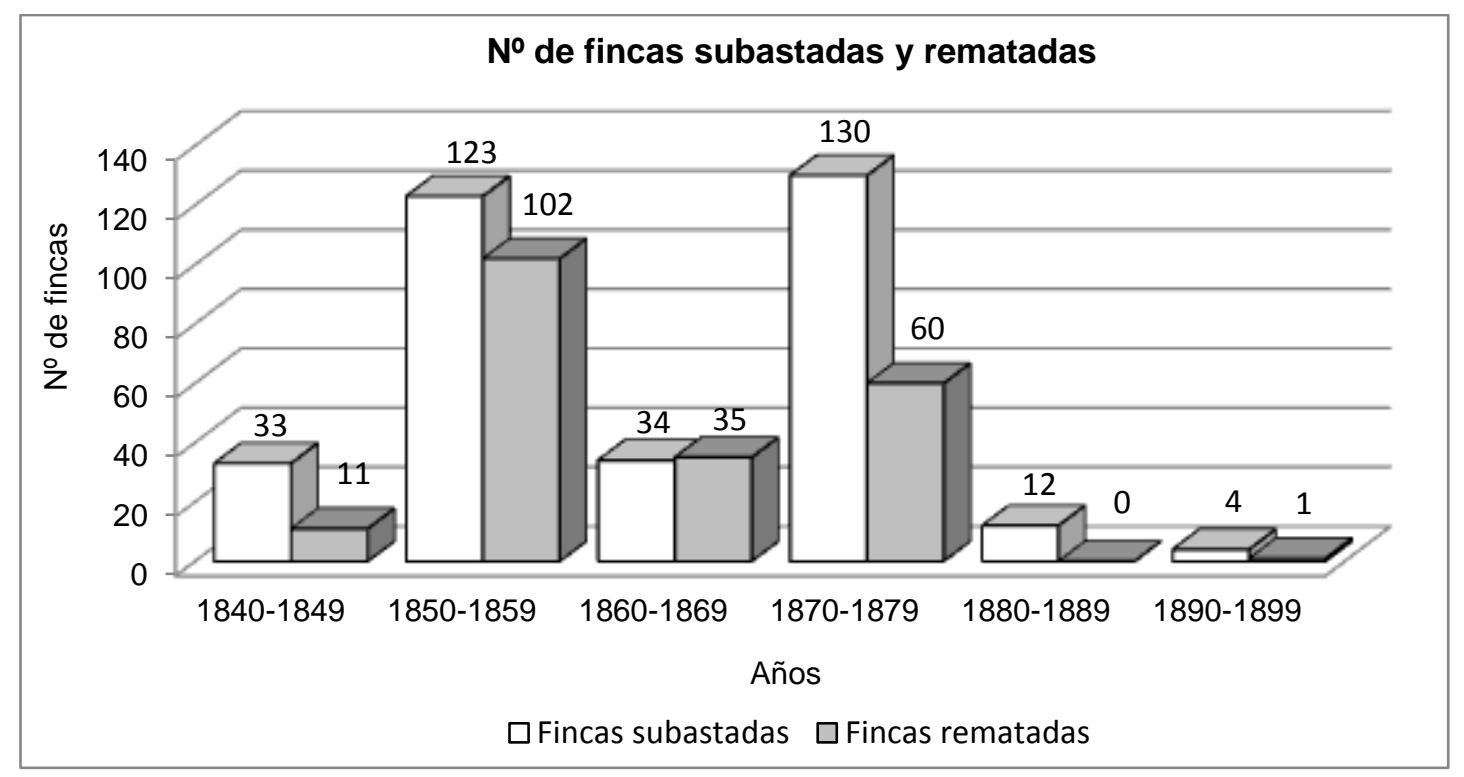

Fig. 2.21. Relación, desglosada por décadas, entre el número de fincas rústicas sacadas a subasta y número de fincas rematadas en Sierra Madrona y Valle de Alcudia en las desamortizaciones del siglo XIX.

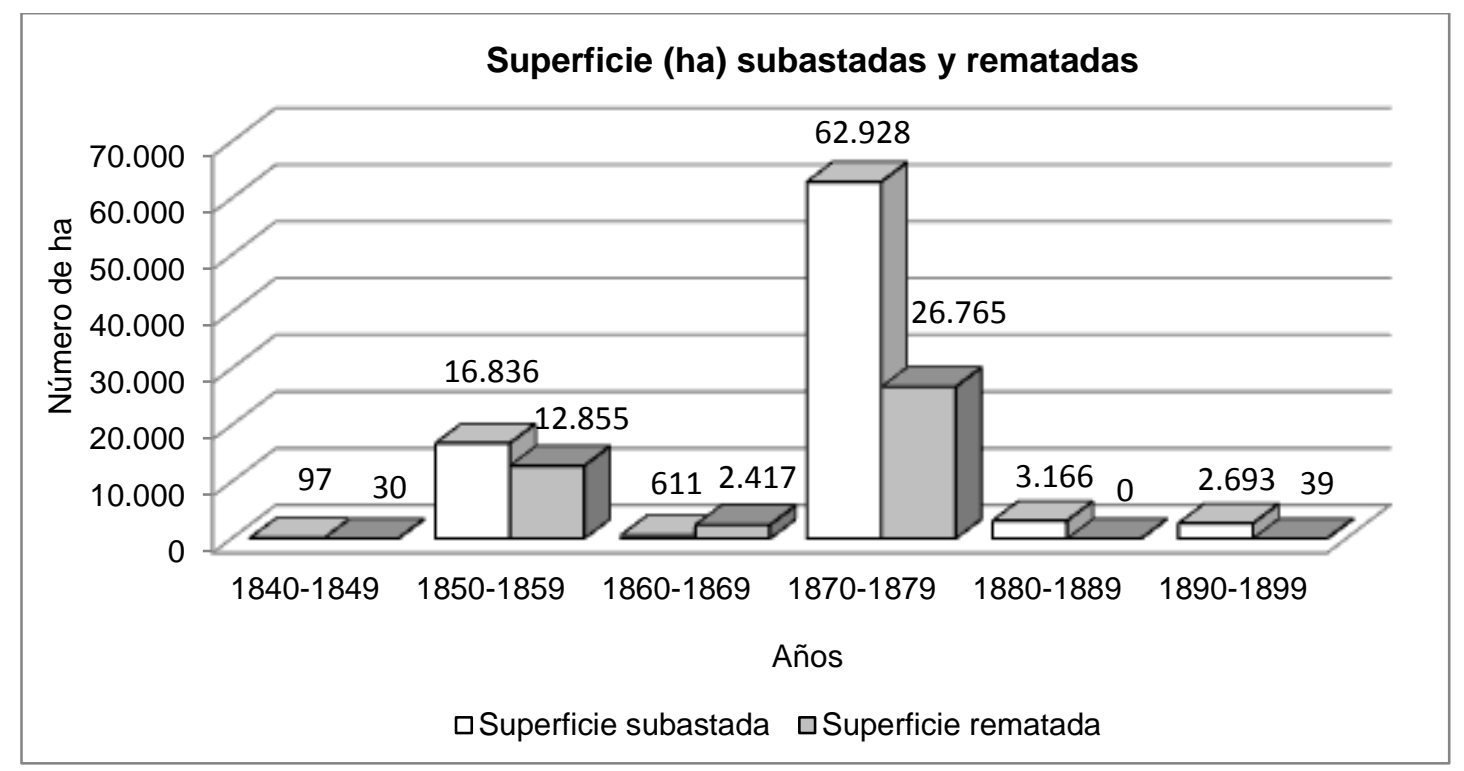

Fig. 2.22. Relación, desglosada por décadas, entre la superficie sacada a subasta y la rematada en Sierra Madrona y Valle de Alcudia durante las desamortizaciones del siglo XIX.

Las 33 fincas que salieron a la venta entre 1840 y 1849 sumaban 97 ha y solo se remató el $30,9 \%$. En parte puede explicarse porque en la desamortización de Mendizábal solo se subastaron propiedades de la iglesia. El temor a la excomunión de los compradores dificultó su venta a pesar de que eran eran huertos y otras parcelas de pequeño tamaño, muy apetecidas para los labradores locales, pero estos contaban con poco capital y el temor del poder de la Iglesia. En las 2 décadas siguientes el número de fincas y superficie subastada y vendidas fue superior, un 76,35\% adjudicado en 1850-59, y más especialmente en 1860-69, al estar incluido ya también el Valle de Alcudia y afianzado el régimen liberal. Pero fue en la década de 1870-1879 cuando se subastaron y remataron la mayor parte de las grandes fincas de la comarca. 
Las hectáreas vendidas bajo la Desamortización de Mendizábal afectaba a las órdenes religiosas, de baja implantación en la comarca. A partir 1841, y bajo la regencia de Espartero fueron los bienes del clero secular. La venta de conventos fue irrelevante, dada su escasez, tan solo se vendieron 2, ambos en 1843, el de las Carmelitas de Almodóvar (que acabó destinado como teatro) y el de los Franciscanos de Chillón (que termino en ruina, Fig. 2.23). Del Valle (1996) muestra como muchos de los 45 conventos suprimidos en la provincia fueron cerrados y, sin dedicación alguna, se deterioraron progresivamente. En 1840 la Junta de Enajenación de Conventos Suprimidos de Ciudad Real alarmaba sobre su deterioro (AHN, LAJBN, libro 3979). Antes se les habían requisado sus bienes artísticos y culturales: 16.118 libros, 750 pinturas y 45 esculturas (AHDCR, Leg. Conventos Suprimidos). El número de libros solo incluye los que se contabilizaron pues, en otros casos, solo aparecen las palabras "muchos libros". También se subastaron en 1837 las campanas de sus iglesias (BOPCR, $\mathrm{n}^{\circ}$ 11, 2-2-1837). En el BOPCR $\mathrm{n}^{\circ} 16$ (16-2-1837) aparece otra subasta del metal de las campanas. En 1840, se enajenaron retablos y maderas doradas a 2 reales y 17 maravedíes la arroba (BOPCR n 87, 1-10-40), la subasta se repitió en 1841 (BOPCR no 42, 20-5-41), los retablos se desmontaron en 1843. El inmenso patrimonio cultural e histórico artístico que había acumulado la iglesia con sus prerrogativas económicas durante siglos se perdió en gran parte. En cuanto a los edificios, algunos se destinaron a vivienda pero, la mayoría, se usaron como almacenes o demolidos para aprovechar sus materiales (Del Valle 1996).

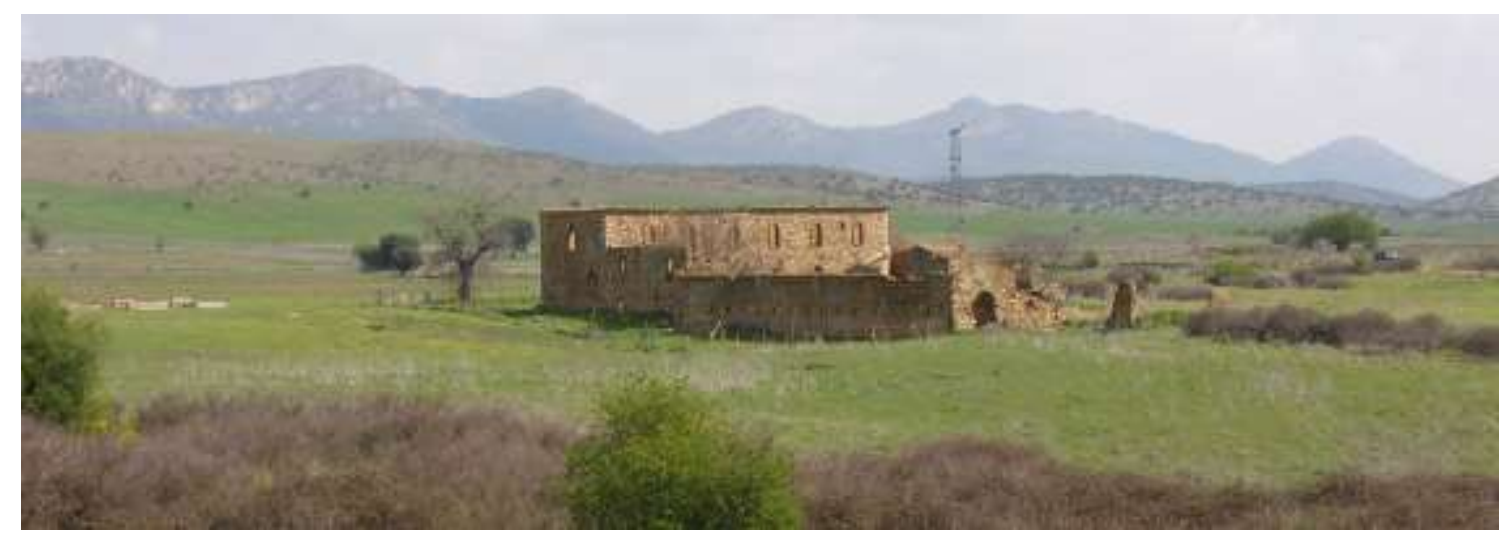

Fig. 2.23. Convento de los franciscanos, en Chillón. Tras la expulsión de los monjes el edificio con su contenido y anexos se vendió en 1843. Lejos de aprovecharse para usos productivos, se expoliaron sus bienes y el edificio acabó arruinándose.

Al relacionar el número de fincas vendidas con la superficie (Fig. 2.24) en las 310 fincas de la comarca analizadas, casi la mitad (147) son menores de una hectárea. En general se trataba de pequeñas parcelas de cultivo (hortícola, cereales, viñas, olivar) junto a los pueblos. El resto de fincas (163) tenían un tamaño mayor, de hasta 1300 ha, como la finca Mochuelos, en el Valle de Alcudia. La superficie media de las 310 fincas fue de 234 ha. 


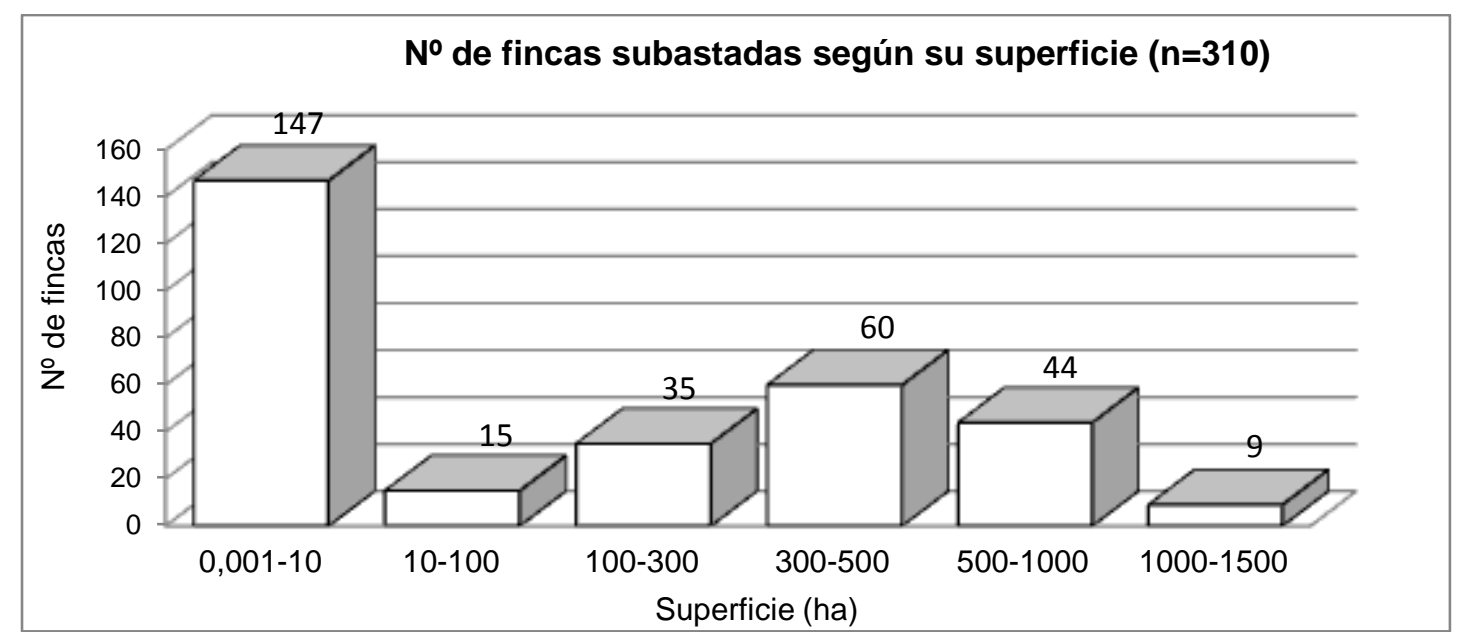

Fig. 2.24. Relación del número de fincas subastadas y la superficie de las mismas.

La propiedad de las fincas vendidas en Sierra Madrona y Valle de Alcudia durante los procesos desamortizadores del siglo XIX, se muestra en las Figs. 2.25 y 2.26.
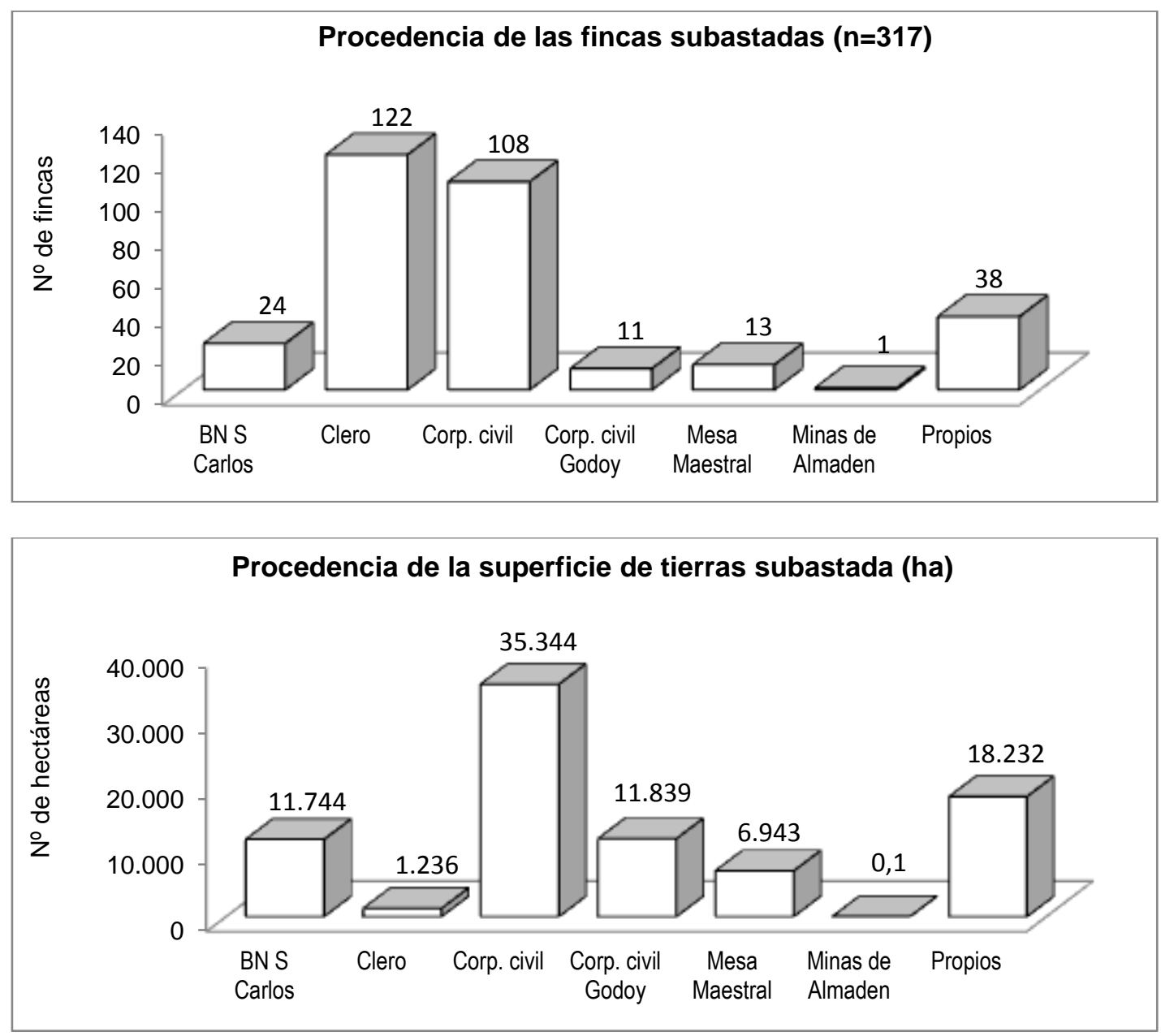

Figs. 2.25 y 2.26. Procedencia de las 317 fincas subastadas en Sierra Madrona y Valle de Alcudia sobre las que se ha encontrado su propietario antes de los procesos desamortizadores del siglo XIX. BNS Carlos = Bienes Nacionales procedentes del secuestro del infante D. Carlos; Corp. civil Godoy = Corporación civil procedente del secuestro de D. Manuel de Godoy. 
El clero era propietario del mayor número de fincas (122, un 38\%) sin embargo este patrimonio no era muy elevado pues todas sus fincas eran de pequeña superficie, en torno a pueblos y monasterios, generalmente dedicadas a huertos y otros cultivos agrícolas. Las grandes fincas (montes, dehesas y pastos) procedían de la Orden Militar de Calatrava (en los secuestros del infante D. Carlos y de Godoy, en corporaciones civiles y Mesa Maestral) y de los pueblos.

En las 309 fincas subastadas de las que se ha podido conocer su uso (Figs. 2.27 y 2.28) en Sierra Madrona y Valle de Alcudia, en un extremo se situaban las pequeñas fincas (157, un 50,8\%), la mayoría pertenecientes al clero $(77,7 \%)$ y de uso solo agrícola (parcelas de cereal, huertos y 2 pequeñas viñas), que representaban un 1,25\% del territorio (muy probablemente menos pues se incluye la finca Arroyo Azogado, de Chillón, de 270 ha, junto a la Dehesa Boyal que aunque en el informe de subasta indica labor, muy probablemente fuera dehesa o dehesa y labor). Por otro lado estaba el resto de fincas (162, un 49,2\%) de media y gran superficie que ocupaban el 98,75\% del territorio vendido. Los 4 montes tenían una media de 818,5 ha, los que eran monte y dehesa de 404,25 ha, los de monte y labor 297,8 ha. La superficie media de las más abundantes dehesas era de 477,6 ha, por 400 ha si era dehesa y labor.
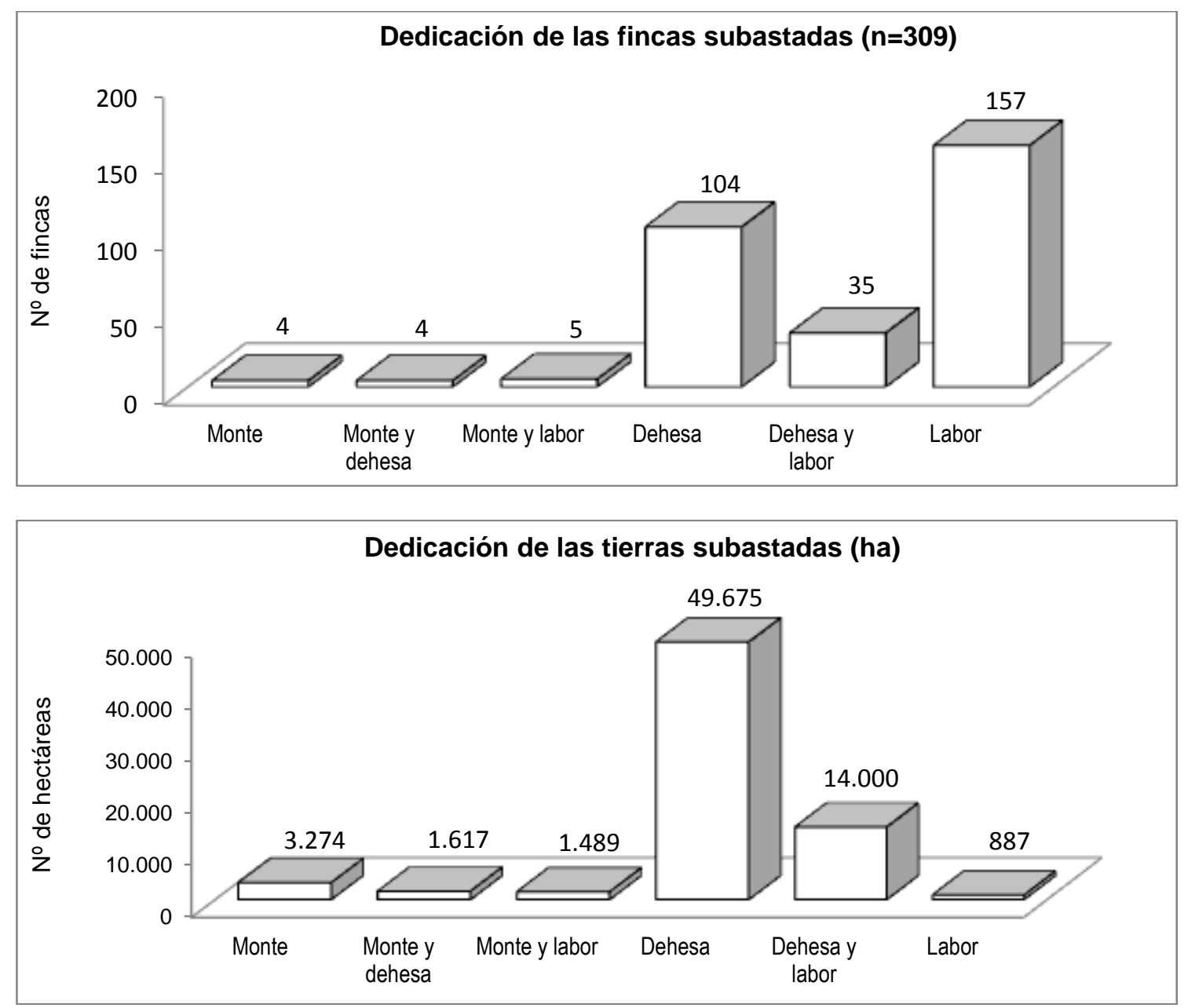

Figs. 2.27 y 2.28. Dedicación de las 309 fincas de Sierra Madrona y Valle de Alcudia al ser subastadas en los procesos desamortizadores del siglo XIX. Lo consignado en los BOVBNs como pequeños quintos, quiñones, cercados, labor y viñas, se han agrupado en "Labor". 
Una idea generalizada de los liberales era que dividiendo por lotes las grandes fincas serían de más fácil acceso a un mayor número de compradores y también la Hacienda Pública obtendría así mayores ingresos. Esta división por lotes de las grandes fincas fue una práctica habitual en el Valle de Alcudia (Fig. 2.29).

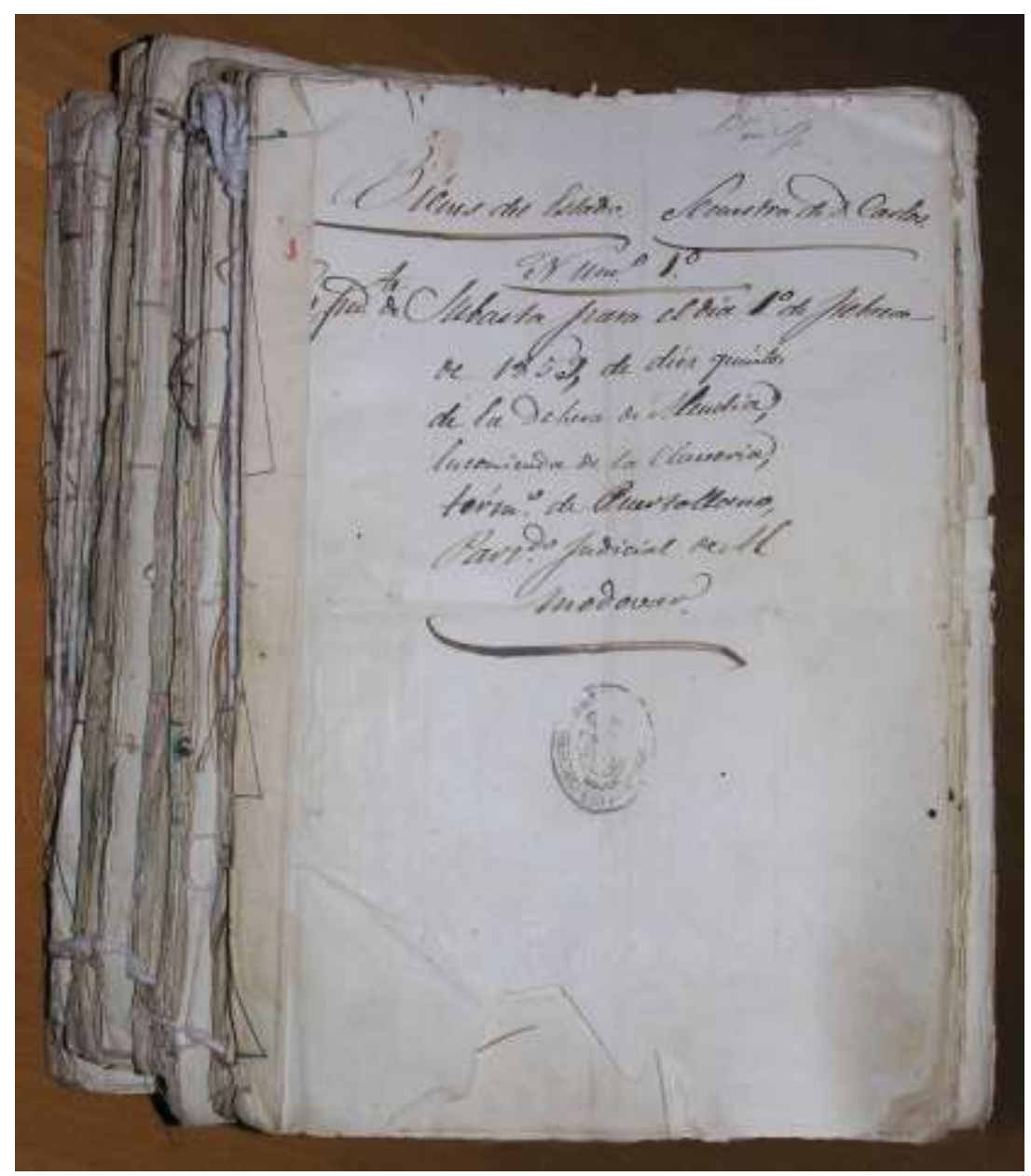

Fig. 2.29. Pliegos para la subasta de 10 Quintos de la Encomienda de la Clavería (denominada así por ser la que se asignaba al clavero de la Orden Militar de Calatrava). Situada en el centro del Valle de Alcudia, en el antiguo término municipal de Puertollano y, a partir de 1842-43, entre los términos ya independientes de Cabezarrubias del Puerto e Hinojosas de Calatrava.

La división por lotes perseguía facilitar las ventas, pero no necesariamente una mejor distribución de la propiedad. Aunque esta práctica facilitó el acceso a la propiedad de los vecinos de los pueblos, numerosos compradores adquirieron varios lotes con lo que muchas fincas mantuvieron su gran extensión. En el caso de la Dehesa de la Clavería que perteneció al infante Carlos, hermano de Fernando VII e incautada por los liberales con motivo de las guerras que llevan su nombre, se hicieron 23 lotes, con una media aprox. de 500 ha. cada uno y se subastaron en 1872. Estos lotes luego fueron reagrupados por los compradores en la medida de sus posibilidades. En este sentido Francisco Montoya adquirió 4 lotes, Manuel Sánchez de Sebastián y José Antonio Uzuarregui compraron cada uno 3 lotes, José María Orallo, Isidro Fernández y Manuel Cárdenal otros 2 lotes cada uno. Los 7 lotes restantes fueron adquiridos separadamente por otros tantos compradores. 
Fueron comunes los especuladores y testaferros que compraron fincas por toda la comarca (Del Valle 1996, 1997, 2010, 2015). Uno de los mayores compradores (Fig. 2.30) fue Manuel María del Valle, que compró 10 fincas de pastos y dehesas en el término de Almodóvar. De estas hemos encontrado los expedientes de 7, normalmente de entre 300 y 500 ha, con una superficie máxima en Hato de Garro, de 1200 ha. La suma de las superficies en estos 7 expedientes asciende a 3.500 ha, pero en el total de las 10 fincas adquiridas probablemente superase las 5.000 ha, lo que le sitúa entre los mayores compradores de toda Castilla-La Mancha.

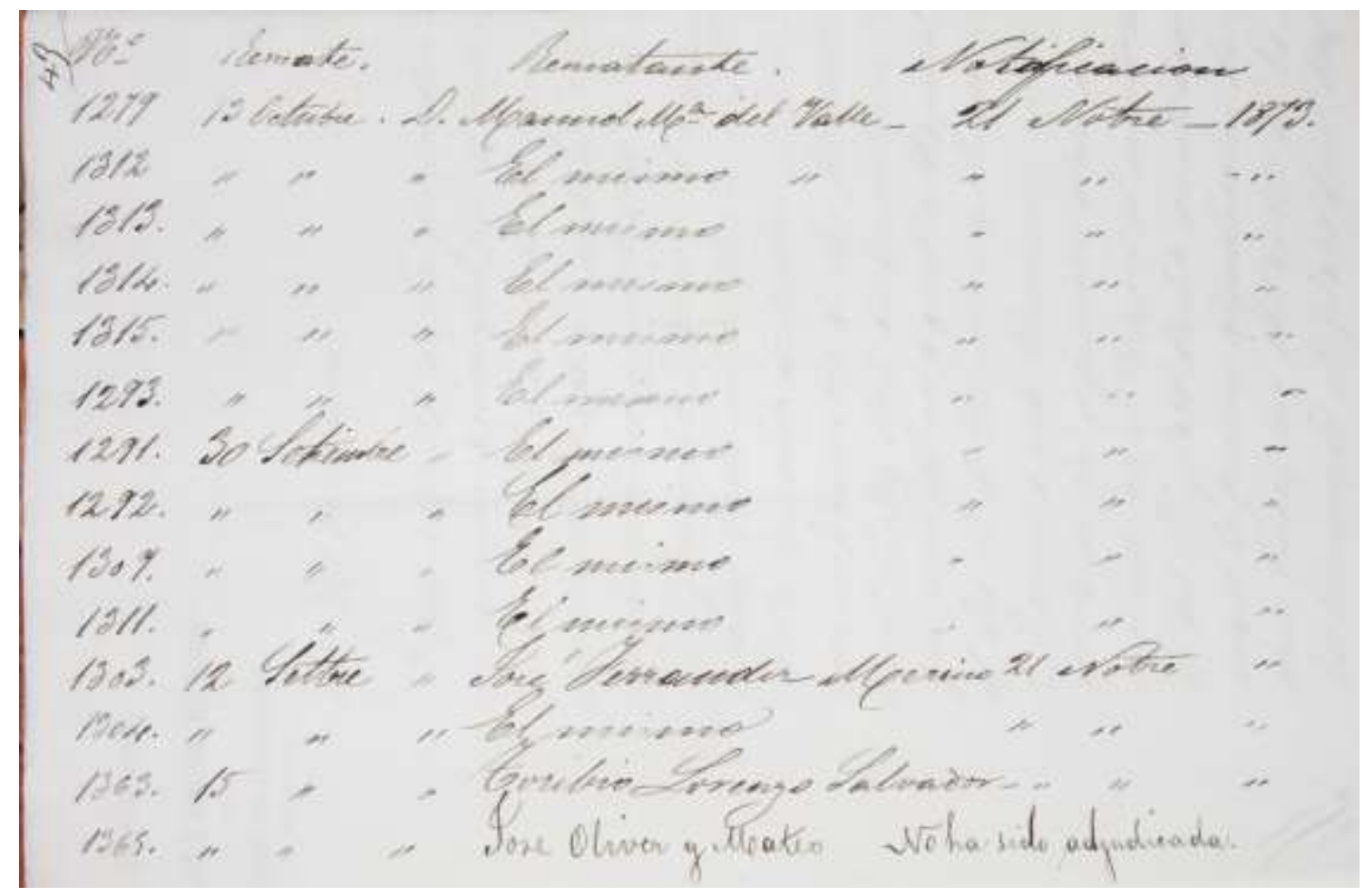

Fig. 2.30. La división por lotes de las grandes fincas no fue obstáculo para mantener el gran tamaño de algunas grandes fincas del Valle de Alcudia. En este manuscrito de ventas (AHP) puede verse como D. Manuel María del Valle adquiere, en 2 subastas, 10 lotes de tierra.

Un caso particularmente curioso es el de la familia Casado, que adquieren fincas en diferentes pueblos. Entre ellos aparecen 2 compradores con el nombre de Juan Casado (suponiendo que no sean la misma persona), entre ambos compraron 30 lotes, todos de pequeño tamaño (una media de 7 ha). Uno compró en Almadén (17 fincas, 99,1 ha), el otro en el extremo opuesto del Valle de Alcudia, en San Lorenzo de Calatrava (13 fincas, 115,3 ha). Es decir, similar número de fincas y similar número de ha. pero en los extremos opuestos del Valle. Las tierras eran de labor, por lo que podrían ser agricultores locales pero no lo parece, uno era de Ciudad Real y el otro de Calzada de Calatrava. Es probable que fueran agricultores, apoderados de los vecinos de los pueblos o simples especuladores, el caso es que, en estos y otros casos, a las subastas se presentaba un muy diverso elenco de personas e intereses. 
Otro caso destacable por traumático fue el de la Comunidad y Tierra de Segovia. El 4 de junio de 1761vendió a la Corona el monte Pinar y Matas de Valsaín y, con el dinero obtenido compró 7 millares de pastos en el Valle de Alcudia por 2.282.794 rs, aprovechando la desamortización de Carlos III de 1769-70 (Tabla 2.2), donde los ganaderos segovianos invernaban tradicionalmente $y$, por tanto, la ciudad, aunque se trataba de una tierra lejana, sabía bien lo que compraba. Los segovianos disfrutaron de estos 7 millares durante casi un siglo, hasta que fueron expropiados en la desamortización general de Madoz (como la mayor parte de fincas de los pueblos en España) y sacados a subasta. Se vendieron a particulares el 4 de abril de 1859 por 3.856.800 rs (Lecea y García 1894), lo que supuso un incremento sobre el precio de compra del 59,19\%, que ingresó Hacienda.

Una de las mayores compras del periodo desamortizador fue la protagonizada por la Sociedad Minero-Metalúrgica de Peñarroya (SMMP). Compró varias fincas en Sierra Madrona, en la zona de La Garganta, entre los términos municipales de Almodóvar y Brazatortas, que en total sumaban 14.000 ha (Quirós 1964). Por otro lado estaban las sociedades de compra, sin intereses por la explotación del terreno como la anterior. Destaca entre estas sociedades, por su gran volumen de compras, la "Sociedad Compradora de bienes baldíos de Almodóvar del Campo", constituida en 1885 y cuyos socios adquirieron 40.000 de las 52.000 ha que compraron estas sociedades en toda Castilla-La Mancha (Del Valle 2015). Pero no compró para repartirse las tierras entre los socios sino para revenderlas, lo que enriqueció a muchos de ellos (Agostini 1926), en un claro proceso especulativo.

Por poblaciones, entre las 188 fincas de las que conocemos al comprador, el mayor número de ha es adquirido por compradores de Madrid (Fig. 2.31).

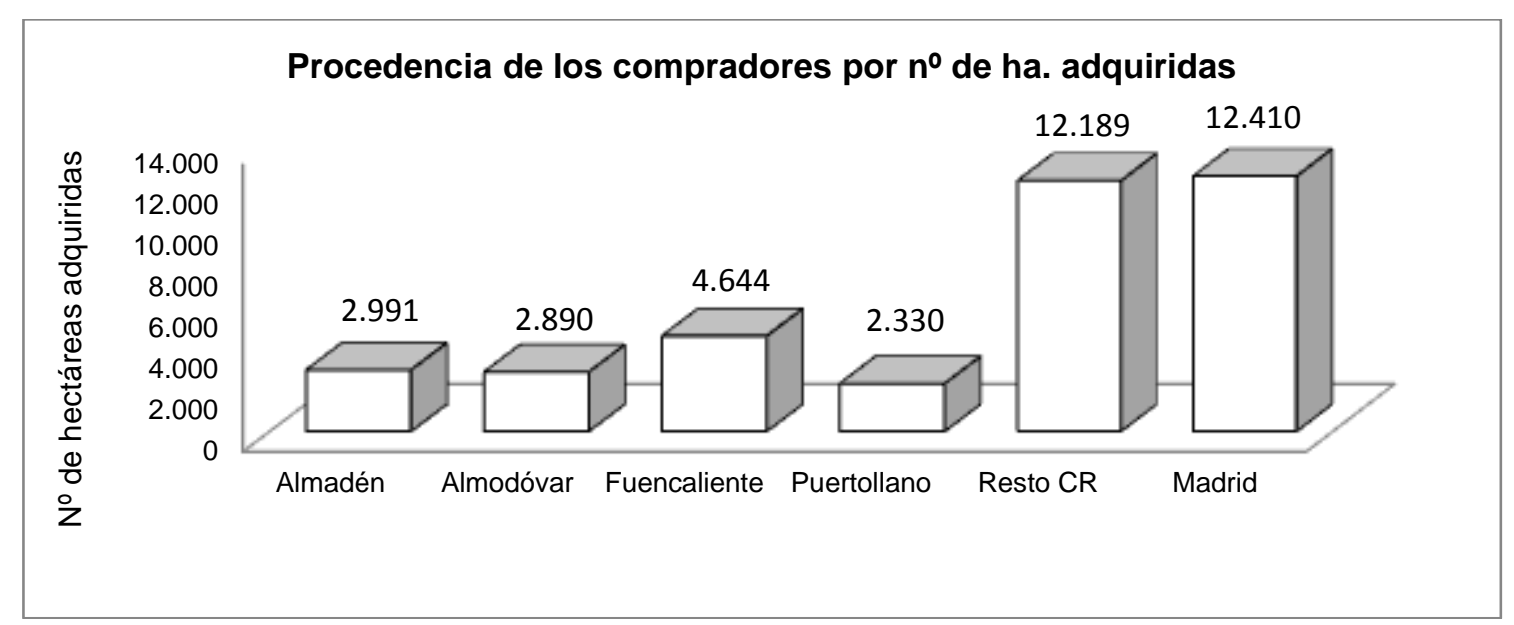

Fig. 2.31. Procedencia de los compradores de las 188 fincas de Sierra Madrona y Valle de Alcudia de las que se conoce comprador, durante los procesos desamortizadores del siglo XIX.

Un tercio de la superficie de las 188 fincas (Fig. 2.31) fue adquirida por compradores locales (Almadén, Almodóvar, Fuencaliente y Puertollano), principalmente fincas de pequeña y mediana extensión. Casi otro tercio es adquirido por compradores de otros pueblos de la 
provincia de Ciudad Real, incluyendo la capital, y casi el tercero restante lo adquirieron compradores de Madrid. Datos similares a los Del Valle (2015) para el conjunto de la provincia de Ciudad Real, donde el peso de la burguesía madrileña fue muy destacado. De algunos compradores no se conoce su origen, aunque fuera requisito obligatorio indicarlo en los informes de remate, por lo que no están incluidos en la Fig. 2.31.

El proceso de ventas de fincas se iniciaba, de acuerdo con los expedientes más completos existentes, con el inventario y posterior tasación. La tasación consistía por lo general en la visita de un perito a la finca para proceder a su delimitación y medición, levantamiento de plano, descripción de sus características físicas y de si estaba arrendada. Finalmente se tasaban sus bienes, en esencia edificios y arbolado, cuando lo tenían, el valor del arrendamiento y el de la superficie de la finca en sí misma.

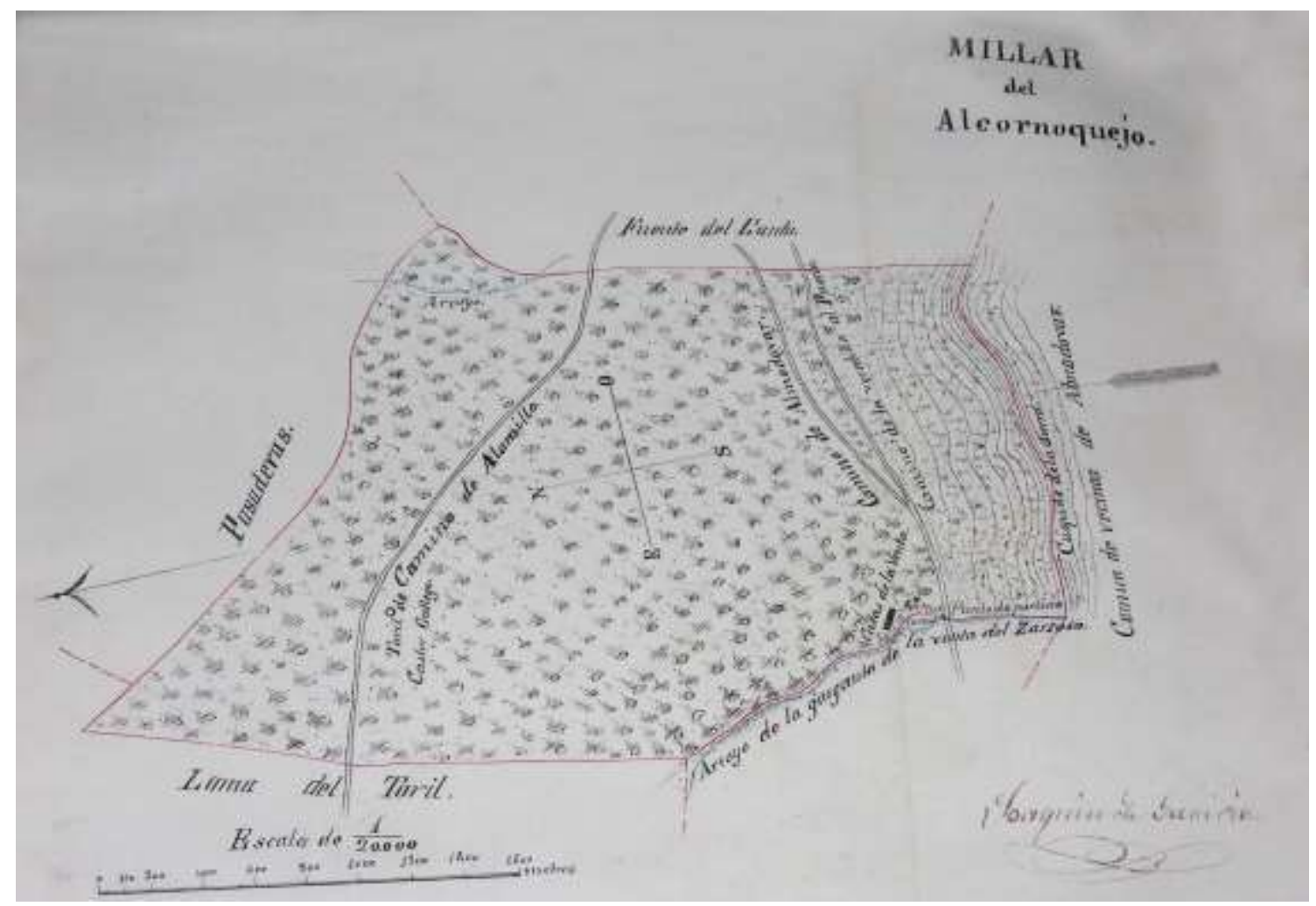

Fig. 2.32. Plano del informe de tasación de la dehesa Alcornoquejo (junto a la sierra de la umbría de Alcudia, Almodóvar del Campo), de 716 ha. Realizado por el ingeniero de montes Joaquín de Gaviria y en el que diferencia la localización del arbolado (10875 encinas y 75 robles) y el monte bajo.

Un plano acompañaba al informe de tasación de la dehesa Alcornoquejo, de 716 ha (Fig. 2.32). En el informe de tasación, además de la superficie, límites y otros datos, se especifica que tiene destinados a pastos de $1^{\text {a }}$ clase 200 ha, de $2^{\text {a }} 235$ ha y el resto cubierto de monte bajo. El arbolado se compone de 1400 encinas de $1^{\mathrm{a}}$ clase, 3025 de $2^{\mathrm{a}}$ y 6375 de $3^{\mathrm{a}}$. Además cuenta con 75 robles. Es curioso que a pesar de su nombre no cuente con alcornoques, en una zona en que son precisamente abundantes y probablemente más lo fueran en el pasado, lo que contribuye a confirmar el proceso general de eliminación de estos y otros árboles al tiempo que se favorecía a 
la encina. La densidad es de 24 encinas/ha si las situamos solo en las 435 ha de pastos. El 54\% de las encinas son de la calidad inferior, lo que refleja probablemente las severas podas a que fueron sometidas para favorecer su fructificación y/o abastecer de leña y madera a las minas de Almadén. Su tasación fue de 101.000 pts en venta y 4040 en renta, desglosado del siguiente modo: el valor del terreno era de 44.675 pts en venta y 1.787 en renta y, el arbolado, 56.325 pts en venta y 2.253 pts en renta. Lo más valioso de la finca es el arbolado que supera el valor del terreno. Es importante destacar pues que la finca sin árboles valdría menos de la mitad.

El valor del arrendamiento establecido para el Alcornoquejo era del 4\% del valor total de la finca. Lo normal en los informes de tasación, eran los precios del arriendo de las fincas en esos momentos que oscilaban entre el 4 y $6 \%$ del valor de la finca. Estos valores decidieron a los posesioneros a comprar, los que pudieron en las subastas y, los que no, posteriormente en las reventas de los especuladores.

Una vez emitido el informe de tasación este se publicaba en el BOVBN de la provincia (Fig. 2.33). Los informes de tasación a veces contenían notables errores, puede que intencionados dada la desigualdad de unos informes a otros y los intereses económicos puestos en juego, o bien eran cometidos al trascribirlos al BOVBN El caso es que fueron comunes las subsanaciones en los BOVBNs. A veces no se trataba de errores sino que al quedar una subasta desierta volvían a reajustarse algunas características de la finca y, el precio de salida, se bajaba un $15 \%$. La subsanación de errores, o cambios interesados, eran frecuentes en las subastas de fincas en el Valle de Alcudia (Fig. 2.34).

La subsanación de errores complica aún más si cabe el seguimiento actual de los expedientes de compra-venta al quedar numerosas subastas desiertas y tener que realizarse nuevas subastas con nuevos precios. Aunque finalmente todo se vendió, esto permite entender mejor los desfases entre tierras subastadas y rematadas de las figuras 2.21 y 2.22 ).

Sobre las 298 fincas de las que se ha dispuesto mejor información, casi la mitad contaban con arbolado pero, al considerar el número de ha con arbolado resulta que el $72 \%$ del territorio estaba más o menos arbolado (Fig. 2.35). Teniendo en cuenta que algunos informes de tasación no indicaron si la finca tenía o no arbolado, es posible que el porcentaje de superficie con arbolado fuera mayor. 


\section{B0LETII}

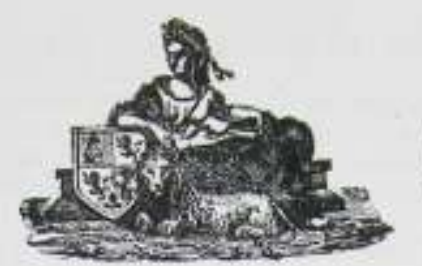

\section{DE

DE LA PROVINCIA DE CIUDAD-REAL.

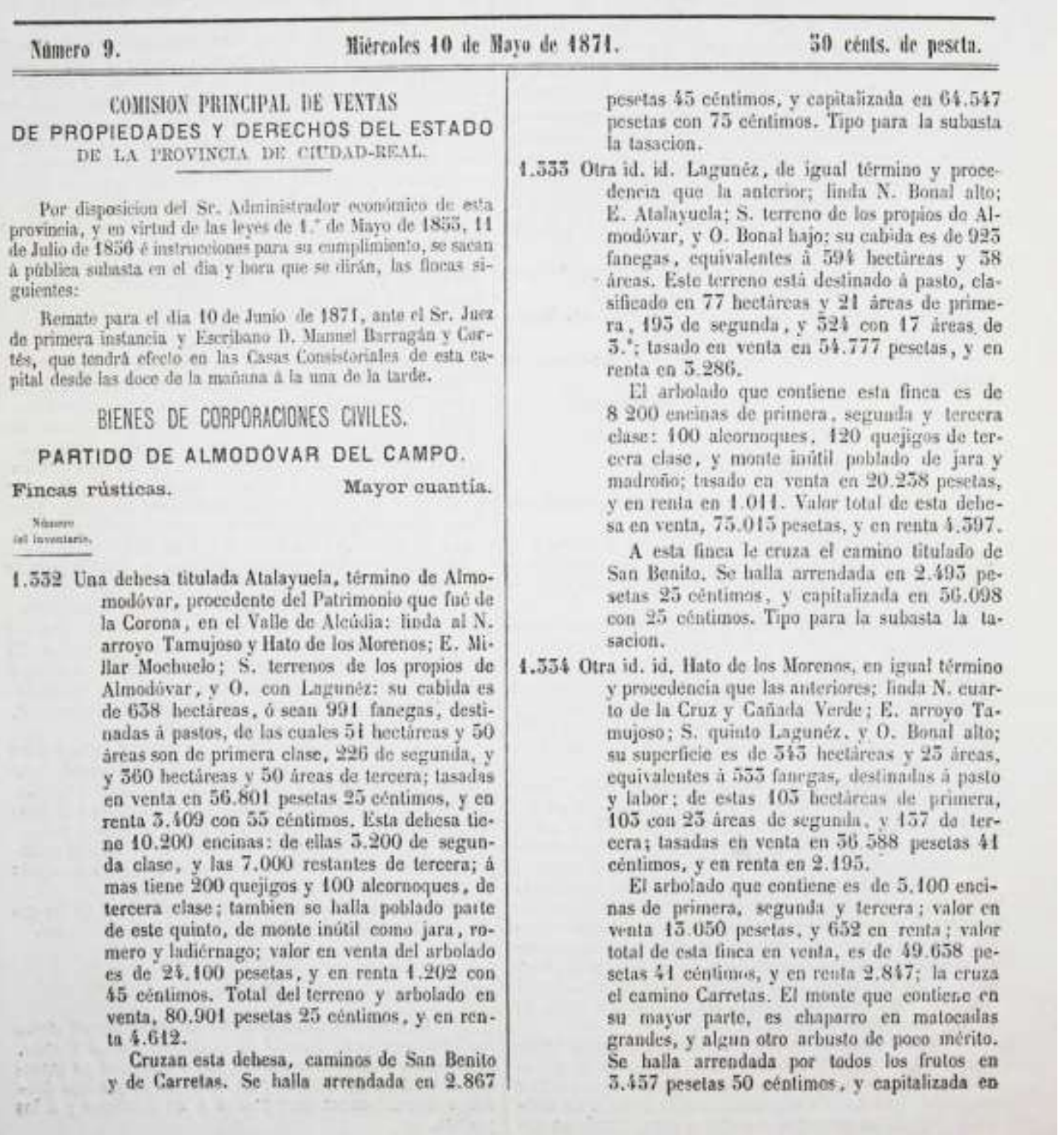

Fig. 2.33. BOVBN en el que se publica la subasta de las dehesas Atalayuela, Lagunez y Hato de los Morenos, en el Valle de Alcudia. Los desgloses carecen de uniformidad en las diferentes fincas en el caso el arbolado, por ejemplo, unos lo desglosaban en $1^{\mathrm{a}}, 2^{\mathrm{a}}$ y $3^{\mathrm{a}}$ clase y otros no. 


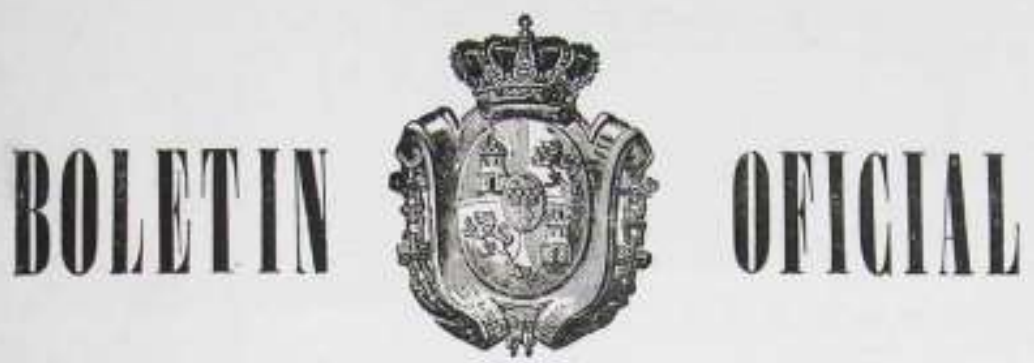

\section{DE VENTAS DE BIENES NACIONALES}

\section{DE LA PROVINCIA DE CIUDAD-REAL.}

COMISION E INVESTIGACION DE BIENES NACIONALES

DE LA PRONINCLA DE CIUDAD-REAL.

\section{ANUTCIO.}

El tipo de la subasta de la finca rústica, núm. 1.268, dehesa denominada Puerto-Suelta, del Valle de la Alcudia, procedente del Patrimonio que fue de la Corona, en término de Brazatortas, que ha de tener lugar el dia 2 de $A$ bril del presente año segun el anuncio en el Boletin Oficial de Ventas de esta provincia, numero 103 , del Juéves 22 de Febrero úlimo, que equivocadamente aparece de 36,450 pesetas de la tasacion, es el de $40.200 \mathrm{pe}$ setas.

La tasacion de la finca núm. 1.272, dehesa llamada Las Trecientas, en el mismo Valle, procedencia y término, y anunciada para su venta en el mismo Boletin que queda referido, se halla tambien equivocada en la cantidad de 36.600 pesetas y es la de 33.600 pesetas, que se figuran para el tipo de la subasta.

El tipo de la subasta, que ha de verificarse el dia 3 del mismo mes y año citados anteriormente, segun el Boletin Ofieial de Ventas, nûm. 104, del Viérnes 23 del mismo mes de Febrero, de la finca número 1.276 , dehesa titulada Llanillos, se halla equivocada, pues aparece con la cantidad de 49.575 pesetas, $\mathrm{y}$ es la de 43.575 .

La tasacion de la finca núm. 1.290, dehesa denominada Los Cuartillos o Cerro del Espino, de la misma procedencia, sitio $y$ termino referido, y anunciada su venta para el mismo dia 3 de Abril, en el mismo Boletin, se halla tambien equivocada; pues aparece en la cantidad de 191.400 pesetas, y es la 101,400 pesetas. Los nums. 1.213, 1.214 y 1.215 , de las fincas deminadas Carrasquilla, Barranquillos y Cobatillas, anunciadas sus ventas en el Boletin Oficial de Ventas de esta provincia, núm. 105, del Mártes 27 de Febrero altimo, para el dia 6 de Abril de este año, se hallan equivocados; pues son 1.313, 1.314 y 1.315 respectivamente los que tienen en el inventario de su procedencia.

Todo lo que se anuncia por medio del presente, con el fin de que llegue í conocimiento de los licitadores que hayan de tomar parte en dichas subastas, y no aleguen ignorancia.

Ciudad-Real 7 de Marzo de 1877.-El Comisionado é Investigador, P. S., Rafael $\boldsymbol{R}$. de Valenzuela.

Inp. de Kamon Clemente Rabigco.

Fig 2.34. BOVN en el que la Comisión de investigación de bienes nacionales de la provincia de Ciudad Real publica la subsanación de toda una serie de errores en tasaciones y publicaciones de anuncios de subastas de fincas en el Valle de Alcudia. 

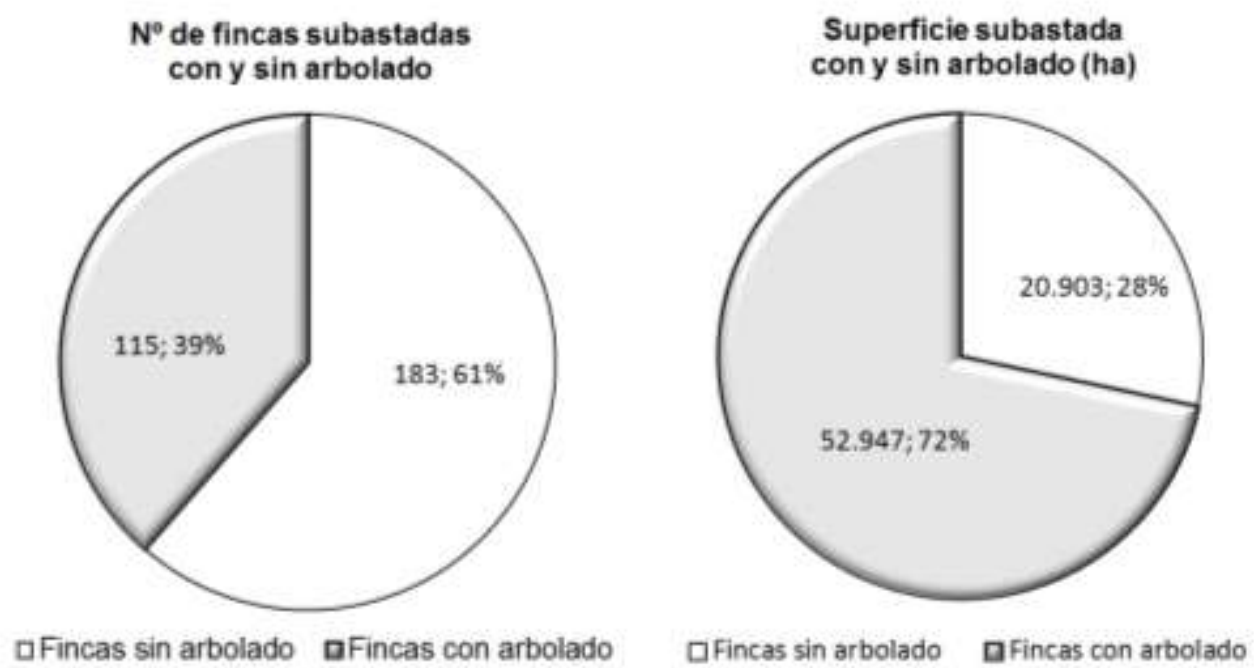

Fig. 2.35. Distribución del $\mathrm{n}^{\circ}$ de fincas y superficie del territorio con arbolado en los informes de tasación para las subastas de tierras en Sierra Madrona y Valle de Alcudia durante los procesos desamortizadores del siglo XIX. Basado en las 298 fincas encontradas en el AHP que contaban con esta información.
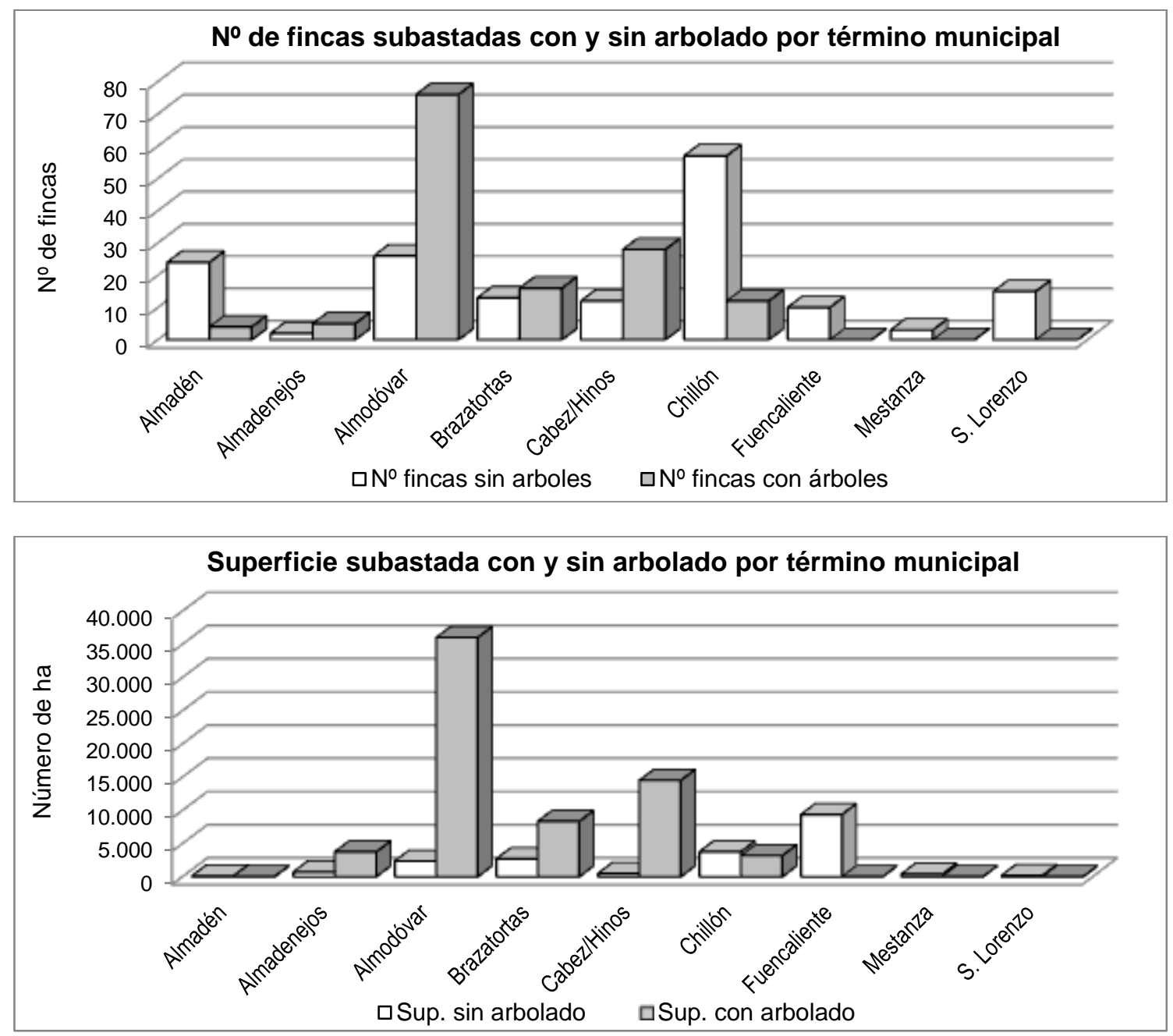

Fig. 2.36 (arriba) distribución del $\mathrm{n}^{\circ}$ de fincas y, Fig. 2.37 (abajo) de hectáreas, con y sin arbolado en los informes de tasación de las subastas de tierras en Sierra Madrona y Valle de Alcudia durante los procesos desamortizadores del siglo XIX. 
Tanto por número de fincas como por superficie, el arbolado caracterizaba el término de Almodóvar del Campo (Figs. 2.36 y 2.37). El mayor número de fincas desarboladas con respecto a las arboladas se sitúa en los extremos occidental y oriental del Valle de Alcudia, en los municipios de Almadén, Chillón y San Lorenzo, pero se debe a que eran fincas agrícolas de escasa extensión. Por el contrario, en Fuencaliente se vendieron 4 grandes montes de unas 1200 ha cada uno, todos de matorral (jara, labiernago, madroña y brezo) sin arbolado, por lo que no fueron exceptuadas. Son los clásicos "eriales a pastos" resultado de su quema reiterada hasta el agotamiento de las cepas de Quercus. Fueron la Loma de Villanueva, el Quinto del Arroyo de la Sierra o Puentecillas, el Quinto Cubillo y Navezuelos (las 2 últimas en la Dehesa de la Raña). De las especies de árboles que se citan en los informes de subasta destaca la encina ( $Q$. ilex) (Fig. 2.38) con el 95,6\% de los pies, seguida del rebollo con el 4,3\%, especie la más dificil de erradicar por su potente rebrote de raíz. Las cifras testimoniales, o inexistentes, de los otros Quercus en solo 2 de los 6 términos municipales representados (Fig. 2.39), son el reflejo de la escasez de alcornoques (probablemente por su tala y descepe, pues resisten bien a los incendios) y de que la mayor parte de los quejigares y robledales no fueron subastados.

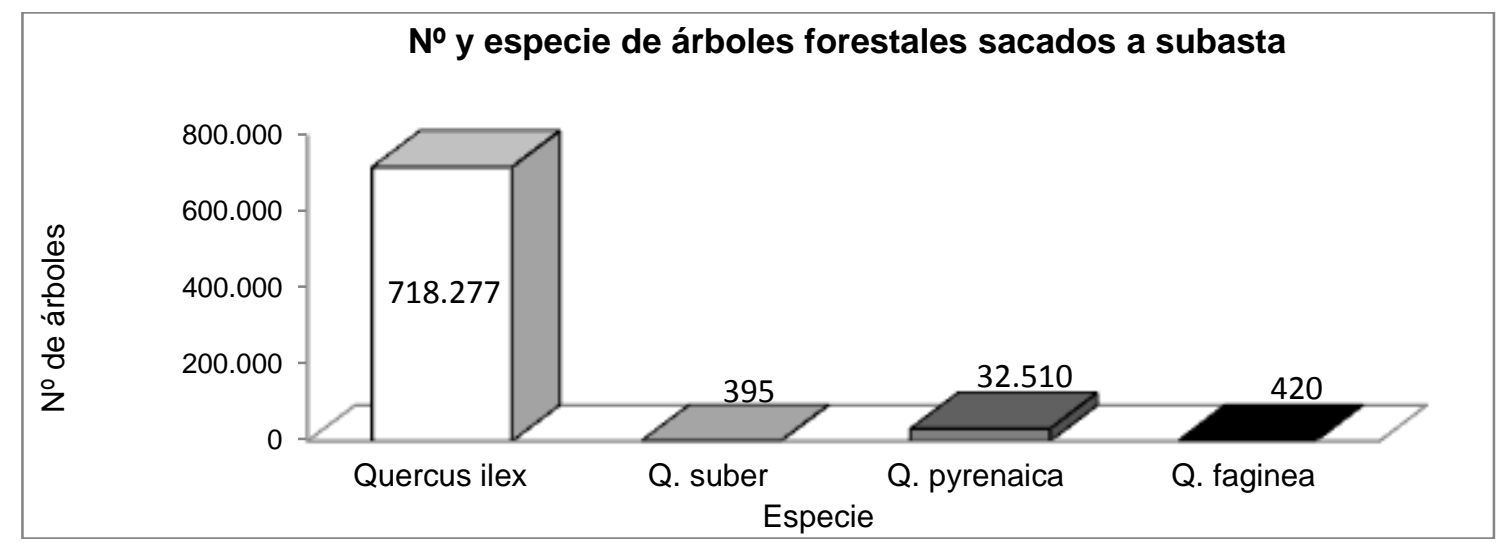

Fig. 2.38. Número de árboles por especie citados en los informes de tasación para las subastas de tierras en Srra. Madrona y Valle de Alcudia en los procesos desamortizadores del siglo XIX.

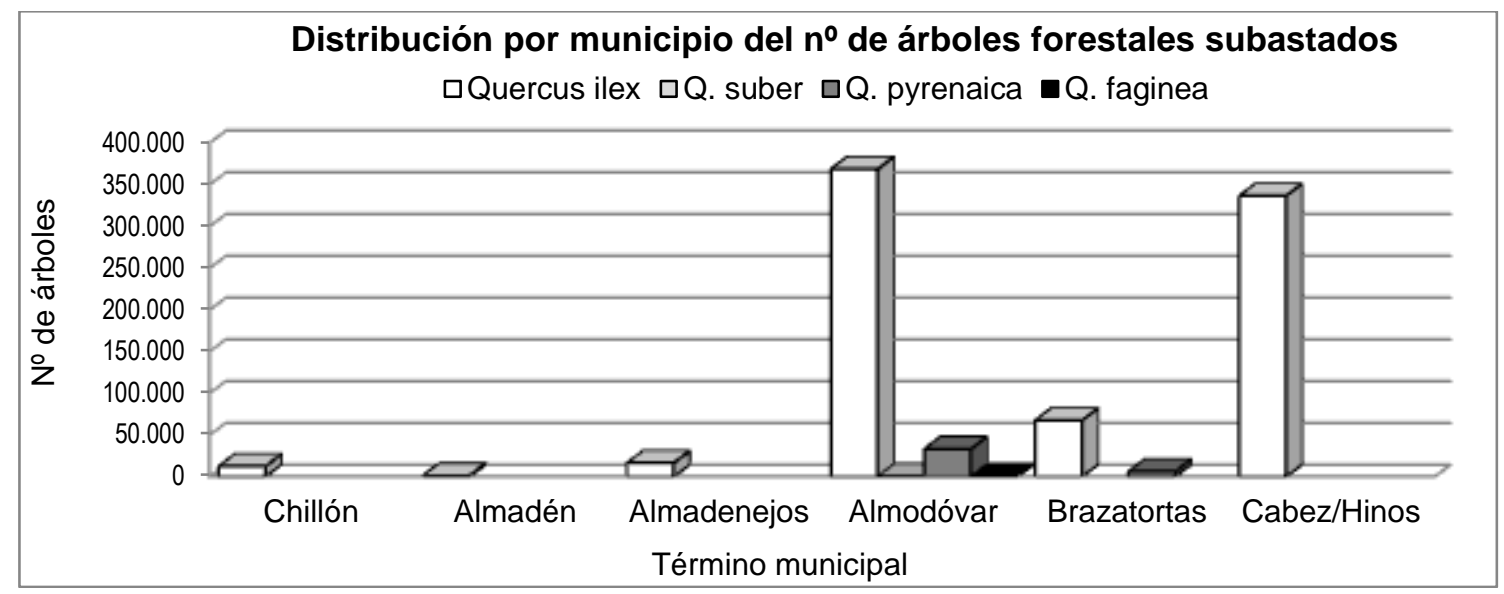

Fig. 2.39. Distribución por términos municipales de las especies de árboles citados en los informes de tasación para las subastas de tierras en Sierra Madrona y Valle de Alcudia durante los procesos desamortizadores del siglo XIX. Se indica el $\mathrm{n}^{\circ}$ de encinas por municipio. 
Tras más de 300 años de intensa minería, a un ritmo aproximado de extracción de 29.000 $\mathrm{m}^{3}$ /año, y el lento crecimiento de los robles en suelos degradados, la comarca mantuvo un mínimo de 718.277 encinas. Pero como en diversos expedientes o informes de tasación no se especifican el arbolado (e.g. las 23 fincas de 500 ha de media de la Encomienda de Clavería) y el que no todas las fincas salieron a subasta (como los 7 millares de la dehesa de Castilseras, en Almadén) permiten afirmar que a mediados del siglo XIX la encina tendría más de 1 millón de pies en la comarca. Como las 115 fincas conocidas con arbolado poseen una extensión de 52.947 ha (Fig. 2.35) con 718.277 encinas, suponía una densidad media de 13,6 encinas/ha.

Los 32.510 robles (Fig. 2.38) de los montes enajenados eran solo una mínima fracción de los existentes pues la gran mayoría de los pies quedaron en los robledales (de melojo y quejigo) no enajenables. El $n^{\circ}$ de pies en estos últimos robledales no figura pues en los informes de tasación $\mathrm{y}$, por tanto, no pueden ser contabilizados, pero si se puede saber la superficie que ocupaban los robledales en la comarca a mediados del siglo XIX, unas 40.000 ha (Tabla 2.6).

\begin{tabular}{|l|l|l|r|r|}
\hline \multicolumn{3}{|c|}{ Robledal en Sierra Madrona y Valle de Alcudia a mediados del siglo XIX } \\
\hline Nombre del monte & Localidad & Especie & \multicolumn{2}{|c|}{ Año } \\
\cline { 4 - 5 } & & $\mathbf{1 . 8 5 9}$ & $\mathbf{1 . 9 6 2}$ \\
\hline Ribera Alta & Almadén & Roble & 26,59 & No datos \\
\hline $\begin{array}{l}\text { Primera demarcación al Sur } \\
\text { de la Sierra de Alcudia }\end{array}$ & Almodóvar del Campo & Roble & $6.547,76$ & $6.548,00$ \\
\hline Segunda demarcación & Almodóvar del Campo & Roble & $6.764,77$ & $6.765,00$ \\
\hline Cuarta demarcación & Almodóvar del Campo & Roble & $3.820,60$ & $3.821,00$ \\
\hline Navamanzano & Fuencaliente & Roble & 128,79 & 129,00 \\
\hline Valle & Fuencaliente & Roble & 32,20 & No datos \\
\hline Nava del Horno & Fuencaliente & Roble & $4.078,18$ & $4.078,00$ \\
\hline $\begin{array}{l}\text { Cereceda, Dehesa y Peña } \\
\text { Escrita }\end{array}$ & Fuencaliente & Roble & 429,52 & 430,00 \\
\hline $\begin{array}{l}\text { Robledo de las Hoyas } \\
\text { Peña Rodrigo yodillo }\end{array}$ & Fuencaliente & Roble & $1.287,91$ & $1.288,00$ \\
\hline Valle del Robledilo & Mestanza & Roble & $1.931,87$ & $1.933,00$ \\
\hline Valle de la Torrecilla & Mestanza & Roble & $1.609,89$ & $1.610,00$ \\
\hline Sierra Alta & San Lorenzo de Ctva. & Roble & $1.931,87$ & $1.932,00$ \\
\hline Sierra de las Huertas & San Lorenzo de Ctva. & Roble & $2.253,85$ & $2.254,00$ \\
\hline Sierra Madrona & Solana del Pino & Roble & $1.390,95$ & $1.390,95$ \\
\hline Sierra Morena & Solana del Pino & Roble & 695,57 & 695,57 \\
\hline Total ha montes de roble $($ Quercus pyrenaica $)$ & & $\mathbf{3 2 . 9 3 0 , 3 2}$ & $\mathbf{3 2 . 8 7 4 , 5}$ \\
\hline $\begin{array}{l}\text { Sexta demarcación de } \\
\text { Sierras de Alcudia al Norte }\end{array}$ & Almodóvar del Campo & Quejigo & $1.933,17$ & $1.933,00$ \\
\hline Sexta demarcación & Almodóvar del Campo & Quejigo & $2.038,13$ & $2.038,00$ \\
\hline Umbría de Ventilla & Fuencaliente & Quejigo & 309,74 & 310,00 \\
\hline Arroyo del Azor & Fuencaliente & Quejigo & 314,89 & 315,00 \\
\hline Umbría del Montero & Hinojosas & Quejigo & 257,58 & 258,00 \\
\hline Valle de Chipon & Mestanza & Quejigo & $1.287,91$ & $1.288,00$ \\
\hline Valle de la Peña & Mestanza & $\mathbf{6 . 7 8 5 , 3 8}$ & $\mathbf{6 . 7 8 6 , 0 0}$ \\
\hline Total ha montes de quejigo $(\boldsymbol{Q}$. faginea $)$ & $\mathbf{3 9 . 7 1 5 , 7 0}$ & $\mathbf{3 9 . 6 6 0 , 5 2}$ \\
\hline Total superficie ocupada por robledales & & & & \\
\hline
\end{tabular}

Tabla 2.6. Superficie aproximada de robledales en Sierra Madrona y Valle de Alcudia a mediados del siglo XIX según la Clasificación general de los montes públicos (CGMP) de 1959 y al Catálogo de montes públicos exceptuados de la desamortización (CMPED) de 1862. 
Los pastos de vuelo (el arbolado, generalmente de encina, que producía ramón y bellota para el ganado) podía suponer mayor valor que los pastos de suelo (las hierbas o yerbas como suelen citarse en documentos históricos). La abundancia y calidad de los pastos de vuelo era posible por el especial interés desde el medievo en conservar la encina frente a otras especies arbóreas. La encina era el mejor complemento por los famosos pastos de suelo del Valle de Alcudia. Esto motivó siempre un celo especial por el predominio de la encina, aunque con muy baja densidad. Es decir, el valor del arbolado, además de ecológico (con todo lo que esto conlleva hacia clima, suelos y biodiversidad) tuvo un valor económico, que explica que tras más de 300 años de explotación minera, aún siguieran quedando más de un millón de encinas en el Valle de Alcudia a mediados del siglo XIX. Esto a su vez induce a pensar que, aunque con las debidas precauciones, la minería no arrasaba con el arbolado, solo talaba y podaba algunos árboles (varios millones en su larga historia en la comarca) pero, por norma, no debía cortar a matarrasa. Para comprobarlo solo basta con ver las numerosas encinas centenarias que aún persisten en Almadén y términos municipales de su entorno inmediato.

Para determinar el peso de la encina en el Valle de Alcudia se ha recurrido a los informes de tasación. Con el número de encinas de la finca y su precio se deduce el valor de cada encina, así como el precio por calidades de $1^{\mathrm{a}}$, de $2^{\mathrm{a}}$ y de $3^{\mathrm{a}}$. También se puede obtener el precio de arrendamiento que tenía cada encina. El número de informes de tasación encontrados que especifican la calidad de la encina es de 64 (Fig. 2.40). Sin embargo lo normal es que después de especificar las cantidades de encinas pertenecientes a las 3 diferentes clases de calidad luego las valoren conjuntamente. Solo en 3 de los informes se especifica el precio de cada calidad, siendo de 4 pts el valor de una encina de $1^{\mathrm{a}}$, entre 1 y 2,5 pts el precio de la encina de $2^{\mathrm{a}} \mathrm{y}$, de 1 pta el precio de la encina de $3^{\text {a }}$. La calidad de los robles también se especifica, aunque no el precio según sus diferentes calidades.

Aunque solo se disponen de datos de aproximadamente 1/3 de las encinas (Fig. 2.40) presentes en el Valle de Alcudia a mediados del siglo XIX, estos aproximan a un estado del encinar en esos años poco satisfactorio. De estas 301.567 encinas solo el $11,7 \%$ eran de $1^{\text {a }}$ calidad, el $27,2 \%$ de $2^{\text {a }}$ calidad y el restante $61,1 \%$ de $3^{\text {a }}$ calidad, lo que en parte reflejaría las severas podas recibidas y la creciente pobreza de los suelos para sustentar un arbolado de calidad en la especie más rústica de todos los Quercus. La importancia económica que tenía el pasto herbáceo para los posesioneros, no impidió que las múltiples talas y podas desde tiempos históricos, de mayor valor económico puntual y necesarias para el funcionamiento de las minas fueran incompatibles con el mantenimiento de los suelos forestales que tuvieron al principio. Además el incremento de la superficie del pasto era el interés que primaba en el ganadero, a lo que se sumaba la imposibilidad del regenerado debido al omnipresente pastoreo, explicarían que la mayoría de las encinas fueran calificadas como de $3^{\mathrm{a}}$ calidad. En los robles, los mayores porcentajes de la $1^{\mathrm{a}}$ $(27,4 \%)$ se debe a su menor número, apenas 0,3 por hectárea, lo que implicaba localizaciones en lugares marginales y/o que fueran respetados desde tiempos antiguos. 

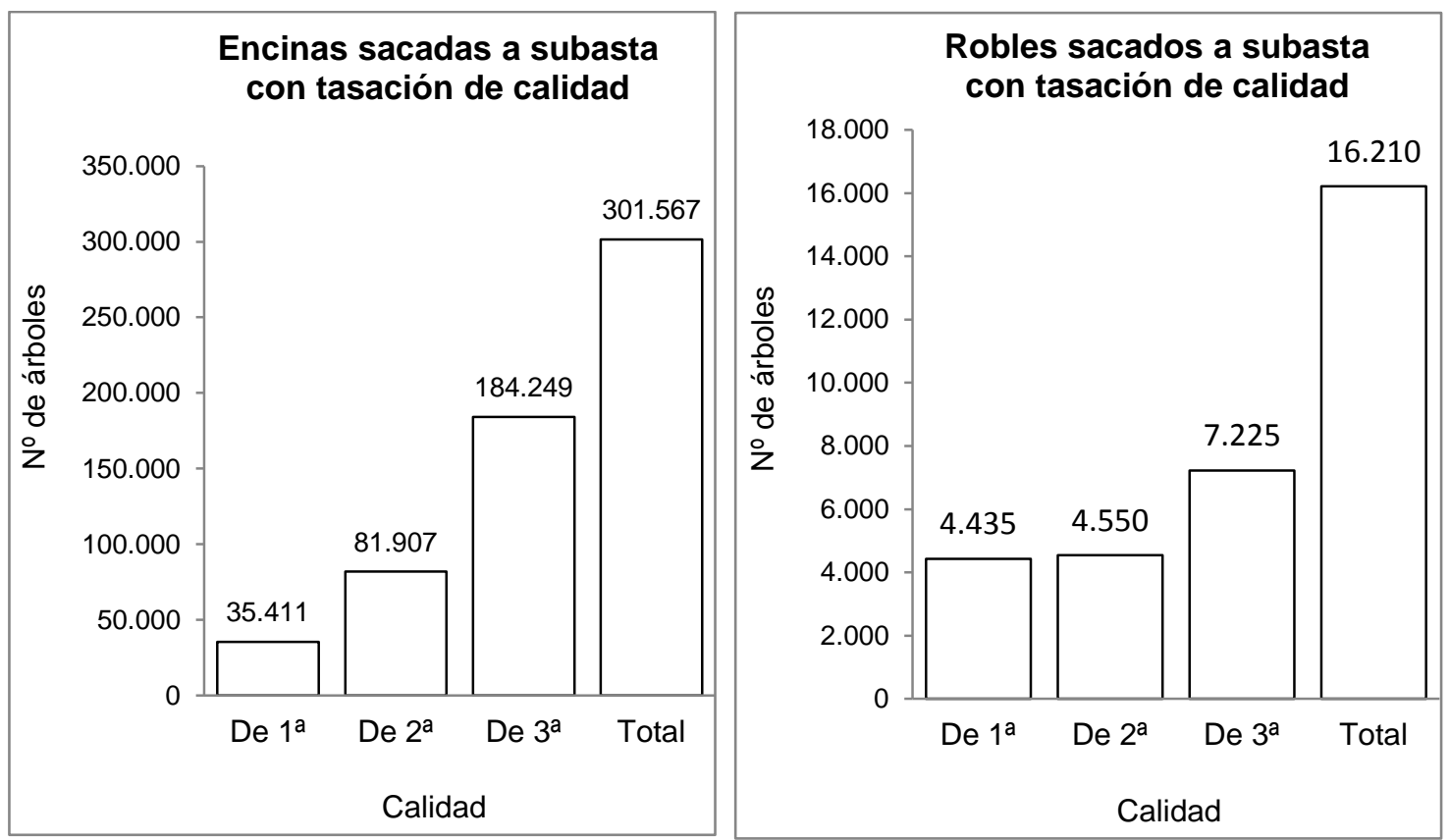

Fig. 2.40. Diferenciación de la calidad de las 301.587 encinas y de los 16.210 robles que contenían estos datos en los 64 informes tasación encontrados.

De las 104 fincas encontradas en las que se especifica que tienen arbolado y el valor de este, se ha restado este para comprobar en cuanto se valoraban las fincas con y sin arbolado (Fig. 2.41).

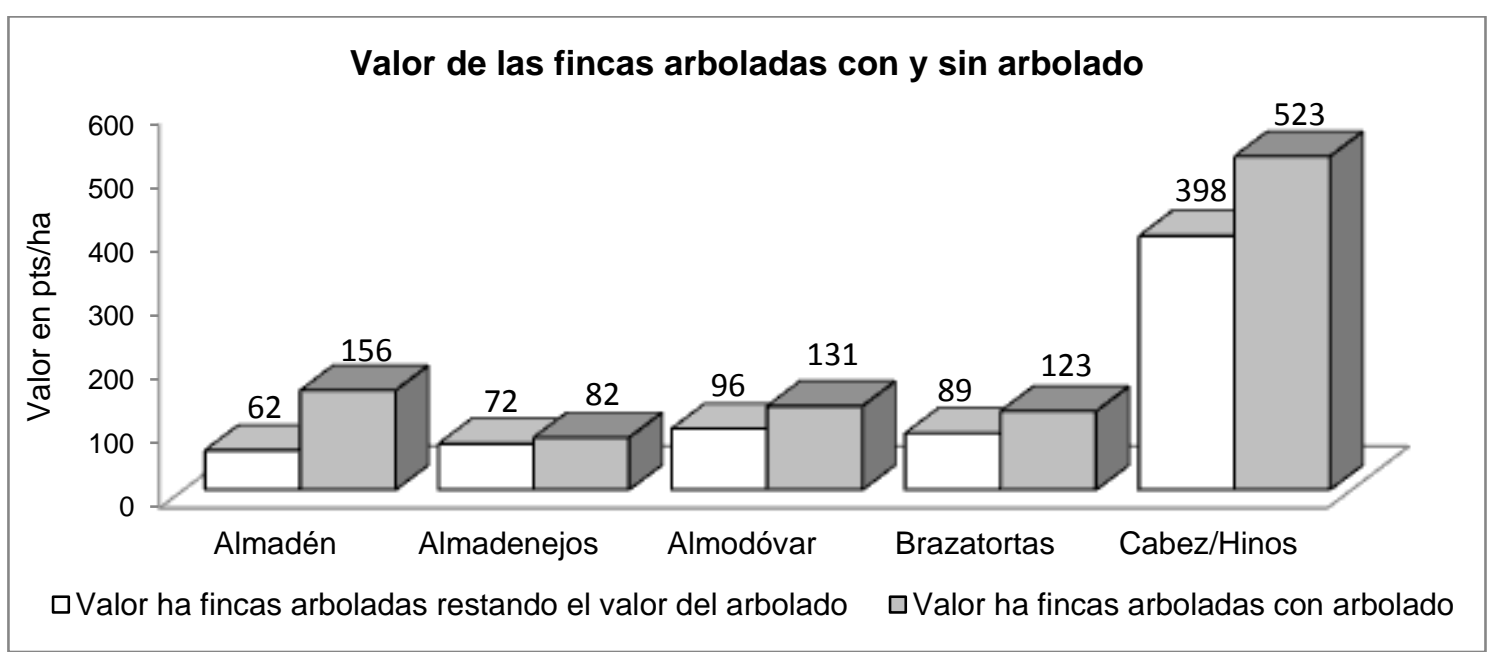

Fig. 2.41. Diferencia de valor de una misma finca con y sin arbolado según el término municipal en que se encontrase. Elaborado con las 104 fincas encontradas en el AHP en las que se muestra el precio del arbolado y el precio total de la finca.

Como parece lógico, en todos los casos, las fincas con arbolado valían más que si no lo tuvieran (Fig. 2.40). Un comprador no ganadero podría talarla y recuperar de inmediato una gran parte de su inversión, en casos como el citado del Alcornoquejo podría suponer recuperar hasta un 55\%. El alto valor de las 24 fincas consideradas en Cabezarrubias e Hinojosas se debe a la alta cotización de las dehesas de la Encomienda de Clavería, tanto por su arbolado que supone el 
49,9 del valor del suelo, como por ser las más cercanas y de más fácil acceso desde Puertollano, Almodóvar, Ciudad Real y Madrid. Mientras en Almadén el valor del suelo era menor que el del vuelo que sustentaba. El menor valor del arbolado lo tenía la vecina localidad de Almadenejos (aunque fuera del Valle de Alcudia se ha incluido aquí como comparación), donde solo suponía el $12,2 \%$ del valor total

La diferencia media en el precio de una finca entre tener o no arbolado, con los datos de las 104 fincas citadas en que su valor medio era de 2.223.093,04 pts y el de su arbolado 539.365,74 pts, supone un $24,26 \%$, muestra en general una mala calidad del arbolado. No obstante estas cifras, debe entenderse que eran los precios de tasación, el precio de salida en subasta solía ser algo superior e incluso llegar a duplicarse en el remate. El mantenimiento del arbolado dependía de los nuevos propietarios (ahora ya particulares) que podían decidir si lo mantenían o no y en qué densidad. Mantener 13,6 encinas/ha si se conservaban las de todas las calidades o reducirla a una si solo se mantenían las de primera calidad, no debía afectar a los que perseguían fines agrícolas, pues más caro sería desceparlas.

\subsubsection{El destino de las fincas vendidas durante los procesos desamortizadores}

El destino que dieron los nuevos propietarios a las fincas que adquirieron en Sierra Madrona y Valle de Alcudia durante los procesos desamortizadores fue muy diversos. Sin embargo los compradores pueden clasificarse principalmente en 3 grupos a la vista de lo ocurrido en las fincas tras su compra y a lo largo del siglo XX, para fines ganaderos, agrícolas o mineros.

\subsubsection{Uso ganadero y mantenimiento de las dehesas}

La gran mayoría de la superficie del Valle de Alcudia mantuvo su uso ganadero para la invernada de la oveja merina trashumante, apareciendo 2 tipos de compradores en las subastas .

Por un lado estaban los ganaderos sin tradición, como Juan Antonio Iranzo Ferrer, que adquirió 3 fincas en el Valle de Alcudia: Hato Pedraza, Cerro Venta y Evilleta Alta (de una media de 350 ha/finca). Este madrileño, negociante de bolsa, pasó posteriormente a ser ganadero y destacado miembro de la Asociación General de Ganaderos del Reino (Del Valle 2015). Institución heredera del Honrado Concejo de La Mesta. La ganadería seguía siendo atractiva para los inversores y se organizaba territorialmente en juntas provinciales. En 1929 el presidente de la Junta provincial de Ganaderos de Ciudad Real era el marqués de Casa-Treviño.

Pero más normal era que los compradores fueran ganaderos de larga tradición como la familia Aránguez, de origen segoviano. Este linaje llegó a ser uno de las mayores propietarios de ganado en el Valle de Alcudia en la transición de los siglos XIX al XX (Rodríguez García, 2006). Su cabaña constaba de 6800 ovejas y cabras, de las que 5300 eran trashumantes, el resto (1500 ovejas) se quedaban todo el año en el Valle de Alcudia, junto con 200 a 300 vacas y 50 yeguas y 2 caballos sementales. Para la trashumancia contaban con 10 a 12 burros, unos 25 perros mastines y unos 6-7 perros de carea. Inicialmente compraron las fincas Quinto del Río, 
Sisonera y Pizarro (de unas 400 ha/finca). La selección de estas fincas en pleno Valle de Alcudia, del término municipal de Almodóvar pero que luego quedarían en el de Brazatortas tras su independencia en 1867, no fue casual. Fueron adquiridas, en la desamortización del año 1769-70, por la Comunidad y Tierra de Segovia (Tabla 2.2) y luego expropiadas y sacadas de nuevo a subasta en la desamortización general de Madoz. Los Aránguez pues, como ganaderos segovianos, conocían bien estas fincas. Posteriormente, además de incrementar su cabaña ganadera compraron las fincas Cañaveras, El Borde y el Cerro de La Albarda. Entrado ya el siglo XX siguieron comprando dehesas, así, a partir de 1930 adquirieron también El Rasillo, Las Presillas y, en la Encomienda del Píngano, las fincas El guijarro, La Guzmanilla y El Píngano. Los intereses de estos y otros ganaderos de larga tradición explica en gran parte por qué el Valle de Alcudia sigue presentando en gran parte el aspecto adehesado de mediados del siglo XIX.

En los años 60 y 70 los ganaderos trashumantes continuaban siendo mayoría en el Valle de Alcudia como así lo atestiguan los empleados a los cronistas Romero y Sanz (1967):

[...] Somos sorianos; yo soy el mayoral [y cuando les dicen haber hablado con un segoviano] Sí; segovianos y sorianos somos la clase que más habemos por aquí [...]

Un veterinario del Valle de Alcudia le dice a estos mismos cronistas que según sus datos debe haber unas 300.000 cabezas de ganado lanar:

[...] En Mestanza hay más de cuarenta mil. En Cabezarrubias e Hinojosas unas dieciocho mil. En Almodóvar que haya ciento veinte mil [...] pues sí; el total debe andar por las trescientas mil $[\ldots]$

Una cifra elevada que ya mencionó Madoz en su DGE hacía un siglo, pero que era similar a la cabaña ovina no trashumante de toda la provincia de Ciudad Real en 1865 (Tabla 2.3).

Pero a partir de los años 70 los bajos precios de la lana, las exigencias de los pastores de mejores salarios y otras variables fueron haciendo cada vez menos rentable la ganadería, tanto la trashumante tradicional como la ganadería en general. Los ganaderos invernantes deberán desprenderse de la cabaña trashumante y, aunque mantengan ovino aún en el siglo XXI (Figs. 2.41 y 2.42), gracias a las subvenciones de la Política Agraria Comunitaria (PAC), diversifican sus explotaciones cada vez más con vacuno y caza mayor. 


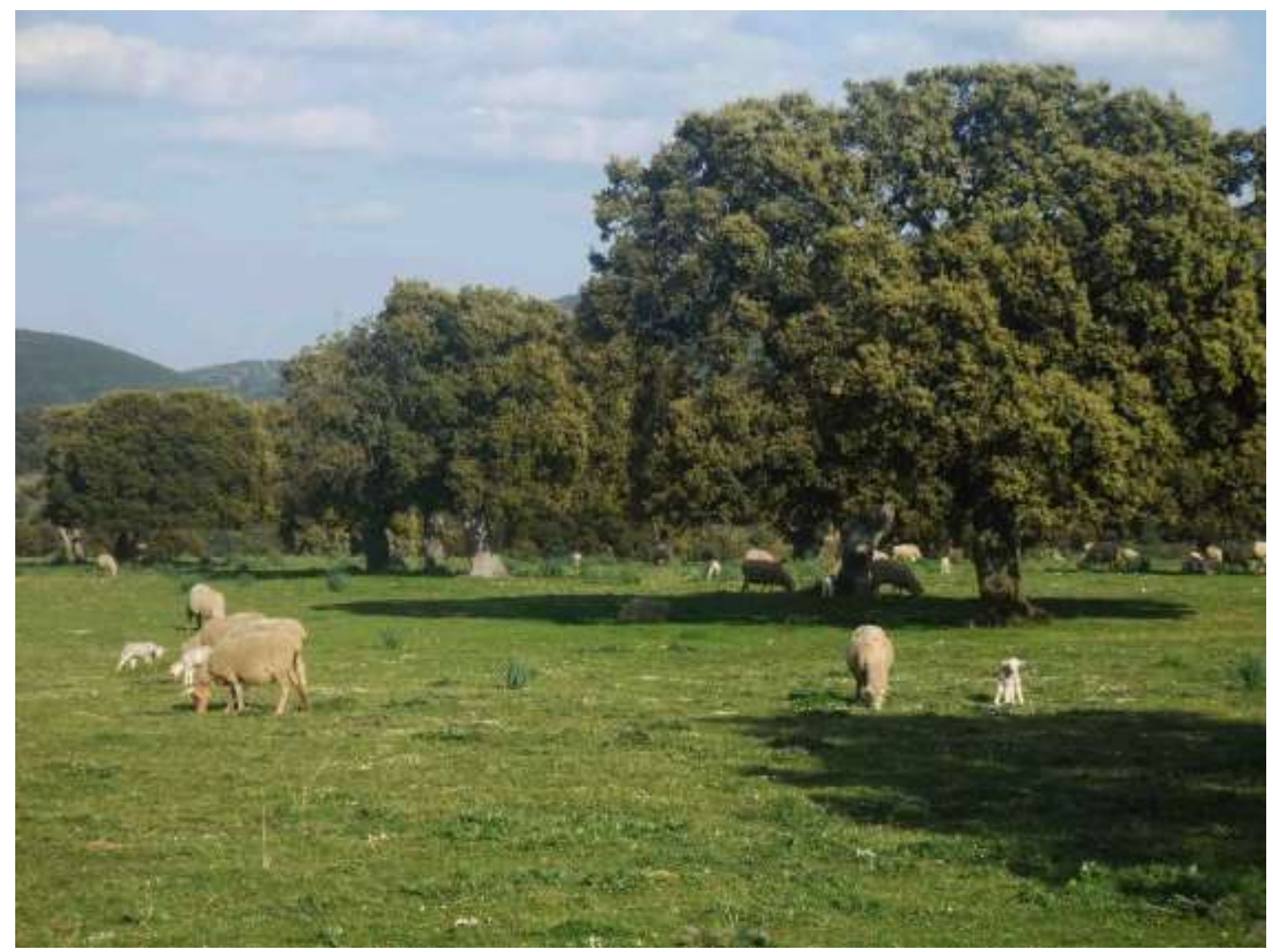

Fig. 2.41. Ganaderos trashumantes sorianos y segovianos adquirieron algunas de las mejores fincas del Valle de Alcudia para asegurarse la invernada de sus rebaños de oveja merina. La mayoría de estas fincas mejoraron su aspecto por la disminución de la severidad de las podas para leña y carboneo, por lo que sus copas son más frondosas y el crecimiento en grosor se ve favorecido. Lo único que está impedido es la implantación de un nuevo regenerado.

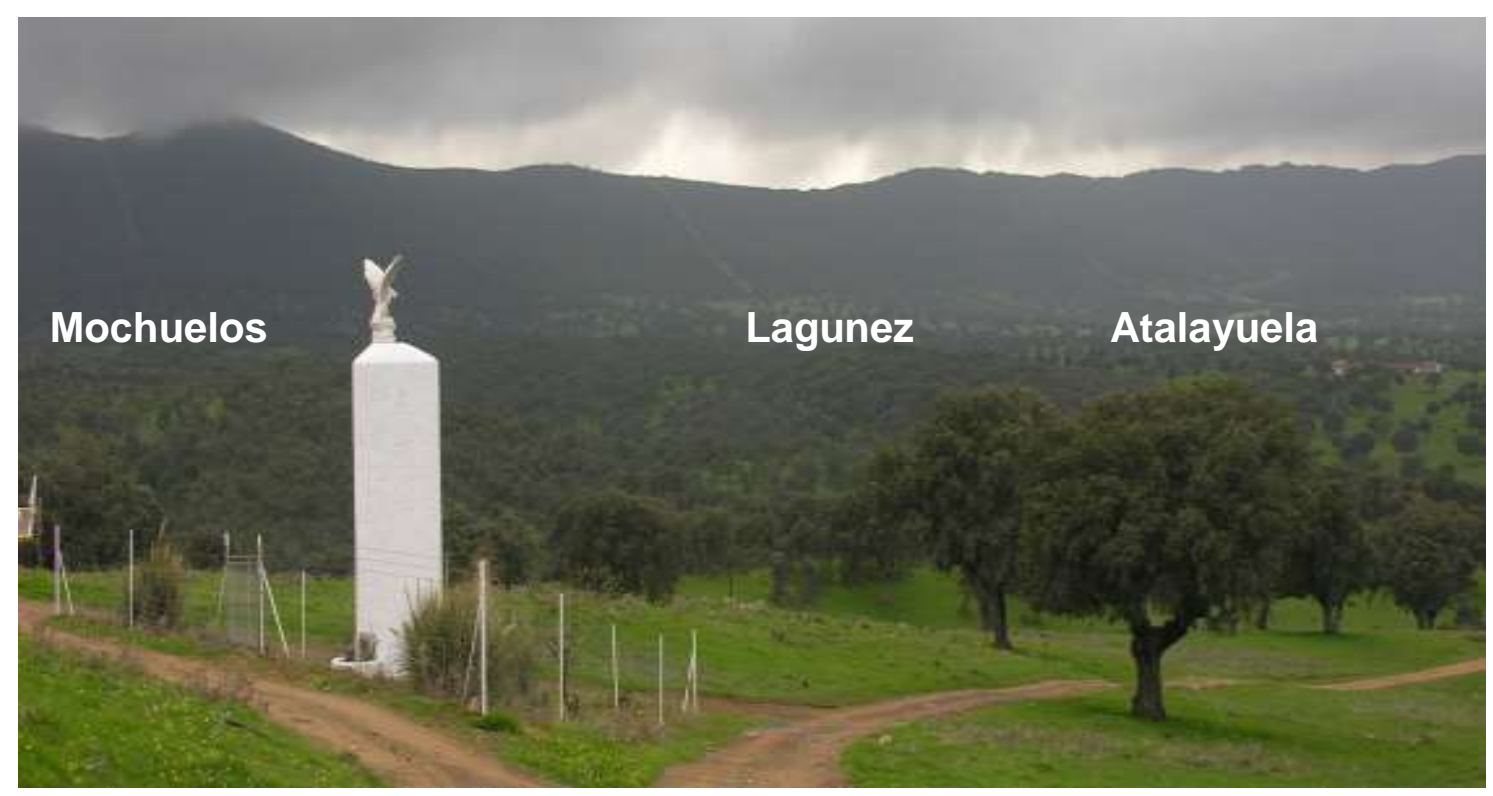

Fig. 2.42. Fotografía realizada desde la Real Encomienda de Mochuelos, al fondo otras fincas similares, Lagunez y Atalayuela subastadas en 1871 (Fig. 32). Lagunez de 594 ha poseía 8200 encinas de $1^{\text {a }}, 2^{\mathrm{a}}$ y $3^{\mathrm{a}}$ clase, sin que diferenciaran el número de cada una. Atalayuela con 638 ha contaba con 10.200 encinas (7000 de $3^{\mathrm{a}}$ y 3200 de $2^{\mathrm{a}}$ ). En la actualidad mantienen gran número de encinas y, en menor cantidad, también alcornoques, quejigos y robles, relegados a la umbría de la sierra. 


\subsubsection{Los intentos de poner en cultivo al Valle de Alcudia}

Un segundo grupo de compradores durante los procesos desamortizadores fueron los agricultores. Entre ellos los de clase relativamente acomodada compraron las fincas de mayor valor relativo, situadas en la proximidad de los pueblos (normalmente propiedad de la Iglesia y órdenes religiosas, menores de 10 ha). El destino de estas tierras agrícolas continuó siendo similar tras la compra (huertos, pequeñas viñas, cereales u olivar).

Menos numerosos pero con mayor extensión de tierras adquiridas (fincas de más de 100 ha), fueron los compradores de la burguesía, generalmente foráneos. Compraron grandes fincas, ya fuera en las subastas o posteriormente, para desarrollar explotaciones agrarias modernas. Entre estos cabe destacar al que a finales del siglo XIX fuera, además de ministro en varias ocasiones, presidente del Congreso y luego del Gobierno, Segismundo Moret y Prendergast que compró la Dehesa de la Vega de San Ildefonso. En esta finca, situada en el actual Guadalmez, se construyó una gran casa (Fig. 2.43) y se propuso, aunque con escaso éxito, desarrollar una rentable y modélica explotación mediante las más modernas técnicas agrícolas, como así puede verse en diarios de la época, como El País en su edición del 30/01/1913:

[...] Poseía en Chillón (Ciudad Real) una finca, a la que se propuso aplicar todas las innovaciones que la ciencia agrícola preconiza para el adelanto de la agricultura. Adquirió máquinas agrícolas, modificó los cultivos, introdujo el riego. Los gastos hechos consumieron una buena parte de su capital, y los resultados económicos no correspondieron a los sacrificios que aquel gran idealista, enamorado del progreso, llevara a cabo [...]

El fracaso se debió a la histórica degradación que había sufrido el suelo. El gran idealista no contó con el consejo de quien por interés profesional le habría recomendado que la vocación del terreno era forestal o, ya en el estado de degradación en que se encontraba, el de erial a pastos. Otros le seguirían con grandes proyectos agrícolas, con idénticos resultados, en la transición de los siglos XIX al XX. Pero no se acabaron aquí los intentos de cultivar el Valle de Alcudia.

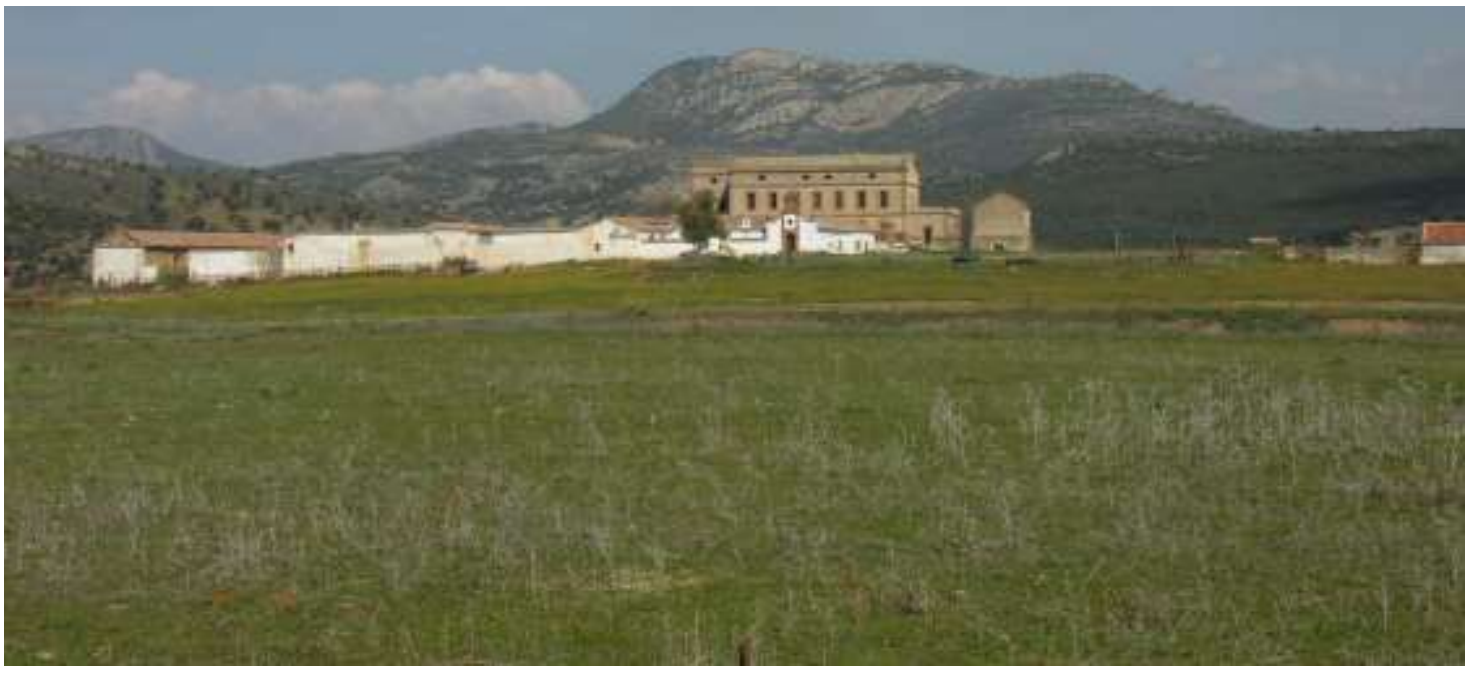

Fig. 2.43. Palacio de Moret, en Guadalmez. Los primeros intentos modernos de poner en cultivo el Valle de Alcudia fracasaron ya a principios del siglo XX. Muchos de los campos puestos en cultivo con los más modernos medios finalmente fueron abandonados y volvieron a lo que debía ser su uso en los siglos anteriores a su consignación a la mina de Almadén en 1646: eriales a pastos. 
En 1932 se aprobó la Ley de Reforma Agraria y se crearon el Instituto de Reforma Agraria (IRA) y el Registro de la Propiedad Expropiable (RPE). Este proceso legislativo iba dirigido contra las tierras mal cultivadas o que eran arrendadas sistemáticamente. Es decir, que durante la Segunda República se pretendió llevar a cabo una dignificación del campesino manchego. En la provincia de Ciudad Real quedaron sujetas a expropiación 296.293,41 ha (Ladrón de Guevara 1988). Sin embargo, el Valle de Alcudia recibió un trato especial por su condición de zona de pastos. Su defensa frente a la roturación y puesta en cultivo fue protagonizada por Carlos Morales Antequera, Jefe del Servicio Agronómico de Ciudad Real. Sus argumentos estaban basados en que el suelo "muy fino y delgado" del Valle de Alcudia impedía el cultivo y, aunque se cultivase, su producción sería tan mínima que apenas daría para alimentar al ganado allí establecido.

El diputado socialista Antonio Cabrera, defendió que la Reforma no perseguía destruir bosques y dehesas de forma indiscriminada, máxime cuando los suelos de determinadas zonas, como el Valle de Alcudia, eran tan poco aptos para uso agrícola. Esto a su vez fue aprovechado por los propietarios de las fincas del Valle para oponerse a su expropiación forzosa (Ladrón de Guevara 2006). Pero, frente a la defensa ante la expropiación y roturación de las fincas del Valle de Alcudia, se encontraban los vecinos de los pueblos (a los que se les habían expropiado sus montes en la desamortización general). Gran parte de la población de pueblos como Mestanza, con un acusado paro y pobreza, veía como causa de su miseria la gran extensión de tierras dedicadas a pastos y en poder de unos pocos propietarios. Así lo manifiesta Jesús Navas, desde Mestanza, en el número 31 de La Leña (14-10-1932):

\section{¡Pobre Mestanza!}

Siguen en función los mismos perros con distintos collares. Triste y dolorosa es la situación en que hoy se encuentra este pueblo rico y desgraciado. Lamentable y lastimoso es ver a sus hijos con los cuerpos decrépitos paseando las calles en busca de algún alimento, y cayéndose de desmayo,...

No debemos consentir que un pueblo como Mestanza que tienen un término de 35000 hectáreas sin cultivar, esté pasando tantas necesidades y tanta miseria. Nada de ir a trabajar a los caminos unos cuantos días al mes. iLa TIERRA! Sólo la tierra es la que puede resolver el problema del hambre y la que ha de traer a nuestros modestos hogares el pan que es la alegría y la felicidad de los pobres.

Señores Alcaldes: Es preciso mirar mejor por los pueblos. Es necesario que no lo tengan en el completo abandono en que lo tienen. Pongan de su parte cuanto puedan para adquirir esas tierras que son las únicas que pueden salvar la situación. No hay que dormirse paisanos.

Lejos de repartir la tierra entre los habitantes de los pueblos, la Ley de 1932 quedó derogada en 1935, cuando se aprobó una nueva Ley para la Reforma de la Reforma Agraria que en esencia anulaba la reforma anterior. Eliminó el RPE, indemnizó a los grandes propietarios expropiados y expulsó a los campesinos de las tierras que legalmente habían ocupado. Pronto los campesinos 
se empezaron a organizar y a ocupar las fincas incluidas en el antiguo RPE, especialmente tras el triunfo del Frente Popular. Así, para 1936 ya se habían ocupado en la provincia de Ciudad Real 26.224 ha por 6219 campesinos (Malefakis 1971). Ante estas ocupaciones (que también implicaba las consiguientes roturaciones de montes), los propietarios se organizaron en torno a Rafael Melgarejo, duque de San Fernando, miembro de la Asociación de Ganaderos del Reino y afectado por estar algunas de sus tierras en el RPE. Defendió una interpelación parlamentaria denunciando la oleada de expropiaciones anárquicas y roturaciones en La Mancha. Le contestó Ruiz Funes, exponiendo que el daño a la ganadería era el argumento de la derecha para oponerse al espíritu de la Reforma, y a continuación saco a relucir el caso del Valle de Alcudia donde aun habiendo un alto porcentaje de paro no se había expropiado nada y por tanto no se afectó a la ganadería (Ladrón de Guevara 2006).

Pasada la guerra civil, a mediados de los años 60 las penurias de la postguerra aún no se habían diluido y, para sobrevivir, los habitantes de la comarca roturaban y cultivaban allá donde podían, tanto en Sierra Madrona como en el Valle de Alcudia pero, como dijo Sabas, propietario de un cortijo en Mestanza (en Romero y Sanz 1967):

[...] esta tierra no es buena para cereales. Aparte de lo poco que da, el terreno tiene mucha pendiente y los ingenieros agrónomos han dicho que no se siembre, que se deje de posío para el ganado. Pero casi nadie hace caso y siguen arando los cerros; luego viene la nube y se lleva la tierra $[\ldots]$

Palabras modernas para un proceso que se venía repitiendo desde la antigüedad. También Aurelio, el dueño de la finca del Águila, veterinario que llegó a ser alcalde de Hinojosas les comenta a estos mismos cronistas hablando de las fincas del entorno:

[...] Antes eran quintos muy estimados por los trashumantes por su excelente pradera, pero en cuanto los roturaron se echaron a perder. Como todo lo que se labra en el valle [...]

Pero a pesar de todas las recomendaciones en contra, la miseria y necesidad de subsistencia empujaba a los habitantes de los pueblos a seguir roturando el Valle de Alcudia aún a mediados del siglo XX, bien para ellos mismos bien para beneficio de los grandes propietarios. Las encinas se carboneaban, para ello se podaban, talaban y con frecuencia se descepaban, como el resto de árboles y arbustos, a mano. Según los testimonios que hemos recogido entre los ancianos de la comarca y que concuerdan con lo descrito por Romano y Sanz (1967) lo normal es que los dueños de grandes fincas contratasen con la gente de los pueblos la "limpieza" (descepe y eliminación de vegetación leñosa) del terreno. Los trabajadores, tras el descuaje del monte la sembraban, obtenían una buena cosecha el primer año y algo menor el segundo. El primer año daban al dueño de la tierra $1 / 4$ de la cosecha, el segundo año $1 / 3$ y al tercer año tenían que irse a descuajar monte a otra finca. 


\subsubsection{La reapertura de viejas minas y la exploración del territorio en busca de nuevas. Los bosques subterráneos.}

Un tercer grupo de nuevos propietarios no perseguían fines ganaderos ni agrícolas, su interés era principalmente minero. A lo largo del siglo XIX, mientras continuaba la explotación de las minas de Almadén, nueva legislación liberaba y fomentaba la explotación minera (Ley Minera de 1825, Bases Generales para la Legislación Minera de 1869). Se incrementó la exploración del territorio, se crearon sociedades mineras y llegaron capitales extranjeros. Se reexplotaron además de las minas tradicionales, otras muchas nuevas de plomo, plata, hierro y cobre que se fueron descubriendo por Sierra Madrona y Valle de Alcudia. También en esos años (en concreto en 1873) se descubre la cuenca minera de Puertollano. Así, además de las citadas minas de mercurio y carbón, en 1844, había ya concesiones sobre 28 minas de plomo, 2 de plomo argentífero, 2 de hierro y 6 escoriales de plomo (Quirós 1969).

La creciente escasez de leña motivó que en Almadén se modificaran los hornos Bustamante. Esta modificación de un sistema centenario resultó altamente beneficiosa por el alto precio de la leña y el mayor rendimiento del horno (Zuaznavar 1880)

[...] Representando el capital de combustible de arbustos en 1876 á 1877, 38.627,50 pesetas, se comprenderá la importancia que tiene la economía deducida, porque consumiendo cada vuelta ó cochura veinte y cinco cargas, término medio, y economizándose de dos á tres cargas, resulta un beneficio del 10 por 100, 6 sea de 16.000 reales anuales aproximadamente; ésto sin contar los resultados obtenidos por una calcinación más perfecta que se traduce en un mayor rendimiento. $[\ldots]$

La mayor mina hasta finales del siglo XIX fue la de Almadén que siempre fue, como se ha visto, un gran sumidero de leña y madera. Pero a finales del siglo XIX, además de ahorrar gran cantidad de leña en los hornos, empezó a utilizarse masivamente el ladrillo y la piedra para asegurar pozos y galerías. Así, según este mismo autor, se emplearon en la mina en esos años 77.000 ladrillos, 30.000 quintales métricos de piedra estéril y $962 \mathrm{~m}^{3}$ de mezcla de cal y arena. Sin embargo, en el resto del territorio las necesidades de madera para entibar aumentaron a lo largo del siglo XIX según se abrían nuevas minas y se incrementaba la extensión de las existentes. Cientos de miles de encinas, quejigos y robles se bajaron a las minas para entibación. Había un auténtico bosque subterráneo. Incendios en el interior de las mayores minas, como las de Almadén o el Horcajo, podían llegar a durar varios meses (e.g. Sainz de Baranda et al. 2004; Gil Bautista 2012), la cantidad de madera en el interior de las minas debía ser inmensa.

El auge minero en plena desamortización implicó que varios compradores de tierras fueran empresarios mineros o aspirantes a serlo. Tal fue el caso de José Genaro Vilanova Jiménez, empresario minero andaluz que adquirió en Mestanza la finca El Encinarejo, de 424 ha. La repercusión de las explotaciones mineras, al contrario que las ganaderas, si tendría una fuerte repercusión ambiental en la comarca, pues a la deforestación del entorno se sumaba la contaminación de suelos, pastos y aguas (Rodríguez Estival 2012). 
Sobre la contaminación de las aguas Romero y Sanz (1967) lo expresan elocuentemente

[...] Más abajo discurre la corriente color lejía del Montoro. Sus aguas adquieren esa tonalidad por verter en ellas los lavaderos de plomo de las minas de Diógenes ... Unos cien metros después las aguas gris-verdosas del Montoro se unen a las negras del Fresnedas, sucias también por utilizarse en los lavaderos de carbón en Puertollano, y corren impetuosas en busca del Guadalquivir. [...]

Pero es el complejo minero del Horcajo, surgido en plena Sierra Madrona a finales del siglo XIX y que llegó a contar con hasta 4500 habitantes (Fig. 2.44), el caso más significativo de explotación minera moderna en la comarca, por dos motivos. El primero por su gran extensión, producción, mano de obra ocupada e impacto ambiental; el segundo por su efímera existencia

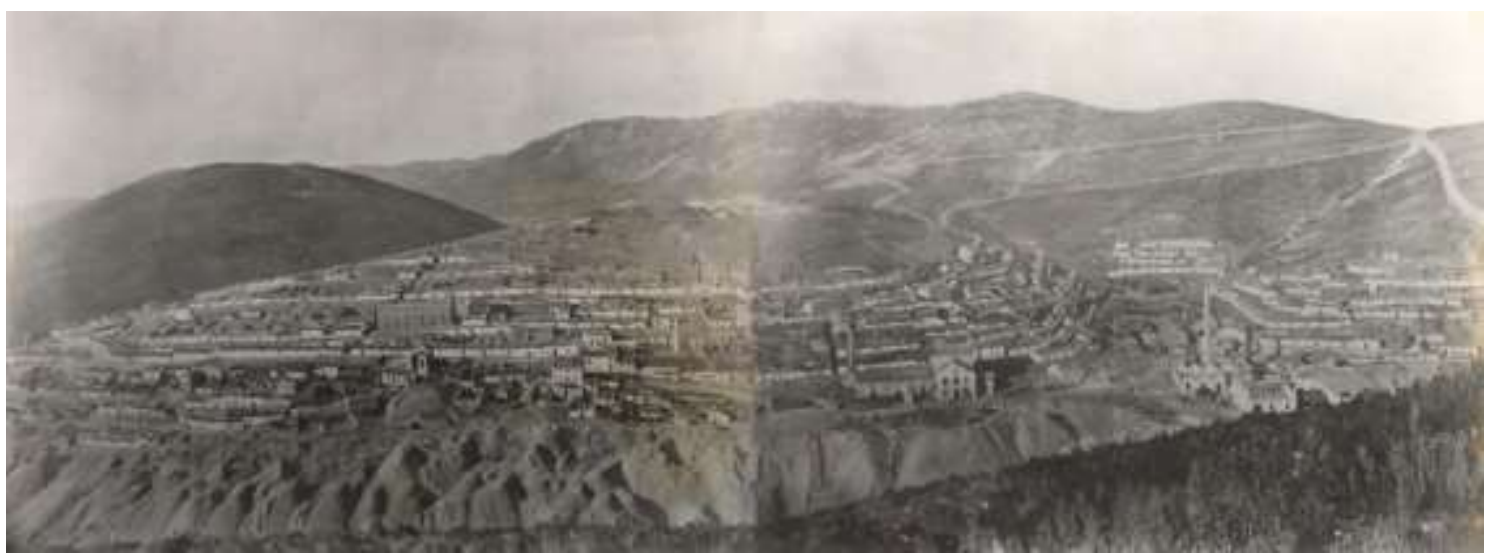

Fig. 2.44. A mediados del siglo XIX El Horcajo era una zona remota cubierta de bosques y matorrales, en plena Sierra Madrona. Pero en poco menos de medio siglo la explotación minera, la consecuente creación del poblado minero que sería casi una ciudad de 4500 habitantes, y las necesidades de madera y leña, deforestaron por completo la zona.

En 1858, el ingeniero de minas Juan Inza, obtuvo la primeras concesiones para explotar unos prometedores afloramientos filonianos en el Horcajo. En esos años, según Avecilla (1878):

[...] no existía ni una casa, ni un chozo, ni el más rústico albergue en aquellas montuosas y casi inaccesibles escabrosidades que apenas había hollado planta humana [...]

Inza vendió las concesiones y tras varios propietarios acabaron siendo explotadas por la compañía "La Minería Española" creada en 1870. Posteriormente fueron adquiridas por el Banco de París en 1882 que para su gestión creó la "Sociedad Minero Metalúrgica del Horcajo". En 1897 esta sociedad adquirió la Dehesa del Horcajo, de 1897 ha. La alta rentabilidad de las minas hizo que esta sociedad las adquiera en 1904 pero por las dificultades técnicas de su explotación pasaron a la Sociedad Minero Metalúrgica de Peñarroya (SMMP) que para su gestión creó la "Nueva Sociedad de las Minas de Horcajo". La SMMP, adquirió 14.000 ha en el entorno del Horcajo tanto para asegurarse la explotaciones de potenciales filones como para abastecer de madera y leña a sus minas (y habitantes del poblado minero). Fue una de la mayores compras de fincas realizadas en España, favorecida por los procesos desamortizadores 
del siglo XIX. El cierre de las minas se produjo en 1911, aunque luego la SMMP las reexplotaría entre 1955-1961. En total la producción fue una de las más importantes en la historia de España, con unas 250.000 Tm de concentrados de galena, con leyes del orden del 70 a $75 \%$ de plomo y con 1,5 a 6 kg de plata/Tm (Quirós 1969).

La deforestación que causó el complejo minero del Horcajo (minas y habitantes del poblado minero) no fue mayor pues el ferrocarril propició la llegada de grandes cantidades de carbón mineral. En el año 1876 funcionaban en las minas 10 máquinas de vapor, alimentadas por carbón traído desde las minas de Peñarroya (Córdoba). El consumo de estas máquinas fue de 2612 Tm solo en 1874 (Quirós 1969). La madera seguía siendo muy necesaria (Fig. 2.45), especialmente para el entibado de las galerías (Figs. 2.46-2.48), pero ya no se encontraba madera de calidad en la zona, por lo que tenía que traerse de Portugal (Quiros 1969), de Cuenca y de Hellín (Hervada 1894). Actualmente todas las minas están cerradas, incluida la histórica de Almadén.

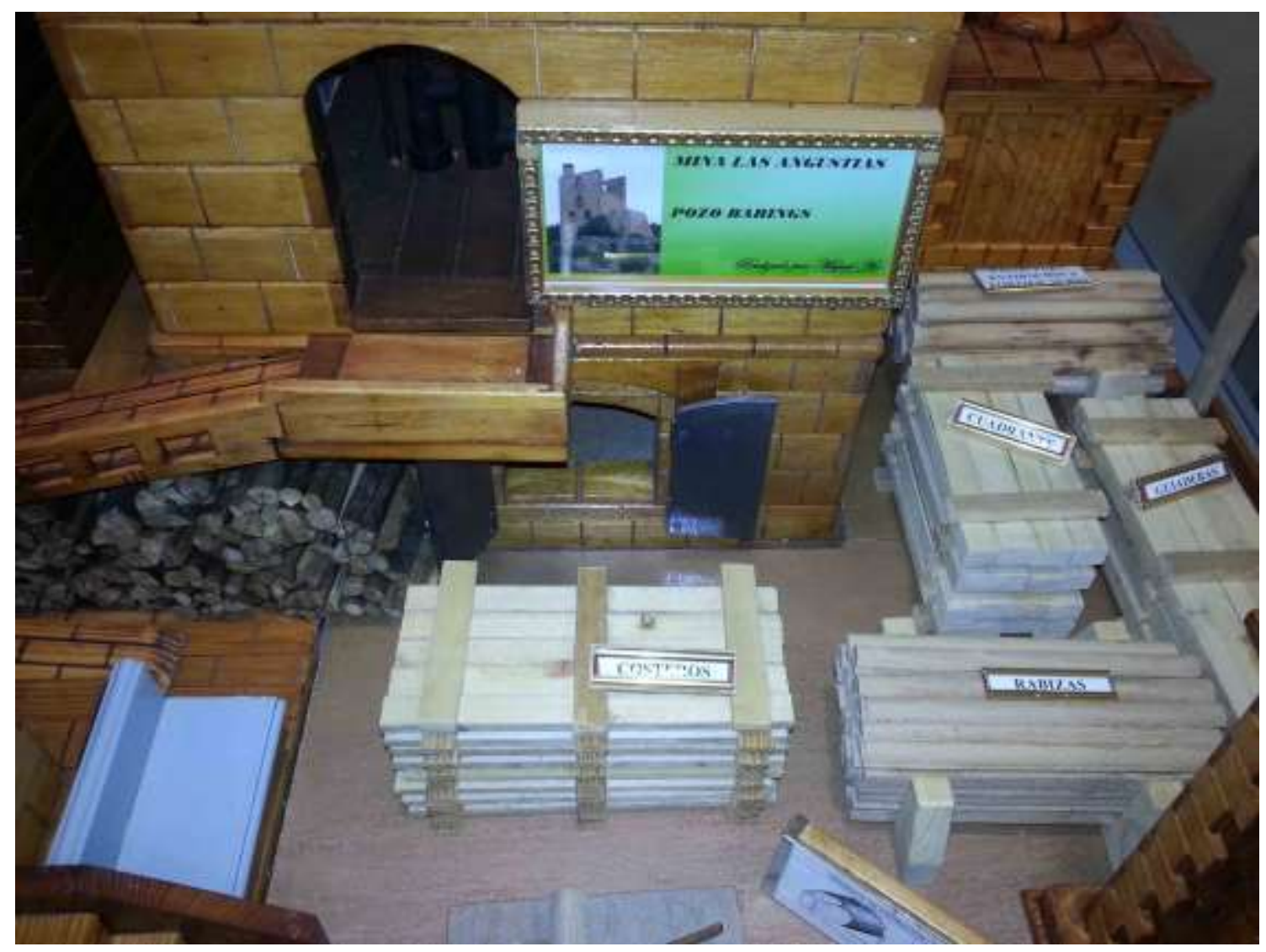

Fig. 2.45. En esta maqueta de una mina de Sierra Morena de la transición de los siglos XIX al XX, puede verse como, aunque la piedra, el ladrillo y el metal ya eran muy usados, aún era necesaria una gran cantidad y diversidad de piezas de madera para el desarrollo de la explotación minera. Palos largos para entibar, cuadrantes, guiaderas, rabizas y costeros son algunas de ellas. Esta madera inicialmente procedía de la comarca, pero a medida que se fueron agotando los recursos forestales tuvieron que ser traidas de otras partes de la península ibérica por ferrocarril. Maqueta del pozo Bearing, mina Las Angustias, del complejo Linares-La Carolina. Museo minero de Linares. 

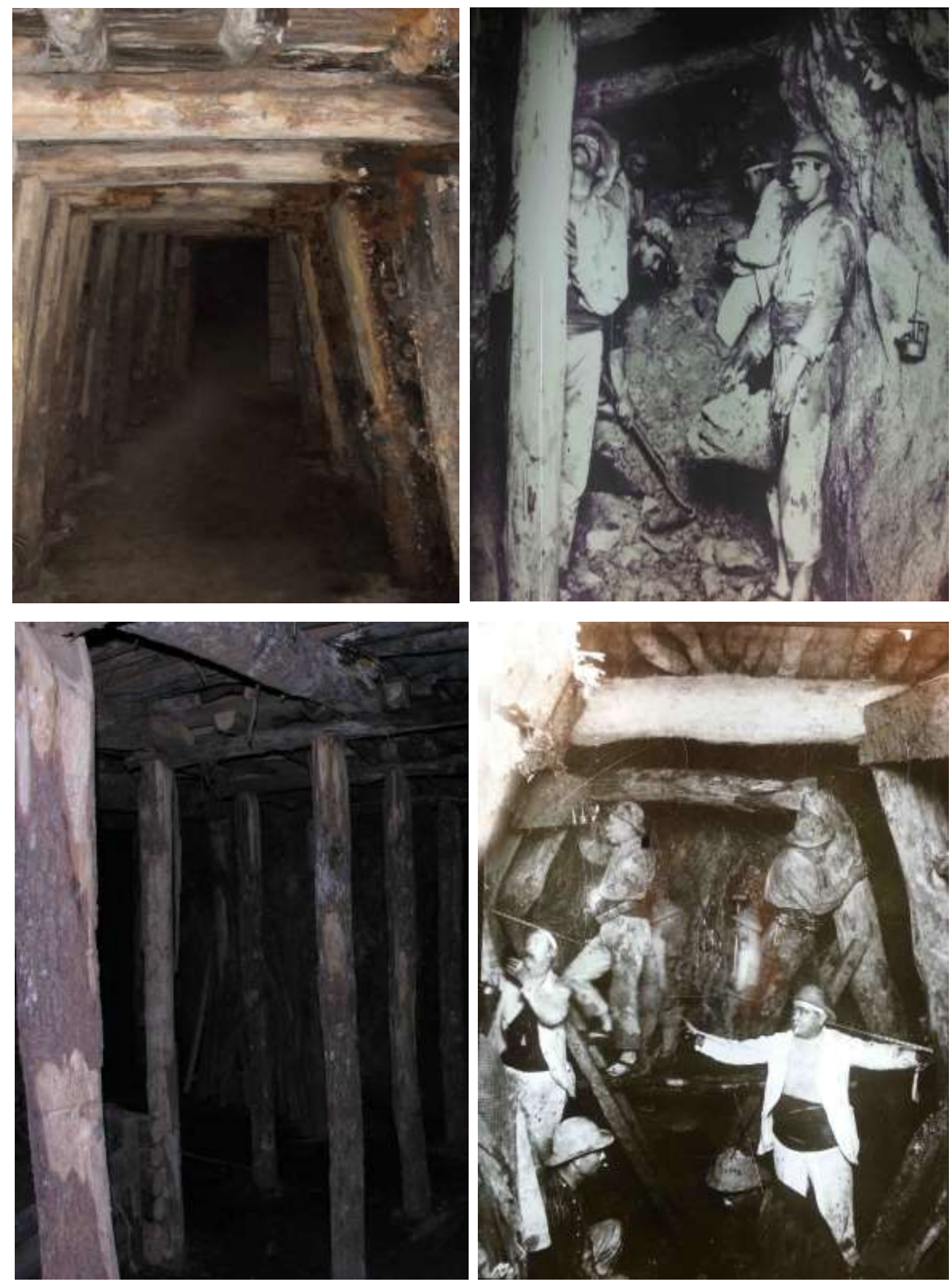

Figs. 2.46-2.48. Desde finales del siglo XIX y más especialmente desde principios del XX las necesidades de leña para los hornos y fundiciones de las minas disminuyeron. Sin embargo la madera siguió siendo necesaria especialmente para el entibado de las minas. Como las galerías se extendieron por cientos de $\mathrm{km}$ en toda Sierra Morena, esto implicaba la existencia de auténticos bosques subterráneos de encinas, quejigos y robles. Las fotos en color son propias de la mina de Almadén, en b/n: Museo minero de linares. 


\subsubsection{Los bienes exceptuados de la desamortización, montes, dehesas y minas.}

La actitud del primer director de la Escuela de Montes, Bernardo de la Torre, a la vez senador del Reino, al no votar con el Gobierno la Ley de Ferrocarriles, llevó a su destitución. Ante los rumores de que una nueva ley pondría en venta los montes para la construcción del ferrocarril, su sustituto, Bernardino Núñez de Arenas (1854), escribe al Ministro de Hacienda y le informa de los males que padecen los montes así como de las consecuencias que tendría su enajenación pues la imposibilidad de su venta ha sido la causa de su salvación. Insiste en la necesidad de dotar al cuerpo de Ingenieros de Montes recién creado de competencias en las labores administrativas, y es categórico: la administración actual [basada en los comisarios de montes] y los ingenieros de montes son de todo punto incompatibles; sobra una de las dos instituciones.

La desamortización general de Madoz de 1 de mayo de 1855, declaró en estado de venta todos los predios rústicos y urbanos, censos y foros pertenecientes al estado, al clero y cualesquiera otros pertenecientes a manos muertas. En su artículo 2, especificaba que estaban exceptuados 9 tipos de bienes más cualquier edificio o finca cuya venta no crea oportuna el Gobierno por razones graves. Tres de ellos afectaban a Sierra Madrona y Valle de Alcudia:

6. Los montes y bosques cuya venta no crea oportuna el Gobierno.

7. Las minas de Almadén.

9. Los terrenos que son hoy aprovechamiento común, previa declaración de serlo, hecha por el Gobierno, oyendo al Ayuntamiento y la Diputación provincial, oirá previamente al Tribunal Contencioso-Administrativo, o al cuerpo que hiciere sus veces, antes de dictar esta resolución.

Una vez aprobada la Ley, el 4 de junio de 1855 debían paralizarse las ventas hasta que no se dispusiera de un reglamento sobre el modo de proceder. Los ingenieros de montes Miguel Bosch y Agustín Pascual trasladaron al Gobierno, el 8 de octubre de 1855, el Informe de la Junta del Cuerpo de Montes, que calificaba a los montes como enajenables o no según la región a la que pertenecían. De acuerdo con la doctrina (esbozada por Jovellanos) de proteger los montes con influencia sobre territorios y economías aledañas o en cotas inferiores. Para facilitar su aplicación se utilizó el criterio de la especie arbórea dominante. El Informe recomendó exceptuar las formaciones ligadas a los terrenos inútiles para la agricultura, a las zonas de grandes pendientes, a las altas montañas o a especies de turnos dilatados. Opina [la Junta] por la venta del monte bajo o inmaderable y la conservación del alto o maderable. Defiende que los montes altos no son del interés particular, porque la riqueza forestal es la única propiedad que gana administrada por el Estado, y esto no sucede si pasa a manos de los particulares (Gil 2007). Considera que debían exceptuarse los abetares, pinabetares, pinares, enebrales, sabinares, hayedos, castañales, abedulares, avellanares, alisedas, acebedas, robledales, melojares, quejigares y piornales. Otros bosques, como encinares, alcornocales o coscojares podían venderse previo reconocimiento por si albergaban algún valor especial. El informe fue muy tenido en cuenta en el Real Decreto de 26 de octubre de 1855, que se publicaría en La Gaceta de Madrid los días 28, 29 y 30 de octubre, 1, 3, 5, 7 y 10 de noviembre de 1855. 
Para establecer que montes debían enajenarse y cuáles no, se creó la Junta Consultiva de Montes. Esta Junta debía seleccionar, clasificar, delimitar y describir los montes que debían exceptuarse de la desamortización. El 16 de febrero de 1859 un R.D. manda clasificar nuevamente los montes públicos para los efectos de las leyes de desamortización, y otro del día siguiente dicta las normas para ejecutarla. Como primera medida se ordena a los ingenieros que, para recoger y comprobar la información que estuviera disponible, se distribuyan por todas las provincias al objeto de que no haya que apelar a los comisarios y peritos más que como auxiliares. En 1859 emitió la Clasificación General de los Montes Públicos, que fue el argumento que llevó a los ingenieros de montes, dentro del Ministerio de Fomento, a ser los gestores de la propiedad pública forestal que no pasó a ser administrada por el Ministerio de Hacienda para proceder a su venta. Con ella, el Gobierno pretendía una mayor vinculación con el sistema político liberal y hacer frente a la galopante deuda pública.

Según la Clasificación General de los Montes Públicos de 1859, realizada por el ingeniero de montes Manuel Fernández Monjardin, en los partidos judiciales de Almadén y Almodóvar se incluían 161 montes públicos con 204.126 ha. Se exceptuaron 48 montes con 58.673,8 ha y se consideraron enajenables 113 con 145.452,2 ha. Constaban como enajenables en el partido judicial de Almodóvar del Campo 24.734,71 ha., pertenecientes a 9 montes propiedad del Estado y 65 propiedad de los pueblos que sumaban 97.480,31 ha. En el de Almadén se consideraron enajenables 39 montes de los pueblos con una superficie de 23.237,22 ha. De todos estos montes públicos, pertenecían a la comarca de Sierra Madrona y Valle de Alcudia 76, con 133.765,78 ha. La relación supuso la difusión del primer inventario de los nombres de los montes de la comarca, cuya superficie era proporcionada por los jefes políticos que tuvieron encomendada hasta 1859 la custodia de los montes junto a comisarios de montes y alcaldes en los pueblos. En Sierra Madrona y Valle de Alcudia, a excepción de la Dehesa de Castilseras (Almadén), propiedad del Estado, el resto eran propiedad de los pueblos.

De los 76 montes de propiedad pública en los pueblos de la comarca, la Clasificación General establecía que 31 (51.121,98 ha) no eran enajenables (Figs. 2.49 y 2.50). Es decir, la Junta Consultiva de Montes consideró que un 40,79\% de los montes de la comarca (un 38,74\% de la superficie total de montes) por su interés nacional no se debía vender.

Como puede verse en las Figs. 2.49 y 2.50 la mayor parte de los montes y de la superficie se sitúan en Almodóvar del Campo, algo normal pues se trata del municipio con mayor término municipal de la comarca, además, en esos años aún no se le había independizado la aldea de Brazatortas. Pero también debe tenerse en cuenta que parte de esos montes, como también ocurre en los municipios de Chillón y Almadén, se encuentran fuera de la comarca, al norte del valle de Alcudia, donde también estos 3 municipios poseen parte de su término municipal. En el caso concreto de Almadén, la mayor parte de la superficie total de sus 15 montes (12.159 ha) correspondía a uno solo en el Valle de Alcudia, la famosa y ya citada Dehesa de Castilseras (7190 ha). 


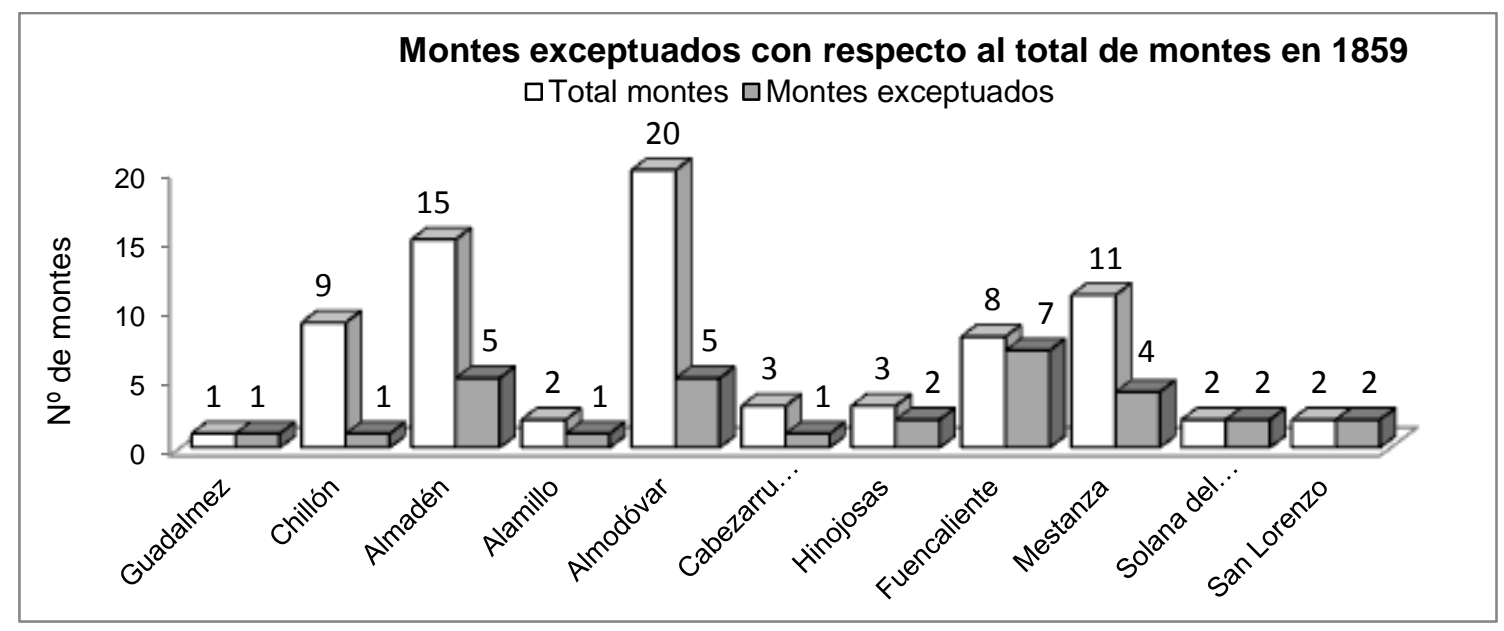

Fig. 2.49. Montes incluidos en la Clasificación General de 1859 en los municipios de Sierra Madrona y Valle de Alcudia, con indicación de los que debían ser exceptuados de la desamortización.

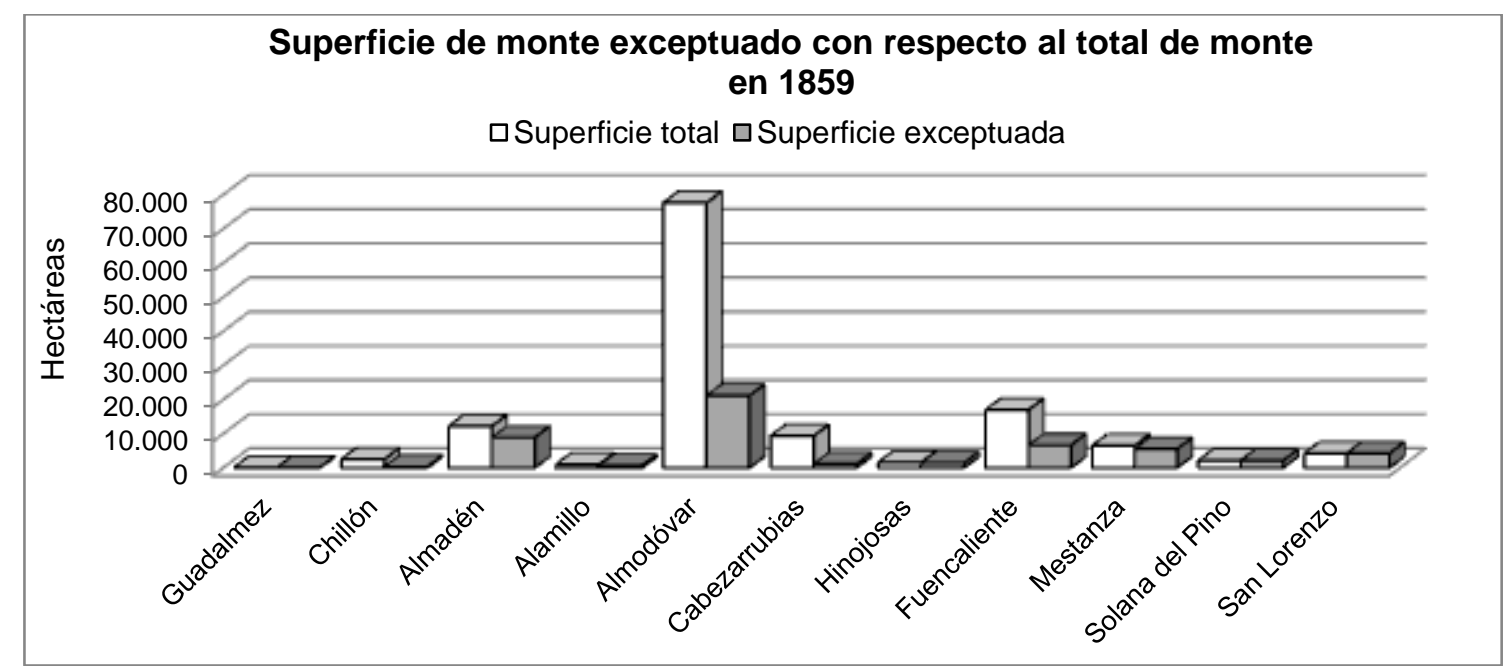

Fig. 2.50. Superficie de montes incluidos en la Clasificación General de 1859 en los municipios de Sierra Madrona y Valle de Alcudia, con indicación de la que se consideraba era exceptuada de la desamortización.

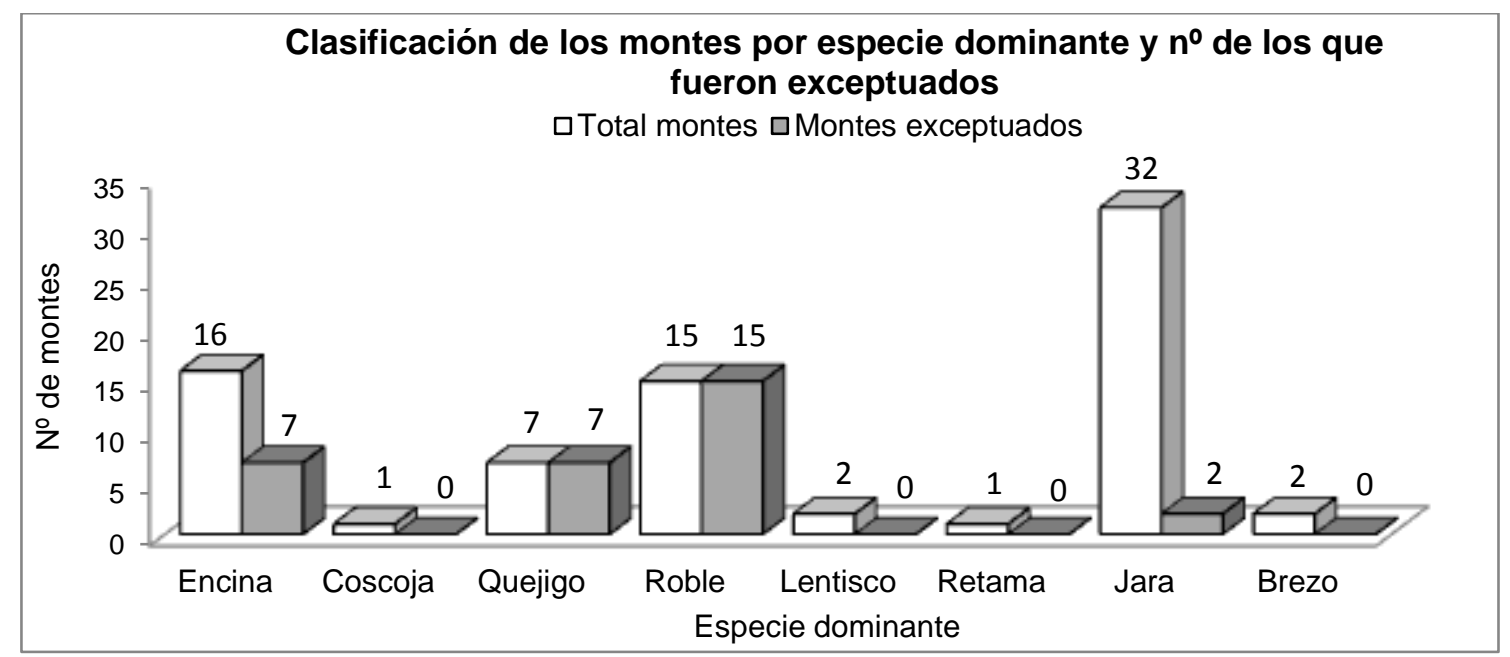

Fig. 2.51. Tipología forestal de los montes incluidos en la Clasificación General de 1859 en los municipios de Sierra Madrona y Valle de Alcudia. Se indica el $n^{\circ}$ de montes según la especie dominante y, de estos, cuantos debían ser exceptuados de la desamortización. 
En 38 de los 76 montes de la comarca los árboles eran dominantes (Fig. 2.51). En el resto también había árboles pero figuraban dentro de la categoría de especies subordinadas. Por ejemplo, en la finca Plazuelas (Almadén), de 248 ha, dominaba el brezo y como "subordinadas" encina, lentisco y madroño; en el jaral de la Solana de la Osa (Almadén), de 77 ha, había alcornoque y quejigo o en la Dehesa Boyal de Mestanza, de 322 ha, donde la especie dominante era la retama, con jara, lentisco y acebuche. Los montes en los que se consignaba mayor superficie era La Raña de Fuencaliente, poseedora de 10.346 ha, en la que dominaba la jara y como subordinadas brezo, madroño y lentisco, y en Almodóvar del Campo el monte denominado "tercera demarcación al Sur de la Sierra de Alcudia" de 5818 ha, dominaba la jara y como subordinadas retama y encina. La densidad y calidad del arbolado en las fincas arboladas no podría considerarse alta, de acuerdo con lo que se deducía de los informes de tasación para la subasta de numerosos de estos montes.

Resulta curioso que se exceptuaran 2 montes de jara (Fig. 2.51); el monte Rosalejo en Hinojosas, que tenía coscoja y retama como especies "subordinadas" y una superficie de 1159 ha, y el grupo de montes "Las Grajas, Navarredondilla, Solana del valle de Ventilla y Rozalejo" en Cabezarrubias, que tenían como "subordinadas" encina y quejigo y un total de 1095 ha. En estos montes el dominio del matorral respondía a las prácticas a la que alude el nombre de "Rozalejo", curiosamente muy similar a la del pueblo de Hinojosas. Estos predios se sitúan en pendientes pronunciadas y junto a ríos, por lo que el ingeniero que realizó la Clasificación los incluyó al aplicar el criterio de ««albergar valores especiales», que en este caso serían protectores.

La Clasificación General de 1859 exceptúa el 100\% de los montes de Sierra Madrona y Valle de Alcudia de roble y quejigo (Fig. 2.51). Con respecto a los 17 encinares se propusieron 7 para ser exceptuados, Quintillos (654 ha) en Alamillo; Dehesas de Castilseras (7190 ha), Gargantiel (90,15 ha) y Boyal (772,75 ha), más otro también llamado Quintillos, en total unas 8826 en Almadén; Arrubiel (322 ha) y la Dehesilla de Guadalmez (51,52 ha) en Chillón. La Dehesa de Castilseras era entre estos encinares, además del mayor monte, el más diverso, pues contaba entre sus especies "subordinadas" con quejigo, coscoja y madroño.

Estos datos eran resultado de las informaciones que tenía las Comisaría de Montes y cuya información pasó a los Distritos en 1859, sin posibilidad de reconocer la superficie exceptuada. Los montes de Almodóvar del Campo figura que pertenecen a los pueblos de la Comunidad de Almodóvar y sus aldeas Brazatortas, Tirteafuera y Fontanosas y los dos del término municipal de Solana del Pino pertenecen al pueblo de San Lorenzo.

$\mathrm{Al}$ considerar las especies arbustivas que figuraban como dominantes (Figs. 2.51 y 2.52), la más común era con diferencia la jara (Cistus ladanifer), en 32 montes, con 66.498 ha (un 49,7\% de la superficie total de montes). Las grandes dehesas con restos de encinar estaban en el Valle de Alcudia, predios que además de proporcionar los pastos a propietarios o posesioneros debían de proveer de leña y madera a la mina. La jara figura como subordinada en la mayoría de los 
encinares salvo en las dehesas que se pastaban y como dominante está presente en montes públicos de todas las sierras de la comarca. Podría llamar la atención la escasez de las otras especies de matorral, como los brezos. Pero la respuesta sobre la escasez de estas ericáceas podría estar en los contratos de abastecimiento de carbón vegetal, siempre de brezo, a las minas de Almadén a lo largo del siglo XVIII (Gil Bautista 2012). Además de en las minas, este tipo de carbón vegetal también era muy usado para abastecimiento de los pueblos, como puede verse por ejemplo en una Orden de 1787 para que los fabricantes de carbón de brezo lo vendieran en primer lugar en Almodóvar del Campo (AMAC, en Agostini 1926). Hacer carbón de brezo suponía desceparlo y, por tanto, erradicarlo del monte, lo que contribuyó al claro dominio de la jara en el paisaje serrano.

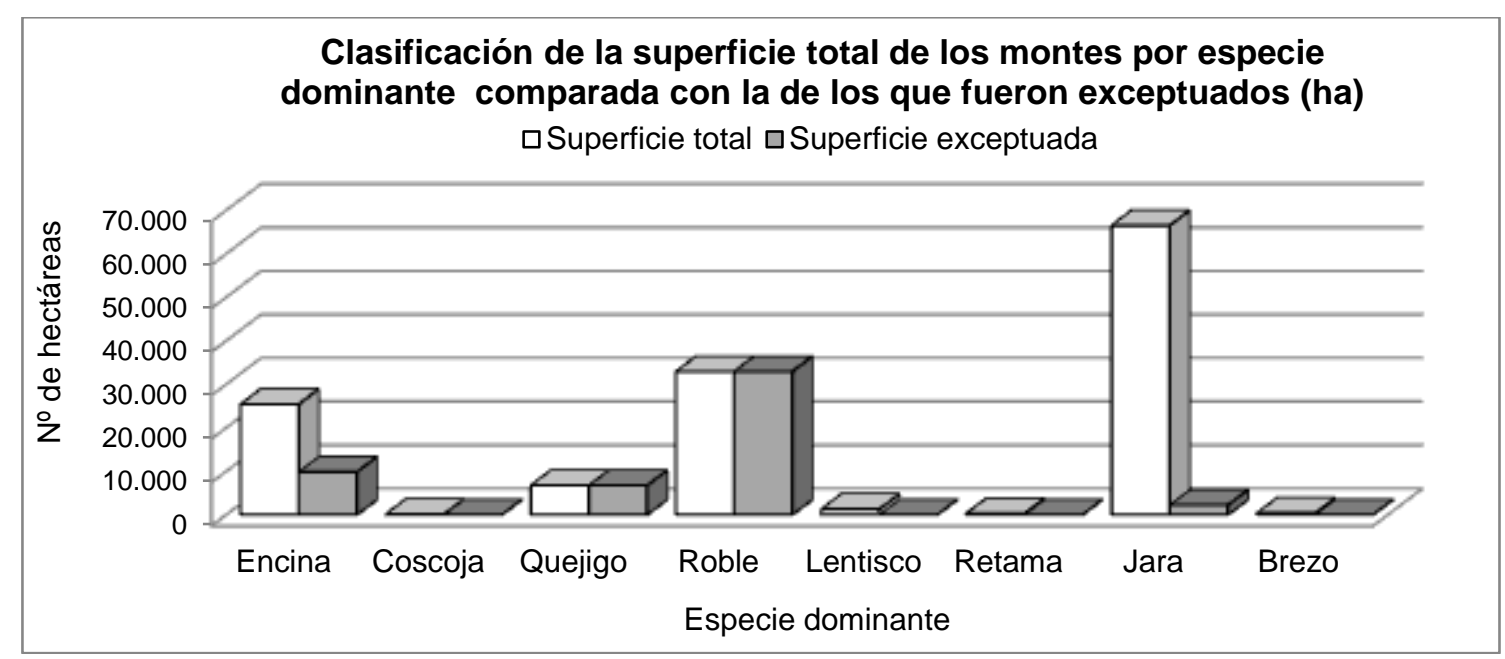

Fig. 2.52. Superficie de los montes incluidos en la Clasificación General de 1859 en los municipios de Sierra Madrona y Valle de Alcudia según su especie dominante. Se indica el $n^{\circ}$ de ha según la especie dominante y, de estas, cuantas debían ser exceptuadas de la desamortización.

En los quejigares y robledales exceptuados la jara también se situaba entre las subordinadas. Excepción era el monte denominado "Valle" (Fuencaliente) de 32,20 ha que tenía como dominante el roble y subordinado quejigo o la "Primera demarcación al sur de la Sierra de Alcudia" (Almodóvar del Campo) de 6.458 ha con el roble como dominante y subordinadas quejigo y encina. Resultados que confirman la documentación histórica que mostraba dehesas de encinas como árbol casi exclusivo en el Valle de Alcudia. Mientras que en los montes de las sierras la selección no fue tan minuciosa por lo que, aun habiendo encinas, la proporción de otras especies arbóreas y arbustivas suele ser superior.

En el resto de montes, además del masivo descepe de los brezos (sus cepas también eran muy valoradas para hacer pipas de fumar-cachimbas-), el pastoreo impuso la quema reiterada del monte cada 3-6 años, hasta el total agotamiento de las especies que antes lo dominaban, dando lugar a los inmensos y pirófitos jarales que citan en la comarca los textos decimonónicos. En los montes de los pueblos, los más pobres y necesitados criaban al vilipendiado y modesto hato de cabras, que era el soporte más importante de su economía, al tiempo que eran los pastores de rebaños más numerosos de los propietarios más ricos. Con las desamortizaciones, el campesinado más humilde perderían estos derechos y tuvieron que incrementar la presión sobre 
la superficie pública que fue exceptuada, lo que daría lugar a enfrentamientos con la administración forestal, conforme ésta se fue implantando en la segunda mitad del siglo XIX.

Esta primera Clasificación de 1859 pareció demasiado proteccionista al Ministerio de Hacienda que demandó una nueva clasificación en la que aparecieran menos montes "exceptuables". Pretendía que los que habían sido considerados como dudosos, categoría que incluía a encinares, alcornocales y coscojares, fueran vendidos sin necesidad de informe por parte de los ingenieros de montes. El Ministerio invalidó la Clasificación por un Real Decreto de 22 de enero de 1862, en cuya redacción no se contó con la Junta Facultativa del Cuerpo de Montes (Calvo 2001). En este RD se decretaba la creación de un Catálogo en el que quedarían excluidos todos los montes menores de 100 ha y, en cuanto a especies a exceptuar, se reducía el listado a pino, roble y haya. Para la confección de este nuevo Catálogo, corrección de errores y reclamaciones, solo tuvieron los ingenieros 2 meses. Ese mismo año de 1862 se publica el Catálogo de Montes Públicos exceptuados de la Desamortización (CMPED) que ya carece de montes donde dominen matorrales, la encina, el alcornoque o la coscoja. El de Ciudad Real fue publicado el 13 de junio de 1862 en el número 74 del BOP, firmado por Enrique de Cisneros, gobernador Civil de la Provincia. Apareció, como en el resto de las provincias, sin corregir errores ni atender reclamaciones (Pérez Soba 2006). Este Catálogo de Montes de 1862 redujo los montes exceptuados de los pueblos de Sierra Madrona y Valle de Alcudia a solo 20 (Fig. 2.53) con 39.660 ha (Fig. 2.54).

Dado el predominio de la encina en la mayoría de sus montes de Sierra Madrona y Valle de Alcudia y estos se declararon no exceptuados de la venta, supuso en la comarca una considerable pérdida de superficie pública a favor de la privada. Con esta decisión el Ministerio de Hacienda validaba el criterio económico que había presidido la transformación histórica en pastizales herbáceos arbolados con encina o pastizales leñosos, también con predominio de la encina y, casi siempre, en detrimento de unos bosques más diversos. El valor económico de la encina se basaba en su mayor adaptación a los intereses humanos y a superar sus intervenciones, pues la encina cuenta a su favor con una mayor capacidad de dispersión, rusticidad y un más difícil agotamiento de su cepa frente a los otros Quercus. Es decir, de no haberse favorecido a la encina, habría muchos más robles y quejigos y, por tanto, muchos más montes se hubieran mantenido como públicos.

En el BOP los montes figuran con su pertenencia, sus cuatro límites en una descripción sencilla, el nombre científico de la especie y el vulgar (Quercus lusitanica para el roble quejigo y $Q$. sessiliflora para el roble común. A diferencia de la Clasificación de 1859, no recoge las especies subordinadas. En la Clasificación de 1859 el alcornoque solo figuraba como especie subordinada en 9 montes como subordinados al quejigo o al roble en los montes de los 2 partidos judiciales de la comarca (Almadén y Almodóvar). 


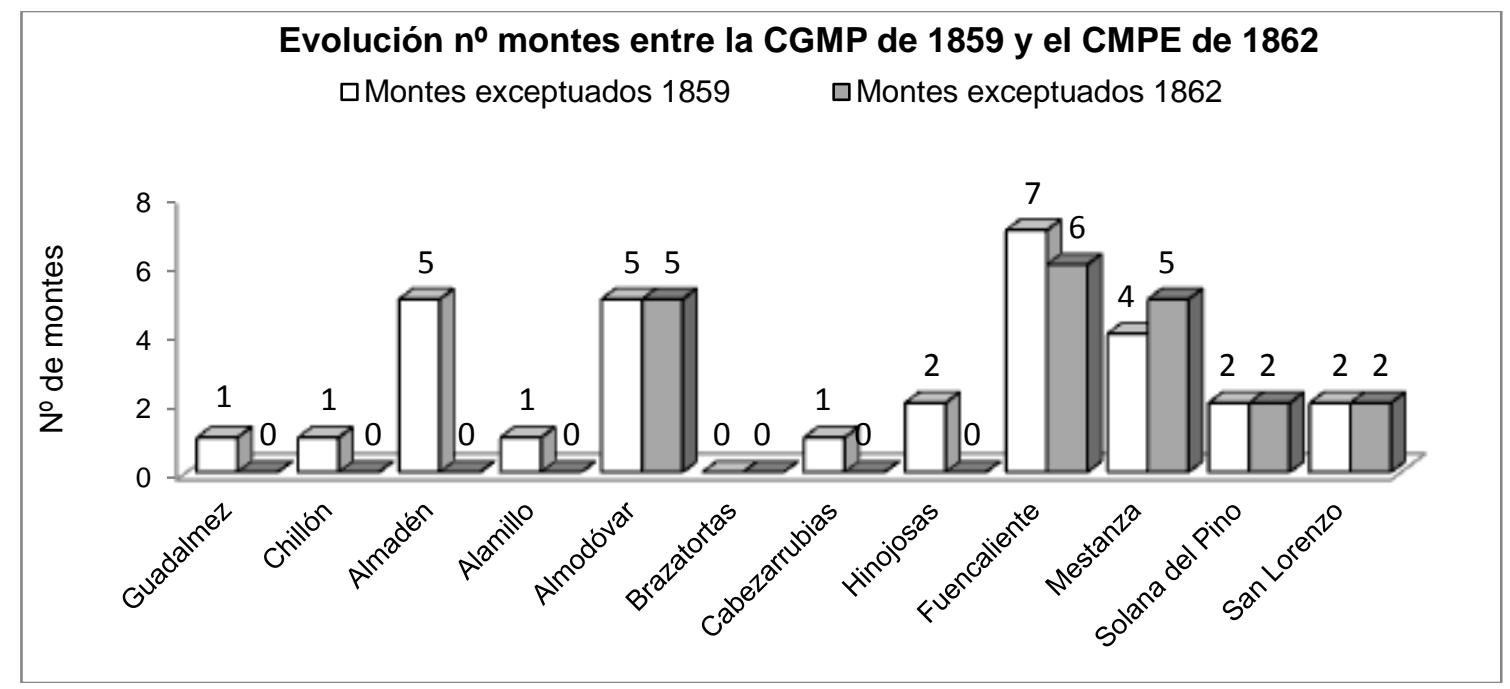

Fig. 2.53. Evolución del número de montes entre la Clasificación General de 1859 y el Catálogo de montes públicos exceptuados de 1862 en los municipios de Sierra Madrona y Valle de Alcudia

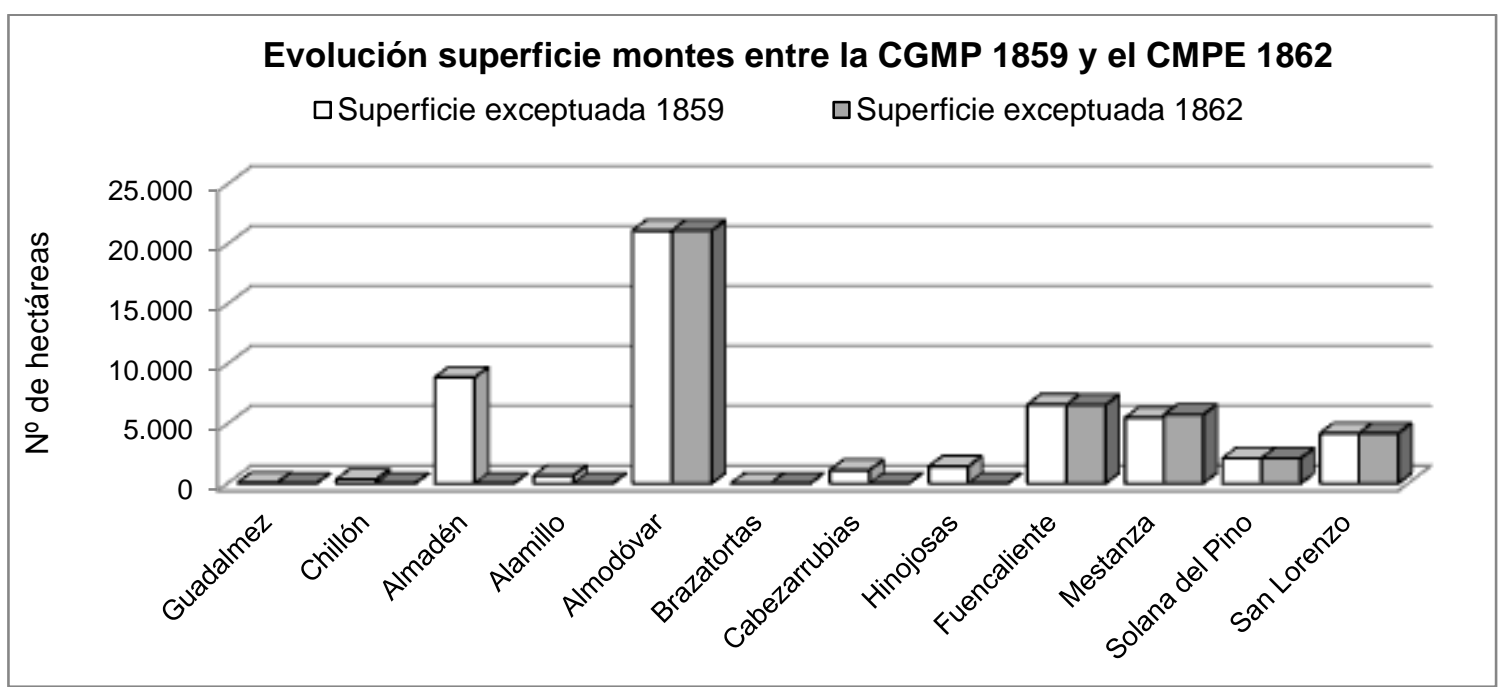

Fig. 2.54. Evolución de la superficie del número de montes entre la Clasificación General de 1859 y el Catálogo de montes públicos exceptuados de 1862 en los municipios de Sierra Madrona y Valle de Alcudia.

De la Clasificación de 1859 al Catálogo de 1862, pasaron a ser enajenables los montes de Guadalmez (51 ha y encina) y de Chillón (322 ha y encina). En Almadén los tres montes de los pueblos (con 27 ha y roble, otro de 772,75 ha y encina, más un tercero sin datos) y el del estado (7.190 ha y encina) dejan de figurar como exceptuados, como también el de Alamillo (654 ha y de encina). Mestanza aumenta en un monte pues incluye la "Umbría del Montero" (de 258 ha y quejigo), que en 1859 parecía que figuraba en Hinojosas, por lo que este municipio pierde los dos con que figuraba en 1859 (Rosalejo de 1059 ha y jara). Cabezarrubias pierde el único considerado (1095 ha y jara). En Solana del Pino y San Lorenzo los dos montes exceptuados se mantienen. Las exigencias del Gobierno predominaron y desaparecen los montes en los que la 
especie dominante era la encina o las diversas especies de matorral (coscoja, lentisco, retama, jara y brezo)

Aunque la superficie de los 20 montes mantuvo las mismas cifras de 1859, el Catálogo tiene un valor añadido al incluir la pertenencia y los confines de cada predio. Algunos son límites identificables con facilidad, e inamovibles, por lindar con los de términos municipales, con otros montes exceptuados o con arroyos, pero en la mayoría son ambiguos o limitan con propiedades particulares. Esta situación, en una época de descontrol administrativo, hará posible la pérdida de superficie pública a favor de los propietarios colindantes en tanto no se produjera el deslinde y amojonamiento de cada monte, lo que será un proceso largo por la falta de una infraestructura forestal que lo permita. En 1860, la provincia de Ciudad Real contaba, pagados con los fondos del Estado y de las provincias, con 1 ingeniero, 4 peritos, 10 guardas mayores y 2 guardas del Estado. Personal que debía atender una superficie provincial de 113 montes exceptuados en 1859 de 155.525,54 ha, además de los 413 montes enajenables que sumaban 435.805,46 ha (Memoria 1861). Es decir, que el mencionado personal debía atender, en años anteriores, 591.331,0 ha, lo que permite entender la precariedad de conocimientos de la realidad forestal de la provincia que, en 1859, estaba bajo la dirección del Comisario de Montes Miguel Medrano y Morales, quién apenas llevaba un año tras sustituir al anterior comisario Venancio Moreno y Basco. Al frente del servicio de montes tras la Clasificación, fue nombrado el ingeniero que la había realizado Manuel Fernández Monjardin (Guía, 1858, 1859, 1860). La defensa de los montes y su conocimiento real solo se podría hacer efectiva si se contaba con un personal técnico y una guardería capaz de controlar la superficie a su cargo.

Entender la precariedad del servicio de montes es posible mediante los presupuestos de los ingresos y gastos de la administración de montes. Los correspondientes al periodo 1854-1860 fueron publicados en la Memoria del Ministerio de Fomento de 1861. Los relativos a Ciudad Real (Tabla 2.7) informan de los gastos ocasionados por los montes que eran pagados con fondos provinciales o municipales, así como los ingresos de los municipios por igual concepto. De su comparación se ve la estabilidad de los gastos provinciales durante los años considerados, así como la reducción de los gastos municipales desde 1854, con el mínimo en 1854. Gastos que son muy elevados frente a unos ingresos que apenas alcanzan la cuarta parte y que explican la penuria presupuestaria del ramo de Montes en una provincia que debía gestionar 591.331,0 ha.

En la "Memoria" de la Dirección General de Agricultura, Industria y Comercio (1861), el redactor de la parte relativa al ramo de Montes señala que los ingresos no mostraban la producción real de los montes pues, considera que era frecuente que las secciones de Fomento en los gobiernos de las provincias atribuyeran como ingresos municipales en concepto de propios una parte de la producción forestal, tal era el caso de la montanera o los pastos, que eran los principales productos de los montes del Valle de Alcudia. Como la no inclusión de las rentas por pasto de los montes era aceptada por los comisarios, se consideraba necesario conocer con precisión qué otros ingresos se computaban a los propios (Tabla 2.7), pues opinaba que una parte muy considerable, acaso la mayor, que se atribuía a éstos se debían incluir como ingresos correspondientes a los montes. Al incorporar gran parte, o la totalidad de la cifra, de la renta de 
propios a la de los montes, el balance mejoraba ostensiblemente en la provincia, pues la cifra de ingresos se multiplicaría por 10 y los montes podían ser objeto de una mejor providencia económica.

\begin{tabular}{|c|c|c|c|c|c|c|c|c|}
\hline & $\mathbf{1 8 5 4}$ & $\mathbf{1 8 5 5}$ & $\mathbf{1 8 5 6}$ & $\mathbf{1 8 5 7}$ & $\mathbf{1 8 5 8}$ & $\mathbf{1 8 5 9}$ & $\mathbf{1 8 6 0}$ & Media \\
\hline $\begin{array}{c}\text { Gastos provinciales } \\
\text { de montes }\end{array}$ & 62.400 & 62.400 & 62.400 & 62.400 & 62.400 & 62.400 & 62.400 & $\mathbf{6 2 . 4 0 0}$ \\
\hline $\begin{array}{c}\text { Gastos municipales } \\
\text { de montes }\end{array}$ & 234.064 & 200.055 & 202.593 & 209.918 & 205.842 & 210.218 & 180.805 & $\mathbf{2 0 6 . 2 1 4}$ \\
\hline $\begin{array}{c}\text { Ingresos } \\
\text { municipales por } \\
\text { montes }\end{array}$ & 33.567 & 19.942 & 54.984 & 13.766 & 72.326 & 109.370 & 172.403 & $\mathbf{6 8 . 0 5 1}$ \\
\hline $\begin{array}{c}\text { Ingresos } \\
\text { municipales por } \\
\text { propios }\end{array}$ & 555.640 & 749.877 & 794.225 & 703.746 & 655.761 & 691.337 & 817.047 & $\mathbf{7 0 9 . 6 6 2}$ \\
\hline
\end{tabular}

Tabla 2.7. Gastos provinciales, gastos e ingresos municipales (en reales de vellón), por razón de montes e ingresos municipales en concepto de productos de propios en los años 1854 a 1860 de la provincia de Ciudad Real, según los resúmenes publicados por la Dirección General de Administración. Fuente: Memoria (1861)

Ante una situación económica que imposibilitaba cualquier comprobación se entiende que los resultados se redujeran a la simple desaparición de los predios que no cumplían las exigencias del Gobierno. Así, la superficie de los 16 montes en los que dominaba el roble exceptuados de la desamortización en la Clasificación de 1859 fue 32.901 ha que se redujo ligeramente en el CMPE de 1862 a 15 montes y 32.874 ha, por la exclusión de las 27 ha del monte Ribera alta de Almadén. A los 5 montes y 6.786 ha que se exceptuaron por tener como especie dominante el "quejigo" en 1859 se le mantuvo número y superficie, si bien en 1862, se la calificó como "roble quejigo". El añadido del término "roble" probablemente fuera para tratar de que estos montes no se vendieran.

La sustitución de comisarios de montes, dependientes de gobernadores civiles y del Director General de Agricultura, por ingenieros de montes, se debió a la mayor capacidad de los segundos para realizar la clasificación general de los montes a efectos de la desamortización según la orden de 6 de marzo de 1856. La situación previa de montes administrados por comisarios, a los que consideraba como agentes electorales, la refleja Mateo Sagasta el 28 de marzo de 1859 en el Congreso de los Diputados (González Doncel y Gil 2013), siete años después de que hubieran acabado sus estudios la primera promoción de ingenieros de montes y, prácticamente estos profesionales carecieran de contenido administrativo:

[...] Me preguntaba el Sr. Ministro de Fomento como una gran razón para establecer estas Secciones, qué deslindes, qué operaciones se han hecho en los montes hasta ahora. Ninguna; lo que se ha hecho ha sido perder los montes [...] el mal parte del Gobierno, que teniendo ingenieros de montes consentía y consiente que fuesen a las provincias comisarios sin ningún género de conocimientos, como no fuesen conocimientos electorales, mientras que jóvenes que 
han hecho su carrera de ingenieros de montes se están en su casa sin tener colocación, después de haber gastado su tiempo y su caudal [...]

Fue necesario que el Gobierno depositase sus expectativas financieras en la desamortización de los montes públicos (1855), de los que poco o nada sabía, para que los ingenieros de montes adquirieran fuerza en una nueva Administración Forestal, que durante las décadas siguientes careció de capacidad para llevar a cabo sus fines y un adecuado control de la desamortización de los montes públicos; cuya responsabilidad fue del Ministerio de Hacienda y de los gobernadores provinciales. En este periodo debió ser habitual la apropiación ilegal de parte de los montes públicos o las peticiones infundadas basadas en ventas simuladas, en informaciones posesorias sin garantía alguna o sustentadas en documentos ambiguos e imprecisos (Calvo 2003). La misma historia que había sido norma en siglos anteriores.

En la "Memoria" arriba citada de 1861 se opinaba que era necesario incorporar a la producción forestal el aprovechamiento directo de los recursos en el monte (consumo en especie) aún consciente de la dificultad de su valoración. Con el fin de conocer esta realidad se dispuso que uno de los primeros cometidos de los ingenieros asignados a los distritos fuera el cómputo de esta cifra, cantidad que se calculó al tiempo que se registraba la producción de los montes públicos en el año de 1860, fecha en la que todas las provincias contaban con un ingeniero, pero la provincia de Ciudad Real es la única de toda España que no presenta este cálculo, lo que refleja las particularidades de la provincia para que se llevara a cabo.

En esta tarea, que la provincia asumió a partir de 1861, se debían diferenciar las cantidades percibidas en dinero, procedente de los remates de los aprovechamientos autorizados o de las cantidades obtenidas como consecuencia de los destrozos debidos al viento, árboles incendiados o una explotación fraudulenta y, tasando, por otro lado, todos los productos que, en función de los usos vecinales, se consumieran en especie y sin pagar por ello retribución pecuniaria. Anualmente, el Distrito debía de elaborar y aprobar los planes de aprovechamientos (art. 87 del Reglamento de 1865) que fijaban la cantidad de productos:

[...] primarios y secundarios que la buena conservación de los montes permita, procurando conciliarla con las obligaciones que el monte tenga que cubrir, así como las exigencias de consumo $[\ldots]$

Los planes anuales permiten aproximar lo que generaban los montes públicos en productos como leñas, maderas o pasto, cuyos valores hasta 1880 están recogidos en las estadísticas oficiales de la época, no siendo publicadas las relativas al periodo 1881-1901 (GEHR 1991). El tipo de aprovechamientos distinguía entre ordinarios — que incluían los que salían a subasta y se cedían al mejor postor - e ingresaba el ayuntamiento propietario, los que disfrutaban gratuitamente los vecinos y los imprevistos o extraordinarios, debidos a derribos de viento, incendios o fraudes. Durante el periodo 1860-80 (Tabla 2.8) en la provincia predominaron los usos vecinales, en su mayoría disfrutados gratuitamente por los vecinos. 


\begin{tabular}{|c|c|c|c|}
\hline & Tipología & Renta & Porcentaje \\
\hline \multirow{8}{*}{ 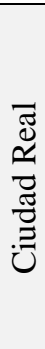 } & Expedientes ordinarios & 2.161 & 27,93 \\
\hline & Usos vecinales & 5.083 & 65,71 \\
\hline & Derribos de viento & 1 & 0,01 \\
\hline & Árboles incendiados & 264 & 3,41 \\
\hline & Árboles cortados fraudulentamente & 227 & 2,93 \\
\hline & Total Ciudad Real & 7.736 & 100,00 \\
\hline & Exceptuados & 2.268 & 29,32 \\
\hline & Enajenables & 5.468 & 70,68 \\
\hline \multicolumn{2}{|c|}{ Total España } & 302.344 & 100,00 \\
\hline \multicolumn{2}{|c|}{ Exceptuados } & 227.485 & 75,24 \\
\hline \multicolumn{2}{|c|}{ Enajenables } & 74.859 & 24,76 \\
\hline
\end{tabular}

Tabla 2.8. Valor total, en miles de pesetas corrientes, de la producción de los montes públicos de Ciudad Rea desde 1861 a 1880, según el carácter de los aprovechamientos y el tipo de monte y su comparación con España. Fuente: GEHR 1991.

El aspecto más llamativo el valor total estimado de los productos se diferencia entre el tipo de montes según fueran exceptuados o enajenables; proporcionando los enajenables el 70,68\% del total, porcentaje que es precisamente el inverso en el resto de España donde los exceptuados eran los que aportaban el 75,24\% del valor total de los productos forestales. Esta significativa diferencia permite opinar que el proceso desamortizador, que fue negativo para la propiedad pública en toda España, en la provincia de Ciudad Real supuso el despojo de lo público a favor de lo privado.

La defensa y conservación de los montes públicos requería la capacidad de oponerse a los abusos cometidos, proceder que se amparaban en la denominada "libertad de aprovechamiento". Evitar las arbitrariedades de los poderosos no era una tarea fácil, pues se escudaban en las necesidades de los vecinos más desposeídos para usar los recursos de los montes públicos o, también, en su capacidad para comprar voluntades. Evitarlo solo podría ser factible si se disponía de personal pero, en particular, que la guardería no dependiera del poder local, pues como señaló García Martino (1871) es:

[...] fiel servidora de quien la nombra y paga, se muestra tan activa y severa para denunciar y vejar a los enemigos de la fracción política a que pertenece el alcalde, como morosa, tolerante y hasta complaciente con los electores amigos [...]

La guardería dejó de ser pagada por los pueblos en junio de 1868, al entrar a formar parte del presupuesto del Ministerio de Fomento. Aunque la revolución de septiembre de ese mismo año dio lugar a numerosos excesos, trajo a finales de año un decreto que determinaba el número y circunstancias del personal subalterno encargado de la custodia y fomento de los montes públicos exceptuados de la desamortización. Como señalaba el texto legal: las Juntas revolucionarias han sentido la necesidad de no dejar abandonada la riqueza forestal, señalando que:

[...] no permiten las apremiantes atenciones del tesoro crear desde luego el número de plazas que son necesarias pero considera que ochenta Ayudantes, trescientos Sobreguardas y 
quinientos Guardas [para todo el país] impedirán cuando menos que los dañadores de los montes ilegalmente conviertan en su provecho las existencias leñosas que pertenecen a la generación presente y a las venideras [...]

En estos años de precariedad de medios, la comarca va a recibir la visita de un manchego ilustre, Máximo Laguna y Villanueva, que la recorre en mayo de 1867 en el marco de los trabajos de la Comisión de la Flora Forestal Española. Algunas de su observaciones aparecen en el primer número de la revista del colectivo (Laguna 1868). Algunos de sus comentarios sobre el pedazo de Sierra Morena que recorre en sus jornadas botánicas, por su interés, son destacables:

[...] Entre las Sierras de Mestanza, y las conocidas por Umbria de Alcudia, se halla el gran valle de ese nombre. Sierra Madrona [...] es á la vez la mas agreste, la mas fragosa, la mas separada de toda población algo importante; vista por la umbría desde la Solana del Pino, por ejemplo, presenta en sus flancos un admirable contraste los manchones negruzcos de las pizarras desnudas con los verdes de los rebollos y los rojizos de los brezos en flor. Los espesos jarales de sus faldas son inagotable criadero de javalies, y en sus cumbres las cabras monteses saltan y se arrojan por las pestañas de las rocas [...]

[...] el número de especies leñosas, observadas por mí en las pocas y ligeras correrías hechas por esa parte de Sierra-Morena, llega ya á noventa y cinco [...] veintitrés son árboles o arbolillos aprovechables como maderas o maderitas; cincuenta y siete arbustos ó matas que pueden aprovecharse principalmente como combustible, y las quince restantes son matitas pequeñas ó plantas de escasa importancia forestal [...] la escasa importancia es relativo, puesto que á poca distancia, en algunos pueblos de la Mancha, donde el combustible falta hasta el punto de que apenas se use otro que la basura y la paja, y donde se venden como leña menuda los manojos de tallitos de una lechetrezna (Euphorbia) y como leña gruesa las Tobas (Onopordon) [...]

[...] las jaras son aquí las matas dominantes, y el que en Mayo haya visitado esta Sierra [...] no habrá dejado de fijar los ojos en el inmenso manto verde-oscuro, abundantemente salpicado de flores blancas, sonrosadas y amarillas, que cubre en esa época del año todos los cerros y colinas, todos los valles y laderas [...]

[...] en los primeros estribos de la Sierra que caen al Norte, basta internarse un poco en esta, penetrar en sus harto solitarios barrancos y despoblados valles para encontrar una vegetación mucho mas variada [...] donde en media hectárea de extensión pueden á veces contarse por docenas las plantas leñosas. Jaras y jaguarzos; mirtos y madroños; lentiscos y cornicabras; ladiernas, acebuches y fresnos; enebros y espinos; aulagas y brezos; coscojas, encinas y melojos; romeros, cantuesos y tomillos; adelfas y sauces; hiniestas y torviscos y yedras y parras silvestres; ¡qué variedad de formas! ¡qué riqueza de colores y olores! i qué fuentes de goces para el verdadero naturalista! [...]

[...] Suele creerse, y yo estaba también en ese error, que los Pinos faltan completamente en esta parte de Sierra Morena; sin embargo, los hay, aunque muy escasos. En unos ásperos 
peñascales de Sierra Quintana, sitio llamado Nava-Manzano [...] se encuentran algunos ejemplares raquíticos y torcidos del Pino negral o maritimo (P. pinaster Ait) [...] iOh naturaleza! ¿Qué de ridiculeces te atribuye la ridícula manía de los que todo quieren explicarlo según leyes que aun nadie conoce! [...]

[...] ¿Cómo se aprovechan sus montes? Difícil de contestar. Montes altos, en rigor no existen, algunos rodales de roble y quejigos [de la Cereceda y de Ventillas], y algunas dehesas de encinas son los únicos que á duras penas merecen ese nombre; el alcornoque no se aprovecha; su corcho solo se emplea en malas colmenas, las que para que todos sea en ellas, primitivo, se cosen con clavos de jara. Todo lo demás es monte bajo; su principal aprovechamiento el del pasto; no siendo, por desgracia, poco frecuente, el de rozas, reducido a rozar el matorral con hocino, quemas sus leñas ya secas, sembrar centeno, por lo común, sobre esas cenizas, enterrar las semillas haciéndola pisotear por machos cabríos (y de ahí las siembras macheadas), recoger una miserable cosecha, y abandonar después el terreno, que vuelve a cubrirse de pujantes jaras, y así aquí y así después mas allá, y así ahora, y así hace siglos [...]

Esta descripción sobre el estado de los montes permite entender cuál era su situación y la que seguiría siendo en décadas posteriores. Era reflejo del pasado y de las reducidas posibilidades de la Administración Forestal en la provincia. En 1874, un Decreto del presidente de la I República de 11 de julio la reforma y propone una distribución del personal facultativo y auxiliar por Distritos, la correspondiente a la provincia de Ciudad Real comprende a 2 Ingenieros (de un total para toda España de 113), 1 Ayudante (de 43), 4 Sobreguardas (de 220) y 10 Guardas (de 352). Cifra que incluye el mismo número de personas de 1859, pero con diferentes categorías. Cifras que suponen que, para el conjunto de España, el número de ayudantes se rebaja al 53\%, al $73 \%$ el de sobreguardas y al $70,4 \%$ el de guardas de los aprobados por las Juntas revolucionarias en 1868.

Con la Restauración borbónica de 1874, los gastos ocasionados durante el sexenio revolucionario y la última guerra carlista (1872-76), llevó a que los políticos más liberales y el Ministerio de Hacienda desearan seguir aumentando la superficie de tierras a vender, frente a la oposición del Ministerio de Fomento que luchaba por defender la propiedad pública forestal. El 8 de noviembre de 1877 una Real Orden propone una nueva revisión de los montes del CMUP exceptuados de la desamortización. Las ventas pocas veces tuvieron resultados satisfactorios para los bosques y en muchos casos las acompañó el agravante del escaso resultado económico obtenido. Una instrucción de 1877 trata de evitar que los compradores de montes, cuyo importe abonaban a plazos, pudieran talar el arbolado si no lo habían pagado en su totalidad. Como comentaría Codorniú (1914):

[...] los rematantes solían talarlos enseguida, y con parte del producto de la corta pagaban al Estado. Aun en frecuentes ocasiones los asolaban con sólo abonar el primer plazo, declarándose luego en quiebra, y realizando un bonito, aunque no honrado negocio [...] 
La falta de presupuestos, la necesidad de consolidar la propiedad pública y la incapacidad de controlar a los ganaderos no permitieron que la recuperación de rasos o el incremento de densidades fueran objetivos de los Distritos Forestales. El de Ciudad Real no pudo llevar a cabo la rectificación del Catálogo de 1862 en Sierra Madrona y Valle de Alcudia hasta quince años después, y lo hizo en 2 periodos diferentes. Los municipios del partido judicial de Almadén en 1893 y, los de Almodóvar, en 1896.

En las revisiones del Catálogo de 1893-96 el número de montes se aumenta a 34, uno de encina, 20 de quejigo y 13 de roble, y su superficie pasa a 60.711 ha en 9 términos municipales: Alamillo (1 monte), Almadén (5), Almodóvar (3), Brazatortas (5), Cabezarrubias (1), Hinojosa (1), Fuencaliente (9), Mestanza (5) y San Lorenzo (4). En Solana del Pino la revisión de 1896 no considera ningún monte exceptuado pues los llamados "Sierra Madrona" y "Sierra Morena" fueron asignados a San Lorenzo, que pasaba así de tener 2 a a tener 4 montes exceptuados. Alamillo, incluyó como exceptuado, la Dehesa del Saladillo, de 2232 ha, con encinas, dehesa que había figurado entre las enajenables en la Clasificación de 1859, pero con una superficie de 322 ha; es decir ¡7 veces! menor a la considerada en 1893. En esta revisión parece que las reclamaciones de los vecinos fueron consideradas. Casi todos los pueblos mantenían así parte de sus montes. Guadalmez, que no tenía ningún monte exceptuado en el CMUP de 1862 ni en su revisión de 1893, conservó la histórica Dehesa de Valdesapos, de 2420 ha. El propietario de esta dehesa era el Duque de Medinaceli pero de ella disfrutaban comunalmente los vecinos (pagando un canon al propietario) desde el siglo XVI. Como el Código Civil de 1889 consideraba que el propietario verdadero de los bienes raíces era el enfiteuta, en este caso los vecinos, se expropió a los históricos propietarios (Mora 2010). La dehesa en 1893 paso a ser propiedad del común de los vecinos, no del ayuntamiento, por tanto era ya privada y no enajenable. Así sigue siendo en la actualidad, administrada por el Ayuntamiento a través de una comisión de agricultores y ganaderos locales.

En cuanto a las especies dominantes en los montes exceptuados en la revisión de 1893-96, siguen siendo quejigos y robles, los únicos que en la comarca permite el RD de 1862. Reitera la posibilidad de enajenación de todos los demás, aunque muchos ya habían sido vendidos. Sin embargo, se mantienen como no exceptuables 2 grandes fincas de encina. La Dehesa del Saladillo (Alamillo), posible en virtud del Apdo. 9 del $\operatorname{Art}^{\circ} 2$ de la Ley de desamortización general de 1855 (ver pag. 183), y la Dehesa de Castilseras (Almadén), el único monte propiedad del Estado, aunque no se incluyera en el Catalogo de 1862, ni en la revisión de 1893 como monte exceptuado.

A finales del siglo XIX numerosos montes públicos permanecían como enajenables por lo que se trató de activar su venta. Para ello, su gestión pasó desde el Ministerio de Fomento al de Hacienda, al que se le encarga formar un catálogo que reúna los montes enajenables junto a los de aprovechamiento común y las dehesas boyales, que aunque no figuraban en el Catálogo de 1862 estaban exceptuados en razón de sus usos. La custodia y defensa de los montes de este catálogo se le encarga a una Sección Facultativa de Montes que se crea en el Ministerio de Hacienda (Mangas 1993). 
Paralelo a este catálogo, y a través de una Ley de contenido financiero dictada a instancias del Ministerio de Hacienda en 1896 (Calvo 2003), se ordenó la revisión y formación definitiva del catálogo de los montes exceptuados de su venta, iniciada por la Ley Madoz, pero bajo un nuevo concepto, el de su utilidad pública. A partir de entonces quedarían definitivamente bajo la custodia de los Distritos Forestales.

Una vez concluida la rectificación del Catálogo de 1862, en el año 1897, se inicia la confección de un nuevo Catálogo de los Montes y demás terrenos forestales exceptuados de la Desamortización por razones de utilidad pública. Formado en cumplimiento a los dispuesto en el Artículo 4 del Real Decreto de 27 de Febrero de 1897. Este nuevo Catálogo se publicará adjunto al Real Decreto de 1 de febrero de 1901

En este nuevo proceso de excepción a la desamortización forestal se sustituyen los criterios de especie y cabida mínima (de 100 hectáreas) por el de "utilidad pública" que, según la ley, las funciones que debían cumplir eran:

[...] masas de arbolado y terrenos forestales que por sus condiciones de situación, de suelo y de área sea necesario mantener poblados o repoblar de vegetación arbórea forestal, para garantizar por su influencia física en el país o en las comarcas naturales donde tenga su asiento, la salubridad pública, el mejor régimen de las aguas, la seguridad de los terrenos o la fertilidad de las tierras destinadas a la agricultura, revisándose, con sujeción a este criterio, el actual catálogo de los montes exceptuados por su especie y cabida. [...]

La tradicional pérdida de los montes públicos, tanto de forma legal, por compra y transformación, o fraudulenta, fue un proceso que cambió con la promulgación y publicación del Catálogo de 1901. La inclusión de un monte en el Catálogo por causa de utilidad pública:

[...] no prejuzgaba ninguna cuestión de propiedad pero sí acreditaba la posesión a favor de la entidad a quien aquel asignaba su pertenencia. [...]

En Sierra Madrona y Valle de Alcudia, de nada sirvió la rectificación que se hizo en 1893-96, pues en el Catálogo de Montes de Utilidad Pública de 1901 (CMUP) aparecerá un número de montes inferior al Catálogo de 1862. El recorte fue considerable. Lo que permitirá vender los montes de casi todos los pueblos que no se hubieran vendido o apropiado: Chillón, Guadalmez, Almadén, Alamillo, Almodóvar, Brazatortas, Cabezarrubias, Hinojosas, Mestanza y Solana del Pino. Solo fueron considerados Montes de Utilidad Pública 10 predios forestales (Tabla 9). De los cuales Fuencaliente posee 9. Sorprendentemente, se incluirá uno nuevo que no figuraba ni en la Clasificación de 1859 ni en el Catálogo de 1862 denominado "Hontanillas" de 234 h, con lo que suman 8 de roble (Quercus tozza) y uno con roble y quejigo (Quercus lusitanica). San Lorenzo conservaría el monte "Sierra Alta" de quejigo; pero en este caso la pertenencia se la atribuye curiosamente al pueblo de Alhambra.

Una nueva rectificación será propuesta el 24 de abril de 1931 y aparecerá en 1933, manteniendo el número de montes, pero en esta ocasión todos están deslindados, por lo que sus superficies 
parece que serán ya las definitivas. También se corrige la partencia del monte "Sierra Alta" a San Lorenzo.

\begin{tabular}{|c|c|c|c|c|c|c|c|c|c|}
\hline \multirow{3}{*}{$\begin{array}{l}\text { Término } \\
\text { Municipal }\end{array}$} & \multirow{3}{*}{$\begin{array}{c}\text { Nombre del } \\
\text { monte }\end{array}$} & \multirow{3}{*}{$\begin{array}{l}\mathbf{1 8 6 2} \\
\text { Sup. }\end{array}$} & \multirow{2}{*}{\multicolumn{2}{|c|}{$\begin{array}{c}1901 \\
\text { Cabida } \\
\end{array}$}} & \multicolumn{5}{|c|}{1933} \\
\hline & & & & & \multicolumn{2}{|c|}{ Cabida } & \multicolumn{2}{|c|}{ Sup. poblada } & \multirow[b]{2}{*}{ Rasa } \\
\hline & & & Total & Forestal & Total & Pública & $\begin{array}{l}\text { Monte } \\
\text { alto }\end{array}$ & $\begin{array}{c}\text { Monte } \\
\text { bajo }\end{array}$ & \\
\hline Fuencaliente & Arroyo del Azor & 315 & 1.994 & 1.990 & 1.929 & 1929 & 350 & 1.579 & \\
\hline \multirow{3}{*}{ Fuencaliente } & \multirow{3}{*}{$\begin{array}{l}\text { Cereceda, } \\
\text { Dehesa boyal y } \\
\text { Peña Escrita }\end{array}$} & \multirow{3}{*}{430} & 1.251 & 1.184 & 1.147 & 1124 & 700 & 424 & \\
\hline & & & 930 & 927 & 889 & 882 & & 882 & \\
\hline & & & 489 & 489 & 526 & 526 & & 526 & \\
\hline Fuencaliente & Hontanillas & & 234 & 234 & 239 & 239 & 239 & & \\
\hline Fuencaliente & Navalmanzano & 129 & 755 & 755 & 874 & 874 & & 825 & 49 \\
\hline Fuencaliente & Nava del Horno & 4.078 & 2.175 & 2.175 & 2.167 & 2.167 & & 2.148 & 19 \\
\hline Fuencaliente & $\begin{array}{l}\text { Robledo de las } \\
\text { Hoyas y Peña } \\
\text { Rodrigo }\end{array}$ & 1.288 & 636 & 636 & 566 & 566 & 300 & 266 & \\
\hline Fuencaliente & $\begin{array}{ll}\text { Umbría } & \text { de } \\
\text { Ventillas } & \\
\end{array}$ & 310 & 1.793 & 1.787 & 1.684 & 1.665 & & 1.655 & 10 \\
\hline San Lorenzo & Sierra Alta & 1.932 & 2568 & 2558 & 2568 & 2558 & & 2558 & \\
\hline
\end{tabular}

Tabla 2.9. Evolución del nº de hectáreas de los Montes de Utilidad Pública de Sierra Madona.

El cambio de cifras es general en todos los montes en los sucesivos documentos legales relativos a los montes que conformarían el Catálogo de Montes de Utilidad Pública de Sierra Madrona. Con la peculiaridad de que unos multiplican su superficie por $6 \mathrm{y}$, otros, la reducen a la mitad. Los cambios requieren un estudio monte a monte. Nava del Horno pasa de 4.078 a 2.175 ha en 1901, mientras que "Arroyo del Azor" de 315 ha pasa a 1.994 ha en 1901 y 1.929 ha en 1933. La pregunta es por qué figuran cifras tan erróneas. La discusión sería larga pero es difícil entender que los alcaldes de los pueblos desconocieran las superficies de sus montes, o por qué los comisarios de montes anteriores a la Administración Forestal modificaron las cifras.

En total, se pasa de 8482 ha en 1862, a 12.895 ha en 1901 de cabida total, de la que pública son 12.735 ha y, finalmente, en 1933, ya todos deslindados baja a 12.589 ha, de la que es pública 11.656 ha. Un nuevo dato de 1933 es que diferencia entre superficie poblada de monte alto, que supone el 15,6 \% de la superficie pública (1589 ha), monte bajo (10.863 ha) y rasos (78 ha).

El grupo de monte públicos de Fuencaliente fue objeto de un Proyecto de Ordenación, firmado por Alejandro G. Heredia el 25 de octubre de 1910. Sobre las 10.257 ha indicadas en el CMUP de 1901 el proyecto difiere en 250 ha de menos. Los montes suman 10.007 ha, como resultado de una mayor información tras su deslinde, por aceptar los enclavados o por la pérdida de superficie pública a favor de los propietarios colindantes sin que se pueda demostrar. Finalmente el CMUP de 1933 la situará en una cifra algo menor: 9.098 ha. de superficie pública. Como dominantes considera 4 especies arbóreas, Quercus pyrenaica, $Q$. faginea, $Q$. ilex y $Q$. suber y divide al grupo de montes en 5 secciones, con 4 cuarteles por sección excepto en una que fueron 3. Consideró que los montes se encontraban en muy mal estado de conservación por lo que propuso como mejora selvícola un turno de trasformación de 80 años. 
Como aprovechamiento futuro del monte estableció un turno de cortas de 160 años por cuartel, con periodos de rotación y regeneración de 20 años, es decir, cada cuartel a su vez se dividió en 8 tramos. Además de estas y otras medidas selvícolas para la regeneración de las masas forestales, trazar pistas y construir casas para los guardas, también proponía el acotamiento de diversas zonas al ganado.

La administración de los montes de los pueblos, y hasta la actualidad, fue compartida entre la administración forestal provincial y el ayuntamiento. El art ${ }^{\circ} 83$ del Reglamento de 17 de octubre de 1925 contenía las instrucciones para la adaptación del régimen de los montes de los pueblos al Estatuto municipal, donde se indicaba como debían celebrarse las subastas de los productos de sus montes. Desde mediados del siglo XX será el Distrito Forestal quien publique los pliegos de condiciones generales reglamentarias y facultativas para la subasta, adjudicación y aprovechamiento de los productos de los montes de UP de los pueblos, siendo los aprovechamientos de pastos los que generan el mayor porcentaje de la producción (Tabla 2.10) de todos los montes de la provincia $(85,4 \%$ como media de los años $1913 ; 1920 ; 1924 ; 1932)$ seguidos de la autorización de roturaciones (10,2\% para la media de los 4 años citados). Mientras que las cifras de madera y leñas son prácticamente despreciables, lo que evidencia el escaso arbolado que poseería la provincia.

\begin{tabular}{|c|c|c|c|c|c|c|}
\hline \multicolumn{7}{|c|}{ Aprovechamientos ordinarios y extraordinarios } \\
\hline Año & madera & leñas & pastos & montanera & corchos & roturaciones \\
\hline 1913 & 3 & 2 & 49 & - & 3 & 0 \\
\hline 1920 & 2 & 1 & 74 & - & - & - \\
\hline 1924 & 0 & 2 & 217 & 3 & - & 46 \\
\hline 1932 & 9 & 1 & 105 & - & - & 7 \\
\hline
\end{tabular}

Tabla 2.10. Valor total, en miles de pesetas corrientes, de la producción de los montes de utilidad Pública de Ciudad, según el carácter de los aprovechamientos. Fuente: G. H. E. R., 1991

En los años 50 fueron redactados y aprobados 3 proyectos de ordenación provisionales en Fuencaliente, en concreto aprobados entre los años 1956 y 1957, el del monte Cereceda, el monte Hontanillas y el del Robledo de las Hoyas y Peña Rodrigo. En estos 3 proyectos, se hace nueva referencia al mal estado de conservación de los montes, lo que presupone que la acción del ganado había imposibilitado que tuvieran lugar la regeneración del grupo de montes. Poco se había avanzado desde el Proyecto de Ordenación de 1910, si es que no se abandonó por completo. Establecen periodos quinquenales que a su vez se dividen en años forestales. La producción de madera de los primeros años forestales puede verse en la Tabla 2.11. 


\begin{tabular}{|c|c|c|c|c|c|c|c|}
\hline \multicolumn{8}{|c|}{ Aprovechamiento de madera y leñas en 3 montes de Fuencaliente entre 1958 y 1962} \\
\hline \multirow[b]{2}{*}{$\begin{array}{c}\text { Nombre del } \\
\text { Monte }\end{array}$} & \multirow[b]{2}{*}{$\begin{array}{c}\text { Año } \\
\text { forestal }\end{array}$} & \multicolumn{3}{|c|}{ Q. pyrenaica $\left(\mathrm{m}^{3}\right)$} & \multicolumn{3}{|c|}{ Q. faginea $\left(\mathrm{m}^{3}\right)$} \\
\hline & & Madera & $\begin{array}{c}\text { Leña } \\
\text { tronco }\end{array}$ & $\begin{array}{l}\text { Leña } \\
\text { copas }\end{array}$ & Madera & $\begin{array}{c}\text { Leña } \\
\text { tronco }\end{array}$ & $\begin{array}{l}\text { Leña } \\
\text { copas }\end{array}$ \\
\hline \multirow{2}{*}{ Cereceda } & 1960-1961 & 38,9 & 48,7 & 58,5 & 15,9 & 30,2 & 50,1 \\
\hline & 1961-1962 & 354,5 & 731,2 & 750,4 & & & \\
\hline \multirow{3}{*}{ Hontanillas } & 1958-1959 & 172,4 & 215 & 281,6 & 0,4 & 7,1 & 3,9 \\
\hline & $1959-1960$ & 200,2 & 291,4 & 490,4 & 5,3 & 7,4 & 9,6 \\
\hline & 1960-1961 & 501,3 & 120,3 & 412,8 & 92,4 & 129,7 & 85,4 \\
\hline \multirow{3}{*}{$\begin{array}{l}\text { Robledo de } \\
\text { las Hoyas y } \\
\text { Peña Rodrigo }\end{array}$} & 1957-1958 & 46,6 & 21,6 & 68,3 & 3,7 & 3 & 6,7 \\
\hline & 1960-1961 & 185,2 & 264,4 & 332,3 & 0 & 6,3 & 7 \\
\hline & 1961-1962 & 677,1 & 428,6 & 1204,3 & & & \\
\hline Total & & 2176,2 & 2121,2 & 3598,6 & 117,7 & 183,7 & 162,7 \\
\hline
\end{tabular}

Tabla 2.11. Aprovechamientos de madera y leña en 3 robledales de Fuencaliente incluidos en los diferentes CMUPs, tras los proyectos de ordenación provisionales de 1956 y 1957. Fuente: JCCM 2001.

En la Tabla 2.11 puede verse consignada con precisión una muestra del aprovechamiento maderero de los robledales de Fuencaliente, aunque en esta ocasión de forma "ordenada" por una administración forestal ya mejor organizada que en el pasado. El problema era que en los pueblos, sus autoridades, no estaban acostumbrados a que se les dijera lo que tenían que hacer en sus montes, por lo que raramente se respetaban estas regulaciones en tanto no se dispusiera de guardería forestal que controlara las ejecuciones. En el monte Hontanillas, en esos años se superó en $114 \mathrm{~m}^{3}$ de madera extraídos con respecto a lo estipulado en su plan de ordenación (Tabla 2.11) y, en el robledo de las Hoyas, se superó por $42 \mathrm{~m}^{3}$. Los deseos de los alcaldes o de quienes les controlaban era la regla y, en el monte, madereros, como pastores, no hacían caso ni a las disposiciones legales ni al criterio de los técnicos.

Como ejemplo concreto de esta planificación sobre el papel puede verse el BOP de Ciudad Real de 3 de septiembre de 1962, que publica el pliego de condiciones para el año forestal 19621963. En el pliego hay nada menos que 41 condiciones generales que han de cumplirse en la subasta, más otras 67 referentes a las distintas clases de aprovechamiento, lo que evidencia una administración garantista y burocratizada. En lo concerniente a la madera, establece el aprovechamiento de 1.820 pies de roble en el monte Robledo de las Hoyas y Peña Rodrigo (Fuencaliente), del que se espera obtener 453,4539 $\mathrm{m}^{3}$ de madera, 190,0781 de leñas gruesas, 244,9533 de leñas de copa y 489,8960 de ramaje. Todo tasado en $216.519,16$ pts. Los pastos en los diferentes montes de UP de Fuencaliente se aprovecharían con 425 cabezas de ovino y 20 de vacuno (Dehesa Boyal), 600 de ovino y 15 de vacuno (Navalmanzano) y 300 de ovino y 50 de vacuno (Robledo de las Hoyas y Peña Rodrigo), y en el de Sierra Alta (San Lorenzo), con 350 de ovino y 12 de vacuno. Sorprende que no se cite al ganado caprino, pese a ser el más habitual en Fuencaliente y en el resto de Sierra Madrona durante siglos y hasta finales del XX. En cualquier caso, las 1.325 ovejas y 85 cabezas de vacuno permitidas, no parecían un problema en las 2.232 ha de los tres montes de Fuencaliente, y la regeneración no debería tener dificultad para establecerse, máxime al disponer de un periodo de 20 años. La carga ganadera no parece 
excesiva pero, siempre que se respetase el número de cabezas y no estuvieran presentes los incendios de los pastores.

En un monte "ordenado" el pastoreo se limitaba en los tramos en regeneración, en tanto esta no se hubiera producido. En el caso del monte "La Cereceda" se prohibió por completo en 1956, pero en compensación se planteó la posibilidad de arrendar para caza mayor sus 1.157 ha. Así se hizo, durante el año forestal de 1957-58, se arrendó por 14.400 pts, pero el arrendatario pronto dejó de serlo, se perdió este tipo de explotación, por lo que el monte fue de nuevo abierto al pastoreo. Se autorizó la entrada de 650 cabezas de ovino (JCCM 2001).

Por último, sobre la evolución de los montes, cabe destacar uno histórico que, aunque fue excluido del CMUP, no se enajenó. Es el caso de la Dehesa de Castilseras, con una superficie actual de casi 9.000 ha, cifra que llama la atención pues en la Clasificación figuraba con 7.190 ha. Extraña un error del $20 \%$ en un monte que pertenece al Estado desde 1778 y que poseía los mejores agrimensores para calcular su superficie real. Actualmente depende del Ministerio de Hacienda que la gestiona a través de la Dirección General del Patrimonio del Estado y este a su vez delega en la sociedad pública Minas de Almadén y Arrayanes SA (MAYASA), del grupo SEPI. Durante gran parte del siglo XX ha venido rigiéndose por lo dispuesto en la Real Orden de 30 de mayo de 1913. Pero más recientemente, la Ley 38/1981 de 9 de octubre, actualiza las normas y dispone la transformación del Consejo de Administración de Minas Almadén y Arrayanes, en Sociedad estatal y estipula que le corresponde a esta sociedad la puesta en explotación agrícola, ganadera y forestal de la finca. En esa Ley se dispone, además de una serie de usos agroganaderos, cinegéticos y recreativos, también que la finca debe en parte ser reforestada, como especifica en sus $\operatorname{art}^{\circ} 14$ y 15 :

[...] 14. La conservación y repoblación forestal de la dehesa se ajustará a un plan técnicamente elaborado que alcanza a unas 2.000 hectáreas de suelo especialmente apto para la repoblación forestal $[\ldots]$

[...] 15. Anualmente se determinará la zona a repoblar procediéndose a su señalización o cercado y adoptándose las medidas que garanticen la debida protección de la zona repoblada. Lo mismo se efectuará para la reposición de marras y calveros [...]

Posteriormente, por Orden de 29 de abril de 1982, se aprobó el reglamento por el que debía regirse en el futuro la explotación de la Dehesa de Castilseras.

\subsubsection{El estado actual de los montes en Sierra Madrona y Valle de Alcudia.}

A principios del siglo XXI, el III Inventario Forestal Nacional (MAGRAMA 2015) muestra como la encina es la especie dominante en la mayor parte del Valle de Alcudia. En Sierra Madrona el dominio se reparte entre encina y robles (quejigo y melojo) seguido del alcornoque $\mathrm{y}$, en menor medida, el enebro y el acebuche 
Parece sorprendente el hecho de que durante al menos 3000 años con periodos de varios siglos de intensa actividad minera por toda la comarca, Sierra Madrona y Valle de Alcudia sigan manteniendo matorrales dehesas y bosques. Si la extracción de madera, más la perdida en los incendios, estuvieran debidamente contabilizadas podrían sumar millones de árboles cortados y millones de Tm de madera sacadas del monte o quemadas en pie. Pero una de las principales características del espacio forestal es precisamente su gran resiliencia que, en el caso de las rebrotadoras mientras no se descepe o agote la cepa, le permite regenerarse continuamente. $\mathrm{Si}$ bien dará el predominio a aquella especie que posea mayor capacidad y rusticidad frente al resto de rebrotadoras o a las especies que no lo sean caso de los pinares. En las Figs. 2.55-2.57 puede verse la distribución actual de los montes en la comarca, diferenciando cual es la especie dominante.

Tras más de 150 años de gestión forestal, pero con mejores resultados tras el abandono de la agricultura y ganadería extensiva, la mayor parte de la comarca ha ido recuperando su cubierta de montes y pastos más o menos arbolados. Gran parte de la superficie que se puso en cultivo desde finales del siglo XIX a finales del XX ha sido abandonada y, como norma el monte va regenerándose, aunque muy lentamente en aquellas zonas que fueron completamente descepadas. Solo algunas grandes áreas permanecen desarboladas (y sin apenas matorral) en el centro del Valle de Alcudia (debido a la conjunción de intensa actividad minera, carboneo y roturaciones del siglo XX, más la actual ganadería que impide la regeneración) y las zonas cercanas a los pueblos, especialmente de Alamillo, Cabezarrubias, Hinojosas y Mestanza (principalmente por la agricultura y la ganadería que impiden la recuperación del monte). 

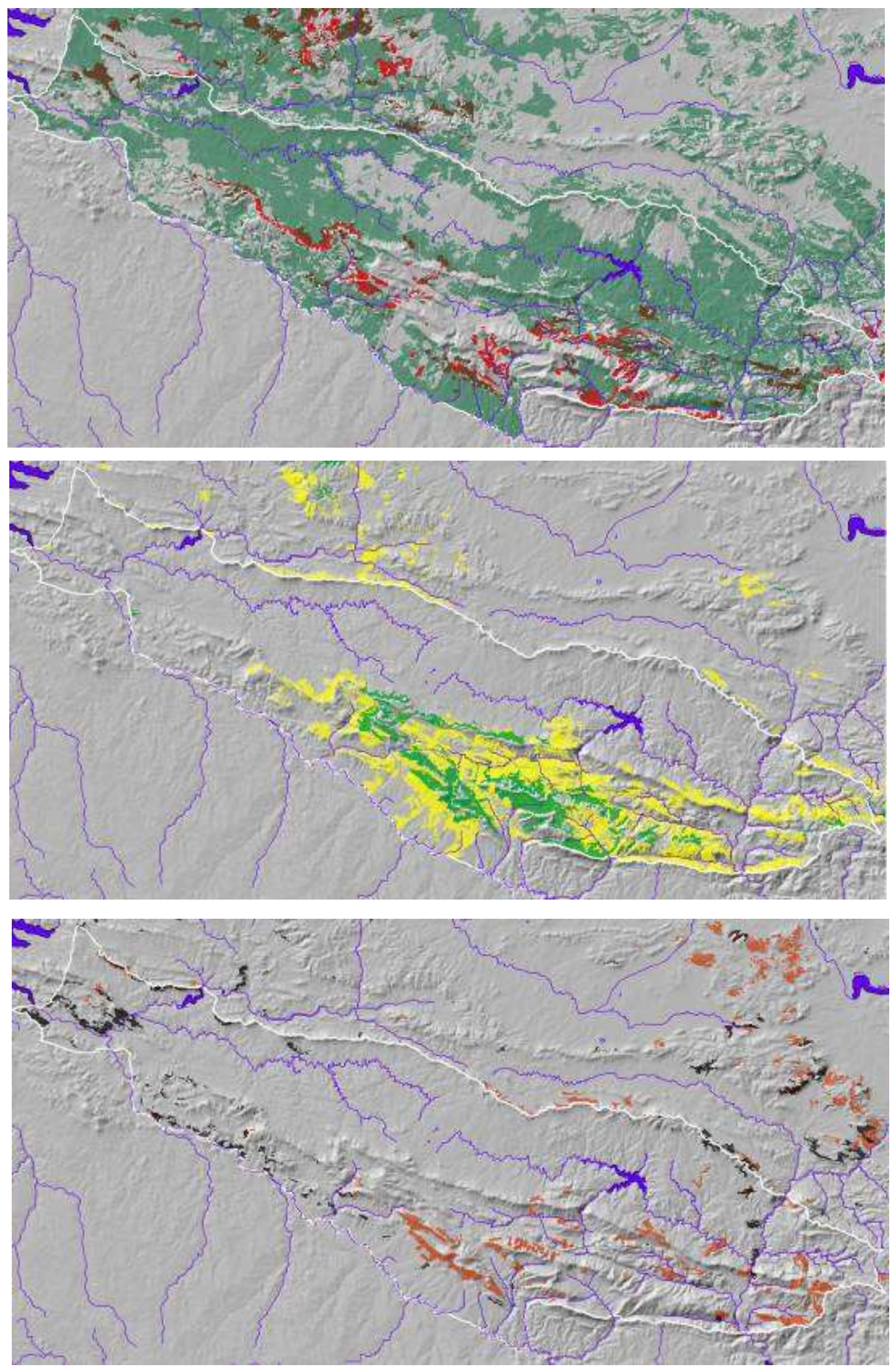

Figs. 2.55-2.57. Formaciones arboladas del SO de la provincia de Ciudad Real en que las principales especies arbóreas de la zona de estudio (delimitada por la línea blanca) son dominantes. Arriba: Quercus ilex (verde) y $Q$. suber (rojo). Centro: $Q$. faginea (amarillo), $Q$. pyrenaica (verde). Abajo: Juniperus oxycedrus (marrón) y Olea europea sylvestris (negro). Fuente: Ministerio de Medio Ambiente 2004. 


\subsubsection{Las repoblaciones forestales del siglo $\mathrm{XX}$}

La minería, el pastoreo, el carboneo y las roturaciones con fines agrícolas en conjunto, fueron reduciendo la extensión y estructura de los bosques. Por todo ello desde la Edad Media no solo se lamentaba la deforestación por parte de la administración y se trataba de ponerla freno, también se promovía la repoblación forestal. No obstante todas las leyes reforestadoras solían quedar en papel mojado y la deforestación continuaba. Así lo refleja en su Proyecto Económico el irlandés Bernard Ward (1762), que vino a España con el encargo de realizar un plan de carreteras para el desarrollo económico del país

[...] El punto de criar montes merece mucha atención; pero es un asunto tan conocido en España, tan favorecido y recomendado por las leyes y ordenanzas, que no nos queda que decir, sino desear que se tomen medidas eficaces, para que estas leyes tengan todo su efecto, porque de nada sirven leyes, sin la ley de la observancia, y solo harémos una, ó dos reflexiones sobre la materia. La primera es, que sin hablar de la utilidad de los árboles para la construccion de navios, casas y otros fines, sirven de mucho beneficio en un pais seco y caliente para mantenerlo fresco [...] Mi segunda reflexión mira a los árboles, que sirven de adorno y al mismo tiempo dan utilidad: las calles de árboles son raras en España [...]

Jovellanos (1795), en su Informe de la Sociedad Económica de esta Corte al Real y Supremo Consejo de Castilla en el Expediente de la Ley Agraria, estableció como premisa la liberalización económica. Opina que al poner en movimiento los mecanismos de la libertad individual se podrían superar los estorbos opuestos al adelanto de la agricultura: los derivados de la legislación, los derivados de la opinión (debidos a las malas prácticas técnicas) y los derivados de la naturaleza (falta de infraestructuras). Acierta con la causa general de la deforestación y muestra a dónde había conducido el aprovechamiento común:

[...] la política hallando arraigado el sistema funesto de legislación pecuaria, le favoreció tan exorbitantemente que hizo de los baldíos una propiedad exclusiva de los ganados; y la piedad mirándolos como patrimonio de los pobres, se empeñó en conservárselos: sin que ni una ni otra advirtiesen, que haciendo común el aprovechamiento de los baldios, era mas natural, que los disfrutasen los ricos que los pobres, ni que sería mejor política, y mayor piedad fundar sobre ellos un tesoro de subsistencias para sacar de la miseria gran número de familias pobres, que dejar en su libre aprovechamiento un cebo a la codicia de los ricos ganaderos, y un inútil recurso a los miserables [...]

Como "verdadero monumento del individualismo" calificará Lucas Olazábal (1898) al Informe de Jovellanos. Su aplicación a lo forestal tendrá funestas consecuencias para los bosques, al tiempo que considera que "el aprovechamiento común" asume un ataque incesante y vigoroso contra la propiedad forestal; es toda una fórmula de devastación, consentida, legitimada y aun acariciada ciegamente por la ley. El dicho lo que es del comun no es de nengun, acepta que hay una menor preocupación para conservarlos y ausencia de trabas para su utilización por los poderosos. 
Las ideas de Jovellanos impulsaron el proceso desamortizador del siglo XIX, pero iniciado mucho antes. Tuvo ventajas notables para todos los gobiernos que la impulsaron, por lo que no extraña el éxito que tuvo

- Económica, al poner en el mercado nuevas tierras de labor.

- Fiscal, aportando ingresos a la Hacienda Pública para aliviar una Deuda agravada por la pérdida de las colonias, las numerosas contiendas bélicas, la modernización del país y la financiación de la vías de ferrocarriles.

- Social, al otorgar el poder a aquellos que pudieran adquirir la tierra.

- Político, al crear grupos adeptos al gobierno que lo promovía.

El 11 de julio de 1877 se publicó la Ley para la mejora y repoblación de los montes públicos, exceptuados de la desamortización, motivada por la abundancia de montes que presentaban claros, calveros o zonas rasas que deberían repoblarse. En dicho año, el Distrito Forestal de la provincia de Ciudad Real, al iniciar el proceso de rectificación del Catálogo de 1862 en el que solo figuraban 57 montes y 89.162 ha, gestionaba una superficie forestal pública que al incluir la enajenable y la exceptuada, era de 265.230 ha, superficie cuyos montes mantendrían las cifras de la Clasificación de 1859, por la penuria de personal. De acuerdo con su vuelo se la caracterizó en 66.986 ha de monte alto, 169.987 de monte bajo, 9.411 ha de claros y calveros y 18.846 ha de rasos. Cuando en 1896 se publica la estadística de las siembras y plantaciones verificadas en los montes públicos y cabeceras de las cuencas hidrológicas, que se habían realizado desde 1877 hasta el año forestal 1894-95, la provincia de Ciudad Real no figurará en ninguna de las relaciones de trabajos efectuados.

La demanda de la necesidad de la repoblación forestal es reclamada con más énfasis por miembros destacados de la sociedad científica, precisando además las especies que consideran adecuadas. Así, el botánico catalán Cipriano Costa (1857) había dicho:

[...] Urge pues sobremanera que el gobierno provea a la conservación y repoblado de los árboles destinados a la construcción civil y naval; no sólo con el ánimo de satisfacer estas necesidades económicas (que aún ahora se llenarían en parte si no faltaran caminos vecinales) si no también para restablecer el equilibrio cosmológico notablemente alterado en nuestra Península. Entre todos los árboles los que mejor pueden llenar dichas condiciones son los pinos en general [...]

El botánico aragonés y posteriormente catedrático en la Universidad Central, Blas Lázaro e Ibiza, como secretario ponente de una Comisión nombrada por la Sociedad Económica Matritense, publica en el Boletín Oficial de la Sociedad de $1^{\circ}$ de abril de 1886 un dictamen sobre "La repoblación de los montes de España", en el que se demanda un plan general de repoblación forestal. Como especies a utilizar recomiendan, en primer término, a las coníferas, «prefiriendo en cada zona las que en ella vegeten espontáneamente», pormenorizadas en un cuadro que, para Castilla la Nueva, son: "Pinus sylvestris L.; P. pinaster Sol.; P. pinea L.; P. laricio Poir. y $P$. halepensis Mill. Paralelamente, señalan que «las cupulíferas y demás árboles 
indígenas ofrecen peores condiciones para las formaciones de bosque y son de desarrollo más lento».

Tardó mucho la acción del gobierno en considerar que los beneficios de la repoblación no solo eran de producción de madera y otros frutos, principal objetivo de cualquier propuesta de inversión pública. Además de cosmólogicos, como decían los primeros ingenieros, las tareas de repoblación generaban riqueza en los pueblos. Así, Elorrieta (1934) dijo sobre la repoblación forestal:

[...] Constituye la solución más apropiada en el caso de un paro obrero, porque, no necesita, en general, para la mayor parte de sus trabajos el aprendizaje ni la especialización, porque pueden emprender casi todos aquellos en cualquier momento y por que las consignaciones y créditos concedidos para ellos se consumen, en su casi totalidad en jornales [...]

En 1935 la República crea el Patrimonio Forestal del Estado (PFE) para emprender la tarea de repoblación general del país, estableciendo planes decenales y presupuesto, pero no llegó a aprobarse y la guerra civil truncó el proyecto. No obstante, desde el bando nacional, en 1938, en plena guerra civil, se ordena a los ingenieros de montes Luis Ceballos y Ximénez de Embún la redacción del Plan General para la Repoblación Forestal de España que se concluirá en 1939. Ese mismo año se restableció el PFE y la repoblación forestal recibe impulso, respaldado por un presupuesto que se mantiene durante décadas y alcanza varios años el 1 por ciento del Presupuesto Nacional (Navarro 1975). El Plan era ambicioso, al querer actuar en todo el territorio apto para su forestación; sus objetivos son restauradores y protectores, aunque aspira a incrementar las producciones futuras. Siglos de explotación y agotamiento de los montes justificaban los 2 primeros. Un crónico y elevado déficit de madera, la necesidad de autoabastecimiento y de divisas para el pago de la deuda generada por la guerra respaldaban el objetivo productor, que se vería limitado por la escasez de terrenos fértiles y profundos, ocupados desde antaño por las producciones agrícolas. Pero fueron sus "fines sociales" (objetivo indicado en la Ley que reorganiza al Patrimonio en 1941) los que dieron a la repoblación forestal un decidido apoyo y estabilidad.

El Patrimonio asumió la gestión de los montes incluidos en el Catálogo pertenecientes al Estado y los que habían sido adquiridos con fondos de la Dirección General de Montes y, además, se le dotó de una política decidida de compras (en especial, de terrenos desamortizados en el siglo anterior) y del establecimiento de consorcios y convenios con particulares y ayuntamientos para su repoblación. Su organización se modificó en 1941 (BOE del 10/04/1941) con el objetivo, fijado en su artículo 1, de:

[...] Restaurar, conservar e incrementar el Patrimonio Forestal del Estado de modo que plenamente llene sus fines nacionales, económicos y sociales [...]

La reforestación pretendía favorecer tanto al Estado como a los pueblos, hasta el punto de que el ingeniero jefe del Distrito forestal participaba en las Juntas Provinciales de Paro (Gómez Mendoza \& Mata Olmo 1992). La repoblación forestal potencialmente podría disminuir el paro pues casi todo su presupuesto estaba destinado a jornales, especialmente en las 2 décadas 
siguientes a la guerra civil, cuando la población agraria era masiva demandante de jornales. En 1955 se alcanza la mayor inversión histórica porcentual de España en reforestación, un 1,16\% del presupuesto general del Estado. Pero aunque porcentualmente su importancia desciende debido al auge industrial, el presupuesto forestal en valores absolutos se sigue incrementando por la necesidad de repoblar las cuencas de los embalses de la Política hidráulica (Gil 2008). Posteriormente el PFE es sustituido, mediante Decreto-Ley de 28-10-1971 por el Instituto Nacional para la Conservación de la Naturaleza (ICONA).

En total se reforestaron en España 3 millones de ha. entre 1940 y 1982, más otro medio millón en años posteriores con motivo del Programa de Reforestación de Tierras Agrarias llevado a cabo por las CCAA y financiado en parte por la Unión Europea. El resumen de estas actuaciones puede verse en la Tabla 2.12.

\begin{tabular}{|l|r|r|r|}
\hline \multicolumn{4}{|c|}{ Repoblaciones forestales en España 1940-1982 (ha) } \\
\hline Grupo de especies & $\mathbf{1 9 4 0 - 1 9 7 5}$ & $\mathbf{1 9 7 5 - 1 9 8 2}$ & \multicolumn{1}{c|}{ Total } \\
\hline Pinos (Pinus) & 2.177 .812 & 423.381 & 2.601 .193 \\
\hline Otras coníferas (Cupressus, etc) & 15.417 & 6.422 & 21.839 \\
\hline Eucaliptos (Eucaliptus) & 221.127 & 52.410 & 273.537 \\
\hline Chopos y álamos (Populus) & 18.102 & 7.170 & 25.272 \\
\hline Otras frondosas (Quercus, etc) & 9.158 & 13.502 & 22.660 \\
\hline Total & $\mathbf{2 . 4 4 1 . 6 1 6}$ & $\mathbf{5 0 2 . 8 8 5}$ & $\mathbf{2 . 9 4 4 . 5 0 1}$ \\
\hline
\end{tabular}

Tabla 2.12. Superficie y especies utilizadas en la repoblación forestal en España entre los años 1940 y 1982. Fuente MAGRAMA 2015b.

En la tabla 2.12 se muestra la época de mayor intensidad de repoblación forestal en la historia de España. El mayor esfuerzo repoblador se desarrolló entre 1940 y 1975 y las especies con mucho más utilizadas, en los dos periodos, fueron los pinos. Estos mismos parámetros se reprodujeron en Castilla-La Mancha, en la provincia de Ciudad Real y en Sierra Madrona. En la provincia de Ciudad Real se plantaron unas 75.000 ha de pinos, más de la mitad (casi 42.000 ha) con P. pinaster (MAGRAMA 2015b). En los montes públicos de Fuencaliente, entre los años 1946 y 1965 se plantaron un total de 3.953 ha de pinos, casi la totalidad $P$. pinaster (MAGRAMA 2015b). Posteriormente se siguieron plantando pero a un ritmo menor. La distribución espacial de estas plantaciones de pinos puede verse en la Fig. 2.58. 


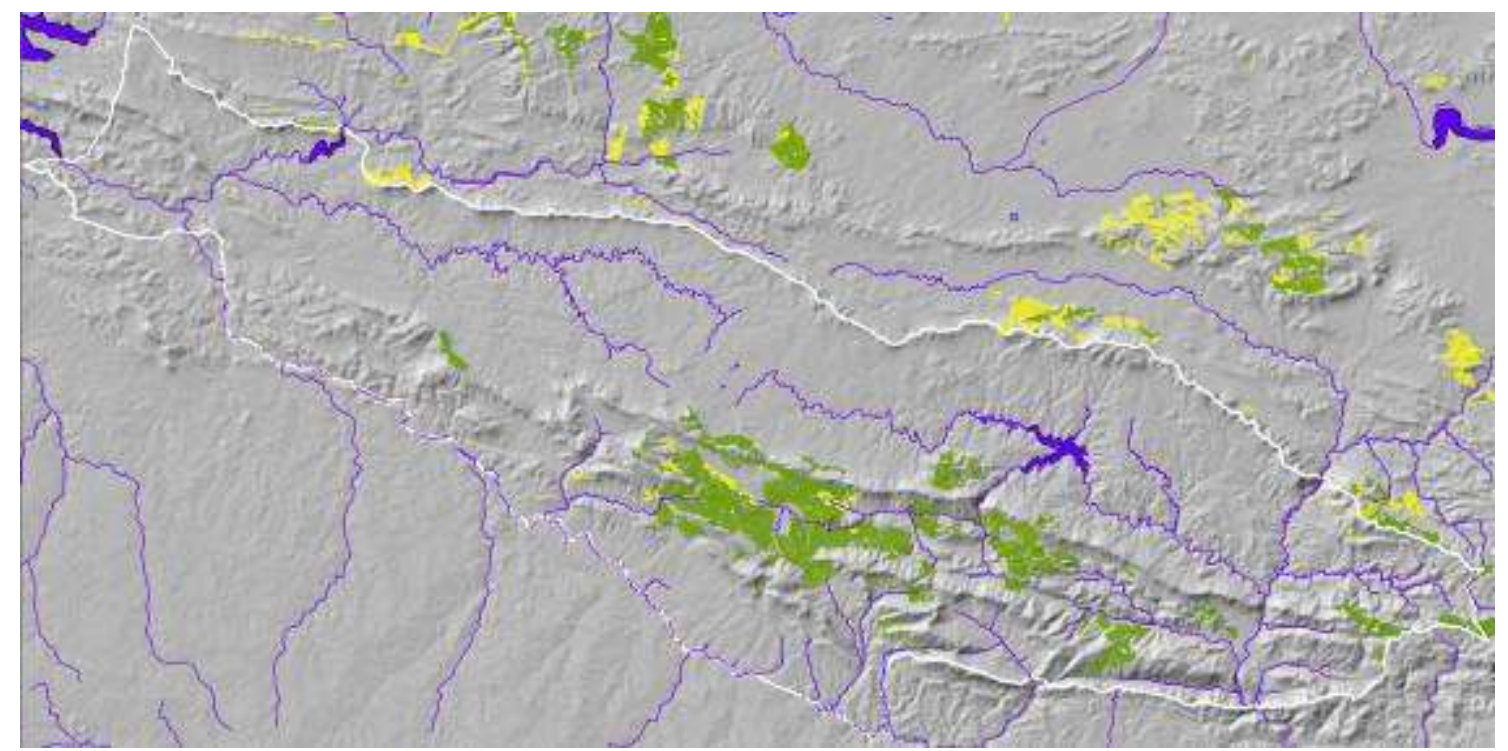

Fig. 2.58. Distribución espacial de las plantaciones de pinos en Sierra Madrona, Valle de Alcudia y otras zonas próximas de la provincia de Ciudad Real. Se plantaron 2 especies de pinos, en color verde las plantaciones de Pinus pinaster y, en color amarillo, las de $P$. pinea. La línea blanca delimita el área de estudio. Fuente: Ministerio de Medio Ambiente 2004.

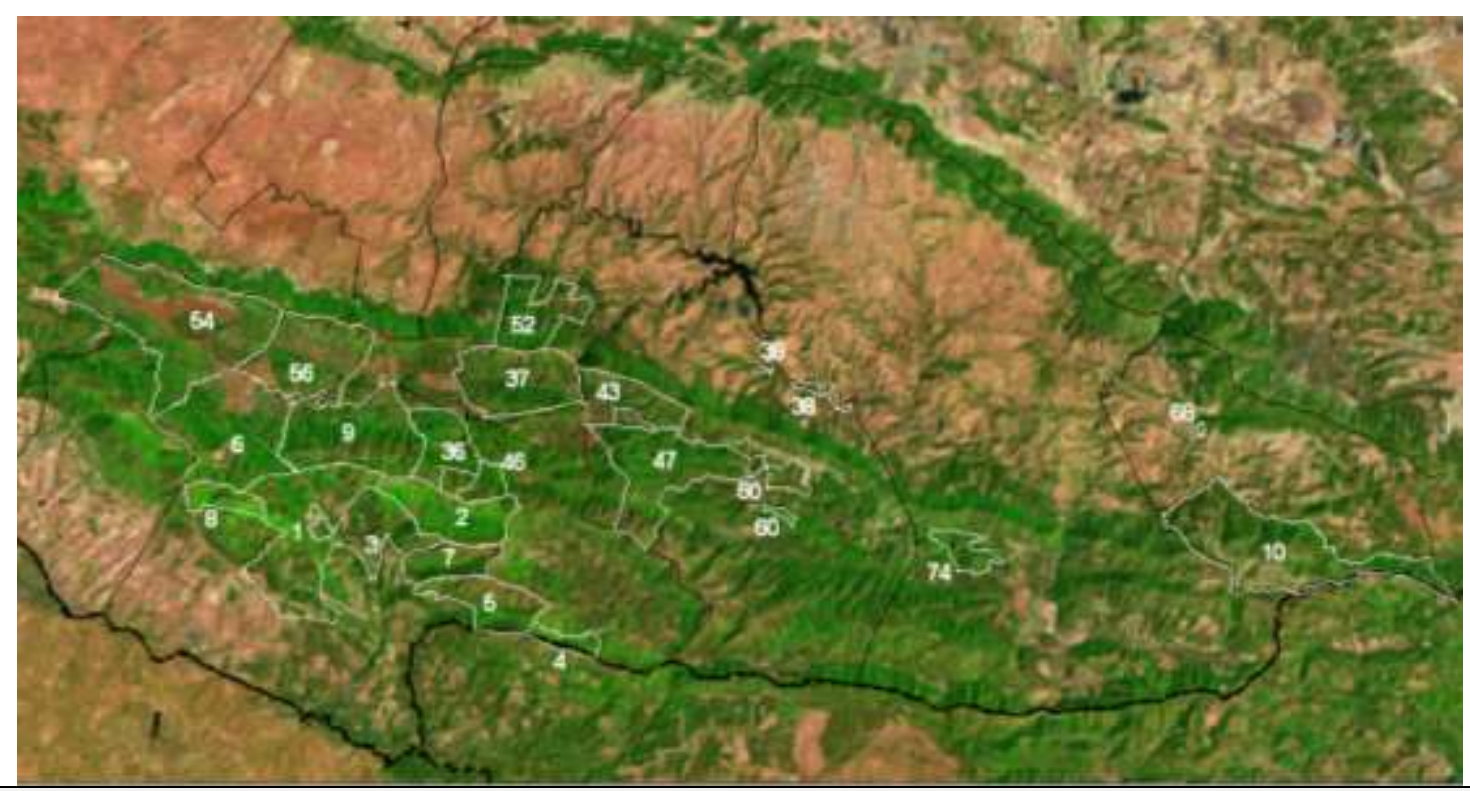

\begin{tabular}{|c|l|c|l|c|l|c|l|}
\hline \multicolumn{7}{|c|}{ Montes de Sierra Madrona y Valle de Alcudia incluidos actualmente en el CMUP } \\
\hline $\begin{array}{c}\text { № en } \\
\text { CMUP }\end{array}$ & $\begin{array}{c}\text { Nombre } \\
\text { del Monte }\end{array}$ & $\begin{array}{c}\text { № en } \\
\text { CMUP }\end{array}$ & $\begin{array}{c}\text { Nombre } \\
\text { del Monte }\end{array}$ & $\begin{array}{c}\text { № en } \\
\text { CMUP }\end{array}$ & $\begin{array}{c}\text { Nombre } \\
\text { del Monte }\end{array}$ & $\begin{array}{c}\text { № en } \\
\text { CMUP }\end{array}$ & $\begin{array}{c}\text { Nombre } \\
\text { del Monte }\end{array}$ \\
\hline 1 & Arroyo de Azor & 7 & Peña Escrita & 38 & Riscales, Nutria y Centeno & 56 & Ojuelo \\
\hline 2 & La Cereceda & 8 & Robledo las Hoyas y PR & 43 & Las Navas & 60 & Redonda y Rabiza \\
\hline 3 & Dehesa Boyal & 9 & Umbría de Ventillas & 46 & Bienvenida & 68 & Hocecillas \\
\hline 4 & Hontanillas & 10 & Sierra Alta & 47 & Mesegales y Coquiles & 74 & Cerros Tontos \\
\hline 5 & Nalvalmanzano & 36 & Cerro Bonal & 52 & Rosalejo y Alamillo & & \\
\hline 6 & Nava del Horno & 37 & Cervigón y S. de Valdoro & 54 & La Garganta & & \\
\hline
\end{tabular}

Fig. 2.59. Distribución espacial de los montes del CMUP en Sierra madrona y Valle de Alcudia. Según Resolución de 16/07/2012, de la Consejería de Agricultura, por la que se aprueba la actualización y revisión de los Catálogos de Montes de Utilidad Pública de las 5 provincias de Castilla-La Mancha. Elaboración propia con datos de la JCCLM. 
Al comparar las Figs. 2.58 y 2.59 puede comprobarse como la mayor parte de las plantaciones de pinos se realizaron en montes del CMUP.

Las plantaciones de pinos emplearon a gran cantidad de trabajadores de los pueblos de la comarca, tanto que hoy es difícil encontrar varones mayores de 80 años que no hubiesen estado alguna vez empleados en tal labor. Inicialmente (años 40) los trabajos de plantación se centraron en los montes del CMUP, es decir, en 7 de los 9 del grupo de Fuencaliente y el único de San Lorenzo. Más tarde se iniciaron las plantaciones en otros montes privados de la comarca a través de convenios con los propietarios, fueron los montes consorciados. Finalmente, en la segunda mitad del siglo XX, especialmente a partir de los años 60, el Estado fue comprando montes a particulares aumentando en $n^{\circ}$ de montes públicos hasta el punto de ser necesario un nuevo CMUP. Este fue publicado en 1968 pero como continuaron las compras de montes por parte de la administración pronto quedó obsoleto.

Ya en el Estado de las Autonomías, la Administración del Estado trasferirá los montes y los presupuestos forestales a la Junta de Comunidades de Castilla-La Mancha (JCCM) que a su vez emprendió una nueva actualización del CMUP provincia por provincia. El proceso se inició en la provincia de Guadalajara en 1999 y se concluyó en la de Toledo en 2007. Por Resolución de 20 de octubre de 2006, de la Consejería de Medio Ambiente y Desarrollo Rural, se aprueba la actualización y revisión del Catálogo de Montes de Utilidad Pública de la provincia de Ciudad Real (DOCM n 245 , de 24 de noviembre). En este nuevo CMUP, entre los montes de la comarca, se pasa de los históricos 10 del siglo XX a 22 a principios del siglo XXI, y de unas 12.500 ha a 24.084 ha. Es decir, se duplica tanto el número de montes como su extensión (Tabla 2.13).

Desde la primera Clasificación de 1859 la superficie de los montes fue cambiando según se medía y corregía debido a las usurpaciones o anexiones por los propietarios colindantes. Las medidas indicadas en la Tabla 2.13 para el siglo XIX son las de la última revisión del CMUP de 1893-1896 por considerarlas más exactas, en el caso de El Rosalejo la medida es la de la Clasificación de 1859 que es donde únicamente aparece. Luego este monte se excluyó de los sucesivos catálogos de los siglos XIX y XX, principalmente porque, aunque tenía encinas, su especie dominante era la jara.

Con respecto a la evolución de las especies arbóreas, como puede verse en la Tabla 2.13, en los 10 montes que estaban en el Catálogo de 1901, el CMUP de 2006 mantiene en 4, la misma especie dominante que figuraba y, en otro, cambia de Q. pyrenaica a Q.suber. 


\begin{tabular}{|c|c|c|c|c|c|c|}
\hline \multicolumn{7}{|c|}{$\begin{array}{c}\text { Superficie y especie dominante en el CMUP de } 2006 \text { en Sierra Madrona y Valle de Alcudia } \\
\text { respecto a los CMUPs del siglo XIX }\end{array}$} \\
\hline \multirow{2}{*}{$\mathbf{N}^{\mathbf{o}}$} & \multirow{2}{*}{ Nombre del monte } & \multirow{2}{*}{$\begin{array}{c}\text { Término } \\
\text { municipal }\end{array}$} & \multicolumn{2}{|c|}{ Superficie (ha) } & \multicolumn{2}{|c|}{ Especies principales } \\
\hline & & & 1859-1897 & 2006 & $1859-1896$ & 2006 \\
\hline 1 & Arroyo del Azor & Fuencaliente & $1.990,00$ & $1.931,51$ & Q. pyrenaica & P. pinaster \\
\hline 2 & La Cereceda & Fuencaliente & $1.184,00$ & $1.119,58$ & Q. pyrenaica & $\begin{array}{l}\text { Q. pyrenaica, } \\
P . \text { pinaster }\end{array}$ \\
\hline 3 & Dehesa Boyal & Fuencaliente & 927,00 & 875,00 & Q. pyrenaica & Q. suber \\
\hline 4 & Hontanillas & Fuencaliente & 234,00 & 239,47 & Q. pyrenaica & Q. pyrenaica \\
\hline 5 & Navamanzano & Fuencaliente & 755,00 & 874,45 & Q. pyrenaica & Q. pyrenaica \\
\hline 6 & Nava del Horno & Fuencaliente & $2.175,00$ & $2.150,98$ & Q. pyrenaica & P. pinaster \\
\hline 7 & Peña Escrita & Fuencaliente & 489,00 & 526,17 & Q. pyrenaica & $P$. pinaster \\
\hline 8 & $\begin{array}{l}\text { Robledo de las Hoyas } \\
\text { y Peña Rodrigo }\end{array}$ & Fuencaliente & 636,00 & 566,00 & Q. pyrenaica & Q. pyrenaica \\
\hline 9 & Umbría de Ventillas & Fuencaliente & $1.787,00$ & $1.665,60$ & Q. faginea & P. pinaster \\
\hline 10 & Sierra Alta & San Lorenzo & $2.558,00$ & $2.633,24$ & Q. faginea & P. pinaster \\
\hline 36 & Cerro Bonal & Cabezarrubias & 875,00 & 490,23 & Q. faginea & P. pinaster \\
\hline 37 & $\begin{array}{l}\text { Cervigón y Solana de } \\
\text { Valdoro }\end{array}$ & Hinojosas & $1.169,00$ & $1.559,01$ & Q. faginea & P. pinaster \\
\hline 38 & \begin{tabular}{|l} 
Riscales, Nutria \\
Centeno
\end{tabular} & Solana del Pino & - & 105,00 & - & Q. ilex \\
\hline 43 & Las Navas & Solana del Pino & - & 786,50 & - & $\begin{array}{l}P . \text { pinaster, } \\
P . \text { pinea }\end{array}$ \\
\hline 46 & Bienvenida & Fuencaliente & - & 265,80 & - & P. pinaster \\
\hline 47 & Mesegales y Coquiles & Solana del Pino & - & $1.735,48$ & - & $\begin{array}{l}P . \text { pinaster, } \\
P \text {. pinea }\end{array}$ \\
\hline 52 & Rosalejo & Hinojosas & $1.159,13$ & 927,25 & $\begin{array}{l}\text { C. ladanifer, } \\
\text { Q. coccifera }\end{array}$ & $P$. pinaster \\
\hline 54 & La Garganta & Brazatortas & $2.922,00$ & $3.208,06$ & Q. faginea & $\begin{array}{l}P . \text { pinaster, } \\
P \text {. pinea }\end{array}$ \\
\hline 56 & Ojuelo & Cabezarrubias & - & $1.544,80$ & - & $\begin{array}{l}P . \text { pinaster, } \\
P . \text { pinea }\end{array}$ \\
\hline 60 & Redonda y Rabiza & Solana del Pino & - & 209,25 & - & Q. ilex \\
\hline 68 & Hocecillas & San Lorenzo & - & 15,66 & - & Q. ilex \\
\hline 74 & Cerro Tontos & Mestanza & - & 655,00 & - & $\begin{array}{l}P . \text { pinaster, } \\
P \text {. pinea }\end{array}$ \\
\hline
\end{tabular}

Tabla 2.13. Evolución de la superficie y especie dominante en los actuales montes del CMUP con respecto a lo que tenían consignado en los CMUPs del siglo XIX.

La "Cereceda" el número 2 del CMUP de 1901, tenía en 1933 el 37,8\% de monte bajo, y el CMUP de 2006, sigue manteniendo a $Q$. pyrenaica como dominante, e incluye a $P$. pinaster en segundo lugar, por ser la especie con la que se repobló en las zonas que fueran más a propósito, pues descepar completamente un monte de Quercus pyrenaica, no es una práctica posible, salvo para la generación de pastizales arbolados y requiere un proceso prolongado de actuaciones, pese a ser una opinión no fundamentada y extendida. En 1933 "Hontanillas", número 4 del CMUP de 1901, tenía toda superficie de monte alto. "Navamanzano", el número 5 del CMUP de 1901, en 1933 se calificaba 825 ha de monte bajo y 49 ha rasas y, ahora, sesún el Catálogo de 2006 sigue siendo $Q$. pyrenaica la especie dominante. Las rasas son roquedos de difícil repoblación y el monte bajo se debió considerar como adecuado para que siguiera evolucionando. "Robledo de las Hoyas y Peña Rodrigo", número 8 del CMUP de 1901, tenía en 
1933. el $47 \%$ de su superficie a monte bajo y su evolución es similar a la anterior, sin que se haga referencia a otra especie en el Catálogo de 2006. La "Dehesa Boyal", número 3 del CMUP de 1901 es la que llama la atención, pues en 1933 señala que toda su superficie es de monte bajo de $Q$. pyrenaica y el CMUP de 2006 señala que la especie dominante es Q.suber y no hace referencia al rebollo, por lo que de ser así supone un ejemplo de la evolución del monte hacia una especie despreciada durante siglos, salvo para usar su casca para curtidos y su corteza para colmenas.

“Arroyo del Azor", el número 1 del CMUP de 1901, "Nava del Horno" el número, 6 del CMUP de 1901, y "Peña Escrita" el número 7 del CMUP de 1901, tenían en 1933 el 81,8\% de la superficie del primero como monte bajo, mientras que en los otros dos lo era el $100 \%$, porcentajes que habla del estado de degradación que debían de tener y el que fueran considerados como robledales como especie dominante en los sucesivos catálogos debió ser una justificación para evitar su desamortización, pues de haber situado a la jara como especie dominante se hubiera enajenado. Esta opinión sirve para explicar que la tabla 5 solo figuren los montes de "Cereceda", "Hontanillas" y "Robledo de las Hoyas" con aprovechamientos de madera y leña en Fuencaliente entre 1958 y 1962.

“Arroyo del Azor" figura en 1859 con 315 ha, dominante el quejigo y subordinadas roble, jara y madroño, pasa a 1862 con igual superficie y como especie cambia a roble y finalmente en 1901 figura con 1.929 ha y roble. A "Nava del Horno" en 1859 se le asignan 4.078 ha, con especie dominante el roble y subordinadas quejigo, jara y brezo y "Peña Escrita" forma parte en 1859 del conjunto de "Sereceda, Dehesa y Peña Escrita" con 429 ha dominante roble, subordinadas, quejigo ,alcornoque y jara y, en 1901, se separa de los otros y figura con 526 ha y especie roble.

Todo ello señala que una parte de estos montes públicos fueron consorciados con el Ayuntamiento para proceder a la repoblación de las zonas más favorables, pudiendo mantener los aprovechamientos de pastos en el resto. "Umbría de Ventillas", monte probablemente cubierto en gran parte por matorral, fue el primero en las que el PFE inició las repoblaciones (1943, 1944, 1945), con reposiciones de marras en 1951 y 1952. En el "Arroyo del Azor", comenzaron al año siguiente (1946 y 1949), siguieron con "Nava del Horno" (1948, 1949, 1951, 1954 y 1958), con “La Cereceda” (1956) y Navalmanzano (1965) (JCCM 2001).

Un aspecto a tener en cuenta en lo que fue el último proceso de degradación de Sierra Madrona y Valle de Alcudia y otros pueblos del entorno fue el carboneo, del que no se dispone de un registro preciso, pero que tuvo una gran intensidad de la explotación hasta la aparición del butano. En los años 50 se pagaba a entre 6 y 8 pts/arroba (Moreno 2007) y subió hasta las 14 pts a mediados de los años 60 (Romano y Sanz 1967). El número de encinas arrancadas o severamente podadas, como quejigos, alcornoques y otros árboles y arbustos debió ser muy importante. 
El Proyecto de Ordenación de Montes de Heredia de 1910 para regenerar las masas naturales se va cumpliendo en parte, como lo muestra el paso a alcornocal de la Dehesa Boyal y la caracterización en solitario de robledales en "Hontanillas", "Navamanzano" y "Robledo de las Hoyas y Peña Rodrigo". En los planes de ordenación provisionales de 1956 y 1957 se proponían también mejoras selvícolas similares a las propuestas en 1910, pero al mismo tiempo se mantenían las repoblaciones de pinos iniciadas en los años 40 y que afectarían a las 78 ha de rasos y las 8305 ha de monte bajo, es decir en el $83,7 \%$ de la superficie total de los 9 montes que poseía Fuencaliente.

En los 12 montes restantes que se incorporan al Catálogo de 2006 por ser comprados por la Administración Forestal a propietarios privados, solo el número 56 "Rosalejo" con 1159 ha aparece en la Clasificación de 1859 y, como ya se señaló, con especie dominante la jara. En 2006 la superficie es de 927,25 ha. En el resto de montes ninguno figura en la Clasificación de 1859 ni como exceptuado ni como enajenable; pero que si figuran en la rectificación de 1893 1897, "Cerro Bonal" en Fuencaliente, "Cervigón y Solana de Valdoro" en Hinojosas y "La Garganta” en Brazatortas. Aunque los ingenieros los caracterizaron con especie dominante el quejigo, podría ser un formalismo para que no se vendieran. Aspecto que no ocurrió por su ausencia en el Catálogo de 1901. Estos tres montes fueron comprados a sus propietarios que, a su vez los habían obtenidos en los proceso desamortizadores. Suman en el Catálogo de 2006, un total de 5.257,3 ha, de las que la mayor parte, el 61,0\%, pertenecen a "La Garganta".

Otros montes como "Las Navas", "Bienvenida", "Mesegales y Coquiles", "Ojuelo" y "Cerros Tontos" no aparecen en la Clasificación de 1859, ni en la rectificación de 1893-97, por lo que fueron montes comprados por el Estado para la repoblación de la superficie de 5.877,38 ha que registran en el Catálogo de 2006, siendo P. pinaster la especie empleada en todos ellos y, también, el pino piñonero en "Cerros Tontos". Con ello se cumplían los fines de recuperar superficie pública y que volvieran a mantener la condición de arbolada que hacía siglos o décadas habían perdido.

Finalmente "Riscales, Nutria y Centeno", "Redonda y Rabiza" y "Hocecillas", también están ausentes en los diferentes catálogos, pero aparecen en 2006, con una superficie de 329,91 ha y como especie la encina. Solo algunos de los nombres del primero de ellos, que hace alusión a riscos y centenos, permite suponer la situación en la que fueron adquiridos, por lo que la especie reseñada habla de la evolución positiva que tuvieron desde el momento de su compra.

También se plantaron pinos en otras zonas de Sierra Madrona y Valle de Alcudia sobre los montes consorciados con los particulares, como La Torrecilla. Por otro lado, también se realizaron nuevas plantaciones de pinos sobre los nuevos montes comprados por el Estado o la JCCM, que tras la compra pasaban a incluirse al CMUP, algunos de gran extensión como La Garganta (3208 ha).

Sobre los métodos de preparación del terreno, la primera tarea era labrar para eliminar la compactación previa y facilitar el contacto directo de las semillas con las partículas del suelo. Se eliminaba la parte aérea del matorral y amontonaba toda la leña y cepas para posteriormente 
quemarlas (ver los montones de cepas en la foto aérea de la Fig. 2.60) y que sus cenizas sirvieran de abono a la futura repoblación. Una vez el terreno despejado, "limpio" como se dice en la sierra, se iniciaba la siembra de los piñones. En general, algunas plantaciones tuvieron poco éxito por no coincidir con tempero y lluvias estivales, lo que llevaría a reposiciones de marras en años sucesivos. La mayoría, especialmente cuando coincidieron con años buenos alcanzaron crecimientos notables. Años después la falta de jornaleros y la llegada de maquinaria forestal permitió que se hicieran aterrazamientos. Los resultados de estas plantaciones, según la Memoria del proyecto de ordenación forestal del grupo de montes de Fuencaliente (JCCM 2001), pueden resumirse, según el método utilizado en que

[...] las siembras directas han dado en general masas de extraordinario aspecto y de una gran producción de madera, mientras que las plantaciones en terrazas son de bastante peor calidad, salvo excepciones, y han llegado, incluso, a fracasar [...]

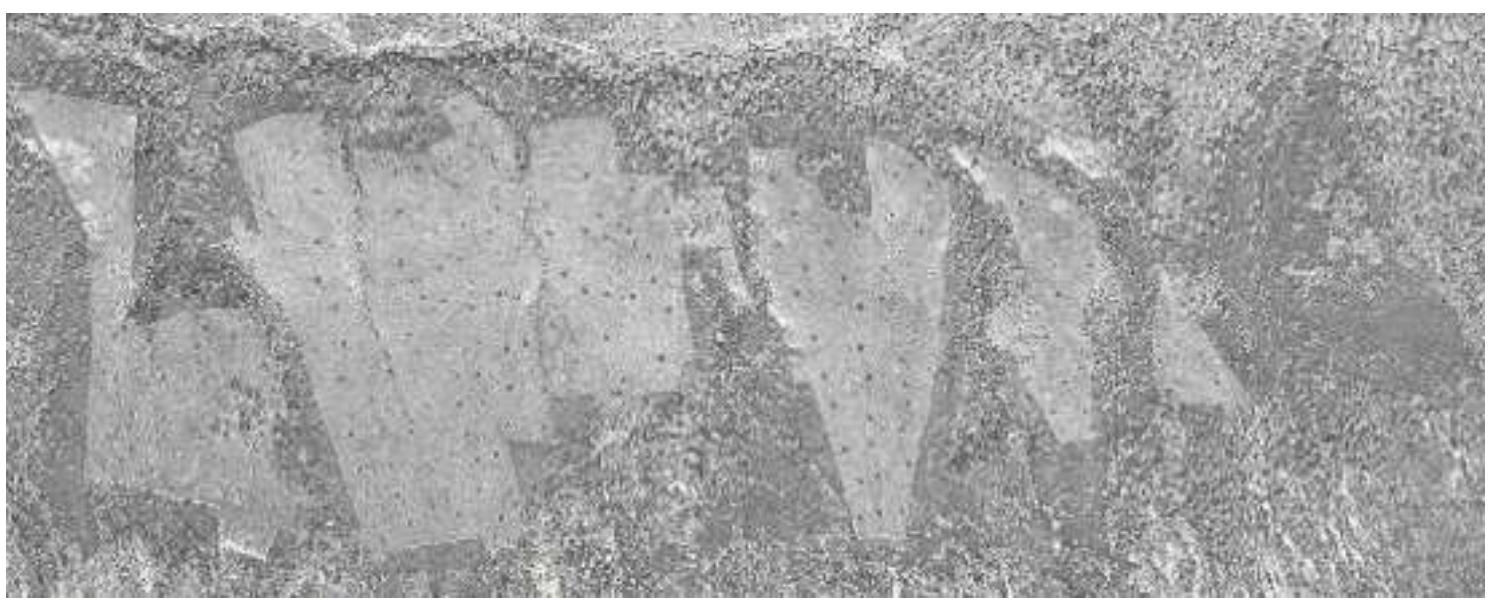

Fig. 2.60. Las plantaciones de pinos de mediados del siglo XX se realizaron generalmente sobre las zonas rasas o calveros de los montes. Para asegurar el éxito de las plantaciones el terreno se roturaba, cepas y leñas se agrupaban en montones que luego eran quemados (en la imagen los puntos oscuros en las zonas roturadas). Umbría del Cereceda, año 1956. Monte que contaba (en los CMUPS de 1933 y 1942) con 700 ha de monte alto y 424 de monte bajo. Fuente CNIG. Vuelo americano serie B.

Fig. 2.61. Fotografía invernal de la misma zona de la Fig. 2.60, pero 60 años después. Rodales de pinos de repoblación entre el monte de robles que se mantuvo.

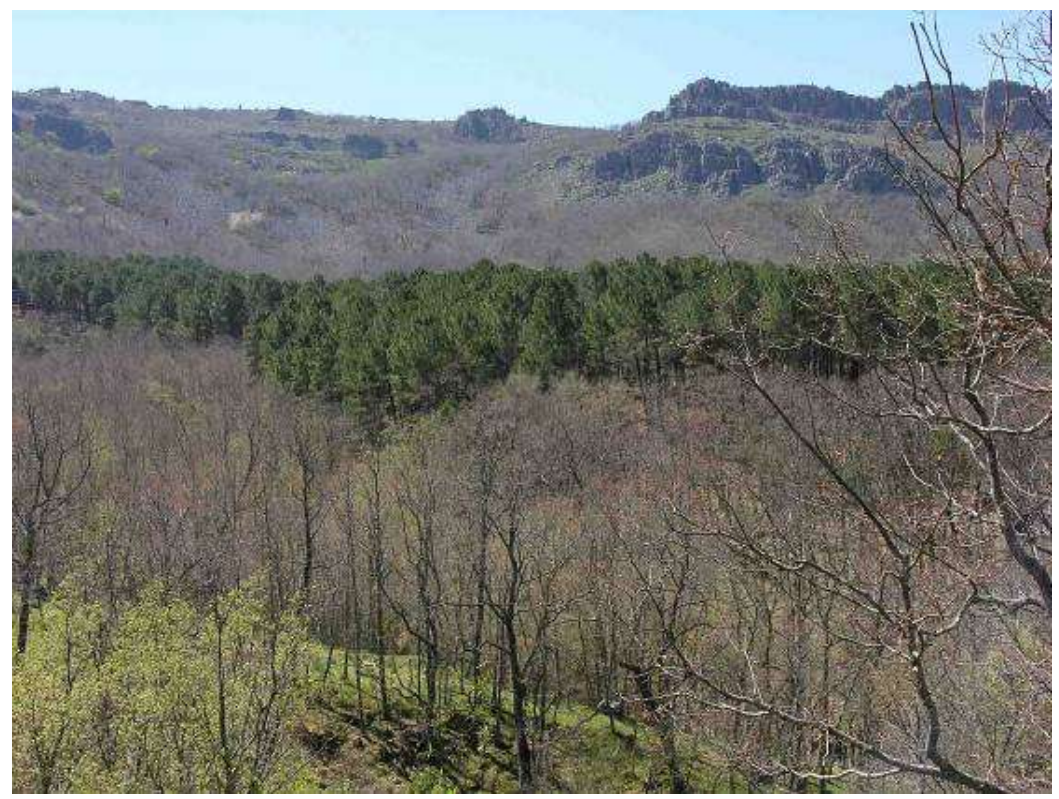




\subsubsection{El abandono del medio rural de finales del siglo $\mathrm{XX}$ y nuevos usos del territorio}

Los procesos desamortizadores pusieron en manos de particulares, generalmente de la burguesía de las grandes ciudades, grandes extensiones de tierras en España que antes pastoreaban o cultivaban los vecinos de los pueblos. Esto, unido a un continuado aumento de la población rural, acabaría provocando revueltas sociales a principios del siglo XX. En la postguerra las penalidades en el mundo rural aumentaron causando serios problemas de supervivencia en las comarcas españolas más pobres. Una de las medidas de la administración para paliar la situación fue precisamente la repoblación forestal, que ocupó una gran mano de obra en los pueblos donde se realizaba desde los años 40. Sin embargo esta actividad no fue suficiente para que ya en los años 60 se iniciara un gran éxodo rural hacia las ciudades que contaban con una creciente industrialización y necesidad de mano de obra (Capel 1967; Ferrer Regales 1989; Silvestre 2003). Este flujo migratorio aumentará además tras la creciente mecanización de las labores agrícolas (García Delgado 1995).

Son numerosos los datos y testimonios sobre estos hechos migratorios en Sierra Madrona y Valle de Alcudia, pero sin duda entre los más contundentes pueden citarse los de Romano y Sanz (1967) que recorrieron a pie el Valle a mediados de los años 60 y recogen numerosos testimonios de las míseras condiciones de vida de la mayoría de los habitantes de los pueblos, cortijos y chozos. En su caminar encuentran una pequeña cuadrilla de 3 hombres, arrancando monte a destajo:

[...] Enseña sus enormes manos, negras, ásperas, de dedos deformes surcados de cortes. Siguen hablando de todos los que viven como ellos por aquellos pueblos. En San Lorenzo, en Mestanza, en Solana, en el Tamaral, en Fuencaliente, en Alamillo, en San Benito [...] Hoy arrancando cepas, mañana arando o segando, después picando piedra en la carretera o en una mina, o haciendo carbón $[\ldots]$

Al duro trabajo y los pobres salarios se une el agotamiento de las minas y/o su pérdida de rentabilidad. Los poblados mineros iban siendo progresivamente abandonados. Muestran como los jóvenes, los recién casados, hombres y mujeres, desean salir de la comarca, a trabajar principalmente en fábricas, minas, comercios (ellos) o a servir (ellas). Siguiendo los pasos de familiares y conocidos hacia Madrid, Barcelona, Bilbao ... e incluso hacia el extranjero. En su epílogo sobre el Valle de Alcudia estos cronistas concluyen:

[...] En 1960 los hombres jóvenes hallaron contratos en Suiza, Francia y Alemania. La emigración ha tomado proporciones masivas y la población ha quedado reducida a la mitad $[\ldots]$

Los mayores aún guardan el recuerdo de la guerra civil y de los maquis (los de la sierra), del hambre, del miedo y de la miseria. Sin estudios, sin tierras ni padrinos, parecía que no quedaban más salidas que sufrir o emigrar. En la Fig. 2.62 y la Tabla 2.14 puede verse el continuo crecimiento de la población hasta principios de la década de 1960, cuando alcanza su máximo histórico (57.334 habs.) y la presión sobre los montes debió ser máxima por sobrepastoreo, extracción de madera y leñas, carboneo, caza, etc. Pero a partir de entonces se produce una gran 
emigración que reduce la población a la mitad en tan solo 30 años. Con la llegada de la democracia y, más especialmente con la llegada de los fondos europeos tras el ingreso de España en la UE en 1986, la emigración fue ralentizándose hasta casi desaparecer a principios del siglo XXI.

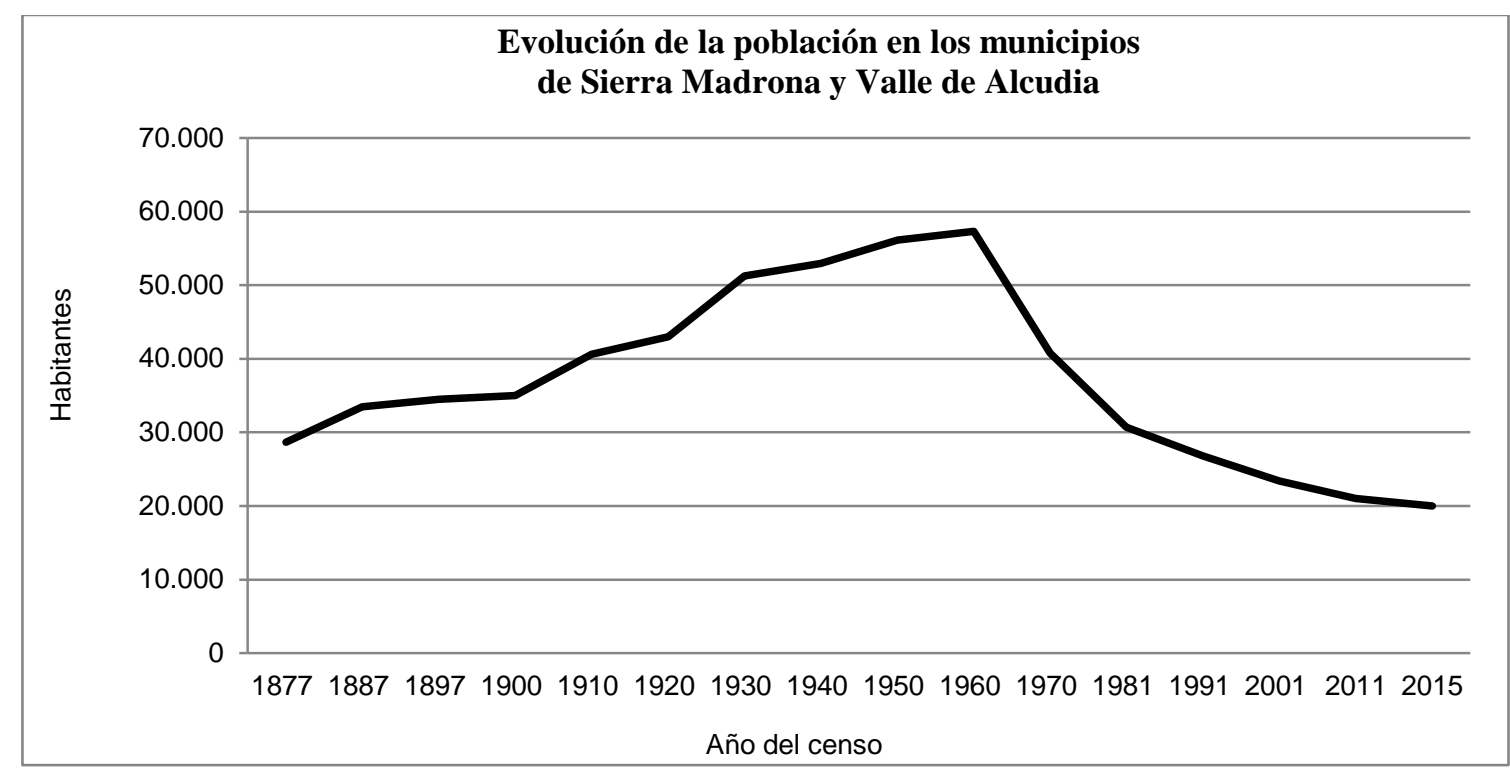

Fig. 2.62. Evolución de la población de la comarca desde finales del siglo XIX a principios del XXI. Se han incluido los municipios de Chillón, Almadén, Almodóvar del Campo y Brazatortas, que aunque tengan su casco urbano fuera de la comarca, poseen dentro de ella gran parte de sus términos municipales. Fuente INE 2015.

\begin{tabular}{|c|c|c|c|c|c|c|c|c|c|c|c|c|c|}
\hline \multicolumn{14}{|c|}{ Población de derecho en los municipios de Sierra Madrona y Valle de Alcudia } \\
\hline Municipio/año & 1900 & 1910 & 1920 & 1930 & 1940 & 1950 & 1960 & 1970 & 1981 & 1991 & 2001 & 2011 & 2015 \\
\hline Almadén & & & 9.879 & 11.888 & 13.168 & 12.707 & 13.587 & 10.910 & 9.722 & 8.012 & 6.830 & 6.064 & 5.794 \\
\hline Almodóvar & 615 & 1.850 & 1.973 & 12.894 & 13.330 & 14.573 & 15.752 & 11.852 & 8.268 & 7.723 & 7.139 & 6.684 & 6.477 \\
\hline Brazatortas & & & & 2.679 & 2.834 & 2.969 & 3.237 & 2.117 & 1.473 & 1.337 & 1.176 & 1.107 & 1.038 \\
\hline Chillón & \multirow{2}{*}{3.418} & \multirow{2}{*}{4.296} & \multirow{2}{*}{4.504} & 4.333 & 4.934 & 5.091 & 4.533 & 3.334 & 2.822 & 2.587 & 2.275 & 2.045 & 1.937 \\
\hline Guadalmez & & & & 1.580 & 1.799 & 2.203 & 2.432 & 1.615 & 1.187 & 1.116 & 1.049 & 902 & 813 \\
\hline Alamillo & 1.387 & 1.517 & 1.666 & 2.023 & 2.321 & 2.688 & 2.408 & 1.374 & 865 & 742 & 663 & 524 & 531 \\
\hline Cabezarru & 997 & 1.210 & 1.489 & 1.852 & 2.001 & 2.070 & 2.152 & 1.113 & 764 & 782 & 621 & 555 & 521 \\
\hline Hinojosas & 1.695 & 2.044 & 2.186 & 2.567 & 2.359 & 2.784 & 2.734 & 1.859 & 1.179 & 923 & 711 & 537 & 499 \\
\hline Fuencaliente & 2.218 & 2.885 & 2.909 & 3.496 & 3.303 & 3.658 & 3.630 & 2.119 & 1.431 & 1.375 & 1.293 & 1.115 & 1.082 \\
\hline Mestanza & 2.821 & 3.445 & 3.294 & 4.785 & 3.666 & 4.023 & 3.239 & 2.019 & 1.597 & 1.094 & 865 & 818 & 724 \\
\hline Solana del Pino & 891 & 975 & 1.404 & 1.781 & 2.070 & 2.219 & 2.603 & 1.702 & 918 & 696 & 502 & 414 & 353 \\
\hline San Lorenzo & 721 & 982 & & 1.359 & 1.165 & 1.128 & 1.027 & 764 & 464 & 382 & 297 & 234 & 231 \\
\hline Total & 35.024 & 40.611 & 42.986 & 51.237 & 52.950 & 56.113 & 57.334 & 40.778 & 30.690 & 26.769 & 23.421 & 20.999 & 20.000 \\
\hline
\end{tabular}

Tabla 2.14. Evolución de la población de la comarca a lo largo del siglo XX y principios del XXI. Se han incluido los municipios de Chillón, Almadén, Almodóvar del Campo y Brazatortas, que aunque tengan su casco urbano fuera de la comarca, poseen dentro de ella gran parte de sus términos municipales. Fuente INE 2015. 


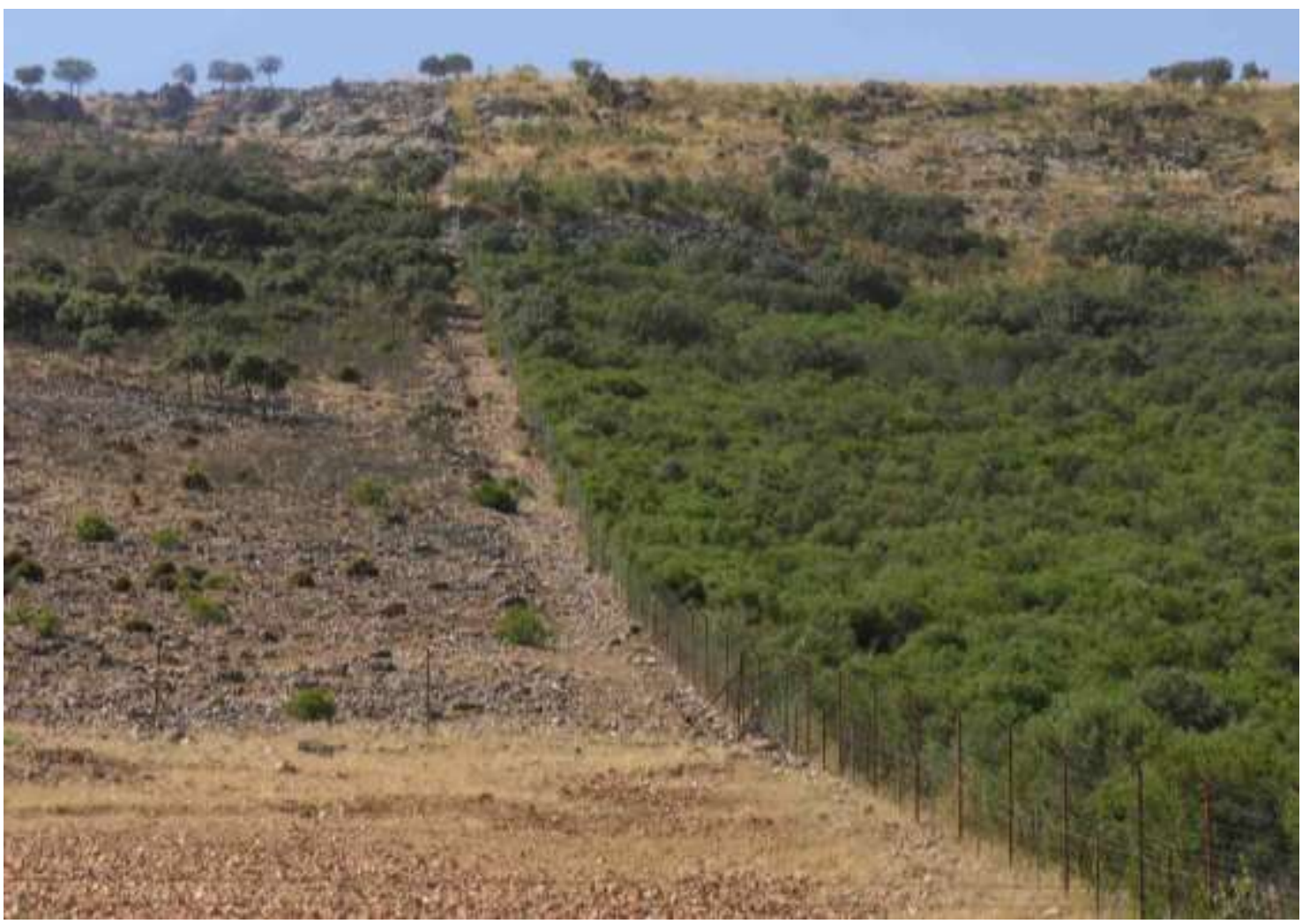

Fig. 2.63. El abandono del medio rural durante las últimas décadas provoca importantes cambios en el paisaje, según la propiedad. A la izquierda el tradicional: en la base el secano y, en el resto, ganado cabrío. A la derecha del vallado el cese de las mismas actividades a excepción de la caza mayor.

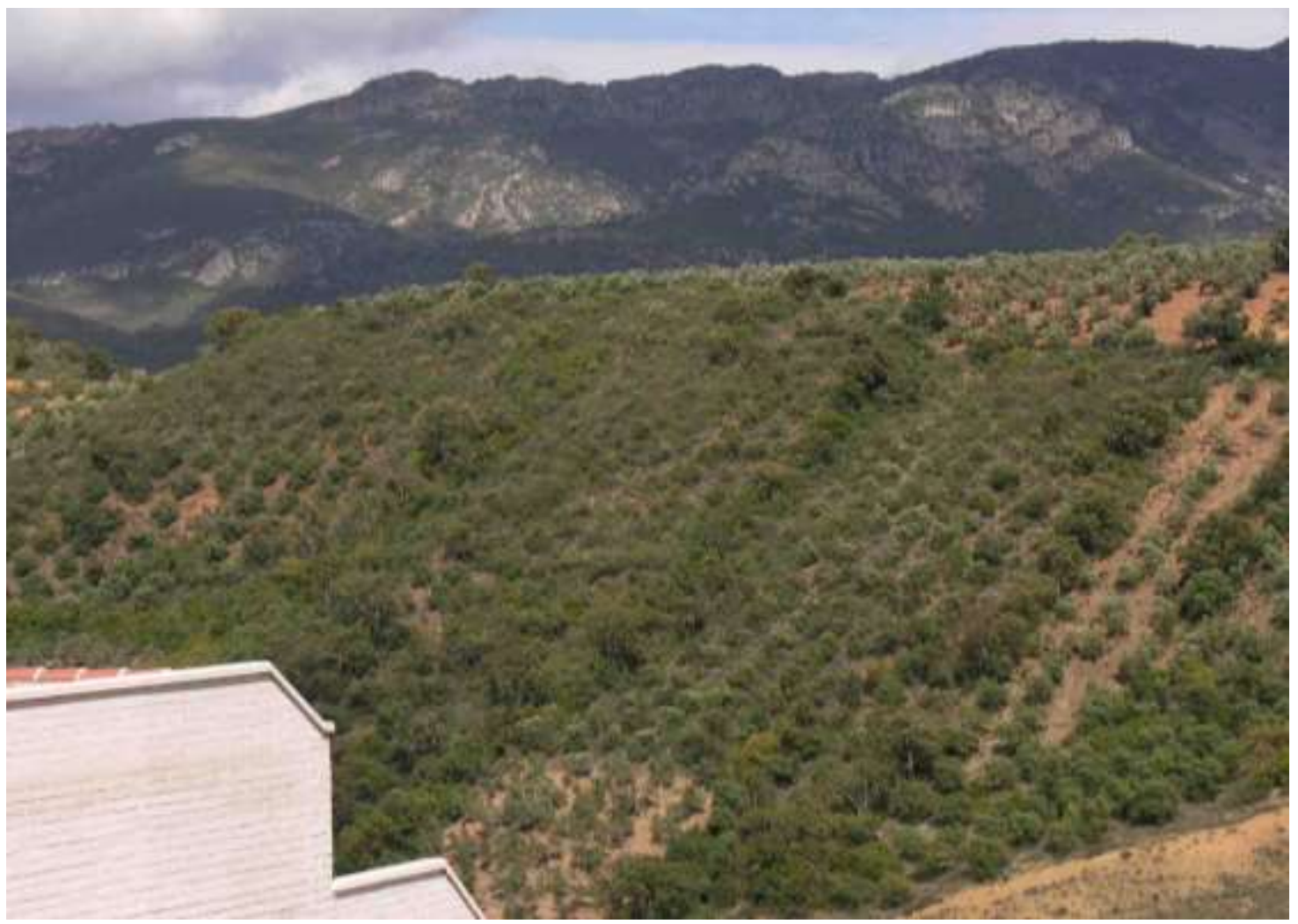

Fig. 2.64. Abandono de olivares, junto al pueblo de Fuencaliente, el cultivo con elevada pendiente, ha supuesto la pérdida del suelo entre líneas y la recuperación natural del monte pone freno a la pérdida de suelo. 
Las tierras abandonadas fueron adquiridas en muchos casos por particulares que así agrandaban y redondeaban sus grandes fincas. En otros casos, como en Valmayor (Fuencaliente), partiendo del aparcelamiento previo que se hizo del Valle para ser colonizado a principios del siglo XX, tras el abandono por los colonos fue reagrupado casi en su totalidad hasta conformar una finca privada de 4.000 ha. Otras tierras fueron compradas por la administración, incrementando así el $\mathrm{n}^{\mathrm{o}}$ de montes del CMUP de los 10 tradicionales del siglo XX a los 22 actuales (Fig. 2.59). Otro fenómeno novedoso fue el retorno vacacional de muchos de los emigrados que se construían chalets y segundas residencias en las pequeñas parcelas de tierra abandonadas por sus padres 30 , 40 o 50 años antes.

El abandono del medio rural, contra toda corriente actual de añoranza de la vida en la naturaleza y de profesiones idealizadas, fue el fin de los procesos regresivos de los sistemas naturales. Los reiterados e históricos incendios de los pastores cesaron, las minas se cerraron, incluidas las de Almadén (en el año 2003), el carboneo y el piconeo también desaparecieron. Por todo ello en conjunto, se inició en los años 70 una lenta pero continua regeneración natural de los bosques en Sierra Madrona. Los 3 inventarios forestales realizados en España desde finales del siglo XX muestran un incremento considerable de las masas forestales, sin tener en cuenta las repoblaciones. El monte mediterráneo, en zonas mesófilas como Sierra Madrona, aunque se queme y se sobrepastoree, si no se descepa, muestra una gran capacidad de regeneración (Charco y García Rayego 2002). Algo similar ocurrió con la fauna, especies raras como el ciervo, o muy raras, incluso al mismo borde de la extinción, como la cabra montés, el corzo, el águila imperial, el buitre negro o la cigüeña negra han iniciado su recuperación. Actualmente algunas como el ciervo llegan a ser incluso muy abundantes. En la transición de los siglos XX al XXI se asiste a una regeneración natural de los montes de la comarca (Figs. 2.63 y 2.64) como no se había visto desde los tiempos previos a la reconquista cristiana en el siglo XIII.

En la actualidad y con perspectiva de futuro, actividades económicas antes impensables son y serán las más rentables. En el Valle de Alcudia la ganadería aún tiene cierta rentabilidad, en gran parte debido a las subvenciones de la PAC, de igual modo que sucede con el cultivo del olivar en el entorno serrano de los pueblos, o del cultivo cerealístico en pueblos como Alamillo. Pero en Sierra Madrona son la caza mayor y el corcho las principales riquezas desde finales del siglo XX. En el caso concreto del municipio de Fuencaliente, la mayor rentabilidad de sus 11.052 ha de montes es la producida por la caza mayor y el corcho. Con los datos disponibles del decenio 1991-2000 la JCCM (2001) (faltaban los datos de algunos años) estableció que la caza mayor produjo al Ayuntamiento unos ingresos mínimos de 197 millones de pts, y el corcho un mínimo de 65 millones. Por detrás se situaban los 44 millones por la madera de los pinos plantados a mediados de siglo y que ya eran maderables (en este cómputo si está la década completa) y las rentas de pastos y cultivos agrícolas, con 7 millones, habían dejado de ser las más importantes. 


\subsection{Referencias}

Agostini, E. 1926. Historia de Almodóvar del Campo y Glosa de su antiguo archivo municipal. Ed.: facsímil de 1990. Diputación provincial de Ciudad Real. 371 pp.

Avecilla, C. 1878. Minas del Horcajo pertenecientes a la compañía comandataria denominada La Minería Española. Madrid. 18 pp.

Basas Fernández, M. 1994. El Consulado de Burgos en el siglo XVI. Diputación Provincial de Burgos, 324 pp.

Bejarano, V. (traductor) 1987. Hispania Antigua según Pomponio Mela, Plinio el Viejo y Claudio Ptolomeo. Fontes Hispaniae Antiquae VII. Schulten, A. \& Maluquer de Motes, J. (Eds.). Instituto de Arqueología y Prehistoria. Barcelona.

Beltrán, F.M. 1992. Romanidad tardía y germanismo. En La Provincia de Ciudad Real II. Historia. Biblioteca de Autores y Temas Manchegos. Diputación de Ciudad Real.

Bensusan, M.P. 2003. Las Vías Pecuarias. Marcial Pons Ediciones Jurídicas y Sociales, Madrid.

Betancourt, Agustín de. 1783. Memorias de las Reales Minas de Almadén (3 tomos). Texto manuscrito en la sección Fondo antiguo de la Bibliotena Nacional. Madrid.

Blazquez, J. M. 1970, Fuentes literarias griegas y romanas referentes a las explotaciones mineras de la Hispania Romana, La minería hispana e iberoamericana: contribución a su investigación histórica: Estudios, fuentes, bibliografía. Vol. 1. Ponencias del I Coloquio Internacional sobre Historia de la Minería. VI Congreso Internacional de Minería. Departamento de Publicaciones, León, 117-150.

Bowles, G. 1775. Introducción a la historia natural y a la geografía física de España. Madrid. Imprenta de D. Francisco Manuel de Mena. 535 pp.

Bunce, R.G.H., Pérez-Soba, M., Jongman, R.H.G., Gómez Sal, A.; Herzog, F.Y. \& Austad, I., eds. 2004. Transhumance and Biodiversity in European Mountains. Report from the EU-FP5 project Transhumount (EVK2-CT-2002-80017). Alterra, Wageningen UR, Wageningen IALE publication series $1.321 \mathrm{pp}$.

Cabo Alonso, A. 1998. "Medio natural y trashumancia en la España peninsular. en: Anes, G.; García Sanz, A. (Coor.), Mesta, trashumancia y vida pastoril, Valladolid, 1994, pp. 23-45.

Calvo, L. 2001. La génesis histórica de los montes catalogados de utilidad pública (18551901). Ministerio de Medio Ambiente, Madrid, 407 pp.

Calvo, L. 2003. El Catálogo de Montes. Origen y evolución histórica (1859-1901). Ministerio de Medio Ambiente, Madrid, 329 pp.

Campos y Fernández de Sevilla, F.J. 2009. Los pueblos de Ciudad Real en las Relaciones Topográficas de Felipe II. Ciudad Real. 1168 pp. 
Cano, Fray A. 1762. Noticia de la Cabaña Real de España. Manuscrito de la Biblioteca de la Real Academia de la Historia. Biblioteca General de Historia, Ciencias, Artes y Literatura, 1834, Madrid pp 5-32.

Capel, H. 1967. Los estudios acerca de las migraciones interiores en España. Revista de Geografía, vol. I, nº 1: 77-101.

Carrasco, G. 2006. Las vías romanas. En: Fuentes, A. (Coord.). Castilla-La Mancha en época romana y antigüedad tardía. Biblioteca Añil. Almud, ediciones de Castilla-La Mancha. 4152.

Casas, J. (Dir.) 2012. La trashumancia en España. Libro Blanco. Ministerio de Agricultura, Alimentación y Medio Ambiente Secretaría General Técnica. Centro de Publicaciones. 128 pp.

Catalán, D. \& de Andrés, M.S. 1975 Crónica del moro Rasis, Madrid, Editorial Gredos, CX + $389 \mathrm{pp}$.

Catálogo, 1901. __ de los Montes y demás terrenos forestales exceptuados de la Desamortización por razones de Utilidad Pública, formado en cumplimiento a lo dispuesto en el artículo 40 del real Decreto de 27 de febrero de 1897. Madrid, Imprenta de la sucesora de M. Minuesa, 873 pp.

Cavanillas, R. 1838. Las minas de Almaden. Imp. del colegio de sordomudos. Madrid. 51 pp.

Censo, 1803. __ de la Riqueza Territorial e Industrial de España en el año de 1799, formado de Orden superior. Madrid. Imprenta Real. 104 pp. +3 estados.

Charco, J. \& García Rayego, J.L. 2002. Análisis de la evolución de bosques mediterráneos mediante fotointerpretación: el caso de Sierra Madrona (Sierra Morena oriental, Ciudad Real). En: J. Charco (Coord.). La regeneración natural del bosque mediterráneo en la península Ibérica. ARBA-MIMAM. Madrid. 197-216.

Clasificación, 1859. general de los montes públicos hecha por el Cuerpo de Ingenieros de Montes en cumplimiento de lo prescrito por Real Decreto de 16 de febrero de 1859 y Real Orden de 17 del mismo mes y aprobada por Real Orden de 30 de setiembre siguiente. Madrid, Imprenta Nacional.

CNIG. Centro Nacional de Información Geográfica. http://fototeca.cnig.es/?\&xy=1105320,3451880,2020443,5514943\&SRS=EPSG:25830\&lyr=Mapa.

Collantes A.E. \& Alfaro, A. (Dirs.) Diccionario de Agricultura práctica y Economía rural, tomo II. 1855. Artículo “Carnero.” Madrid. 100-145.

Conde de Montarco, 1959. El ganado lanar merino. Editorial Prensa Española, Madrid, 40 pp.

Corchado, M. 1963. Pasos naturales y antiguos caminos entre Jaén y La Mancha. Boletín del Instituto de Estudios Gienenses 38: 9-37. 
Corchado, M. 1969. Estudio sobre vías romanas entre el Tajo y el Guadalquivir. AEArq 42: 124158.

Corchado, M. 1973. Desamortización frustrada en el siglo XVIII. Separata de los Cuadernos manchegos. II época. 3: 87-197.

Corchado, M. 1977. Las yerbas de Alcudia en los siglos XVII y XVIII. 20000 kms, Revista de la Diputación Provincial de Ciudad Real. 9: 25-30.

Corchado, M. 1984. La orden de Calatrava y su Campo. Ciudad Real. Instituto de Estudios Manchegos. 272 pp.

Corominas, J. \& Pascual, J.A. 1984. Diccionario crítico etimológico castellano e hispánico. Reeditada obra completa (6 vols.) por la Editorial Gredos, Madrid, entre 1991-1997.

Costa, A.C. 1857. Noticias botánico-agrícolas sobre los pinos de Cataluña. Revista de Agricultura, tomo VI: $34-42$.

De Covarrubias, S. 1611. Tesoro de la Lengua Castellana o Española. Imp. Luís Sánchez. Madrid. 78 páginas.

De la Fuente, J.M. 1929. Fauna de la provincia de Ciudad Real. Obra publicada parcialmente. Vistos los manuscritos en la Diputación Provincial de Ciudad Real, donde actualmente se conservan.

De Palencia,A. 1490. Universal vocabulario en latín y en romance. Reeditado por la Comisión Permanente de la Asociación de Academias de la Lengua Española. Madrid. 1967, 2 Vols.

De Terán, M. 1952. Vida pastoril y nomadismo. Revista de la Universidad de Madrid. Vol. VI, $n^{\circ}$ 3: 375-393.

Del Valle, A.R. 1996. Desamortización y cambio social en La Mancha, 1836-1854. Ciudad Real, Biblioteca de Autores Manchegos, 332 pp.

Del Valle, A.R. 1997. La desamortización de Madoz en la provincia de Ciudad Real. Instituto de Estudios Manchegos (CSIC). Ciudad Real. 167 pp.

Del Valle, A.R. 2006. Crecimiento agrario y desigualdad social, 1900-1930. En: Del Valle (Coord.) Historia agraria de Castilla-La Mancha. Siglos XIX- XXI. 117-162.

Del Valle, A.R. 2015. El poder de la propiedad. Élites y desamortización en la España interior (Madrid y Castilla-La Mancha). Biblioteca Añil. 267 pp.

Díez Navarro, A. (Ed. de 1994). Quaderno de Leyes y Privilegios del Honrado Concejo de la Mesta por el licenciado Andrés Díez Navarro. Edición facsímil, acompañado de dos trabajos introductorios de González Díez, E. \& García Sanz, A. Editorial Lex Nova, Madrid.

Dirección General de Agricultura, Industria y Comercio. 1861. Memoria elevada al Excmo. Sr. Ministro de Fomento por la Dirección General de Agricultura, Industria y Comercio sobre el estado de los ramos dependientes de la misma en octubre de 1861. Madrid. Imprenta 
Nacional. 471 pp.

Domergue, C. 1990. Les mines de la Péninsule Ibérique dans l'antiquité romaine. Collection de 1'École Française de Rome, vol. 127. Roma.

Elliott, J.H. \& de la Peña, J.F. 1979-80. Memoriales y cartas del Conde Duque de Olivares. 2 vols. Madrid.

Elorrieta, O. 1934. El Patrimonio Forestal de España. Informe presentado a la comisión encargada de formular las bases para su formación, Madrid. 41 pp.

Estadística, 1896,___ de las siembras y plantaciones verificadas en los montes públicos y cabeceras de las cuencas hidrológicas desde la publicación de la ley de 11 de julio de 1877 hasta fin del año forestal de 1894-95. Madrid, Imprenta de Ricardo Rojas, 239 pp.

Esteban, L. E. 1991. Agricultura y ganadería en Ciudad Real. Siglos XIX y XX. Ciudad Real. Biblioteca de Autores Manchegos, 163 pp.

FEAGAS, Federación Española de Asociaciones de Ganado Selecto. 2011. Encuentros con la Sostenibilidad. Trashumancia, Desarrollo Rural y Biodiversidad. Ganadería Extensiva y Desarrollo Territorial en el marco de la Red Rural Nacional FEADER -MARM.

Feijoo, A. 1990. La desamortización del siglo XIX en Castilla-La Mancha. Toledo. Junta de Comunidades de Castilla-La Mancha. 301 pp.

Feliciano, H.R. 1999. La economía hispanoamericana durante el siglo XVIII, Documentación indiana en Simancas. Valladolid: 51-65.

Fernández Ochoa, C., Zarzalejos, M. \& Hevia, P. 1994. Sisapo I. Excavaciones arqueológicas en La Bienvenida, Almodóvar del Campo (Ciudad Real). Patrimonio Histórico-Arqueología Castilla-La Mancha, 10. Toledo. 143-151.

Ferrer Regales, M. 1989. Redistribución espacial y jerárquica de la población española. En: Análisis del desarrollo de la población española en el periodo 1970-1986. Grupo de Población de la A.G.E. Madrid: Síntesis, D.L

García Delgado, J.L. 1995. La economía española durante el franquismo. Temas para el debate. http://www.vespito.net/historia/franco/ecofran.html

García Martín, P. \& Sánchez Benito, J.M. 1997. Contribución a la historia de la trashumancia en España, Madrid, 1986. (2 ed. renovada, 1997).

García Martín, P. 1988. El Honrado Concejo de la Mesta en el Antiguo Régimen (1700-1836). Ministerio de Agricultura, Madrid.

García Martín, P. 1990. La Mesta, Madrid.

García Martín, P. 2006. La principal sustancia de estos reinos: El Honrado Concejo de la Mesta. En: Actas del I Congreso Nacional de Vías Pecuarias. Ministerio de Medio Ambiente, Madrid, pp. 85-102. 
Garcia Martino, F. 1871. Los montes y el Cuerpo de Ingenieros en las Cortes Constituyentes.. Manuel Minuesa. Madrid. 454 pág.

García Sanz, A. 1978. La agonía de la Mesta y el hundimiento de las exportaciones laneras, un capítulo de la crisis económica del antiguo régimen en España. Agricultura y sociedad. 6: 283-356.

García Sanz, A. 1978. La agonía de La Mesta y el hundimiento de las exportaciones laneras: un capítulo de la crisis económica del Antiguo Régimen en España. Agricultura y Sociedad 6: 283-356.

Gascón, F. 1978 (2 $2^{\text {a }}$ ed. 1994). El Valle de Alcudia durante el siglo XVIII. Ediciones del Orto. $609 \mathrm{pp}$.

Gascón, F. 1981 (2ª ed. 1995). Puertollano y su comarca. Ediciones del Orto. 402 pp.

GEHR 1991. Estadísticas históricas de la producción agraria española, 1859-1935. Grupo de Estudios de Historia Rural. Ministerio de Agricultura, Pesca y Alimentación. Madrid. 1231 pp.

GEHR, Grupo de Estudios de Historia Rural. 1994. Más allá de la propiedad perfecta, el proceso de privatización de los montes públicos españoles (1859-1926). Noticiario de historia agraria. 8: 99-152.

Gil Bautista, R. 2012. Almadén y sus reales minas de Azogue en el siglo XVIII. Tesis doctoral. Facultad de Filosofía y Letras. Universidad de Alicante. 770 pp.

Gil Crespo, A. 1957. La Mesta de Carreteros del reino. Anales de la Asociación Española para el Progreso de las Ciencias XXII: 210-230.

Gil, L. 2003. La voz "montes" y la transformación histórica del espacio natural. Actas de la II Reunión sobre Historia Forestal. Cuadernos de la SECF 16: 19-30.

Gil, L. 2007. La Ciencia de Montes. En: L. Gil \& M. Torre (Eds.). Atlas Forestal de Castilla y León. Junta de Castilla y León. Consejería de Medio Ambiente. Valladolid. 193-236.

Gil, L. 2008. Pinares y rodenales; la diversidad que no se ve. Discurso del Académico Electo Excmo. Sr. D. Luis Gil Sánchez leído en el acto de su recepción pública el día 23 de septiembre de 2008. 191 pp + Contestación.

Gil, L. 2010. Una desmedida devoción por los matorrales (o por qué estabilizar el paisaje humanizado). Conferencias y Ponencias del $5^{\circ}$ Congreso Forestal Español. Ávila, 21-25 de Septiembre de 2009. Cuadernos de la SECF 31, 41-76.

Godoy, M. 1836. Memorias críticas y apologéticas para la historia del reinado del Señor D. Carlos IV de Borbón». III tomos. Madrid. Imprenta de Sancha. 
Gómez Mendoza, J. y Mata Olmo, R., 1992. "Actuaciones forestales públicas desde 1940. Objetivos, criterios y resultados", Agricultura y Sociedad, 65: 15-64.

Gómez Vozmediano, M.F. 2000. La minería en el Valle de Alcudia y sus aledaños durante el antiguo régimen (1250-1860). Campo de Calatrava, Revista de Estudios de Puertollano y comarca. 2: 77-190.

González Doncel, I. \& Gil, L. 2013. Dasonomía y práctica forestal. En: Silva, E. (Ed.) Técnica e Ingeniería en España. Vol. VII. El Ochocientos. De las profundidades a las alturas. Real Academia de Ingenieria. Institucion «Fernando El Catolico» Prensas de la Universidad de Zaragoza. 559-602.

González, J.A. (IP). 2008. Valoración económica de la biodiversidad y los servicios de los ecosistemas ligados a la trashumancia en la Cañada Real Conquense: implicaciones para la gestión de los agroecosistemas mediterráneos en el contexto del cambio global. Laboratorio de Socio-Ecosistemas, Universidad Autónoma de Madrid. http://www.uam.es/gruposinv/socioeco/ficha_proyecto_4.htm

González, T. 1829. Censo de Población de las Provincias y Partidos de la Corona de Castilla en el Siglo XVI. Madrid, Imprenta Real

Gordo, J. \& Gil, L. 1990. Los bosques españoles y el catálogo de montes de utilidad pública». Ecología, fuera de serie $\mathrm{n}^{\circ} 1$, pp. 113-127.

Guía, 1858-1860. de Forasteros en Madrid. Madrid, Imprenta Nacional.

Herraiz, O. 2010. Aspectos Jurídicos y Sociales de las Vías Pecuarias. Congreso Nacional de Vías Pecuarias II, 2010. Ministerio de Medio Ambiente, Rural y Marino.

Hervada, H. 1894. Laboreo. Memoria del Horcajo. Curso 1893-1894. Escuela Técnica Superior de Ingenieros de Minas. Madrid.

Hervás y Buendia, I. 1899-1918. Diccionario Histórico- Geográfico de la Provincia de Ciudad Real. 2 vols. Ciudad Real. Ed. facsímil Diputación Provincial de Ciudad Real en 2002 pp.

Hevia, P. 2003. El Patrimonio Minero del Valle de Alcudia y Sierra Madrona. Mancomunidad de Municipios del Valle de Alcudia y Sierra Madrona.Ciudad Real.

Hill, J.M. 1957. Universal Vocabulario de Alfonso de Palencia. Registro de voces españolas internas. Madrid, Real Academia Española. 212 pp.

ICONA-DGBA. 1991-1997. Serie Cuadernos de la trashumancia. Números 0-24. ICONA. http://www.marm.es/es/biodiversidad/temas/vias-pecuarias/fondodocumental-de-vias-pecuar ias/index2010-11-11 20.53.46.2640.aspx

INE 1985. Censo de la Corona de Castilla de 1571. 2 tomos. Disponible en internet en http://www.ine.es/ss/Satellite?L=es_ES\&c=INEPublicacion_P\&cid=1254735117797\&idp=1 $254735117797 \& \mathrm{p}=1254735110606 \&$ pagename $=$ ProductosYServicios\%2FPYSLayout $\&$ titte ma=Publicaciones+hist\%C3\%B3ricas 
INE 2008. Censo de Pecheros. Carlos I 1528. Tomo I. 406 pp. Disponible en internet en http://www.ine.es/ss/Satellite?L=es_ES\&c=INEPublicacion_P\&cid=1254735117797\&idp=1 $254735117797 \& \mathrm{p}=1254735110606 \&$ pagename=ProductosYServicios\%2FPYSLayout $\&$ titte ma $=$ Publicaciones+hist\%C3\%B3ricas

INE 2015. http://www.ine.es

Izquierdo, R. 2002a. Época visigoda. En: Castilla-La Mancha medieval. Biblioteca Añil. Ciudad Real: 13-36.

Izquierdo, R. 2002b. Etapa de dominio musulmán (siglos VIII-XI). En: Castilla-La Mancha medieval. Biblioteca Añil. Ciudad Real: 37-72.

JCCM. 2001. Proyecto de ordenación forestal del grupo de montes de Fuencaliente (Ciudad Real). Tomo I, Memoria e Inventario.

Jovellanos, M. de. 1795. Informe de la Sociedad Económica de esta corte al Real y supremo Consejo de Castilla en el expediente de ley agraria, extendido por su individuo de número el Sr. D. Gaspar Melchor de Jovellanos á nombre de la Junta encargada de su formación, y con arreglo á sus opiniones. Imprenta de Sancha. Madrid.

Junta General de Estadística. 1868. Censo de la ganadería de España según el recuento verificado en 24 de setiembre de 1865. Imprenta de Julián Peña. Madrid. LII. 224 pp.

Klein, J. 1979. La Mesta. Alianza Universidad. Madrid. 457 pp.

Ladrón de Guevara, M.P. 1988. La Reforma Agraria en la II República; el Registro de la Propiedad Expropiable en Ciudad Real. En: VVAA, Transformaciones burguesas, cambios políticos y evolución social. JCCM. 95-111.

Ladrón de Guevara, M.P. 2006. Reformismo Agrario y Experiencia Revolucionaria. 1931-1938. En: Del Valle (Coord.) Historia agraria de Castilla-La Mancha. Siglos XIX- XXI. 239-270.

Laguna Sanz, E. 1986. Historia del Merino. Secretaría General Técnica (MAPA) Madrid. 224 $\mathrm{pp}+$ Anexos.

Laguna, M. 1968. Un pedazo de Sierra Morena. Rev. For. Econ. Agric. 1: 437-450.

Le Flem, J.P. 1975. ¿Miguel Caxa de Leruela, Defensor de la Mesta?, Introducción en la reedición de Miguel Caxa de Leruela, Restauración de la antigua abundancia de España, Nápoles. 1631. Madrid Instituto de Estudios Fiscales. XV-LII.

Lecea y García, C. 1894. La Comunidad y tierra de Segovia: estudio histórico-legal acerca de su origen extensión, propiedades, derechos y estado presente. Segovia. Establecimiento Tipográfico Ondero.

López González, C., Postigo, E. \& Ruíz González, J.I. 1988. Las órdenes militares castellanas en la época moderna: una aproximación cartográfica. Cuaderno de Estudios Manchegos. 18: 215-272. 
López Salazar, J. 1986. Estructuras agrarias y sociedad rural en La Mancha (s. XVI-XVII). Ciudad Real, Instituto de Estudios Manchegos, 743pp.

López Salazar, J. 1987. Mesta, pastos y conflictos en el Campo de Calatrava (S. XVI). El Mundo Rural. Monografías de Historia moderna 4. CSIC. Madrid. 214 pp.

López Salazar, J. 1994. La Sección de Órdenes Militares y la investigación en Historia Moderna. Cuadernos de Historia Moderna. 15: 325-373.

López Sánchez, A. 2015. Balancing management and preservation of mediterranean scattered oak woodlands (dehesas) in human-dominated landscapes. Tesis doctoral. ETSI Montes. Universidad Politécnica de Madrid. 237 pp.

Luzón, J. M. 1970. Instrumentos mineros de la España Antigua. En La minería Hispana e Iberoamericana. Contribución a su investigación histórica. Vol I. León. Cátedra de San Isidoro. 221-258.

Madoz, P. 1847-1848. Diccionarios Geográfico, histórico y estadístico de España y sus posesiones de ultramar. Madrid.

MAGRAMA 2015a. III Inventario Forestal Nacional. www.magrama.gob.es/es/biodiversidad/ servicios/banco-datos-naturaleza/informacion-disponible/ifn3.aspx

MAGRAMA 2015b. Anuarios de Estadística Agraria. Consultado el 10 de junio de 2015. www.magrama.gob.es/es/estadistica/temas/ publicaciones/ anuario-de-estadistica.

MAGRAMA. 2012. Caracterización de las comarcas agrarias de España. Tomo 16. Provincia de Ciudad Real. Grupo de Agroenergética de la Escuela Técnica Superior de Ingenieros Agrónomos de la Universidad Politécnica de Madrid (GA- UPM). Ed. Secretaría General Técnica. Ministerio de Agricultura, Alimentación y Medio Ambiente. 155 pp.

Maldonado, F.J., Sainz, H. \& Sánchez de Dios, R. 1988. Distribución y estado de conservación de los bosques en España, Madrid. UAM-WWF. 1998.

Malefakis, E. 1971. Reforma agraria y revolución campesina en la España del siglo XX. Ariel. Barcelona.

Mangas, J. M. 2001. Catálogo de montes de utilidad pública (1855-1901). I. Primera época: origen y formación del catálogo (1855-1865). Montes. Revista de ámbito forestal, 66: 5-15.

Mangas, J. M. 2002. Catálogo de montes de utilidad pública (1855-1901). y II. Segunda época: Revisión y consolidación del Catálogo (1865-1901). Montes. Revista de ámbito forestal, 67: $27-33$.

Mangas, J.A. 1984. La propiedad de la tierra en España: los Patrimonios Públicos. Herencia contemporánea de un reformismo inconcluso. Madrid. Instituto de Estudios Agrarios, Pesqueros y Alimentarios. 350 pp. 
Mansilla, L. \& Iraizoz, J.M. 2012. Aproximación al laboreo de minas y a la metalurgia en las Minas de Almadén (Ciudad Real). De re metallica (Madrid): revista de la Sociedad Española para la Defensa del Patrimonio Geológico y Minero (19): 79-93.

Manzano, P. \& Casas, R. 2010. Past, present and future of Trashumancia in Spain: nomadism in a developed country. Pastoralism - Research, policy and practice, vol. 1, 1: 72-90.

Marín Barriguete, F. 1992. Los Reyes Católicos y el Honrado Concejo de la Mesta. Una desmitificación necesaria. Cuadernos de Historia Moderna, 13, Editorial Complutense, Madrid. 109-141.

Martínez Fronce, F.M. 1989. Una cuadrilla mesteña: la de Cuenca. Diputación provincial de Cuenca. 128 pp.

Matilla, A. 1958. Historia de las Minas de Almadén. Vol. I. Madrid.

Matilla, A. 1987. Historia de las Minas de Almadén. Vol. II. (Desde 1646 a 1799). Madrid, Minas de Almadén y Arrayanes, S.A. e Instituto de Estudios Fiscales, 491 pp.

Medrano y Treviño, D. 1843. Consideraciones sobre el estado económico, moral y político de la provincia de Ciudad Real. Madrid. Imp. Carrera de San Gerónimo. 92 pp.

Ministerio de Agricultura, 1933. Catálogo de los Montes de Utilidad Pública de la provincia de Ciudad Real. Rectificado en 1933 en cumplimiento de la dispuesto en la Orden Ministerial de 24 de Abril de 1931. Madrid.

Ministerio de Medio Ambiente. 2004. Mapa Forestal de España 1:50.000. Provincia de Ciudad Real. Dirección General para la Biodiversidad. Ed.: Organismo Autónomo de parques Nacionales. en CD.

Mora, C. 2010. Guadalmez, de manantial a río. Ed. Diputación de Ciudad Real. 246 pp.

Núñez de Arenas, B. 1854. Cartas sobre la existencia y conservación de los montes dirigidas al Excmo. Señor Ministro de Fomento por el Ilustrísimo Señor D. Bernardino Nuñez de Arenas. F. de P. Mellado, Madrid, 44 pp.

Olazábal, L. de. 1898. Desamortización forestal [1860]. Cuarenta años de propaganda forestal: colección de memorias, artículos e informes, Madrid, Imprenta de Ricardo F. Rojas. 203205.

Oroz, J. \& Marcos, M. 1983. San Isidoro de Sevilla. Etimologías. II (Libros XI-XX). Madrid, Biblioteca de Autores Cristianos. 614 pp.

Ortiz, M. 1992. Época Isabelina. In La Provincia de Ciudad Real II. Historia.Biblioteca de Autores y Temas Manchegos. Diputación de Ciudad Real. 390-398.

Pascual, A. 1859-1861. Memoria de los productos de la agricultura española reunidos en la Exposición general de 1857, Madrid, 1128 pp. +CXLVIII de índices. 
Pérez Soba, I. 2006. La rectificación del Catálogo de Montes de Utilidad Pública de la Provincia de Zaragoza Revista Aragonesa de Administración Pública. 28: 167-252.

Pozuelo, C. \& Pozuelo, F. 1994. Historia de San Lorenzo de Calatrava. Ciudad Real. 108 pp.

Quirós, F. \& Planchuelo, G. (1992 ). El paisaje Geográfico del Valle de Alcudia, el Campo de Calatrava y el Campo de Montiel, Ciudad Real. Diputación de Ciudad Real.

Quirós, F. 1964. La desamortización, factor condicionante de la estructura de la propiedad agraria en el Valle de Alcudia y Campo de Calatrava. Estudios Geográficos. 96: 367-407.

Quirós, F. 1965. Sobre geografía agraria del Campo de Calatrava y el Valle de Alcudia. Estudios geográficos. 99. 207-230.

Quirós, F. 1969. La Minería en el Valle de Alcudia y Campo de Calatrava. Estudios Geográficos, XXX, 117. Madrid.

Rades y Andrada, F. de. 1572. Chrónica de las tres órdenes y cavallerías de Sanctiago, Calatrava y Alcántara en la qual se trata de su origen y successo, y notables hechos en armas de los maestres y caualleros de ellas: y de muchos senores de título y otros nobles que descienden de los maestres: y de muchos otros linajes de España. Toledo: J. de Ayala, reimpresión facsímil de Barcelona: Ediciones El Albir, 1980.

RAE, Real Academia Española, 1815. Fuero Juzgo en latín y castellano cotejado con los más antiguos y preciados códices. Real Academia Española. Ibarra. Madrid. 232 pp.

Retuerce, M. \& Lozano, I. 1986. La dominación islámica. Siglos VIII al XII. La historia de la provincia de Ciudad Real. Ciudad Real: 65-88.

Retuerce, M. 1995. La meseta islámica como tierra de frontera. en Alarcos, el fiel de la balanza. Servicio de Publicaciones de la Junta d Comunidades de Castilla-La Mancha. 81-98.

Rodríguez Estival, J. 2012. Contaminación por plomo en caza mayor y ganadería de la zona minera del Valle de Alcudia y Sierra Madrona: uso de biomarcadores para el estudio de efectos subletales. Tesis doctoral. Instituto de Investigación en Recursos Cinegéticos. UCLM. 216 pp.

Rodríguez García, F. 2006. La trashumancia y los Aránguez. Biblioteca Oretana. Colección Historia. IV. 47-79.

Rodriguez Pascual, M. 2001. La Trashumancia: cultura, cañadas y viajes. Edilesa. 2001.

Rodriguez Picavea, E. 1994. La formación del feudalismo en la meseta meridional castellana. Siglo Veintiuno de España Editores. 427 pp.

Roldán, L., García Camacho, S., Marina, M.C. \& Pozuelo, F. 1993. Proyecto de Investigación: Abenójar. C.P. Ntra. Sra. de la Encarnación. Ayuntamiento de Abenójar. 305 pp.

Romano, V. \& Sanz, F. 1967. El Valle de Alcudia. Alfagura. 303 pp. 
Ruhstaller, S. 1995. Materiales para la lexicología histórica. Estudio y repertorio alfabético de las formas léxicas toponímicas contenidas en el Libro de la Montería de Alfonso XI, De Gruyter. Edición reimpresa en 2014. 212 pp.

Ruiz Gómez, F. 1992. La repoblación de Ciudad Real en los siglos XII y XIII. La Provincia de Ciudad Real II. Historia. Biblioteca de Autores y Temas Manchegos. Diputación de Ciudad Real.

Ruíz Gómez, F. 2002. El antiguo reino de Toledo y las tierras de La Mancha en los siglos XIXIII. Castilla-La Mancha medieval. Biblioteca Añil. Ciudad Real: 73-168.

Ruiz, M. \& Ruiz, J.P. 1986. Ecological History of Trashumance in Spain. Biological Conservation, 36: 73-86.

Ruiz, M. 2001. The ecological and economical rationale for transhumance practices in Spain. En: Bunce, R.G.H., Pérez-Soba, M., Jongman, R.H.G., Gómez Sal, A.; Herzog, F.Y. \& Austad, I., Eds. 2004. Transhumance and Biodiversity in European Mountains. Report from the EU-FP5 project Transhumount (EVK2-CT-2002-80017). Alterra, Wageningen UR, Wageningen IALE publication series 1.

Sáinz de Baranda, B., Palero, F.J., García, G. (2004): El Horcajo, las piromorfitas más famosas del mundo. Bocamina, 13: 32-68

Salkield, L.U. 1970. Ancient sdlags in the south west of the Iberian peninsula. En: La minería Hispana e Iberoamericana. Contribución a su investigación histórica. Vol I. León. Cátedra de San Isidoro. 85-98.

San Miguel, A. 1994. La Dehesa Española. Origen Tipología, Características y Gestión. Ed. Fundación Conde del Valle Salazar. Madrid. 96 pp.

San Miguel, A. 2001. Pastos naturales españoles. Aprovechamiento y posibilidades de mejora. Coedición Fundación Valle de Salazar-Mundi Prensa. Madrid 320 pp.

Sánchez Albornoz, C. 1946. La España musulmana. El Ateneo. Buenos Aires.

Sánchez Gómez, L.A. 1993. Las dehesas de Sayago. Explotación, trabajo y estructura social, Caja España, Zamora. 355 pp.

Sarrión, F.J. \& Burgaz, A.R. 2002. Los líquenes epífitos como bioindicadores de la regeneración natural de los bosques mediterráneos de fagáceas. En J. Charco (Coord.): La regeneración natural del bosque mediterráneo en la Península Ibérica. Evaluación de problemas y propuesta de soluciones. ARBA-Ministerio de Medio Ambiente.

Silvestre, J. 2003. Datos con respecto a los migraciones interiores en España. Facultad de Económicas y Empresariales. Zaragoza: Universidad de Zaragoza.

Simón Segura, F. 1974. La desamortización de 1855 en Ciudad Real. Hacienda pública española. 27: 87-114. 
Valverde, J.A. 1996. Sobre la autoría del Tratado de Montería del siglo XV. Revista de Literatura Medieval, VIII: 229-237.

Valverde, J.A. 2005. Reyes, osos, lobos y espátulas. Madrid, Editorial Quercus V \& V. 189 pp.

Ward, B., 1779. Proyecto Económico, en el que se proponen varias providencias, dirigidas á promover los intereses de España con los medios y fondos necesarios para su plantificación: escrito en el año de 1762. Madrid, Ibarra, 400 pp.

Zarzalejos, M.M. 1994. La búsqueda de Sisapo: hipótesis sobre la reducción geográfica de la capital del cinabrio hispano. Espacio, Tiempo y Forma. Serie II, Historia Antigua, T.7: 175191.

Zarzalejos, M.M. 2011. La investigación arqueológica de los paisajes mineros antiguos en la vertiente norte de Sierra Morena (provincia de Ciudad Real). De Re Metallica, 17: 55-66.

Zarzalejos, M.M., Fernández, C. y Hevia, P. 2004. El proyecto Sisapo-La Bienvenida (Almodovar del Campo, Ciudad Real). Investigaciones arqueológicas en Castilla La Mancha: 1996-2002. 163-180.

Zuaznavar, M. 1880. Almadén en noviembre de 1879. Artículos publicados en la revista minera. Imp. J.M. Lapuente. Madrid. 


\section{CAPÍTULO 3}

\section{EL PINAR DE NAVALMANZANO; UN BOSQUE EN PELIGRO DE EXTINCIÓN QUE RESUME LA HISTORIA NATURAL DE SIERRA MADRONA}

\section{Resumen}

Tradicionalmente se ha considerado a los pinares ibéricos como propios de terrenos de condiciones edafoclimáticas extremas, como las que aparecen en la alta montaña. Por este motivo y por la inexistencia de masas naturales en la actualidad no se tenían en consideración en amplias zonas del SO ibérico como Sierra Morena, Montes de Toledo o Extremadura. Zonas en las que, aunque repoblaciones artificiales de pinos como Pinus pinaster se adaptan bien al terreno, con buenos crecimientos, se negaba su naturalidad. Sin embargo, numerosas evidencias parecían indicar que sí eran autóctonos aunque sus masas naturales ya hubieran desaparecido.

Con el fin de comprobar si P. pinaster pudo estar distribuido en el pasado por el SO ibérico se realiza un estudio multidisciplinar, con análisis de publicaciones sobre paleobotánica, textos antiguos y un minucioso proceso de búsqueda de topónimos por toda Sierra Morena, desde Albacete hasta al Algarbe portugués. Todas las secuencias paleopolínicas analizadas del entorno de Sierra Madrona, Valle de Alcudia y comarcas limítrofes del Campo de Calatrava, La Serena y Sierra Morena centro-oriental, muestran polen de pino. Se encuentran macrorrestos (maderas y carbones) de $P$. pinaster en yacimientos de la Edad del Bronce y del Hierro, también textos medievales y modernos hablan de pinos en Sierra Madrona y otras áreas de la provincia de Ciudad Real y otras del entorno silíceo del Macizo Ibérico. En cuanto a los topónimos referentes a pinos, se han encontrado más de un centenar.

Se complementa este análisis con una intensa búsqueda de ejemplares de $P$. pinaster que hayan podido sobrevivir en Sierra Morena y, más especialmente, en las diferentes serrezuelas del complejo de Sierra Madrona (entre Córdoba, Jaén y Ciudad Real). Se han encontrado 2 poblaciones, una en Sierra Quintana (con solo 2 ejemplares, uno de ellos centenario) y otra ya indicada por Laguna en 1868 pero apenas conocida, en la sierra de Navalmanzano. Sobre esta segunda se ha realizado un inventario sistemático para conocer sus características dasométricas y otros datos. También se han georeferenciado todos sus pies con un GPS inframétrico, a fin de situar exactamente cada pie y poder así seguir su evolución futura. En el primer inventario sistemático en 2003 se encontraron y midieron 1212 pies en 2 subpoblaciones, a los que hay que añadir otros 11 ejemplares más aislados en su entorno. La densidad y altura de los árboles es muy baja, debido tanto a la juventud de la mayoría de los pies como a que buena parte de ellos crecen sobre roquedos. A excepción del estrés que supone crecer sobre roquedos, el estado sanitario de la masa puede considerarse bueno, pero, recientemente (en 2015), se ha detectado la llegada de la procesionaria del pino, procedente de las repoblaciones realizadas a mediados del siglo XX en el entorno, donde este lepidóptero si llega a ser abundante. Un aspecto destacado del estudio del pinar relicto de Navalmanzano ha sido la muerte súbita de 4 de los mayores pies 
del pinar, en enero de 2005, probablemente por la conjunción de una fuerte helada y una intensa sequía que iniciaría el proceso de seca de estos grandes pinos.

Todo esto permite confirmar que, al menos $P$. pinaster, es autóctono en Sierra Morena y comarcas próximas de Badajoz y Ciudad Real. El proceso de extinción holocénico de los pinares comenzó probablemente durante las explotaciones mineras de época romana, pero no llegaron a desaparecer por completo. Se han encontrado restos de pinares supervivientes a más de 3000 años de explotaciones mineras e incendios forestales recurrentes.

La supervivencia de las 2 poblaciones de $P$. pinaster autóctono en Sierra Madrona tiene un valor especial para confirmar nuestra hipótesis de que esta especie puede formar bosques de forma completamente natural en altitudes medias y altas del SO ibérico. La población de Sierra Madrona es una de las más interesantes de la especie en toda su área de distribución en los países del Mediterráneo occidental. Tanto por su carácter marginal, como por su compleja historia de supervivencia y su excepcional papel bioindicador para la reinterpretación de los paisajes forestales de los países mediterráneos.

\subsection{Introducción}

\subsubsection{Evolución del género Pinus en la península Ibérica}

Tras la extinción Permo-Triásica, hace unos 250 Ma, el ambiente del Mesozoico favoreció el desarrollo de las gimnospermas. Una amplia diversificación les llevó a dominar prácticamente todos los ecosistemas terrestres. En el Triásico aparecen las pináceas y el género Pinus L. probablemente a mediados del Jurásico (Axelrod 1986; Millar 1998). Los fósiles más antiguos son del Cretácico y del Hemisferio Norte (Millar 1998). Hoy, el género posee una evolución de más de 130 Ma, una gran vitalidad y su diversidad reúne a 130 especies (The Plant List 2013). El fósil más temprano de un inequívoco pino procede del Cretácico inferior (Alvin 1960) y, en la península Ibérica es Pinoxylon riojanus del Cretácico inferior (Nido et al. 1998). Filogenéticamente, las vías evolutivas parten de un origen cretácico (Willyard et al. 2007) y muestran, a mediados de este periodo (Willyard et al. 2007; He et al. 2012), su división en las dos ramas actuales. El subgénero Strobus (Haploxylon), cuyas especies tienen un solo haz vascular central en las acículas de sus braquiblastos, y el subgénero Pinus (Diploxylon), siempre con dos haces en las acículas, que incluye las especies ibéricas actuales y con estrategias como la corteza más gruesa o la serotínia, adaptadas para dominar en zonas bajo la influencia de incendios forestales, cuya intensidad y recurrencia aumentó en el Cretácico, debido a la subida de las temperaturas y de los niveles de oxígeno (He et al. 2012; Keeley 2012).

En el Terciario, al menos desde el Mioceno se datan conos de pinos ibéricos (Teixeira y Pais 1976). En el Plioceno de Portugal se cita un posible ancestro, $P$. praepinaster, descrito en base a un estróbilo y acículas en grupos de tres, próximos a $P$. canariensis y polen parecido a $P$. pinaster (Teixeira 1944). Polen de tipo P. pinaster se encuentra en el Pleistoceno Medio en Portugal (Teixeira 1943; Teixeira y Pais 1976). Más tarde, en el Pleistoceno Superior y el 
Holoceno, el polen tipo pinaster aparece en numerosos yacimientos distribuidos por casi toda la península Ibérica (Carrión et al. 2012). Pero además del registro polínico, también se ha encontrado la especie, durante el Pleistoceno superior y el Holoceno mediante la identificación de macrorestos (maderas, estróbilos). Estos se han encontrado en Portugal (e.g. Figueiral 1995; García Amorena et al. 2007) y diversas zonas de España, tanto en el Norte [e.g. Montes de León, Cuenca del Duero y el Sistema Ibérico (Mallada 1892; Richter \& Eckstein 1986; Rubiales et al. 2007; Morla et al. 2009], como en el Sur [Andalucía, Extremadura y Murcia (Rodríguez Ariza \& Esquivel 1989; Rodríguez Ariza 2000; Alcalde et al. 2004; Duque 2004; Rubiales et al. 2010)].

Las regiones de procedencias de $P$. pinaster definidas en España (Alía et al. 1996), considera al pinar de Fuencaliente, en Sierra Madrona, como una zona de conservación por la pequeña extensión de la población y su aislamiento geográfico de las más cercanas (Fig. 3.1). Caracteriza a este pinar, del que señala está formado por 200 pies de pino negral, por una altitud de 800-1000 m y un climodiagrama basado en los registros de 10 años de la estación de Fuencaliente, situada a una altitud de $880 \mathrm{~m}$ y a $4,5 \mathrm{~km}$ del pinar. La pluviometría media es de $655 \mathrm{~mm}$, con $12 \mathrm{~mm}$ en los meses de julio y agosto, una temperatura media de $14,9^{\circ} \mathrm{C}$ y 5 meses (noviembre-marzo) de helada probable (Alía et al. 1996).

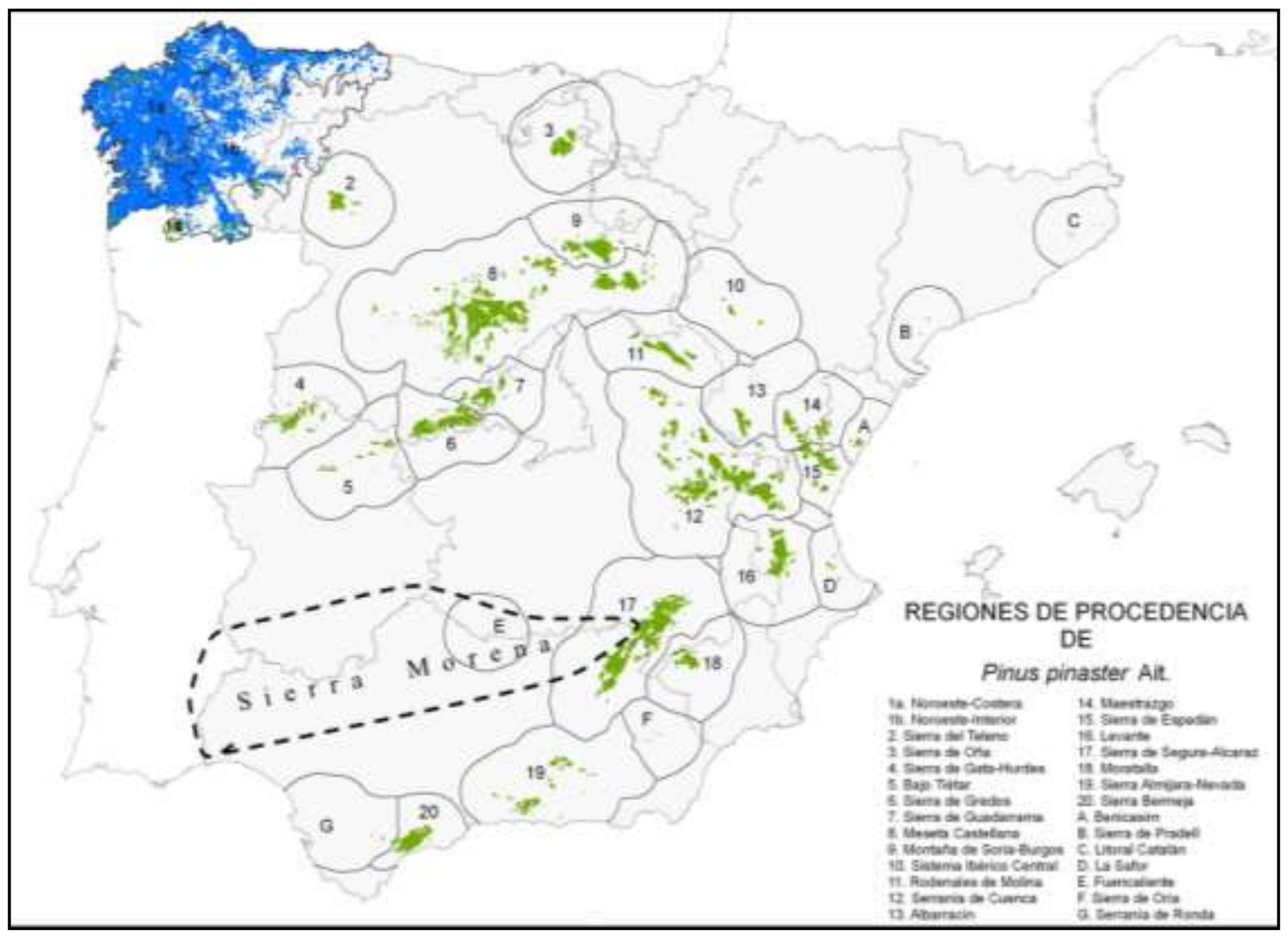

Fig. 3.1. Regiones de procedencia de Pinus pinaster en España (Alía et al. 2009). Fuencaliente figura como una Región de Procedencia Especial (E) La línea discontinua añadida indica el ámbito de Sierra Morena, situada entre Portugal, Extremadura, Castilla-La Mancha y Andalucía. Es de notar que los autores no hacen referencia a la presencia natural de la especie en la Isla de Menorca (Fraga, 1996). 
Pinus pinaster, especie nativa del Mediterráneo occidental, es poseedora de una gran diversidad edáfica como muestran los trabajos de Nicolás \& Gandullo (1967), frente a estudios anteriores que no situaban a la especie en la serie de la encina sobre suelos calizos (Ceballos 1942, 1944). Es la calidad de estación la que determina la altura dominante de sus rodales naturales, alcanzando los 28,7 m a los 60 años en las masas astur-galaicas y, en el resto de España, la mejor calidad se caracteriza por $23 \mathrm{~m}$ a los 80 años (Nicolás \& Gandullo 1967). Trabajos más concretos muestran que, en Boiro (La Coruña), a los 30 años la altura dominante es de 20,4 m, mientras que en Entrimo (Orense) a los 36 años es de 24,2 m, (Bará \& Toval, 1983). La especie tiene un rango de tolerancia térmica muy dependiente de la procedencia (Alía et al. 1996). También se caracteriza esta especie por su buena adaptación al fuego, con una gruesa corteza y un alto nivel de serotinidad (Tapias et al. 2001, 2004). La posesión de una gran diversidad genética en la península Ibérica hace considerar que $P$. pinaster tuvo aquí uno de sus refugios durante las glaciaciones (González Martínez et al. 2002, 2005), donde experimentó importantes avances y retrocesos territoriales durante los procesos glaciares e interglaciares del Cuaternario, como evidencia el registro paleopolínico (e.g. Rubiales et al 2010). Es decir, que con mayor o menor densidad, estaría relativamente bien distribuido por las solanas de Sierra Morena a lo largo del Cuaternario.

\subsubsection{El último bosque de $P$. pinaster de Sierra Morena}

El pinar de P. pinaster de Sierra Madrona es el último de toda Sierra Morena (Fig. 3.1) y, por tanto, una población en peligro de extinción por su baja demografía y aislamiento de otros pinares naturales, único superviviente de una región en la que debió tener una mayor presencia, hoy desconocida. Estas poblaciones constituyen ecosistemas de gran valor biogeográfico. Desde el punto de vista de la biología de la conservación esta población puede ser un referente para entender las extinciones por la acción humana a escalas temporales y espaciales.

El análisis genético aproxima las vías de recuperación de la especie en la Península Ibérica, situando filogenéticamente a los pinos de Sierra Madrona próximos a los del Sistema Ibérico y más alejados de los de las sierras béticas (Salvador et al. 2000). Este y otros trabajos (GonzálezMartínez et al. 2005) muestran que los pinos de Sierra Madrona tienen un número muy bajo de alelos, probablemente por el tamaño tan reducido de la población actual que, sin embargo, estaba en recuperación a finales del siglo XX.

Por su singularidad genética, esta población merece especial atención pues cualquier nueva amenaza podría acabar con ella. Máxime en los tiempos actuales de clima cambiante y creciente humanización del medio (Resco et al. 2007; Sattout \& Nemer 2008; Allen et al. 2010; Akhani et al. 2010; Clark et al. 2011; Vose et al. 2012; Anderegg et al. 2013). Cuando la superficie del bosque se reduce en extremo, o sobreviven muy pocos árboles, la supervivencia del ecosistema puede verse amenazada por causas que a priori no parecieran preocupantes. Por eso no debe subestimarse el impacto de factores como la llegada de especies exóticas, enfermedades, bajo éxito reproductor o regresión (e.g. Kramer \& Havens 2009). 
Aunque hay referencias escritas sobre pinos en Sierra Madrona desde el siglo XIII, a principios del siglo XXI no se conocían ni su distribución exacta ni ningún otro dato relevante más allá de la existencia de un pequeño pinar en Fuencaliente, con pinos de pequeño porte sobre una ladera rocosa expuesta al sur (Laguna 1868, 1870; Gil et al. 1991; Alía et al. 1996).

Ante todas estas premisas, el objetivo de este capítulo es precisar la reducida demografía a la que se alude en 1996 por Alía et al. y conocer mediante la localización, inventario y caracterización de los últimos ejemplares autóctonos de $P$. pinaster de Sierra Morena, su evolución entre los años 2002 y 2015

\subsection{Material y métodos}

\subsection{1. Área de estudio}

Sierra Morena es un conjunto de sierras paleozoicas, con depósitos Plio-Cuaternarios (rañas), caracterizada por sus materiales precámbricos y paleozoicos. Se sitúa en el Macizo Ibérico, entre las zonas Centroibérica, Ossa-Morena y Sudportuguesa. El clima es mediterráneo cálido, sin heladas, salvo en las cumbres y umbrías de las partes más altas, donde en invierno el hielo puede formarse y permanecer en zonas sin radiación solar directa. La temperatura media anual es de $15^{\circ} \mathrm{C}$, la media invernal ronda los $8^{\circ} \mathrm{C}$ y la media estival $\operatorname{los} 25^{\circ} \mathrm{C}$. Las precipitaciones medias anuales oscilan entre los $500 \mathrm{~mm}$ en las partes exteriores de la Sierra y los $1.200 \mathrm{~mm}$ de las partes más interiores y occidentales (AEMET 2011). La vegetación natural la formarían diversos tipos de bosques, aunque actualmente domina la encina Quercus ilex subsp. rotundifolia por la acción antrópica. En las zonas más altas y agrestes, la diversidad de topoclimas hace aumentar la diversidad forestal y, por tanto, la biodiversidad en general. En Sierra Madrona y en la Sierra de San Andrés, donde se superan los 800 m de altitud, son frecuentes, además de los bosques esclerófilos de $Q$. ilex y $Q$. suber, los semicaducifolios de $Q$. faginea y $Q$. pyrenaica.

Aunque ya reducidos a las Sierras de Navalmanzano y Quintana, los pinares autóctonos de Pinus pinaster también tuvieron que ser comunes en el pasado. Sin embargo, su casi total desaparición motivó que, aunque fueran citados por Laguna a finales del siglo XIX (1868, 1870), carecieron de presencia en los estudios florísticos de Sierra Madrona (e.g. Rivas Goday 1950; Peinado \& Martínez Parras 1985; Ladero et al. 1987; Cano \& Valle 1990). García Río (1999) en su aportación al estudio de la flora de Sierra Morena, en la que incluye 50 taxones que son novedad para la flora de la provincia o para Sierra Morena, tampoco incluye a la especie.

La masa principal, sobre la que se centra gran parte del estudio, se localiza en las coordenadas $38^{\circ} 25^{\prime} 8^{\prime}$ ' $\mathrm{N} ; 4^{\circ} 15^{\prime} 14^{\prime}$ 'O, en la vertiente sur de la sierra de Navalmanzano, sobre el dorso meridional de un anticlinal desventrado, compuesto por materiales paleozoicos, donde dominan las cuarcitas del Ordovícico muy erosionadas (García-Rayego 2006). La pendiente media en el pinar es de un $40 \%$, por lo que, deforestada, fue muy propensa a la pérdida de los horizontes orgánicos hace siglos del suelo y al afloramiento de la roca madre. La temperatura media anual 
es de unos $14,5^{\circ} \mathrm{C}$ y la precipitación media anual ronda los $670 \mathrm{~mm}$. Salvo en la parte alta de la sierra, en verano se superan los $40^{\circ} \mathrm{C}$, lo que provoca una alta evapotranspiración y acusado déficit hídrico estival. No obstante este déficit se ve en parte compensado con la lluvia horizontal, una condensación de humedad que a veces, al amanecer, se forma sobre la Sierra Morena andaluza (mar de nubes) y que, a medida que avanza la mañana, asciende hasta llegar a las cumbres de Sierra Madrona (Fig. 3.2).

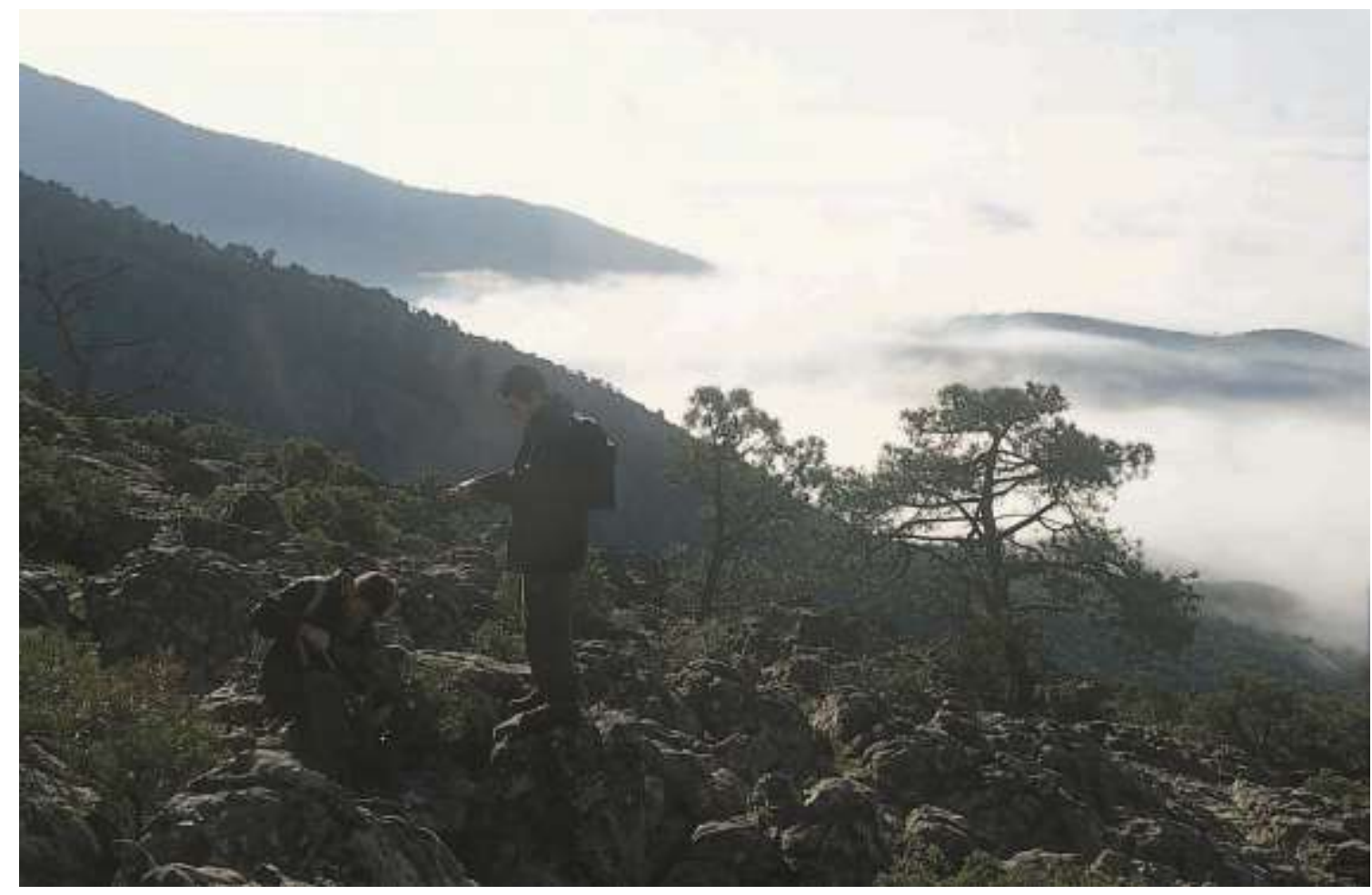

Fig. 3.2. Vista del pinar durante la realización del inventario, al fondo a la izquierda Sierra Quintana. La Sierra Morena jiennense aparece cubierta por el mar de nubes.

En esta ladera de solana, además del pino, es frecuente el enebro (Juniperus oxycedrus) y, en menor medida, la encina (Quercus rotundifolia), el alcornoque ( $Q$. suber) y el madroño (Arbutus unedo). Más raros, pero también presentes, son el quejigo (Q. faginea subsp. broteroi) y el roble melojo ( $Q$. pyrenaica). La umbría de la sierra de Navalmanzano, donde solo se ha encontrado un pino adulto, es un robledal de $Q$. pyrenaica.

\subsubsection{Análisis territorial}

Una revisión de las publicaciones sobre paleobotánica con estudios localizados en Sierra Morena oriental y áreas próximas del Campo de Calatrava y La Serena permite comprobar las especies que constituyeron los bosques a lo largo del Cuaternario. Mayor esfuerzo se ha centrado en el último periodo glaciar y, en particular, en el Holoceno. 
La existencia de motivos vegetales desde las primeras manifestaciones artísticas asimilados a la especie (Alía et al. 1996) y, como otra opinión de menor subjetividad, los topónimos medievales que se pueden relacionar con la especie (Gil 1990) constituyen metodologías adecuadas para la búsqueda de los relaccionados con pinos y pinares en todos los sectores de Sierra Morena, desde la Sierra del Relumbrar, en la provincia de Albacete, hasta el bajo Guadiana, en el Algarve portugués. La principal fuente de información ha sido la base de datos del Instituto Geográfico Nacional (IGN). Como la mayor parte se obtuvieron sobre la última versión del mapa, se procedió a su localización en las primeras versiones que datan de finales del siglo XIX, época en que no se habían realizado repoblaciones forestales. En general, todos se contrastaban con su entorno inmediato y se aceptaban sí, analizadas las fotos aéreas más antiguas, no muestran repoblaciones de pinos por el entorno. Cuando en el entorno inmediato a un topónimo existían otros similares solo se consideró el original.

Las referencias históricas a la presencia de los pinos en Castilla-La Mancha (Gil 1996) son otra fuente de información que se complementa con la arqueobotánica y, así, permite la discusión de las posibles causas de extinción. Para ello se revisaron documentos relativos a las órdenes militares u otros de origen medieval o moderno, como ordenanzas municipales, pleitos y otros tipos de textos existentes en los archivos históricos de los pueblos.

Finalmente, se acudió a un método, alejado de las fuentes escritas y de relativo esfuerzo, que se centra en los recorridos personales por Sierra Madrona; en particular, las cumbres y vertientes expuestas al sur del eje principal de Sierra Madrona, sierra del Rey, sierra de Valdoro, sierra de la Solana, sierra de Dormideros, sierra de Navalmanzano y Sierra Quintana. Se han utilizado prismáticos para zonas lejanas o poco accesibles, con óptica diversa pero principalmente de 8x30, 10x40 y 10x50 aumentos. En la sierra de Navalmanzano se utilizó un dirigible equipado con una cámara fotográfica de control remoto, tanto para obtener fotografía aérea cercana del pinar conocido, como para explorar zonas próximas poco accesibles (Fig. 3.3).
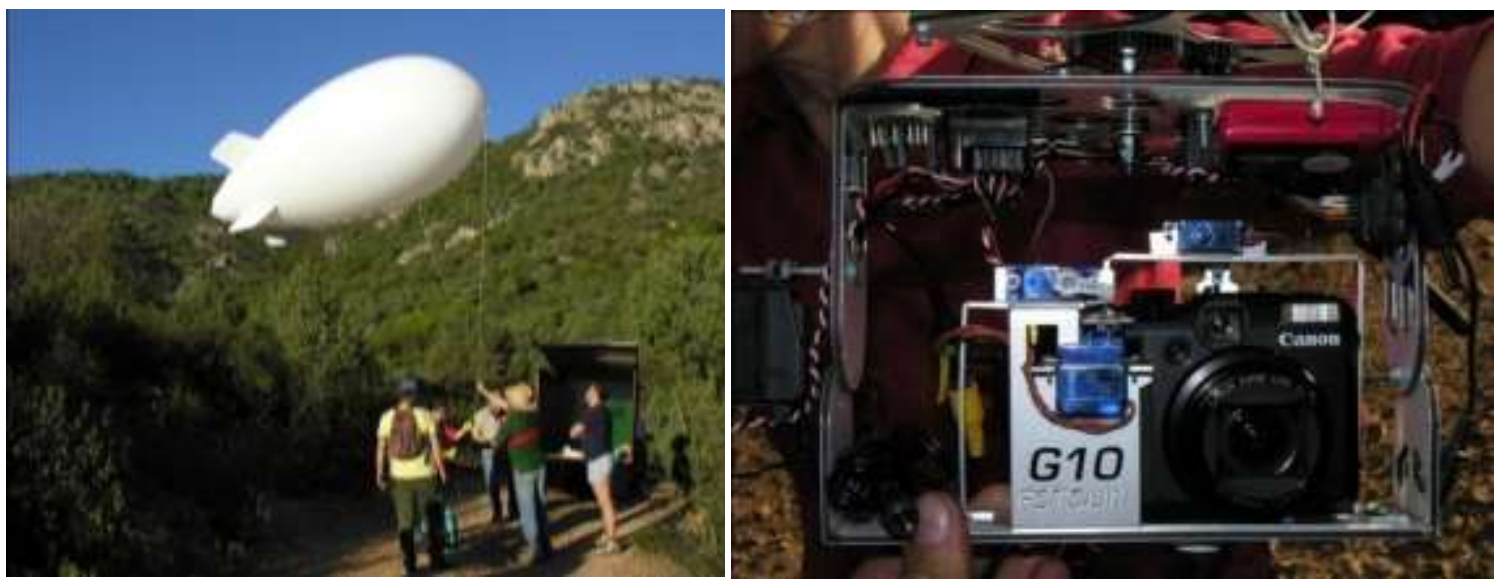

Fig. 3.3. Para la exploración de las zonas inaccesibles de Sierra Morena se utilizaron diversos métodos, incluida la fotografía aérea cercana por control remoto desde de un pequeño dirigible. 


\subsubsection{Inventario dasométrico del pinar de Navalmanzano}

Durante el año 2002 se planteó el inventario del pinar de Navalmanzano sobre el terreno. Esta planificación se hizo sobre una ortofotografía del IGN a escala 1: 5.000, sobre la que se superpuso una retícula UTM de $50 \mathrm{~m}$ de lado. Es decir, se dividió la zona susceptible de tener pinos en 95 parcelas cuadradas de $2.500 \mathrm{~m}^{2}$ cada una.

En el 2003 se midieron todos los pies con tallo lignificado, tomando los datos habituales de altura y diámetro del tronco a $1,3 \mathrm{~m}$ de altura que se aproxima a la altura del pecho (DAP). Como muchos de los pies no alcanzaban la altura de $1,3 \mathrm{~m}$, se midió a todos los pies el diámetro en la base del fuste, a ras de suelo (Dbase). Para las alturas superiores a los $3 \mathrm{~m}$, se utilizó un medidor infrarrojo de la marca Vertex. Los diámetros se registraron usando forcípula o calibre para diámetros inferiores a $5 \mathrm{~cm}$. Se anotaron otras variables que serán objeto de otros capítulos (número total de conos y conos cerrados, si el pino era rupícola o no, daños producidos por el ciervo u otras causas y otras observaciones).

En 2004, la distribución espacial de cada uno de los pies inventariados se localizó mediante GPS con un margen de error menor de $1 \mathrm{~m}$ (GPS inframétrico, de la marca Trimble).

\subsubsection{Vigor y supervivencia de pies adultos.}

En las primeras visitas del año 2002 y, más especialmente en los años 2003 y 2004, conforme se cuantificaron, midieron y georreferenciaron todos los árboles del pinar, se observaron una docena de árboles adultos caídos (Fig. 3.4) pero no se detectó ningún síntoma de pérdida de vigor en la masa.
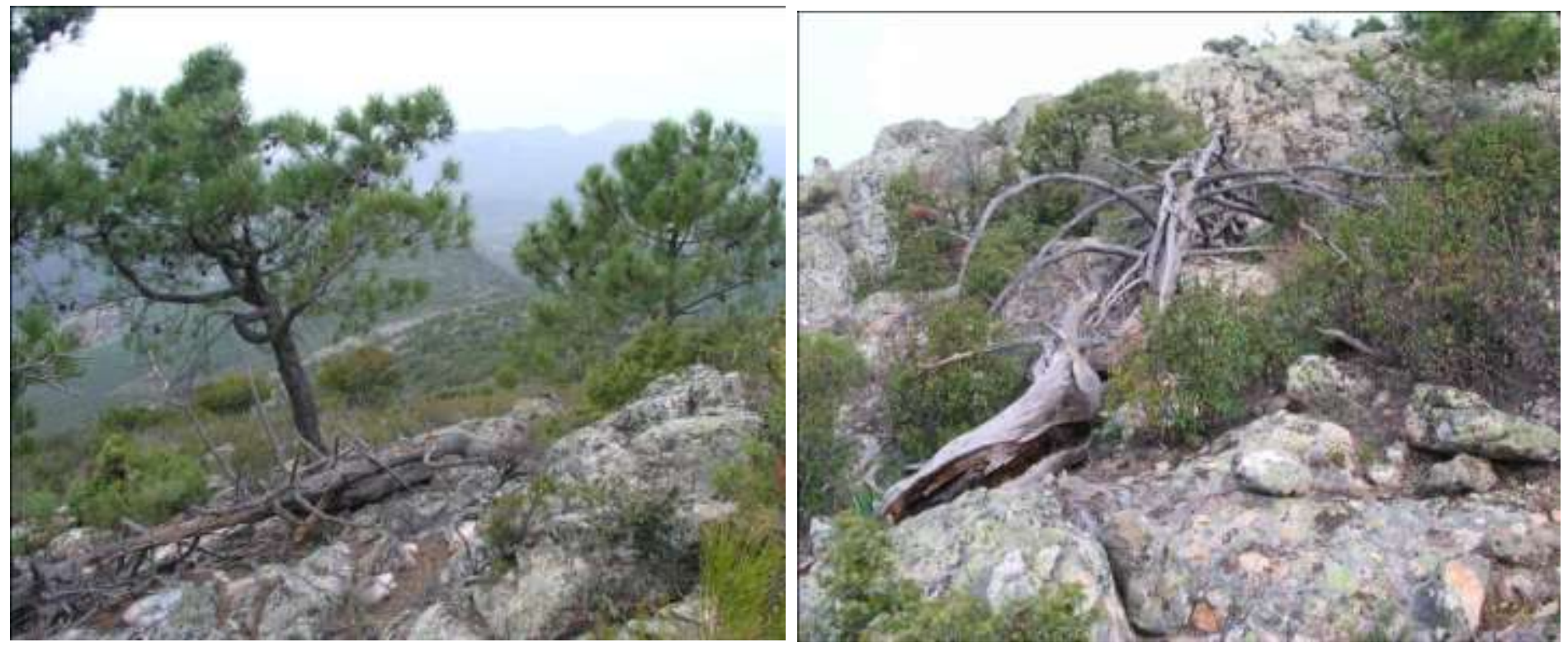

Fig. 3.4. Ejemplos de árboles adultos ya en el suelo desde hacía años cuando se realizaba el inventario. 
Sin embargo, en enero de 2005 se observó el colapso repentino de 4 de los mayores pinos, todos localizados en una sola de las cuadrículas del inventario. Los pies mostraron un decaimiento generalizado y las acículas pasaron de un color verde intenso a rojizo en pocas semanas y se secaron completamente (Figs. 3.5 y 3.6). En los meses siguientes perdieron la corteza y, entre 2006 y 2008, cayeron al suelo. Este colapso no se volvió a manifestar en el resto del pinar.

En 2009, se realizó un segundo inventario en 10 parcelas circulares de $15 \mathrm{~m}$ de radio. El centro de las parcelas se hizo coincidir con el centro de las cuadrículas UTM de $50 \mathrm{~m}$ de lado de las columnas F y H (Fig. 3.14). Una de las parcelas estudiadas comprendía a una parte significativa de los pinos que sufrieron un decaimiento súbito en 2004, por lo que se dispuso del diámetro y altura en 2009 en todos los árboles localizados en el interior de estas parcelas.
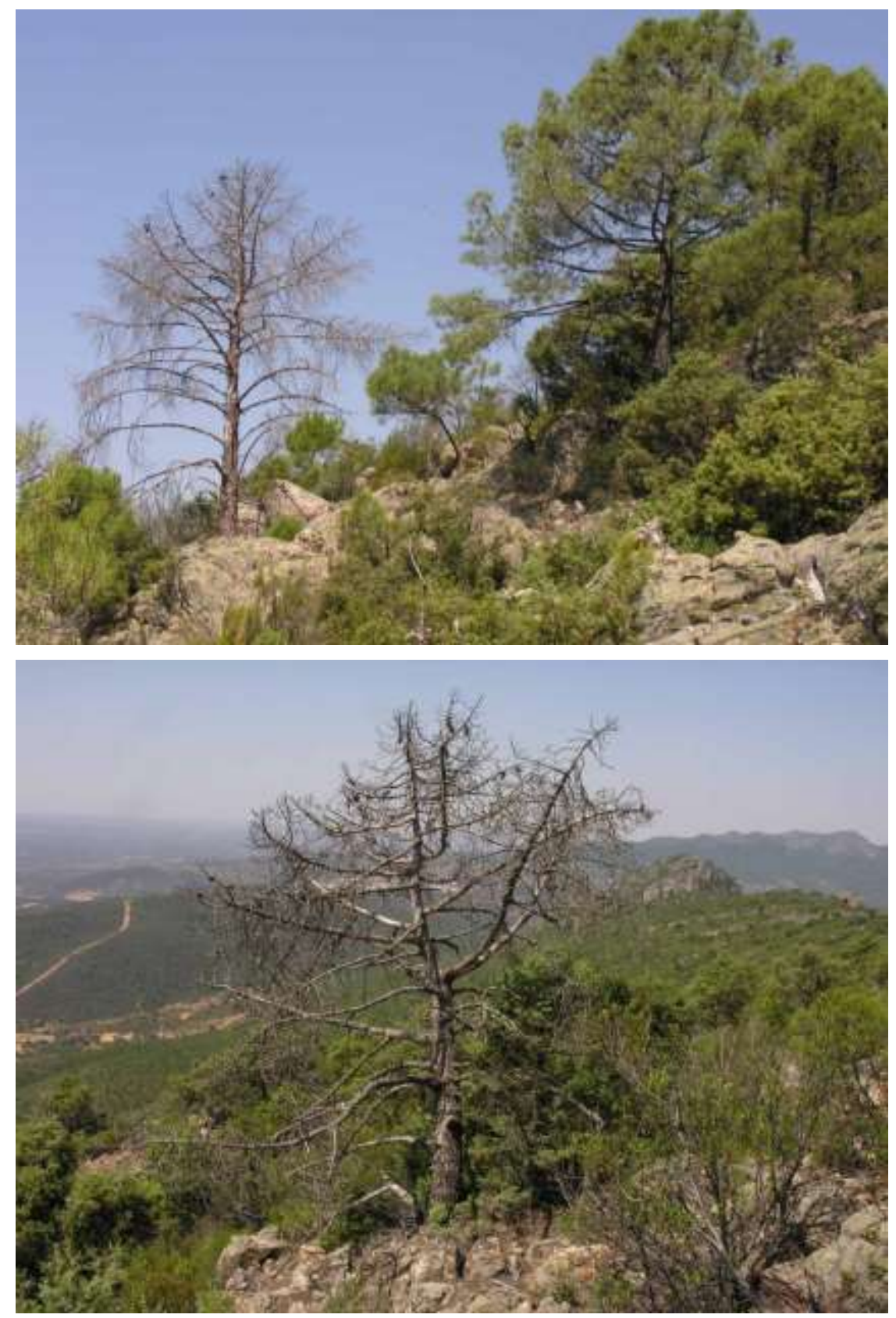

Figs. 3.5 y 3.6. Muerte súbita de 2 de los mayores pinos de la sierra de Navalmanzano en enero de 2005. 
Estas muertes no fueron coincidentes con ninguna observación relacionada con la sanidad forestal, ni en estos árboles ni en el resto del pinar. La ausencia de plagas o enfermedades fue general desde la realización del inventario de 2003 hasta 2009. Por lo que se acudió a los datos climáticos históricos de las estaciones meteorológicas más próximas y, para evaluar el contexto climático regional, los de las estaciones de las capitales de provincia del entorno de Sierra Morena.

\subsection{Resultados}

\subsubsection{Datos bibliográficos y toponímicos}

\subsubsection{Paleobotánica}

La presencia de pinos en Sierra Morena data desde al menos el Plioceno inferior (hace unos 3,63 Ma) fecha en que aparecen restos fosilizados de hojas y polen en los yacimientos de Lepe y Casa del Pino (Huelva) (Peñalba 1985; Barrón et al. 2003). En Andévalo (Huelva) ya en el Holoceno tardío, hace unos 4000 años, se ha encontrado polen abundante de pino (Nocete et al. 2005; Fuentes et al. 2006). Del mismo momento, son las secuencias polínicas que muestran presencia de pinos en la vecina comarca de La Serena, (e.g. Grau et al. 2004). En la Serena, además de polen, también se han encontrado restos de madera y carbones de $P$. pinaster en casi todos los poblados de la Edad del Bronce, del Hierro y del periodo romano (e.g. Alcalde et al. 2004; Duque 2004).

En el Campo de Calatrava se han obtenido 7 secuencias paleopolínicas en el Guadiana medio (en torno a las Tablas de Daimiel, Ciudad Real). Comprenden un periodo desde hace unos 250 Ka hasta la actualidad, por lo que incluyen los últimos periodos glaciares e interglaciares (García Antón et al. 1986; Dorado Valiño et al. 2002; Valdeolmillos et al. 2003; Valdeolmillos 2005; Gil García et al. 2007; revisión completa en Ruíz Zapata et al. 2010). Interesante resulta también la secuencia de Arenales de San Gregorio (Ciudad Real) que, aunque reciente (Holoceno) muestra presencia de pinos en el centro de La Mancha (Ruiz-Zapata et al. 2000). Pero sin duda cabe destacar, por su mayor proximidad a Sierra Madrona, las secuencias paleopolínicas de la laguna volcánica de Fuentillezjos (Ciudad Real), con una cronología máxima desde el Pleistoceno superior, hace unos 167.000 años. La presencia de pinos se constata en el entorno de esta laguna durante el interglaciar Riss-Würm, hace unos 140.000 años (Gil-García et al. 2013) y durante el último máximo glacial y el Holoceno (Ruiz Zapata et al. 2008, 2012; Vegas et al. 2008, 2010).

En la propia Sierra Madrona, al pie de la ladera en cuyas alturas está el actual pinar, aparece polen de pino en los sondeos realizados por Díaz Fernández (1992). Aunque no incluyen datación comprenden un periodo aproximado de los últimos 2000 años.

Los datos paleobotánicos encontrados en Sierra Morena oriental y su entorno de La Serena y el Campo de Calatrava muestran la vegetación prehistórica e histórica de Sierra Madrona y Valle de Alcudia. Los pinos formaban con más o menos abundancia parte del paisaje. Especialmente 
comunes, incluso dominantes, en los periodos glaciares, y más escasos pero también presentes, en los interglaciares, como el Holoceno actual (Fig. 3.7), donde se observa su descenso que parece ligado a un incremento progresivo de la encina.

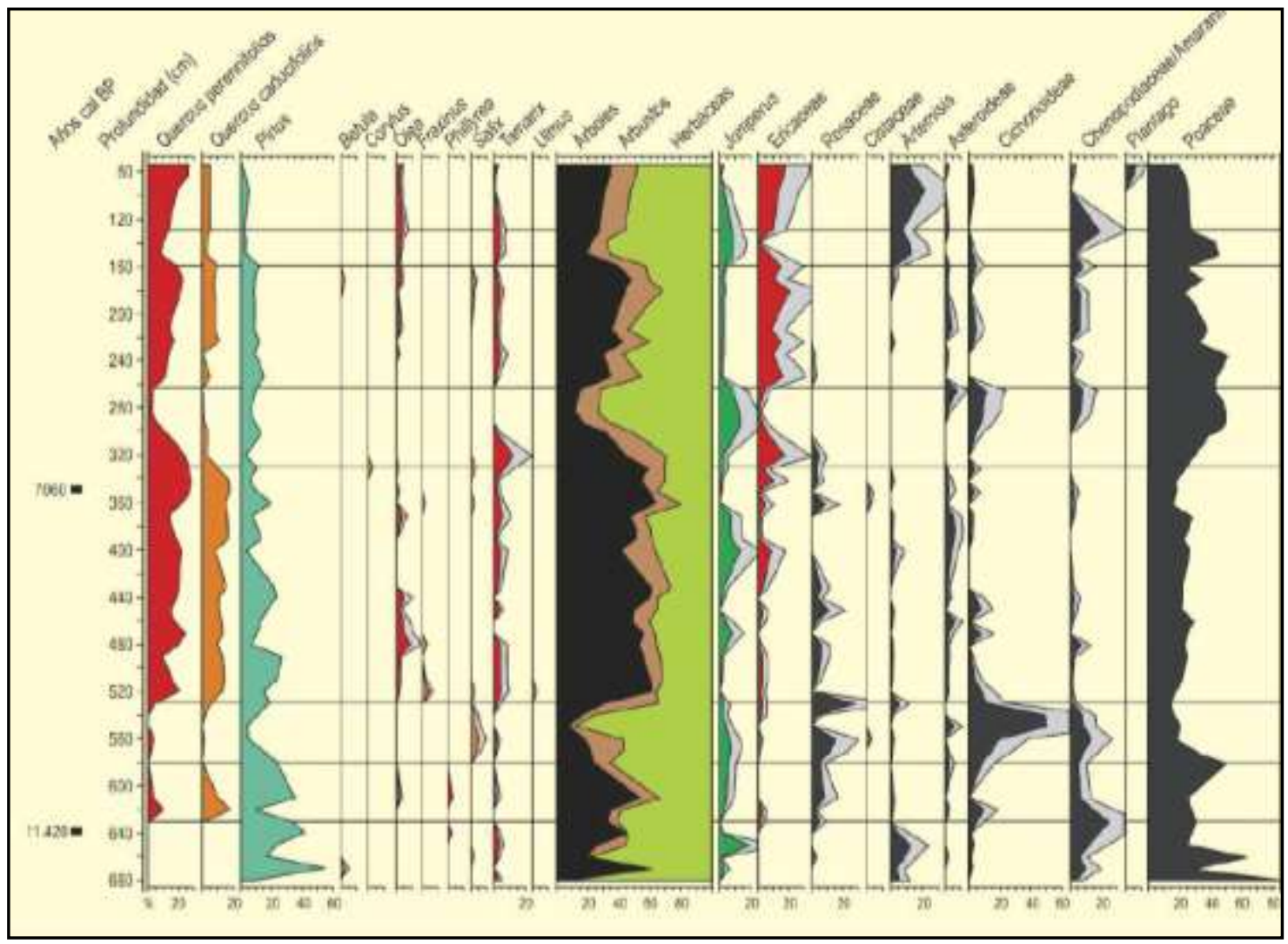

Fig. 3.7. Secuencia paleopolínica del Campo de Calatrava, aguas abajo del PN de las Tablas de Daimiel, cerca de Ciudad Real. Comprende el tardiglaciar y casi todo el Holoceno. Los pinos, con menor importancia que en la base del diagrama, están presentes salvo en su final. Redibujado de Dorado-Valiño et al. (2002) en Carrión et al. 2012.

\subsubsection{Historia y Toponimia}

Los resultados se presentan de forma cronológica si bien, en ocasiones, para una mejor comprensión de la evolución de un topónimo o de la presencia histórica de pinares se acude a un periodo más largo. La cita histórica más antigua sobre pinos en Sierra Morena oriental y zonas del entorno del Campo de Calatrava y La Serena, se sitúa en Sierra Madrona, concretamente en Sierra Quintana (Gil 1991). Responde a los límites meridionales de las donaciones que el Rey Sancho III otorgó a la Orden Militar de Calatrava y confirmadas en 1189 mediante Carta de Donación de su hijo Alfonso VIII (Ortega Cotes \& Ortega Zuñiga 1761)

\section{[...] ficut descendunt aquae de Vallemajori ad caput del pinar, $[\ldots]$}

Casi un siglo después, Alfonso X en 1269 confirma los límites de los territorios de la Orden Militar de Calatrava con el Concejo de Córdoba:

[...] descenden las aguas de Val mayor, a la cabeza del Pinal [...] 
Posteriormente, en 1274, cuando se delimitan los territorios de la Orden Militar de Calatrava con el Concejo de Córdoba, se confirma este límite "al primer mojón que va en la cabeza del Pinarejo (Corchado 1984).

En 1293 Sancho IV, reunido el Concejo de la Mesta en Guadalajara (Ortega Cotes \& Ortega Zuñiga 1761) otorga que las vacas y las yeguas del Convento de los Frailes de la Cavalleria de la Orden de Calatrava:

[...] anden salvos, e seguros por todas las partes de mios Regnos, e pascan las yerbas, e beban las aguas assi como los mios mismos [...]

Otras citas de topónimos aparecen en el Libro de la Montería del Rey Alfonso XI, escrito hacia el año 1350. En el Libro III, capítulo XXII, se dice:

[...] Sierra de Pinos es buen monte de oso et de puerco en ivierno [...] Et es el armada á las Navas, que son cabo del camino, que va á la Puebla [...]

[...] Monte del Rey es buen monte de oso et de puerco en ivierno. Et son las vocerías, la una por la senda que vá entre la sierra, et el monte, que non pase contra la sierra: et la otra en el camino que va de la Puebla á Fornachos, que non pase contra sierra de Pinos $[\ldots]$

Posteriormente, en el cercano Campo de Montiel Fernando Colón, hijo del Almirante, en su obra sobre los caminos de España (hacia el 1520), menciona la presencia de pinares en los caminos de Villanueva de los Infantes a Montiel y hacia Ruidera:

[...] Villanueva de los Infantes [...] e fasta montyel ay dos leguas llanas e por todas partes cerros y tierra de pinares $[\ldots]$

[...] Villanueva de los Infantes [...] e fasta la Otylla ay cuatro leguas de tierra llana e de montes e de pinares $[. .$.

En la misma obra de Fernando de Colón, junto a las Tablas de Daimiel, menciona que desde Malagón:

[...] e fasta Daymiel hay cuatro leguas llanas de montes baxos e a legua e media entramos en un pinar dicho cacatena questara legua e media e dos leguas pasamos a Guadiana [...]

Retornando al inicio de la Edad Moderna, la documentación medieval también alude a la presencia de pinos en la sierra de Córdoba (Córdoba de la Llave 1990). Este autor cita un documento del 17 de noviembre de 1500, en el que Juan Fernández arrienda a Juan Ruiz, ollero, una heredad de viñas, zumacares y aceitunos en el pago de la Mesa de la Cruz, en la sierra de la ciudad, y lo hace con todo lo que en ella se contiene, salvo los pinos, de los que se puede aprovechar, pero no sacar ni vender (APC, 14-34, 1, 33r)

La fuente general más importante para los territorios de la Corona de Castilla son las Relaciones Topográficas de Felipe II. En ella, los pueblos debían responder en el Interrogatorio de 1576 a 
57 preguntas. Aunque gran parte se han perdido, se dispone de una recopilación de las relativas a la provincia de Ciudad Real (Viñas \& Paz 1971; Campos 2009). La pregunta más destacadas para el conocimiento de la vegetación es la 18, en la que se inquiere sobre la abundancia o no de leña, el tipo de vegetación o la fauna; y la pregunta 35, que afecta a los materiales empleados en la construcción de las casas y si disponen de ella o los traen. Las contestaciones a la 18 son estériles en cuanto a la presencia de pinares como fuente local de leña. Un ejemplo es la dada por la villa de "Hernan Caballero", que se complementa con la 23, relativa a si abundan las fuentes y aguas:

[...] Es tierra abundosa de leña menuda, jarales y labiérnagos y lentiscos y romero y coxcoxa y poco monte pardo y baxo [...]

\section{[...] y la otra se llama la fuente de los Pinos de Val de Santa Maria [...]}

En cuanto al empleo de la madera de pino las respuestas más destacables las proporcionan Alcolea de Almodóvar y Malagón. La primera responde:

[...] y las maderas de los dichos edificios se traen de fuera parte, porque los montes de los términos de ella no son bastantes para ello, y las maderas son de pinos y se traen de Luciana y Piedrabuena $[\ldots]$

Las respuestas de Luciana y Piedrabuena manifiestan ser abundantes en leña local, no hay mención a pinos ni pinares en relación con la obtención de maderas. En cuanto a Malagón, tampoco señala al pino como fuente de leña, pero en cuanto a la madera responden:

[...] y la madera de pino se trae ahora de la Sierra de Cuenca [...]

Malagón está separada de Daimiel por el Guadiana y, la última, responde que es muy falta de leña, solo tiene escobas en las tierras de labor cuando llevan tres años de descanso y, en cuanto a la madera, señala que se trae de la sierra de Cuenca o de Alcaraz, sin mencionar especie.

En relación con Villanueva de los Infantes y Montiel, ambas mencionadas por Fernando Colón en su obra sobre los caminos de España, en la primera contestan:

[...] Es tierra que ha sido muy abundosa en leña y ahora hay razonable dispusición acabarse muy presto sino se pone otro medio del que hay que van a ser falta [...]

[...] y la madera se trae de las Sierras de Alcaraz y Segura [...]

Y las respuestas de Montiel:

[...] es tierra fértil y falta de leña [...]

[...] que de madera se suelen proveer de Alcaraz y otras partes [...]

Las Relaciones manifiestan la existencia y uso de las maderas locales, pero también los diferentes orígenes que tiene la madera de pino, utilizada con frecuencia. Algunos ejemplos de donde se usan (y el lugar donde se extraen) son: Albaladejo (ciudad de Alcaraz y de Segura de la Sierra), Arenas de San Juan (Cuenca y su tierra), Argamasilla de Alba (sierra de Cuenca), Bolaños (sierra de Cuenca y Alcaraz), Caracuel (sierra de Segura y Cuenca), Calzada de 
Calatrava (Cuenca), Corral de Calatrava (sierra de Cuenca), Puertollano (sierra de Cuenca), Santa Cruz de Mudela (la ciudad de Alcaraz), Villamayor de Calatrava (sierras de Cuenca y Alcaraz), Viso del Marqués (Alcaraz y de Segura). En el caso de Chillón no señalan origen y se limitan a decir que usan "alguna de pino".

Las Relaciones Topográficas de Felipe II de la villa de Fuencaliente no aportan ninguna información en relación con la existencia de pinares. Las respuestas a las preguntas 18 y 35 dicen:

[...] es muy abundante de leñas de muchas y diversas montañas como es robles, alcornoques, quexijos y encinas y otros montes comunes como son jarales, romero, arraigan brezales, ladiernagos y madroños[...]

[...] la casas y edificios de la dicha villa son comunes y pobres, porque tan solamente estan hechos de piedra y tierra, [...] aunque es verdad que hay abundancia de madera para ellos [...]

En cuanto a la villa de Nava el Pino, las respuestas de los vecinos a las preguntas 1, 18 y 35 de las Relaciones Topográficas de Felipe II son:

[...] queste pueblo después que se fundó no se ha llamado más otro nombre sino Nava el Pino y que la causa porque se llama Nava el Pino es questos declarantes oyeron decir quel término deste lugar es una posada de un vecino de Toledo que se llama al presente Francisco Gutiérrez, y que en medio desta posada oyeron decir estos declarantes, questaba un pino y que esta es la causa porque se llamo ansina y questos declarantes no conocieron este pino más de oírselo decir a sus padres [...]

[...] abundosa de leña y que la leña es jara y los arboles que tienen alcornoques [...]

[...] la madera de las casa es cortada en la mesma tierra de alcornoques [...]

Solana del Pino es un núcleo rural ubicado en el sur del Valle de Alcudia y en medio de Sierra Morena, con una extensión actual del municipio de 17.425 ha, pero que no figura en las Relaciones ni en el Interrogatorio de Lorenzana, porque hasta el año 1791 dependió de Mestanza. La zona dependió de la Orden de Calatrava, y formaba parte del Cuartel de Tiñosa, una de las divisiones de la gran Dehesa Real que, durante siglos, fue uno de los mayores espacios de invernada de los rebaños trashumantes de La Mesta. Solana del Pino es de fundación moderna, pues se reunió en ella la población de los caseríos que había en el Corchuelo, Heras-altas y Casas-quemadas (Madoz 1849). En su actual escudo destaca una silueta de pino, atribuible al pino piñonero.

Refiriéndose al pinar de Zacatenas señalado por Colón (h. 1520), Corchado (1982) lo recoge por ser origen de maderas que se utilizan en 1782 en las obras en el Sacro Convento de Daimiel:

[...] 80 tirantes de pino de Cuenca de la dehesa de Zacatenas a 11 rs uno [...]

De este entorno geográfico y cronológico se dispone de la información que proporciona el Interrogatorio del Cardenal Lorenzana (Sánchez González et al. 1985). En ella se pregunta a 
los párrocos de los pueblos, sobre quince cuestiones. La contestación que da el de "Fernancavallero", en 1782 dice:

A la quinta [...] que los nombres de las sierras comprendidas dentro del termino sobredicho son la de la Bivora, la de Nabarredonda, la del Tamaral, la de los Pinos, la de Baldelobos, la de el Medio y la de la Pililla [...] y la que llaman de los Pinos asta los barrancos de Marin, que es donde corresponde la raia de el termino desta villa y de alli en adelante toca a Porzuna y Piedrabuena; dicha sierra de los Pinos es en todo igual a las antecedentes y todas ellas respecto de esta población corren como a el nordeste: Por los intermedios de dichas sierras corren dos arroios [...] el de los Pinos [...] nace donde llaman Baldecasarejo, que es el balle que media entre la sierra sobredicha de el Tamaral i la que sigue que es la de los Pinos [...]

A la sesta [...] que de echo estan pobladas de chaparros, coscojas, acebuches, lentiscos, corcicabras, enebros, jaras retamas, romeros, espinos y brezos, ai el de la dehesa boial, que asimismo esta poblada de encinas, chaparros, alamos, algunos membrillos, con abundancia de parras que, entretegidas con las zarzas que las ai arto crecidas [...]

Nava el Pino tiene como municipio vecino a Fontanarejo, villa que pertenecía a la comarca de los Montes de Toledo, territorio dependiente de la ciudad de Toledo desde el siglo XIII. En 1820, Juan Antonio López, agrimensor y Francisco Martínez Robles, catedrático de Agricultura, informan a las Cortes del Trienio Liberal de la situación existente en la comarca y de la necesidad de repartir el terreno en pequeñas porciones entre los vecinos mediante su enajenación a censo enfitéutico (López y Martínez, 1821). El 27 de agosto de 1827 y el 27 de enero de 1829 Fernando VII dicta Reales Órdenes que disponían las medidas para repartir estos terrenos entre los vecinos de los pueblos. Para la realización de los trabajos sobre el terreno se constituyó una Comisión de Señalamiento de Término y Dehesa de los Montes de Toledo, encargada asimismo de formar los expedientes, redactar la Memoria Geodística (sic) -o geodésica- reglamentaria de cada dehesa y confeccionar los planos topográficos. Uno de estos planos fue el del término y dehesa boyal de Fontanarejo, realizado en 1829 y conservado (Caja 3.792/2) en el Fondo de la Intendencia de la Provincia conservado en el Archivo de la Diputación de Toledo (Cruz 2004)

En el mencionado plano (Fig. 3.8), uno de los topónimos es el "Cerro del Reventón de los Pinos". En los actuales mapas 1:50.000 y 1:25.000 del IGN ya no se muestra nombre alguno de ese promontorio, ahora ocupado, como el resto de la zona por un extenso jaral de Cistus ladanifer. Sin embargo, un pastor local afirma que al mencionado cerro lo conoce como "Peñón de los Pinos", del que nace un Arroyo de los Pinos que si aparece con ese nombre en los actuales mapas del IGN (Fig. 3.9). 


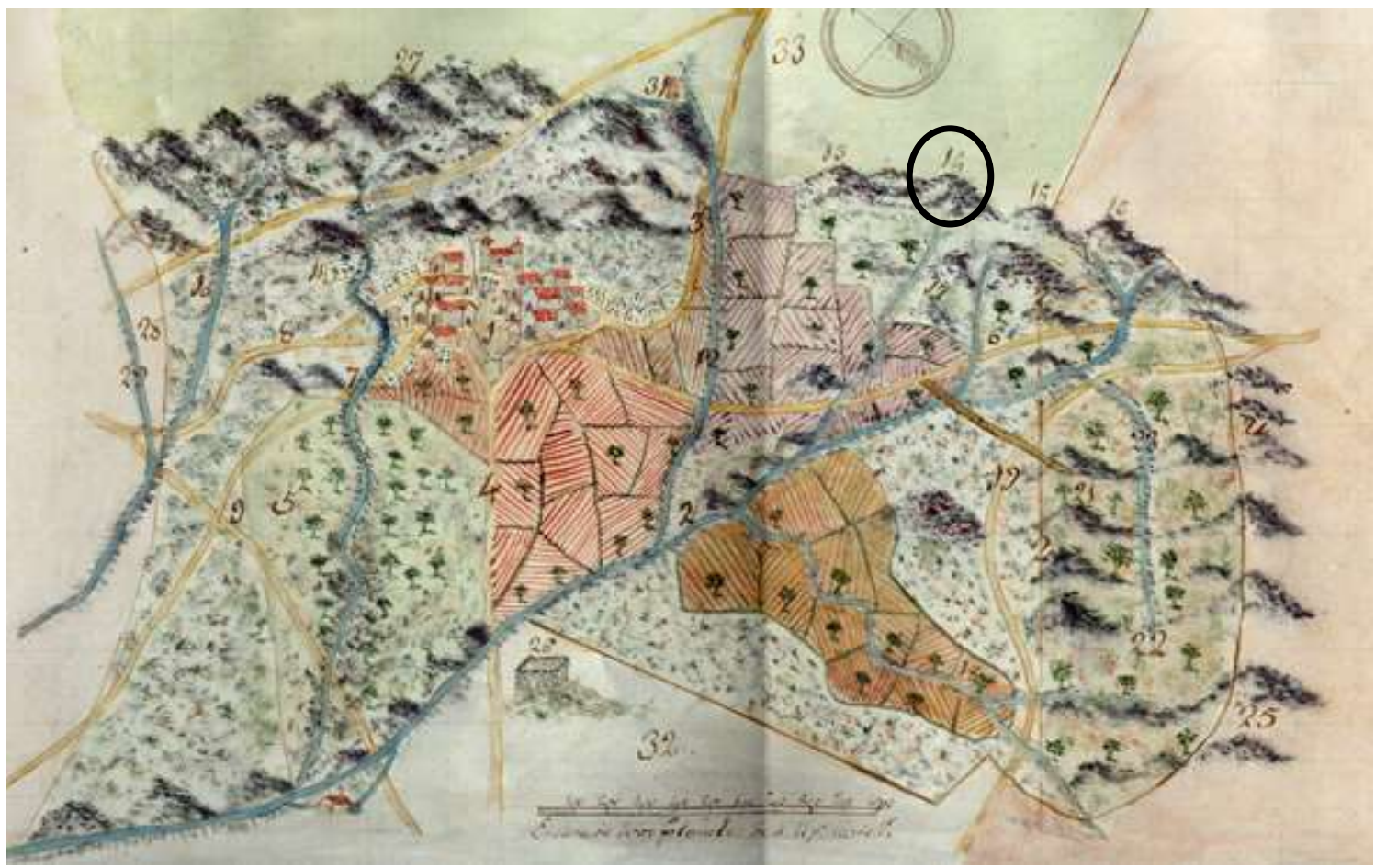

Fig 3.8. Plano del término y dehesa boyal de Fontanarejo, realizado en 1829, el número 14 (señalado con un círculo) es un cerro al que se denomina en la leyenda del plano como "Reventón de los Pinos". Nótese que desde este cerro surge un arroyo.

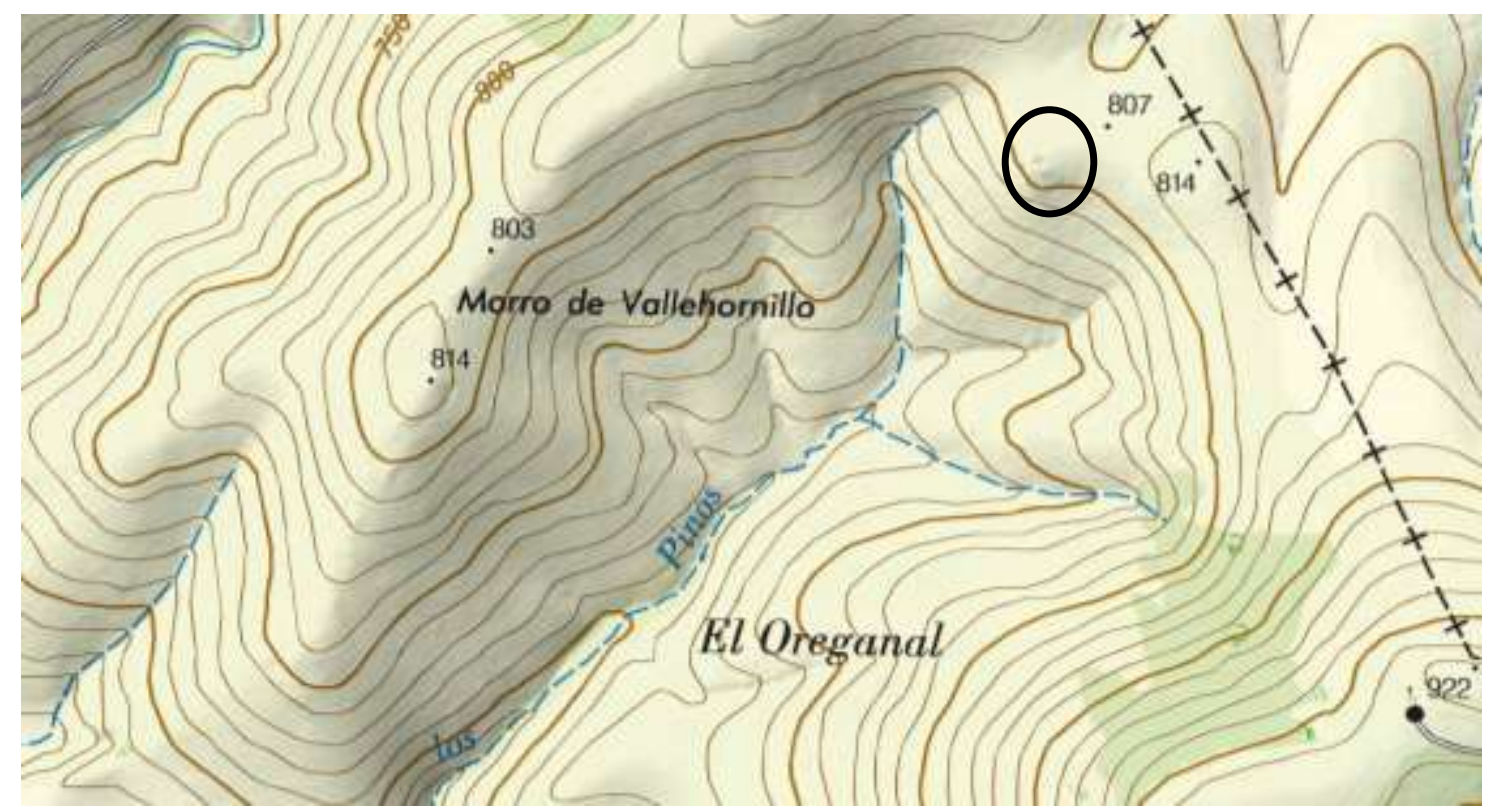

Fig. 3.9 Mapa 1:25.000 actual, en el que figura un Arroyo de los Pinos que tiene su origen en lo que se conoció como el "Cerro del Reventón de los Pinos" o "Cerro de los Pinos", señalado con el círculo. Mapa base del IGN.

El Catastro del Marqués de la Ensenada (1759), constituye otra fuente de relevancia, también limitada a la Corona de Castilla, en este caso sin incluir al País Vasco. En Guadalupe (Cáceres) cita que la sierra está "povlada de pinos" de los que no se obtiene fruto "por ser silvestres" (Ezquerra \& Gil 2008). Así debió continuar al menos en parte hasta principios del siglo XIX 
cuando para reparar los tejados del Convento de Guadalupe se utilizó madera de pino. Noticia descrita un siglo después por el fraile franciscano Germán Rubio en 1926:

[...] en 1815, fue arrasado con este motivo pinar alto, poniéndose luego en aquellas alturas un hermoso castañar. [...]

Otra fuente para el conocimiento de la vegetación forestal que llega a mediados del siglo XIX es la que se considera como la primera estadística forestal, la Clasificación General de los Montes Públicos de 1859, elaborada a instancias del Gobierno para iniciar el proceso desamortizador (González Doncel \& Gil 2013). La provincia de Ciudad Real carece de cualquier mención a los pinos como especie dominante o subordinada de los montes públicos, ya sean del estado, pueblos o corporaciones civiles. Pero permite saber en qué situación se encuentra la Sierra de Pinos citada en el Libro de la Montería. Perteneciente al pueblo de Hornachos y bajo la denominación de "Sierra junto a Pinos", figura uno de los montes exceptuados de la desamortización con una superficie de 129 hectáreas y con especie dominante la "jara" y subordinada el enebro. Entre los enajenables del mismo pueblo figura la "Dehesa de Pinos", de 1.597 hectáreas y con especie dominante la encina.

En cuanto al resultado más general de presencia de topónimos relativos a pinos en los mapas del IGN se han encontrado 111 topónimos que podrían hacer referencia a pinos autóctonos, que se reducen a 83 cuando se prescinde de los derivados. La tipología de estos topónimos en Sierra Morena se muestra en la Fig 3.10, así como su distribución provincial en la Fig. 3.11. De los 83 topónimos considerados "naturales" 40 se refieren a pinos y 43 a pinares.

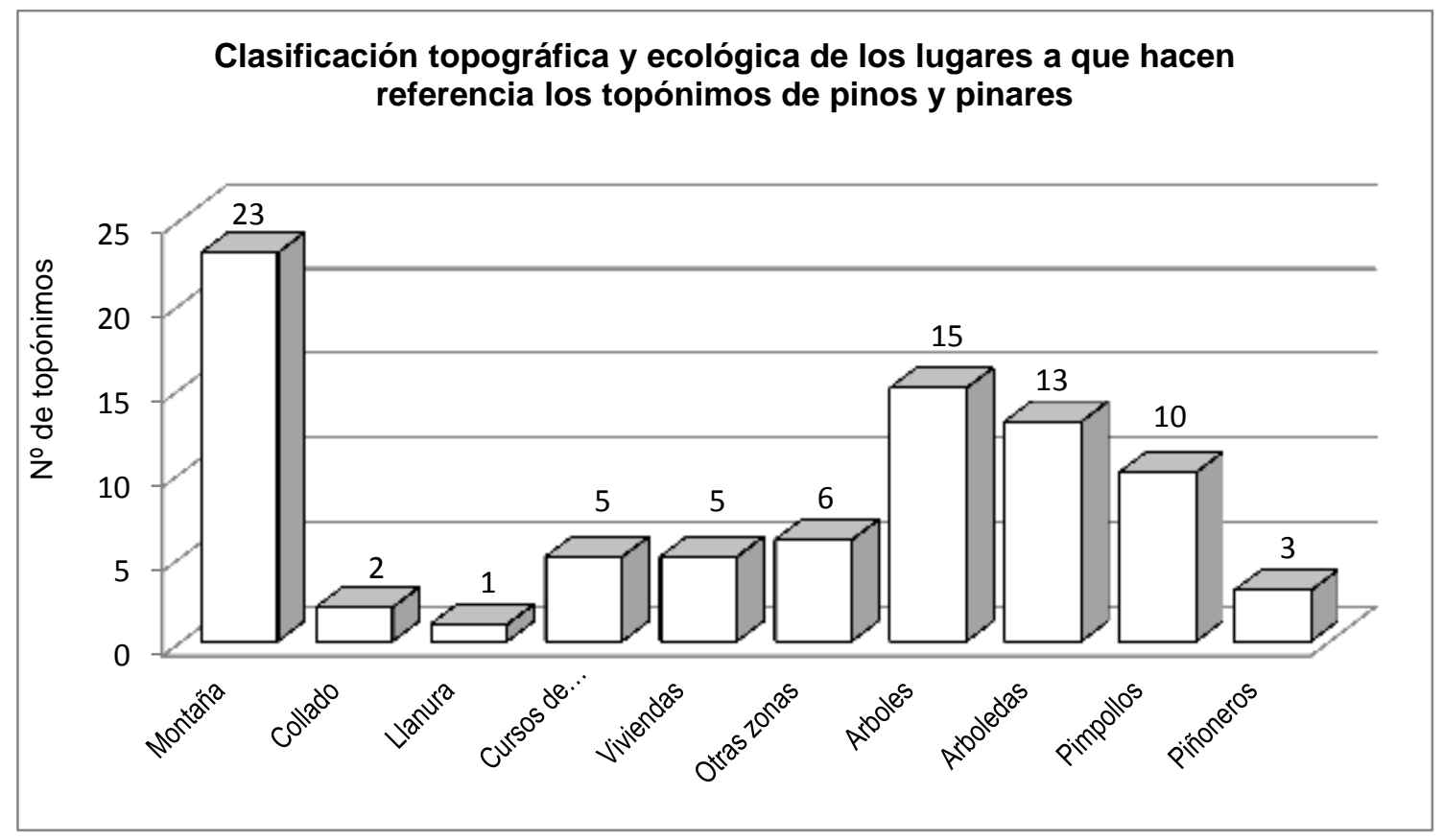

Fig. 3.10. Distribución de los topónimos que incluyen voces relativas a los pinos en Sierra Morena, clasificados según los accidentes topográficos o formaciones forestales. 


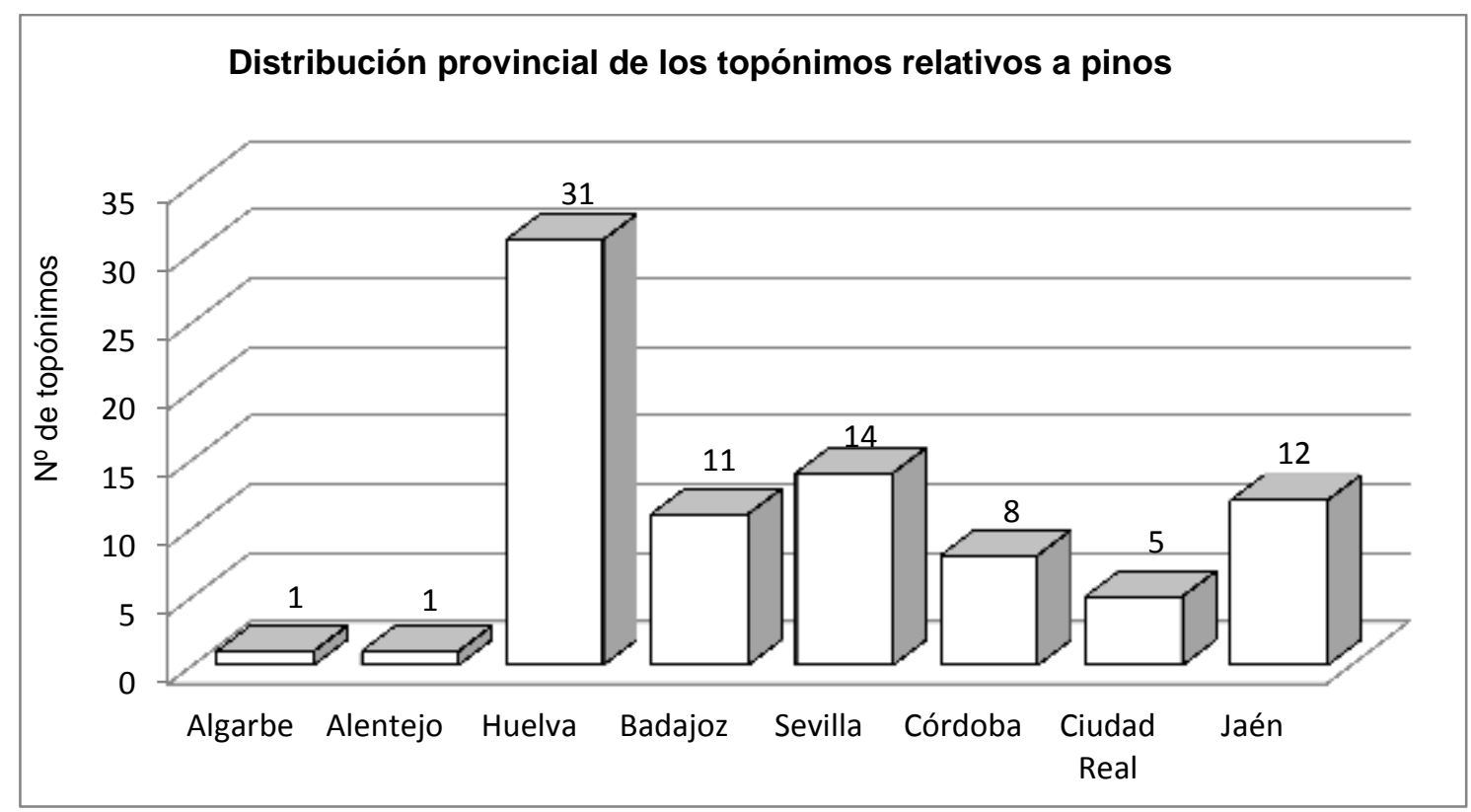

Fig. 3.11. Distribución de los topónimos que incluyen voces relativas a los pinos en Sierra Morena de acuerdo con su frecuencia en las diferentes provincias

La distribución espacial y tipológica de los 83 topónimos puede verse en la Fig. 3.12. La relación completa de topónimos con el número que permite su identificación en la figura se incorpora como Anexo.

La búsqueda de pinos o pinares, en las zonas de Sierra Morena con presencia de topónimos o histórica, no dio resultados positivos, a excepción de los cercanos al último bosque de $P$. pinaster (Fig. 3.13), limitado al paraje conocido como "Hoya de los Pinos" en la vertiente sur de la Sierra de Navalmanzano, como resultado más destacado los confinados a la proximidad del topónimo más antiguo, el de Burcio del Pino pero, ya, en la provincia de Jaén. 


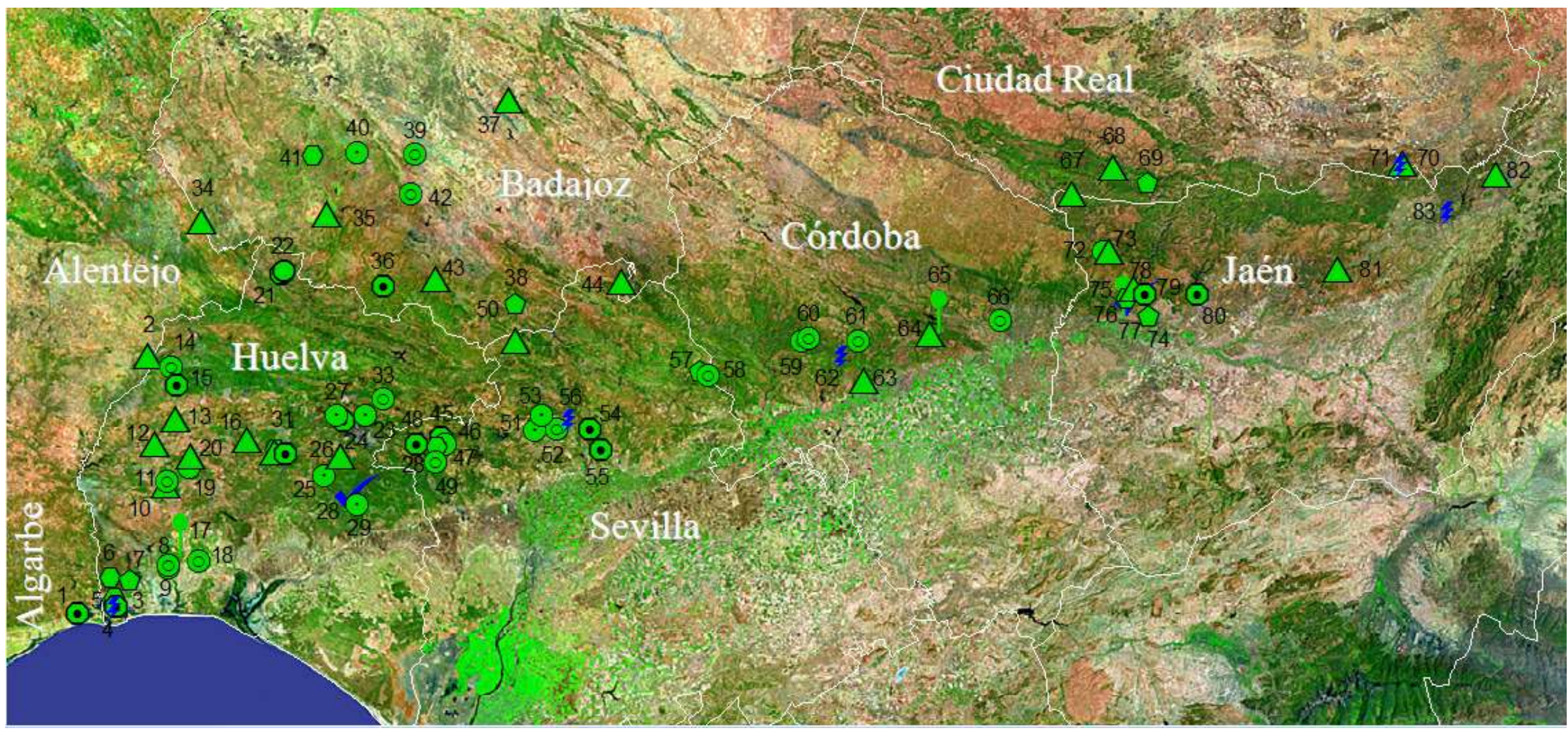

Fig. 3.12. Distribución en Sierra Morena de topónimos relativos a posibles a pinos de origen natural. Los diferentes símbolos representan el accidente topográfico u otros elementos naturales a los que dan nombre los pinos, también se diferencian los topónimos relativos a jóvenes pinos. Cartografía de base: IGN.

$\triangle$ Montañas, cerros, cabezos, lomas; $\square$ Collados; $\checkmark$ Llanuras; $\bigcirc$ Cursos de agua, fuentes, pasadas; $\square$ Caseríos, casas, cortijos; $\xi$ Otras zonas (rochos, dehesas, majadas, etc.); $\odot$ Árboles adultos, pinos; ๑ Arboledas, pinares; $\odot$ Árboles jóvenes, pimpollos; ? Topónimos relativos a Pinus pinea. 


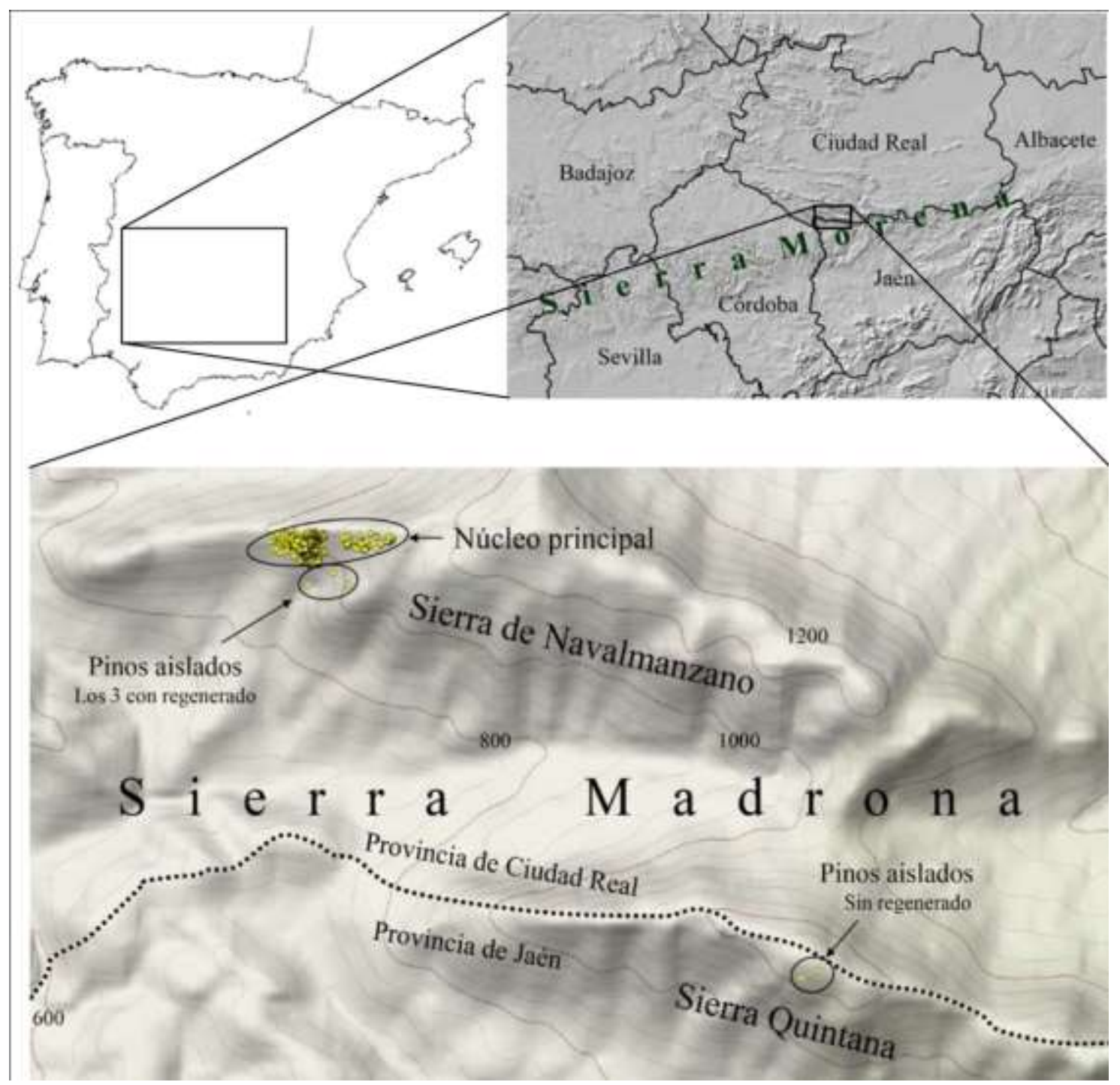

Fig. 3.13. Localización de Sierra Madrona en el contexto de Sierra Morena, con la distribución de los últimos ejemplares de $P$. pinaster autóctonos (círculos verdes).

\subsubsection{Inventario dasométrico del pinar de Navalmanzano}

El bosque de $P$. pinaster se ha subdividido en 2 subpoblaciones, una occidental (con 1.007 pies) y la otra oriental (con 205 pies), ambas en el núcleo principal definido en la Fig. 3.13 y centrado en la Fig. 3.14. En total se inventariaron 1.212 pies, cuyo resumen dasométrico se recoge en la Tabla 3.1, con una distribución espacial muy heterogénea. Los pinos por el norte llegan hasta la línea de cumbres donde aparecen árboles rupícolas centenarios (Fig. 3.15). De las 95 parcelas inicialmente establecidas, solo se encontraron pinos en 49 con densidades muy variables. Así, en 6 cuadrículas se registró un solo individuo en los $2.500 \mathrm{~m}^{2}$. La superficie del pinar de acuerdo a las cuadrículas con al menos un individuo fue de 12,25 ha; 7,75 ha en la subpoblación occidental y 4,50 ha la subpoblación oriental. 


\begin{tabular}{|l|c|c|c|c|c|c|c|}
\hline \multicolumn{7}{|c|}{ Datos dasométricos del Pinar de Navalmanzano (cm) } \\
\hline & Min. & $1^{\circ}$ Cuartil & Mediana & Media & $3^{\circ}$ Cuartil & Max. & $\begin{array}{c}\text { Desviación } \\
\text { estándar }\end{array}$ \\
\hline Altura & 4,00 & 45,00 & 90,00 & 199,50 & 250,00 & 1650,00 & 249,73 \\
\hline Dbase & 0,16 & 3,18 & 7,00 & 11,42 & 14,96 & 68,75 & 12,34 \\
\hline DAP & 0,00 & 0,00 & 0,00 & 5,38 & 4,46 & 56,34 & 10,51 \\
\hline
\end{tabular}

Tabla 3.1. Distribución de la altura, el diámetro basal (Dbase) y el diámetro a $1,30 \mathrm{~m}$ de altura (DAP) de los 1.212 pies del pinar de Sierra Madrona.

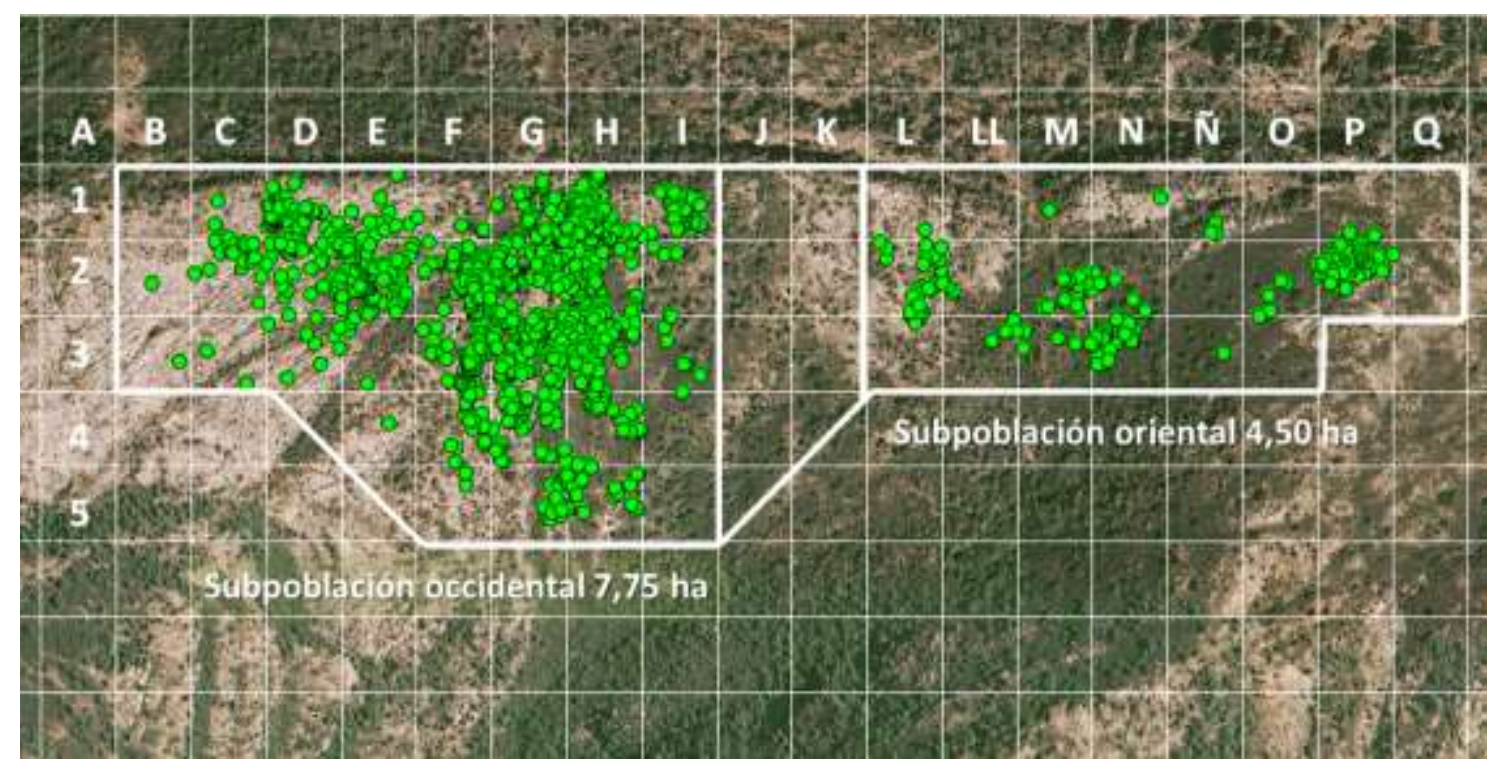

Fig. 3.14. Distribución de los pinos (puntos verdes) en el pinar de $P$. pinaster de la vertiente sur de la sierra de Navalmanzano. Cuadrículas UTM de 50x50 m, sobre ortofotografía del IGN.

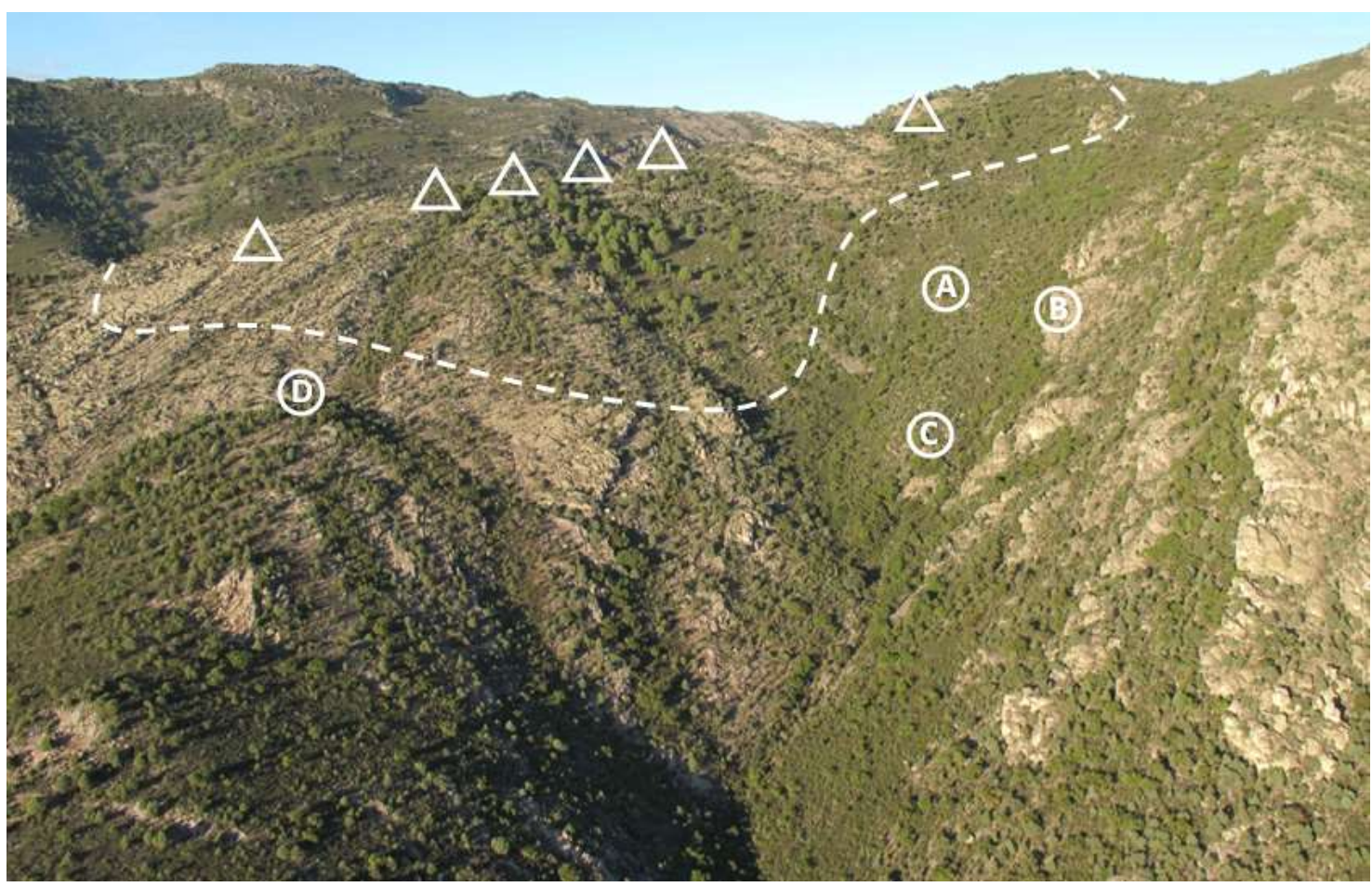

Fig. 3.15. Vista aérea del pinar de Sierra Madrona. En la parte superior, la línea discontinua muestra el perímetro del pinar. Los triángulos sitúan a los pinos que crecen sobre roquedos cerca de la línea de cumbres y tienen altura media superior a $7 \mathrm{~m}$ y DAP superior a $40 \mathrm{~cm}$, . Los círculos son pinos aislados. 


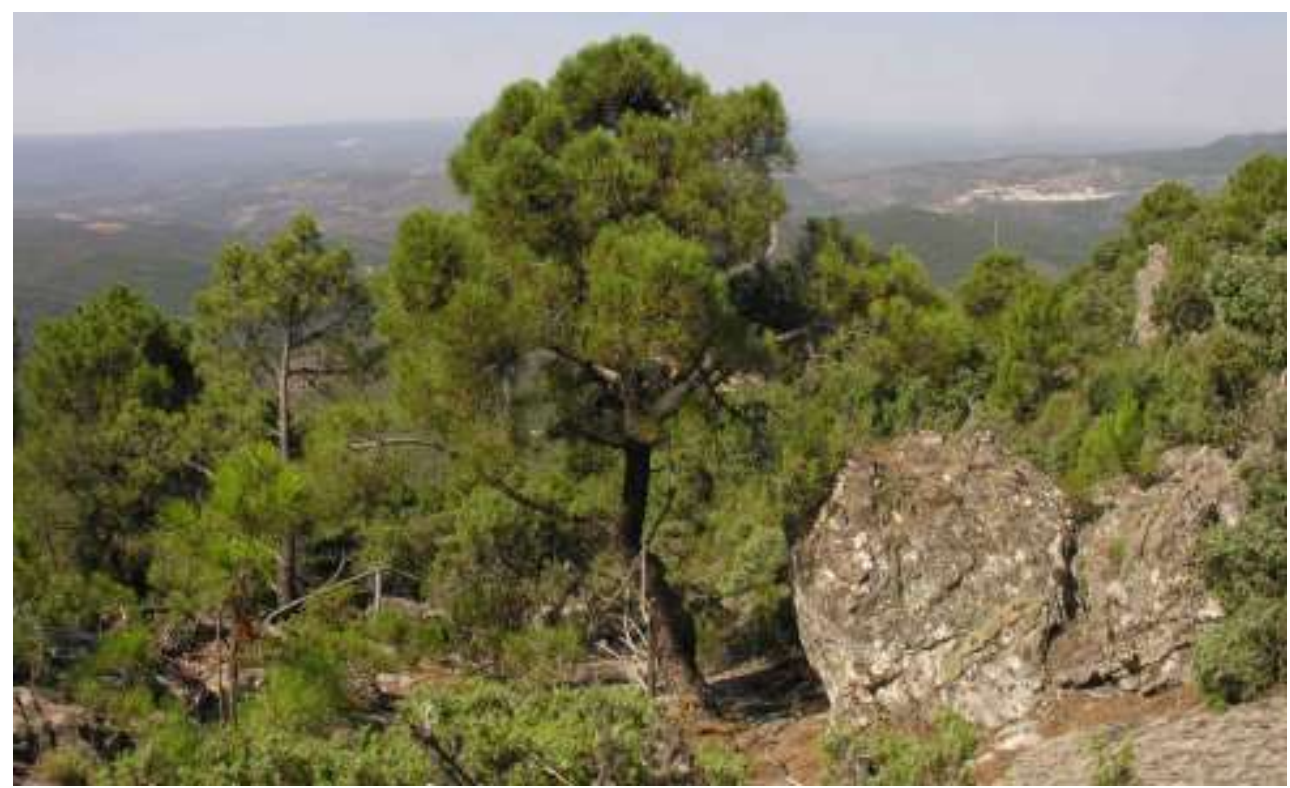

Fig. 3.16. Vista del pinar desde su parte central superior (en la cresta de la sierra). Al fondo a la derecha el pueblo de Fuencaliente (Ciudad Real); más distante y a la izquierda, Azuel (Córdoba).

La densidad media es de 98,94 pies/ha; Los pinos a los que por su mayor altura se les pudo medir el diámetro normal sumaron 430 pies, con una densidad de 34,4 pies/ha. El área basimétrica de estos pies es de $1,08 \mathrm{~m}^{2} / \mathrm{ha}$.

El 73,6\% de los pinos miden menos de $200 \mathrm{~cm}$ de altura (Fig. 3.17). La distribución de clases diamétricas (Fig. 3.17) refleja que la mayor parte de los árboles no permiten la medición del diámetro a 1,30 y su caracterización requiere acudir al diámetro basal del tronco. La abundancia de estos árboles, el 64,5\% de los pinos (782 pies), no guardan relación de su altura con el diámetro basal (Fig. 3.17), pues 691 pinos se sitúan sobre fisuras de una roca madre continua (Fig. 3.19), muchos con aspecto de "bonsai". Así, pies con diámetros de $30 \mathrm{~cm}$ en la base no superan $2 \mathrm{~m}$ de altura, por lo que no son cuantificables por el DAP y no aparecen en la relación altura/DAP (Fig. 3.18). La distribución espacial y cuantitativa de los pinos rupícolas se muestra en la Fig. 3.19.
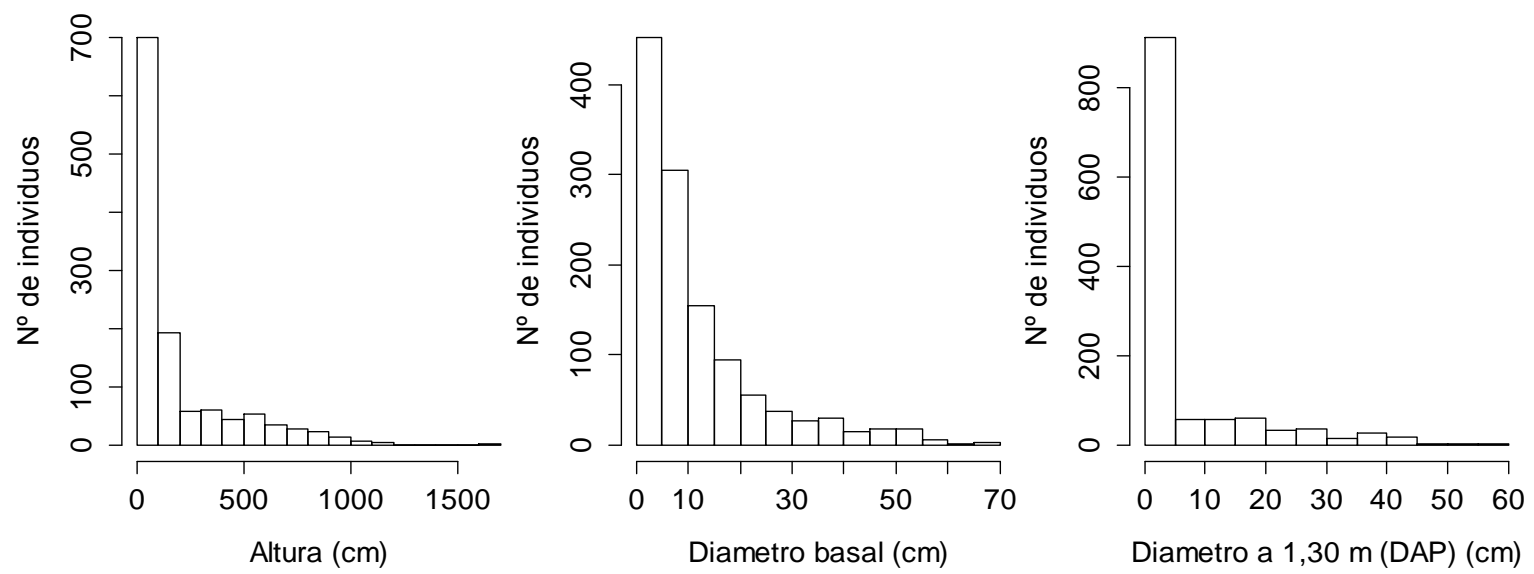

Fig. 3.17. Histograma de frecuencias de los pinos del pinar de la sierra de Navalmanzano de 3 variables dendrométricas: altura, diámetro basal y diámetro normal (DAP). 

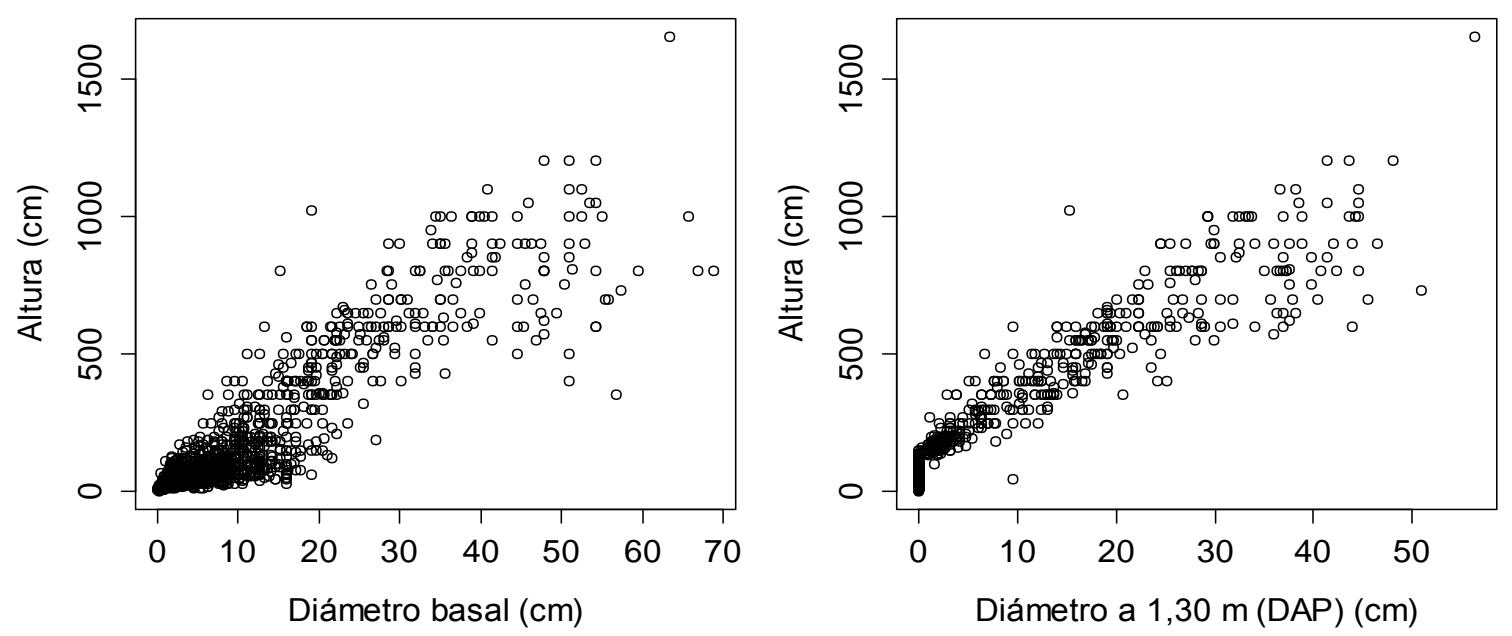

Fig. 3.18. Relaciones altura/diámetro de los pinos de Navalmanzano.

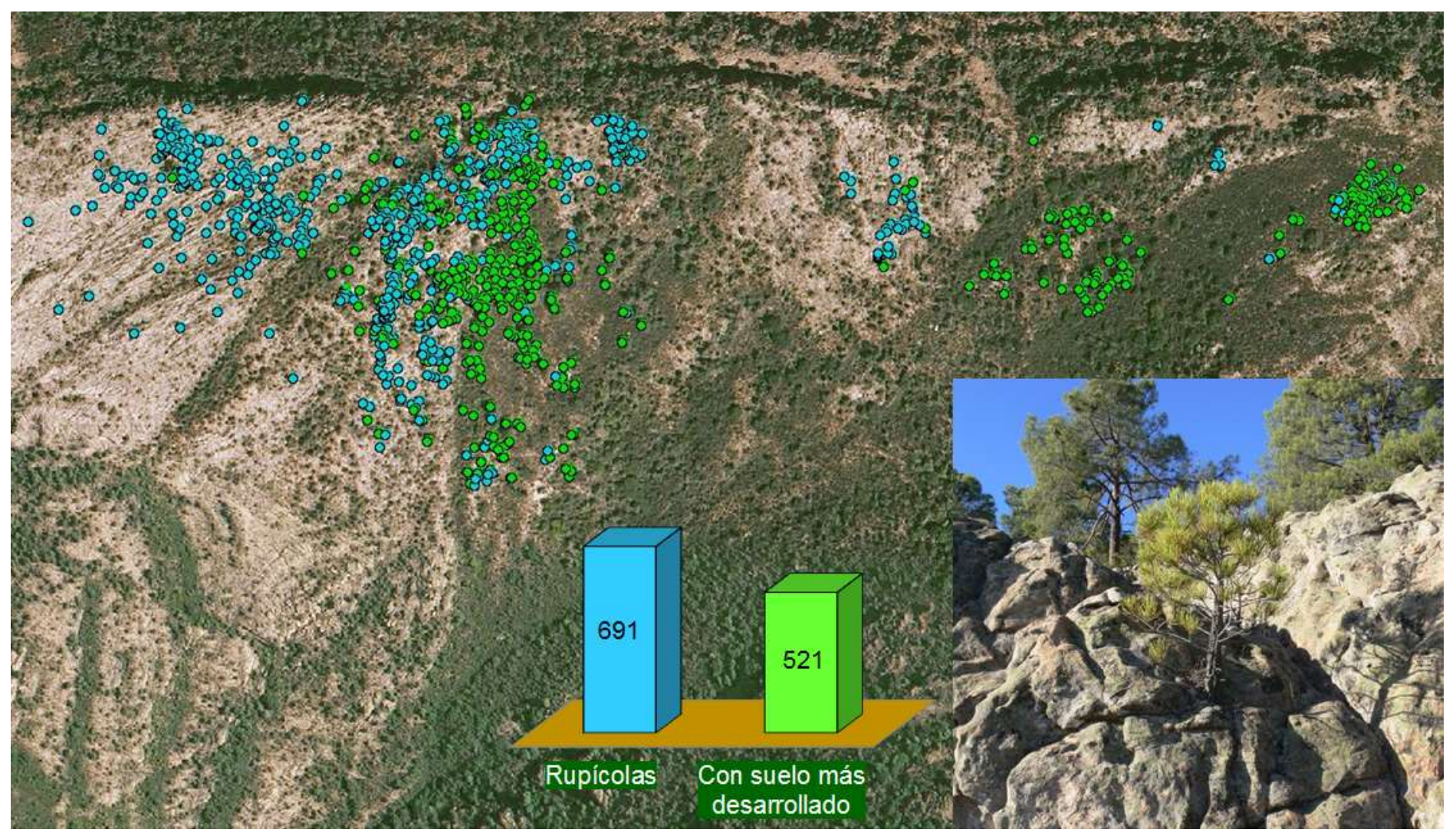

Fig. 3.19. Distribución espacial, sobre fotografía aérea, y cuantitativa de los pinos rupícolas y los que crecen sobre suelo más desarrollado. En la fotografía de la parte inferior derecha puede verse un claro ejemplo de pino rupícola.

Más de la mitad de los 1.212 pinos crecen sobre roquedos, con un desarrollo del sistema radical probablemente muy reducido. En cuanto a la distribución espacial de las clases de altura y clases diamétricas, como se observa en la Fig. 3.19 es muy heterogénea. De las 49 parcelas en que se localiza el pinar, en 25 de ellas más del 50\% de los pinos se asientan sobre suelos rupícolas, por lo que la altura media es inferior a $300 \mathrm{~cm}$ en 42 cuadrículas (Fig. 3.20). Alturas 
superiores a los $300 \mathrm{~cm}$ solo aparecen cuando más del 50\% de los pinos se localizan sobre suelos con horizontes edáficos.
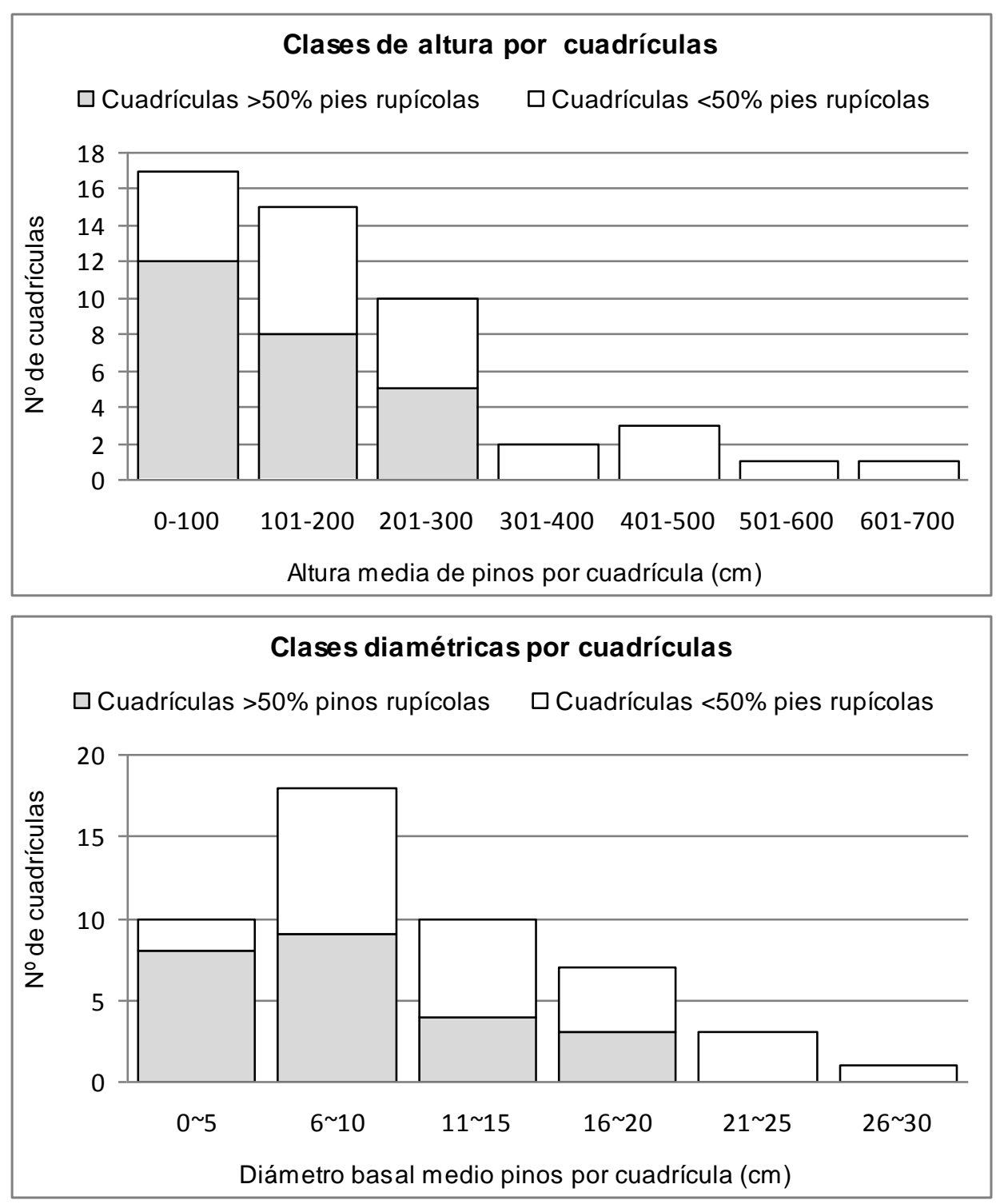

Fig. 3.20. Histograma de frecuencias de cuadrículas por clases de altura media y diámetro basal medio.

Los pinos inventariados en 2009 en las 10 parcelas fueron 125, cuyos resultados se resumen en la Tabla 3.2. En el año 2003, y en la misma superficie, el número de pinos caracterizados fue de 134. En 2009, por tanto, faltaban 9 pinos, por lo que los datos de la tabla 2 hacen referencia a los 125 supervivientes. De los 9 pinos desaparecidos 3 eran pies rupícolas que se secaron, otros 3 murieron a causa del escodado del ciervo, otros 2 colapsaron de forma súbita en 2005 y, el noveno, por el impacto de uno de los 2 anteriores al caer.

De la Tabla 3.2 se deduce que la altura media de los árboles creció un 18,5\%, mientras que el diámetro basal lo hizo en un $14,2 \%$ y el diámetro normal el 13,3\%. 


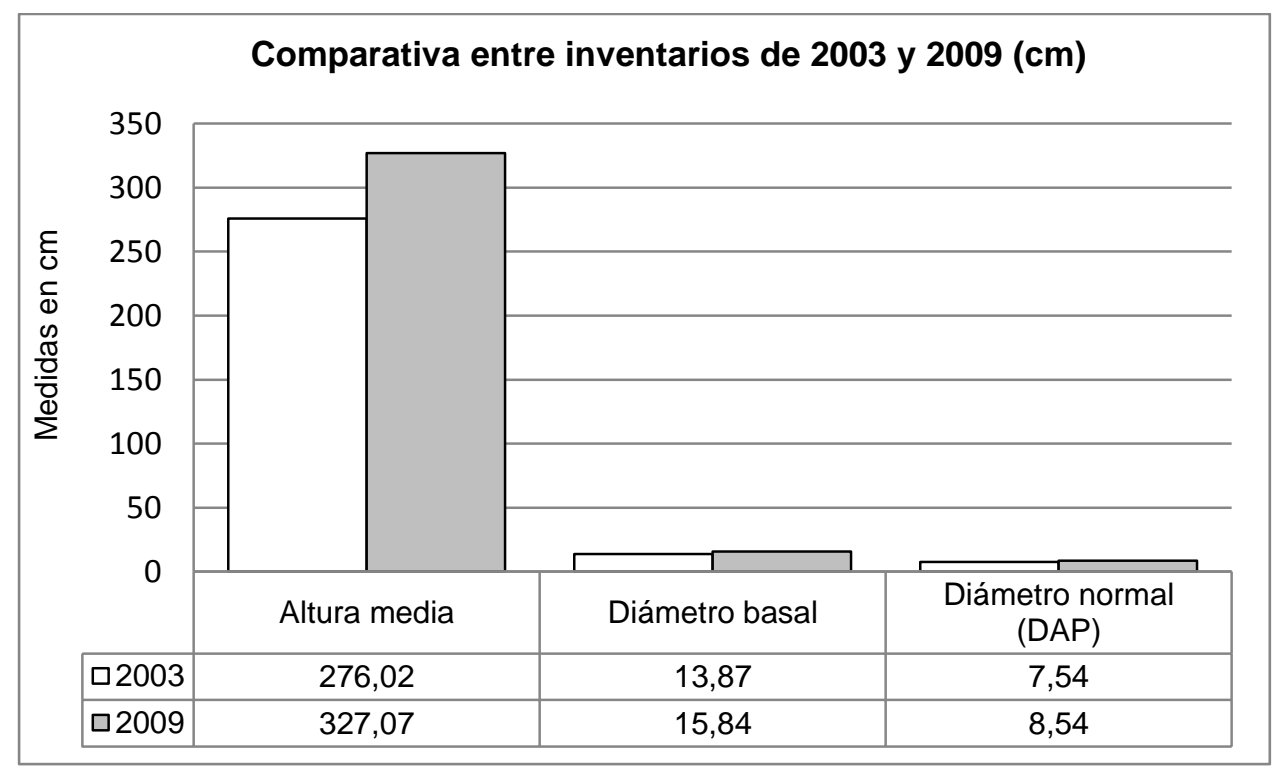

Tabla 3.2. Datos comparativos del crecimiento de los pinos entre los inventarios realizados en 2003 y 2009 en el pinar de la sierra de Navalmanzano.

\subsubsection{Características de los 13 pinos aislados en la sierra de Navalmanzano y en Sierra}

\section{Quintana}

Además de los 1212 pinos inventariados en el pinar de la sierra de Navalmanzano, aparecen otros 11 pies más aislados en el entorno (Tabla 3.3 y Figs 3.13 y 3.15). Entre estos, 9 se encuentran en 3 pequeños grupos (aquí denominados A, B y C), compuestos por un pie adulto y otros 2 más pequeños en su entorno inmediato (regenerado). El pino B es el poseedor del mayor número de conos, con el 63,3\% de ellos cerrados (Tabla 3.3).

\begin{tabular}{|c|r|r|r|c|c|c|c|c|}
\hline \multicolumn{10}{|c|}{ Pinos aislados en la Sierra de Navalmanzano } \\
\hline Árbol & $\begin{array}{c}\text { Altura } \\
(\mathbf{c m})\end{array}$ & $\begin{array}{c}\boldsymbol{\emptyset} \text { Base } \\
(\mathbf{c m})\end{array}$ & $\begin{array}{c}\boldsymbol{\emptyset} \mathbf{1 , 3 0} \\
(\mathbf{c m})\end{array}$ & Conos & Cerrados & Altitud & $\begin{array}{c}\text { Coord. } \\
\mathbf{X}\end{array}$ & $\begin{array}{c}\text { Coord. } \\
\text { Y }\end{array}$ \\
\hline A & 790 & 31,83 & 28,01 & 61 & 3 & 1020 & 390711 & 4252837 \\
\hline A1 & 21 & 0,32 & 0,00 & 0 & 0 & 1020 & 390711 & 4252837 \\
\hline A2 & 18 & 0,32 & 0,00 & 0 & 0 & 1020 & 390711 & 4252837 \\
\hline B & 600 & 31,19 & 26,42 & 550 & 350 & 1010 & 390714 & 4252746 \\
\hline B1 & 55 & 7,64 & 0,00 & 0 & 0 & 1010 & 390714 & 4252746 \\
\hline B2 & 220 & 6,68 & 3,18 & 1 & 0 & 1010 & 390714 & 4252746 \\
\hline C & 710 & 32,47 & 29,28 & 63 & 0 & 930 & 390580 & 4252716 \\
\hline C1 & 47 & 1,59 & 0,00 & 0 & 0 & 930 & 390580 & 4252716 \\
\hline C2 & 133 & 2,55 & 0,00 & 0 & 0 & 930 & 390580 & 4252716 \\
\hline D & 48 & 3,18 & 0,00 & 0 & 0 & 965 & 390342 & 4252880 \\
\hline E & 710 & 25,46 & 21,01 & 12 & 0 & 995 & 390358 & 4253171 \\
\hline
\end{tabular}

Tabla 3.3. Pinos aislados de la Sierra de Navalmanzano y su regenerado. Datos del año 2009. 
El pino A (Tabla 3.3) muestra una severa cicatriz en el tronco, a 1,5 m de altura (Figs. $3.21 \mathrm{y}$ 3.22), producida por el escodado del ciervo. La herida no es reciente y se cierra bien. En cambio el pino B1 sufría un escodado tan intenso que el ciervo se dejó una cuerna entre las ramas (Fig. 3.23 y 3.24). Junto al pino B hay además, otras 2 plántulas de apenas 2 años. El pino $C$ se localiza en una zona en la que se observan restos de un antiguo incendio en la zona y presenta la regeneración de dos individuos en su proximidad (Fig. 3.25 y 3.26). El pino E se halla en la umbría de la sierra de Navalmanzano, en el robledal, a unos $80 \mathrm{~m}$ ladera abajo de la subpoblación occidental del pinar.

Al otro lado del valle de Navalmanzano, sobre la cumbre más elevada de Sierra Quintana, cerca del vértice geodésico del Burcio del Pino o Morrón del Pino (1290,1 m), se han encontrado otros 2 pinos más, ya en la provincia de Jaén. Ambos crecen directamente sobre roquedos, por lo que su crecimiento es muy lento y su edad avanzada, especialmente en el pino "G", de mayor porte y mucho más expuesto al sol y al viento. Por el grosor de su tronco y teniendo en cuenta que crece sobre un roquedo, muy probablemente el pino "G" supere la edad de 100 años. En la proximidad de estos 2 pinos rupícolas no se ha observado regenerado. Los datos dasométricos y geográficos de estos pinos pueden verse en la Tabla 4, imágenes de su estado en la Figs. 3.27 a 3.31 .

\begin{tabular}{|c|c|c|c|c|c|c|c|c|}
\hline \multicolumn{7}{|c|}{ Pinos aislados en Sierra Quintana } \\
\hline Árbol & $\begin{array}{c}\text { Altura } \\
(\mathbf{c m})\end{array}$ & $\begin{array}{c}\emptyset \\
\mathbf{( c m})\end{array}$ & $\begin{array}{c}\boldsymbol{\emptyset} \mathbf{1 , 3 0} \\
(\mathbf{c m})\end{array}$ & Conos & Cerrados & Altitud & $\begin{array}{c}\text { Coord. } \\
\text { X }\end{array}$ & $\begin{array}{c}\text { Coord. } \\
\text { Y }\end{array}$ \\
\hline F & 350 & 29,28 & 25,15 & 1 & 1 & 1275 & 393894 & 4250252 \\
\hline G & 700 & 45,00 & 40,00 & - & - & 1225 & 393825 & 4250162 \\
\hline
\end{tabular}

Tabla 4. Pinos de Sierra Quintana. Los del pino "G" son aproximados pues se halla en un roquedo de difícil acceso. Datos del año 2006.

La primera ascensión a Sierra Quintana se realizó en el verano de 2006, cuando se encontraron, midieron y fotografiaron los 2 pinos que aquí sobreviven. En la primavera de 2015 se realizó un nuevo ascenso para comprobar su evolución. No se apreció crecimiento ni cambio significativo, ni se observó regenerado. 


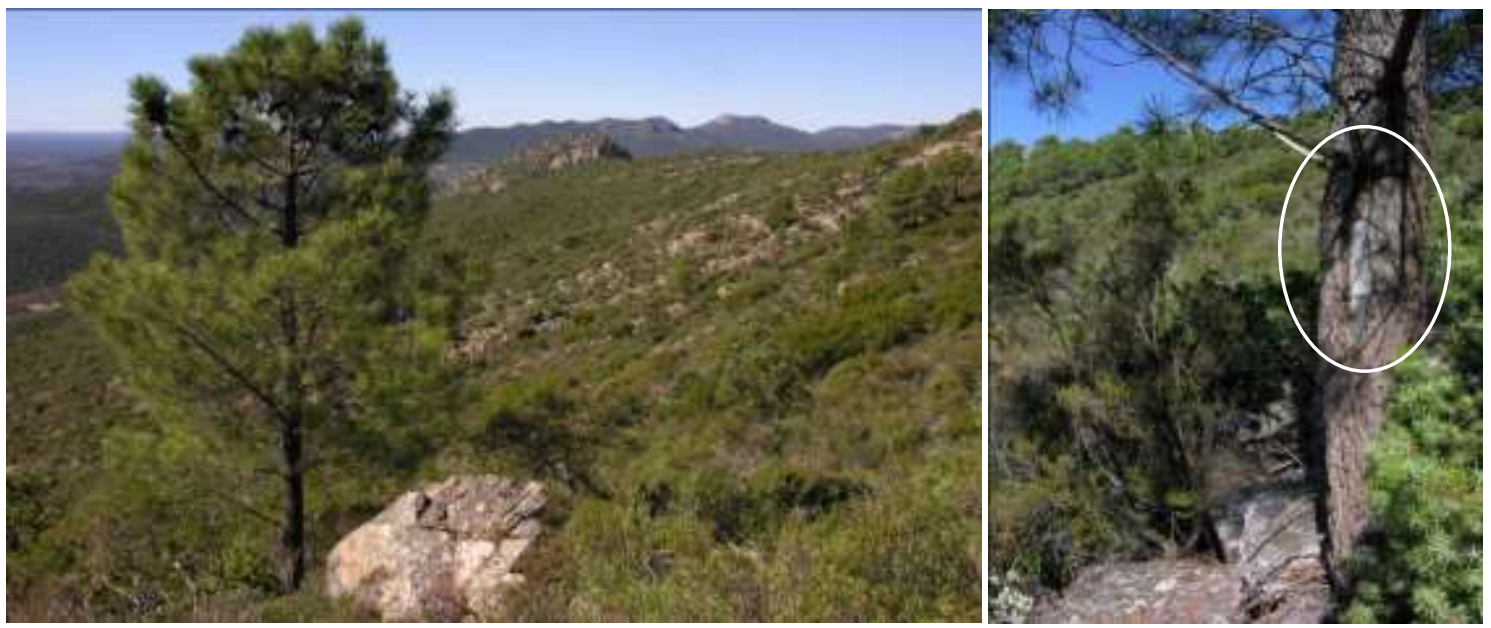

Figs. 3.21 y 3.22. Pino aislado A, con tronco muy dañado por el escodado del ciervo.
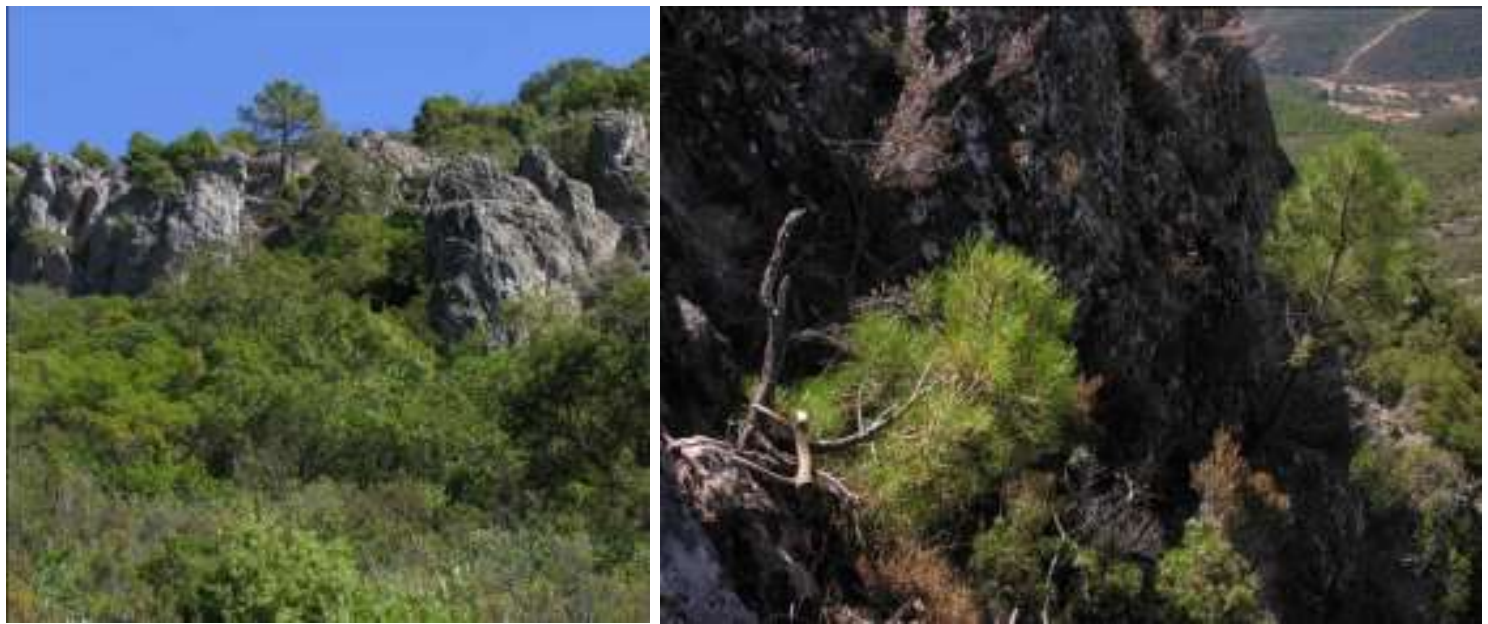

Figs. 3.23 y 3.24. Pino aislado B, con uno de sus 2 vástagos tan escodado por el ciervo que hasta se dejó aquí la cuerna.

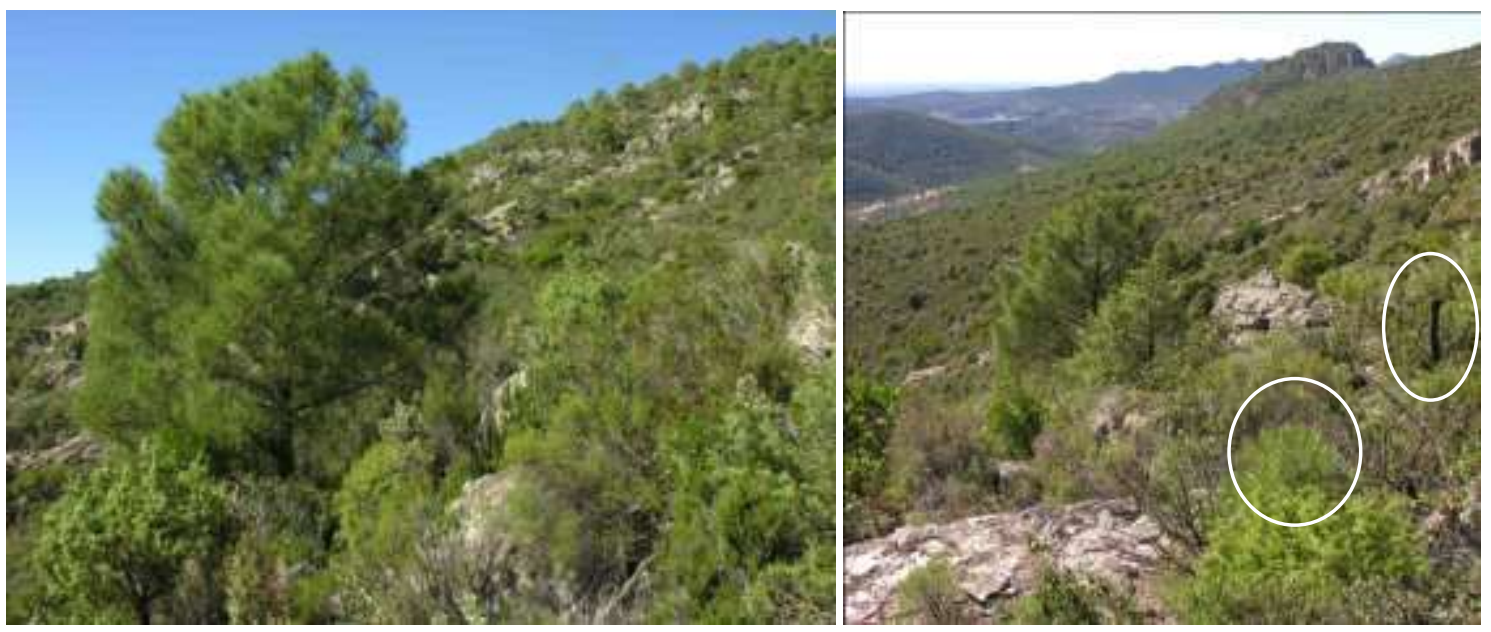

Figs. 3.25 y 3.26. Pino aislado C. En la parte centro-izquierda de la imagen derecha el óvalo señala el tronco recto y ennegrecido de un enebro, vestigio del último incendio en la zona. El círculo marca un pequeño pino, regenerado del pino $\mathrm{C}$ que debió sobrevivir al incendio. 


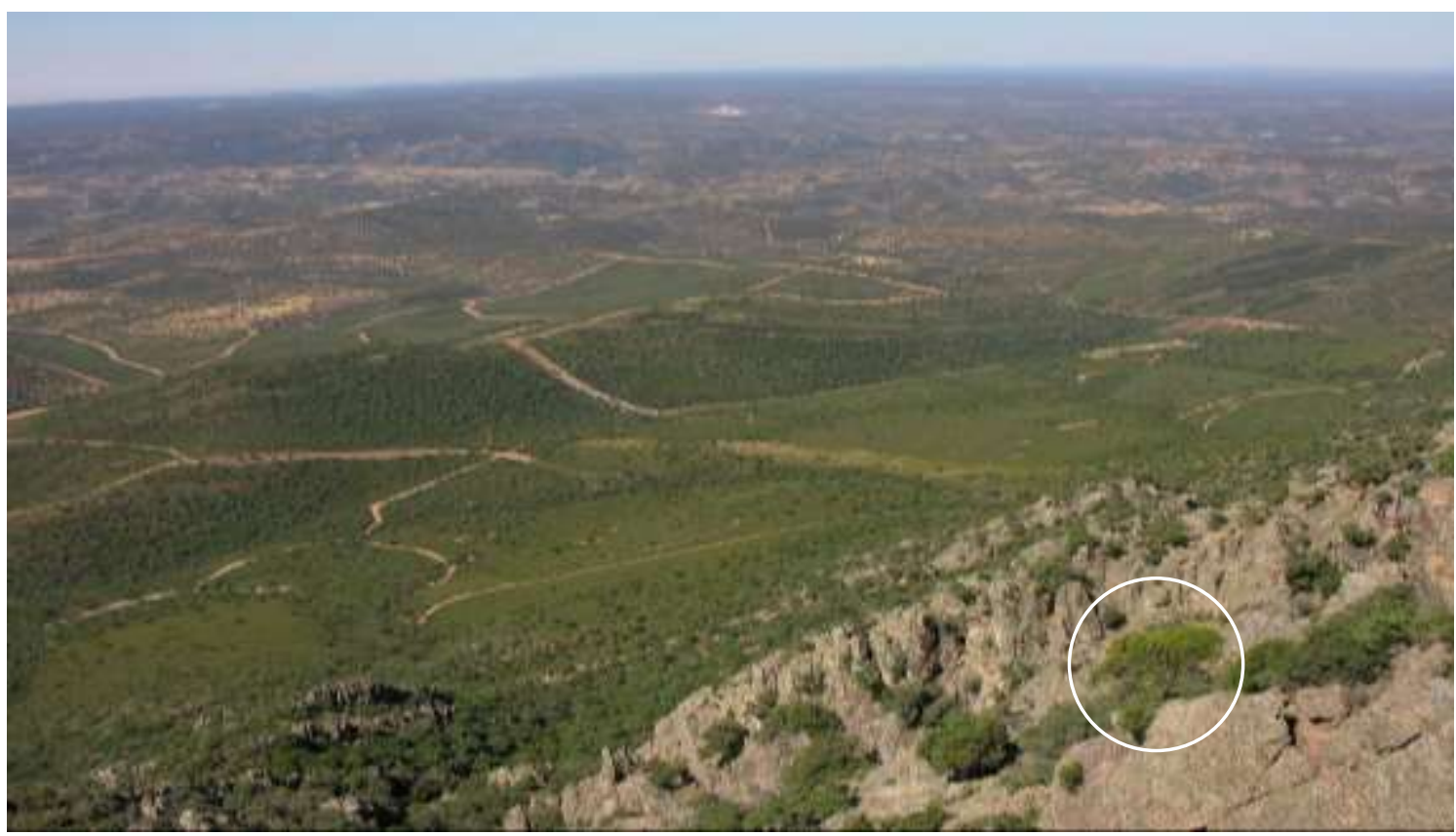

Fig. 3.27. Pino aislado G. Vista de Sierra Morena desde la cumbre de Sierra Quintana. En el centro-izda. los montes de Andújar (Jaén). Al fondo Cardeña, Azuel y Los Pedroches (Córdoba).

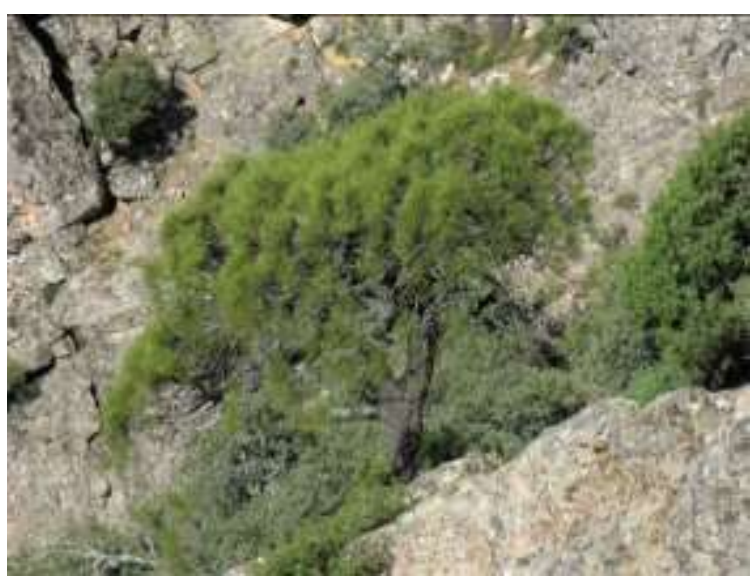

Fig. 3.28. Pino aislado G, vista de levante.
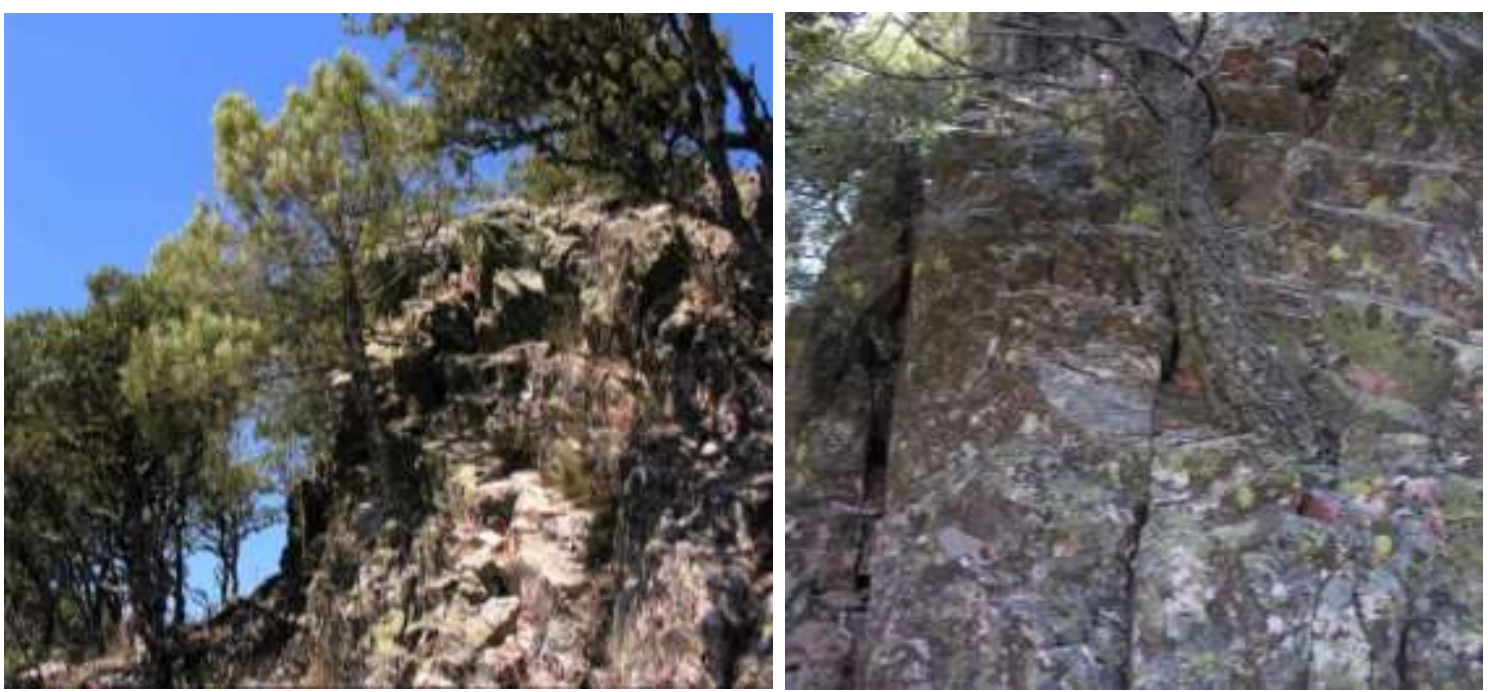

Figs. 3.30 y 3.31. Pino aislado F, el segundo de los pinos supervivientes de Sierra Quintana.

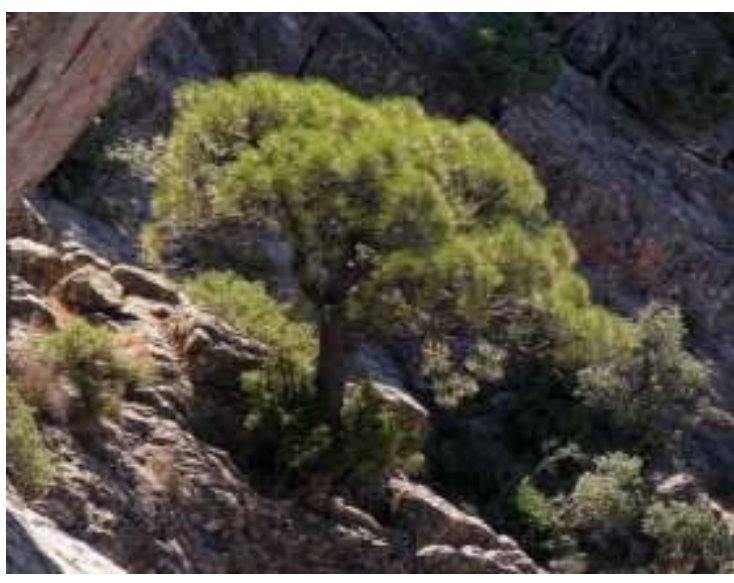

Fig. 3.29. Pino aislado G, vista de poniente. 


\subsubsection{Vigor y supervivencia de pies adultos.}

Los cuatro pinos cuyo colapso se observó en 2004 eran rupícolas y alcanzaban alturas de 5.98, $9.07,10,03$ y 12,01 m. Todos se localizaban en la cuadrícula F-3, en la que se inventariaron 82 árboles, de los que 11 superaban los $4 \mathrm{~m}$ de altura. Los 2 de mayor altura fueron de los que sufrieron una muerte súbita. La altura media de los 100 mayores pinos de todo el pinar es de 8,51 m. Lo que implica que 3 de los 4 pinos caídos, con más de $9 \mathrm{~m}$ de altura, estaban por encima de la media, es decir, eran de los mayores árboles.

La cuadrícula F-3, se sitúa en un promontorio rocoso relativamente elevado y con escaso suelo. La medición en 2009 de la parcela circular de 15 m de radio, incluyó a 32 de los 82 pinos inventariados en 2003 correspondiente a la cuadricula F-3. En la parcela circular se sitúan 2 de estos pinos caídos, el 979 (con $6 \mathrm{~m}$ de altura y 28,97 cm de DAP en 2003) y el 1153 (con $12 \mathrm{~m}$ de altura y 43,61 cm de DAP en 2003). La Fig.3.32 muestra la altura de los 32 pinos de la parcela circular en el inventario de 2003 y de 28 pinos en 2009, pues un pino (983) se ha secado por el escodado de los ciervos y el pino 1157 se ha tronchado y secado al caerle encima el pie 1153. El crecimiento es generalizado en 25 de los pinos, pero 2 (971 y 975) decrecen por el escodado del ciervo y otro (978) fue arrancado por el escodado pero sigue vivo. A pesar de estas pérdidas la altura media en general aumenta. En 2003, de los 28 pinos que seguían vivos en 2009, la altura media era de 1,30 y en 2009, la altura media sube hasta 1,56 m.

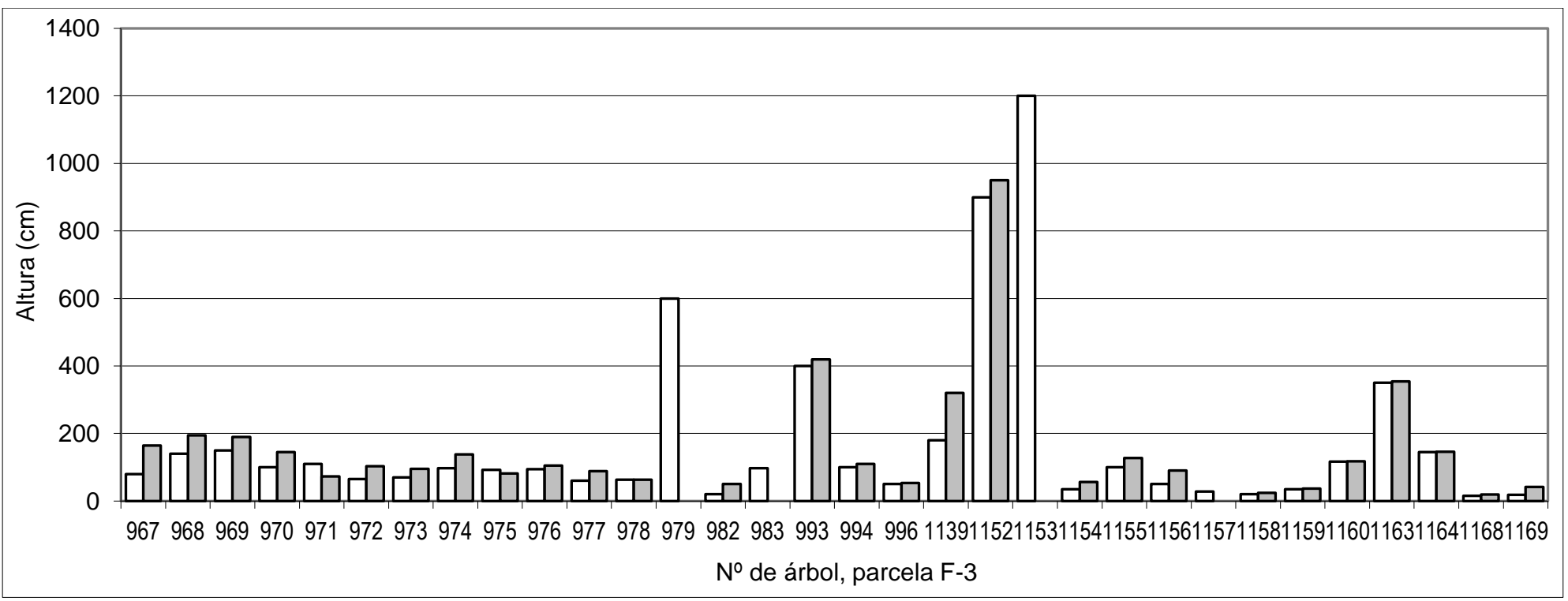

Fig. 3.32. Comparativa de la altura de los pinos situados en la parcela circular F-3, entre el año 2003 (barras blancas de la izda.) y el año 2009 (barras grises de la dcha.).

La observación de las variables climáticas muestra que la noche del 27 al 28 de enero de 2005 fue de las más frías de las últimas décadas, incluso la más fría en algunas estaciones desde que Agencia Estatal de Meteorología (AEMET) ofrece series de datos históricos. El 28 de enero de 2005, el observatorio de Córdoba registró $-8,2^{\circ} \mathrm{C}$, temperatura que fue durante el periodo 1959 - 
2015 la mínima absoluta. También fue la mínima absoluta durante el periodo 1955-2015 la del observatorio de Badajoz con $-7,2^{\circ}$ C. En Ciudad Real la mínima de ese día fue de $-9,0^{\circ} \mathrm{C}$ (alejada de su mínima histórica de $-13,8^{\circ} \mathrm{C}$ del 3 de enero de 1971). El termómetro instalado en el año 2002 en el pinar de Navalmanzano, mostró una temperatura mínima de $-12,5^{\circ} \mathrm{C}$ entre enero y marzo de 2005. Después de la helada extrema hubo una inusual falta total de pluviometría durante el mes anterior.

Del resto de vegetación leñosa presente en el monte, tanto arbórea como arbustiva, se observó que las intensas heladas de enero-marzo de 2005 solo afectaron visiblemente al mirto (Myrtus communis L.), especie de la que murieron todos los ejemplares (cientos, posiblemente miles) por encima de los $820 \mathrm{~m}$ de altitud.

Los troncos de los árboles secos (Figs. 3.5 y 3.6), tras perder progresivamente su resistencia mecánica, fueron derribados por el viento a lo largo de los años 2006, 2007 y 2008. A finales de 2008 ya estaban los 4 caídos en el suelo (Fig. 3.33).

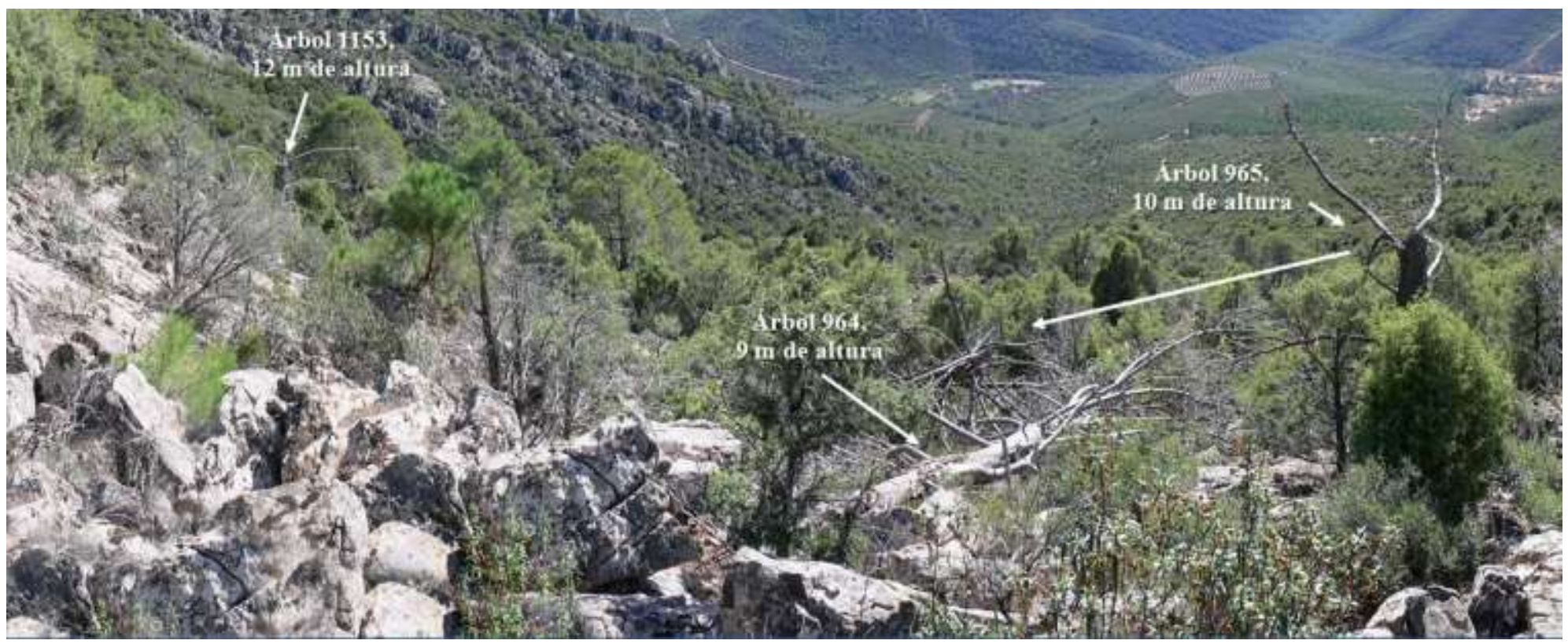

Fig. 3.33. Tres de los pinos caídos a lo largo de los años 2006-2008 en la parcela F-3 tras su muerte súbita a principios del año 2005.

\subsection{Discusión}

\subsubsection{Historia}

Las secuencias paleopolínicas disponibles confirman la presencia de los pinos, no solo en épocas históricas como en el Andévalo (Huelva), La Serena (Badajoz), el Campo de Calatrava o Fuentillezjos (ambos en Ciudad Real) sino desde el Pleistoceno superior en los yacimientos de Lepe y Casa del Pino (Huelva). Todas las secuencias paleopolínicas analizadas, como la de la Fig. 3.7, se encuentran en concordancia con la generalidad de la península Ibérica (Carrión et al. 2012). Las pinturas rupestres (desde el Neolítico hasta la Edad del Hierro) incluyen motivos 
arboriformes por toda Sierra Morena oriental (López \& Soria 1988). Algunos de ellos, por su "ramificación" y estructura general, podrían asimilarse a la forma de un pino. Aun entendiendo que se trata de un arte esquemático, en algunos casos la similitud de algunos motivos permite opinar sobre su adscripción pinariega.

En ausencia del hombre, los pinos fueron dominantes o estuvieron presentes en los terrenos menos aptos para las frondosas por clima, suelo, o presencia recurrente de incendios naturales que no permiten la evolución edáfica en las pendientes que, en castellano, se califican como "empinadas". En zonas montañosas de Guatemala, México y SO de EEUU son típicos los bosques mixtos de Pinus y Quercus, conocido como bosque mixto de pino/encino (Sánchez Velázquez et al. 2008). Estos bosques naturales, bajo un clima similar al mediterráneo, ayudan a entender la composición de los bosques de Sierra Madrona hasta el Calcolítico, pues la milenaria intervención humana los ha modelado hasta el punto de que ahora no sea fácil entender cuál es su dinámica natural.

La eliminación de los pinos y pinares en Sierra Morena fue un proceso progresivo que llevaría sucesivamente a la extinción local en numerosos puntos o prácticamente regional. Durante la Edad del Bronce, del Hierro y hasta bien entrado el periodo romano la presencia de maderas y carbones de $P$. pinaster es común en yacimientos de la vecina comarca de La Serena (e.g. Duque 2004). Hace casi 3000 años, tartésicos y turdetanos iniciaron la explotación de las numerosas minas de plata, plomo y cinabrio del Valle de Alcudia y su entorno de Sierra Morena, luego oretanos, cartagineses y romanos (e.g. Hevia 2003; Zarzalejos 2011), con la consecuente deforestación que esto implica. Para entibar las galerías la madera de pino era apropiada por su resistencia, estructura recta y uniforme, como señala Plinio (N.H. XXXIII, 21, 3). Además, se conserva bien en condiciones húmedas, como las galerías de las minas, si hay presencia de cobre, plomo o zinc (Shepherd 1993). El pino era valorado para la construcción de artefactos para el desagüe de las minas como el tornillo de Arquímedes o las norias (Vitrubio X, VI) donde la madera de pino y encina eran las más utilizadas (Ojeda 2006). La mina de Riotinto poseía ocho parejas de norias para drenar el agua de las galerías y subirlas $29 \mathrm{~m}$ de altura. La noria existente en el Museo de Huelva ha permitido el estudio de las maderas con las que estaban hechas (Rodríguez Trobajo 2006) Así los radios fueron fabricados con madera de Abies sp. (muy probablemente A. pinsapo Boiss.). Los cangilones eran de Pinus nigra / P. sylvestris y los discos y tapas de Pinus pinaster. Actualmente ninguna de estas 3 especies vive de forma natural en el entorno de Riotinto, pero sí pudieron estar presentes en tiempos históricos en la Sierra de Aracena.

Sin embargo, la fundición era el proceso que mayores cantidades de madera requería. El combustible empleado dependía de la fase de fundición o del mineral tratado pero en general las maderas más utilizadas para quema directa, o hacer carbón, eran el pino, la encina y los robles (Cleere 1976; Edmonson 1987; Cauuet et al. 1999; García Romero 2004) especies -entoncesmuy abundantes en Sierra Morena. El carbón constituyó la fuente principal de combustible en la minería del periodo romano como, posteriormente, en las ferrerías que perdurarían hasta tiempos recientes. Hacer carbón implicaba la reducción del peso de la madera o leña en una 
quinta parte y el aumento de su capacidad calorífica lo era en igual proporción (Forbes 1950). Este menor peso permitía trasportar este combustible de zonas forestales situadas a medias y largas distancias del lugar de uso. Menos conocido es el uso que relata Teofrasto (Historia Plantarum, V, 9, 3, según Díaz Regañón 1988):

[...] los herreros buscan el carbón del pino (peuke) con preferencia al de roble. No es tan fuerte, pero responde mejor al soplo del fuelle porque tarda más en desvanecerse [...]

El carbón de pino, aunque de menor potencia calorífica, fue muy empleado en las fundiciones y ferrerías por proporcionar una llama más viva.

Domergue (1990) enumera la existencia de 241 minas en época romana en el entorno de Sierra Morena (39 en Ciudad Real, 22 en Jaén, 83 en Córdoba, 40 en Badajoz, 13 en Sevilla y 44 en Huelva). Esta abundancia de minas y sus efectos colaterales dan sentido a la frase de Plinio (Historia Naturalis, XXXIII, 21, 67): Cetero montes Hispaniarum aridi sterilisque et in quibus nihil aliudgignatur huic bono fertiles esse coguntur. Cuya traducción (Bejarano, 1987) sería

[...] Por otra parte, los montes de las Hispanias áridos y estériles y en los que ninguna otra cosa se cría, están obligados a ser fértiles en esta riqueza [la minera]

Aridez y esterilidad que, en nuestra opinión, aludía a la causada por la creación de nuevos paisajes desforestados por las operaciones mineras. En el caso de Rio Tinto, Luzón (1970) da 20 millones de Tm de escorias y opina que para semejante volumen de producción de escorias de fundición habrian sido serían necesarias 6 millones de toneladas de carbón vegetal. Mientras que Salkield (1970) señala que $1 \mathrm{Tm}$ de escoria de pirita de cobre requeriría de 1,8 Tm de carbón vegetal. Cifras que exigirían la tala de cientos de miles de árboles al año y la deforestación de extensas comarcas. En el caso concreto de Sierra Madrona también se han documentado numerosas minas y fundiciones romanas como las de Almadén, Diógenes, Valmayor o Valderrepisa (Quirós 1969; Domergue 1967, Fernández Rodríguez \& García Bueno 1993; Hevia 2003; Zarzalejos 2011).

El comienzo de la deforestación por los incendios provocados por los pastores fue una de las causas que facilitaron la observación de la riqueza minera. Relación que se puede deducir de las manifestaciones de autores griegos clásicos en el Timeo (De mirab. auscult. 87).

[...] Se dice que cuando en Iberia los bosques habian sido encendidos por los pastores y la tierra se había calentado, fluía plata del suelo, y cuando además se producían grietas y la tierra reventaba, se acumulaban grandes masas de plata [...]

Como más probable y ya con presencia humana, los restos e indicios de pinos en Sierra Morena y áreas próximas del Macizo Ibérico pertenecerían a $P$. pinaster y $P$. pinea. Polen de ambos tipos, maderas y carbones aparecen en Sierra Morena y La Serena (Carrión et al. 2012), aunque con bastante más frecuencia los macrorestos son de $P$. pinaster (e.g. Duque 2004, Rubiales et al. 2008). En las zonas más cálidas, de menor pluviometría, y con suelos graníticos y arenosos la especie podría ser $P$. pinea, mientras que en los más frescos y sobre sustratos cuarcíticos y 
pizarrosos, como en Sierra Madrona, Valle de Alcudia y La Serena, la especie principal, fue $P$. pinaster.

Si actualmente no hay más pinares naturales en Sierra Morena, se debe entender que no es por razones climáticas, pues el clima interglaciar de los últimos 4500 años no ha experimentado grandes cambios, lo que sí ha sufrido un cambio, no perceptible en ocasiones, son las condiciones edáficas debidas a la erosión antrópica. Los horizontes orgánicos han desaparecido conforme lo fue la cobertura arbórea original debido a los reiterados incendios forestales. Este cambio impide el almacenamiento de agua en estos lugares, lo que para las fagáceas dificulta superar la sequía estival y las obliga a un porte achaparrado y a una falta de vigor patente en gran número de las formaciones actuales con Quercus. Cuando la degradación del suelo es máxima, mostrando la roca, las condiciones son más favorables para los pinos por su capacidad de almacenar agua en la albura del fuste (Gil 2008), pero ni aquí sobreviven ya sus formaciones por la eliminación humana de los pinares; tanto por los beneficios que proporcionaban como por su incapacidad de rebrote.

Si la minería supuso una actividad deforestadota le siguió otro hito de la historia de esta región pues, como señaló Sánchez Albornoz (1956): desde el 722 toda la península fue alguna vez frontera entre moros y cristianos y sufrió talas e incendios que la privaron de los bosques que antes la cubrían. Atravesada Sierra Morena por las antiguas calzadas romanas, estas comarcas fueron lugar de paso de los ejércitos de unos y otros, hasta ser durante cinco siglos un vasto territorio de frontera, donde el único aprovechamiento económico, por su movilidad, fue el ganadero. Este uso ganadero, en particular el de los ganaderos locales fue también de vital importancia pues sus reiterados incendios fueron eliminando pinos y pinares por toda Sierra Morena y otras áreas del SO ibérico. Pero aún en el siglo XVI se hacen referencias a pinares en varias partes de la provincia de Ciudad Real. Gracias a la obra de Hernando Colón (1520) se sabe de la existencia de pinares en la Dehesa de Zacatenas, masa que se relacionaría con la Sierra de los Pinos que figura como límite de Fernancaballero en el Interrogatorio del Cardenal Lorenzana en 1852. Pero la Dehesa ha tenido una historia con muchos altibajos históricos en su cobertura y densidad forestal. Así, en las condiciones para el arrendamiento de las rentas de la Mesa Maestral en 1489, y por tres años (Solano 1978), respecto a Zacatenas, se dice:

[...] Otrosy con condiçion que en la corta de la leña seca de Çacatena e de las otras leñas y $i$ coscoja i xara i retama i madroño que se acostumbraron sacar los dichos tres años pasados [...]

En 1564 las ordenanzas de Montiel establecen que se nombren cuatro Caballeros de la Sierra para vigilar lo preceptuado y siendo su misión la "guarda y conservación de los montes, pinares, viñas y dehesas" (Corchado 1971).

Que los pastores siguieron incendiando los montes durante siglos en Sierra Morena y su entorno, lo recogen ordenanzas y pleitos entre comunidades colindantes. Así, destacamos esta Orden de 1565 (Archivo Histórico Municipal de Ciudad Real, Legajo 131): 
[...] Para que en los montes que se quemaren en todo el Campo de Calatrava, por 5 años, no dejen entrar ganados en ellos, porque los mismos ganaderos los quemaban adrede para que sus ganados tuvieran tallos y retoños nuevos que comer, en perjuicio de los árboles [...]

En 1575, el vicario del Campo de Montiel alude a un dato general para toda la provincia "hay una casa lavadero de lanas, donde ordinariamente se lavan cincuenta mil arrobas [...] lo que ha sido causa de destruir los montes e padecer gran necesidad de leña" (Corchado 1971).

Este comportamiento es el que explica la desaparición de las especies que daban los nombres a topónimos como el de Sierra de Pinos citado en el Libro de la Montería (1350) y que saltando hasta mediados del XIX ya no recoge la presencia de la conífera, salvo en la denominación de dos montes públicos del pueblo de Hornachos: "Sierra junto a Pinos" y "Dehesa de Pinos", la primera es un jaral y la segunda tiene, en dicho momento, como especie dominante a la encina, que se erige como el árbol predominante del mundo rural por su rusticidad, excelente aptitud a la fructificación, a la poda y a la producción del mejor carbón para su uso por la población. Esta frutalización de los espacios forestales estaba recogida por el Fuero Juzgo (RAE 1815).

La pérdida de la cubierta vegetal y de la frondosidad de su cobertura se deduce de la comparación de dos fuentes separadas por poco más de dos siglos: el Libro de la Montería (1350) y Las Relaciones Topográficas de Felipe II (1578). En el primer texto, Malagón, Mestanza y la solana de Alcudia, entre muchos más, son considerados buen monte de oso en invierno y, por el contrario, la especie ya no figura en las Relaciones.

Llama la atención la degradación de la vegetación, tanto la ausencia a los pinares que figuran solo como topónimos en Fernán Caballero en las descripciones de 1578 y de 1782. También es de destacar la respuesta de Alcolea y Malagón respecto al origen de la madera de pino, que en el primer caso señalan a Luciana y Piedrabuena, villas que no indican su existencia ya a finales del XVI, pero la contestación de Malagón apunta a una menor distancia cronológica de su extinción local: se trae ahora de la Sierra de Cuenca. Pero la presencia de pinares la confirma tanto Colón (h. 1520) como su empleo en las obras del Sacro Convento de Daimiel en 1782. La historia de la regresión de los pinares y su extinción regional la recoge con precisión la secuencia paleopolínica del Campo de Calatrava, aguas abajo del PN de las Tablas de Daimiel (Fig. 3.7).

También se asiste a la extinción de animales — ahora emblemáticos — como los osos y de especies forestales más exigentes que la encina, como son los castañares citados en Luciana y Malagón en el Libro de la Montería. O por el contrario como la encina no es mencionada en la Dehesa de Zacataenas en 1489. En Fuencaliente, villa que es muy abundante de leñas de muchas y diversas montañas como es robles, alcornoques, quexijos y encinas, es citada en último lugar la especie que ahora domina por la regresión de los otros Quercus debido a la degradación del suelo. Pero, asimismo, la naturalidad del pinar de Navalmanzano lo confirma el estudio paleopolínico (Díaz Fernández 1992) y es aceptada en recientes trabajos (García Río 2004, 2006).

Aunque los pastos se han considerado un factor económico de primer orden en España (Buxadé 1996). Gracias a sus producciones anuales, frente a décadas o siglos en las especies forestales, a excepción de la leña, la ganadería era poseedora de mayor interés (e.g. Quirós 1965; Gascón 
1978; Klein 1979; Bauer, 1980; Montserrat \& Fillat, 1990). Esta percepción empieza a cambiar hacia 1950 en Sierra Morena, cuando los pueblos serranos alcanzan su máxima densidad de población histórica. A partir de esa década y en las de 1960 y 1970, se produce un abandono del medio rural al tiempo que se produce una gran concentración de la propiedad. En la década de 1970 desaparece casi por completo la ganadería y ya no se incendia sistemáticamente el monte, al contrario, cualquier conato de incendio intenta ser rápidamente extinguido con modernos medios terrestres y aéreos de la administración del Estado o de las CCAA.

Los efectos sobre los bosques de los incendios provocados cada 3-6 años favorecen a las especies rebrotadoras (de los géneros Quercus, Arbutus, Erica, Phillyrea, Myrtus, etc ...), cuya desaparición exige el levantamiento de la cepa o su agotamiento por sobrepastoreo, y a las germinadoras de ciclo corto (Cistus, Halimium, Rosmarinus, Lavandula, etc ...), frente a las especies germinadoras de ciclo más largo (Pinus). Los pinos necesitan al menos de 8-10 años para poder producir semillas pero, de no tener ese tiempo, los pinares desaparecen tras un solo episodio de incendio seguido de pastoreo. La recurrencia y severidad de los incendios ha sido muy intensa durante siglos hasta acabar con una especie como $P$. pinaster que destaca precisamente por estar adaptada al fuego dado el grosor de su corteza y la alta serotinidad de sus conos (Tapias et al. 2004; Fernandes et al. 2005).

\subsubsection{Toponimia}

Para situar localmente algunas de las extinciones es útil el conocimiento de los fitotopónimos. Un ejemplo es el cerro de el "Reventón de los Pinos" (Fontanarejo, Ciudad Real). Reventón alude en estas comarcas a grandes y repentinos brotes de agua tras intensas lluvias (son frecuentes en el sur de España, siendo el más famoso el espectacular reventón que se produce anualmente en el nacimiento del río Mundo -Albacete-). La alusión a la conifera todavía se mantiene entre los habitantes de la zona y, su presencia pasada, ha quedado constancia en el arroyo que desciende desde el cerro del reventón "Arroyo de los Pinos" topónimo aun reconocido en la cartografía del IGN (Fig. 3.9). La validez de la toponímia para rastrear especies o formaciones ya desaparecidas ha sido puesta de manifiesto por diversos autores (e.g. Morala 2007; García Latorre \& García Latorre 2007; Ezquerra \& Gil 2008 o Carrillo et al. 2010). Al aplicarlo a Sierra Madrona en concreto y a Sierra Morena en general su validez la confirman los abundantes yacimientos con restos de polen y macrorestos, aludidos anteriormente, en zonas relativamente próximas a Sierra Madrona y Valle de Alcudia de Extremadura (sur de Cáceres y Badajoz) y Toledo, donde la presencia de pinares aparecen con edades superiores a los 1800 años (Duque 2004; López-Sáez \& López-García 2005; López Sáez et al. 2007).

En el área de Sierra Morena la gran mayoría de los topónimos actuales irían formándose a partir de los siglos XII y XIII, conforme los castellanos se fueron asentando y distribuyendo por estas comarcas. Salvo por la existencia de un vacío humano total, heredarían, o trasladarían a la nueva lengua los nombres antiguos si constituían referencias valiosas para la identificación del territorio. En el presente trabajo, la razón de su presencia sería la rareza del pino en el entorno próximo frente a otras especies más comunes. La escasez de pinos y pinares, tras el largo 
periodo como tierra de frontera, supuso una posible recuperación de las formaciones forestales que, volverían a decaer con el auge de la población y las roturaciones para fines agrícolas y ganaderos, las necesidades de leña y madera de la población y las minas, más, lo que es peor para los montes, los recurrentes incendios forestales de los pastores locales.

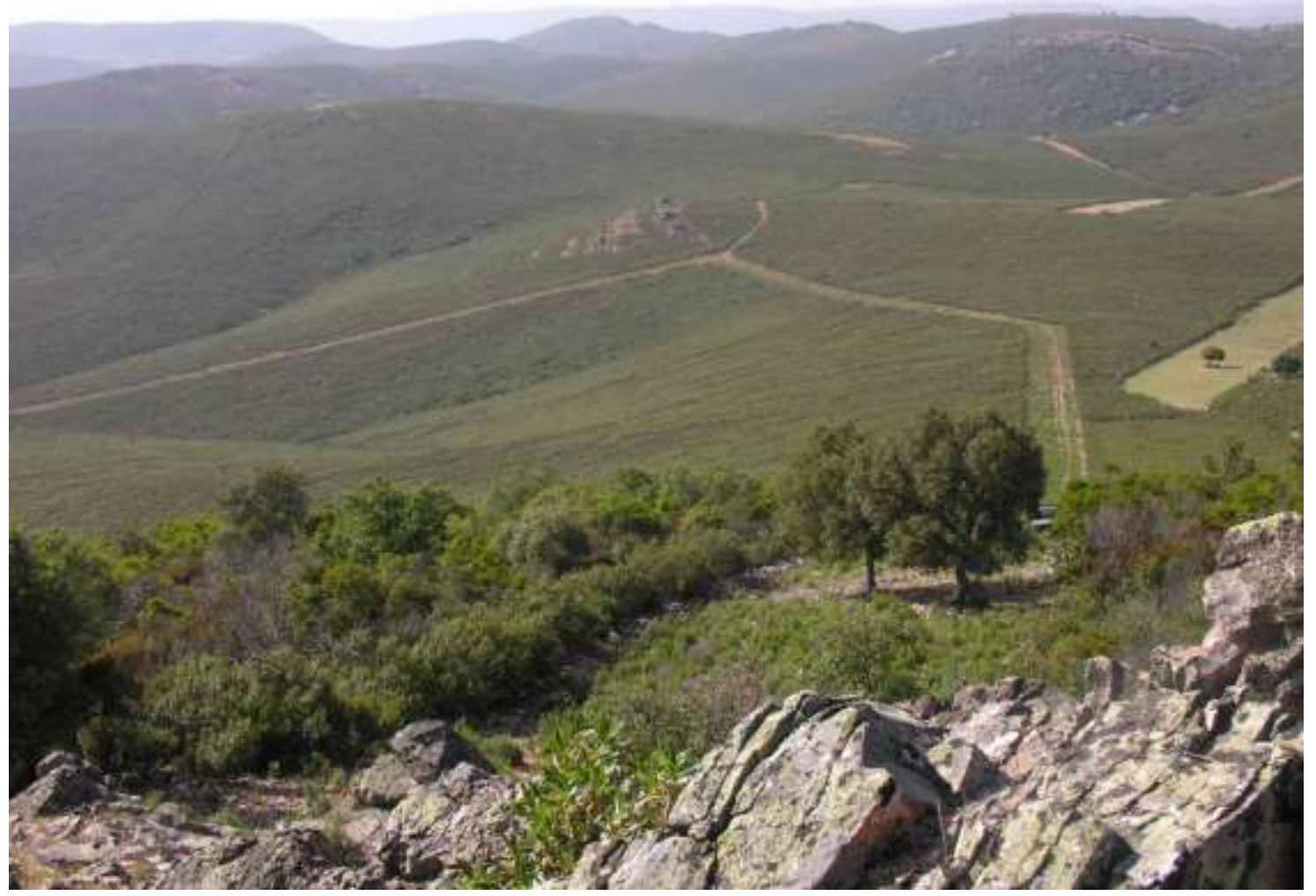

Fig. 3.34. Cumbres entre los términos de Fontanarejo y Alcoba de los Montes, vistas desde el Cerro de Los Barranquillos. Los afloramientos en el centro de la imagen se corresponden con el "Cerro del Reventón de los Pinos" en el plano del año 1829, y "Cerro de los Pinos" como le sigue conociendo la población local. De aquí nace el topónimo actual de "Arroyo de los Pinos".

El estudio fitotoponímico de Sierra Morena en relación a los pinos, ha mostrado como resultado la presencia de 83 topónimos a los que se pueden calificar como de aparición antigua. Entre los considerados, los de mayor importancia son los que indican elevaciones del terreno (23 topónimos, un 28\%). Esta abundancia se justifica por ser las zonas más altas las de menor aptitud para la agricultura, por lo que se convirtieron en refugio para las especies forestales. De este rasgo deriva la voz 'monte' con el significado de la antigua silva latina en la versión castellana del Fuero Juzgo a partir de la latina (Gil 2003). El resto de topónimos relacionados con collados, cursos de agua o pinares en general, apoyan la existencia en el pasado de pinos y pinares y, mientras no se evidencie y justifique una opinión contraria, la abundancia de su número, pese a la inexistencia de pinares en los últimos siglos, es un claro exponente de una distribución de la conífera más amplia en el pasado. 


\subsubsection{El pinar de Navalmanzano: inventario y evolución reciente}

En esencia, primero por la minería y, después, por los incendios forestales, los pinares de $P$. pinaster, antes extendidos por las sierras del SO ibérico, fueron desapareciendo hasta su total exterminio, a excepción de las nuevas cifras que se aportan: 2 pinos en Sierra Quintana (uno de ellos centenario) y los 1223 inventariados en la sierra de Navalmanzano (1212 en el pinar y 11 más dispersos en su entorno).

Respecto a los 200 pies de pino negral a que aludían Alía et al (1996) como tamaño de la población de la sierra de Navalmanzano, los datos aquí presentados no expresan un gran crecimiento de la población en los 7 años trascurridos (1996-2003) hasta el primer inventario sistemático que aquí se presenta, lo que entraña es un más adecuado conocimiento de la zona. Aunque los pinos de Navalmanzano dispersaban sus semillas el pinar no se expandía debido a los recurrentes incendios forestales por lo que se mantuvo en los reducidos lugares que poseían condiciones climáticas favorables para que la semilla tuviera oportunidades de establecerse. El pinar manifiestaba su incapacidad para salir históricamente de las zonas rocosas bajo un régimen frecuente de incendios.

El abandono de esta práctica hace unos 50 años es lo que permite llegar a la actual estructura del pinar de la sierra de Navalmanzano y que tenga fuera de los roquedos casi la mitad de los pinos (521 pies) (Fig. 3.19). La importancia del roquedo como refugio se deduce de la gran mayoría de pies de pequeña altura, unos por su juventud pero la mayoría por crecer sobre litosuelos estrictos. Las alturas varían bastante en función del sustrato sobre el que crece cada pino o de si éste ha sido más o menos dañado por la fauna silvestre. El 73,6\% de los pinos no superan los 2 $\mathrm{m}$ de altura y, en cuanto a la distribución espacial, en 42 de las 49 parcelas en que hay pinos, la altura media no supera los $3 \mathrm{~m}$. Por tanto, la relación edad/altura adquiere valores especiales por presentar en los roquedos limitaciones a su crecimiento. Los pinos sobre suelos con algún espesor tienen alturas y diámetros normales pero los rupícolas apenas crecen en altura, además de estar en zonas más elevadas y expuestas a los rigores climáticos.

Ha sido importante la dispersión de los pinos fuera de los roquedos, a fin de que se recupere una masa en estado más natural. En el futuro, como es propio del actual periodo interglaciar, se mezclará con encinas, alcornoques, quejigos y robles, presentes también en la zona de forma natural, pero con unas densidades y dimensiones en que no podrán competir por altura con las alcanzadas por los pinos en condiciones más propias para la vegetación arbórea que el roquedorefugio. Si al cabo de varias décadas o siglos se incendiara este bosque mixto, sería la existencia de un destacado banco aéreo de semillas, tal como manifiesta el pino B, que con 6,0 $\mathrm{m}$ de altura y $26,4 \mathrm{~cm}$ de diámetro normal posee 350 piñas cerradas, el que facilitaría una mayor expansión del pinar.

Esta expansión no se produce en absoluto en Sierra Quintana, donde no se ha observado ninguna regeneración en las 2 ocasiones que se ha buscado en torno a los 2 últimos pinos supervivientes en los años 2006 y 2015. La relativa lejanía entre ellos y más aún con los de la sierra de Navalmanzano, es un importante obstáculo para la polinización. 
De acuerdo con los datos de ambos inventarios (2003 y 2009) y la población de partida "recluida" en los roquedos, el pinar de la sierra de Navalmanzano está en expansión. El vigor de los árboles localizados fuera del roquedo no manifiesta la existencia de problemas. La helada de la noche del 28 de enero de 2005 , que en el pinar alcanzó $-12,5^{\circ} \mathrm{C}$, y unidos sus efectos a la sequía (durante ese mes de enero no llovió nada y apenas en los siguientes), desencadenó la muerte de 4 árboles adultos (entre los mayores de todo el pinar) aparentemente sanos. El no afectar al resto del arbolado, cualquiera que fuera su dimensión, permite deducir que estos ejemplares estaban en el límite de su vida biológica con una fuerte desproporción entre la parte aérea que es visible y su sistema radical, que no lo es. Tal desproporción se agudizó frente a un evento climático adverso para la parte aérea a la que no puede responder el sistema radical, en particular por la sequía coincidente

Mayor incidencia tienen las repoblaciones de pinos en la sierra de Navalmanzano y su entorno. La mariposa de la procesionaria, especie autóctona, se ha desarrollado con virulencia en estas nuevas plantaciones, de las que no se ha logrado erradicarla y la plaga, en fase epidémica, ha llegado al pinar autóctono. Actualmente se están aclarando las densidades en las repoblaciones; incluso se ha eliminado el $100 \%$ de los pinos en algunos rodales, pero la presencia de estas repoblaciones en las últimas 6-7 décadas ha hecho posible que la procesionaria del pino se incorpore a la entomofauna del pinar de Navalmanzano. Es de esperar que una nueva gestión forestal contribuya a devolver el equilibrio natural a esta población.

Otro aspecto a destacar es la posible introgresión genética que desde las ya citadas repoblaciones forestales se produce en el pinar autóctono (Ramírez-Valiente y RobledoArnuncio 2015) que, por la diferencia demográfica entre ambas poblaciones, alterará la estructura genética de esta "Región de procedencia especial de $P$. pinaster de la sierra de Navalmanzano".

\subsection{Referencias}

Akhani, H., Djamali, M., Ghorbanalizadeh, A. \& Ramezani, E. 2010. Plant biodiversity of Hyrcanian relict forests, N, Iran: An overview of the flora, vegetation, palaeoecology and conservation. Pakistan Journal of Botany 42, 231-258.

Alcalde, C, García Amorena I, Gómez, F. Maldonado, J. Morla, C., Postigo, J.M., Rubiales, J.M. \& Sánchez, L.J. 2004. Nuevos datos de carbones y maderas fósiles de Pinus pinaster Aiton en el Holoceno de la Península Ibérica. Invest. Agrar: Sist. Recur. For. Fuera de serie. 152-163.

Alía, R., García del Barrio, J.M., Iglesias, S., Mancha, J.A., De Miguel, J., Nicolás, J.L., Pérez, F. \& Sánchez, D. 2009. Regiones de procedencia de especies forestales en España. Organismo Autónomo Parques Nacionales, Madrid. 363 pp.

Alía, R., Martin, S., De Miguel, J., Galera, R.M., Agúndez, D., Gordo, J., Salvador, L., Catalán, G. \& Gil, L. 1996. Las regiones de procedencia de Pinus pinaster Aiton en España. Ministerio de Medio Ambiente. Madrid. 
Allen, C.D., Macalady, A.K., Chenchouni, H., Bachelet, D., McDowell, N., Vennetier, M., Kitzberger, T., Rigling, A., Breshears, D.D., Hogg, E.H.T., Gonzalez, P., Fensham, R., Zhang, Z., Castro, J., Demidova, N., Lim, J.-H., Allard, G., Running, S.W., Semerci, A. \& Cobb N., 2010. A global overview of drought and heat-induced tree mortality reveals emerging climate change risks for forests. Forest Ecology and Management, 259: 660-684.

Alvin, K.L.1960. Further conifers of the Pinaceae from the Wealden Formation of Belgium. Institut Royal des Sciences Naturelles de Belgique. Mémoires. 146. Bruselas. 39 pp.

Anderegg, W. R. L., J. Kane, \& L.D.L. Anderegg. 2013. Consequences of widespread tree mortality triggered by drought and temperature stress. Nature Climate Change. 3: 30-36.

Axelrod, D.I. 1986. Cenozoic history of some western American pines. Annals of the Missouri Botanical Garden, 73:565-641.

Bará, S. \& Toval, G. 1983. Calidad de estación del Pinus pinaster Ait. en Galicia. INIA. Serie: Recursos Naturales, 24. Madrid.

Barrón, E., Muñiz, F. \& Mayoral, E. 2003. Aspectos macroflorísticos del Plioceno de Lepe (cuenca del Guadalquivir, Huelva, España). Consideraciones paleoecológicas. Boletín de la Real Sociedad Española de Historia Natural (Sección Geológica). 98: 91-109.

Bauer, E. 1980. Los montes de España en la historia. Ministerio de Agricultura. Madrid.

Bejarano, V., (traductor) 1987. Hispania Antigua según Pomponio Mela, Plinio el Viejo y Claudio Ptolomeo. En: Schulten, A. \& Maluquer de Motes, J., (Eds.). Fontes Hispaniae Antiquae VII. Instituto de Arqueología y Prehistoria, Barcelona.

Buxadé, C., 1996. Zootecnia. Bases de producción animal. XX tomos. Mundi-Prensa. Madrid.

Campos y Fernández de Sevilla, F.J. 2009. Los pueblos de Ciudad Real en las Relaciones Topográficas de Felipe II. Ciudad Real. 1168 pp.

Cano, E. \& Valle, F. 1990. Formaciones boscosas en Sierra Morena oriental (Andalucía, España). Acta Botanica Malacitana 15: 231-237.

Carrillo, A.F., Carrión, J.S., Fernández Jiménez, S. \& Román, J.L. 2010. Toponimia y biogeografía histórica de plantas leñosas ibéricas. Editum. Murcia. 246 pp.

Carrión, J.S., Fernández, S., González Sampériz, P., López Merino, L., Peña, L., Burjachs, F., López Sáez, J.A., García Antón, M., Carrión Marco, Y., Uzquiano, P., Postigo, J.M., Barrón, E., Allué, E., Badal, E., Dupré, M., Fierro, E., Munuera, M., Rubiales, J.M., García Amorena, I., Jiménez Moreno, G., Gil Romera, G., Leroy, S., García-Martínez MS, Montoya E, Fletcher W, Yll E, Vieira M, Rodríguez-Ariza MO, Anderson S, Peñalba C, Gil García MJ, Pérez Sanz, A, Albert RM, Díez MJ, Morales-Molino C, Gómez Manzaneque F, Parra I, Ruiz Zapata B, Riera S, Zapata L, Ejarque A, Vegas T, Rull V, Scott L, Abel Schaad D, Andrade A, Manzano S, Navarro C, Pérez Díaz S, Moreno E, Hernández-Mateo L, Sánchez Baena JJ, Riquelme JA, Iglesias R, Franco F, Chaín C, Figueiral I, Grau E, Matos M, Jiménez Espejo F, Valle-Hernández M, Rivas-Carballo R, Arribas A, Garrido G, Muñiz F, Finlayson G, Finlayson C, Ruiz M, Pérez Jordá G, Miras Y. 2012. Paleoflora y Paleovegetación de la Península Ibérica e Islas Baleares: Plioceno-Cuaternario. Ministerio de Economía y Competitividad, Madrid. 
Cauuet, B., Domergue, C., Dubois, C., Pulou, R., Tollon, E. 1999. La production de cuivre dans la province romaine de Lusitanie. Un atelier de traitement du mineral à Vipasca, en J.G. Gorges et F. G. Rodriguez Martín (eds.): Économie et territorie en Lusitanie romaine, Collection de la Casa de Velázquez, 65, Madrid, pp. 279-306.

Ceballos, L. 1942. Síntesis de los aspectos de la vegetación en los montes españoles. Revista Intersylva. 1.

Ceballos, L. 1944. Síntesis de los aspectos de la vegetación en los montes españoles. Euclides. 35: 27-38.

Clark, J.S., Bell, D.M., Hersh, M.H., Nichols, L., 2011. Climate change vulnerability of forest biodiversity: climate and competition tracking of demographic rates. Global Change Biol. $17,1834-1849$.

Cleere, H., (1976): Some operating parameters for Roman iron Works, Bolletin of the Institute of Archaeology, University of London 13, pp. 233-246.

Colón, F. ¿1517-1523?: Descripción y Cosmografia de España. Manuscrito de la Biblioteca Colombina editado por la Sociedad Geográfica, 3 tomos, Madrid, 1908, (tomo II), 1910 (tomo I) y 1915 (tomo III), edición facsímil, Sevilla, Padilla Libros, 1989, 360, 334 y 85 pp.

Corchado, M., 1982. El Campo de Calatrava. Parte III: Los Pueblos y sus Términos. Ciudad Real, Instituto de Estudios Manchegos, 567 pp.

Corchado, M. 1971. Avance de un estudio geográfico-histórico del Campo de Montiel. Instituto de Estudios Manchegos-Patronato José María Cuadrado del CSIC. Ciudad Real.

Córdoba de la Llave, R. 1990 La industria medieval de Córdoba. Obra Cultural de la caja de Ahorros de Córdoba, 416 pp.

Cruz Arias, M. J. 2004. Fondo de Intendencia de la Provincia Conservado en el Archivo de la Diputación de Toledo. Archivo Secreto: Revista Cultural de Toledo n², Pp 6-35.

Díaz Fernández, P.M. 1992. Historia de la vegetación en Sierra Madrona y su entorno: una contribución a su estudio. Tesina de doctorado. Facultad de Biología. UCLM.

Díaz Regañón, J. (traductor), 1988. Teofrasto. Historia de las plantas. Madrid, Editorial Gredos.

Domergue, C. 1967. La mine antique de Diogenes (province de Ciudad Real).Melanges de la Casa de Velasquez, IIII: 29-91.

Domergue, C. 1990. Les mines de la Péninsule Ibérique dans l'antiquité romaine. Collection de l'École Française de Rome, vol. 127. Roma.

Dorado Valiño, M., Valdeomillos, A., Ruiz Zapata, M.B., Gil García, M.J. \& Bustamante, I. 2002. Climatic changes since the Lateglacial/Holoceno tran-sition in the Mancha plain (South Central Iberian Peninsula, Spain) andtheir evidence in Las Tablas Daimiel marshlands. Quaternary International, 93-94: 73-84.

Duque, D.M. 2004. La gestión del paisaje vegetal en la Prehistoria Reciente y Protohistoria en la Cuenca Media del Guadiana a partir de la Antracología. Tesis Doctoral. Dpto. Historia. Facultad de Filosofía y Letras. Universidad de Extremadura. 849 pp.

Edmonson, J. C. 1987. Two industries in Roman Lusitania: mining and garum production, BAR Internacional Series 362, Oxford. 
Ezquerra, F.J. \& Gil, L. 2008. La transformación histórica del paisaje forestal en Extremadura. III Inventario Forestal Nacional, 1997-2007. Ministerio de Medio Ambiente, Madrid. 304 pp

Fernández Rodríguez, M. \& García Bueno, C. 1993. La minería romana de época republicana en Sierra Morena: el poblado de Valderrepisa (Fuencaliente, Ciudad Real) [Apéndice: monedas halladas en el nacimiento de Valderrepisa (Fuencaliente, Ciudad Real)]. In: Mélanges de la Casa de Velázquez. Tome 29-1. Antiquité et Moyen-Age. 25-50.

Figueiral, I. 1995. Charcoal analysis and the history of Pinus pinaster (cluster pine) in Portugal. Review of Palaeobotany and Palynology, 89: 441-454

Forbes, R. J., 1950. Metallurgy in Antiquity, Leiden.

Fraga, P. 1996. Notes florístiques de les Illes Balears (IX). Butll. Soc. Hist. Nat. Balears, 39: 205-208. Palma de Mallorca.

Fuentes, N., Carrión, J.S., Fernández, S., González Sampériz, P., Nocete, F., Alex, E., Pérez, C. \& Lizcano, R. 2006. Análisis polínico del yacimiento arqueológico de La Junta (Puebla de Guzmán, Huelva). Anales de Biología, 28: 73-83.

García Latorre, J. \& García Latorre, J. 2007. Almería: hecha a mano. Una historia ecológica. Fundación Cajamar. Almería.

García Rayego, J.L. 2006. "Modelados de detalle en roquedos cuarcíticos de áreas de montaña media apalachense de la Meseta sur y Sierra Morena oriental”. Ería, 71: 269-282.

García Río, R. 1999. Aportaciones a la flora de Sierra Morena (Ciudad Real, España). Botanica Complutensis 23: 115-132.

García Río, R. 2004. Flora vascular de Sierra Madrona y su entorno (Sierra Morena, Ciudad Real, España). Ecología, 18: 147-214.

García Río, R. 2006. Flora y vegetación de Sierra Madrona y Valle de Alcudia. Bases científicas para su conservación. Centro de Investigaciones Ambientales del Mediterráneo (CIAMED). Ciudad Real. 336 pp.

García Romero, J. 2004. Metalurgia romana del cobre en el sur de Hispania. En: Romero Macías, J.A. \& Romero Macías, E. (eds.): Metallum. La minería Suribérica, Huelva, pp. 105-125.

García Amorena, I., Gómez Manzaneque, F., Rubiales, J.M., Granja, H.M., Soares, G. y Morla, C. 2007. The Late Quaternary coastal forests of western Iberia: A study of their macroremains. Palaeogeography, Palaeoclimatology, Palaeoecology 254, 448-461

García Antón, M., Morla C, Ruiz Zapata MB, Sainz Ollero H. 1986. Contribución al conocimiento del paisaje vegetal Holoceno en la Submeseta Sur Ibérica: análisispolínico de sedimentos higroturbosos en el Campo de Calatrava (Ciudad Real,España). En: López Vera, F. (Ed.), Quaternary Climate in Western Mediterranean. 1. Publicaciones de la Universidad Autónoma de Madrid, Madrid.: 189-204.

Gascón, F. 1978 (2ª ed. 1994). El Valle de Alcudia durante el siglo XVIII. Ediciones del Orto. $609 \mathrm{pp}$.

Gil L., 1991. Consideraciones históricas sobre Pinus pinaster Aiton en el paisaje vegetal de la península Ibérica. Estudios Geográficos, Tomo LII, 202, 5-27. 
Gil, L. 2003. La voz "montes" y la transformación histórica del espacio natural. Actas de la II Reunión sobre Historia Forestal, Valladolid, 18 y 19 de septiembre 2003. Cuadernos de la SECF, 16: 19-30.

Gil, L. Gordo, J., Alía R., Catalán G. \& Pardos J.A. 1990. Pinus pinaster Aiton en el paisaje vegetal de la península Ibérica. Ecología, fuera de serie no 1: 469-495.

Gil, L. 1996. Reseña Geográfico-Histórica de los montes de Castilla-La Mancha. En: Introducción a la Memoria del Segundo Inventario Forestal Nacional 1986-1995, CastillaLa Mancha, Ciudad Real. MAPA, 1995. 12-30.

Gil, L. 2008. Pinares y rodenales; la diversidad que no se ve. Discurso del Académico Electo Excmo. Sr. D. Luis Gil Sánchez leído en el acto de su recepción pública el día 23 de septiembre de 2008. 191 pp + Contestación.

Gil García, M.J., Ruiz Zapata, M.B., Santisteban, J.I., Mediavilla, R., López Pamo, E. \& Dabrio, C.J. 2007. Late Holocene environments in Las Tablas de Daimiel (southcentral Iberian peninsula, Spain). Vegetation History and Archaeobotany, 16(4): 241-250.

Gil García, M.J., Ruiz Zapata, M.B., Vegas, J., García Cortés, A., Galán, L., Ortiz Menéndez, J.E. \& García Rincón, J.M. 2013. Pollen record during the Eemian from the Fuentillejo maar-lake sequence (Ciudad Real, Spain). En: Pollen 2013. 2nd International APLE-APLF Congress. 17-20 Septiembre 2013, Madrid.

González Doncel, I. \& Gil, L. 2013. Dasonomía y práctica forestal. M. Silva Suarez, [Ed.] Técnica e Ingeniería en España. Vol. VII. El Ochocientos. De las profundidades a las alturas. 559-602. Real Academia de Ingenieria. Institucion «Fernando El Catolico» Prensas de la Universidad de Zaragoza, Zaragoza.

González Martínez, S.C., Gerber, S., Cervera, M.T., Martínez-Zapater, J.M., Gil, L. \& Alía, R. 2002. Seed gene flow and fine-scale structure in a Mediterranean pine (Pinus pinaster Ait.) using nuclear microsatellite markers. Theoretical and Applied Genetics 104: 1290-1297.

González Martínez, S.C., Gil, L., Alía, R. 2005. Genetic diversity estimates of Pinus pinaster in the Iberian Peninsula: a comparison of allozymes and quantitative traits. Investigación Agraria: Sistemas y Recursos Forestales, 14: 3-12.

Grau, E., Duque, D.M. \& Cuenca, C. 2004. Paleoambiente y paisaje de La Serena. En A. Rodríguez Díaz (Ed.): El edificio protohistórico de "La Mata" (Campanario, Badajoz) y su estudio territorial. Universidad de Extremadura. Cáceres. 31-62.

He, T., Pausas, J.G., Belcher, C.M., Schwilk, D.W. y Lamont, B.B. 2012. Fire-adapted traits of Pinus arose in the fiery Cretaceous. New Phytologist 194: 751-759. doi: 10.1111/j.14698137.2012.04079.x.

Hevia, P. 2003. El Patrimonio Minero del Valle de Alcudia y Sierra Madrona. (Mancomunidad de Municipios del Valle de Alcudia y Sierra Madrona).Ciudad Real.

Keeley, J.E. 2012. Ecology and evolution of pine life histories. Annals of Forest Science, in Annals of Forest Science, 69: 445-453.

Klein, J. 1979. La Mesta. Alianza Universidad. Madrid.

Kramer, A.T., Havens, K., 2009. Plant conservation genetics in a changing world. Trends in Plant Science, 14 : 599-607. 
Ladero, M., Pérez Chiscano, J.L. \& Amor, A. 1987. La España luso-extremadurense. En: Peinado, M. \& Rivas-Martínez (Eds.): La Vegetación de España. Serv. Publ. Univ. Alcalá de Henares. Madrid. 453-487.

Laguna, M. 1868. Un pedazo de Sierra Morena. Revista Forestal Económica y Agrícola, 1: $437-$ 450.

Laguna, M. 1870. Resumen de los trabajos verificados por la Comisión de la Flora Forestal Española durante los años de 1867 y 1868. Madrid.

López, J.A \& Martínez Robles, F. 1821. Memoria sobre la pertenencia, extensión, cantidad de tierras, población y administración de los Montes de Toledo por el Ayuntamiento de esta Ciudad y sobre el sistema que deberá adoptarse en su repartición y enajenación presentada a Cortes Generales.

López, M.G. \& Soria, M. 1988. (Eds.). El arte rupestre en Sierra Morena Oriental. La Carolina (Jaén).

López Sáez, J.A., López García, P., Cortés Sánchez, M. 2007. Paleovegetación del Cuaternario reciente: Estudio arqueopalinológico. En: Cortés Sánchez M. (Ed), Cueva Bajondillo (Torremolinos). Secuencia cronocultural y paleoambiental del Cuaternario reciente en la Bahía de Málaga. Centro de Ediciones de la Diputación de Málaga, Junta de Andalucía, Universidad de Málaga, Fundación Cueva de Nerja y Fundación Obra Social de Unicaja. Málaga. 139-156.

López Sáez, J.A. \& López García, P. 2005. Análisis palinológicos en el dolmen de Azután (Toledo): una aproximación a los inicios de la agricultura y la ganadería en la Meseta Sur. En: Bueno Ramírez, P., de Balbín, R., Barroso, R. (Eds). El dolmen de Azután (Toledo), Áreas de habitación y áreas funerarias en la cuenca interior del Tajo. Universidad de Alcalá de Henares y Diputación de Toledo, Alcalá de Henares. 225-234.

Luzón, J.M. 1970. Instrumentos mineros de la España Antigua. En La minería Hispana e Iberoamericana. Contribución a su investigación histórica. Vol I. León, Cátedra de San Isidoro. 221-258.

Madoz, P. 1849. Diccionario Geográfico y Estadístico de España. Tomo XIV, 850 pp.

Mallada L., 1892. Catálogo de las especies fósiles encontradas en España. Boletín de la Comisión del Mapa Geológico de España, tomo XVIII, 1-253.

Millar CI (1998) Early evolution of pines. In: Richardson DM (ed). Ecology and biogeography of Pinus. Cambridge University Press, Cambridge. 69-91.

Montserrat, P., Fillat, F. 1990. The systems of grassland management in Spain. En: Breymeyer, A. (Ed.) Managed Grasslands. Elsevier Science Publishers. Amsterdam. Cp 3: 37-70.

Morala, J.R. 2007. El bosque oculto en la palabra. En: Gil, L. \& Torre, M. (Eds.): Atlas forestal de Castilla y León. Tomo I. León. Junta de Castilla y León. 287-308.

Morla, C., Alcalde Olivares, C., Hernández, L., García Antón, M., García, M., García, C., Guerrero, S., Morales, C., Moreno, E., del Nido, J. \& Postigo, J.M. 2009. Investigaciones paleobotánicas en la cuenca central del Duero. $5^{\circ}$ Congreso Forestal Español. SECF, Junta de Castilla y León, Ávila. 1-16. 
Nicolás, A. \& Gandullo, J.M. 1967. Ecología de los pinares españoles. I. Pinus pinaster Ait. IFIE, Ministerio de Agricultura, Madrid.

Nido, J., Gómez Manzaneque, F., Masedo, F., Morla, C., Roig, S. \& Sánchez Hernando L.J., 1998. Identificación de un dendrolito en el Cretácico inferior (Aptiense) del Sistema Ibérico septentrional (La Rioja, España). Consideraciones paleoambientales. Revue Paleobiol. Geneve, 17(2): 513-523.

Nocete, F., Riquelme, J.A., Nieto, J.M., Buxó, R., Queiroz, P., Carrión, J.S., Gil, I. \& Tames, M. 2005. Andévalo. Patrimonio arqueológico. El yacimiento de la Junta de los Ríos. Modelo de recuperación, análisis e interpretación del registro arqueológico en la Presa del Andévalo-Huelva. Ministerio de Medio Ambiente, Dirección General del Agua, Confederación Hidrográfica del Guadiana.

Ojeda Calvo, R. 2006. La Rota del Museo de Huelva: apuntes sobre el origen, adscripción, uso y funcionalidad de una rueda para evacuación de agua hallada en Minas de Riotinto, $L a$ rueda elevadora de agua de las minas de Riotinto: memoria de intervención, $\mathrm{PH}$ Cuadernos, 18 , Sevilla.

Ortega Cotes, I.J. \& Ortega Zuñiga, P. 1762. Bullarium Ordinis Militiae de Calatrava, Antonio Matin. Madrid.

Peinado, M. \& Martínez Parras, J. M., 1985. El paisaje vegetal de Castilla-La Mancha. Junta de Comunidades de Castilla-La Mancha. 230 pp.

Peñalba, M.C. 1985. Estudio esporopolínico del Neógeno occidental de la Cuenca del Guadalquivir. Tesis de licenciatura, Universidad de Salamanca, 198 pp.

Quirós, F. 1965. Sobre geografía agraria del Campo de Calatrava y el Valle de Alcudia. Estudios geográficos. 99: 207-230.

Quirós, F. 1969. La Minería en el Valle de Alcudia y Campo de Calatrava. Estudios Geográficos, XXX, 117. Madrid.

Ramírez Valiente, J.A., Robledo Arnuncio, J.J. 2015. Adaptive consequences of humanmediated introgression for indigenous tree species: the case of a relict Pinus pinaster population. Tree Physiology, 34: 1376-1387.

Real Academia Española. Fuero Juzgo en latín y castellano cotejado con los más antiguos y preciados códices. Madrid. Ibarra. 1815.

Resco, V., Fischer, C. \& Colinas, C. 2007. Climate change effects on mediterranean forests and preventive measures. New forests, 33: 29-40

Richter, K. \& Eckstein, D. 1986. Dendrocronología aplicada en la provincia de Teruel. Primer avance 1985-86. Kalathos, 5-6: 199-210.

Rivas Goday, S. 1950. Una visita geobotánica al valle de Alcudia y Sierra Madrona. Memoria de la Inspección Provincial de Farmacia y Colegio Oficial de Farmacéuticos de Ciudad Real. Ciudad Real.

Rodríguez Trobajo, E. 2006. Material y cronología de las rotae del Museo de Huelva. La rueda elevadora de agua de las minas romanas de Riotinto: memoria de intervención. Sevilla. 4161. 
Rodríguez Ariza, M.O. \& Esquivel J.A. 1989. Una aplicación del análisis de correspondencias en la valoración de antracoanálisis de Los Millares. Cuadernos de Prehistoria de la Universidad de Granada 14-15: 81-108.

Rodríguez Ariza, M.O. 2000. El paisaje vegetal de la Depresión de Vera durante la Prehistoria reciente. Una aproximación desde la antracología. Trabajos de Prehistoria, 57: 145-156.

Rubiales, J.M., García Amorena, I., García Álvarez, S. \& Morla, C. 2008. Anthracological evidence suggests naturalness of Pinus pinaster in inland southwestern Iberia. Plant Ecology, 200: 155-160

Rubiales, J.M., García Amorena, I., Génova, M., Gómez Manzaneque, F. \& Morla, C. 2007. The Holocene history of highland pine forests in a submediterranean mountain: the case of Gredos mountain range (Iberian Central range, Spain). Quaternary Science Reviews, 26, 1759-1770.

Rubiales, J.M., García Amorena, I., Hernández, L., Génova, M., Martínez, F., Gómez, F. \& Morla, C. 2010. Late Quaternary dynamics of pinewoods in the Iberian Mountains. Review of Palaeobotany and Palynology, 162: 476-491.

Ruiz Zapata, M.B., Vegas, J., García Cortés, A, Gil García, M.J., Torres, T., Ortiz, J.E., Galán L. \& Pérez González, A. 2008. Comportamiento de la vegetación durante el último máximo glaciar en la secuencia FU-1 (Laguna del maar de Fuentillejo, Campo de Calatrava, Ciudad Real). Polen, 18: 37-459.

Ruiz Zapata, B., Gil García, M.J. \& de Bustamante, I. 2010. Paleoenvironmental reconstruction of Las Tablas de Daimiel and its evolution during the Quaternary period. En: Sánchez Carrillo, S. \& Angeler, D.G. (Eds.). Ecology of Threatened Semi-Arid Wetlands: Long-Term Research in Las Tablas de Daimiel. Springer XVI: 23-43.

Ruiz Zapata, B., Vegas, J., Gil-García, M.J., Gallardo-Millán, J.L., Galán, L., Ortiz, J.E., Moreno, L., García-Cortés, A. \& Torres, T., 2012. Registro polínico durante el SaalienseEemiense en la secuencia lacustre del maar de Fuentillejo (Ciudad Real). GeoTemas 13, 4 pp.

Ruiz Zapata, M.B., Pérez-González, A., Dorado Valiño, M., Valdeolmillos Rodríguez, A., Bustamante Gutiérrez, I., Gil-García, M.J., 2000. Caracterización climática de las etapas áridas del Pleistoceno Superior en la Región Central Peninsular. Geotemas 1 (4), 273-278.

Salkield , L.U. 1970. Ancient sdlags in the south west of the Iberian peninsula. En: La minería Hispana e Iberoamericana. Contribución a su investigación histórica. Vol I. León, Cátedra de San Isidoro. 85-98.

Salvador, L., Alía, R., Agúndez, D. \& Gil, L. 2000. Genetic variation and migration pathwais of maritime pine (Pinus pinaster Ait.) in the Iberian Peninsula. Theoretical and Applied Genetics. 100 (1): 89-95.

Sánchez Albornoz, C. 1946. La España musulmana. El Ateneo. Buenos Aires.

Sánchez González, R., Rodríguez de Gracia, H. \& Porres de Mateo, J. 1985. Los pueblos de la Provincia de ciudad Real a través de las descripciones del cardenal Lorenzana. Caja de Ahorros de Toledo, 302 pp. 
Sánchez Velázquez, L.R., J. Galindo González \& F. Díaz Fleischer (Eds.). 2008. Ecología, manejo y conservación de los ecosistemas de montaña en México. Comisión Nacional para el Conocimiento y Uso de la Biodiversidad, Universidad Veracruzana. México, D.F.

Sattout, E.J. \& Nemer, N. 2008. Managing climate change effects on relic ecosystems: Applying monitoring program in Lebanese cedar forests. Biodiversity 9 (3 \& 4): 122-130.

Shepherd, R. 1993. Ancient Mining. London and New York: Institution of Mining and Metallurgy by Elsevier Applied Science. Cased. 494 pp.

Solano, E. 1978. La Orden de Calatrava en el siglo XV. Publicaciones de la Universidad de Sevilla, Sevilla.

Tapias R., Gil L., Fuentes Utrilla P. \& Pardos J.A. 2001. Canopy seed banks in mediterranean pines of southeastern Spain. A comparison between Pinus halepensis Mill., P. pinaster Ait., P. pinea L. and P. nigra Arn. Journal of Ecology 89: 629-638.

Tapias, R., Climent, J., Pardos, J.A. \& Gil, L., 2004. Life histories of Mediterranean pines. Plant Ecology 171: 53-68.

Teixeira C., Pais J. 1976. Introdução à paleobotânica. As grandes fases da evolução dos vegetais. Lisboa, 210 pp.

Teixeira, C., 1943. Note sur les argiles à végétaux de Porto-Covo. Com. Serv. Geol. Portugal, XXIV. 1-5.

Teixeira, C., 1944. Pinheiro fóssil do Pliocenico de Rio-Maior. Bol. Soc. Broter. XIX-2a Série ( $1^{\mathrm{a}}$ parte), 201-208.

The Plant List. 2013. Version 1.1. http://www.theplantlist.org/ (visitado el 30-11-2015).

Valdeolmillos, A., 2005. Registro paleoclimático y paleoambiental de los últimos 350.000 años en el Parque Nacional de las Tablas de Daimiel (Ciudad Real). Ph.D. Thesis. Universidad de Alcalá, Alcalá de Henares, 281 pp.

Valdeolmillos, A., Dorado Valiño, M., Ruiz-Zapata, M.B., Bardají, T. \& Bustamante, I., 2003. Paleoclimatic record of the Last Glacial Cycle at Las Tablas de Daimiel National Park (Southern Iberian Meseta, Spain). In: Ruiz-Zapata, M.B., Dorado Valiño, M., Valdeolmillos, A., Gil-García, M.J., Bardají, T., de Bustamante, I., Martínez Mendizábal, I. (Eds.), Quaternary Climatic Changes and Environmental Crises in the Mediterranean Region. Alcalá de Henares, pp. 222-228.

Vegas, J., Ruiz Zapata, M.B., Ortiz, J.E., Galán, L., Torres, T., García Cortés, A., Gil García, M.J., Pérez González, A. \& Gallardo, J.L. 2010. Identification of arid phases duringthe last $50 \mathrm{kyr}$ Cal BP from the Fuentillejo maar lacustrine record (Campo de Calatrava Volcanic Field, Spain). Journal of Quaternary Science, 25 (7): 1051-1062.

Vegas, J., Ruiz Zapata, M.B., Ortiz, J.E., Galán, J., Torres, T., García Cortés, A., Pérez González, A. \& Gallardo, J.L. 2008. Identificación de las principales fases áridas del Pleistoceno superior en el registro sedimentario lacustre del mar de Fuentillejo (Campo de Calatrava). Geotemas, 10: 1467-1470.

Viñas, C. y Paz, R. 1971. Relaciones histórico-geográfico-estadísticas de los pueblos de España hechas por iniciativa de Felipe II: Ciudad Real. Madrid. 
Vose, J.M., Peterson, D.L. \& Patel Weynand, T. (Eds.). 2012. Effects of Climatic Variability and Change on Forest Ecosystems: A Comprehensive Science Synthesis for the U.S. Forest Sector. USDA. Portland. 265 p.

Willyard, A., Syring, J., Gernandt, D.S., Liston, A. \& Cronn, R. 2007. Fossil calibration of molecular divergence infers a moderate mutation rate and recent radiations for Pinus. Mol Biol Evol. 24: 90-101.

Zarzalejos, M. 2011. La investigación arqueológica de los paisajes mineros antiguos en la vertiente norte de Sierra Morena (provincia de Ciudad Real). De Re Metallica, 17: 55-66. 


\section{CAPÍtULOO 4}

\section{ANÁLISIS DEL REGENERADO EN EL PINAR DE NAVALMANZANO: FACTORES LIMITANTES Y PROPUESTAS DE ACTUACIÓN.}

\section{Resumen}

La importancia biogeográfica del pinar de Pinus pinaster Ait. de Navalmanzano se debe a ser el último de una masa de pinares más extensa en el pasado. A pesar de su relevancia para la conservación de los recursos genéticos de esta especie en la península ibérica, no existen estudios previos sobre la regeneración de esta masa. En este capítulo se presentan los trabajos realizados para mejorar el conocimiento y determinar, en su caso, problemas que pudieran comprometer su regeneración.

Para cuantificar la regeneración se procedió, en primer lugar, a la medición de la edad en una muestra de 72 individuos y al conteo del regenerado presente en toda la superficie del monte. A continuación se evaluó la densidad de las especies secundarias del bosque. Se cuantificó el banco aéreo de semillas contando todos los conos presentes en el dosel del pinar (abiertos y cerrados) y se midió la temperatura de apertura en una muestra de 110 conos. Adicionalmente, se estudió -mediante ensayos en laboratorio y en campo- la potencia germinativa de las semillas del pinar de Navalmanzano. Finalmente, se estudió el efecto de la ardilla roja sobre el banco aéreo de semillas contabilizando el número de conos comidos por este esciúrido.

Los resultados muestran una regeneración de 30,2 brinzales/ha de dimensiones inferiores a 2 $\mathrm{cm}$. El número promedio de conos por pie adulto es de 54,5. No obstante, la producción de conos se concentra en 315 individuos (del total de 1212). La proporción de conos maduros, incluyendo los serótinos, es alta (un 53,6\% del total) estimándose unas existencias de 749 conos/ha, con unas 72,4 semillas/cono. En los ensayos de germinación en laboratorio se ha observado que un 64,5\% de las semillas son viables. En un ensayo en campo germinó el $66 \%$. Por todo esto se estima que en 2003 había unas 36.000 semillas viables/ha, cantidad que asegura la regeneración. La temperatura de apertura de los conos serótinos se produce a partir de los $46,5^{\circ}$ C. Los ensayos de germinación en campo muestran diferencia significativas según estén o no protegidas de los herbívoros. En 2005 las ardillas habían consumido un 30\% de los conos cerrados, porcentaje que se eleva al 70\% en 2009.

Los datos muestran un gran potencial de regeneración en producción y capacidad germinativa de las semillas y el regenerado, aunque lentamente, se produce. Sin embargo, el futuro de la masa resulta preocupante por la disminución del banco aéreo de semillas causada por la ardilla. La elevada predación de este sciúrido sobre los conos dificulta -o incluso anula- la capacidad de regeneración del pinar tras un incendio forestal. 


\subsection{Introducción}

\subsubsection{Regeneración natural en masas de Pinus pinaster.}

Los pinares naturales de Pinus pinaster Ait. de Sierra Madrona han sufrido en su historia numerosas perturbaciones por los incendios forestales reiterados originados por los pastores locales. Si los incendios forestales tienen una recurrencia mayor a la natural, incluso especies como P. pinaster, con adaptaciones genéticas al fuego como la serotínia (Tapias et al., 1997; Tapias et al., 2004) acaban desapareciendo en grandes áreas. Su pervivencia solo sería posible sobre litosuelos o en suelos con un espesor edáfico reducido donde la casi inexistencia de vegetación impediría el avance del fuego. En esta especie la diseminación de semillas es de dos tipos: la anual y la retardada respecto a la maduración de la semilla o serotínia (del latín serus, tardío). En este caso, la apertura de los conos se retrasa al menos un año, permaneciendo en el árbol hasta que altas temperaturas los abren, lo que ocurre en todos los conos serótinos como respuesta a un incendio. Tras un fuego, las semillas encuentran un ambiente sin competidores inter e intraespecíficos para el desarrollo de los brinzales (Fig. 4.1)

El estudio de la regeneración se ha efectuado en varias zonas del área de distribución de la especie. Los factores más importantes para el éxito de la regeneración son el volumen del banco aéreo de semillas (Tapias et al., 2001) y la cantidad de semillas dispersas tras el fuego (Gil et al. 1990; Martínez et al. 2002; Martínez-Sánchez et al. 1996; Tapias et al. 1997).

Sin embargo, si la recurrencia de los incendios es inferior a la edad de inicio de la formación de estróbilos femeninos, más la suma de los dos años requeridos para que las semillas maduren, se compromete la persistencia del pinar. La primera floración en $P$. pinaster está descrita a partir de 5 años, siendo menos frecuente a partir de los 4 según Tapias y Gil (2000). Se puede aceptar que habría semilla viable a partir de los 7 años de edad en los pinos más precoces; datos que varían en las diferentes poblaciones y dentro de una población (Martín et al. 1998; Fernandes \& Rigolot 2007). Cuando los intervalos entre incendios son pequeños (periodos de menos de 15 años) conducen a la extinción local del pinar (Alcalde et al. 2004) y al aumento de la erosión por la pérdida de la cobertura arbórea. La frecuencia de los fuegos de origen antrópico explicaría una de las principales causas (si no la principal) de la casi total extinción de los pinares en Sierra Morena.

La regeneración en las masas de $P$. pinaster, sin considerar el incendio forestal, se debe a procesos mal conocidos. En primer lugar, la época y las distancias de dispersión de semillas determinan el éxito de la regeneración y la estructura espacial del regenerado, pero su estudio se reduce a un único pinar poseedor de piñas no serótinas (Juez et al 2014). Además, el transporte de semillas fuera de la influencia del progenitor materno aumenta las probabilidades de germinación y primer desarrollo, reduciendo la competencia del arbolado adulto (González Martínez et al. 2006).

De los factores ambientales, muchos trabajos apuntan a que las lluvias otoñales y primaverales son los más importantes (Rodríguez García et al. 2011a; Gil et al, 2009), lo que ha influido en la apertura de las piñas en dos épocas distintas (Ruiz de la Torre, 2006). Pero la regeneración 
también la condicionan factores como la calidad del suelo (Gandullo et al., 1994; Arduini, et al., 1998; Madrigal et al., 2006; Rodríguez-García et al., 2007, 2011b) y la competencia, junto a la facilitación interespecífica (Madrigal et al. 2005, 2006; Calvo et al. 2006; Rodríguez-García et al. 2007, 2011b). En pinares con adaptaciones similares al de Navalmanzano -con una recurrencia mayor de incendios naturales y alta serotinidad- como el de Tabuyo del Monte (León), las variables que más inciden son la profundidad del suelo (con influencia positiva) y la insolación (influencia negativa) (Vega et al. 2005). En cuanto a la competencia interespecífica, en ambientes poco productivos, como el del pinar de Navalmanzano, no parece ser importante. Estudios realizados en Almazán-Gayubas (Soria) se observó una relación positiva entre la altura del matorral y la densidad de regeneración del pinar de $P$. pinaster (Rodríguez-García et al. 2007).

La mayoría de los estudios sobre regeneración de $P$. pinaster se han realizado en masas que crecen en calidades buenas de estación. Así, Rodríguez Soalleiro et al. (2008) consideran que los tratamientos de regeneración aplicados a la especie dan resultados positivos. Sus trabajos muestran que $P$. pinaster es una especie cuya regeneración natural es fácil por aclareo sucesivo o cortas a hecho. Por el contrario, nuestros conocimientos sobre la regeneración en masas marginales y de peor calidad de estación (como el pinar de Navalmanzano) son muy limitados, por no señalar que inexistentes para nuestros objetivos.

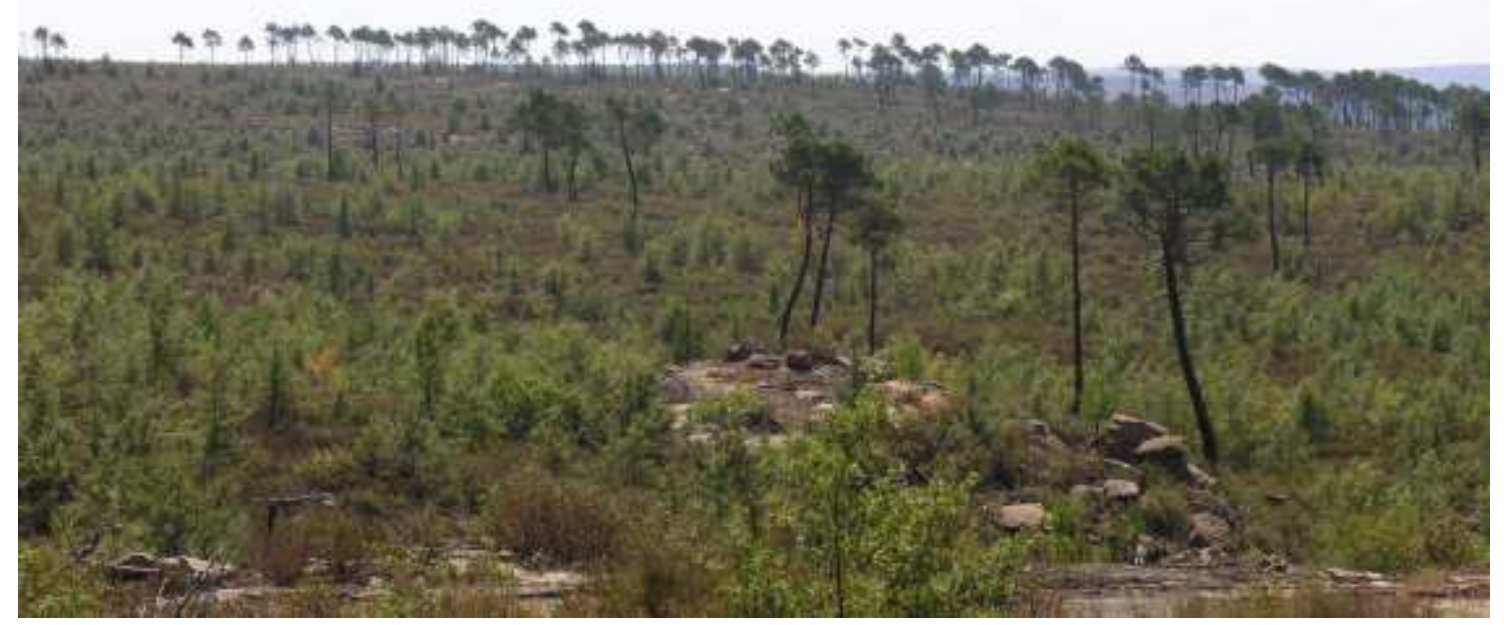

Fig. 4.1. Algunas poblaciones de Pinus pinaster están bien adaptadas al fuego. Aunque en un incendio forestal de copas la mayoría de los árboles muere, el fuego abre los conos serótinos y favorece una extensa regeneración, haya o no árboles vivos. Si además hay supervivientes, estos actuarán en los años siguientes como dispersores de semillas, contribuyendo a una regeneración más eficaz. En la imagen regenerado de $P$. pinaster en Alcolea del Pinar (Guadalajara) 8 años después del incendio de 1997. 


\subsubsection{Impacto de la expansión demográfica de la ardilla roja}

La ardilla roja (Sciurus vulgaris L.) es un esciúrido distribuido ampliamente por Europa y el centro y norte de Asia. En la península Ibérica se han descrito varias subespecies a partir de las definiciones de Cabrera (1905, 1914). S. vulgaris L. subsp infuscatus Cabrera, de gran tamaño, es propia del centro y sur de España y en su área de distribución el autor incluye "Sierra Morena y Valle de Alcudia". Más de 20 años antes la había citado Martínez Reguera (1881) en Sierra Morena oriental. Ambos autores coinciden en que su carne es exquisita y el segundo, además, que se persigue a la ardilla por su piel y especialmente por las cerdas de su cola para brochas, cepillos, etc. Esto último implica persecución directa y una mayor probabilidad de llevarla al borde de la extinción en un hábitat, además deforestado, de Sierra Morena. Las ardillas han sido perseguidas en numerosos países, además de por su carne y piel, por alimentarse de frutos (piñones, almendras, nueces) y cortezas de árboles, cultivados y forestales (Purroy 2014), con el impacto económico que esto acarrea (e.g. Anónimo 1802; Martínez Reguera 1881; Bowles 1920; Hosley 1928). En Escocia, en 1903, se creó un club para reducir las ardillas (Highland Squirrel Club) que eliminó 30.000 ejemplares en sus primeros 30 años (Shorten 1954). Por su persecución directa, la especie desaparece de amplias regiones de Europa. En Portugal ocurrió a finales del siglo XVI (Telles-Antunes 1985).

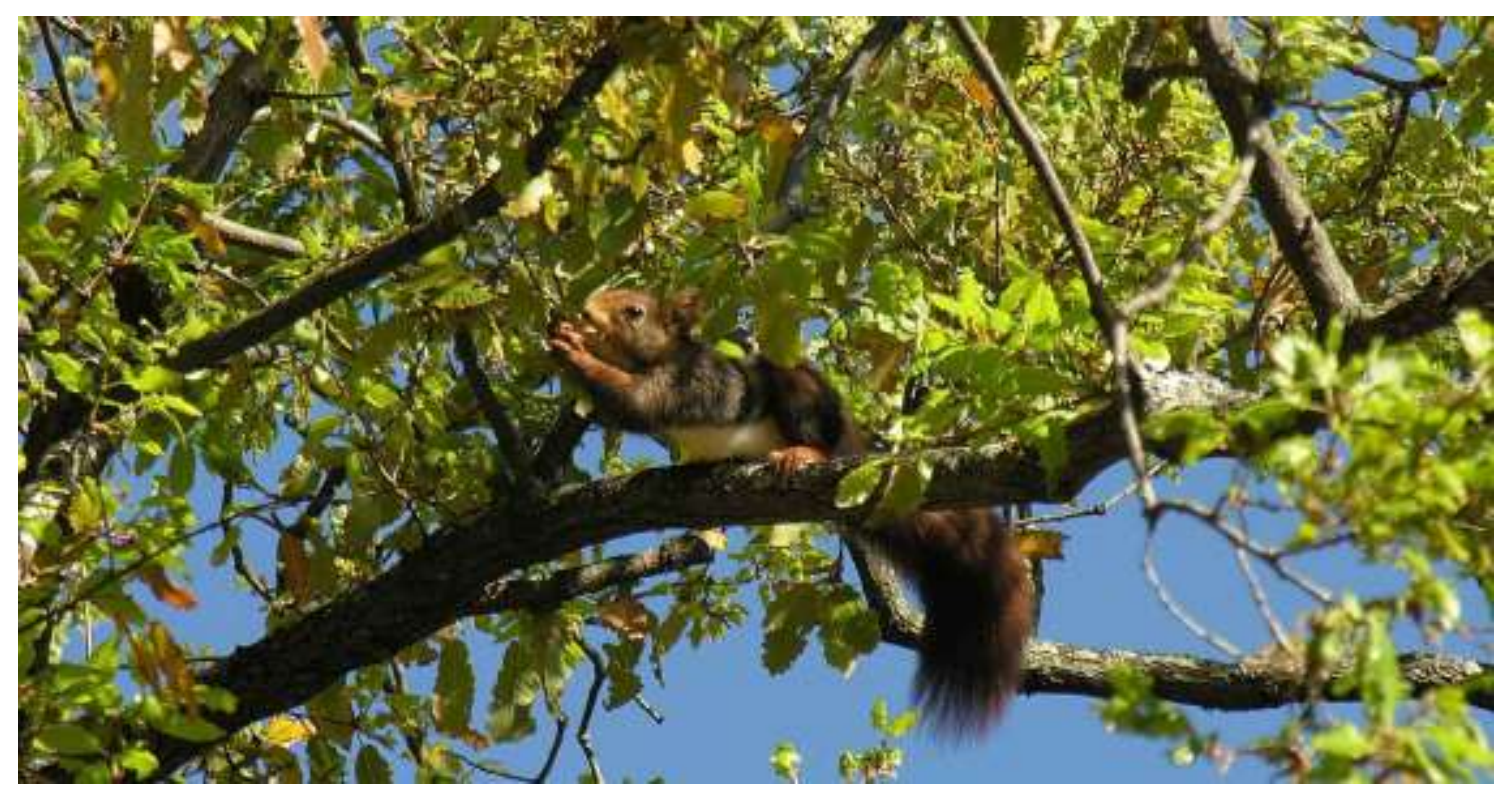

Fig. 4.2. Tras la suelta en 1987 de 28 ardillas en las repoblaciones de pinos de Fuencaliente, estas proliferaron y se extendieron por toda Sierra Madrona. En la imagen, tomada en abril de 2006, una ardilla sobre un quejigo ( $Q$. faginea), abriendo una cecidia, en la umbría de la sierra de Navalmanzano.

A finales del siglo XX, el abandono del medio rural favorece que la especie se recupere de forma natural, pero las simpatías que despierta en las sociedades urbanas promueven sueltas o reintroducciones (Fig. 4.2) hasta devenir en plaga en algunas regiones de Europa occidental (e.g. Holmes 2015). Entre las claves de la expansión de la ardilla destacan las reforestaciones 
con pinos, casi 4.000.000 de ha. en España (MAGRAMA 2015a), hábitat apropiado para la especie (Valverde 1967; Palomares 1988, Peris et al. 1999; Ferreira et al. 2001; Moleón y Gil 2003; Purroy 2014). En la provincia de Ciudad Real, donde los pinares habían casi desaparecido (solo algunos rodales de $P$. pinea en La Mancha) se repoblaron unas 75.000 ha de pinos, más de la mitad (casi 42.000 ha) con $P$. pinaster (MAGRAMA 2015b). En los montes públicos de Fuencaliente, entre los años 1946 y 1965 sumaron un total de 3.953 ha de pinos, casi la totalidad P. pinaster (MAGRAMA 2015b). Dos décadas después, en 1987, el servicio de montes de la Delegación provincial de Medio Ambiente de la provincia soltó 28 ardillas rojas en Fuencaliente, en concreto en Erillas de Cepas, Collado del Brezal (agentes medioambientales com. pers.). En pocos años se extendieron por Sierra Madrona, siendo comunes los avistamientos por toda la sierra al comienzo del siglo XXI. Entre 2001 y 2002 no existían indicios de presencia de ardilla en el pinar de Navalmanzano pero, en 2003, se observa un ejemplar y las primeras piñas comidas en el suelo.

El presente capítulo evalúa el estado actual de la regeneración del pinar de Navalmanzano tras más de 50 años sin incendios forestales. En primer lugar se aproxima la estructura de edades de la masa para evaluar la regeneración. En segundo se cuantifica el banco aéreo de semillas y se estudia la serotínia de los pies adultos. Además, se analiza la germinación para cuantificar el potencial germinativo de las semillas recolectadas en pies adultos. Por último se evalúa la repercusión de la ardilla roja en el pinar y su efecto en el banco aéreo de semillas. El objetivo es comprender los procesos de regeneración en este bosque relicto de Sierra Madrona, evaluar si existen limitaciones y proponer, si procediera, actuaciones que garanticen su conservación.

\subsection{Material y métodos}

\subsubsection{Estructura de edades y estado del regenerado}

Para conocer la estructura de edades de la masa se realizaron 2 tomas de datos. En el año 2002 se midió la edad de 12 de los individuos que superaban los 5,5 metros de altura con el fin de identificar los pinos más viejos. En el año 2015, se seleccionaron al azar 72 pinos entre los 1007 georreferenciados en 2004 (Fig. 4.3), todos de la subpoblación occidental del pinar. La edad se midió con una barrena de Pressler en los individuos cuya dimensión lo permitía. Los anillos de crecimiento se determinaron por conteo visual directo, salvo en algunas muestras que por su mayor dificultad hubo que recurrir a macrofotografía que posteriormente se analizaba en el ordenador. Los pies en los que por su pequeño tamaño no fue posible usar la barrena, la edad se estudió contando los anillos sobre la sección basal en laboratorio.

Para conocer la regeneración del pinar, durante el inventario de 2003, se registraron los individuos con tallo leñoso y diámetro basal inferior a $2 \mathrm{~cm}$, así como los brinzales con tallo sin lignificar (entre uno y dos años de edad).

La competencia interespecífica se cuantificó mediante el conteo de la especie arbustiva de mayor porte y presencia (Juniperus oxycedrus L.) y de las 4 especies arbóreas presentes en el 
área del pinar (Quercus ilex L., $Q$. suber L, Q. faginea Lam. y $Q$. pyrenaica Wild.). Para ello se valoró la presencia de estas especies por hectárea en toda la superficie del pinar.

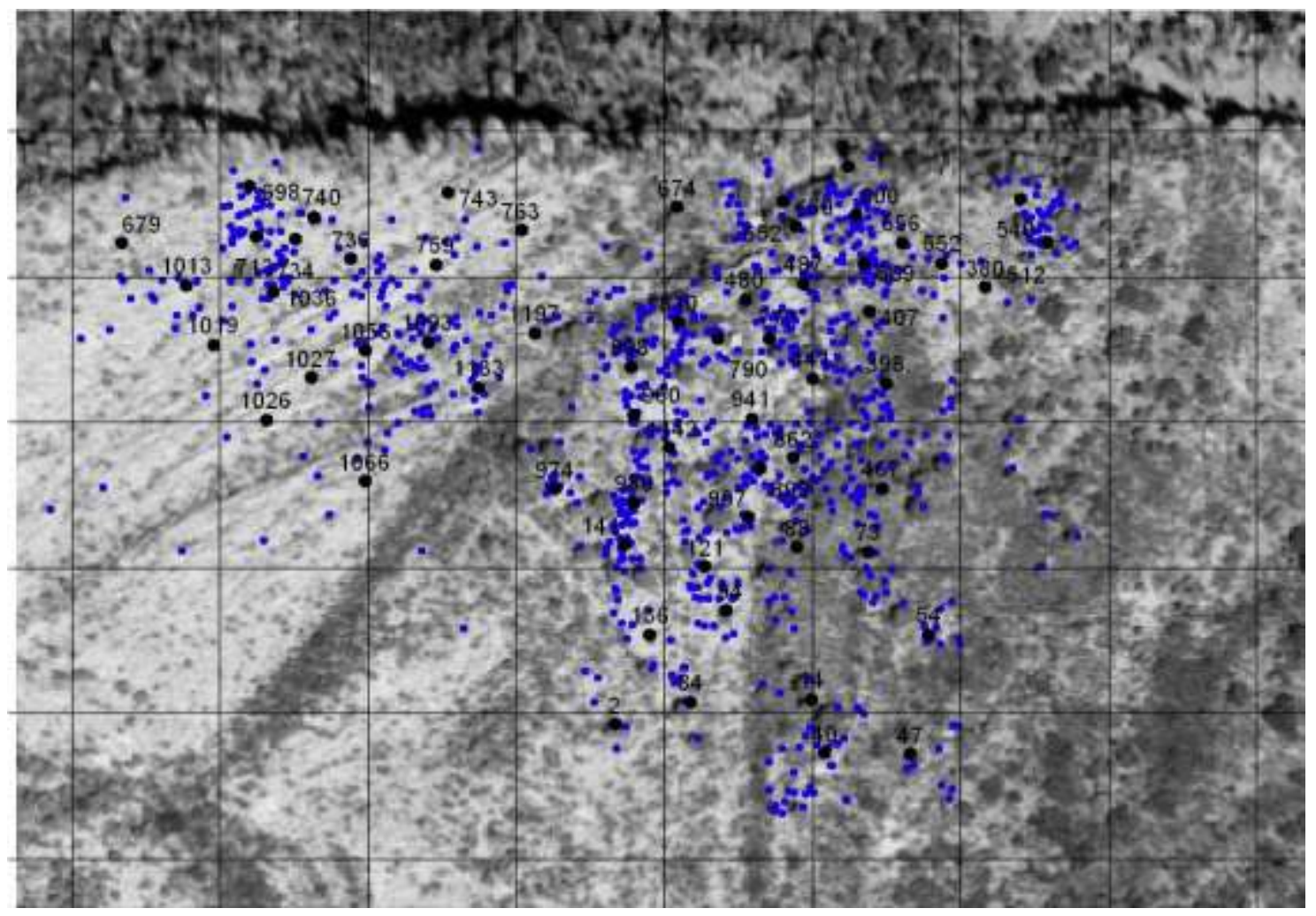

Fig. 4.3. Localización de los 72 pinos (puntos negros), entre los 1007 pinos (puntos azules) de la subpoblación occidental del pinar de Navalmanzano, seleccionados para medirles la edad en 2015.

\subsubsection{Evaluación del banco aéreo de semillas y obtención de piñones.}

En los muestreos de 2002 y 2009 se contaron los conos en cada pino por una sola persona. Cuando su altura destacaba o poseía un elevado número de conos (más de 50) el conteo lo realizaron 2 personas que contrastaron sus datos y sí las diferencias eran significativas se volvían a contar hasta consenso. En cada árbol se diferenciaron la presencia en la copa de piñas abiertas y cerradas

En el año 2002 se seleccionaron 10 árboles entre los más productores de conos del pinar, se recolectaron 100 conos (10 conos/árbol), se abrieron y se les extrajo las semillas.

Posteriormente en el año 2009, se realizó un segundo inventario en 10 parcelas circulares de 15 $\mathrm{m}$ de radio. El centro de las parcelas se hizo coincidir con el centro de las cuadrículas UTM de 50 m de lado de las columnas F y H (Fig. 4.4). En todos los árboles localizados en el interior de estas parcelas se contó el número de conos totales presentes así como el número de conos cerrados. 


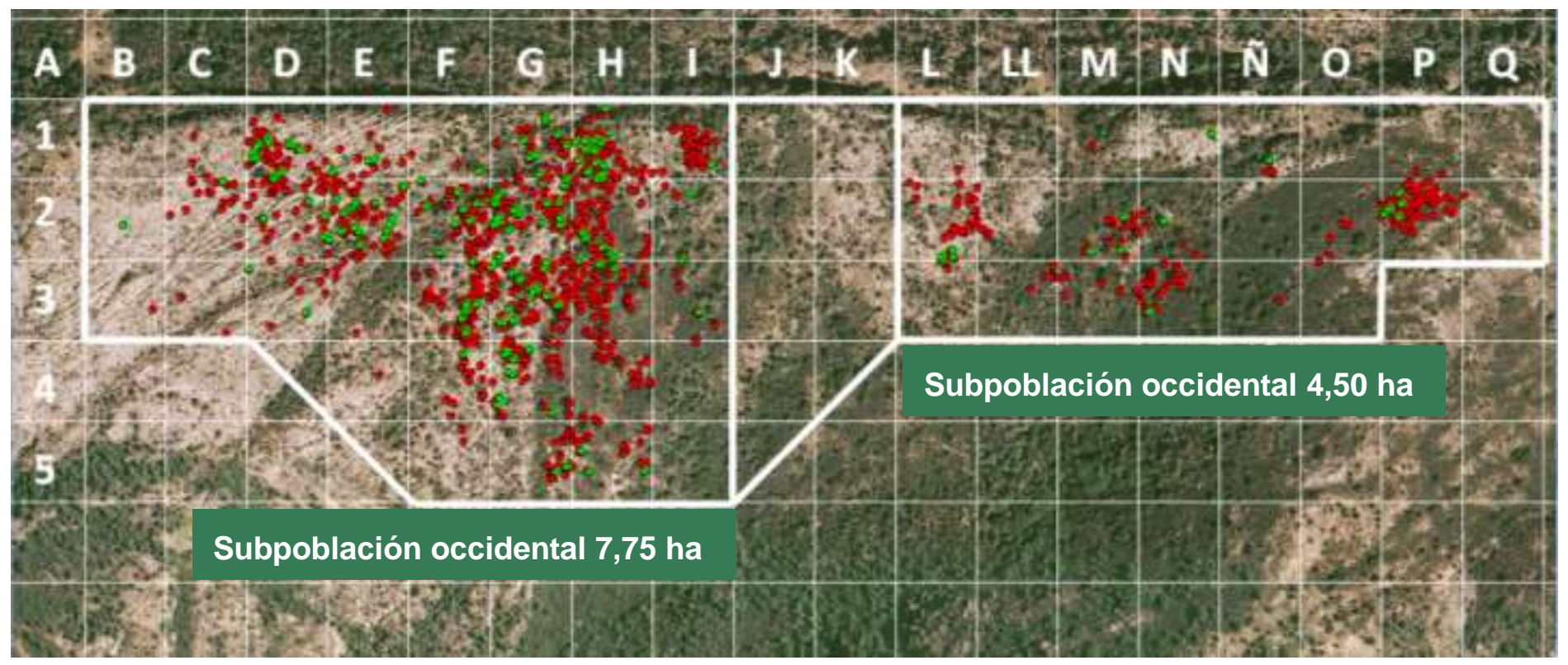

Fig. 4.4. Distribución de los pinos de la sierra de Navalmanzano (puntos rojos) y el regenerado observado (pies leñosos con diámetro basal $<2 \mathrm{~cm}$, puntos verdes). Cuadrículas de $50 \mathrm{~m}$ de lado $\left(2500 \mathrm{~m}^{2}\right)$.

\subsubsection{Determinación de la temperatura de apertura de las escamas}

Para determinar la temperatura de apertura de las escamas seminíferas se realizaron 2 ensayos en 2002 y 2005. En el primero se usaron las 100 piñas citadas de 10 de los pinos más productores. Para ello, se sumergieron en agua templada $\left(20^{\circ} \mathrm{C}\right)$ elevando la temperatura hasta conseguir la ruptura del sellado de las escamas por la aparición de una burbuja de aire y un sonido característico y se anotaba la temperatura de apertura de cada cono.

En 2005, 10 piñas procedentes de 10 pinos elegidos al azar se introdujeron en una estufa eléctrica marca Memert de $900 \mathrm{w}$, aumentando progresivamente la temperatura desde los $18^{\circ} \mathrm{C}$ hasta $\operatorname{los} 50^{\circ} \mathrm{C}$.

\subsubsection{Ensayos de germinación en campo y laboratorio}

De las semillas extraídas en 2002 se separaron las vanas y se dispusieron en bandejas para el seguimiento de su germinación en campo. Las semillas previamente a la siembra, realizada el 8 de octubre del 2002, se pregerminaron mediante su inmersión en agua destilada durante 48 horas y, a continuación, se dividieron en dos grupos para realizar la siembra en el campo:

1. La mitad de las semillas se depositaron en bandejas (llamadas "NP", no protegidas) de PVC rellenas con tierra del lugar y depositadas entre los matorrales, semienterradas, de modo que la parte superior de las bandejas y las semillas quedaban próximas a la superficie del suelo. Las semillas y, posteriormente, las plántulas, quedaron expuestas a los agentes bióticos o abióticos. 
2. La otra mitad de las semillas (denominadas "P”, protegidas) se depositaron en otras tantas bandejas con igual tipo de sustrato, pero en el interior de un vallado de exclusión para ungulados (Tabla 4.1) y protegidas individualmente por una malla mosquitera que impidiera el acceso y la depredación por micromamíferos, aves, reptiles, insectos y otros invertebrados de mediano y gran tamaño.

\begin{tabular}{|l|c|}
\hline \multicolumn{2}{|c|}{ Características del vallado } \\
\hline $\mathrm{N}^{\mathrm{o}}$ de metros de lado & $10 \mathrm{~m}$ \\
\hline Superficie cercada & $100 \mathrm{~m}^{2}$ \\
\hline Altura de la malla & $1,50 \mathrm{~m}$ \\
\hline Alambre guía & $2,7 \mathrm{~mm}$ \\
\hline Puerta & Galvanizada de $1 \times 1,50 \mathrm{~m}$ \\
\hline
\end{tabular}

Tabla 4.1. Características del vallado de exclusión de ungulados instalado en la parcela de experimentación

Las semillas de los 2 tratamientos se distribuyeron en 2 lugares del pinar separados por unos 20 m. La altitud, la exposición al sur y su disposición fueron similares.

Se instaló un termómetro de temperaturas máximas y mínimas durante todo el periodo de seguimiento. El termómetro se dispuso a ras de suelo y protegido de la luz solar directa. Posteriormente se haría un seguimiento de la germinación de las semillas cada 7 días. El grupo de bandejas $\mathrm{P}$ se situó dentro del vallado de exclusión de ungulados. Este vallado, además protegía a 5 jóvenes pies de $P$. pinaster preexistentes.

En las semillas extraídas en 2005, para el segundo estudio de la temperatura de apertura de las piñas, se eliminaron las vanas y se utilizaron en un $2^{\circ}$ ensayo de germinación. La siembra se realizó el 20 de octubre de 2005. Previamente, se depositaron en un recipiente con agua durante 48 horas $\mathrm{y}$, posteriormente, 20 minutos en una suspensión líquida de CAPTAN 2\%. Las semillas se dispusieron en bandejas de aluminio de 0,5 1. con un sustrato de perlita. Bandejas y perlita previamente fueron esterilizadas en autoclave durante 20 minutos a $120^{\circ} \mathrm{C}$. Las bandejas se introdujeron en una cámara de cultivo marca «Ibercex« de $6 \mathrm{~m}^{3}$, una temperatura de $20^{\circ} \mathrm{C}$, humedad del $70 \%$ y un fotoperiodo de $12 \mathrm{~h}$ diarias, con una intensidad lumínica de $125 \mu \mathrm{mol}$. $\mathrm{m}^{2} \cdot \mathrm{s}^{-1}$. Se fumigaron 2 veces/semana con CAPTAN $2 \%$ ó TIRAM $2 \%$, alternativamente.

\subsubsection{Influencia de la ardilla en el banco aéreo de semillas}

En marzo de 2005 se realizó un conteo de las piñas consumidas por la ardilla. El conteo se realizó en cinco cuadrículas: E-1, G-3, I-3, LL-2 y P-2 (Fig. 4.4). Se anotó, cuando los había, el número de conos comidos por las ardillas que aparecían en la base de cada pino o en su entorno inmediato. De haber tangencia de copas de dos o más pinos el cono comido se asignaba al pie más cercano. 


\subsection{Resultados}

\subsubsection{Estructura de edades y estado del regenerado}

En la Tabla 2 se presentan los datos de edad y altura de 12 pinos, elegidos entre los mayores árboles del pinar. El individuo de mayor edad tiene 127 años, una altura de $8 \mathrm{~m}$ y 0,37 $\mathrm{m}$ de diámetro a la altura del pecho (DAP), mientras que la media de los pies muestreados es de 64,2 años. Algunos árboles, localizados en suelos más desarrollados, superan los $10 \mathrm{~m}$ de altura con edades superiores a los 27 años (Fig. 4.5), presentando un crecimiento que tiene como asíntota en los de mayor edad los $11 \mathrm{~m}$. Por el contrario los pinos rupícolas muestran crecimientos más pequeños, pese a contar con edades que superan los 70 años. El árbol de mayor altura mide 8,5 $\mathrm{m}$, tiene un DAP de 0,40 m. y una edad de 79 años en 2002.

\begin{tabular}{|c|c|c|c|c|}
\hline \multicolumn{5}{|c|}{ Edad y altura de 12 de los mayores pinos } \\
\hline & Mínima & Mediana & Media & Máxima \\
\hline Edad (años) & 26 & 65,5 & 64,2 & 127 \\
\hline Altura (m) & 5,5 & 8,3 & 8,3 & 11 \\
\hline
\end{tabular}

Tabla 4.2. Resumen de los datos de edad y altura obtenidos sobre 12 de los mayores árboles del pinar de Navalmanzano estudiados en 2002.

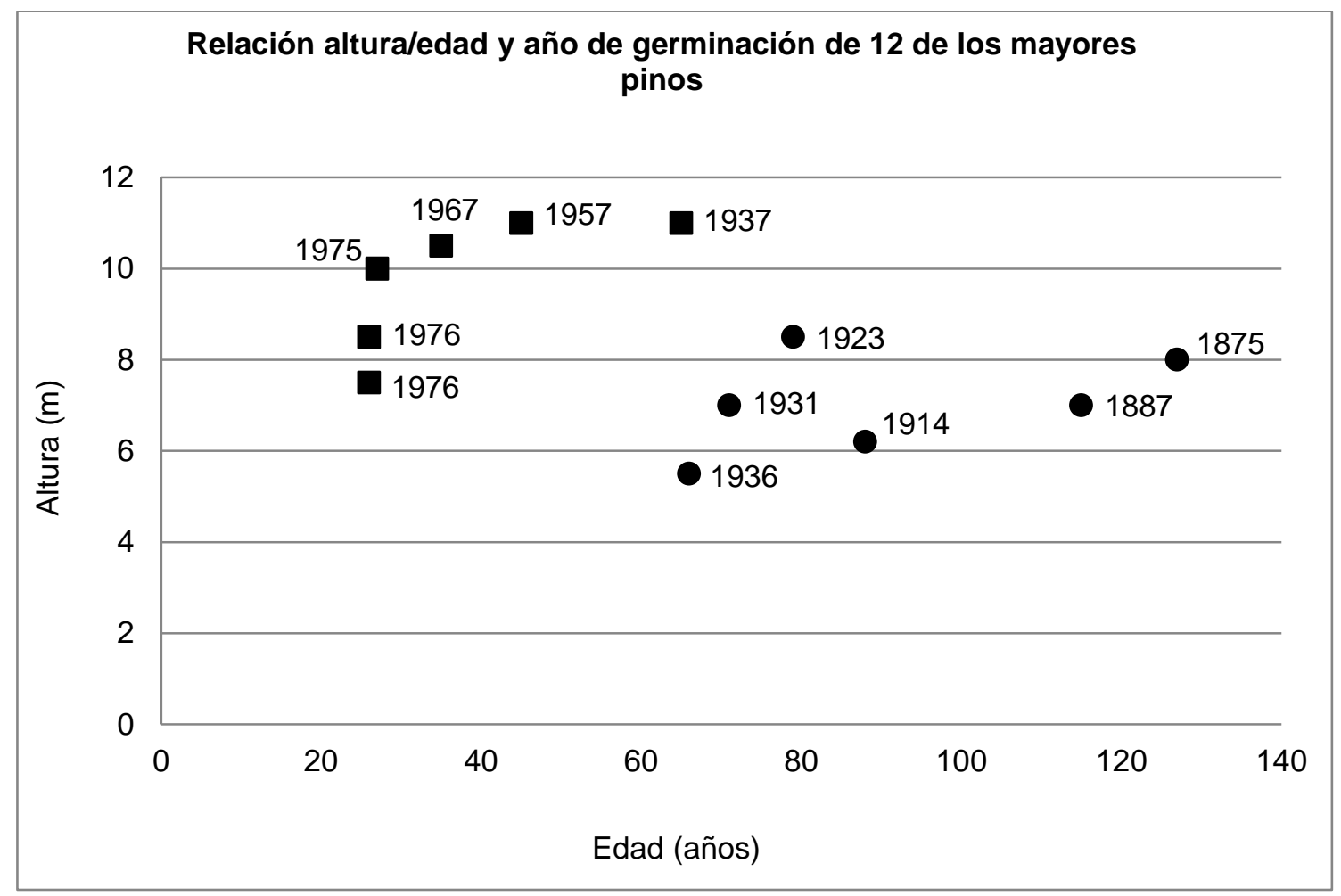

Fig. 4.5. Relación entre la altura y la edad de 12 de los mayores árboles del pinar de Navalmanzano. Cuadrados: pies sobre suelos desarrollados; círculos: pinos sobre roquedos (rupícolas). 


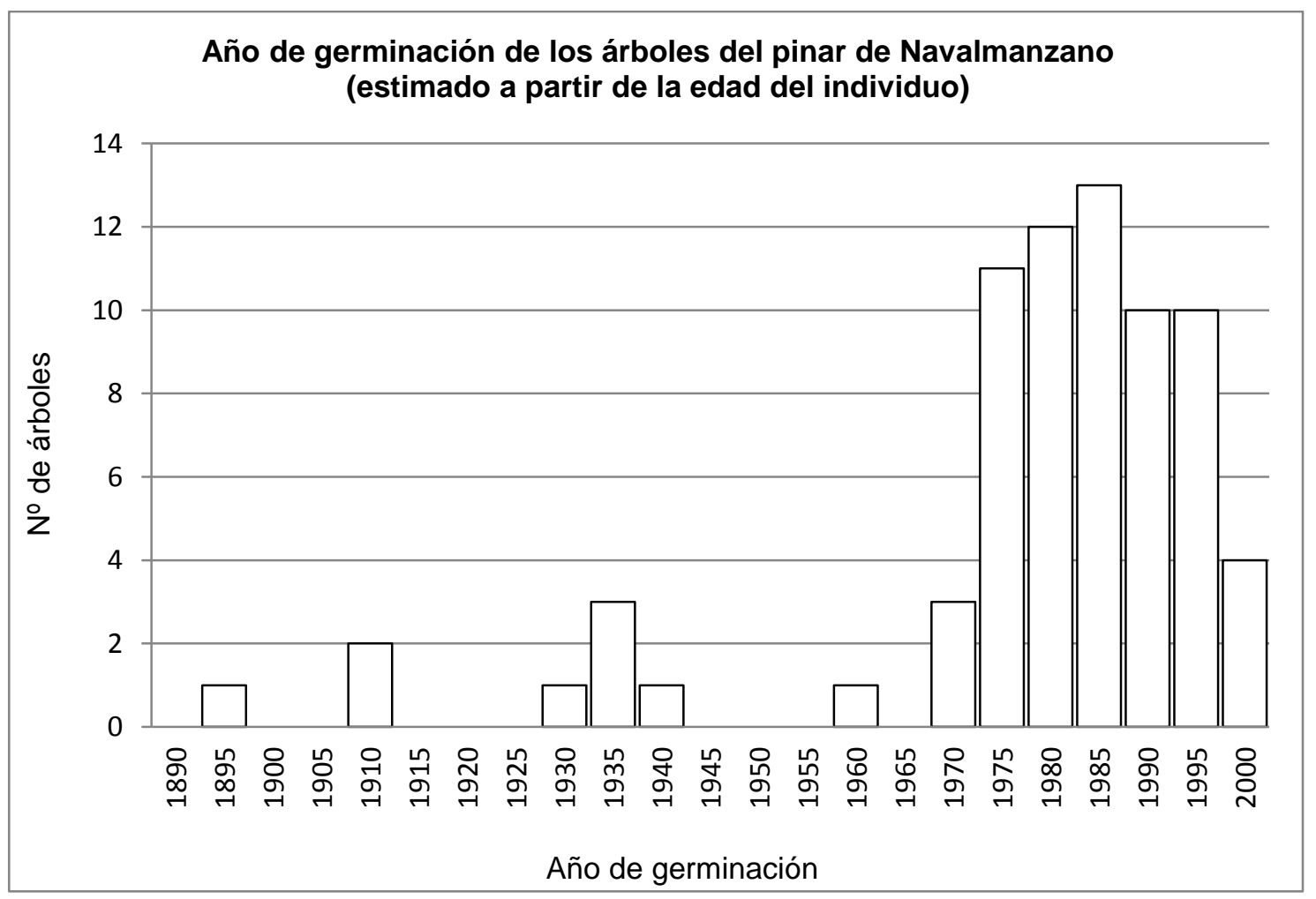

Fig. 4.6. Histograma de frecuencias de incorporación de los 72 árboles seleccionados, a los que se midió la edad.

En 2015, los datos de edad de los 72 pinos estudiados permiten ver un histograma la estructura de la regeneración del pinar durante el último siglo (Fig. 4.6). El 84,7\% de los individuos estudiados nacieron entre los años 1970 y 2000, mientras que los individuos nacidos antes del 1960 (9 pinos), son una fracción reducida de la muestra. El pino más viejo de los medidos nació en 1895, teniendo unas dimensiones actuales de $8 \mathrm{~m}$, diámetro en la base $0,54 \mathrm{~m}$ y DAP $0,37 \mathrm{~m}$.

Durante la ejecución del inventario en 2003 se contabilizaron 1212 pies, lo que supone 98,94 pies/ha. De estos, 226 tenían ya tallo lignificado pero diámetro basal aún inferior a $2 \mathrm{~cm}$. Esto supone una densidad de 18,45 pies/ha, distribuidos de forma más o menos homogénea por todo el pinar (Fig. 4.4). Las plántulas más jóvenes, de hasta unos 2 años, con tallo aún poco leñoso aparecen dispersas por el pinar en número más reducido, lo que dificultaba su observación. En total se contaron 193 plántulas (15,75 plántulas/ha).

En la Fig. 4.7 se presentan los resultados del inventario de las especies acompañantes. La especie más común es el enebro (J. oxycedrus) con una densidad de $141 \mathrm{pies} / \mathrm{ha}$, siendo la práctica totalidad pies de escaso porte. La densidad de la encina ( $Q$. ilex) es menor que la del enebro (58 pies/ha) y, salvo excepciones, son pequeños rebrotes de cepa, por lo que su cobertura es mínima. Menor aún es la presencia del alcornoque ( $Q$. suber) pero con pies de porte más o menos arbóreo. Los robles ( $Q$. faginea y $Q$. pyrenaica) estan presentes de forma muy puntual, con algunos pies jóvenes, esbeltos. 


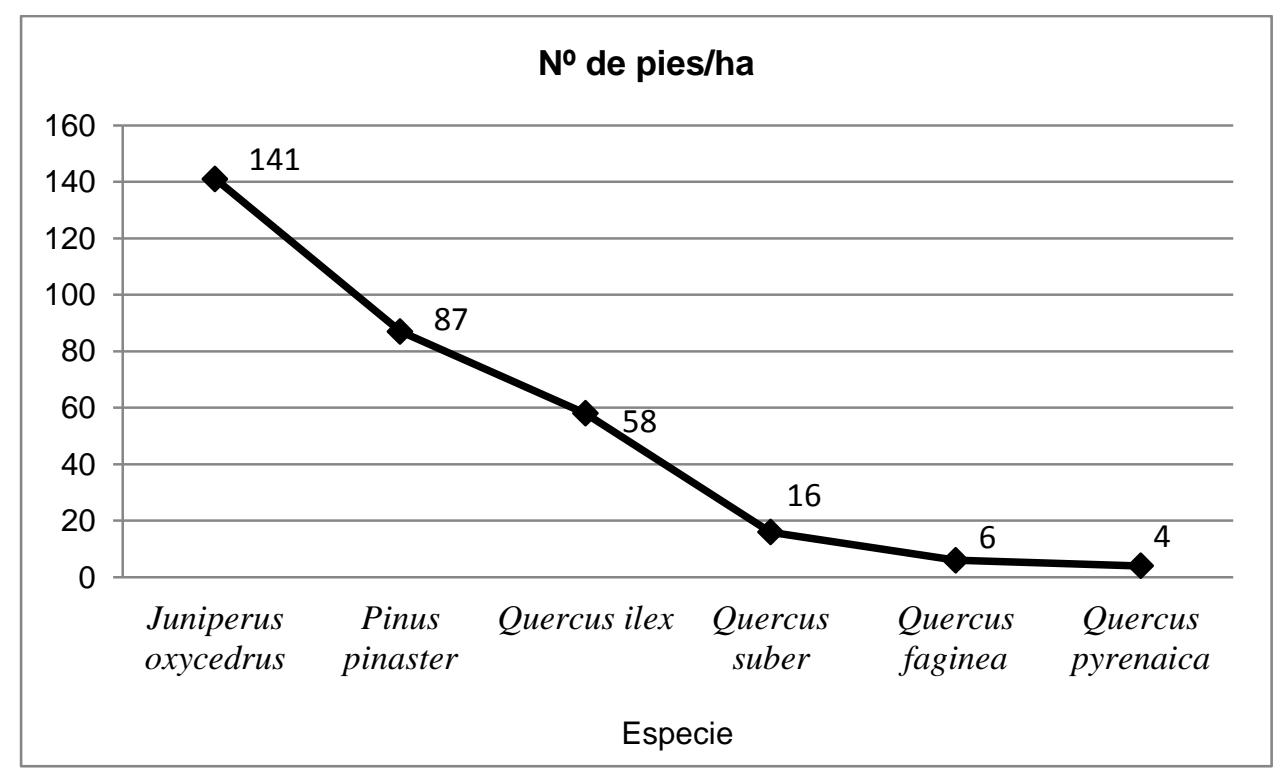

Fig. 4.7. Densidad aproximada de las especies arbóreas que aparecen en el pinar.

\subsubsection{Evaluación del banco aéreo de semillas}

El número total de piñas en las copas en 2003 fue de 17.188. La producción se concentró en 315 árboles que, a excepción de 4 pies, todos superan $1 \mathrm{~m}$ de altura. El porcentaje de árboles con conos respecto al total de pies (1212) es del 26\%. Los conos cerrados sumaban $9.176(53,6 \%)$ dato que implica una existencia media de 749 conos cerrados/ha. La distribución de los conos entre los 315 árboles productores, se recoge en la tabla 4.3 y la Fig. 4.8.

\begin{tabular}{|c|c|c|}
\hline \multicolumn{3}{|c|}{ Distribución del $\mathbf{n}^{\mathbf{0}}$ de conos en los $\mathbf{3 1 5}$ pinos } \\
\hline $\begin{array}{c}\text { Parámetros } \\
\text { estadísticos }\end{array}$ & $\begin{array}{c}\mathrm{N}^{\mathbf{o}} \text { conos } \\
\text { totales/pino }\end{array}$ & $\begin{array}{c}\mathrm{N}^{\mathbf{o}} \text { conos } \\
\text { cerrados/pino }\end{array}$ \\
\hline Mínimo & 1 & 0 \\
\hline $1^{\text {o }}$ Cuartil & 5 & 3 \\
\hline Mediana & 16 & 10 \\
\hline Media & 54,56 & 29,13 \\
\hline $3^{\circ}$ Cuartil & 60,5 & 31 \\
\hline Máximo & 587 & 587 \\
\hline Desv. estándar & 90,99 & 56,92 \\
\hline
\end{tabular}

Tabla 4.3. Distribución del número de conos totales y cerrados en los 315 pinos productores. Se muestra sobre el valor total de conos por pino y sobre el valor de conos cerrados por pino.

El pino que ha producido 587 conos, todos cerrados (Tabla 3), es el árbol 716 (situado en la cuadrícula D1, Fig. 4.4), un pino rupícola de $7 \mathrm{~m}$ de altura y 47,75 $\mathrm{cm}$ de DAP (verlo en relación al hábitat y demás pinos en la Fig. 4.13). Los 121 pinos rupícolas con conos cerrados poseen un total de 7.497 conos, de los que en 2003 permanecían cerrados 3.709. Por lo que las 
piñas del árbol 716 suponen el 15,8\% de todas las piñas. En la zona rupícola se localizan 7 pinos, incluido el anterior, con más de 100 conos cerrados/pino y un total de 1.467 piñas cerradas, lo que supone el 39,6\% del banco aéreo en la zona de roquedo de la subpoblación occidental.
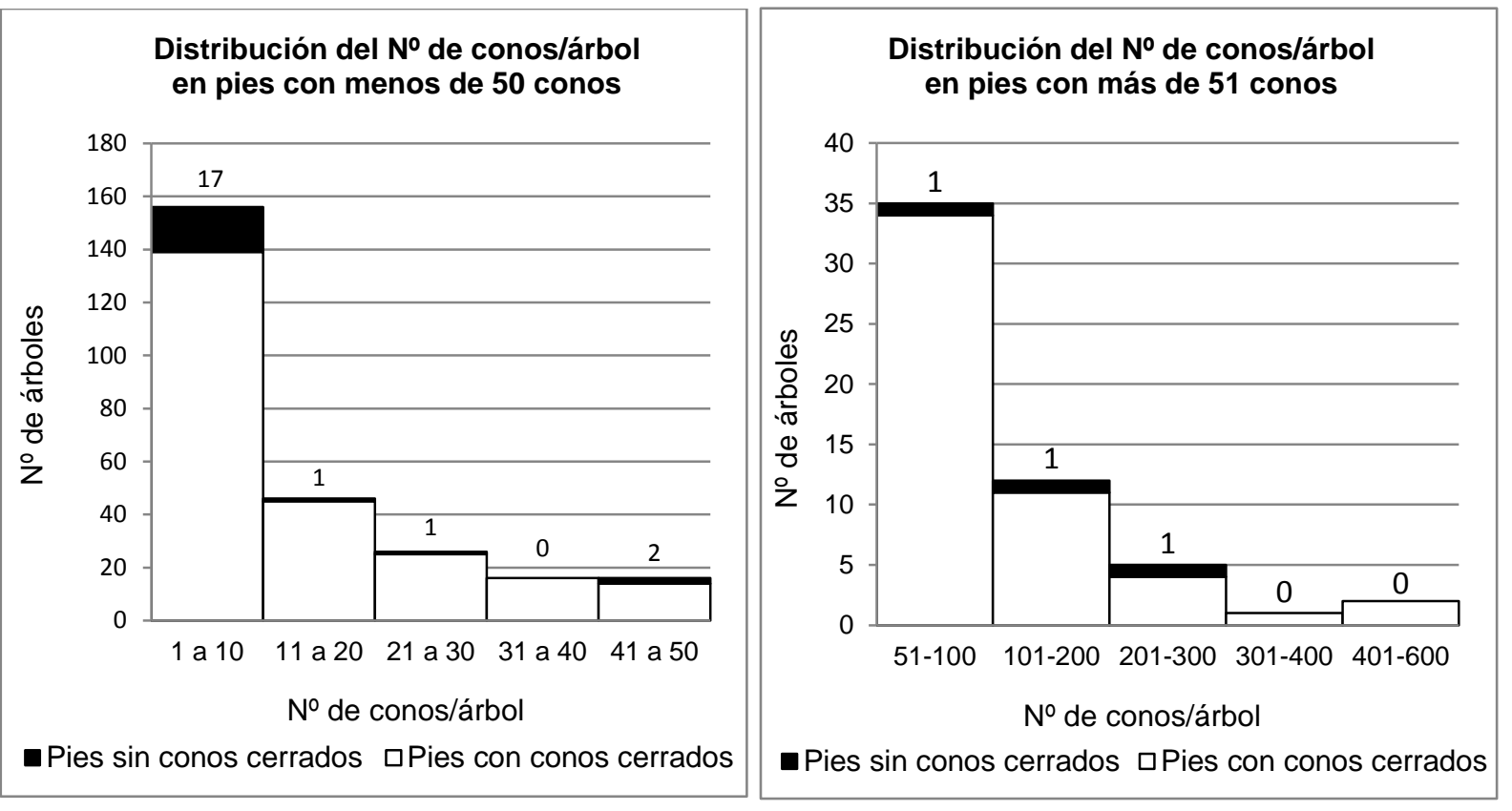

Fig. 4.8. Distribución del $\mathrm{n}^{\circ}$ de conos por pino en los 315 pies con piñas, por categorías de la producción total (abiertos más cerrados): de 1 a 50 conos (Izda) y de 51 a 600 conos (Dcha.) En cada columna se reflejan los 24 pinos que tenían todas sus piñas maduras abiertas

De los 315 pinos productores, solo una porción muy reducida de 24 pinos $(7,6 \%)$ pueden calificarse como no serótinos (Fig, 4.8), pues todas sus piñas estaban abiertas, además de ser escasamente productores pues la parte más numerosa presentaba menos de 11 piñas por árbol. Destacan dos ejemplares como más productores, por presentar entre 401 y 600 piñas.

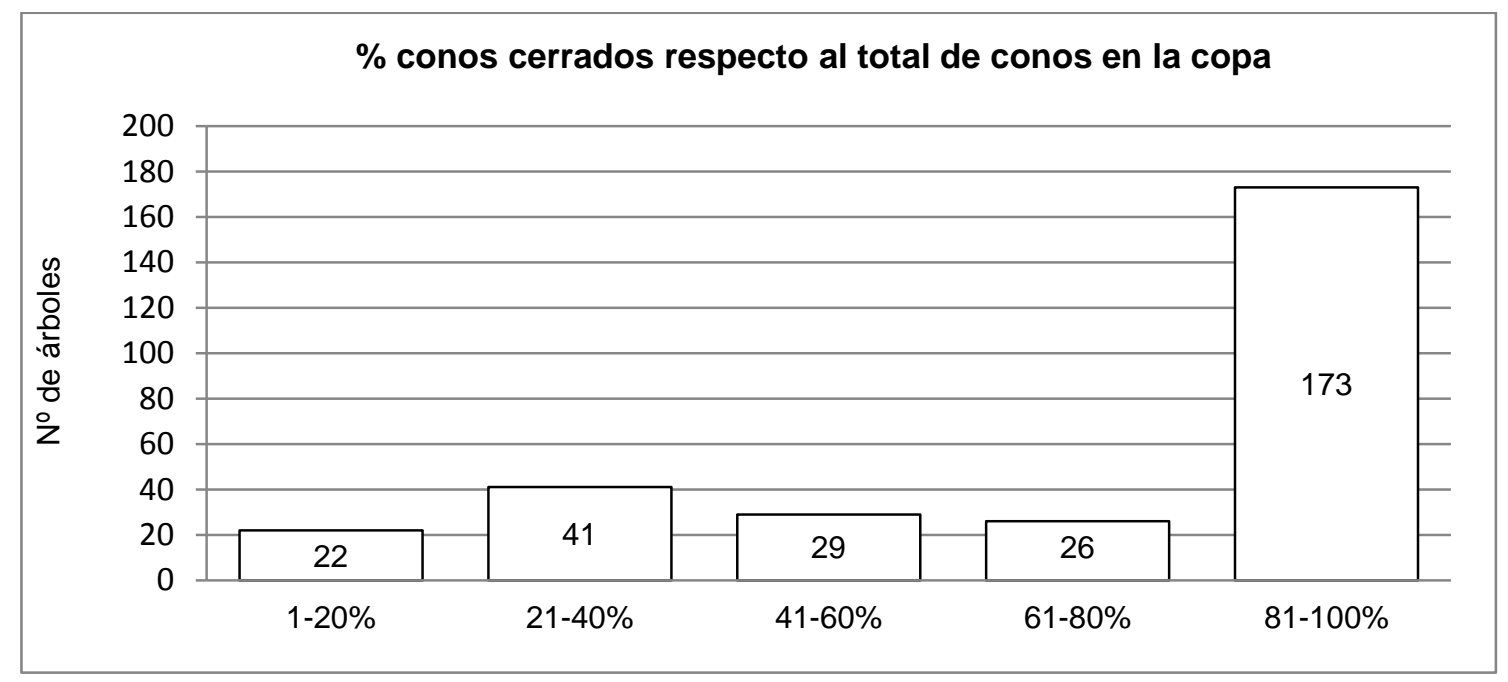

Fig. 4.9. Porcentaje de conos cerrados con respecto al total de los pinos que poseían conos cerrados y abiertos en la copa; desglosado por categorías. 
En 170 árboles de los 315 con conos (54\% de los que fructifican) todos los conos presentes en sus ramas estaban cerrados. La presencia de conos cerrados en las copas domina en esta población, pues el 54,9\% de los pinos productores de piñas tenían en sus copas más del $80 \%$ de sus 5.431 conos cerrados (Fig. 4.9).

Estas 5.431 piñas suponen el 59,2\% del total de las piñas cerradas. Entre estos árboles los hay que tienen desde un solo cono cerrado (26 pinos), 2 cerrados (15), 3 cerrados (11), entre 11 y 30 (45 pinos) hasta la cantidad máxima de 587 conos que poseía un único árbol. En general, los pinos poco productores de piñas son los que poseen los menores porcentajes de conos cerrados sobre el total de piñas, que nunca superan el 55\% (Fig. 4.11). Por el contrario en los que más fructifican el porcentaje de conos cerrados es siempre superior al 50\% (Fig. 4.12).

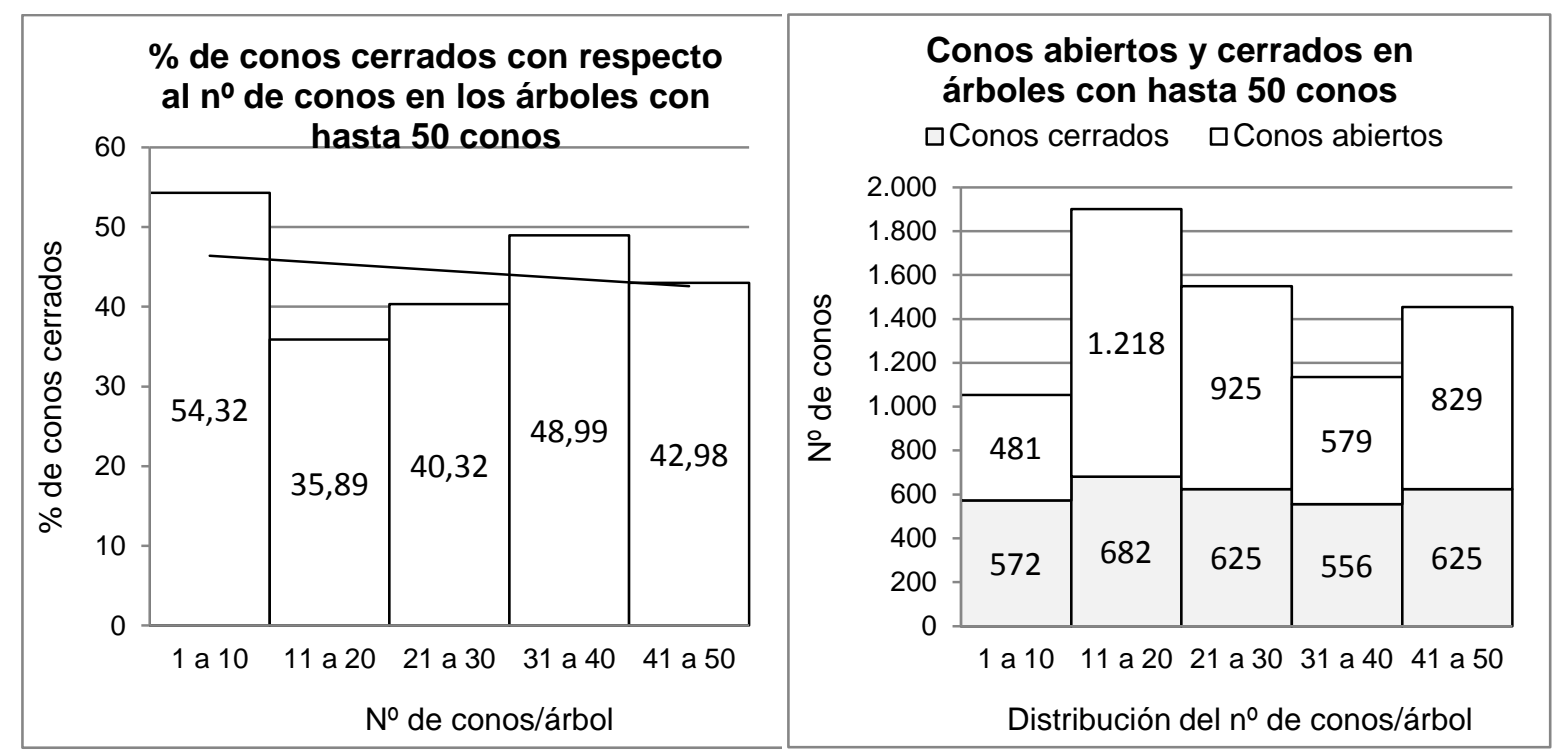

Fig. 4.11. Distribución del número de conos abiertos respecto al total por árbol desglosado por categorías de 1 a 50 conos por pino.

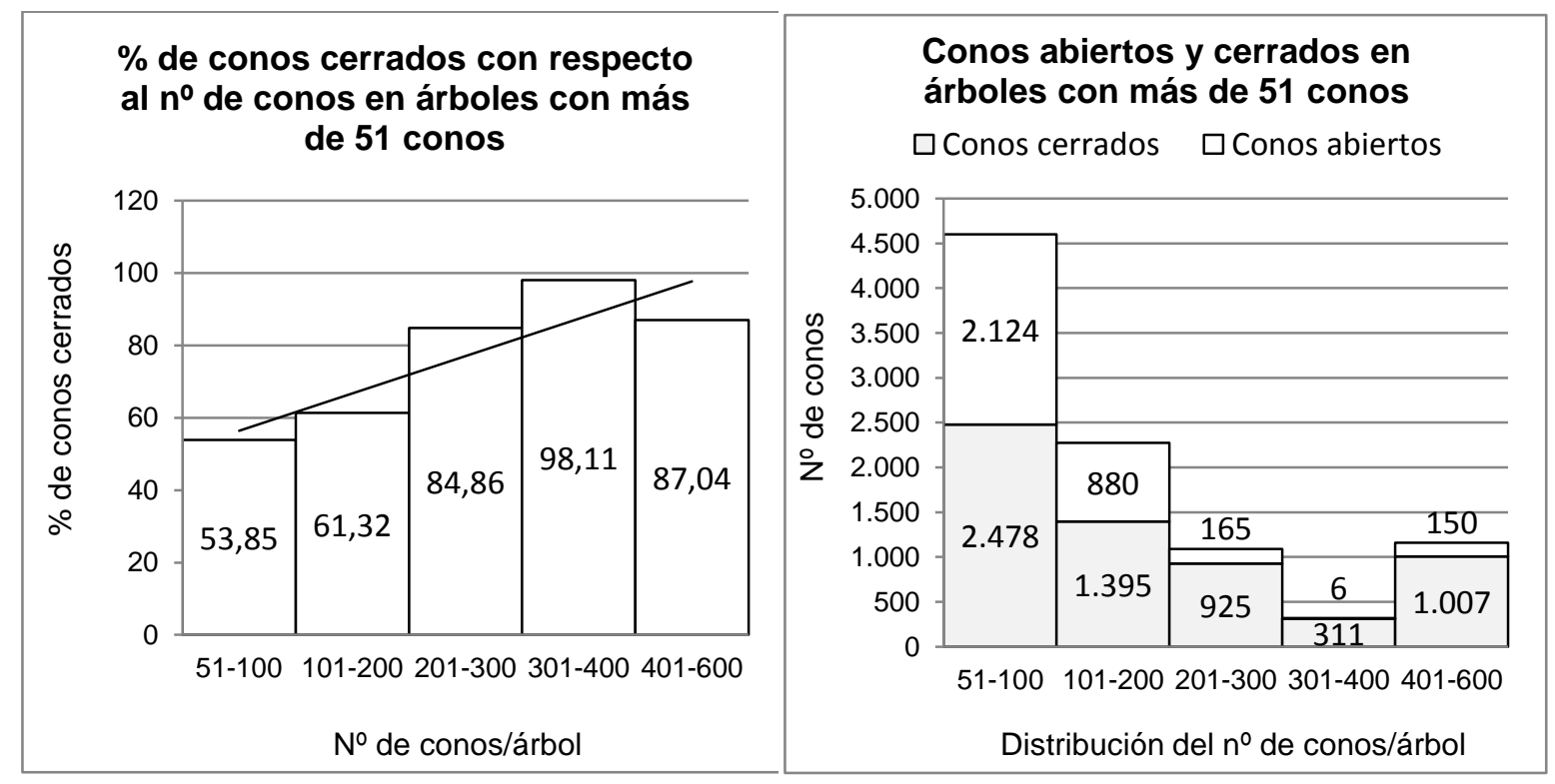

Fig. 4.12. Distribución del número de conos abiertos respecto al total por árbol desglosado por categorías por categorías de más de 51 conos por pino. 
Entre los conos cerrados se han encontrado algunos con más de 40 años. Se abrió uno de ellos (Fig. 4.10), se sembraron 10 semillas en una maceta con tierra local y 4 germinaron.

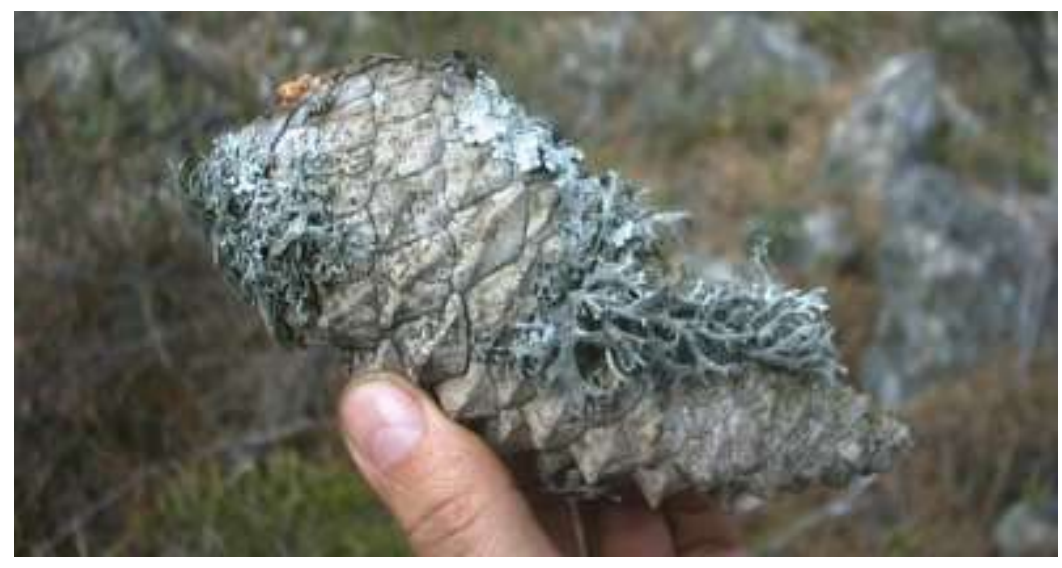

Fig. 4.10. Los conos serótinos suponen un porcentaje importantes de los presentes en las copas. En la imagen un cono maduro de más de 40 años que no ha dispersado las semillas aún viables de su interior.

La distribución espacial de los pies con piñas no parece mostrar patrones de agregación, localizándose de forma más o menos homogénea por todo el pinar. En las zonas más rocosas (las de color más claro en la Fig. 4.13, aparecen cuatro cuadrículas donde todos carecen de piñas pero esto se debe a que esos pinos son muy jóvenes.

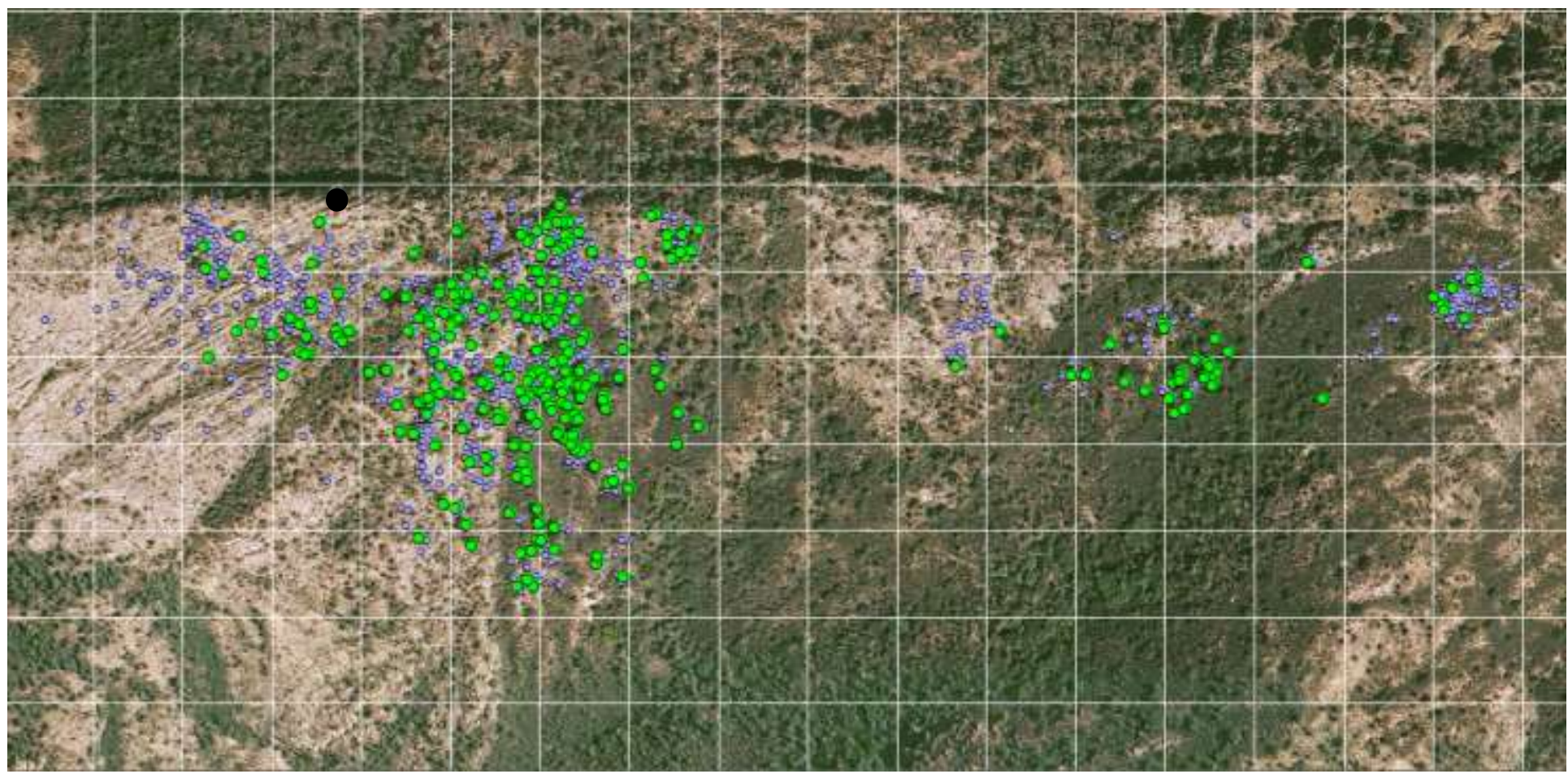

Fig. 4.13. Distribución espacial de la producción de conos. En color verde pinos con conos; en color azul pino sin conos. El punto negro es el pino 716, el mayor productor de toda la población. 
Al cuantificar de nuevo las existencias de piñas cerradas presentes en los pinos de 10 parcelas en el inventario del año 2009, los resultados muestran que de los 50 pies con piñas cerradas en 2003 se pasó a 29 pies en 2009.

Es decir, en 6 años 21 pies (un 42\%) perdieron todos sus conos cerrados. La Fig. 4.14 muestra el descenso desde un 63,9\% del número de conos cerrados respecto al total en el año 2003, a un $23,85 \%$ del total contado en 2009. En concreto, el número de conos cerrados hallados en 2009 (394 conos) representa el $30 \%$ de los conos presentes en 2003.

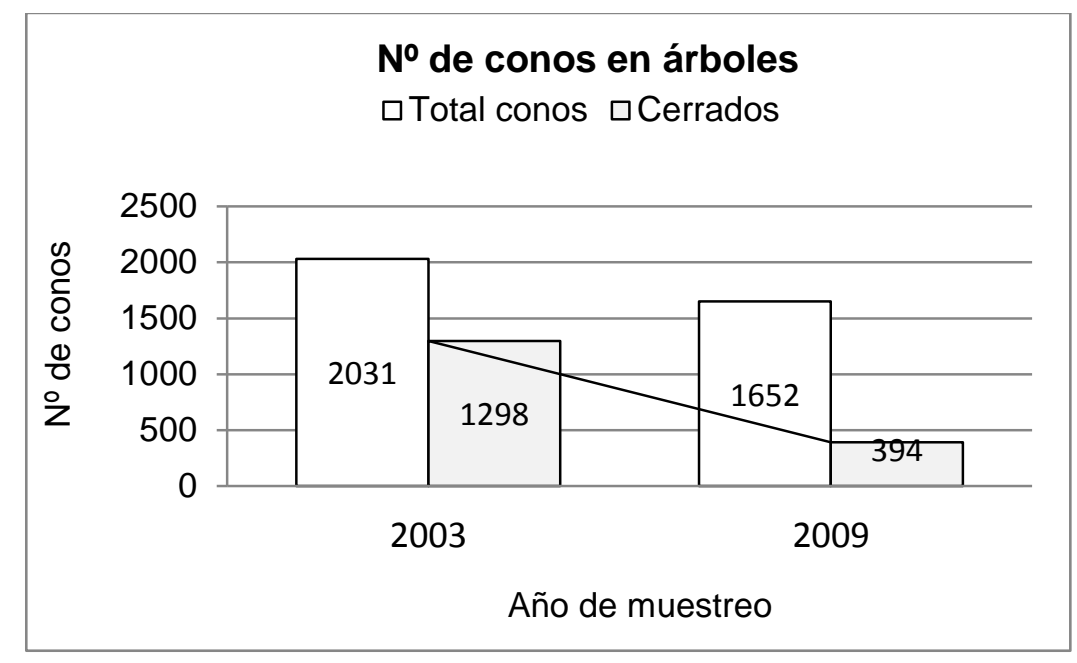

Fig. 4.14 Evolución del número total de conos y cerrados en los 134 árboles muestreados en los años 2003 y 2009.

\subsubsection{Determinación de la temperatura de apertura de los conos}

La temperatura de apertura de los 100 conos sumergidos en agua caliente se situó siempre por encima de los $46,5^{\circ} \mathrm{C}$, con una media de $48,1^{\circ} \mathrm{C} \pm 1,6$. En los 10 conos que se colocaron en un horno eléctrico comenzaron a abrirse a $\operatorname{los} 46,3^{\circ} \mathrm{C}$, con una media de $48,4^{\circ} \mathrm{C} \pm 2,1$. Valores que se pueden comparar con la Fig. 4.15 que muestra las temperaturas máximas anuales de la localidad de Puertollano (a unos $30 \mathrm{~km}$ y $750 \mathrm{~m}$ de altitud -el pinar está a unos $1000 \mathrm{~m}$ de altitud-). 


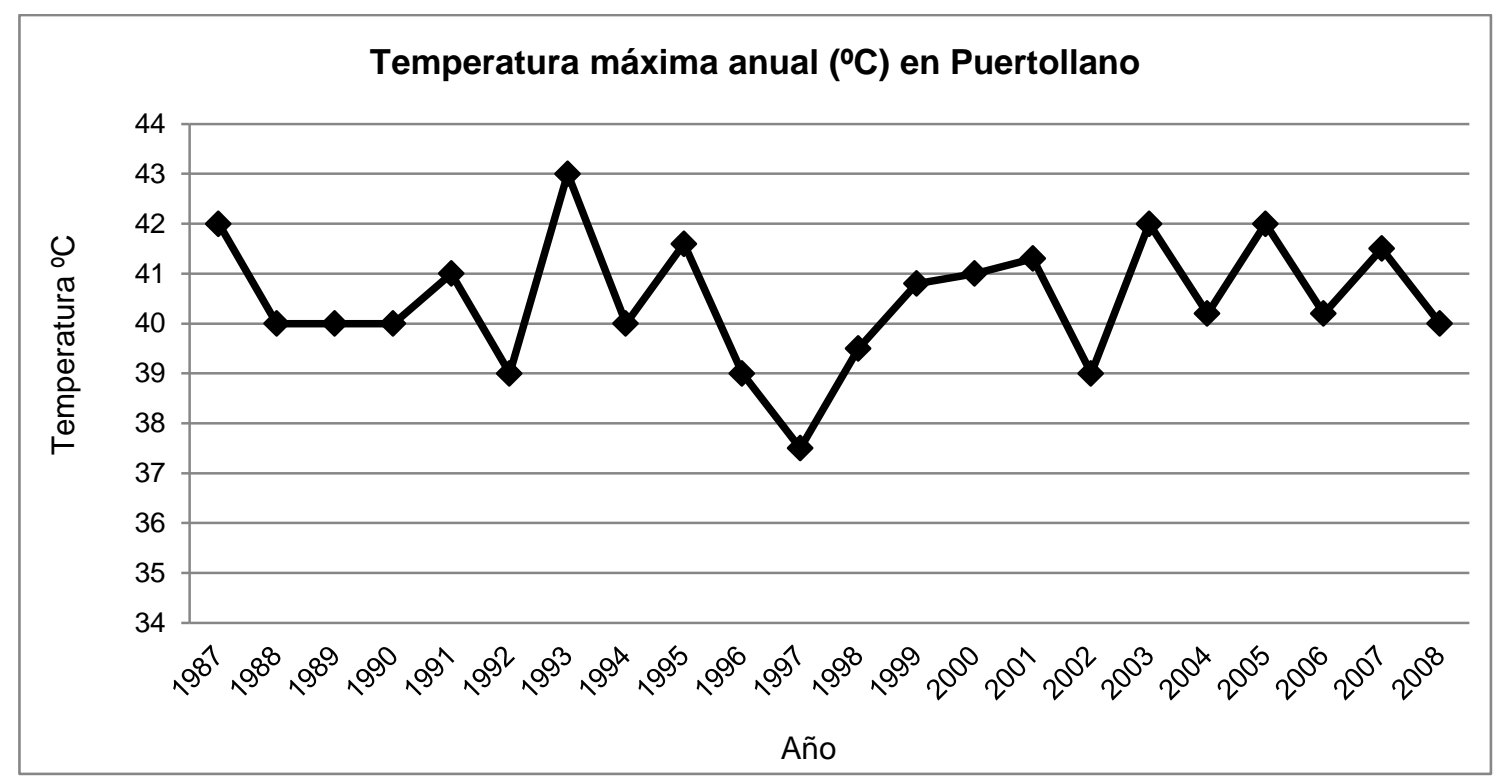

Fig. 4.15. Temperaturas máximas registradas en la estación meteorológica de ENCASUR, en Puertollano (Ciudad Real).

\subsubsection{Ensayos de germinación en campo}

De las 100 piñas recolectadas de 10 árboles (10 conos/árbol) se obtuvieron 7.844 semillas, de las que 1326 resultaron vanas (16,9\%). Es decir 6518 semillas viables, un promedio de 65,18 semillas/piña, pero con una gran variación entre árboles (Fig. 4.16). Algunas de las piñas se observaron con deterioros destacados y fueron descartadas. En el pino $\mathrm{n}^{\mathbf{o}} 4$, las 10 piñas recolectadas presentaron todos sus piñones con el embrión y las reservan con pudrición, lo que no afectaba a las 58 vanas que carecían de embrión en su interior. Si se exceptúan los 10 conos de este árbol la producción de las 90 piñas de 9 pinos daría de una media de 72,4 semillas/cono.

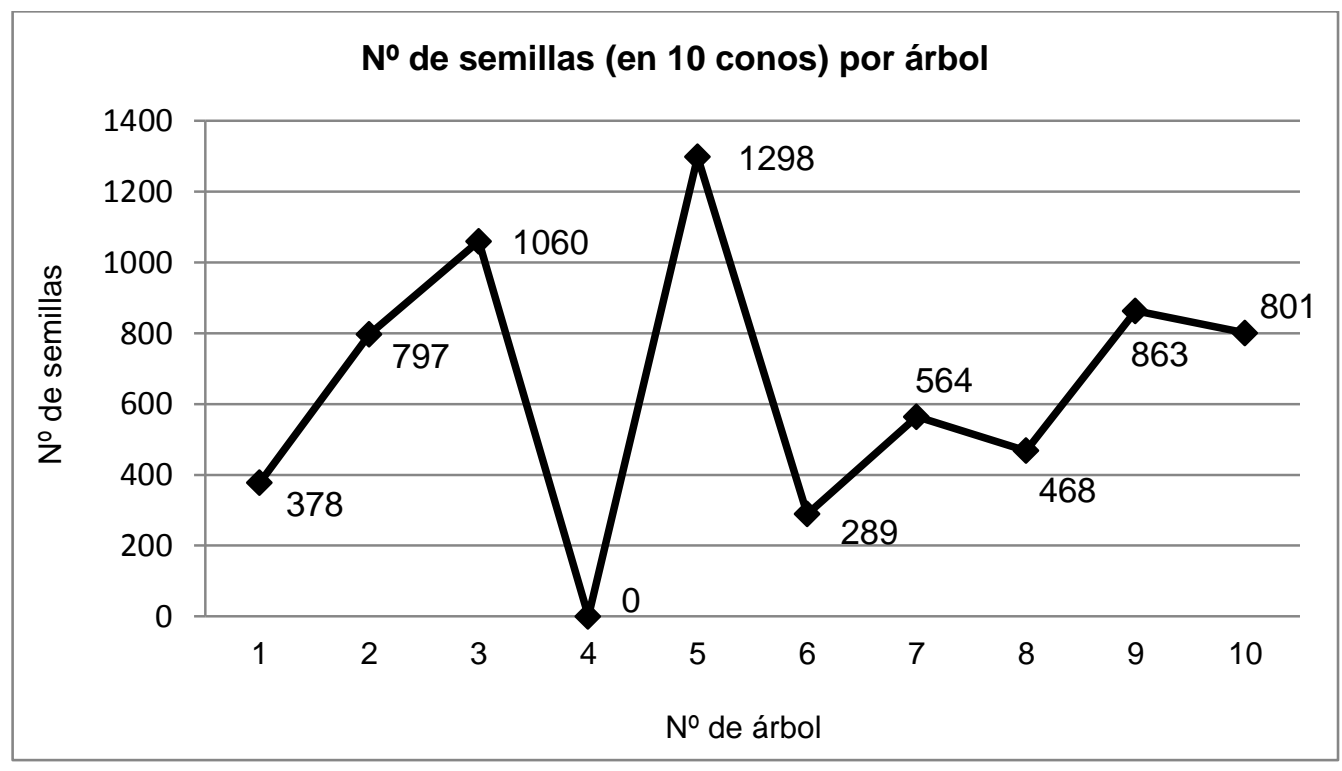

Fig. 4.16. Número de semillas viables en los 10 conos de cada uno de los 10 pinos. 
Las 6.518 semillas viables obtenidas en 9 pinos se dividieron en grupos iguales. Los resultados obtenidos del ensayo de germinación en campo fueron muy diferentes dependiendo del grupo de bandejas considerado (Protegidas frente a No Protegidas) (Tabla 4.4). En las bandejas protegidas, de las 3259 semillas sembradas se observó la germinación de 2.161 (Fig. 4.17), lo que representa una germinación del 66,3\%.

\begin{tabular}{|c|c|c|}
\hline \multicolumn{2}{|c|}{ Diferencias de germinación entre grupos de bandejas } \\
\hline & Bandejas protegidas (P) & Bandejas sin protección (NP) \\
\hline $\begin{array}{c}\text { Semillas observadas } \\
\text { (porcentaje) }\end{array}$ & $2161(66,3 \%)$ & $7(0,21 \%)$ \\
\hline
\end{tabular}

Tabla 4.4. Plántulas observadas de las 3259 semillas dispuestas tanto en bandejas protegidas como sin protección.

En las bandejas sin protección se observaron apenas 7 plántulas, el $0,21 \%$ de las semillas sembradas, el 1 de diciembre. De las 7 plántulas, cuatro aparecieron entre los pedregales que rodeaban las bandejas. Las semillas no germinadas (3.252) permanecieron durante todo el invierno en las bandejas a expensas de la fauna, sin que las consumiera o se las llevara. Solo bien entrada la primavera (abril) y hasta el mes de julio, se observó la dispersión de un centenar de semillas en un radio aproximado de $2 \mathrm{~m}$ alrededor de las bandejas, sin que fueran abiertas ni consumidas.

Las plántulas observadas en cada fecha en las bandejas protegidas se recogen en la Fig. 4.17. Se aprecia un significativo descenso de la germinación posterior al 3 de noviembre. En la siguiente semana las germinaciones aumentan a valores algo mayores a los observados el 3 de noviembre que, casi se anulan, en la observación del 1 de diciembre. La Fig. 4.18 muestra la precipitación mensual durante los meses del experimento, procedente de las estaciones meteorológicas más próximas, una de ellas en el sopie de la umbría de la sierra de Navalmanzano. La Fig. 4.19 muestra la temperatura registrada en la ya señalada estación de Puertollano. En la Fig. 4.20 pueden verse los resultados de germinación en campo en una de las bandejas Protegidas. 


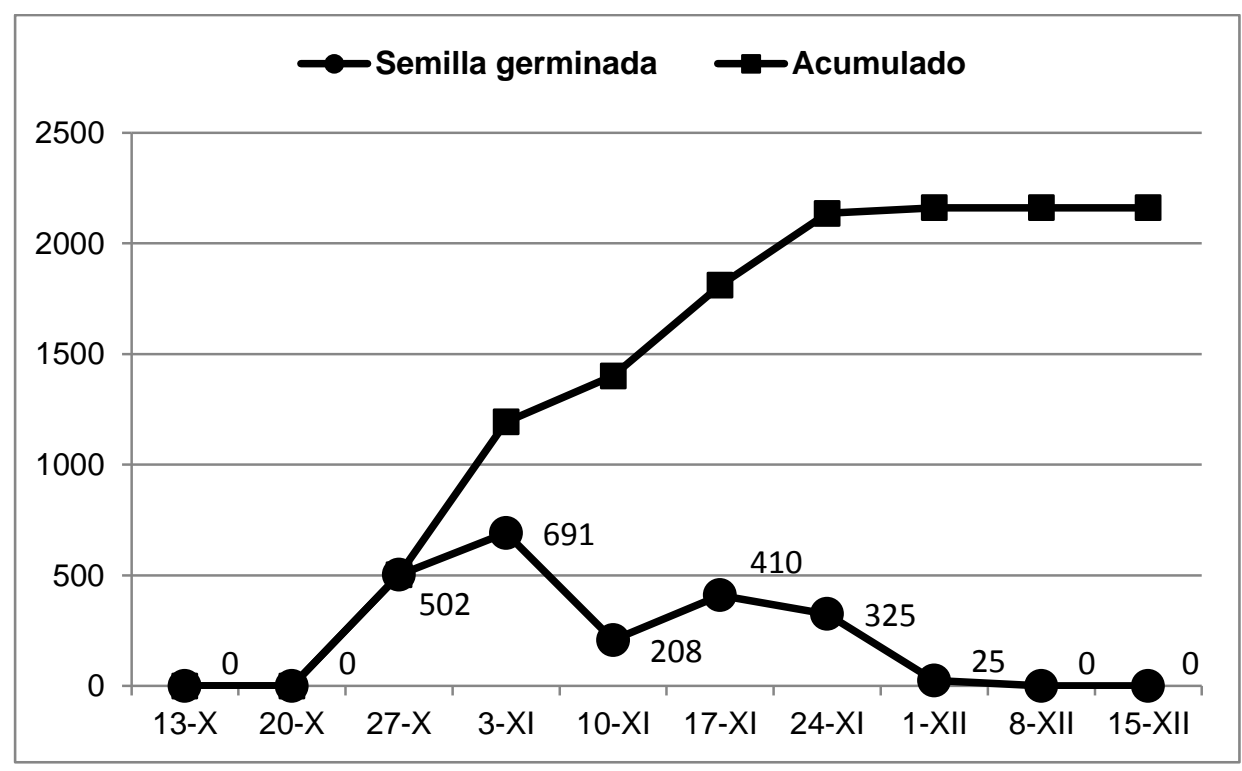

Fig. 4.17. Curvas de germinación del grupo de bandejas protegidas. $\mathrm{n}=3259$, fecha inicio 5-10-2002.

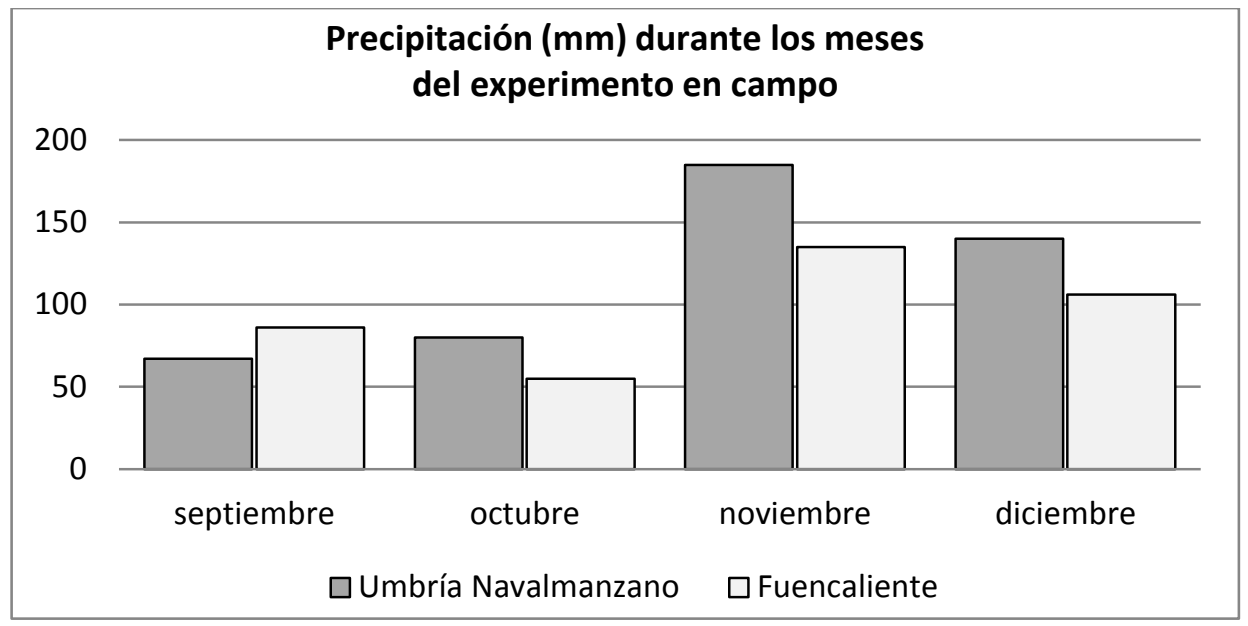

Fig. 4.18. Precipitación total mensual en las estaciones meteorológicas más próximas durante la realización de los ensayos de germinación en campo (otoño de 2002). La de la umbría de la sierra de Navalmanzano es un pluviómetro instalado en la casa del guarda mayor de la finca y, la de Fuencaliente, una estación dependiente de la AEMET.

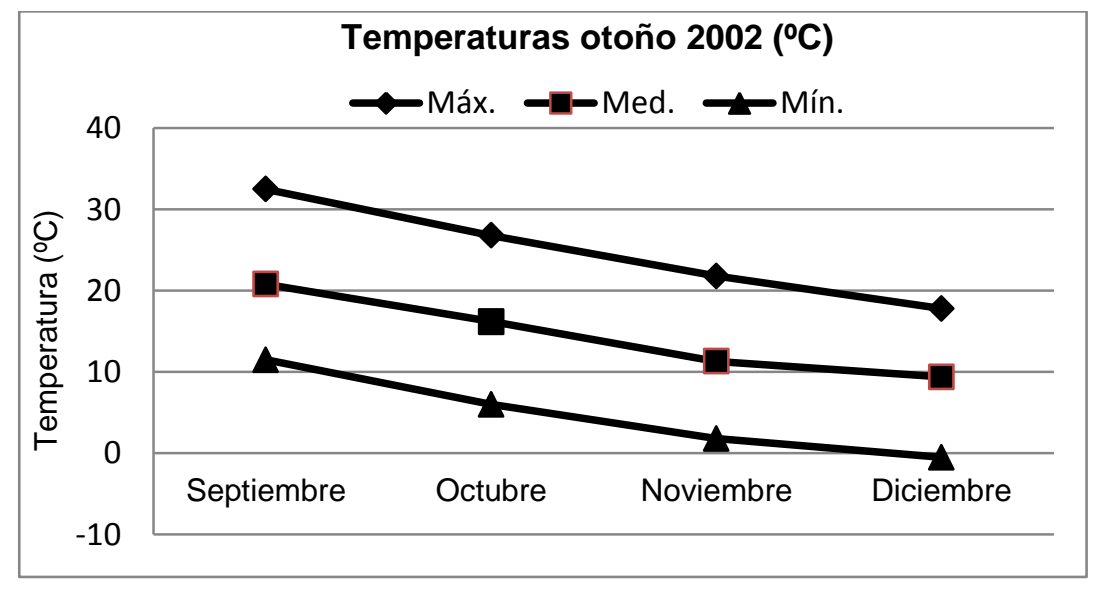

Fig. 4.19. Temperaturas máxima, media y mínima en Puertollano (a 750 msnm) en los meses de duración del ensayo en campo. Fuente: ENCASUR 


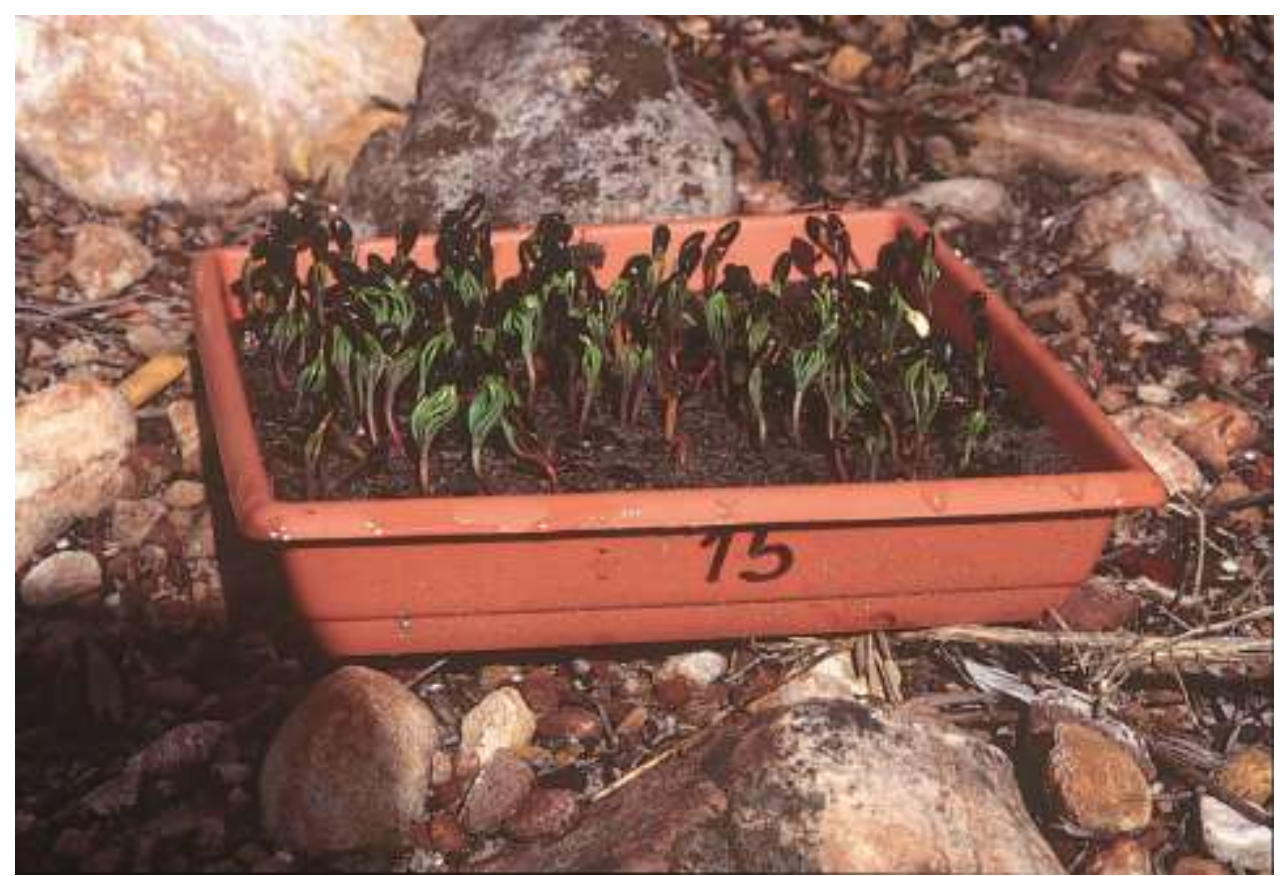

Fig. 4.20. Una de las bandejas protegidas mostrando las semillas germinadas en los ensayos de germinación en campo.

\subsubsection{Ensayos de germinación en laboratorio}

De las 10 piñas recolectadas en 2005 se extrajeron 902 piñones (media de 90,2 piñones/piña). De las 805 semillas utilizadas 169 resultaron vanas por lo que el número final de semilla sembrada fue de 645. La germinación fue del 64,5\% con un total de 413 plántulas (Figs. 4.21 y 4.22) El resto de las semillas no germinadas fueron descubiertas al día 32 y se las observó a todas una mucosidad envolvente, tejidos de aspecto lechoso y embrión inviable.

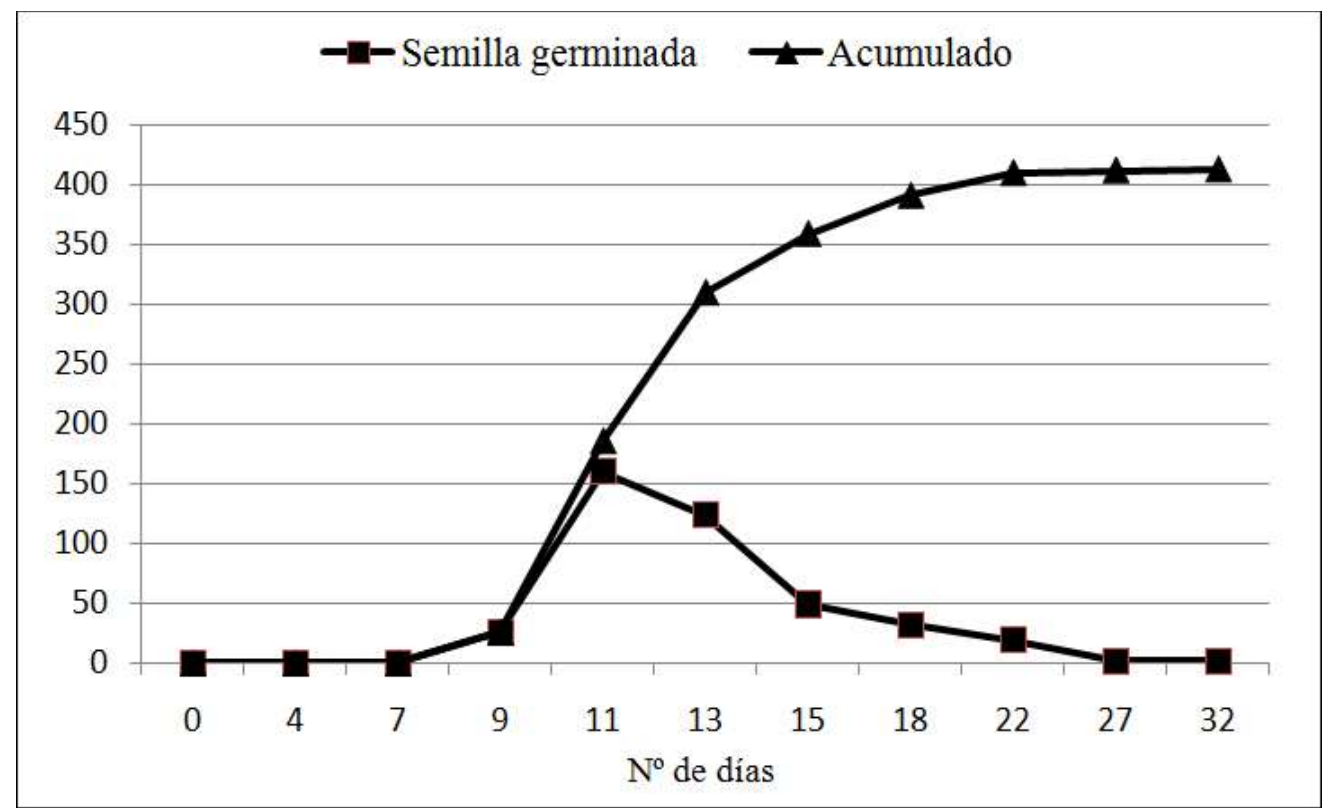

Fig. 4.21. Curvas de germinación con $\mathrm{t}^{\mathrm{a}}$, luz y humedad controladas. $\mathrm{n}=645$. Fecha inicio 20-10-2005. 


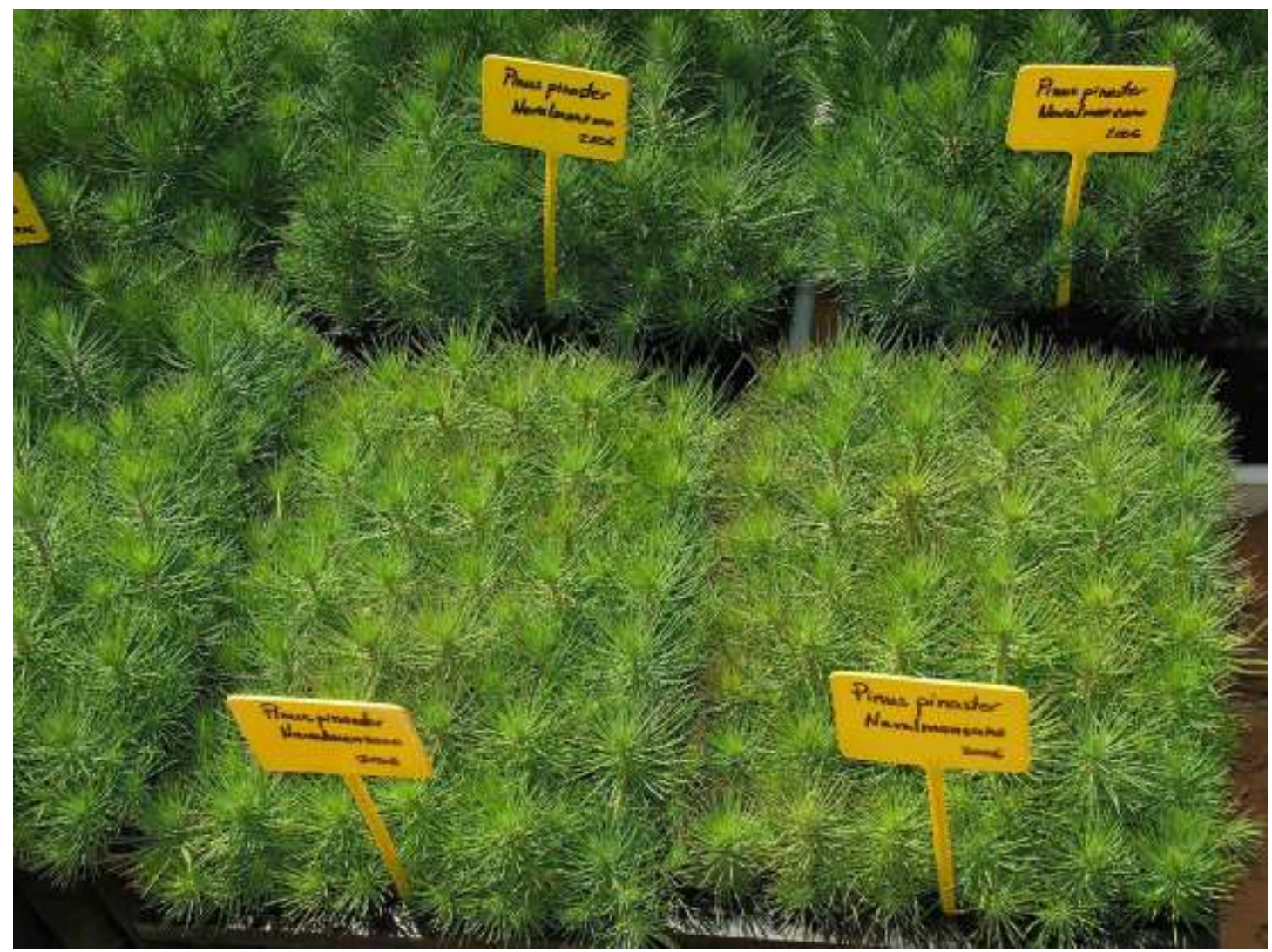

Fig. 4.22. Plántulas obtenidas en los ensayos de germinación en laboratorio durante el otoño de 2005.

\subsubsection{Influencia de la ardilla en el banco aéreo de semillas}

En el año 2005 se contaron 359 conos comidos por las ardillas (porcentaje 30,4\% de las piñas (Tabla 4.5). en las cinco cuadrículas UTM seleccionadas. El porcentaje de conos comidos varía sustancialmente entre parcelas, el menor es el de la E1, donde no se observó ninguna piña comida; siendo la que menor fructificación presenta. El valor máximo lo registra la parcela LL2 , en la que todos los conos cerrados han sido comidos. En números absolutos destaca la parcela G-3, la que incluía mayor número de pinos y la mayor fructificación, en la que se encontraron 265 conos comidos, lo que representa el 74\% de piñas comidas en las 5 cuadrículas.

\begin{tabular}{|c|c|c|c|c|c|c|}
\hline \multicolumn{7}{|c|}{ Consumo de conos cerrados por la ardilla en 5 parcelas de 2500 $\mathbf{~ m}^{\mathbf{2}}$} \\
\hline $\begin{array}{c}\text { Cuadrícula } \\
\text { UTM }\end{array}$ & $\begin{array}{c}\text { Total pinos } \\
\text { cuadricula }\end{array}$ & $\begin{array}{c}\text { Pinos con } \\
\text { conos }\end{array}$ & $\begin{array}{c}\text { Total conos } \\
\text { (abiertos y } \\
\text { cerrados) }\end{array}$ & $\begin{array}{c}\text { Conos } \\
\text { cerrados }\end{array}$ & $\begin{array}{c}\text { Comidos por } \\
\text { la ardilla }\end{array}$ & $\begin{array}{c}\% \text { de conos } \\
\text { cerrados } \\
\text { comidos }\end{array}$ \\
\hline E-1 & 16 & 1 & 11 & 11 & 0 & $0 \%$ \\
\hline G-3 & 99 & 26 & 2143 & 779 & 265 & $34 \%$ \\
\hline I-3 & 8 & 5 & 293 & 136 & 15 & $11 \%$ \\
\hline LL-2 & 9 & 1 & 193 & 63 & 63 & $100 \%$ \\
\hline P-2 & 79 & 11 & 380 & 191 & 16 & $8,4 \%$ \\
\hline Total & $\mathbf{2 1 1}$ & $\mathbf{4 4}$ & $\mathbf{3 0 2 0}$ & $\mathbf{1 1 8 0}$ & $\mathbf{3 5 9}$ & $\mathbf{3 0 , 4 \%}$ \\
\hline
\end{tabular}

Tabla 4.5. Cantidad y distribución espacial de los conos consumidos por las ardillas en 2005. 
En mayo y junio de 2015 se visitó de nuevo la zona, observando más conos comidos por las ardillas. El árbol n 716 , al que en 2003 se le contaron 587 conos, todos cerrados, en 2015 ya no conservaba ningún cono maduro cerrado en la copa. En el suelo del entorno inmediato de este pino se contabilizaron 128 conos consumidos por las ardillas, algunos hacía varios años pero otros muy recientemente (Fig. 4.23).

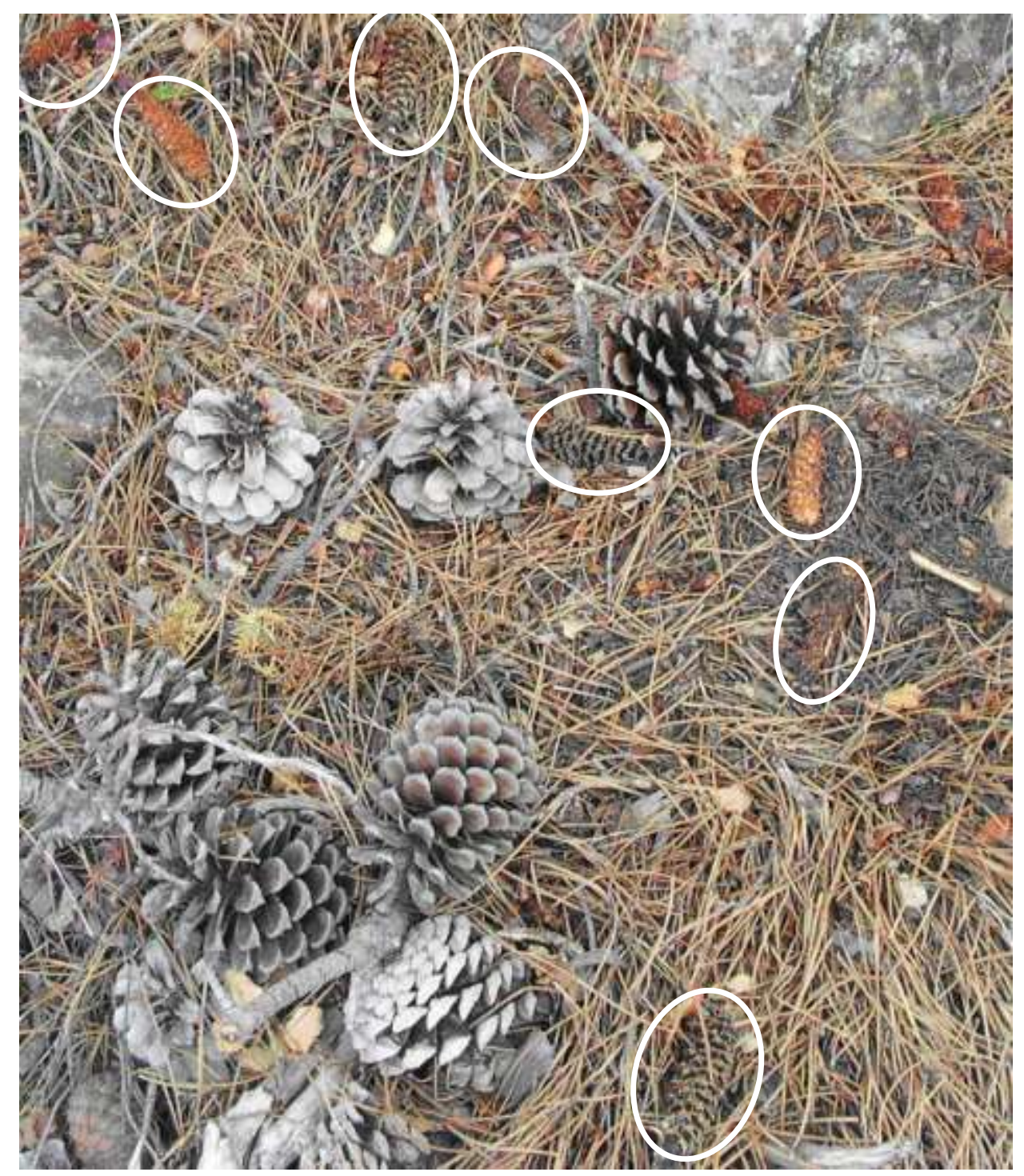

Fig. 23. Conos abiertos desprendidos del árbol, junto a conos comidos por las ardillas.

\subsection{Discusión}

\subsubsection{Evaluación del potencial del regenerado}

La distribución de edades del pinar de Navalmanzano confirma que, hasta la desaparición de los incendios, el pinar se regeneraba solo en litosuelos, lo que se observa en la edad de la mitad de los pinos de mayor tamaño nacidos entre 1895 y 1936 (Fig. 4.5), pinos con una relación altura/diámetro diferente a los que crecen en buenos suelos y que llegan a los 11 metros de 
altura frente 5,5 o $7 \mathrm{~m}$ para edades similares en el roquedo, y a partir de unos pocos árboles adultos que proveyeron del mayor porcentaje de semilla viable al entorno, pues los siete más productores en 2003 contenían el 39,6\% de las piñas. También serían los máximos productores en décadas anteriores.

La germinación es discontinua entre 1895 y 1965 y, a partir de 1970, se observa continua (Fig. 4.6) y abundante a partir de 1975, cuando ya lleva varias décadas de ausencia de incendios. La regeneración fuera del roquedo aparece a partir de 1937 (Fig. 4.5), en plena guerra civil, y estos pinos junto los que se van incorporando poco a poco, alcanzan tamaños que permiten mayores incorporaciones a partir de 1975. Aunque los incendios son propios de los países mediterráneos (ver revisión en Pausas et al. 2009), comunicaciones personales de antiguos pastores de Sierra Madrona comentan que prendían fuego a matorrales y chaparrales cada 3-6 años para favorecer la aparición de pastos herbáceos y rebajar la talla de las plantas leñosas a la altura de la boca del ganado caprino. Los incendios, iniciados en épocas antiguas, provocaron una erosión creciente hasta descubrir las enormes lanchas que, al final, sus intersticios y discontinuidades fueron el refugio de unos pocos pinos centenarios; algunos situados sobre bolsas de suelo subterráneas bajo las lanchas que fructificaban de forma abundante. La roca desnuda en amplias superficies de cumbres, y partes altas de laderas en exposición sur, fueron un factor que detenía el fuego en los roquedos por falta de combustible y, el ganado, carecía del aliciente para recorrerlos por el reducido número de vegetales.

Destaca que el 9,2\% (12 de los 130 con piñas) de los pinos de la zona refugio producen el $50,6 \%$ (1.878) de los conos cerrados. Considerando que hay 691 pinos, esos 12 pinos generaban un banco aéreo que permitió la persistencia en el tiempo del pinar, pese a la reducida probabilidad de que las semillas lograran encontrar un lugar adecuado para crecer y fructificar. Los piñones dispersados cada año lo eran por la apertura de una fracción de los conos formados en años anteriores.

La regeneración a partir de 1970 se une a la reducción casi general de la ganadería en Sierra Madrona y ya no se incendia sistemáticamente el monte. La guerra civil y la posguerra supusieron una bajada demográfica y un paréntesis para que el incendio no tuviera la generalidad de décadas y siglos anteriores. La emigración rural propicia la incorporación de nuevos individuos (Fig. 4.6), ligada a las repoblaciones forestales en el entorno que exigían el acotamiento al pastoreo, a la par que proporcionaban jornales a unos pueblos de economía agraria de subsistencia (Gil 2008). En 2003, el primer inventario del monte contabiliza 1.212 pinos. Del total, 470 eran rupícolas y 130 presentaban fructificación, mientras que de los no rupícolas, 469 eran mayores a $2 \mathrm{~cm}$ de diámetro basal, de los que 185 pies ya presentaban conos, y a los que se añaden 226 brinzales (19,5 brinzales/ha) con diámetro basal inferior a 2 $\mathrm{cm}$. El regenerado hasta 2003, fuera de las zonas refugio sumó 742 individuos (el 61,2\% del pinar), la mayoría a partir de 1970, doblando la cifra de los pinos del roquedo. Esta regeneración destaca frente a la observada en 2015, cuya ausencia a simple vista no justificó su evaluación. Estos 742 pinos regenerados a partir de 1970 en las 12,25 ha del pinar contrastan con los 1500- 
2000 pies/ha que se considera como límite inferior tras cortas de regeneración en $P$. pinaster (Rodríguez Soalleiro et al. 2008).

La escasez de plántulas y el cese de la incorporación de individuos a partir del 2000 se puede atribuir a los múltiples factores que afectan el proceso de regeneración de la especie (Rodríguez García et al. 2007, 2011a, 2011b). El presente estudio confirma que la abundancia de espacios vacíos, junto a la falta de competencia interespecífica, que por su densidad (Fig. 4.7), porte y escasa cobertura no condicionan el establecimiento de nuevos brinzales. El enebro es la más común pero su pequeño porte, a veces arborescente, frente a pinos de edades similares no parece ser un factor que impida la regeneración del pinar. Visualmente, la jara pringosa (Cistus ladanifer L.) es la especie más frecuente -incluso abundante en zonas con buen suelo- pero su hoja estrecha forma matorrales poco frondosos que permiten a la luz llegar ampliamente al suelo. Esta jara puede ser una especie facilitadora para la germinación y desarrollo de las plántulas, como se ha mostrado para otros matorrales (Rodríguez-García et al. 2007). En definitiva, el matorral de Navalmanzano, es compatible con la expansión del pinar.

En 2003 el banco aéreo de semillas era importante, aunque los pinos productores fueran un bajo porcentaje (26\%), lo que se debe a la abundancia de pinos en el roquedo que no pasan de $1 \mathrm{~m}$ de altura. Esta altura es a la que fructifican otras poblaciones de pinos de la especie como Tabuyo (1,01 m alcanzados a los 6 años), Sierra Bermeja (0,99 a los 7 años) o Torneros de Jamuz (León) que fructifica a los 5 años con $0,77 \mathrm{~m}$. Siendo más frecuente que lo hagan con alturas mayores y edades similares las poblaciones de climas más favorables (Tapias y Gil 2000) . También se debe a la falta de una fructificación importante en los incorporados después de 1990, cuyo número suponen el 40\% de los nacidos desde 1975 tal como aproxima la figura 6.

De los pies productores, dominan los que tienen una parte de su cosecha con conos cerrados, pues solo 24 pinos no son serótinos y dispersan sus semillas en el año siguiente a su maduración, antes del verano siguiente, por lo que de llegar un incendio no habría semillas en el banco aéreo. El carácter serótino de esta población es importante, pues el 59,5\% de los pinos que poseen conos en la copa (291) tienen más del 80\% cerrados (Fig.9). Este porcentaje medio solo lo poseen tres de las 17 poblaciones de Pinus pinaster analizadas por Tapias y Gil (2000): Tabuyo (97\%) y Torneros $(83,7)$, ambas de la procedencia de la Sierra del Teleno y Sierra Bermeja $(83,1 \%)$ que, además, se limitan a las dos últimas fructificaciones.

La importancia del banco aéreo en 2003 se deduce de los 9.176 conos cerrados, a los que al aplicar la media de 72,4 semillas/cono supone 54.232 semillas/ha, cifra que supera a 6 (Ayora, Mazarete, Coca, Boniches, Piedralaves y el Tiemblo) de las 14 poblaciones estudiadas (Tapias y Gil 2000); si bien en Navalmanzano la superficie estimada del pinar es una aproximación.

La temperatura de 48,1 $\pm 1,6^{\circ} \mathrm{C}$ de apertura de los conos muestra unos valores de los más elevados de la especie. Solo Tabuyo $\left(49,3 \pm 1,5^{\circ} \mathrm{C}\right)$ y Torneros $\left(49,9 \pm 1,6^{\circ} \mathrm{C}\right)$, la superan. Estas temperaturas están relacionadas con el porcentaje de conos serótinos, pues cuanto mayor diferencia haya entre la temperatura de apertura y la máxima del año mayor número de conos cerrados permanecerá en la copa. Así observamos que las máximas anuales en Puertollano (Fig. 
4.15) se mueven alrededor de los $42^{\circ} \mathrm{C}$ o inferiores. Solo un año fue de $43^{\circ} \mathrm{C}(1994), 5^{\circ} \mathrm{C}$ por debajo de la media de apertura. Siendo además estas temperaturas a $750 \mathrm{~m}$ de altitud, mientras que la zona refugio esta 450 metros por arriba, lo que atempera los valores de Puertollano. Hay que considerar que las piñas con el paso del tiempo quedan más ocultas en la copa (Molina et al. 1997) y en particular las expuestas al Norte serán las que mayor tiempo permanezcan cerradas y la xeriscencia la manifiesten más las situadas en la solana de la copa y años como los del 1994 con temperaturas anuales más altas. El gran porcentaje de conos cerrados, junto las altas temperaturas de apertura detectadas en la población de Navalmanzano son resultado de una larga evolución adaptativa a los incendios forestales. Un largo historial de incendios forestales frecuentes ha repercutido en la adaptación y permanencia de los pinares de Sierra Madrona. Incendios naturales frecuentes supone la pérdida de cobertura vegetal y una mayor probabilidad de coincidencia con lluvias postincendio que rejuvenecen el suelo conforme mayor sea la pendiente y como los sustratos son de poca fertilidad permiten el dominio del pinar frente a otras formaciones de mayor nivel evolutivo, pero que requieren suelos profundos para superar estíos secos.

Los ensayos de germinación de semillas en campo y en laboratorio muestran que el pinar de la Sierra de Navalmanzano no tiene problemas de producción de semillas viables. En el ensayo de germinación en laboratorio, en condiciones óptimas, la germinación fue de un 64,5\%, inferior al $66,3 \%$ de las semillas protegidas en el pinar. Diferencias que no son significativas, si bien el número de semillas dispuestas fue muy superior en las bandejas de campo (3.259) que en laboratorio (645). En campo el máximo de germinación ocurre a los 29 días (Fig, 4.17), mientras que en el laboratorio fue a los 11 días (Fig. 4.21). La germinación responde a la existencia de lluvias previas a la siembra, así como durante los meses de octubre y, en particular, durante noviembre, con más de $175 \mathrm{~mm}$ de precipitación mensual, lo que permite se dupliquen las germinaciones el 17 de noviembre frente a la semana anterior y se mantenga el 23 de noviembre, aunque en menor número que la semana anterior, pero un 50\% superior al 10 de noviembre, pues las temperaturas del mes, de acuerdo con Puertollano (Fig. 4.19), no son contrarias a que tenga lugar esta respuesta. El frío de la primera semana debió ser la causa de la bajada observada el día 10, la subida de temperaturas y la lluvia pudo ser causa de una ruptura de la dormición y que este ensayo supere los del laboratorio.

Lo que si es significativo es el reducido establecimiento de semillas en la zona de campo no protegida, lo que evidencia su predación por la fauna granívora y el reducido número de semillas establecidas, apenas el $0,21 \%$ que, sería difícil superaría la predación por los herbívoros durante la larga etapa invernal. Aunque las semillas tenían un tratamiento de pregerminación sencillo, de solo inmersión en agua, los resultados apuntan a que la población es poseedora de una dormición que amplíe el periodo de germinación de las semillas que se dispersan anualmente de los conos xeriscentes. De manera que las semillas no germinadas, tanto en campo como laboratorio, son el resultado de una dormición que debe ser anulada. La no germinación por existencia de dormición explica la pudrición de las semillas en laboratorio, pese al tratamiento antifúngico que se les practicó durante los 32 días del ensayo. 
Como muestra la Fig. 4.6, la regeneración del pinar de Navalmanzano hasta mediados del siglo XX solo se producía en los roquedos refugio debido a los recurrentes incendios forestales, donde las circunstancias edáficas para germinar distan de ser las adecuadas. Desde finales del siglo XX, ya sin incendios forestales germina relativamente bien en el entorno del roquedo, con frecuencias destacadas y significativamente diferentes de la zona anterior. Fuera de los roquedos, en las zonas con más suelo, el pinar tiene un gran potencial de expansión, máxime cuando la competencia intraespecífica es todavía baja y sin que aquellas otras especies que por mayor porte o edad pudieran desplazarlo lo estén haciendo pues parece poco posible bajo las circunstancias edáficas actuales y por las menores densidades que muestran (Fig. 4.7).

\subsubsection{El efecto de la ardilla}

La reciente llegada y el asentamiento de la ardilla roja en el pinar puede ser un problema en el futuro para la regeneración del pinar. Aunque los datos de consumo obtenidos constituyen una aproximación, por reducirse la evaluación a 1,25 ha, en el año 2005 la ardilla había consumido el 30\% de los conos serótinos de las cuadrículas estudiadas (Tabla 4.5). Porcentaje algo menor si se tiene en cuenta que se habría incorporado una cosecha de piñas, pero llamativo si se acepta su presencia por primera vez en el año 2003. En el pinar de Navalmanzano la ardilla encuentra un nicho trófico con abundante presencia de conos cerrados que, posiblemente, no constituye un rasgo de las repoblaciones de pinos colindantes. En las repoblaciones de pinos del siglo XX en Sierra Madrona se utilizó semilla de diversos orígenes, como el de las Landas (Francia), con apenas conos serótinos o que poseen bajas fructificaciones, por la sociedad Peñarroya en la Garganta, una finca de 15.600 ha situada entre los términos municipales de Brazatortas y Almodóvar del Campo. En 1912 Peñarroya realizó la ordenación forestal de la finca y en 1968, ya con todas las explotaciones de Peñarroya en la provincia de Ciudad Real agonizantes, se vendió una parte al Patrimonio Forestal del Estado (en 1971, ICONA), 3.285 ha del monte "La Garganta.". En otras partes de Sierra Madrona pudieron ser muy utilizada las semillas procedentes de los arenales del Duero, entre ellas las de Coca, que carece de conos serótinos (Gil et al. 2009).

En 2009, cuatro años después, se realizó un nuevo muestreo sobre 134 pinos para conocer la evolución de diversas variables como medidas, daños y producción de conos. Se comprobó que frente a las 1298 piñas cerradas en 2003 en la copa de esos 134 árboles, en 2009 había solo 394. Esto implica pasar de un 30,4\% de piñas pérdidas entre 2003 y 2005 a un 69,6\% en el año 2009 con respecto a las existencias en 2003 (Fig. 4.14). Fracción menor al no considerar todas las cosechas incorporadas entre ambos muestreos, pero suficientemente elevada para considerar la pérdida progresiva del banco aéreo de semillas. Otra forma de apreciar la incidencia de las ardillas es comparar el 63,9\% conos cerrados frente a totales en 2003, que se reduce al 23,85 en 2009. En este periodo las piñas xeriscentes y serótinas de cada fructificación anual se incorporan. Pero mientras las xeriscentes se dispersan en alguno de los años sucesivos hasta su conteo en 2009, la proporción frente a los conos que permanecen cerrados debería ser similar en 
ambos años. Lo que no es así, de manera que las 394 piñas de 2009 habrán desaparecido en un periodo de 6 años. Aspecto que se confirma, cuando en el año 2015 se comprueba que numerosos árboles han perdido ya el $100 \%$ de sus conos maduros cerrados.

La llegada y asentamiento de la ardilla ha provocado un drástico descenso del volumen del banco aéreo de semillas y, sin duda, lo eliminara por completo. Esta especie prefiere los pinares para vivir y entre su principal alimento se encuentran los piñones (e.g. Valverde 1967; Purroy y Rey 1974; Palomares 1988; Andreu et al. 2000). Esto resulta particularmente grave para la supervivencia del último pinar de $P$. pinaster de Sierra Morena, pues está perdiendo la capacidad de dispersar propágulos anualmente o tras un incendio. Esto supondrá el progresivo envejecimiento de la masa y su fin a largo plazo en general o, en caso de incendio forestal, el fin inmediato tras el fuego de la población surgida en los últimos 50 años fuera de los roquedos.

El asentamiento de la ardilla en el pinar de la sierra de Navalmanzano a principios del siglo XXI es un problema nuevo para la supervivencia de este pequeño bosque relicto. Pero la ardilla no es una especie invasora, es autóctona, solo faltó en la zona durante unas pocas décadas. La baja densidad de árboles permite a casi todos los predadores potenciales de la ardilla (ver referencias en Purroy 2014) presentes en la zona, poder cazarla aquí; lo que parece no haber ocurrido hasta ahora. Caso de que se reajuste el equilibrio natural, la convivencia entre pinos y ardillas no debería suponer ningún problema para el futuro a largo plazo del pinar de la sierra de Navalmanzano.

La regeneración del pinar de Navalmanzano es lenta dadas las particulares condiciones edafoclimáticas de la zona, pero se produce a un ritmo que permite la renovación y expansión de la masa. Sin embargo el consumo de semillas por parte de la ardilla parece excesivo y creciente, hasta el punto de que se corre un serio riesgo de pérdida del banco aéreo de semillas. Esto implicaría el fin de la masa a largo plazo en los roquedos (por envejecimiento) y a corto plazo fuera de ese refugio en cuanto se produzca el primer incendio forestal. Sería aconsejable realizar un seguimiento de la población de ardillas y, si fuera necesario, controlar su densidad hasta que con el concurso de sus predadores naturales se reajuste el equilibrio natural.

\subsection{Referencias}

Alcalde C., García Amorena, I., Gómez, F., Maldonado, J., Morla, C., Postigo, J.M., Rubiales J.M. \& Sánchez, L.J. 2004. Nuevos datos de carbones y maderas fósiles de Pinus pinaster Aiton en el holoceno de la Península Ibérica. Investigación Agraria: Sistemas y Recursos Forestales, fuera de serie. Octubre de 2004: 152-163.

Andreu, J., Llimona, F. \& Espelta, J. M. 2000. Predació de l'esquirol (Sciurus vulgaris) sobre el pi blanc (Pinus halepensis) a la Serra de Collserola. Pp. 219-223. En: Llimona, F., Espelta, J. M., Guix, J. C., Mateos, E., Rodríguez-Teijeiro, J. D. (Eds.). I Jornades sobre la Recerca en els sistemes naturals de Collserola : aplicacions a la gestió del Parc. Consorci del Parc de Collserola, Barcelona. 
Anónimo, 1802. On squirrels destroying young trees. The farmer's magazine 3: $446-447$.

Arduini, I., Kettner, C., Godbold, D.L., Onnis, A. \& Stefani, A. 1998. Ph Influence on root growht and nutrient uptake of Pinus pinaster seedlings. Chemosphere 36, (4-5): 733-738. <doi: 10.1016/S0045-6535(97)10116-3>.

Bowles, J.H. 1920. The California Gray Squirrel an enemy to the Douglas fir. Amer. Forestry 26: 26.

Cabrera, A. 1905. Las ardillas de España. Boletín de la Real Sociedad Española de Historia Natural, 5: 225-231.

Cabrera, A. 1914. Fauna ibérica; mamíferos. Museo Nacional de Ciencias Naturales. Madrid. $528 \mathrm{pp}$.

Calvo, L., Marcos, E., Tarrega, R., Santalla, S., Torres, O., Valbuena, L. \& Luis-Calabuig, E. 2006. The competition effects of understory on Pinus pinaster natural regeneration after wildfire. Forest Ecology and Management 234: S190. doi:10.1016/j.foreco.2006.08.309.

Fernandes, P.M. \& Rigolot, E. 2007. The fire ecology and management of maritime pine (Pinus pinaster Ait.). Forest Ecology and Management 241: 1-13. doi:10.1016/j.foreco. 2007.01.010.

Ferreira, A. F., Guerreiro, M., Álvares, F. \& Petrucci-Fonseca, F. 2001. Distribución y aspectos ecológicos de Sciurus vulgaris en Portugal. Galemys, 13: 155-170.

Gandullo, J.M. \& Sánchez Palomares, O. 1994. Estaciones ecológicas de los pinares españoles. ICONA. Madrid.

Gil, L. 2008. Pinares y rodenales; la diversidad que no se ve. Discurso del Académico Electo Excmo. Sr. D. Luis Gil Sánchez leído en el acto de su recepción pública el día 23 de septiembre de 2008. 191 pp + Contestación.

Gil, L. Gordo J., Alía R., Catalán G. \& Pardos J.A.1990. Pinus pinaster Aiton en el paisaje vegetal de la península Ibérica. Ecología, fuera de serie no 1: 469-495.

Gil, L., López, R., García-Mateos, A. \& González-Doncel, I. 2009. Seed provenance and fire related traits of Pinus pinaster in central Spain. Int. J. Wildland Fire 18: 1003-1009.

González-Martínez, S.C., Burczyk, J., Nathan, R.A.N., Nanos, N., Gil, L., \& Alía, R. 2006. Effective gene dispersal and female reproductive success in Mediterranean maritime pine (Pinus pinaster Aiton). Molecular Ecology, 15(14): 4577-4588.

Holmes, M. 2015. The perfect pest: natural history and the red squirrel in nineteenth-century Scotland. Archives of natural history. Volume 42, Issue 1: 113-125.

Hosley, N.W. 1928. Red squirrel damage to coniferous plantations and its relation to changing food habits. Ecology, 9: 43-48.

Juez, L., González Martínez, S.C., Nanos, N., de Lucas, A.I., Ordóñez, C., del Peso, C., \& Bravo, F. 2014. Can seed production and restricted dispersal limit recruitment in Pinus pinaster Aiton from the Spanish Northern Plateau?. Forest Ecology and Management, 313, 329-339. 
Madrigal, J.; Hernando, C. \& Vega, J.A. 2006. Diseño de una metodología para la obtención de modelos de regeneración de especies arbóreas tras grandes incendios forestales: aplicación al caso de Pinus pinaster Ait. IV Congreso Forestal Español. SECF. Zaragoza.

Madrigal, J.; Hernando, C.; Martínez, E.; Guijarro, M.\&Díez, C.-2005. Regeneración postincendio de Pinus pinaster Ait. en la Sierra de Guadarrama (Sistema Central, España): modelos descriptivos de los factores influyentes en la densidad inicial y la supervivencia. Invest. Agrar.: Sist. Recur. For. 14(1): 36-51.

MAGRAMA 2015a. Anuarios de Estadística Agraria. (visitado 12 de octubre de 2015). www.magrama.gob.es/es/estadistica/temas/ publicaciones/ anuario-de-estadistica.

MAGRAMA 2015b. III Inventario Forestal Nacional. www.magrama.gob.es/es/biodiversidad/ servicios/banco-datos-naturaleza/informacion-disponible/ifn3.aspx (visitado 12-10-2015).

Martín, S; Díaz-Fernández, P.M. \& de Miguel, J. 1998. Regiones de Procedencia de Especies forestales Españolas: Descripción y principales características. Géneros Abies, Fagus, Pinus y Quercus. Organismo Autónomo de Parques Nacionales. Madrid.

Martínez, E., Madrigal, J., Hernando, C., Guijarro, M., Vega, J.A., Pérez Gorostiaga, P., Fonturbel, M.T., Cuiñas, P., Alonso, M. \& Beloso, M.C., 2002. Effect of fire intensity on seed dispersal and early regeneration in a Pinus pinaster forest. Forest Fire Research and Wildland Fire Safety, Luso, Portugal (Viegas D. ed.).

Martínez Reguera, L. 1881. Catálogo descriptivo de los mamíferos del término de Montoro. Madrid. 414 pp.

Martínez-Sánchez J.J., Herranz J.M., Guerra J. \& Trabaud L., 1996. Natural recolonization of Pinus halepensis Mill. and Pinus pinaster Ait. in burnt forest of Sierra de Alcaraz - Segura mountain system (SE Spain). Ecologia mediterranea XXII (1/2), 17-24.

Moleón, M. \& Gil-Sánchez, J. M. 2003. Distribución, vías de introducción, expansión y apuntes sobre la taxonomía de las poblaciones de ardilla roja (Sciurus vulgaris) en la provincia de Granada (SE de España). Acta Granatense, 2: 45-54.

Molina, C., Tapias, R. \& Gil, L. 1997. Influencia de la posición de la copa y del año de maduración en la germinación de las semillas de Pinus pinaster Ait. de la Sierra del Teleno (León, Noroeste de España). Investigación Agraria: Sistemas y Recursos Forestales 6(1-2), 53-66.

Palomares, F. 1988. Notas sobre la introducción y expansión de la ardilla común en Sierra Nevada, sureste de España. Doñana, Acta Vertebrata, 15: 254-259.

Pausas, J.G., Llovet, J., Rodrigo, A. \& Vallejo, R. 2009. Are wildfires a disaster in the Mediterranean basin? - A review. International Journal of Wildland Fire, 17: 713-723.

Peris, S.J., Reyes, E. \& Hernández, L. 1999. Atlas de los mamíferos silvestres de la provincia de Salamanca. Diputación de Salamanca, Salamanca. 159 pp.

Purroy, F.J. 2014. Ardilla roja - Sciurus vulgaris. En: Enciclopedia Virtual de los Vertebrados Españoles. Salvador, A., Luque-Larena, J. J. (Eds.). Museo Nacional de Ciencias Naturales, Madrid. http://www.vertebradosibericos.org. 
Purroy, F. J. \& Rey, J. M. 1974. Estudio ecológico y sistemático de la ardilla (Sciurus vulgaris) en Navarra. I. Distribución, densidad de poblaciones, alimentación, actividad diaria y anual. Boletín de la Estación Central de Ecología, 3 (5): 71-82.

Rodríguez García, E., Gratzer, G., \& Bravo, F. 2011a. Climatic variability and other site factor influences on natural regeneration of Pinus pinaster Ait. in Mediterranean forests. Annals of forest science, 68(4), 811-823.

Rodríguez García, E., Bravo, F. \& Spies, T.A.-2011b. Effects of overstorey canopy, plant-plant interactions and soil properties on Mediterranean maritime pine seedling dynamics. Forest Ecology and Management, 262: 244-251. <doi:10.1016/j.foreco.2011.03.029>.

Rodríguez García, E.; Juez, L.; Guerra, B. y Bravo, F.-2007. Análisis de la regeneración natural de Pinus pinaster Ait. en los arenales de Almazan-Bayubas (Soria, España). Investigación Agraria: Sistemas y Recursos Forestales, 16(1): 25-38.

Rodríguez Soalleiro, R., Serrada, R., Lucas, J.A, Alejano, R., del Río, M., Torres, E. \& Cantero, A. 2008. Selvicultura de Pinus pinaster Ait. subsp. mesogeensis Fieschi \& Gaussen. En: Serrada, R., Montero. G. Reque, J.A. (Eds), Compendio de selvicultura aplicada en España. INIA. Ministerio de Educación y Ciencia, Madrid. 399-430.

Ruiz de la Torre, J. 2006. Flora mayor. Organismo Autónomo de Parques Nacionales. Madrid. $1756 \mathrm{pp}$.

Shorten, M. 1954. Squirrels. Collins, London.

Tapias R., Bertomeu M., Gil L. \& Pardos J.A. 1997. El papel evolutivo del fuego como factor de selección natural en masas de pinos mediterráneos. Estudio de los conos serótinos y la floración precoz. II Congreso Forestal Español, Pamplona. Tomo V, 455-459.

Tapias R., Gil, L., Fuentes Utrilla, P. \& Pardos J.A. 2001. Canopy seed banks in mediterranean pines of southeastern Spain. A comparison between Pinus halepensis Mill., P. pinaster Ait., P. pinea L. and P. nigra Arn. Journal of Ecology, 89: 629-638.

Tapias, R. \& Gil, L. 2000. Adaptación reproductiva de las especies ante el fuego. En Velez, R. (coord.). La defensa contra incendios forestales. Fundamentos y experiencias. 4.36-4.66. Mcgraw-Hill. Interamericana de España. Madrid.

Tapias, R., Climent, J., Pardos, J.A. \& Gil, L., 2004. Life histories of Mediterranean pines. Plant Ecology, 171: 53-68.

Telles-Antunes, M. 1985. Sciurus vulgaris no Cabeço da Arruda, Muge: presença e extinção em Portugal. Arqueologia, 12: 1-16.

Valverde, J.A. 1967. Nueva ardilla del S.E. español y consideraciones sobre las subespecies peninsulares. Boletín de la Real Sociedad Española de Historia Natural (Biología), 65: 225248.

Vega J.A., Hernando C., Madrigal J., Pérez-Gorostiaga, P., Guijarro M., Fonturbel, M.T. \& Cuiñas P. 2005. Regeneración de Pinus pinaster Ait. tras incendios forestales y medidas selvícolas para favorecerla. IV Congreso Forestal Español, Zaragoza. 352.7 pp. 


\section{CAPítUlO 5}

\section{IMPACTO DEL ESCODADO DEL CIERVO EN EL PINAR DE NAVALMANZANO.}

\section{Resumen}

El pinar de Navalmanzano, una vez superados los históricos procesos deforestadores locales, se regenera progresivamente (pero lentamente) y se expande territorialmente. Sin embargo, la creciente densidad del ciervo rojo (Cervus elaphus L.) puede constituir un peligro para su evolución. En este capítulo se estudia y se cuantifica el efecto del escodado producido por el ciervo en el último bosque relicto de Pinus pinaster Ait. de Sierra Morena. En concreto, se analiza la presencia de daños por escodado sobre los pies inventariados en el año 2003 y se genera un modelo de probabilidad de daño usando el modelo lineal generalizado. La evolución del nivel de daño producido se cuantifica a través de un segundo muestreo realizado en 2009. Además, en el año 2003 se instaló un pequeño cercado de exclusión de herbívoros dentro del monte para estudiar su efecto en la recuperación de los daños sufridos por el ciervo. Los resultados indican que el escodado se produce de forma muy abundante llegándo a afectar el 33 $\%$ de los pies inventariados en 2003. Además, se aprecia una clara selección del ciervo por determinados diámetros de tronco y ramas (pies de entre 10-20 cm) en una búsqueda de acceso fácil a la muy aromática resina de esta especie. Analizada la evolución del nivel de daños entre 2003 y 2009 se observa una tendencia creciente, tanto por el número de árboles dañados como por la intensidad del daño. El uso del cercado de exclusión experimental durante 12 años (20032015) ha demostrado, además, que el escodado del ciervo es la principal amenaza para la supervivencia de este pinar relicto. Para proteger a este bosque se plantea la reducción efectiva de la densidad de ciervo hasta niveles compatibles con la conservación de la masa forestal. Se desestima el vallado de la zona por su coste, su problemático mantenimiento y su impacto ambiental.

\subsection{Introducción}

A mediados del siglo XIX el ciervo aunque presente en toda Sierra Morena no era abundante (Morales 1904). Sin embargo, actualmente, la reducción de la presión humana y la extinción de sus grandes predadores como el oso (Ursus arctos L.) y el lobo (Canis lupus L.) ha provocado una expansión de la población de ciervo sin precedentes. En la década de 1970 se inició la explosión demográfica y la expansión del ciervo, aquí como en otras muchas áreas de todo el Hemisferio Norte (e.g. Gill 1990; Mattioli et al. 2001; Gordon et al. 2004; Milner et al. 2006, Apollonio et al. 2010; San Miguel et al. 2010). En Irlanda, por ejemplo, la expansión del ciervo entre 1978 y 2008 fue de un 565\% (Carden et al. 2011). En España las poblaciones de ciervo (que llegaron al borde de la extinción a mediados del siglo XX) aumentan sin cesar desde hace unos 50 años y, de unos pocos cientos de ejemplares cazados hacia 1950, se pasó a cazar unos 
45.000 ciervos/año a principios de los años 90 (Soriguer et al. 1994), en torno a los 100.000 en 2007 y 130.000 en 2011 (Garrido 2012).

Las densidades de ciervo en Sierra Morena se mantienen -interesadamente- muy elevadas, hasta 60 ciervos $/ \mathrm{km}^{2}$ (Azorit 2005), lo que puede generar serios daños ambientales, económicos y sociales. Actualmente se consideran densidades sostenibles las situadas en torno a los 0,3-5 individuos $/ \mathrm{km}^{2}$ (e.g. Nahlik 1974; Ueckermann 1982; Kraus 1992). En zonas con hábitat de reducida calidad, como la Sierra de Baza (SE de España), un grupo de expertos (Granados et al. 2001) teniendo en cuenta los daños que ocasiona el ciervo con $3,5 \mathrm{ind} / \mathrm{km}^{2}$, proponen reducir su densidad a $2 \mathrm{ind} / \mathrm{km}^{2}$. No obstante, en los países mediterráneos (donde abunda el matorral palatable y otoño, invierno y primavera son las mejores estaciones por la abundancia de pastos y frutos -bellotas-) estas densidades podrían elevarse hasta los $10 \mathrm{ind} / \mathrm{km}^{2}$ en terrenos con muy buena calidad de hábitat. Pero todas estas densidades óptimas de 0,3-10 ind $/ \mathrm{km}^{2}$ se hallan muy lejos de la media que obtienen Acevedo et al. (2008) de unos $20 \mathrm{ind} / \mathrm{km}^{2}$ en 22 zonas del sur de España ( 8 de ellas en Sierra Morena oriental, donde se halla el bosque relicto de $P$. pinaster objeto de este estudio).

En numerosos países del Hemisferio Norte (y en otros donde se ha introducido el ciervo) el continuo incremento de las densidades de estos ungulados provoca serios impactos ambientales (e.g. Craven \& Hygnstrom 1994; Cote et al. 2004; Stockton et al. 2005) y pérdidas de hasta un $50 \%$ de biodiversidad, llegando incluso a provocar la extinción local de algunas especies (Anderson \& Katz 1993; Stockton et al. 2005; Perea et al. 2014). A esto hay que sumar los daños en la agricultura y la conflictividad social que esto provoca (e.g. Putman \& Moore 1998), el incremento de accidentes de tráfico (e.g. Bissonette et al. 2008; RACC 2011) y el auge de trasmisión de enfermedades para animales y personas (e.g. Gortázar et al. 2006; Linden et al. 2010).

Los daños que causan los ciervos en los bosques son destacados desde antiguo (e.g. Beal 1899). En Europa, la especie que produce mayores daños a los bosques es el ciervo rojo (Ueckermann 1982). La revisión de estudios desarrollados a lo largo del siglo XX en los bosques templados del Hemisferio Norte muestra que los daños que causan los ciervos a los bosques son de tres tipos: ramoneo, descortece y escodado (Gill 1992). Los dos primeros para alimentación, el ramoneo en mayor o menor medida durante todo el año y el descortezado principalmente en invierno, cuando se reduce la disponibilidad trófica del ecosistema, especialmente si el suelo está cubierto de nieve. El escodado es el daño que los cérvidos causan a los árboles y arbustos por el frotamiento de sus cuernas. En su gran mayoría, los estudios se han centrado en los dos primeros tipos de daños, los más importantes, pues a veces causan serios daños ecológicos y económicos (Putman \& Moore 1998; Rooney 2001; Palmer \& Truscott 2003; Côté et al. 2004; Beguin et al. 2011; Randall \& Walters 2011; Perea et al. 2014). Mientras que la atención prestada al escodado ha sido muy reducida al no ser un tipo de daño observado con frecuencia.

El escodado lo realizan los ciervos macho para quitarse el epitelio velloso o terciopelo de la cuerna, durante el verano, pero también el resto del año como muestra de poder y territorialidad 
frente a otros machos (Schloeth 1968; Langvatn 1982; Whitehead, 1993). Es decir, hay que diferenciar entre escodado (en bibliografía anglófona rubbing o "thrashing") que es el frotamiento de la cuerna contra troncos y ramas (se produce en cualquier momento del año) y el descorree (fraying) frotamiento que solo se produce en verano para eliminar los restos del epitelio velloso de la cuerna. En la península Ibérica se han observado diferentes momentos de máxima intensidad. Así, Costa \& Sáenz de Buruaga (1994) indican una máxima actividad de escodado en la Cordillera Cantábrica en los meses de julio y agosto, coincidiendo con la caída del terciopelo. Sin embargo, apenas $400 \mathrm{~km}$ al Este, Ramos et al. (2006) observan en el NE de Portugal la máxima actividad de escodado entre septiembre y febrero, con pico en Noviembre, coincidiendo con la época de celo y por tanto de máxima interacción entre machos. Tras analizar diferentes datos Massei \& Bowyer (1999) concluyen que la selección de especies para el escodado de los cérvidos depende de las propiedades aromáticas (entre las que destaca la resina), del diámetro del tallo y de la facilidad de acceso.

En este estudio se plantea la hipótesis de que el último pinar natural de P. pinaster de Sierra Morena se encuentra en regresión y peligro de extinción por el incremento de las poblaciones de ciervo. Se establece como objetivo cuantificar y evaluar los daños que provoca el ciervo por escodado y su incidencia sobre el pinar relicto. Se proponen, finalmente, unas directrices de gestión sostenible para este bosque relicto.

\subsection{Material y métodos}

\subsubsection{Diseño del trabajo de campo.}

En el año 2003 se realizó el inventario de todos los pies leñosos de $P$. pinaster del pinar de la sierra de Navalmanzano (capítulo 3). Durante la realización del inventario se cuantificaron también los daños provocados por el ciervo. Se registró la diversa tipología de daños mediante inspección visual usándose una escala de 0-5 (Fig. 1). En el pinar hay dos tipos de fuste susceptibles de ser dañados: el que aún no ha alcanzado los $2 \mathrm{~m}$ de altura (pimpollo, que puede ser dañado en su totalidad) y el que los ha superado (árbol aún joven pero con una copa ya fuera del alcance del ciervo). En el segundo caso los ciervos dañan con la cuerna directamente al tronco, produciéndole la eliminación de la corteza, por el frotamiento de la cuerna, en torno a $1,5 \mathrm{~m}$ de altura en todo el perímetro del tronco (el "anillado"), causando la muerte del árbol. En la clasificación de la Fig. 5.1 el nivel 0 implica ausencia de daños, tratándose de árboles totalmente sanos, los siguientes niveles implican un nivel de daño creciente de 1 a 5 . 

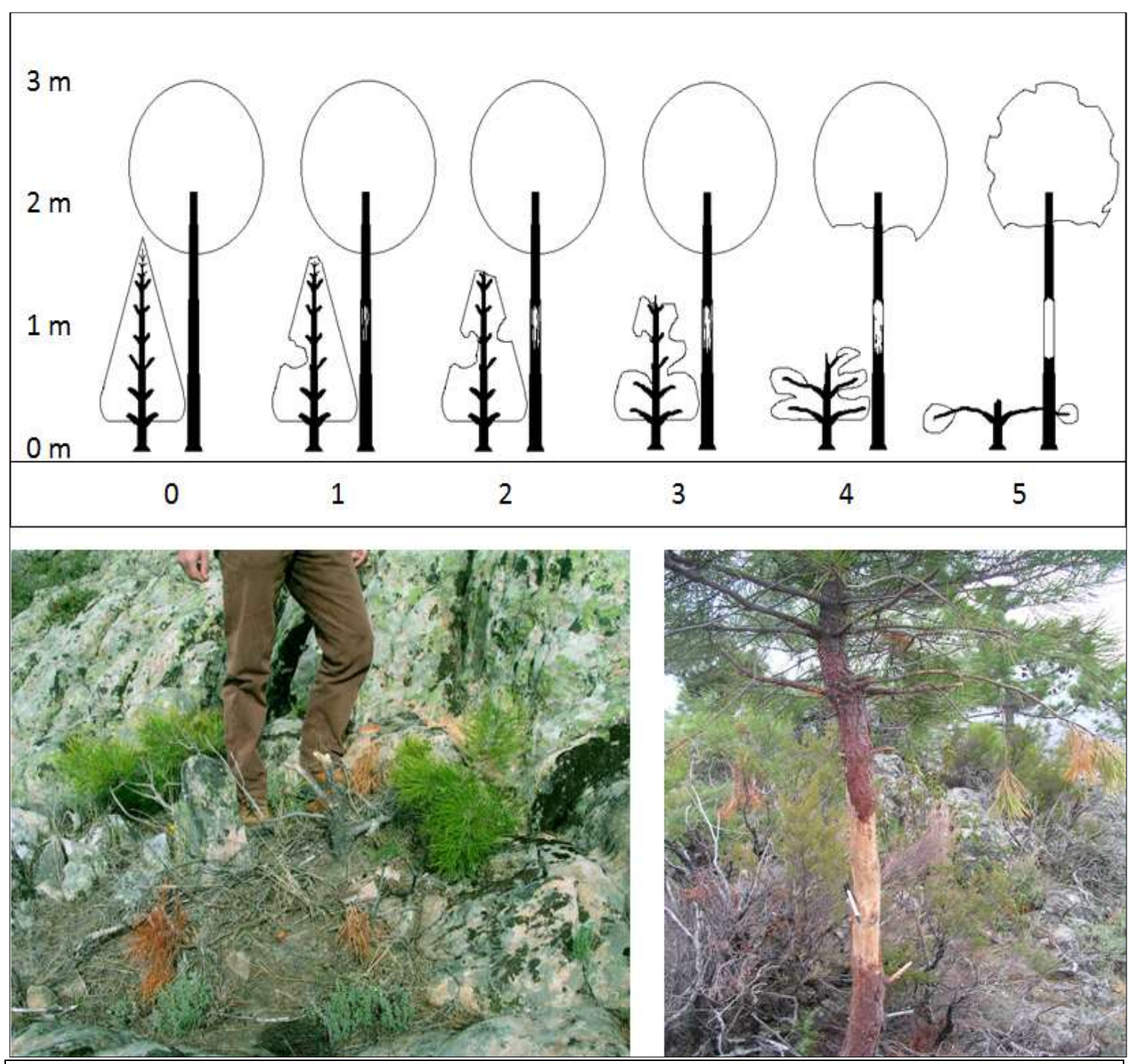

0. Ausencia de daño, árbol sano.

1. Daño muy leve. En pimpollos de hasta un $10 \%$ de la copa. En jóvenes árboles el tronco muestra daños en la corteza pero no en el floema.

2. Daño leve. En pimpollos pérdida del $10 \%$ al $25 \%$ de la copa. Pérdida de algunas ramas y/o guía principal. En jóvenes árboles el tronco ha perdido corteza, muestra el floema hasta en el $25 \%$ del perímetro.

3. Daño medio. En pimpollos pérdida del $25 \%$ al $50 \%$ de la copa. Pérdida de hasta la mitad de las ramas y/o guía principal. El pie responde a los daños aumentando el grosor y longitud de sus ramas más bajas. En jóvenes árboles el tronco, muestra el floema hasta en el 50\% del perímetro.

4. Daño severo. En pimpollos pérdida del $50 \%$ al $75 \%$ de la copa. Pérdida de más de la mitad de las ramas y/o guía principal. El pie responde a los daños aumentando el grosor y longitud de sus ramas más bajas. En jóvenes árboles el tronco muestra el floema hasta en el 75\% del perímetro.

5. Daño muy severo. En pimpollos pérdida del $75 \%$ al $100 \%$ de la copa. Pérdida de hasta la mitad de las ramas y/o guía principal, las últimas ramas bajas crecen rastreras por el suelo. En jóvenes árboles el tronco muestra el floema hasta en el $100 \%$ del perímetro.

Fig. 5.1. Esquema y leyenda de los diferentes niveles de daños producidos por el ciervo en los pinos. En las fotografías dos pinos afectados por escodado muy severo (nivel 5). Imagen de la Dcha. con un bolígrafo sobre el anillado del tronco como escala aproximada del diámetro del pino y del daño. 
En el año 2009 se cuantificó de nuevo el daño causado por los ciervos en una muestra de árboles estudiados en 2003. Para ello se inventariaron todos los individuos que se hallaban incluidos en 10 parcelas circulares (de $15 \mathrm{~m}$ de radio) con centro coincidente con el de 10 de las parcelas cuadradas del inventario de 2003 (las de las columnas F y H, Fig. 5.4).

Como estudio complementario, se instaló -en el año 2003- un pequeño vallado (10 x 10 m) de exclusión de herbívoros para proteger los cinco pinos que quedaron en su interior. A continuación, durante los años 2009 y 2015, se tomaron los datos de las principales variables dendrométricas de estos pinos así como el nivel de daños producido por los ciervos.

\subsubsection{Análisis de datos}

En primer lugar los datos fueron tratados como los de un inventario pie a pie calculando los índices selvícolas más importantes como el área basimétrica, la densidad y las alturas medias para el total del monte. Tras un primer análisis exploratorio se puso de manifiesto que el impacto producido por el ciervo sobre los pinos no era homogéneo presentándose un mayor impacto en pies de menor tamaño. Para estudiar las preferencias del ciervo para escodar, así como para evaluar el impacto de dicha práctica sobre el estado selvícola de la masa, se estableció en primer lugar que la variable de interés a ser analizada es de tipo presenciaausencia de daños sobre cada pie inventariado.

Se ajustaron varios modelos estadísticos que estiman la probabilidad de que un pino esté afectado por el ciervo. Al tratarse de una variable dependiente de tipo presencia-ausencia (variable binomial) el análisis se basó en la teoría del Modelo Linear Generalizado (GLM, en sus siglas en inglés) para variables binomiales. La estimación de los parámetros de los modelos se ha hecho mediante máxima verosimilitud, usando el comando glm del lenguaje R (www.rproject.org). La significación estadística de los parámetros estimados se ha hecho mediante la prueba de Wald. En todos los casos la bondad del ajuste del modelo fue conformada a través de la prueba $\chi^{2}$ sobre la ratio de verosimilitud de dos modelos analizados. También se usaron los gráficos de los residuos de los modelos construidos para confirmar la validez de estos.

Tras el ajuste de los modelos descritos se ha visto que la relación entre la probabilidad de daño por ciervo guardaba una relación no lineal con las covariables analizadas (altura y diámetros del individuo). En estos casos se empleó la técnica de los polinomios fraccionales (Royston and Ambler 1998) que se usan ampliamente en la modelización cuando se requiere mantener la naturaleza continua de la(s) covariable(s) del modelo pero se sospecha que la relación entre ella(s) y la respuesta puede ser no lineal (Hosmer et al. 2013). La idea básica de este método es determinar el valor $p$ de la covariable $\left(x^{p}\right)$ que proporciona el modelo con el mejor ajuste a los datos. El ajuste de modelos con polinomios fraccionales se ha hecho a través del paquete $m f p$ del lenguaje R. El modelo que finalmente se elige es el que tiene el mayor valor para el logaritmo de la verosimilitud. Lógicamente, para ser elegido el modelo final, se tiene que 
confirmar su superioridad estadística no solamente frente al modelo nulo (el que no incorpora ninguna covariable) sino también al correspondiente modelo con la covariables sin transformar (modelo lineal). Dicha superioridad se ha confirmado mediante la prueba j-cuadrado de la ratio de verosimilitud de los dos modelos.

La evolución del nivel de daño observado sobre (i) los individuos del segundo muestreo (año 2009) y (ii) los pinos incluidos en el cercado de exclusión se analizó mediante técnicas de estadística descriptivita.

\subsection{Resultados}

\subsubsection{Distribución de los daños causados por el ciervo}

En el inventario de 2003, del total de 1212 pinos inventariados, se han encontrado 401 pinos dañados por los ciervos, un $33 \%$ de la población total. El daño se produce siempre por escodado siendo nulos o imperceptibles el ramoneo y el consumo de corteza. En la Fig. 5.2 se muestra un claro patrón de selección de determinados árboles para el escodado.

Pinos dañados $(n=401)$

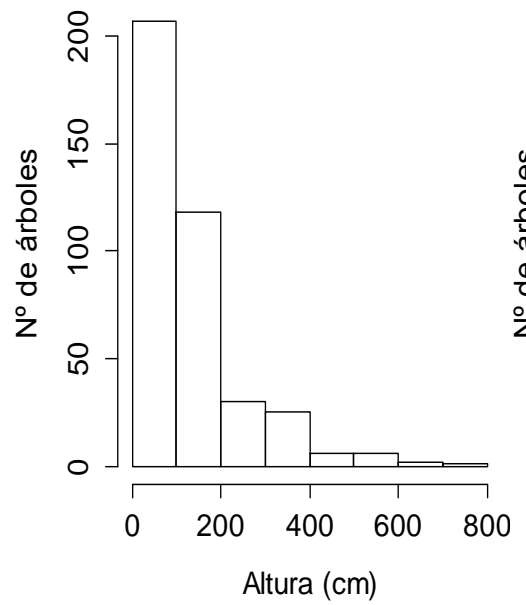

Pinos dañados $(n=401)$

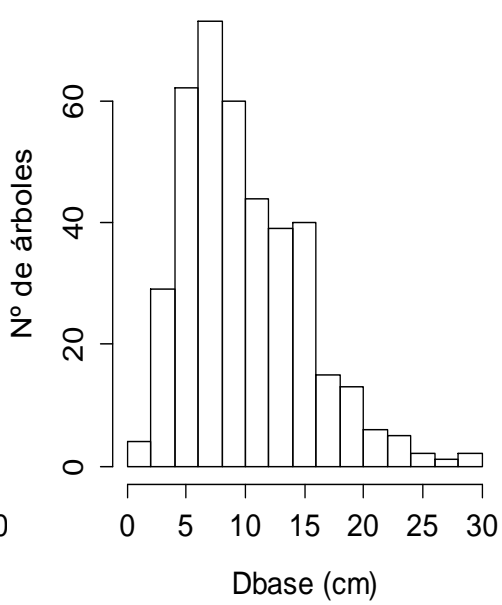

Pinos dañados $(n=138)$

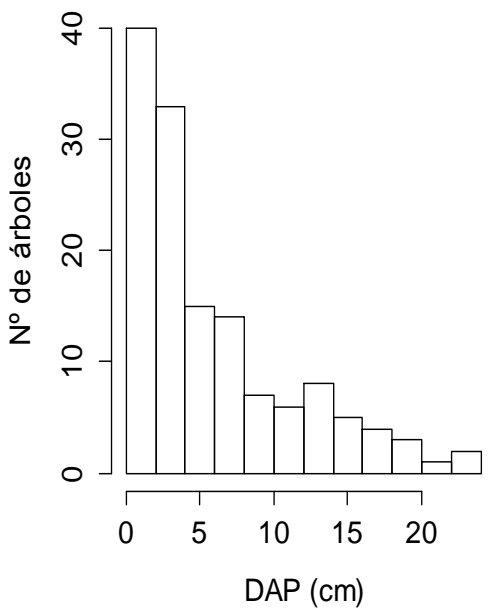

Fig. 5.2. Clases de altura y diamétricas de los pinos seleccionados por los ciervos para realizar el escodado.

Teniendo en cuenta la altura de los 401 pies dañados el escodado se concentra en los que tienen menos de $4 \mathrm{~m}$ de altura, es decir, en 377 pies (un 94\% del total) y, entre estos, la selección se centra aún más entre los menores de $2 \mathrm{~m}$ de altura (322 pies, un 80,3\%). En cuanto al diámetro basal, el escodado se concentra en los pinos con un rango de diámetro basal entre 2 y $20 \mathrm{~cm}$, en cuyo rango se hallan 378 pies dañados, es decir, un 94,3\% del total y, dentro de ese rango, a su vez, el mayor número de pies dañados se concentra entre los 4 y $16 \mathrm{~cm}$. En cuanto a los 138 
pies dañados que superan $1,3 \mathrm{~m}$ de altura, el mayor número de estos (102 pies, un $74 \%$ ) tienen diámetros normales inferiores a $8 \mathrm{~cm}$.

El escodado ha sido observado directamente in situ e, incluso, se han encontrado cuernas de ciervo entre las ramas bajas de los pinos más dañados. Los daños más leves (niveles 1 y 2) se distribuyen por un mayor rango de alturas y diámetros de tronco pero, a medida que el daño se va haciendo más severo (niveles 3,4 y 5) ese rango disminuye, concentrándose estos graves daños en alturas menores como consecuencia del decrecimiento generalizado del árbol por la pérdida de ramas y guía principal (Fig. 5.3).
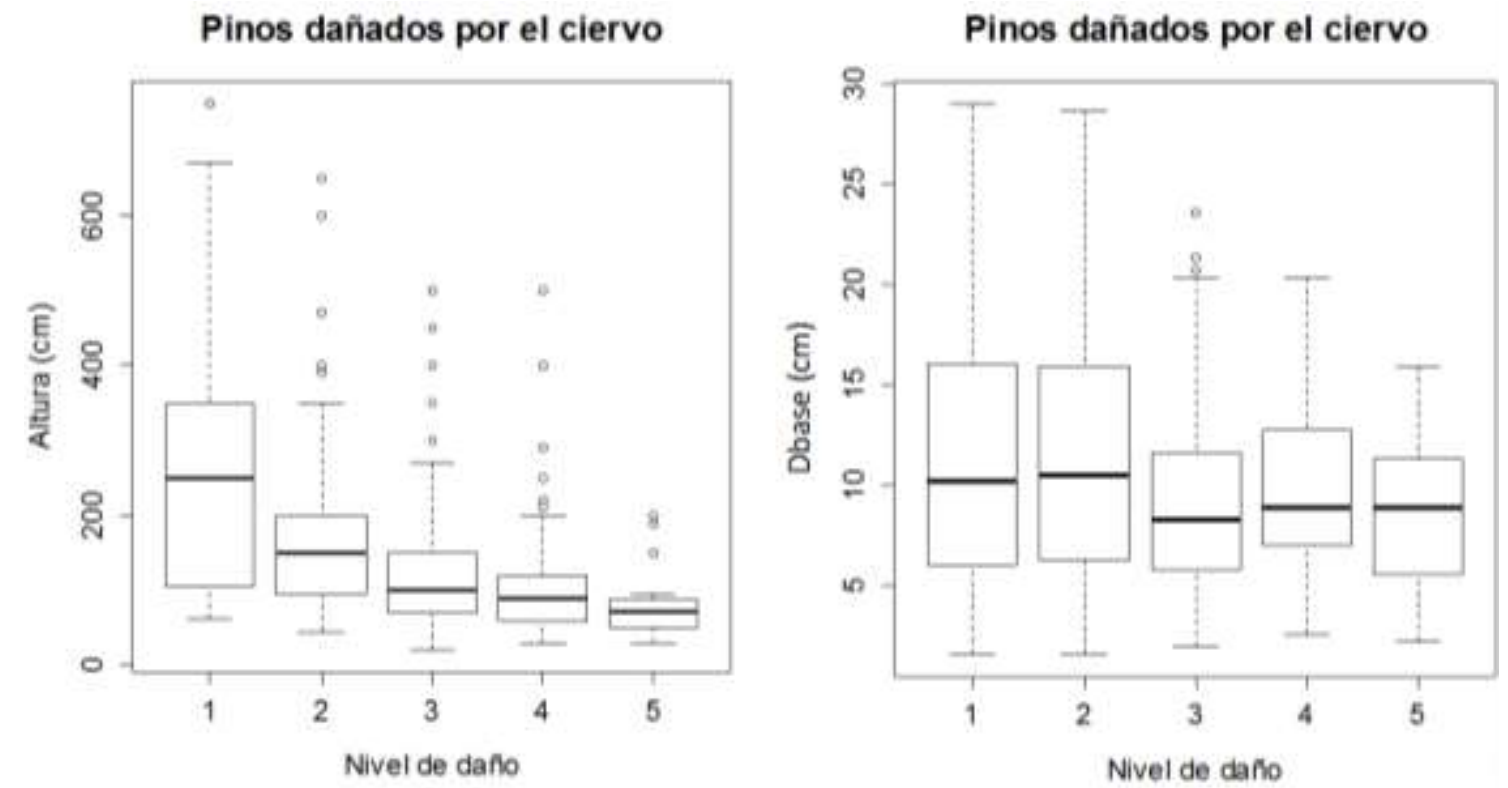

Fig. 5.3. Distribución de los diferentes niveles de daño producido por el ciervo a los pinos según su altura (Izda.) y diámetro basal del tronco (Dcha.).

En cuanto a la distribución sobre el terreno de los daños (y de su nivel), no se observa un patrón espacial de incidencia del ciervo, afectando de forma similar a todo el pinar (Fig. 5.4). De las 49 parcelas de $2500 \mathrm{~m}^{2}$ con pinos, se han encontrado daños en 41 de ellas $(83,7 \%)$.

El daño del ciervo por escodado afecta tanto a los pinos rupícolas, los que crecen directamente sobre los roquedos, como los que aparecen sobre suelos relativamente buenos. Aunque a veces se ha observado que pinos rupícolas susceptibles de ser dañados por su altura menor de $2 \mathrm{~m}$, no son dañados por situarse en roquedos de difícil acceso para el ciervo. 


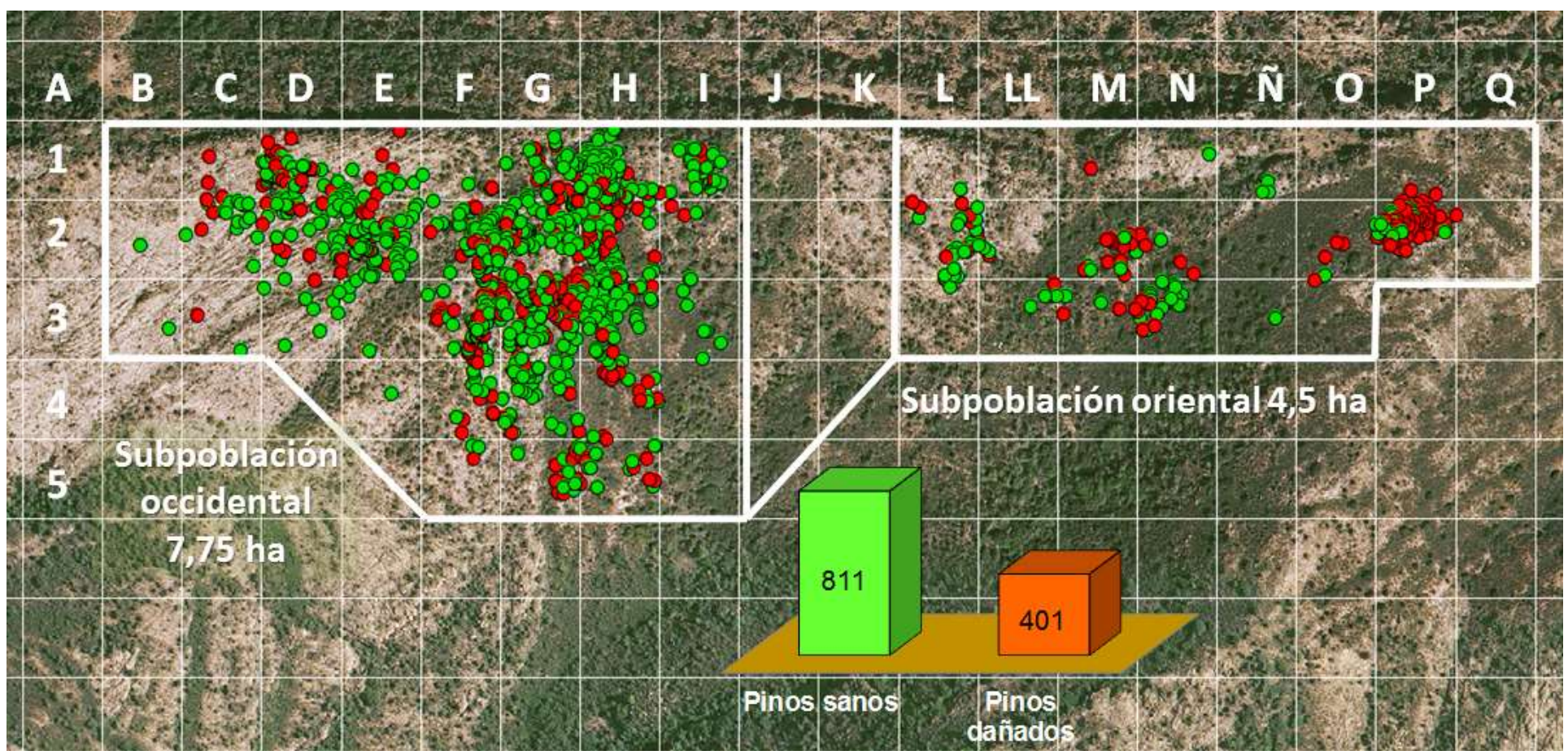

Fig. 5.4. Distribución espacial de los árboles del pinar autóctono de Sierra Madrona. Cada cuadrícula es una parcela de $50 \mathrm{~m}$ de lado $\left(2500 \mathrm{~m}^{2}\right)$. En color verde los 811 árboles sanos, en rojo los 401 pies dañados por el escodado del ciervo.

\subsubsection{Dendrometría de los pies dañados}

En la Fig. 5.5 se puede observar como el logaritmo de los "odds" de pies dañados presenta una relación no lineal con las principales variables dendrométricas del individuo (diámetro en la base y normal así como con la altura del individuo) alcanzando valores por encima de 0 en pies con $10 \mathrm{~cm}$ de diámetro basal (5 $\mathrm{cm}$ de diámetro normal).
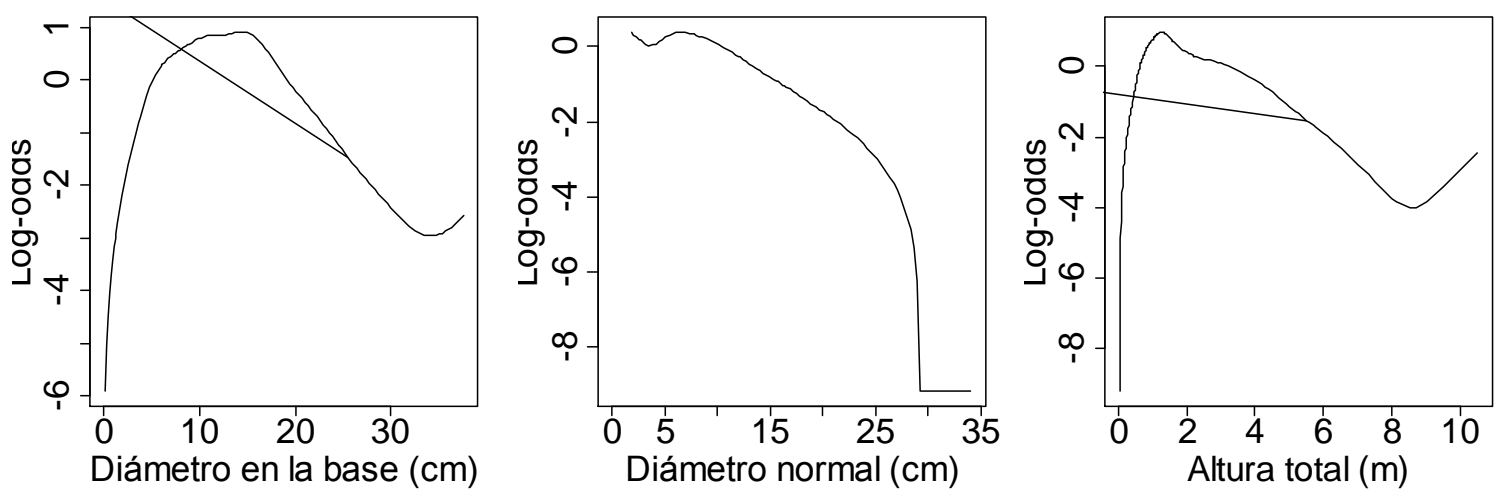

Fig. 5.5. Logaritmo de los odds de pies dañados según diámetros basal y a 1,30 m, y según la altura. 
Al presentarse una relación no lineal entre los odds del daño y las principales variables dendrométricas del individuo afectado se ha considerado oportuno discretizar dichas variables antes de proceder a ajustar el modelo de probabilidad de ser dañado por un ciervo. En la Tabla 5.1 se presenta dicha discretización para la altura total y el diámetro basal (los límites de las categorías se han establecido atendiendo a criterios selvícolas y estadísticos). La categoría base de la altura (A0) cuenta con los pies de mayor altura (más de $4 \mathrm{~m}$ ) al presentarse estos como los de menor impacto por ciervo (odds=0,09). Las categorías A2 (altura entre 1,3 m y $4 \mathrm{~m}$ ) y A1 (altura entre 0 y $1,3 \mathrm{~m}$ ) se presentan con odds igual a 1,46 y 0,65 , respectivamente, implicando que para cada pie no dañado existen 1,46 (A2) y 0,65 (A1) pies dañados. De la misma forma se puede observar que para cada pie no dañado de las categorías diamétricas D1 y D2 existen 0,56 y 1,91 pies dañados, respectivamente.

\begin{tabular}{|c|c|c|c|c|r|r|}
\hline Variable & Código & $\begin{array}{c}\text { Rango de la } \\
\text { clase }\end{array}$ & No atacados & Atacados & Total & Odds \\
\hline Altura & A0 & Más de $4 \mathrm{~m}$ & 185 & 18 & 203 & 0,09 \\
\hline & A1 & $0-1.3 \mathrm{~m}$ & 435 & 286 & 721 & 0.65 \\
\hline & A2 & $1.3-4 \mathrm{~m}$ & 91 & 133 & 224 & 1.46 \\
\hline & - & Total & 711 & 437 & 1148 & - \\
\hline \multirow{2}{*}{$\begin{array}{c}\text { Diámetro } \\
\text { en la } \\
\text { base }\end{array}$} & D0 & Más de 20 & 179 & 24 & 203 & 0,13 \\
\cline { 2 - 7 } & D1 & $0-10 \mathrm{~cm}$ & 447 & 250 & 697 & 0,56 \\
\cline { 2 - 7 } & D2 & $10-20 \mathrm{~cm}$ & 85 & 163 & 248 & 1,91 \\
\cline { 2 - 7 } & - & Total & 711 & 437 & 1148 & - \\
\hline
\end{tabular}

Tabla 5.1. Clases de alturas y diámetros usados en el modelo logístico

En la Tabla 5.2 se presentan los resultados obtenidos tras el ajuste del modelo logístico de la probabilidad del impacto en función de la altura del individuo $\left(\chi^{2}=132,75 ; p<0,001\right)$ y del diámetro en la base $\left(\chi^{2}=149,25 ; p<0,001\right)$. Según las estimaciones del primer modelo, los individuos de las categorías A1 y A2 son 4,18 y 15 veces (respectivamente) más probable de ser dañados por ciervo si se comparan con los individuos de la categoría A0 (pinos con alturas mayores de $4 \mathrm{~m}$ ). Parece, por tanto, confirmarse una clara preferencia de los animales hacia los individuos de la categoría A2. Además, según las estimaciones del segundo modelo (Tabla 3) los individuos con diámetro en la categoría D2 son 14,3 veces más probable de ser atacado por ciervos si se comparan con los individuos de la categoría D0. Además, según se desprende de la Tabla 2, los intervalos de confianza de los estimadores de la ratio de los odds no incluye el valor de uno en ninguno de las categorías de alturas o diámetros. 


\begin{tabular}{|c|c|c|c|c|c|c|c|c|}
\hline & & & & & & \multicolumn{3}{|c|}{ Odds ratio } \\
\hline $\begin{array}{c}\text { Modelo/ } \\
\text { Covariable }\end{array}$ & Categoría & Coeficiente & SE & z-value & $\mathrm{p}$ & Estimado & \multicolumn{2}{|c|}{ CI (95\%) } \\
\hline \multirow{3}{*}{$\begin{array}{l}\text { Modelo para la } \\
\text { altura }\end{array}$} & A0 & $-2,33$ & 0,24 & $-9,43$ & $<0,001$ & 0,09 & & \\
\hline & A1 & 1,91 & 0,25 & 7,39 & $<0,001$ & 6,75 & 4,18 & 11,58 \\
\hline & $\mathrm{A} 2$ & 2,70 & 0,28 & 9,61 & $<0,001$ & 15,02 & 8,84 & 26,84 \\
\hline \multirow{3}{*}{$\begin{array}{l}\text { Modelo para el } \\
\text { diámetro basal }\end{array}$} & D0 & $-2,00$ & 0,21 & $-9,244$ & $<0,01$ & & & \\
\hline & D1 & 1,42 & 0,23 & 6,17 & $<0,01$ & 4,17 & 2.7 & 6.71 \\
\hline & D2 & 2.66 & 0,25 & 10,42 & $<0,01$ & 14,30 & 8.81 & 24.04 \\
\hline
\end{tabular}

Tabla 5.2. Modelos de regresión logística para la probabilidad de que un árbol sea dañado, usando como covariables la altura y el diámetro basal.

SE: Error Standard; CI: Intervalo de Confianza; A0, A1, A2, D0, D2, D2: ver Tabla 5.1.

Según se desprende de los análisis previos, los pies que han superado un cierto tamaño, en cuanto a su altura y diámetro se refiere, consiguen disminuir el riesgo de ser dañados. El efecto conjunto de las covariables (altura, diámetro en la base y diámetro normal) sobre la probabilidad de ser dañado por algún ciervo no se puede estudiar mediante las técnicas de análisis utilizadas en el apartado anterior, al presentarse una relación no lineal entre ambas covariables. Para poder superar los problemas estadísticos impuestos por estas condiciones se utiliza la técnica de los polinomios fraccionales.

Para explorar la compleja relación entre los odds del daño y las covariables candidatas se presentan los resultados de los dos ajustes por polinomios fraccionales (Tabla 5.3). El modelo 1 se ha generado usando la altura total y el diámetro en la base, como covariables, mientras que el modelo 2 incluye la altura total y diámetro normal (1,3 $\mathrm{m}$ de altura). Se ha conseguido la convergencia en ambos casos con todos los coeficientes valorándose de forma significativa (Tabla 5.3). De los modelos obtenidos, se elige finalmente el primero (modelo 1) no solo porque presenta una menor desviación residual (1094,4 modelo 1 y 1210,7 para el modelo 2) sino por el menor índice de AIC (1104,4 para el modelo 1 frente a 1216,7 del modelo 2).

\begin{tabular}{|c|c|c|c|c|c|}
\hline & & Coef. & EE & Valor z & $\operatorname{Pr}(>|z|)$ \\
\hline \multirow{5}{*}{$\begin{array}{c}\text { Modelo 1 } \\
\text { Deviance }=1094,4 \\
\text { AIC }=1104,4\end{array}$} & Constante & $-3,06$ & 1,45 & $-2,11$ & 0,048 \\
\hline & $\log \mathrm{H}$ & 2,92 & 0,43 & 6,73 & $<0,001$ \\
\hline & $\mathrm{H}^{\wedge} 0.5$ & $-5,61$ & 0,75 & $-7,43$ & $<0,001$ \\
\hline & $(\mathrm{D} / 10)^{\wedge} 0.5$ & 9,77 & 1,12 & 8,69 & $<0,001$ \\
\hline & $(\mathrm{D} / 10)^{\wedge} 0.5 * \log (\mathrm{D} / 10)$ & $-3,96$ & 0,57 & $-6,92$ & $<0,001$ \\
\hline \multirow{3}{*}{$\begin{array}{c}\text { Modelo } 2 \\
\text { Deviance }=1210,7 \\
\text { AIC }=1216,7\end{array}$} & Constante & 3.06 & 0.27 & 11.30 & $<0,001$ \\
\hline & $(\mathrm{Dn}+0.1) / 10$ & -1.91 & 0.15 & -11.96 & $<0,001$ \\
\hline & $\mathrm{H}^{\wedge}-0.5$ & -2.51 & 0.21 & -11.77 & $<0,001$ \\
\hline
\end{tabular}

Tabla 5.3. Modelos de regresión logística con polinomios fraccionales.

H: Altura total; D: Diámetro en la base; Dn: Diámetro normal; Coef: Coeficiente estimado; EE: Error estándar 
Como cabía esperar -tras los análisis presentados en el apartado anterior- el modelo elegido por el algoritmo contiene dos términos para ambas covariables, con potencias $\{\mathrm{p} 1=0, \mathrm{p} 2=0.5\}$ para la altura total y $\{\mathrm{p} 1=0.5, \mathrm{p} 2=0.5\}$ para el diámetro en la base. De acuerdo con los resultados del ajuste el modelo 1 es significativamente mejor que el correspondiente modelo lineal $\left(\chi^{2}=\right.$ 358,08; $g l=3 ; p<0,001)$ o el modelo nulo $\left(\chi^{2}=431.08 ; g l=4 ; p<0,001\right)$.

El modelo 1 se puede escribir como:

$$
g(x, \boldsymbol{\beta})=\beta_{0}+\beta_{1} \log H+\beta_{2} \sqrt{H}+\beta_{3} \sqrt{\frac{D}{10}}+\beta_{4} \sqrt{\frac{D}{10}} \cdot \log \frac{D}{10}
$$

siendo $g(x, \boldsymbol{\beta})$ los logits con vector de parámetros $\boldsymbol{\beta}$ y $H, D$ la altura total y el diámetro en la base, respectivamente. La interpretación de los parámetros en este tipo de modelos, sin embargo, no es tan fácil de hacer puesto que ecuación anterior incluye combinaciones de variables y algunas transformaciones bastante complejas entre las covariables. No obstante, una validación ecológica del modelo se considera imprescindible antes de poder usarse en la práctica. Con este objetivo se presenta en la Figura 6, la estimación de la probabilidad de sufrirse un daño por ciervos en función de su diámetro (en la base) y su altura total. Según estas estimaciones la probabilidad del daño aumenta rápidamente durante la fase de primer desarrollo en altura, pasando de 0,5 para individuos con alturas de $0,7 \mathrm{~m}$ aproximadamente cuyo diámetro en la base es $5 \mathrm{~cm}$. A continuación la probabilidad del daño alcanza su valor más alto (0.75) para individuos con alturas de $1,5 \mathrm{~m}$ y $11 \mathrm{~cm}$ de diámetro en la base. Llama la atención que la probabilidad del daño se mantiene por encima del 0,5 hasta una altura de $3,5 \mathrm{~m}$ aproximadamente (19 $\mathrm{cm}$ de diámetro en la base). Finalmente, conviene destacar que la probabilidad del daño desciende por debajo del 0,2 para individuos ya maduros de $5 \mathrm{~m}$ de altura y $25 \mathrm{~cm}$ de diámetro en la base.

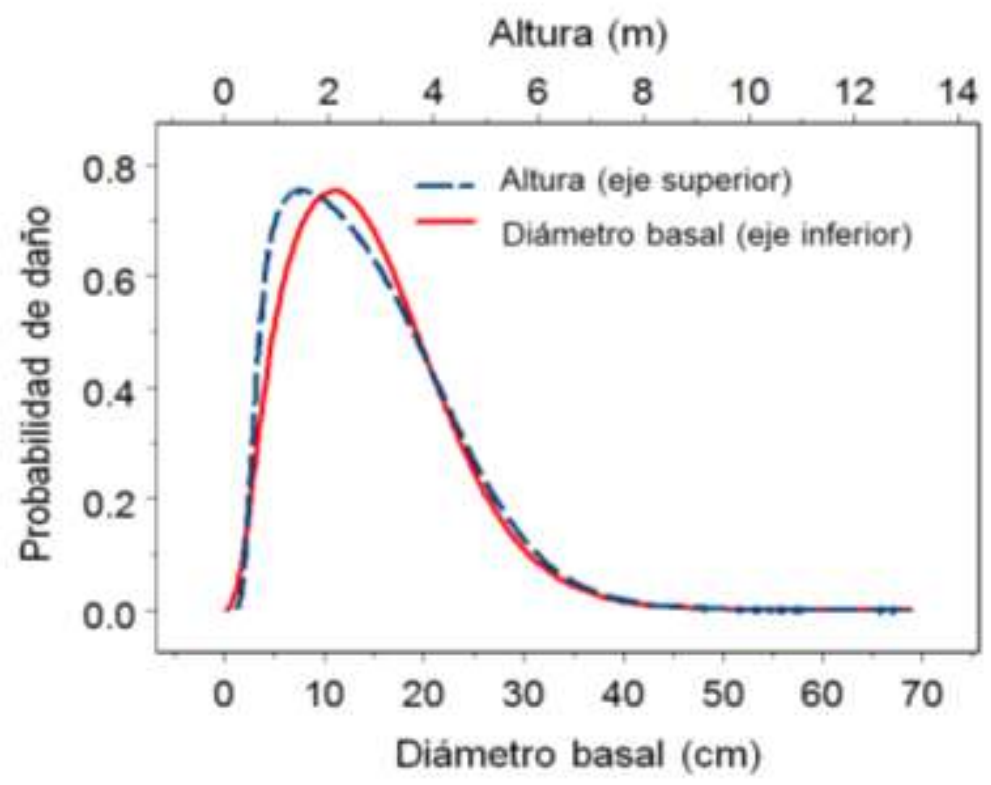

Figura 6. Probabilidad de observarse daños por ciervo en función de la altura total y el diámetro basal del árbol, según las estimaciones del modelo 1. 


\subsubsection{Evolución de los daños causados durante el periodo 2003- 2015.}

El número de pies dañados por ciervos en el año 2009 (48 pies) fue superior al detectado en 2003 (40 pies dañados), observándose un incremento porcentual del $20 \%$ en el número de pies afectados. Además, durante este periodo, se ha observado un crecimiento significativo en el diámetro normal medio de los pies no-dañados ( $25 \%$ de aumento ó 4,5 $\pm 3,9 \mathrm{~mm} / \mathrm{año}$ ) mientras

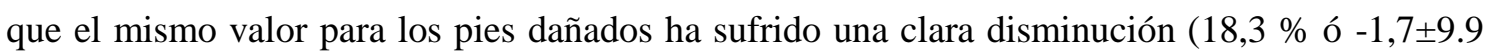
$\mathrm{mm} /$ año, Figura 5.7). Un patrón parecido se observa para la evolución de la altura media: el incremento en altura de los pies no dañados fue significativo $(11.1 \pm 11.0 \mathrm{~cm} /$ año $)$ mientras que el mismo incremento para los pies dañados fue no significativo $(3.6 \pm 13.5 \mathrm{~cm} / \mathrm{año})$. El crecimiento en diámetro basal, sin embargo, fue significativo para ambos grupos de individuos (dañados y no dañados, Figura 5.7).
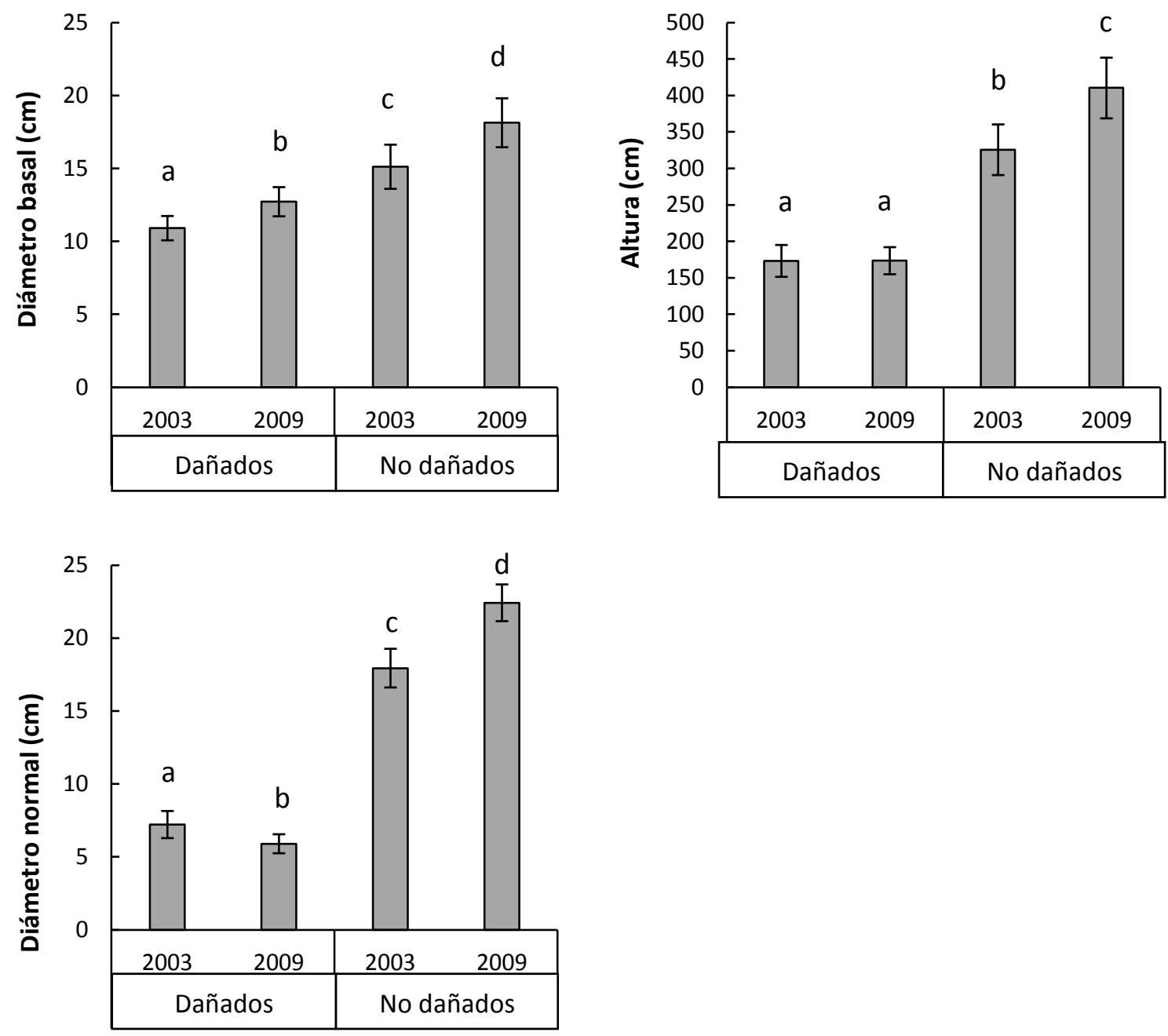

Figura 5.7. Evolución del diámetro medio (basal y normal) y de la altura media en los pies dañados y no dañados por ciervo durante el periodo 2003-2009

En el vallado de exclusión de herbívoros, los 5 pinos presentes en 2003 mostraban una altura media de 1,18 m y su nivel medio de daños por el ciervo fue de 3,6 (2 pinos con nivel de daño " 3 " y 3 pinos con nivel "4"). Estos 5 pinos, aunque crecían sobre un suelo relativamente bueno, 
estaban seriamente amenazados de muerte pues el daño de los ciervos una vez iniciado suele continuar hasta acabar con la vida del árbol. Sin embargo, en el año 2009, tras 6 años protegidos por el vallado, los 5 pinos se recuperaban bien y crecían hasta doblar su altura media $(2,47 \mathrm{~m})$, un crecimiento medio de 21,1 cm/año (Fig. 8). En 2015 los pinos han cicatrizado los daños presentes en 2003 y su altura media es de $3,91 \mathrm{~m}$.

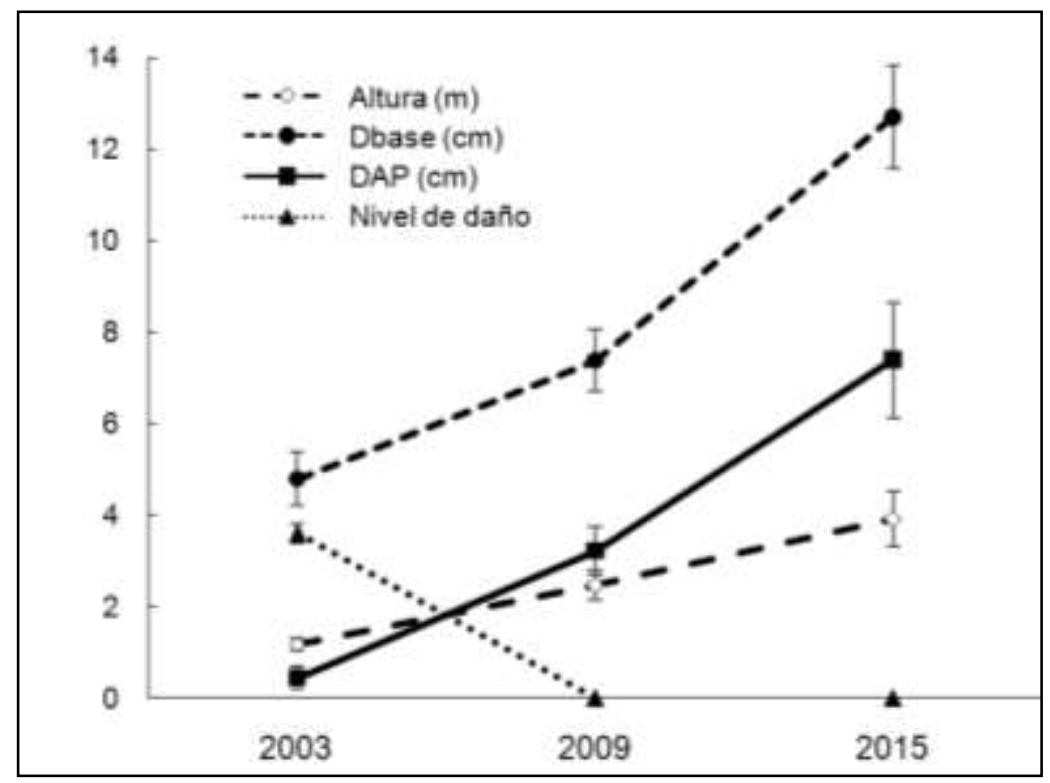

Fig. 8. Recuperación de los 5 pinos del interior del vallado de exclusión durante el periodo 2003-2015 tras el cese de los daños de ciervo. Su crecimiento se muestra a través de 3 variables dendrométricas: altura, diámetro basal (Dbase) y diámetro normal (DAP).

\subsection{Discusión}

En 2003 el 33\% de los pies del pinar autóctono de la sierra de Navalmanzano presentaba daños por el escodado del ciervo. El porcentaje de daños observado es muy superior al mencionado en otros trabajos como, por ejemplo, el 3\% de pies dañados encontrado por Schloeth (1968) en masas forestales de Suiza, o incluso del 25\% de pies dañados de Aranda et al. (1995) en España (dato más alto observado hasta ahora). Además, el incremento de los daños en 2009 confirma que el escodado del ciervo sobre el pinar en 2003 no fue un hecho puntual sino que es un problema creciente.

Además, como puede verse en la Fig 5.4, el daño provocado por los ciervos parece afectar prácticamente a toda la masa por igual. Esta distribución espacial contrasta con los datos obtenidos por Ramos et al. (2006) sobre plantaciones de P. pinaster y otras especies arbóreas, en el NE de Portugal, donde el ciervo solo afecta por escodado a los árboles próximos a los bordes de las plantaciones. Esto puede deberse a que en el interior de una plantación de pinos no suele haber mucha vegetación palatable para el ciervo, como hemos observado en las plantaciones de pinos de Sierra Morena y en otras zonas de los países mediterráneos. En cambio en el pinar autóctono, al ser una masa irregular y de baja densidad, aparecen entre los pinos 
plantas palatables de numerosas especies (herbáceas, arbustivas y arbóreas) por lo que el ciervo se adentra con frecuencia por toda la zona para alimentarse y escodar.

En 2009, debido al escodado del ciervo, el crecimiento en altura y en diámetro de los pies afectados se ha visto reducido debido a la eliminación de parte de las ramas (incluida la guía principal, ver Fig. 5.1). El escodado afecta negativamente al crecimiento en altura de los pinos, aunque no tanto al crecimiento del diámetro basal. A veces pinos a los que se les midió el diámetro normal en 2003 no se les pudo medir en 2009 porque la altura del pino había sido rebajada por el ciervo (eliminando el tallo principal) por debajo de esa altura. Además de desramar y matar a los jóvenes pinos de menos de $2 \mathrm{~m}$ de altura, a veces también se produce el "anillado" de troncos de árboles de más de $2 \mathrm{~m}$ de altura y de hasta $30 \mathrm{~cm}$ de diámetro basal.

Sobre los motivos que llevan al ciervo a seleccionar determinadas especies para el escodado en el monte mediterráneo, Moreno et al. (2001) en su estudio sobre Pistacia terebinthus L. coincide con otros autores en que el ciervo selecciona ejemplares jóvenes, con corteza más fina y con el menor índice de abundancia. En Sierra Madrona se ha observado el escodado además de en P. pinaster, en Quercus ilex, Q. faginea, Q. pyrenaica, Olea europea, Phillyrea angustifolia, Myrtus communis o Arbutus unedo, sobre pies leñosos jóvenes, pero también sobre los viejos ejemplares de jara pringosa Cistus ladanifer L., especie muy aromática y abundante. Todas estas especies están presentes en el pinar aquí estudiado pero el ciervo parece seleccionar exclusivamente al pino, la especie más abundante (no se han observado daños en individuos de las demás especies presentes en el pinar).

El ciervo selecciona a pinos que le sea fácil descortezarlos para producir la secreción de los canales resiníferos del xilema secundario. La edad del pino no parece ser determinante para el escodado, lo realmente importante para el ciervo es el acceso a la resina. Por tanto, los pinos que sufren daños son aquellos cuyas ramas y troncos de menos de $15 \mathrm{~cm}$ de diámetro están al alcance de la cuerna del ciervo, normalmente desde el suelo hasta los $2 \mathrm{~m}$ de altura. Si el tronco supera los $15 \mathrm{~cm}$ de DAP no suele ser dañado por que ya ha desarrollado una corteza muy gruesa que dificulta al ciervo el acceso a la resina. A pesar de existir un amplio rango de alturas (de 4 a $1650 \mathrm{~cm}$ ) y de diámetros de tronco (de 0,16 a 68,75 $\mathrm{cm}$ de base y hasta $56 \mathrm{~cm}$ de DAP) (capítulo 3) el ciervo selecciona para el escodado principalmente a los individuos menores de 3(4) $\mathrm{m}$ de altura y de $30 \mathrm{~cm}$ de diámetro basal (Fig. 2). Analizados los datos estadísticamente se comprueba que la probabilidad de que un pino sea dañado por el ciervo depende de su altura y su diámetro, siendo más probable que sean dañados los pinos menores de $4 \mathrm{~m}$ de altura y de menos de $30 \mathrm{~cm}$ de diámetro basal (Figs. 5.5 y 5.6). La selectividad del ciervo por determinados tamaños permite entender por qué en Sierra Madrona los pinos que nacieron entre las décadas de 1960 y 1970 (cuando cesaron los incendios y la densidad de ciervo aún era baja) hoy, con más de 40 años de edad y superadas las alturas y diámetros de tronco críticos, crecen sin problemas. Sin embargo los pinos que nacieron en las 4 últimas décadas (sin incendios pero ya con una alta densidad de ciervos) sufren serios daños por el escodado y muchos de ellos acaban muriendo. 
Los 5 pinos protegidos por el vallado de exclusión experimental instalado en 2003, estaban muy dañados por el ciervo (nivel medio de daños de 3,6). Estos jóvenes pinos estaban condenados a morir por el escodado del ciervo en 2003 pero, protegidos por el vallado, fueron cerrando sus heridas y duplicaron su altura en 2009. En 2015 han multiplicado su altura 3,3 veces y todos presentan fructificaciones.

Tanto por los resultados de la evolución de los daños entre los inventarios de 2003 y 2009 , como por lo ocurrido en el interior del cercado de exclusión con respecto al exterior, puede concluirse que el ciervo constituye en la actualidad un serio riesgo para la conservación de este pinar relicto. El escodado del ciervo es bien conocido en Sierra Morena desde antiguo por las gentes del lugar y descrito en la bibliografía desde al menos el siglo XIX (Martínez Reguera 1881). Pero el daño que las bajas densidades de ciervo producían sobre el pinar eran mínimas (no se han encontrado evidencias de daños en pinos con más de 50 años de edad). Ahora, con casi un $40 \%$ de los pinos dañados del total de la población, con escaso número de pinos adultos (a salvo de los ciervos pero de reducida longevidad dado los litosuelos en que viven), se vislumbra un dudoso futuro para el pinar relicto de Navalmanzano. Aunque las duras condiciones edafoclimáticas (capítulo 3) parecen ralentizar el regenerado del pinar, no lo impiden. En cambio la ardilla, al consumir el banco aéreo de semillas (capítulo 4) y el daño por escodado del ciervo, si frenan la expansión del pinar y pueden amenazar incluso con su total eliminación a largo plazo si desaparece la regeneración de la masa.

Por primera vez se documenta un proceso de escodado de ciervo tan severo sobre una masa forestal en general y sobre $P$. pinaster en particular. El escodado del ciervo no parecía un daño importante pues en zonas que se ha estudiado y cuantificado no suele superar el 3\% de la mortalidad de las especies seleccionadas (Hannan \& Whelan 1989, Maizeret \& Ballon 1990; Aranda et al. 1995). Aunque a veces la selectividad del ciervo por determinadas especies si puede llegar a causar un serio daño si la especie preferida para el escodado está en regresión como el roble Quercus petraea (Matts.) Liebl., cada vez más escaso en el N de España, donde el ramoneo y el escodado de los cérvidos está reduciendo considerablemente su presencia (Costa \& Saenz de Buruaga 1994). En zonas mediterráneas la cornicabra (P. terebinthus) sufre una pérdida de vástagos por escodado que afecta a más del 50\% de los ejemplares (Aranda et al. 1995; Moreno et al. 2001). Pero tanto estas últimas como otras especies de los géneros Fagus, Quercus, Corylus, Betula, Alnus, Olea, Fraxinus, Phillyrea, Arbutus y otras muchas de los bosques del Hemisferio Norte, tienen la capacidad de rebrotar, en cambio la mayoría de las pináceas no. De modo que aunque los pinos son muy resistentes al escodado, si la intensidad de este llega a eliminar su parte aérea acaba con la vida del pino y el impacto sobre el bosque es mucho mayor.

Este estudio explica por qué la supervivencia del pinar relicto de Sierra Madrona está muy amenazada por el escodado del ciervo y, en cambio, apenas afecta a las numerosas repoblaciones de pinos ( $P$. pinaster y $P$. pinea) realizadas en toda Sierra Morena. El hecho de que apenas hayan sufrido el escodado se debe a que cuando se realizaron (desde mediados del siglo XX) las densidades de ciervo eran muy bajas y cuando empezaron a ser altas (a finales de 
ese siglo) los pinos (plantados en zonas con buenas condiciones edafoclimáticas) ya habían superado las medidas críticas de supervivencia al escodado $(15 \mathrm{~cm}$ de DAP y más de $4 \mathrm{~m}$ de altura).

Para evitar el impacto de los cérvidos sobre cultivos agrícolas y forestales, pastos, ecosistemas y especies amenazadas se han estudiado y puesto en práctica numerosos métodos físicos y repelentes químicos (e.g. Swihart et al. 1990; Nolte 1998; Bandoh 1998; Wagner \& Nolte 2001; Orihashi et al. 2002; MacGo-wan 2004; Santilli et al. 2004; Álvarez 2009). Sin embargo estos métodos o no son realmente efectivos o, cuando lo son, constituyen soluciones puntuales que no resuelven el problema de fondo. El vallado del área a proteger es la solución más recurrente en todos los ámbitos y países pero a veces su elevado precio (instalación y adecuado mantenimiento) lo hace poco práctico. Además las vallas tienen el problema añadido de causar impactos ambientales y paisajísticos poco deseables. En Escocia, para proteger la regeneración de los pinares de P. sylvestris se han vallado numerosas áreas (Palmer and Truscott 2003) pero en esta zona las vallas son la principal causa de mortalidad de aves amenazadas como el urogallo (Tetrao urogallus L.) y el gallo lira (T. tetrix L.) (Catt et al. 1994). Además de otros vertebrados, numerosas especies de aves se ven afectadas por impacto con los vallados en Europa y Norteamérica (e.g. Moss et al. 2000; Bevanger \& Brøseth 2000; Baines \& Andrew 2003; Wolfe et al. 2007). En España también se ha documentado la muerte por impacto en vallas de aves como el búho real (Bubo bubo L.), grulla (Grus grus L.) o avutarda (Otis tarda L.) (ANSER 2010). También algunas rapaces muy raras y amenazadas como el halcón peregrino (Falco peregrinus Tunstall), águila culebrera (Circaetus gallicus Gmelin) o buitre negro (Aegypius monachus L.) (Arenas 1993) y hasta el águila imperial (Aquila adalberti Brehm) (Blanco 1994). Todas las especies de rapaces citadas viven en Sierra Madrona y podría afectarles el vallado del pinar, máxime teniendo en cuenta que se sitúaría en la parte alta y cumbre de una ladera expuesta al sur que las aves planeadoras (en especial el buitre negro) atraviesan a muy baja altitud (casi rozando pinos y rocas de la cumbre, como observamos en varias ocasiones mientras trabajábamos en el pinar), además comprobamos sobre el terreno que es zona de caza habitual de águila real (Aquila chrysaetos L.) y esporádica de águila imperial.

Actualmente en los países del Hemisferio Norte para proteger los bosques relictos y otros valiosos ecosistemas, así como los cultivos, la seguridad en las carreteras y la salud pública, afectados por la expansión de los cérvidos, lo más deseable es reducir las poblaciones de estos ungulados hasta niveles considerados sostenibles. Estos niveles, como se indicó más arriba y dependiendo de la calidad del hábitat, se sitúan en las zonas templadas y mediterráneas del Hemisferio Norte entre 0,3-10 individuos $/ \mathrm{km}^{2}$.

\subsection{Referencias}

Acevedo, P., Ruiz-Fons, F., Vicente, J., Reyes-García, A.R., Alzaga, V. \& Gortazar, C. 2008. Estimating red deer abundance in a wide range of management situations in Mediterranean habitats. Journal of Zoology 276: 37-47. 
Álvarez, D. 2009. Efecto de repelentes sobre ramoneo de corzo (Capreolus capreolus L.) en una repoblación de Pinus pinaster A. Proyecto fin de carrera. I.T. Forestal. E.U. de Ingenierías Técnicas de Mieres. Universidad de Oviedo.

Anderson, R.C. \& Katz, A.J. 1993. Recovery of browse-sensitive tree species following release from white-tailed deer Odocoileus virginianus Zimmerman browsing pressure. Biological Conservation 63: 203-208.

ANSER, 2010. Infraestructuras peligrosas para las aves. (Visitado 10-03-2015). http://naturimagenes.blogspot.com.es/2010/11/infraestructuras-peligrosas-para-las.html

Apollonio, M., Andersen, R. \& Putman, R. 2010. Introduction. En: Apollonio, M., Andersen, R. \& Putman, R. (Eds.). European Ungulates and Their Management in the 21st Century. 1-14. Cambridge University Press. Cambridge.

Aranda, Y., Orueta, J.F. \& Fandos, P. 1995. Análisis de la selección de escodaderos por parte del ciervo (Cervus elaphus L.) en ambiente mediterráneo. Ecología. 9: 395-401.

Arenas, R. 1993. La importancia de las mallas cinegéticas en la ecología de la fauna salvaje de Sierra Morena. En: El ciervo en Sierra Morena (Arenas, A. \& Perea, A. Eds.). Universidad de Córdoba, 105-119

Azorit, C. 2005. La importancia de la gestión de los ciervos en Sierra Morena oriental. Real academia de ciencias veterinarias de Andalucía oriental. Anales 18 (1): 15-21.

Baines, D. \& Andrew, M. 2003. Marking of deer fences to reduce frequency of collisions by woodland grouse. - Biological Conservation 110: 169-176.

Bandoh, T. 1998. Study of damage caused by sika deer to private forests and the problem of protection techniques. Hoppo Ringyo 50:197-200. (en japonés).

Beal, W.J. 1900. Damage done to young trees by Deer and Elk. Michigan Academy of Science, Ann. 1899-1900. Rept. 2: 83-84.

Beguin, J., Pother, D., Côté, S.D, 2011. Deer browsing and soil disturbance induce cascading effects on plant communities: a multilevel path analysis. Ecology Applied, 21: 439-451.

Bevanger, K. \& Brøseth, H. 2000. Reindeer Rangifer tarandus fences as a mortality factor for ptarmigan Lagopus spp. - Wildlife Biology 6: 121-127.

Bissonette, J.A., Kassar, C. \& Cook, L.J., 2008. Assessment of costs associated with deervehicle collisions: human death and injury, vehicle damage, and deer loss. Human Wildlife Conflicts, 2, 1: 17-27.

Blanco, J.C. 1994. Influencia de los cercados en la fauna no cinegética. En: Vallados cinegéticos. Incidencia ambiental, social y económica. CODA. 39-44.

Carden, R., Carlin, C.M., Marnell, F., Mcelholm, D., Hetherington, J. \& Gammell, M.P. 2011. Distribution and range expansion of deer in Ireland. Mammal Rev. 41, 4: 313-325.

Catt, D.C., Dugan, D., Green, R.E.,Moncrieff, R., Moss, R., Picozzi, N., Summers, R.W. \& Tyler, G.A. 1994. Collisions against fencesby woodland grouse in Scotland. Forestry 67, $105-118$.

Costa, L., Sáenz de Bueruaga, M., 1994. Impacto del escodado por cérvidos en la vegetación forestal de la montaña Cantábrica meridional (España). Investigaciones Agrarias. Sistemas y Recursos Forestales, 3(2): 183-197. 
Côté, S.D., Rooney, T.P., Tremblay, J.P., Dussault, C. \& Waller, D.M. 2004. Ecological impacts of deer overabundance. Ann. Rev. Ecol. Evol. Syst. 35, 113-147.

Craven, S. \& Hygnstrom, S. 1994. Deer. Prevention and control of wildlife damage. Wildlife Committee. 25-39.

Garrido, J.L. 2012. La caza. Sector económico. Valoración por subsectores. FEDENCA-EEC, Madrid, 24 pp.

Gill, R. 1990. Monitoring the status of European and North American Cervids. GEMS Information Series 8: UNEP, Nairobi, $277 \mathrm{pp}$

Gill, R.M.A. 1992. A review of damage by mammals in north temperate forests. 1. Deer. Forestry 65, 145-169.

Gordon, I.J., Hester, A.J. \& Festa-Bianchet, M. 2004. The management of wild large herbivores to meet economic, conservation and environmental objectives. Journal of Applied Ecology 41:1021-1031.

Gortázar, C., Acevedo, P., Ruiz-Fons, F.J. \& Vicente, J. 2006. Disease Risks and Overabundance of Game Species. European Journal of Wildlife Research. 52: 81-87.

Granados J.E., Cabrera, M.C., García, J. \& Fandos, P. 2001. El ciervo común (Cervus elaphus Linneo 1758) en el parque natural de la Sierra de Baza (Granada). Galemys 13 (2): 27-37.

Hannan, M.J., Whelan, J., 1989. Deer and habitat relations in managed forests. In: Mammals as pest. Putman, R.J., Ed. Champman \& Hall, London. New York.

Hosmer, Jr, D.W., Lemeshow, S. \& Sturdivant, R.X. 2013. Applied logistic regression (Vol. 398). John Wiley \& Sons.

Kraus, P. 1992. Differences in the influence on vegetation exerted by red deer Cervus elaphus L. 1758 and fallow deer Cervus dama L. 1758 with special regard to population density. En: B. Bobek, K. Perzanowski y W. Regelin (eds). Global Trends in Wildlife Management Transaction. Trans. 18 th IUGB Congress, Krakow, 1987. Swiat Press, Krakow-Warszawa, vol. 2. 559-602.

Langvatn, R. 1982. An investigation of fraying damage on trees caused by red deer. Tidsskriftfor Skogbruk 90: 270-281.

Linden, A., Grégoire, F., Nahayo, A., Hanrez, D., Mousset, B., Massart, L., De Leeuw, I., Vandemeulebroucke, E., Vandenbussche, F. \& de Clercq, K. 2010. Bluetongue virus in wild deer, Belgium, 2005-8. Emerging Infectious Diseases. 16: 833-836.

MacGo-wan, B., Severeid, L. \& Skemp, F. 2004. Control of deer damage with chemical repellents in regenerating hardwood stands. Walnut pest management.

Maizeret, C. \& Ballon, P. 1990. Analysis of causal factors behind cervid damage on the cluster pine in the landes of Gascony. Gibier Faune Sauvage 7, 275-291.

Martínez Reguera, L. 1881. Catálogo descriptivo de los mamíferos del término de Montoro. Madrid. 414 pp.

Massei, G., Bowyer, R.T., 1999. Scent marking in fallow deer: effects of lekking behaviour on rubbing and wallowing. Journal of Mammalogy. 80: 633-638.

Mattioli, S., Meneguzo, P.G., Ugnoli, A. \& Nicoloso, S. 2001. Red deer in Italy: recent changes in range and numbers. Hystrix Italian Journal of Mammalogy. (n.s.) 12 (1): 27-35. 
Milner, J., Bonenfant, C., Mysterud, A., Gaillard, J.M., Csányi, S. \& Stenseth, N.C. 2006. Temporal and spatial development of red deer harvesting in Europe - biological and cultural factors. Journal of Applied Ecology 43: 721-734.

Morales, P. 1904. Las monterías en Sierra Morena a mediados del siglo XIX. Editorial Velázquez. Madrid.

Moreno, A., Rodríguez, C., Ferrandis, C. \& de las Heras, J. 2001. Impacto del escodado del ciervo (Cervus elaphus L.) sobre la cornicabra (Pistacia terebinthus L.) en «Quintos de Mora» (Los Yébenes, Toledo). Invest. Agr.: Sist. Recur. For. Vol. 10 (1): 81-93.

Moss, R. 2001. Second extinction of capercaillie (Tetrao urogallus) in Scotland? - Biological Conservation 101: 55-257.

Nahlik, D. 1974. Deer Management. David \& Charles, Ed., Vancouver, Canada, 250 pp.

Nolte, D. 1998. Efficacy of selected repellents to deter deer browsing on conifer seedlings. International Biodeterioration. Biodegradation. 42 (2-3) : 101-107.

Orihashi, K., Yasui, Y., Kojima, Y., Terazawa, M., Kamoda, S., Kasahara, H. \& Takahashi, Y. 2002. Development of a Method for Forest Cafeteria Tests for Evaluating Chemical Deterrents against Bark Stripping by Sika Deer (Cervus nippon yesoensis). Journal Forest Res. 7: 35-40.

Palmer, S.C.F. \& Truscott, A.M. 2003. Browsing by deer on naturally regenerating Scots pine (Pinus sylvestris L.) and its effects on sapling growth. Forest Ecology and Management 182 (2003) 31-47

Perea, R., Girardello, M. \& San Miguel, A. 2014. Big game or big loss? High deer densities are threatening woody plant diversity and vegetation dynamics. Biodiversity Conservation 23: $1303-1318$

Putman, R.J. \& Moore, N.P., 1998. Impact of deer in lowland Britain on agriculture, forestry and Conservation habitats. Mammal. Review. 28: 141-164.

RACC. 2011. Accidentes de tráfico con animales. análisis de la situación a nivel europeo y español. Ministerio del Interior, Dirección Gral. De Tráfico. 76 pp.

Ramos, J.A., Bugalho, M.N., Cortez, P. \& Iason, G.R. 2006. Selection of trees for rubbing by red and roe deer in forest plantations. Forest Ecology and Management. 222: 39-45.

Randall, J.A.\& Walters, M.B. 2011. Deer density effects on vegetation in aspen forest understories over site productivity and stand age gradients. Forest Ecology and Management. 261: 408-415.

Rooney, T.P. 2001. Deer impacts on forest ecosystems: a north American perspective. Forestry 74: 201-208.

Royston, P., \& Ambler, G. 1998. Multivariable fractional polynomials. Stata Technical Bulletin, STB-43: 24-32.

San Miguel, A., Perea, R. \& Fernandez Olalla, M. 2010. Wild ungulates vs. extensive livestock. Looking back to face the future. Options Meditérranneenes 92:27-34.

Santilli, F., Mori, L. y Galardi, L. 2004. Evaluation of three repellents for the prevention of damage to olive seedlings by deer. European Journal Wildlife Research, 50: 85-89. 
Schloeth, R. 1968. Analysis of rubbing and fraying by red deer in an alpine habitat (Swiss National Park). Swiss Commission for Natural Sciences 11, 75

Soriguer, R.C., Fandos, P., Bernaldez, E. \& Delibes, J.R.. 1994. El ciervo en Andalucia. Estación Biológica Doñana. Consejo Superior de Investigaciones Científicas (C.S.I.C.). Sevilla. 243 pp.

Stockton, S.A., Allombert, S., Gaston, A.J. \& Martin, J.L. 2005. A natural experiment on the effects of high deer densities on the native flora of coastal temperate rain forests. Biological Conservation. 126:118-128.

Swihart, R.K. \& Conover, M.R. 1990. Reducing deer damage to yews and apple trees: testing big game repellent, rope!, and soap as repellents. Wildlife Society Bulletin. 18: 156-162.

Ueckermann, E. 1982. Managing german red deer (Cervus elaphus L.) populations. En: Biology and management of the cervidae. Wemmer, C.M. (Ed.). Smithsonian Institution Press. Washinton, D.C. London.

Wagner, K. \& Nolte, D. 2001. Comparison of active ingredients and delivery Systems in deer repellents. Wildlife Society Bulletin. Vol. 29, 1.

Whitehead, G.K. 1993. The Whitehead encyclopedia of deer. Swan Hill Press, London.

Wolfe, D.H., Patten, M.A., Shochat, E., Pruett, C.L. \& Sherrod, S.K. 2007. Causes and patterns of mortality in lesser prairie-chickens Tympanuchus pallidicinctus and implications for management. Wildlife Biology 13 (Suppl. 1): 95-104. 


\section{CONCLUSIONES GENERALES}

\section{Capítulo 1}

1.1. Sierra Madrona y Valle de Alcudia pueden considerarse como una única comarca geográfica y natural, con un pasado geológico, ecológico e histórico comunes.

\section{Capitulo 2}

2.1. La comarca estuvo cubierta de bosques hasta que el hombre comenzó a desarrollar principalmente 4 tipos de explotación, incompatibles entre ellos, con los consecuentes conflictos sociales que esto implicaba. Los 4 afectaron gravemente a los bosques y fueron:

2.1.1. El pastoreo local (estante), principalmente de cabras, de subsistencia, en sierras y montes de relieve más abrupto. Los pastores, para generar pasto herbáceo, quemaban cada 3-6 años los montes, una tragedia histórica, muy perjudicial para los bosques, que desaparecieron, para los suelos, que en gran parte se perdieron, y para un número indeterminado de especies de flora y fauna que, al menos localmente, se extinguieron.

2.1.2. El pastoreo foráneo (invernante), de oveja merina, inmerso en la economía europea por la alta calidad de su lana. Los mejores pastos (Valle de Alcudia), estaban reservados para ganaderos invernantes que aclararon el bosque favoreciendo a la encina. Aunque estos no quemaban los montes pues valoraban al arbolado y sus frutos para las ovejas.

2.1.3. La minería (mercurio, plomo, plata, etc.), explotada desde hace más de 3000 años, con 2 picos de máxima actividad, en el periodo romano y, más especialmente, desde la reconquista cristiana hasta el siglo XX. Millones de metros cúbicos de leña y madera se quemaron en hornos y fundiciones o se usaron para entibar las galerías.

2.1.4. La agricultura fue la actividad más lesiva pues si bien contribuyó a mejorar la economía de numerosas familias (especialmente con el olivar) los montes eran eliminados. Incendios, pastoreo y talas permitían el regenerado del monte si cesaban, pero sobre los terrenos cultivados el monte desaparecía, sin posibilidad de regeneración dada la pérdida del suelo por erosión y de fuentes semilleras, cepas y raíces.

2.2. La desamortización de la comarca, principalmente en el siglo XIX, supuso una enorme operación de privatización de tierras pero, al contrario que en otras áreas de España, aquí no afectó especialmente al estado de conservación de los montes, a veces incluso aseguró la conservación de gran parte del arbolado remanente al quedar en manos de ganaderos invernantes.

2.3. De los 76 montes de la Clasificación de 1859, el recien creado Cuerpo de Ingenieros de Montes propuso que fueran exceptuados 31 pero finalmente solo 10 lo serían, todos dominados por robles. Estos y otros montes comprados por la Administración posteriormente fueron 
conformando el Catálogo de Montes de Utilidad Pública que en la actualidad cuenta con 26 montes. En muchos de ellos, y en otros consorciados con particulares, se realizaron plantaciones de pinos a partir de 1940, por lo que los pinares actualmente tienen un fuerte protagonismo en el paisaje.

2.4. La principal causa de eliminación de arbolado en el siglo $X X$ fueron la puesta en cultivo de gran parte del Valle de Alcudia y el intenso carboneo de miles de encinas que fueron arrancadas o severamente podadas. Esta intensa eliminación de arbolado, en zonas ya previamente aclaradas, se refleja hoy en grandes áreas de pasto totalmente desarboladas, esteparias.

2.5. Los nuevos usos del territorio, en la transición de los siglos XX al XXI, caza mayor, saca de corcho y turismo rural, adecuadamente desarrollados, son compatibles con la recuperación y conservación de los bosques.

\section{Capítulo 3}

3.1. Los análisis sobre publicaciones de paleobotánica muestran de forma inequívoca la presencia histórica de pinos en el SO ibérico. En los periodos glaciares como interglaciares, siempre coexistieron, con más o menos dominancia, los géneros Pinus y Quercus.

3.2. El análisis de textos antiguos, más los resultados de la búsqueda de topónimos, confirman también la presencia histórica de pinos en Sierra Morena y otras áreas próximas del SO ibérico. Su extinción, como probablemente también la de otras especies de los géneros Taxus, Betula, Ilex o Prunus (que aún viven en comarcas vecinas), se debió a la alta recurrencia de incendios forestales de los pastores locales, así como a la necesidad de abastecimiento de leña y madera para la población y las minas.

3.3. En Sierra Madrona sobreviven 2 poblaciones autóctonas de Pinus pinaster. Una la descubrimos realizando esta tesis en Sierra Quintana, con ya sólo 2 árboles (uno de ellos centenario). La otra en la sierra de Navalmanzano, con 1212 pies que han sido medidos y georeferenciados, por lo que ha podido verse que el cese de los incendios está permitiendo la expansión de la masa. Aunque se ha buscado por el resto de Sierra Morena y comarcas vecinas de Castilla-La Mancha, Extremadura y Andalucía, puede concluirse que estas son ya las 2 últimas poblaciones en todo el macizo hercínico del SO ibérico.

\section{Capítulo 4.}

4.1. El pinar de Navalmanzano se encuentra en fase de expansión pero esta es lenta. Los estudios de producción de conos, semillas y germinación muestran sin embargo que tiene un gran potencial de regeneración. La competencia intra e interespecífica son bajas y, fuera de los roquedos, con mejor suelo, aunque el crecimiento es bueno, la regeneración sigue siendo escasa. Puede concluirse que muy probablemente esta lenta regeneración se deba al déficit hídrico 
estival, especialmente acusado en la solana en que se halla el pinar, expuesta a los vientos cálidos y desecantes del Sur.

4.2. En los últimos años la regeneración se ha reducido aún más al asentarse aquí una población de ardilla, antes inexistente, que está consumiendo la mayor parte del banco aéreo de semillas. Además de reducir las posibilidades de regeneración en la actualidad, podría representar la total desaparición del pinar en caso de incendio. Es necesario realizar un seguimiento de la población de ardilla, reajustar el equilibrio natural y, en definitiva, mantener su población compatible con la conservación del pinar.

\section{Capitulo 5}

5.1. Además de los problemas de regenerado observados, existe otro factor que reduce la velocidad de crecimiento e incluso mata a los jóvenes pies con tronco ya leñoso. Es el escodado del ciervo que afecta a la fracción joven del pinar. No se han observado daños de ciervo de ningún tipo en pies viejos, lo que permite concluir que el problema es relativamente reciente y coincidente con la expansión del ciervo a partir de la década de 1970.

5.2. Para minimizar el impacto del ciervo, se descarta el vallado del pinar por los inconvenientes de coste y adecuado mantenimiento posterior que esta medida supone, máxime en áreas de alto valor ornitológico. Se propone en cambio como solución más eficaz para la protección del pinar

y de otras valiosas especies y ecosistemas de la zona, reducir la densidad del ciervo y, en cualquier caso, asegurarse que desciende su presión sobre el pinar. 


\begin{tabular}{|c|c|c|c|c|c|c|c|}
\hline \multicolumn{8}{|r|}{ ANEXO } \\
\hline \multicolumn{8}{|c|}{ Topónimos referentes a pinos encontrados en Sierra Morena } \\
\hline ID & Provincia & Topónimo & Huso & $\mathbf{X}$ & $\mathbf{Y}$ & Altitud & Observaciones \\
\hline 1 & Algarbe & Pinheira & 29 & 101178 & 4126489 & 8 & \\
\hline 2 & Alentejo & Monte dos Pinheiros & 29 & 122095 & 4202315 & 211 & No hay plantaciones cerca pero si, unos $800 \mathrm{~m}$ al SE un Monte dos Eucaliptos \\
\hline 3 & Huelva & Pozo del Pino & 29 & 112222 & 4131030 & 35 & \\
\hline 4 & Huelva & Pinar de Platilla & 29 & 112394 & 4128582 & 30 & Genera Casa del Pinar de Platilla. \\
\hline 5 & Huelva & Pasada del Pinillo & 29 & 112004 & 4128065 & 5 & Es un cauce de agua que genera que la zona se llame también así. \\
\hline 6 & Huelva & Rocho del pino & 29 & 110512 & 4137104 & 50 & \\
\hline 7 & Huelva & Casa del pinar & 29 & 116304 & 4136399 & 80 & \\
\hline 8 & Huelva & Pino Romero & 29 & 127613 & 4139947 & 60 & \\
\hline 9 & Huelva & Pino Roncero & 29 & 127815 & 4140468 & 70 & \\
\hline 10 & Huelva & Loma del Pinillo & 29 & 127236 & 4164547 & 200 & Genera el Barranco del Pinillo y Cabezo del Pinillo, están juntos. \\
\hline 11 & Huelva & El Pino & 29 & 127400 & 4165407 & 200 & \\
\hline 12 & Huelva & Cabezo del Pinillo & 29 & 123821 & 4176651 & 215 & \\
\hline 13 & Huelva & Cabezo del Pimpollar & 29 & 129852 & 4183749 & 206 & \\
\hline 14 & Huelva & Pino & 29 & 128520 & 4198899 & 280 & Genera Alto del Pino y Arroyo del Pino. \\
\hline 15 & Huelva & Pinar de Las Contiendas & 29 & 130540 & 4193575 & 325 & $\begin{array}{l}\text { Se divide entre Primer Pinar de Las Contiendas y, unos } 1400 \mathrm{~m} \text { al NO, Segundo Pinar de Las } \\
\text { Contiendas. Zona con numerosas plantaciones de pinos. }\end{array}$ \\
\hline 16 & Huelva & Cumbre del Pimpolloso & 29 & 151132 & 4177852 & 190 & \\
\hline 17 & Huelva & Casa de los Piñeros & 29 & 131345 & 4149828 & 152 & \\
\hline 18 & Huelva & Pino de la Herrería & 29 & 136863 & 4141758 & 120 & \\
\hline 19 & Huelva & El Pinillo & 29 & 133621 & 4169481 & 215 & \\
\hline 20 & Huelva & Loma del Pimpollar & 29 & 134481 & 4172893 & 260 & \\
\hline 21 & Huelva & Cinco Pinos & 29 & 161244 & 4226553 & 440 & \\
\hline 22 & Huelva & Llanos del Pino & 29 & 161710 & 4227490 & 445 & \\
\hline 23 & Huelva & El Pimpollar & 29 & 185605 & 4184443 & 470 & Genera Casa el Pimpollar. Justo en la zona hay una plantación de pinos. \\
\hline 24 & Huelva & Pinos Corona & 29 & 179480 & 4183224 & 290 & En su entorno hay numerosas plantaciones de pinos. \\
\hline 25 & Huelva & La Pimpollosa & 29 & 173479 & 4166981 & 250 & Genera Cabezo de la Pimpollosa, de 343 msnm., y Barranco de La Pimpollosa. \\
\hline 26 & Huelva & Loma de los Pinos & 29 & 178913 & 4172979 & 370 & \\
\hline
\end{tabular}




\begin{tabular}{|c|c|c|c|c|c|c|c|}
\hline 27 & Huelva & El Pimpollo & 29 & 177525 & 4184600 & 350 & Numerosas plantaciones en su entorno. \\
\hline 28 & Huelva & Collado de los Pinos & 29 & 182949 & 4161458 & 241 & \\
\hline 29 & Huelva & Los Pinitos & 29 & 183627 & 4158480 & 200 & Genera Rochos de los Pinitos. \\
\hline 30 & Huelva & Cerca del Pino & 29 & 159498 & 4174896 & 280 & Aquí no pero muy cerca hay plantaciones. \\
\hline 31 & Huelva & Umbría del Pinar & 29 & 159112 & 4174237 & 350 & No hay plantaciones recientes en esta umbría. \\
\hline 32 & Huelva & Pinar del Hierro & 29 & 162222 & 4173522 & 230 & \\
\hline 33 & Huelva & El Pino & 29 & 190992 & 4189509 & 605 & Genera Alto del Pino, Casa del Pino y Arroyo del Pino. \\
\hline 34 & Badajoz & Cerro de Los Pinos & 29 & 138090 & 4242364 & 285 & \\
\hline 35 & Badajoz & Cerro de la Pinela & 29 & 174806 & 4244068 & 446 & \\
\hline 36 & Badajoz & Pinar de Alba & 29 & 190916 & 4222852 & 730 & Unos $2 \mathrm{~km}$ al E del Cortijo de los Castillejos y $5 \mathrm{~km}$ al NE de la Sierra Madrona de Badajoz \\
\hline 37 & Badajoz & Sierra de Pinos & 29 & 228342 & 4277963 & 762 & Genera Cerro del Pino y Cortijo del Pino. Todo en la Sierra de Hornachos (Badajoz). \\
\hline 38 & Badajoz & Cortijo de los Pinos & 29 & 230343 & 4218133 & 578 & No hay plantaciones en el entorno. \\
\hline 39 & Badajoz & El Pino & 29 & 200178 & 4261515 & 502 & Genera Cortijo del Pino. \\
\hline 40 & Badajoz & Los Pimpollares & 29 & 183383 & 4262412 & 660 & Genera Cortijo de Los Pimpollares. En el entorno todo son bosque y dehesas. \\
\hline 41 & Badajoz & Majada del Pino & 29 & 170289 & 4261594 & 635 & Genera Casa de La Majada del Pino y Cortijo del Pino. Entorno con monte natural. \\
\hline 42 & Badajoz & El Pino & 29 & 199142 & 4250133 & 525 & Olivares y dehesas. \\
\hline 43 & Badajoz & Cerro del Pinito & 29 & 206728 & 4225259 & 715 & \\
\hline 44 & Badaj-Sevil. & Loma del Pino & 30 & 261357 & 4224513 & 560 & Genera Arroyo del Pino y Cortijo del Pino. \\
\hline 45 & Sevilla & Los Pinos & 29 & 208190 & 4178025 & 285 & Genera Casas de las Cercas de los Pinos. \\
\hline 46 & Sevilla & El Pimpollo & 29 & 209288 & 4176139 & 280 & \\
\hline 47 & Sevilla & Cerca del Pino & 29 & 207193 & 4175615 & 460 & \\
\hline 48 & Sevilla & Los Pinos & 29 & 200920 & 4176170 & 350 & \\
\hline 49 & Sevilla & El Pino & 29 & 206663 & 4170902 & 250 & \\
\hline 50 & Sevilla & Sierra del Pimpollar & 29 & 230109 & 4206805 & 800 & Hay plantaciones de pinos en la sierra. \\
\hline 51 & Sevilla & El Pimpollar & 29 & 235478 & 4180580 & 370 & No hay parece haber repoblaciones de pinos en el entorno. \\
\hline 52 & Sevilla & El Pino & 30 & 242100 & 4180677 & 280 & Genera Cortijo del Pino. \\
\hline 53 & Sevilla & El Pimpollar & 30 & 237600 & 4185120 & 370 & $\begin{array}{l}\text { Foto aerea muestra monte natural, no parece haber repoblaciones de pinos. Genera Cortijo del } \\
\text { Pimpollar, la Fuente del Pimpollar y Arroyo de la Fuente del Pimpollar. }\end{array}$ \\
\hline 54 & Sevilla & El Pinarillo & 30 & 255093 & 4174659 & 110 & \\
\hline 55 & Sevilla & El Pinar de Manchallana & 30 & 251997 & 4180603 & 320 & Plantaciones de pinos por doquier. \\
\hline 56 & Sevilla & Vado de los Pinos & 30 & 245821 & 4183089 & 55 & \\
\hline 57 & Sevilla & Casa del Pinillo & 30 & 284346 & 4198406 & 420 & \\
\hline 58 & Sevilla & Pina & 30 & 286815 & 4196843 & 360 & Genera Casa de Pina. \\
\hline 59 & Córdoba & Pino Segundo & 30 & 314331 & 4206571 & 500 & Zona con varias repoblaciones de pinos. \\
\hline
\end{tabular}




\begin{tabular}{|c|c|c|c|c|c|c|c|}
\hline 60 & Córdoba & El Pino & 30 & 316431 & 4207467 & 550 & $\begin{array}{l}\text { Zona con varias repoblaciones de pinos dispersas. Genera: Casa del Pino, otra Casa del Pino, el } \\
\text { Castillejo del Pino, Casa del Castillejo del Pino, Arroyo del Pino. }\end{array}$ \\
\hline 61 & Córdoba & Pino de Jesús & 30 & 330609 & 4206707 & 360 & \\
\hline 62 & Córdoba & Vega de los Pinos & 30 & 326105 & 4201627 & 160 & \\
\hline 63 & Córdoba & Cerro del Pino & 30 & 332741 & 4195215 & 342 & \\
\hline 64 & Córdoba & Monte de los Pinos & 30 & 352292 & 4208796 & 240 & \\
\hline 65 & Córdoba & El Piñonero & 30 & 354872 & 4215332 & 430 & \\
\hline 66 & Córdoba & El Pino Molina & 30 & 372324 & 4212624 & 240 & \\
\hline 67 & Ciudad Real & Burcio del Pino & 30 & 393998 & 4250218 & 1290 & También conocido como Morrón del Pino. \\
\hline 68 & Ciudad Real & Solana del Pino & 30 & 406272 & 4258076 & 725 & \\
\hline 69 & Ciudad Real & Cortijo del Pino & 30 & 416168 & 4253484 & 470 & \\
\hline 70 & Ciudad Real & Cerro Pino & 30 & 491184 & 4259316 & 822 & \\
\hline 71 & Ciudad Real & Arryo. de la Fuente del Pino & 30 & 490584 & 4258320 & 700 & Nace en el Cerro Pino. \\
\hline 72 & Jaén & El Pinillo & 30 & 402704 & 4233076 & 685 & \\
\hline 73 & Jaén & Cuesta del Pino & 30 & 405228 & 4233364 & 660 & \\
\hline 74 & Jaén & Caseria de Pino Gordo & 30 & 416342 & 4214706 & 300 & \\
\hline 75 & Jaén & Collado de Pino Ventas & 30 & 412732 & 4218656 & 600 & \\
\hline 76 & Jaén & La Piñonera & 30 & 409235 & 4219791 & 665 & \\
\hline 77 & Jaén & Dehesa el Pinar & 30 & 409924 & 4219184 & 670 & \\
\hline 78 & Jaén & Cerro Pino & 30 & 412540 & 4222456 & 415 & \\
\hline 79 & Jaén & Los Pinos & 30 & 415306 & 4220664 & 505 & \\
\hline 80 & Jaén & La Pineda & 30 & 430532 & 4220528 & 355 & Todo el entorno es olivar. \\
\hline 81 & Jaén & Loma del Pino & 30 & 472288 & 4228224 & 660 & \\
\hline 82 & Jaén & Loma de los Pinos & 30 & 518980 & 4255900 & 780 & \\
\hline 83 & Jaén & Arroyo del Pino & 30 & 504744 & 4244604 & 570 & \\
\hline
\end{tabular}


